\title{
MODELAGEM DE PROCESSO \\ “SUPPLY CHAIN" INFORMADO USANDO TECNOLOGIA RFID: ESTUDO DE CASO PARA A CADEIA DO AGRONEGÓCIO
}


ROBERTO CANDIDO

\section{MODELAGEM DE PROCESSO " SUPPLY CHAIN" INFORMADO USANDO TECNOLOGIA RFID: ESTUDO DE CASO PARA A CADEIA DO AGRONEGÓCIO}

Tese apresentada à Escola Politécnica da Universidade de São Paulo para obtenção do Título de Doutor em Engenharia

Área de Concentração:

Engenharia Naval

Orientador:

Prof. Dr. José Reinado Silva

São Paulo

2013 
Autorizo a reprodução e divulgação total ou parcial deste trabalho, por qualquer meio convencional ou eletrônico, para fins de estudo e pesquisa, desde que citada a fonte.

Este exemplar foi revisado e alterado em relação à versão original, sob responsabilidade única do autor e com a anuência de seu orientador.

São Paulo, de março de 2013.

Assinatura do autor

Assinatura do orientador

Biblioteca Poli USP

FICHA CATALOGRÁFICA

Candido, Roberto

Modelagem de processo informado de supply chain usando tecnologia RFID: estudo de caso para a cadeia do agronegócio /

R. Candido. -- ed.rev. -- São Paulo, 2013.

$148 \mathrm{p}$.

Tese (Doutorado) - Escola Politécnica da Universidade de São Paulo. Departamento de Engenharia Naval e Oceânica.

1. Cadeia de suprimentos (Modelagem) 2. Agronegócio 3. Rádio (Freqüência) I. Universidade de São Paulo. Escola Politécnica. Departamento de Engenharia Naval e Oceânica II. t. 


\section{DEDICATÓRIA}

Aos meus filhos Gabriel e Vinícius e a minha esposa lolanda, pela compreensão de minha ausência e da importância desta titulação para a carreira docente e principalmente pelo apoio nos momentos de dificuldade.

Aos meus pais, Ivette e Lybio, ele que já nos deixou, pela riqueza do exemplo, nos mostrando os valores a serem seguidos e a eterna vontade de vencer pelo trabalho honesto. 


\section{AGRADECIMENTOS}

Quero externar meus agradecimentos

Ao professor Dr. José Reinaldo Silva por ter acreditado na viabilidade da proposta de trabalho e ter estado sempre pronto a fornecer orientações necessárias para concretização deste trabalho.

Aos amigos da Universidade Tecnológica Federal do Paraná que acreditaram e incentivaram ao ingresso e à conclusão deste Doutorado.

Ao corpo docente do Departamento de Engenharia Naval, na pessoa do professor Marcelo Ramos Martins, pela presteza e disponibilidade no atendimento as nossas demandas.

Aos amigos da empresa Limagrain Guerra do Brasil, na pessoa de Ricardo Guerra, que abriram as portas da empresa para que esta pesquisa pudesse ser realizada.

Ao amigo Fabiano Holetz da empresa Haco Etiquetas, pelas informações fornecidas e pronto atendimento as solicitações.

Aos amigos da 3M, na pessoa de Jefferson Denofrio, que de forma irrestrita estiveram a disposição para consolidar o modelo proposto através do empréstimo de laboratórios e equipamentos.

Ao amigo do D-Lab José Armando San Pedro Miralles pela colaboração no desenvolvimento dos aplicativos necessários ao trabalho.

Enfim venho estender os meus agradecimentos a todos os que, direta ou indiretamente, contribuíram para a realização deste trabalho. 


\section{SUMÁRIO}

\section{INTRODUÇÃO}

$\begin{array}{ll}1.1 \text { CENÁRIO } & 14\end{array}$

1.2 JUSTIFICATIVA DO TRABALHO 17

$\begin{array}{ll}1.3 \text { DELIMITAÇÃO DO ESTUDO } & 19\end{array}$

$\begin{array}{ll}1.4 \text { OBJETIVOS } & 20\end{array}$

1.4.1 Objetivo Geral $\quad 20$

$\begin{array}{ll}\text { 1.4.2 Objetivos Específicos } & 20\end{array}$

$\begin{array}{ll}\text { 1.4.3 Estrutura da Tese } & 20\end{array}$

2. REVISÃO DE LITERATURA 22

2.1 CADEIAS DE ABASTECIMENTO 22

2.1.1 "Supply Chain Management” 26

2.2 TECNOLOGIA RFID 32

2.2.1 Histórico da Tecnologia RFID 32

2.2.2 Aspectos técnicos do RFID 41

2.2.3 Modelo básico de um Sistema RFID 44 
2.3 AGRONEGÓCIOS E "SUPPLY CHAIN"

2.4 O PAPEL DAS SEMENTES NO AGRONEGÓCIO

2.5 A EVOLUÇÃO DO SETOR DE SERVIÇOS

2.6 PRINCÍPIOS DE PROCESSOS INFORMADOS

2.7 "WORKFLOW MANAGEMENT"

2.7.1 "Business Process"e "Workflow"

\section{METODOLOGIA}

3.1 MÉTODOS

3.2 OBJETO DO ESTUDO 


\section{LISTA DE FIGURAS}

Figura 1 - Evolução Comportamental do Supply Management 23

Figura 2 - Áreas do Abastecimento 25

Figura 3 - Configuração Básica do SCM Colaborativo 30

Figura 4 - Estrutura de Memória de um "Tag” 34

Figura 5 - Exemplos de QR Code 36

Figura 6 - Relacionamento entre aplicações do RFID 39

Figura 7 - Processos de negócio $\quad 41$

Figura 8 - Vida em rede 42

Figura 9 - Componentes básicos de um sistema RFID 45

Figura 10 - Modelo de comunicação RFID 47

Figura 11 - Acoplamento Indutivo $\quad 49$

Figura 12 - Componentes lógicos de um leitor 50

Figura 13 - Camadas do Protocolo de Leitor EPC global 53

Figura 14 - Fases de implantação do RFID no SCM 55

Figura 15 - Sistema Agroindustrial 60

Figura 16 - Modelo de Agrocluster 61

Figura 17 - Modelo de Manufatura Informada 68

Figura 18 - Uso de RFID 69

Figura 19 - RFID Inserido na nuvem da Internet 70 
Figura 20 - Fases para tomada de decisão

Figura 21 - Evolução dos sistemas de Gerenciamento de Negócios

74

Figura 22 - Três dimensões do Workflow

76

Figura 23 - Exemplos de Rede Petri

78

Figura 24 - Exemplo Aplicativo WF Nets

89

Figura 25 - Organograma Redefinido

92

Figura 26 - Diagrama UML Use Case SCM do Milho

95

Figura 27 - Diagrama UML Use Case do Planejamento

96

Figura 28 - Diagrama UML Use Case da Contratação do Campo

97

Figura 29 - Diagrama UML Use Case do Plantio

98

Figura 30 - Diagrama UML Use Case da Colheita 100

Figura 31 - Diagrama UML Use Case do Recebimento 102

Figura 32 - Diagrama UML Use Case do Beneficiamento 105

Figura 33 - Diagrama UML Use Case de Venda 108

Figura 34 - Fluxo das Informações Permanentes 109

Figura 35 - Fluxo das Informações Compostas

Figura 36 - Fluxo das Informações Independentes

Figura 37 - Leitor/gravador Portátil

Figura 38 - Trajetórias da semente de milho

Figura 39 - Workflow Master do Supply Chain da Semente de milho 
Figura 40 - Workflow Receber Sementes na Portaria

Figura 41 - Workflow Classificar Sementes na Torre

Figura 42 - Workflow de Armazenar Sementes em Big Bag

Figura 43 - Workflow de Avaliar Sementes em laboratório

Figura 44 - Workflow de Tratar Sementes

Figura 45 - Workflow de Ensacar Sementes

Figura 46 - Workflow de Deslocar Palet para Câmara Fria

Figura 47 - Workflow da Expedição aos Clientes

Figura 48 - Estrutura da Memória de um Tag RFID

125

Figura 49 - Posicionamento de Estações de Conversação RFID 126

Figura 50 - Estação Leitor / Gravador RFID na Portaria

Figura 51 - Tela de Gravação de dados 128

Figura 52 - Tela de Relatório de Recebimento

Figura 53 - Estação 2 para Torre Seletiva e de Tratamento

Figura 54 - Tela de Gravação de dados na Torre

Figura 55 - Tela de Gravação Tratamento

Figura 56 - Estação 2 para Controle de Palets

Figura 57 - Tela de Gravação para Ensacamento e Colocação em Palet 132

Figura 58 - Tela de Gravação na expedição. 
Figura 59 - Tela de leitura do RFID junto a sacas de semente

Figura 60 - Antena em forma de Pad 3M

Figura 62 - Leitor / Gravador 3M

Figura 63 - Arquitetura do Sistema

Figura 64 - Modelo Protótipo de Sistema Informado do Agronegócio

139

Figura 65 - Pontos para conversa;cão - Leitor Gravador de "tag".

Figura 66 - Dinâmica de troca de Informações 


\section{LISTA DE TABELAS}

Tabela 1 - Questões a serem respondidas pelo Supply Chain

Tabela 2 - Comparativo RFID e Código de barras

Tabela 3 - Faixas de Frequência do RFID 48

Tabela 4 - Classe de Identificadores EPCGlobal 50

Tabela 5 - Simbologia para WFNet 9YAWL

79

Tabela 6 - Sequência de Procedimentos para Modelo 90

Tabela 7 - Estudo da capacidade de memória na fase Granel 121

Tabela 8 - Estudo da capacidade de memória na fase Big Bag 121

Tabela 9 - Estudo da capacidade de memória na fase Sacas 


\section{RESUMO}

CANDIDO, R. Modelagem de Processo "Supply Chain" Informado usando Tecnologia RFID: Estudo de Caso para a Cadeia do Agronegócio. 2013. $148 f$ Tese (Doutorado) - Departamento de Engenharia Naval da Escola Politécnica da Universidade de São Paulo, São Paulo. 2013.

Este trabalho tem como objetivo apresentar uma Metodologia pra implantar um Modelo de Processo Informado de "Supply Chain" usando tecnologia RFID (Radio Frequency Identification) aplicado ao Agronegócio. Para criação deste Modelo desenvolveu-se uma Metodologia própria utilizando-se de Ferramentas Computacionais Livres que conduziram a criação de um programa especializado para o "Supply Chain" da Semente de Milho, que foi o caso escolhido para o estudo. Os procedimentos adotados para criação deste Modelo podem facilmente ser remodelados para outras Cadeias do Agronegócio, tais como a Carne, as Frutas, Grãos Comerciais, gerando assim vantagens competitivas aos produtos até então vistos como puras commodities. As aplicações tradicionais do RFID têm sido limitadas ao posicionamento de produtos em armazéns, deixando abertas muitas possibilidades de estudo, como é o caso do Modelo Informado, permitindo ao consumidor final do produto ter todas as informações necessárias para garantia da qualidade junto ao item. A integração de conhecimentos originados no "Supply Chain", Processo Informado, RFID e Agronegócio é feita com base em uma estrutura que distribui a informação entre os equipamentos e bancos de dados associados aos leitores de RFID. Neste trabalho a questão da segurança contra leitura não autorizada não foi incluída.

Palavras Chave: Processo Produtivo Informado, "Supply Chain" (Cadeia Abastecimento), RFID (“Radio Frequency Identification”) 


\begin{abstract}
CANDIDO, R. Modelagem de Processo Supply Chain Informado Usando Tecnologia RFID: Estudo de caso para a cadeia do Agronegócio. 2013. $148 f$ Tese (Doutorado) - Departamento de Engenharia Naval da Escola Politécnica da Universidade de São Paulo, São Paulo. 2013.
\end{abstract}

This paper aims to present a methodology to deploy a Process Model Informed "Supply Chain" using RFID (Radio Frequency Identification) applied to Agribusiness and Precision Agriculture. The intent of this proposal is to allow tend users of precision agriculture product to handle all the data need to ensure the quality of a target product. Traditional applications of RFID have been limited to product placement in stores, leaving a wide possibility of innovations in Supply Chain management. This case is strongly observed in agribusiness, a very important issue in Brazilian economy, where commodities are susceptible to failure or block orders. The coalescing of knowledge from Supply Chain, Process Informed, RFID and Agribusiness Study is made by a fair distribution of information among tags and databases, generally connected to RFID readers.

Finally, a case study was included related to the supply of corn seeds to a culture inserted in the paradigm of precision agriculture.

Keywords: Production Process Informed Supply Chain (Supply Chain), RFID (Radio Frequency Identification) 


\section{INTRODUÇÃO}

\subsection{CENÁRIO}

O Mercado Consumidor cada vez mais exigente busca fornecedores em qualquer parte do Mundo estimulando a competitividade das organizações, que por sua vez, buscam oferecer aos clientes produtos com maior qualidade, menor preço e menor prazo de entrega.

Buscando atender as exigências dos clientes, empresas têm procurado novos mecanismos de monitoramento e controle que gerem informações instantâneas dos processos produtivos e permitam a atuação imediata em caso do comprometimento da qualidade. Por outro lado, a garantia da qualidade gera no cliente a necessidade de conhecer detalhes da produção do item, o que, no caso de alguns produtos, exige pesquisa em banco de dados dos produtores, e em outros casos torna-se simplesmente impossível, pois estas informações dependem do próprio processo de fornecimento.

Acompanhar a produção através de relatórios gerenciais e sistemas computacionais tem sido a alternativa utilizada pelas organizações para terem o histórico do item produzido e também promoverem ações corretivas em caso de falhas. Esta ação pode ser entendida como uma busca da rastreabilidade do item, conceito que vem sendo amadurecido em função de novas formas de gestão aliadas a novas tecnologias de TI (Tecnologia da Informação), definida como a capacidade de conhecer a origem e o caminho percorrido por um produto até o consumidor final, FELÍ́CIO (2001).

A rastreabilidade tem sido uma aliada na Gestão da Qualidade, pois permite identificar os problemas da Produção com exatidão e, por conseguinte atuar de forma eficiente e rápida sobre eles. Segundo LARA e SOARES (2003) a rastreabilidade já é um realidade em alguns segmentos, principalmente para os exportadores de gêneros alimentícios da comunidade européia. A evolução do conceito de rastreabilidade do item reforçou a necessidade da integração dos processos produtivos e das parcerias com atores da cadeia de suprimentos, o que 
consolidou o conceito moderno de Supply Chain (Cadeia de Suprimentos), que na definição de LI, GODON e VISICH (2010); SABBAGHI e VAIDYANATAH (2008) aglutinam métodos e ações envolvidas na geração de um produto ou serviço, para que este possa chegar ao cliente garantindo sua satisfação, portanto, permitindo o gerenciamento eficiente de todos os processos e atores, como: fornecedores, pedidos, montagens, estoques, entrega, etc.

A utilização do código de barras tem permitido "rastrear" o item durante o Supply Chain, porém, com uma característica limitadora, pois todas as informações sobre o produto são armazenadas em bancos de dados e não são acessíveis facilmente aos interessados, principalmente aos clientes finais. $\mathrm{Na}$ verdade a informação não acompanha o produto e, portanto não é dinâmica e nem suficientemente individualizada por item (ao contrário de um Processo Informado), sendo, portanto somente uma chave da informação.

Este modelo de gestão com as informações centralizadas em bancos de dados traz um questionamento inevitável: “Como as informações de uma Cadeia de Suprimento podem ser distribuídas e incorporadas pelos seus atores, de acordo com uma hierarquia de acesso?"1

A resposta para esta questão indica que para o Supply Chain ser cada vez mais eficiente o conceito de "rastreabilidade" precisa ir além do posicionamento do item, é preciso que um Sistema de Informação (SI) que lhe dê suporte e transforme os dados coletados em informações úteis para tomada de decisões, além de fazer com que estas informações circulem entre os parceiros.

A disponibilidade universal dos dados de forma aberta precisa atender a normativas e regulamentações existentes de forma equivalente ao código de barras,

\footnotetext{
${ }^{1}$ Na verdade o problema se divide em dois: o primeiro é achar um método que permita fazer uma distribuição adequada da informação, sendo parte dela acoplada ao produto e outra parte acoplada ao Banco de Dados dos processos; a segunda parte do problema é evitar que esta informação assim distribuída seja acessada por agentes não autorizados. Este trabalho se propõe a estudar somente o primeiro problema.
} 
atendendo e atender ao EPC (Código Eletrônico de Produto),-Global, o que o qualifica como um Sistema de Processo Informado.

O dispositivo RFID, equipamento desenvolvido para reconhecimento de aviões aliados na segunda guerra mundial, é atualmente usado como substituto do código de barras que acompanha o produto, e pode ser a solução para esta questão, pois este equipamento proporciona uma dinâmica de comunicação em tempo real que permite a "conversação" entre um produto na Cadeia de Suprimentos (Supply Chain) e o Sistema de TI que gerencia o Processo. Nesta conversação é possível trocar dados com o RFID, e estes ficam armazenados e disponíveis junto ao produto para qualquer um dos atores da Cadeia de Suprimentos. Esta aplicação do RFID, ainda não explorada, permitirá que a informação acompanhe o item, tornando-o mais útil do que uma simples "evolução do código de barras". Afirmam DOLGUI e PROTH, (2008), que: A combinação da tecnologia RFID com softwares de gestão existentes no mercado criam um sistema de Inteligência na Manufatura, através da velocidade de respostas e coleta de dados.

LEE e JINWCO (2008) e SMITH (2005) mostram que outra vantagem do RFID é não necessitar de contato físico com o elemento monitorado, eliminando as operações manuais existentes no código de barras. Para tanto, todo sistema estruturado na Tecnologia RFID é constituído de três elementos básicos que são: antena, leitor e dispositivo RFID (Tag).

É questão relevante a maneira escolhida para estruturar uma aplicação do RFID, pois segundo afirmam GLOVER \& BHATT (2007) não se pode negligenciar no entendimento do Processo onde será feita a aplicação. Desta maneira a Modelagem do Negócio, ou parte dele, se apresenta como peça fundamental para se conhecer com profundidade um Processo a ser Pesquisado. Em uma primeira análise, o RFID tem aplicabilidade em qualquer Supply Chain que necessite de informações imediatas e disponíveis junto ao item, ou seja, da entrega de matéria Prima até o fornecimento ao cliente, porém sua Modelagem é indispensável. 
Buscando a melhor configuração para a Pesquisa, observa-se que o Supply Chain é tradicionalmente subdividido em quatro grandes áreas: FORNECIMENTO, MANUFATURA, DISTRIBUIÇÃO E CONSUMO. Para este estudo o foco foi a Manufatura, ou seja, a fase em que o produto é gerado e os processos não dependem unicamente da logística interna ou externa. Sendo assim, a comprovação que nela for feita pode facilmente ser estendida às demais. Outra particularidade considerada para a escolha da MANUFATURA como objeto de estudo é que especificamente na Cadeia do Agronegócio, o processo se confunde com a prestação de um SERVIÇO, conforme descrito na abordagem moderna dos "manufacturing services". Assim, os resultados deste trabalho podem ser aplicados no setor industrial onde os serviços e os processos ocupam papel dominante SPHORER et all. (2009) e SPHORER et al. (2008). A escolha do estudo de caso obedeceu justamente a este critério de abrangência e generalidade.

A partir da consolidação deste Modelo aplicativo do RFID ao "Supply Chain", através de um Piloto para o agronegócio (Semente de milho), focada na MANUFATURA/SERVIÇO (beneficiamento da semente), se terá a possibilidade de estendê-lo a outros produtos, com o diferencial, inovador e inédito, de que todas as informações relevantes do processo podem ser acessadas a qualquer momento, seja para promover correções, ou para comprovação da qualidade do produto, seja para introduzir informação necessária ao redirecionamento do próprio processo.

\subsection{JUSTIFICATIVA DO TRABALHO}

As atividades humanas sempre estiveram envolvidas com a produção, inicialmente com a fabricação de ferramentas rudimentares para caça, depois pela produção de alimentos, passando pela construção de cidades, até chegar à revolução industrial que dá início a produção de bens duráveis e a geração de novas demandas.

A globalização dos mercados foi a última barreira que influenciou diretamente a produção, pois clientes e concorrência se espalham pelo mundo. Novos métodos de Gestão e Controle precisam ser criados, para oferecer ao "Cliente" menor custo, menor prazo de entrega e maior qualidade. 
A inexistência de um Modelo diferenciado de Gestão do "Suply Chain" através da aplicação da tecnologia RFID ("Radio Frequency Identification"), transformando-o num Processo Informado é a justificativa principal deste estudo e a escolha da Manufatura como o foco representativo dentre as quatro etapas existentes (Fornecimento, Manufatura, Distribuição e Consumidor) possibilita dar foco a pesquisa e estender o modelo as demais, quando necessário, e também porque o maior número de operações está nela contida.

A escolha da "Supply Chain" da Semente de Milho foi o pilar central para viabilizar o estudo desta Tese, pois a partir da sua definição criou-se um Modelo e validou-se a aplicação inédita do RFID como pivô central de um Processo Informado do Agronegócio e as principais motivações para sua escolha foi:

$\checkmark$ A importância econômica do segmento na economia Nacional;

$\checkmark \quad$ A capacidade do segmento em absorver e implantar novas tecnologias;

$\checkmark \quad$ A exigência dos clientes finais do segmento, principalmente externos.

$\checkmark \quad$ O grau de inovação tecnológica que o segmento já possui.

Por outro lado, os avanços da Automação e Controle têm possibilidades aplicativas nas Cadeias do Agronegócio, pois o aporte tecnológico está basicamente focado na pesquisa de variedades de plantas, linhagem de animais e novos implementos para o campo.

No intuito de conduzir a pesquisa num "Supply Chain" que possa ser representativa para o segmento Agroindustrial se escolheu o Milho, cultura que tem margem para absorver custos de inovação. Para limitar a pesquisa, sem perder a caracterização do segmento, estruturou-se então a pesquisa para o "Supply Chain das Sementes de Milho" que permitiu simulações, observações, correções do modelo, isto porque, os processos podem ser observados em um único momento facilitando o Estudo de Caso. 


\subsection{DELIMITAÇÃO DO ESTUDO}

A pesquisa foi realizada na empresa LIMAGRAN - GUERRA SEMENTES LTDA., produtora de diversos tipos de grão e sediada no município de Pato Branco no Estado do Paraná.

A empresa iniciou suas atividades no ano de 1979, como uma pequena produtora de sementes de soja e trigo, no ano de 1992 aumentou sua participação no mercado com a produção de sementes de Milho. Em 1997 a aquisição de novas unidades produtoras na região consolida seu crescimento e em 2010 buscando diversificar os negócios e começa a industrialização de alimentos estabelecendo parceria com o grupo Francês Limagrain, que deve proporcionar sua internacionalização e expansão no mercado, com o nome de Limagrain Guerra do Brasil.

A empresa historicamente tem ações empreendedoras que dão sustentabilidade e vanguarda no Mercado, motivo que a levou participar desta Pesquisa, prevendo no futuro prover seus produtos de um diferencial competitivo no com a tecnologia RFID incorporada a cada pacote de semente produzido.

O Estudo realizado buscou suprir a falta de informações gerenciais que permitam atuação imediata no processo reduzindo os prejuízos com indenizações, perda de clientes, descrédito na marca, baixa lucratividade. 


\subsection{OBJETIVOS}

\subsubsection{Objetivo Geral}

Este trabalho tem como objetivo propor um MODELO DE PROCESSO INFORMADO PARA O "SUPPLY CHAIN" DO AGRONEGÓCIO baseado em uma aplicação de RFID com memória estendida.

\subsubsection{Objetivos Específicos}

$\checkmark$ Estudar o comportamento do "Supply Chain" para a Semente de Milho pela sua representatividade no Agronegócio, escolhida como modelo de referencia.

$\checkmark$ Integra os conceitos de "Supply Chain", com o de um sistema informado, isto é, manuseando mais dados do que a simples identificação.

$\checkmark$ Analisar o impacto da tecnologia RFID em um Modelo Informado de "Supply Chain" do Agronegócio.

$\checkmark$ Escolher ferramentas computacionais de Modelagem de Processo que tenham uso "free", para construir a Metodologia de Implantação de um Processo Informado de "Supply Chain".

$\checkmark$ Levantar o fluxo de informações e do Processo da "industrialização" da semente de Milho, caracterizando-o como um Serviço.

$\checkmark$ Criar um Protótipo do Modelo Informado de "Supply Chain" aplicado ao fluxo de beneficiamento da Semente de Milho.

$\checkmark$ Desenvolver um software para dar suporte ao Protótipo desenvolvido em Laboratório.

$\checkmark$ Levantar os resultados obtidos pelo Protótipo e recomendações de cuidados a serem observados na aplicação do Modelo na escala real.

$\checkmark$ Propor novos estudos que ampliem as aplicações de Modelos Informados de "Supply Chain" com uso da tecnologia RFID. 


\subsubsection{Estrutura da Tese}

A tese está dividida em 6 (seis) capítulos: Introdução, Revisão da Literatura, Metodologia, Modelo Proposto; Resultados, Conclusão e Trabalhos Futuros.

Capítulo 1 - Introdução apresenta a estrutura da Tese enfocando os pontos que necessitam ser aprofundados, tais como: Supply Chain Management, RFID e agronegócio. A partir destes pontos mostra como se limitou a pesquisa definindo então seus Objetivos Gerais e Específicos.

Capítulo 2 - Revisão da Literatura apresenta os temas que dão sustentação aos assuntos tratados na Tese, principalmente pontos como a Evolução da Logística, do Supply Chain Management, RFID, Sistemas de Serviço do Agronegócio, Workflow e Modelagem de Negócios.

Capítulo 3 - Metodologia que mostra a forma que a pesquisa foi realizada, justificando as ferramentas utilizadas, e principalmente o Estudo de caso realizado.

Capítulo 4 - Proposta do Modelo e Estudo de caso desenvolvido com base na análise de Workflow na empresa Limagran Guerra buscando a partir da Cadeia de Sementes de Milho, desenvolver um Modelo de Informado de Processo para o Beneficiamento (Manufatura) de sementes de milho com uso do RFID.

Capítulo 5 - Resultados que apresentam a discussão do processo estudado e sua possível expansão para outros nichos de aplicação seja no agronegócio ou não, incluindo o setor industrial.

Capítulo 6 - Conclusão e Trabalhos Futuros onde as conclusões da Tese são delineadas, levantando considerações e sugestões para a continuidade do trabalho, incluindo agora uma possível parceria com a empresa 3M. 


\section{REVISÃO DA LITERATURA}

\subsection{CADEIAS DE ABASTECIMENTO}

Todo processo produtivo precisa receber insumos de Fornecedores, transformá-los em Produtos, cuidar da Distribuição e garantir a satisfação do Cliente. Estas etapas do processo produtivo, que durante os anos, tiveram diversas formas de organização compõem a chamada Cadeia de Abastecimento, que para ser entendida precisa do suporte de conceitos descritos em seguida.

\subsubsection{Logística}

A atividade logística surgiu com as movimentações militares no passado que buscavam conquistas e riquezas através da guerra. Estes deslocamentos da tropa, por grandes distâncias, necessitavam de movimentação proporcional de alimentos, armamentos, fardamentos e animais, ou seja, uma atividade logística compatível com cada missão. As primeiras notícias de organização destas atividades ocorrem com as ações gregas, passando pelo império romano, pela expansão territorial promovida por Napoleão, até transformar-se em disciplina digna de estudo em meados de 1800 nos Estados Unidos.

Segundo FIGUEIREDO E ARCADER (1988) no século 20 o processo de industrialização foi alavancado por: novos modelos de gestão, novas tecnologias, e pela Logística, temas estes que foram assumindo papel cada vez mais relevante na gestão das organizações levando a ampliação da quantidade de informatização pervasiva nos seus recursos de informática. Neste período a relação entre clientes e fornecedores toma uma configuração colaborativa e surge o conceito de "Supply Chain". Até meados da década de 60 a Cadeia de Suprimento era empurrada pela Manufatura, o que gerava muito estoque associado à incerteza de venda. Nesta situação os prejuízos eram inevitáveis, pois não existia o menor entrosamento entre as partes da Cadeia de Suprimentos. Este modelo produtivo era mais afetado quando a cadeia era fragmentada, gerando também estoques intermediários de peças e matéria prima; na seqüência, os anos 70 foram marcados pela importância dada ao cliente, enquanto os anos 80 foram marcados pelo desenvolvimento de 
novas ferramentas de gestão, que buscavam o aumento da produtividade, tais como: "Just in Time", "QFD", "CEP”, etc. Neste período também se buscou estudar e fortalecer a Cadeia de Suprimentos, com envolvimento de clientes e fornecedores, na busca de resultados melhores para a produção e a Qualidade Total passa a ser um requisito básico das organizações. No século 21 o Mercado tornou-se totalmente globalizado e as empresas precisam planejar a produção, gerenciar fornecedores e entregar seus produtos em qualquer parte do mundo, com qualidade universal e única, ou seja, o "Suppy Chain" é global. Este período é também caracterizado pelo surgimento de um setor de serviços forte. A mobilidade se insere também nos Processos Produtivos e a Cadeia de Suprimentos e os dados precisam acompanhar os produtos, processos e serviços. A Figura 1 ilustra o descrito pelos autores, mostrando a modificação Comportamental na condução dos "Supply Chain" ao longo dos anos, quando se observam, por exemplo, o aumento do relacionamento com o cliente, o aumento do uso de técnicas gerencias, a diminuição de estoques, aumento no gerenciamento de transportes, etc. Neste contexto, é crescente a influência da computação pervasiva, onde se inclui dados distribuídos.

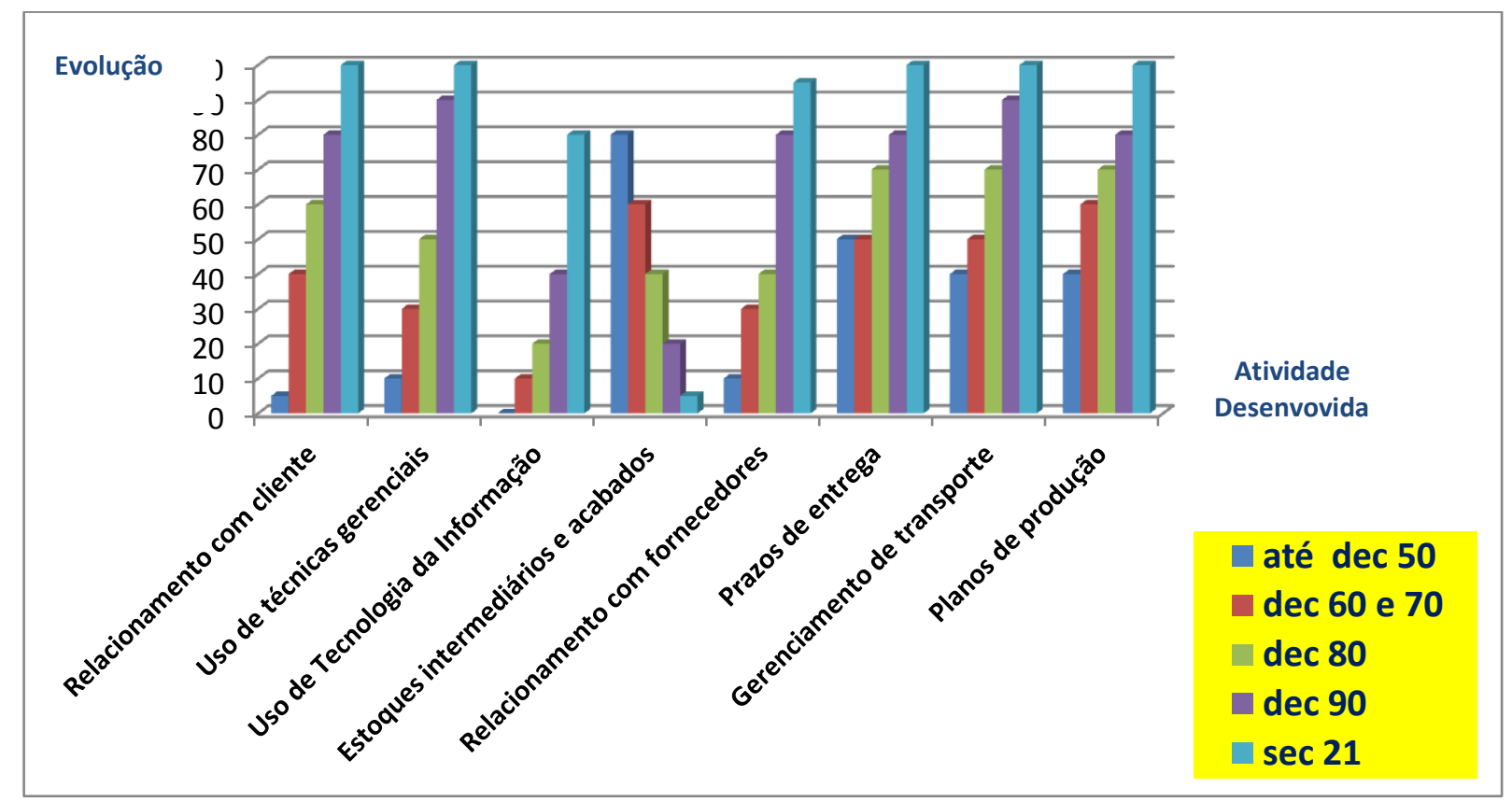

Figura 1 - Evolução Comportamental do Supply Chain - Próprio 
Os conceitos de Logística aceitos no passado vinculavam a atividade com Gestão de movimento e armazenamento de mercadorias, conceitos estes que tem se modificado durante os anos. NETO e JUNIOR (2008) apropriam-se da definição do "Council of Logísticas Management", como o mais apropriado, definindo Logística como a parte do "Supply Chain" que planeja, implanta e controla o fluxo e o armazenamento eficiente e econômico de matéria prima, materiais semi-acabados e produtos acabados, bem como as informações de cada um deles.

Com o aumento da amplitude das atividades vinculadas a Logística a Tecnologia da Informação passa a ser ferramenta indispensável ao seu desempenho, levando autores como WANG, CHENG LIN e H. LIN, (2006 p. 378) a afirmar que "... com o advento da Internet as soluções baseadas na Web, facilitam os processos de Gestão, disseminando e compartilhando informações entre os parceiros do Projeto".

O aumento da exigência dos clientes fez com que os Mercados evoluíssem e as Empresas buscassem formas de profissionalizar as atividades de Logística. GOMES (2004 p.36), afirmam que "A partir do momento em que os produtos vão se tornando commodities, o serviço ao cliente toma importância maior na diferenciação de produtos. Ele é o fornecimento consistente das utilidades de tempo e lugar, ou seja, os produtos não têm valor até que estejam nas mãos dos clientes na hora e local exigidos." Sendo assim, o mercado se ajusta e abre novas oportunidades para a especialização e novos negócios são desenvolvidos. Ao contrario do que se poderia esperar, a especialização diminui custos, pois evita desperdícios.

Academicamente a o "Supply Chain" é dividida em quatro áreas interdependentes (Fornecedor, Manufatura, Distribuição e Consumidor), que facilitam os encaminhamentos entre os diversos atores do processo. A Figura 2 ilustra esta divisão. 


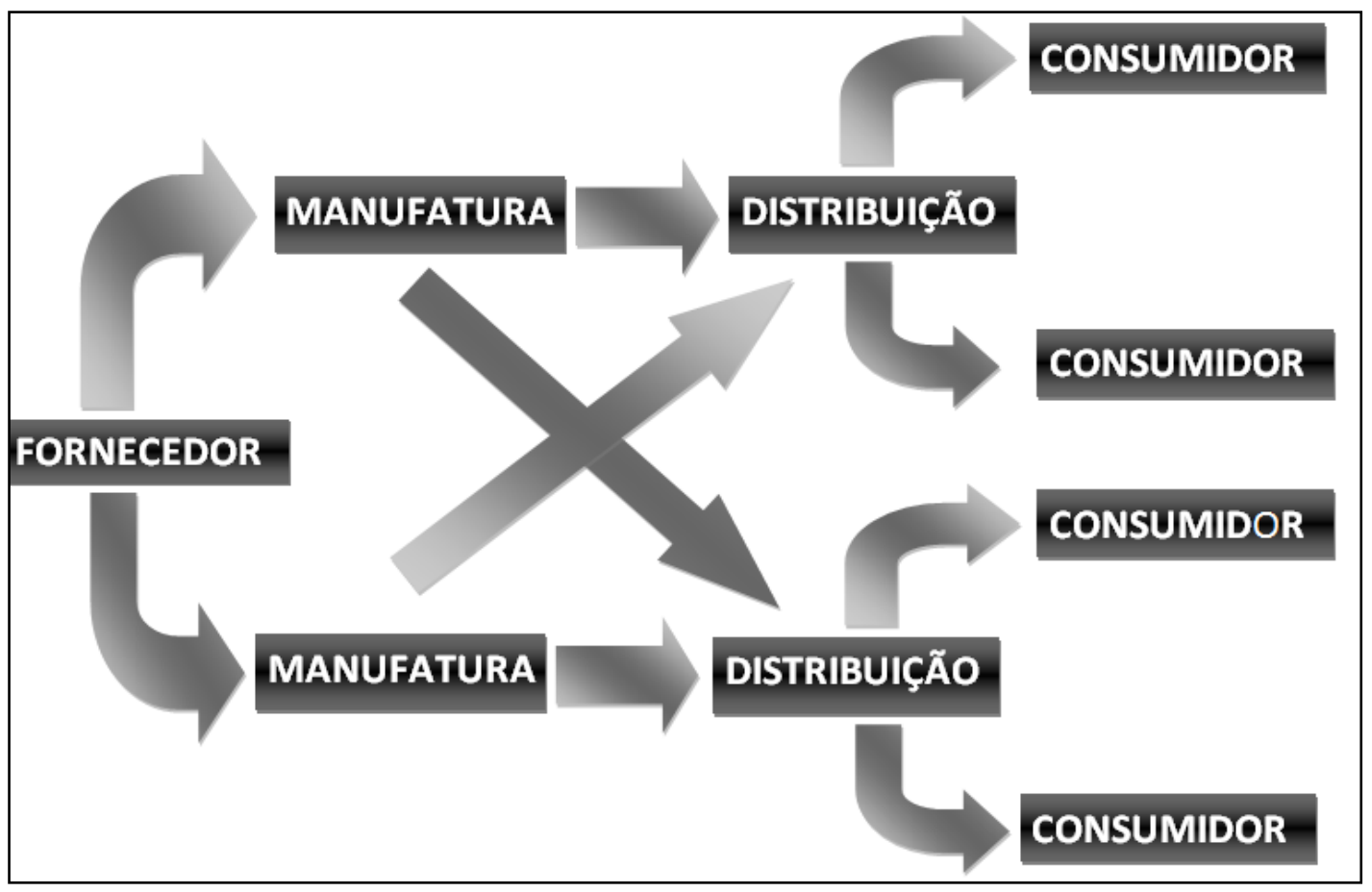

Figura 2 - Áreas do Abastecimento - NETO e JUNIOR (2008 p. 46)

Em meados de 50 surge o termo Logísitica Integrada, quando além do estudo do tranporte, de estoques e de armazenagem, buscou-se a integraçao com o fornecedor, suprimentos, produção, distribuição e principalmente com o cliente, que passa a ser o foco principal do processo, conforme afirma GOMES (2004).

A configuração de um "Supply Chain" é descrito por WANG, CHENG LIN e H. LIN, (2006 p. 378) como: "O controle da Cadeia de Suprimento é um aspecto integral do Supply Chain Management (SCM), que no caso é composto por um grupo de empresas e indivíduos que trabalham de forma colaborativa numa rede de Abastecimento totalmente relacionada para a satisfação do cliente final." 


\subsection{2 "Supply Chain Management"}

As exigências do Mercado levam as organizações a buscarem eficiência em toda a Cadeia de Suprimentos por diversos motivos, dentre eles a diminuição do Ciclo de Vida dos Produtos e a incorporação de novas Tecnologias. Qualidade, Preço e Prazo, cada vez mais são pré-requisitos básicos de qualquer produto, o que acentua as características de "commodities", conseqüentemente diminuindo a fidelidade do cliente a marca.

A manutenção dos clientes pelas organizações está cada vez mais ligada aos detalhes, e os Processos Logísticos tornam-se mais importantes, como evolução natural no universo da Logística o "Supply Chain Management - SCM" (Gerenciamento da Cadeia de Suprimentos) vem sendo uma prática amplamente adotada para garantir a satisfação do cliente.

O "EPC (Electronic Product Code) Global" afirma que: "O SCM tem como objetivo aumentar o desempenho das empresas na cadeia globalizada de fornecimento, maximizando valor para o cliente e minimizando custos". Portanto, o SCM é uma forma de trabalho integrado que permite diversas empresas fornecerem seus produtos e serviços compondo de forma complementar um resultado que gere a satisfação do cliente. Segundo o EPC Global a sinergia produzida entre os parceiros pode ser encontrada no:

$\checkmark \quad$ Planejamento das solicitações;

$\checkmark \quad$ Atendimento dos clientes conforme acordos firmados;

$\checkmark \quad$ Aperfeiçoamento das atividades estratégicas da empresa;

$\checkmark \quad$ Sintonia entre Recebimento, Produção e Expedição;

$\checkmark$ Busca constante da redução de custos com estoques,

$\checkmark \quad$ Redução dos tempos necessários para resolução de problemas, entre outros. 
O conceito de SCM é bastante recente, teve sua origem na década de 90, com duas vertentes, uma que julga o SCM como uma extensão da logística integrada e outra que o entende como sendo uma mudança na forma de gerenciamento. O Portal Brasileiro do SCM fornece a seguinte definição:

"Supply Chain é todo esforço envolvido nos processos e atividades empresariais que criam valor na forma de produtos $\mathrm{e}$ serviços para o consumidor final, sendo também uma forma integrada de planejar e controlar o fluxo das mercadorias. Em outras palavras, a expressão supply chain engloba todos os esforços empenhados na elaboração e na distribuição de um produto ou serviço, desde o primeiro fornecedor até o consumidor final. Assim, o Supply Chain Management engloba o gerenciamento da oferta e da demanda, matérias-primas, manufatura, acompanhamento de estoque e pedidos, além dos controles de distribuição e entregas."

Completando a definição QUEIROZ E COSTA CRUZ (1999 p. 4), afirmam que: "O Supply Chain (SC) engloba a logística, mas é mais do que isso. Inclui o fluxo de materiais e produtos até os consumidores, envolvendo também as organizações que são partes desse processo."

Contribuindo com a consolidação do conceito ASSUMPÇAO (2003 p.6), afirma que no SCM "princípio básico é assegurar maior visibilidade dos adventos relacionados à satisfação da demanda, com o objetivo de minimizar os custos das operações produtivas e logísticas entre as empresas, constituintes do fluxo de materiais, componentes e produtos acabados." Completando este raciocínio GOMES (2004), indica que a Cadeia de Suprimentos pode ser entendida como uma evolução da Logística, diferenciando-se na extensão das relações, enquanto esta se preocupa com a otimização dos fluxos internos da organização, a primeira reconhece que isto é insuficiente para garantir a satisfação do cliente.

QUEIROZ e CRUZ (1999) lembram da importância do SCM ter o suporte de um Sistema Robusto de TI (Tecnologia da Informação) que permita realizar todas as trocas de informações exigidas pela Cadeia de forma parceira e harmônica. Esta rede de informações deve possibilitar o perfeito alinhamento entre pedidos e programações de produção, facilitando o planejamento de longo prazo e melhorando a qualidade das decisões. Segundo NETO e JUNIOR, (2000) a implantação, operação e manutenção de um SCM precisa considerar os seguintes detalhes: 
$\checkmark \quad$ Ser planejado para o atendimento das necessidades do cliente, buscando superar suas expectativas.

$\checkmark \quad$ Desenvolver um plano de treinamento do pessoal envolvido seja interno ou externo à organização.

$\checkmark \quad$ Definir níveis de serviços com responsabilidades na cadeia.

$\checkmark \quad$ Segmentar as atividades entre os parceiros, de acordo com a capacidade de cada um.

$\checkmark \quad$ Utilizar de Tecnologia da Informação (TI) para integrar as operações.

$\checkmark \quad$ Definir exatamente as demandas e seu comportamento, orientando a produção e a P\&D\&I (Pesquisa, Desenvolvimento e Inovação).

$\checkmark \quad$ Desenvolver de métricas para avaliar o desempenho dos parceiros e objetivos.

A Cadeia de Suprimento é dividida em quatro áreas o Fornecimento, a Manufatura, a Distribuição e o Cliente, cada um destes segmentos tendo questões a serem respondidas pela aplicação do SCM, conforme mostra a Tabela 1.

\begin{tabular}{|c|c|}
\hline SEGMENTO & QUESTÕES \\
\hline Fornecimento & $\begin{array}{l}\text { - Quais serão os fornecedores de cada produto ou serviço dentro da SC? } \\
\text { - Quais são os padrões de qualidade de cada fornecedor? } \\
\text { - Qual a capacidade dos fornecedores cumprirem os prazos de entrega? } \\
\text { - Qual a distância e os meios de transporte viáveis a cada fornecedor? } \\
\text { - Quais os meios de comunicação apropriados para cada fornecedor? } \\
\text { - Quais as garantias de cada fornecedor para satisfação do cliente final? } \\
\text { - Qual o custo da realização de um pedido? }\end{array}$ \\
\hline Manufatura & $\begin{array}{l}\text { - Qual a localização de cada planta industrial? } \\
\text { - Quais as vias de acesso a planta? } \\
\text { - Qual a qualificação de Mão de obra necessária? } \\
\text { - Quais as necessidades emergentes para a produção? } \\
\text { - Qual o custo de produção de um item? }\end{array}$ \\
\hline Distribuição & $\begin{array}{l}\text { - Qual a proximidade com os Centros consumidores? } \\
\text { - Quais os locais apropriados para armazenamento? } \\
\text { - Qual o custo dos deslocamentos e manutenção? } \\
\text { - Qual o custo de armazenamento? }\end{array}$ \\
\hline Consumidor & $\begin{array}{l}\text { - Qual a qualidade exigida? } \\
\text { - Qual o nível de serviço a ser oferecido? } \\
\text { - Que valores estão dispostos a pagar? } \\
\text { - Como a Cadeia de Suprimento o deixará satisfeito? }\end{array}$ \\
\hline
\end{tabular}


Lembram NETO, OLIVEIRA e GHINATO (2002) que o SCM altera o conceito de que a concorrência acontece nas unidades organizacionais de forma independente, e sim nas cadeias de suprimento, logo todas as etapas estão envolvidas no único objetivo de "atender ao cliente".

Os resultados do "Supply Chain Management" (SCM) são positivos, mas encontram barreiras durante a implantação, sendo a mais significativa o rompimento das culturas estabelecidas nos componentes da cadeia de Suprimento, comum em qualquer novo processo nas organizações, pois cada parceiro tem uma cultura que precisa ser reconstruída.

As observações acima estão focadas em aspectos internos da organização que é "patrocinadora" da cadeia, mas os reflexos do SCM, também acontecem externamente, conforme as características recorrentes na cadeia indicadas por NETO, OLIVEIRA E GHINATTO (2002 p. 3):

- Percepção em relação aos consumidores, que devem receber melhores serviços, melhores produtos e com preços justos.

- Desenvolvimento de relacionamentos comerciais confiáveis e leais, onde as empresas são comprometidas com as metas da cadeia e mão somente com suas próprias metas.

- Ampliação da integração entre as empresas não apenas no sentido de interligar seus sistemas de informação, mas, sobretudo na postura colaborativa que todos os elos da cadeia devem ter.

- Integração e não simplesmente interface entre os diferentes elos da cadeia.

- Consolidação da estratégia competitiva da empresa e do desempenho geral com a realidade e os objetivos de toda cadeia de suprimentos.

- Reestruturação e consolidação de fornecedores e clientes. Isso geralmente significa reduzir o número e aprofundar o relacionamento com um conjunto de empresas dispostas a desenvolver uma parceria com um resultado sinérgico.

- Partilha de informações e integração da infra-estrutura com clientes e fornecedores. Isto torna possível obter entregas "Just-in-time" e "just-in-sequence" e diminuir o nível de inventário.

- Fornecimento de soluções partilhadas para problemas e o envolvimento de fornecedores desde o começo do desenvolvimento de novos produtos. 
Nesta linha no texto da EPC Global - RFID4u, encontra-se uma recomendação implícita que diz:

Os Sistemas de Informação são a espinha dorsal da Cadeia de Suprimentos e estão baseadas em aquisições automáticas de dados para gestão da Informação. Neste sentido abre campo pra a tecnologia RFID, em função de suas ótimas características de coletar dados instantaneamente ao longo da cadeia. O uso do código EPC na cadeia permite a localização imediata do item e a exclusividade de seus dados, levando, portanto ao atendimento satisfatório do cliente final.

HOLWEG, HOLMOSTROM e SMAROS (2005 p.9) apresenta quatro níveis de parceria que podem ocorrer numa no SCM na Figura 3, e que cada uma delas tem características bem definidas. Nela o quadrante 1 exemplifica o tradicional de um um SC, com envolvimento modesto dos parceiros, enquanto no quadrante 3 a melhor opção é apresentada,pois estão sincronizadas as atividades de Planejamento e do Gerenciamento de Reposição, reduzindo custos de produção, armazenagens e transporte.

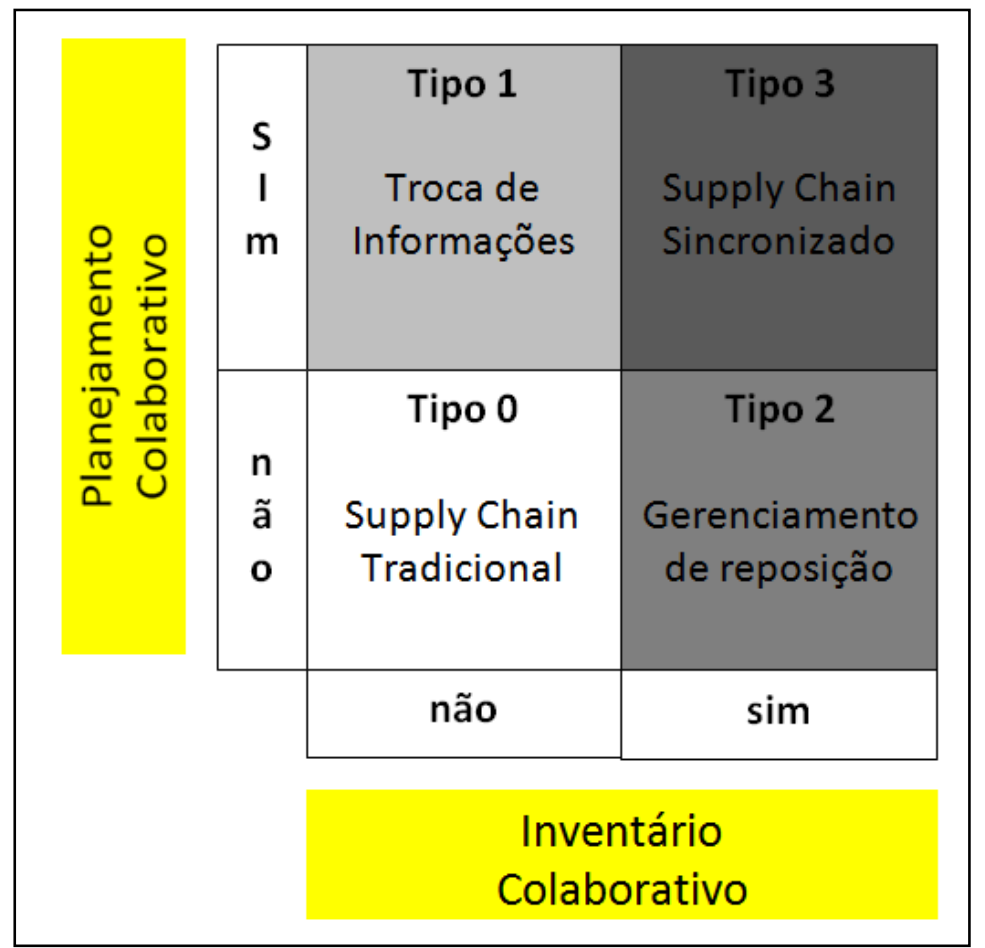

Figura 3 - Configuração Básica do SCM Colaborativo - HOLWEG, HOLMSTROM e SMAROS (2005 p.9) 
Mesmo com resultados positivos no mercado existem dificuldades na implantação do SCM por dois motivos principais:

$\begin{array}{ll}\checkmark & \text { Pelo desconhecimento do conceito. } \\ \checkmark & \text { Pela necessidade da mudança de cultura. }\end{array}$

Para facilitar a implantação de um SCM QUEIROZ e CRUZ (1999 p.13), recomendam os sete princípios criados pela Andersen Consulting, que seguem:

\section{1 - Segmentação dos clientes com base nos serviços $f$}

Uma SCM efetiva agrupa consumidores por suas distintas necessidades de serviço, sem se interessar no tipo de indústria, para depois prover serviços sob medida para os diferentes segmentos.

\section{2 - Personalizar a rede Logística}

Desenvolver suas redes logísticas, as empresas necessitam focar-se nos serviços requeridos e na lucratividade dos segmentos de consumidores previamente identificados.

3 - Ouvir os sinais do Mercado para orientar o planejamento.

O setor de vendas e o de planejamento de operações devem se entender através de toda a cadeia de suprimento com o intuito de detectar sinais de alerta de mudanças de padrões de demanda e de promoções.

4 - Diferenciar o produto o mais próximo do cliente.

As empresas nos dias de hoje não tem grandes estoques para compensar erros de previsão. Em vez disso elas necessitam diferenciação de produto no processo de manufatura próximo à demanda de consumo final.

5- Gerenciar estrategicamente os recursos do "Supply Chain". Trabalhando junto com seus principais fornecedores para redução de custos de seus materiais e serviços, os líderes da SCM aumentam a margem de lucro de ambos os lados.

6 - Desenvolver o Supply Chain com tecnologias estratégicas.

A tecnologia de informação é uma das pedras fundamentais do sucesso da SCM e ela deve dar suporte a diversos níveis de tomada de decisão. Deve ainda dar uma visão clara do fluxo de produtos, serviços e informação.

7 - Adotar medidas de avaliação de desempenho.

Além de monitorar funções internas da SC, os bons sistemas de medição, devem adotar medidas que podem ser aplicadas a cada elo da cadeia. "Lembrando que estas medidas incluem tanto as métricas de serviço como as financeiras, como suas verdadeiras lucratividades. 
A implantação do SCM não é tarefa fácil, mas segundo GOMES (2004), sua aplicação deve buscar alcançar os seguintes objetivos:

$\checkmark$ Aumento da sinergia entre os parceiros;

$\checkmark$ Redução de custos e variação de demandas;

$\checkmark \quad$ Entregas precisas de produtos com menores custos;

$\checkmark \quad$ Agregar valor com redução de estoques e fornecedores.

\subsection{TECNOLOGIA RFID}

A busca de melhorarias para o Supply Chain leva, portanto a busca de novas tecnologias que ofereçam condições de alcançá-las, garantindo assim envolvimento dos parceiros e a satisfação do cliente. A retomada de estudos da tecnologia RFID, tem se apresentado com uma alternativa a ser considerada viável em novos modelos de Processos.

O termo RFID (Radio Frequency Identification) é a denominação de uma Tecnologia de rastreamento e reconhecimento através de ondas de rádio freqüência que permite a troca de informações entre dispositivos eletrônicos e um sistema de retaguarda com armazenamento de dados em memória própria.

\subsubsection{Histórico da Tecnologia RFID}

O uso dos dispositivos RFID teve origem no final da Segunda Guerra Mundial, em função da necessidade da Força Aérea Britânica reconhecer seus próprios aviões em meio às aeronaves inimigas. A baixa qualidade da informação oferecida pelos radares, que apenas indicavam a aproximação de um avião, não permitia reconhecer se este era amigo ou inimigo, gerando muitas baixas pelo "fogo amigo".

$\mathrm{Na}$ década de 70 a tecnologia RFID é retomada e tem novo impulso com a abertura da concessão da patente americana para estudo de sistemas com memória regravável. Também neste período o governo americano incentiva a pesquisa de sistemas de rastreamento de material radioativo e de animais.

LU, HUANG e LI (2011) e ZHU, MUCHOPADHYAY e KURATA (2011), afirmam que a tecnologia RFID tem se tornado popular porque Governos e Instituições o têm como questão estratégica e buscam determinar como o ele pode trabalhar em tempo 
real, nas mais diversas aplicações, tais como a automação industrial, a construção civil, a segurança pessoal e patrimonial.

A freqüência de trabalho dos dispositivos RFID é um importante fator de especificação orientado pela aplicação desejada. Os primeiros projetos usando a tecnologia RFID foram elaborados para trabalhar com baixa freqüência, na casa dos $125 \mathrm{kHz}$, somente na década de 70 estudos permitiram o uso da Alta Freqüência, já na casa de $13,56 \mathrm{MHz}$. A década de 80 foi marcada pelo uso da Ultra Alta Freqüência (UHF) quando os dispositivos RFID passam a fazer leituras a distâncias superiores a 10 metros.

Em meados de 1990 foi criada a Auto-id-Center no MIT (Massachusetts Institute of Technology) no intuito de parametrizar o uso da tecnologia, iniciativa esta que transforma o RFID num número de série, ao invés de um banco de dados. Esta orientação produziu a redução de preço unitário do dispositivo e permitiu também interligá-lo a sistemas de Internet, embora o tenha limitado a uma evolução simples do código de barras. Em 2003 o Auto-id-Center encerra suas atividades e transfere sua atuação para o Auto-ID Labs.

Assim como o Código de Barras os dispositivos RFID recebem uma numeração do Código Eletrônico de Produto (EPC) que segundo HESSEL et all (2009) é formado por um conjunto de 96 bits, o que permite gravar maior numero de informações comparativamente ao Código de Barras, permitindo vincular objetos físicos a um sistema de TI.

REI (2010), mostra em seu trabalho que a memória de um RFID está dividida em quatro Bancos de Dados:

Memória Reservada - KILL: destina-se a armazenar um password para "matar" o dispositivo depois que este cumpre sua tarefa, ou seja, desabilita permanentemente a Tag, deixando-a inutilizada. Esta é uma forma de garantir a segurança das informações nela contidas. Normalmente ocupa um espaço de 32 bits.

$\checkmark \quad$ Memória EPC: É a parte da Memória que registra o Código Eletrônico do Produto, que é único em todo o mundo e permite que um item seja reconhecido universalmente.

$\checkmark \quad$ Memória ID: Este banco guarda o número de série da Tag, fornecida pelo seu fabricante, também é único e indissociável. 
$\checkmark \quad$ Memória do Utilizador (Opcional) - USER - É o espaço de memória destinado para o usuário, que poderia inclusive não existir.

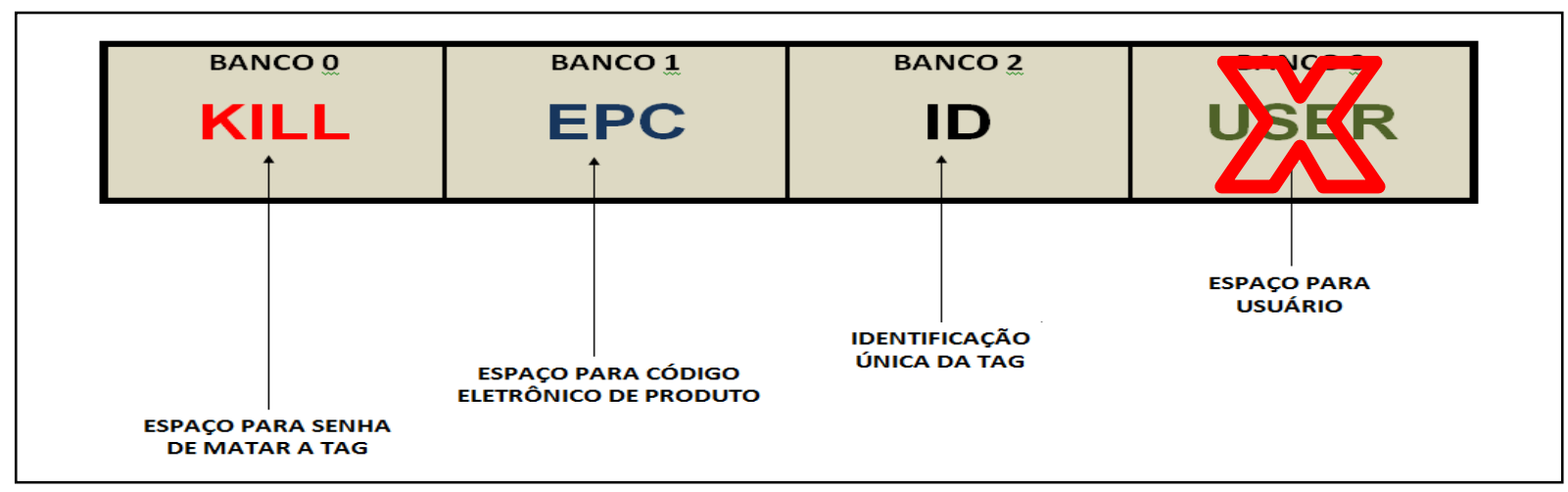

Figura 4 - Estrutura de Memória de um Tag - Próprio.

A Figura 4 ilustra a concepção do RFID na década de 90, quando o usuário tinha pouca disponibilidade de memória para armazenamento de dados, sendo praticamente forçado usá-lo como uma estrutura evolutiva do Código de Barras fator que certamente atrasou a sua aplicabilidade.

A evolução da Tecnologia da Informação ( $\mathrm{TI}$ ) na última década tem levado a uma nova visão do papel do RFID nos Processos Informados. Para tanto, a ampliação da memória disponível ao usuário tem sido uma demanda cada vez maior, mostrando uma tendência de que os dispositivos trabalhem com Memórias Expandidas cada vez maiores, permitindo assim aplicações mais nobres do que a simples substituição do código de barras.

Atualmente para atender as novas aplicações os equipamentos RFID podem apresentar diversas formas construtivas, embora as mais usuais sejam as Tags, pequenos adesivos incorporados ao item que ao facilitarem a "conversação" com o sistema de TI melhoram o desempenho do Supply Chain. SABBAGHI e VAIDYANATHAN (2008 P.75) potencializam o fato ao afirmarem que: "As aplicações do RFID e Eletronic Product Code (EPC), têm um vasto potencial de melhorar a eficiência e a eficácia da Cadeia de Suprimento. A tecnologia RFID pode ajudar de forma ampla, organizações e indivíduos a aumentar a produtividade."

Segundo GLOBER e BHATT (2007) as Tags RFID podem ser encontradas em três tipos de configuração: 
$\checkmark$ Passivas: Que não possuem baterias internas e a alimentação acontece pelo o sinal de rádio freqüência recebido pela antena. Este tipo de tag transmite e armazena poucos dados com leituras a pequenas distâncias.

$\checkmark \quad$ Ativas: Possuem fonte própria que é usada para alimentação de seus circuitos e também para transmissão de dados aos leitores, esta característica permite maior armazenagem de dados e maior distância para leituras.

$\checkmark$ Semipassivas: Esta forma hibrida utiliza sua fonte de energia apenas para alimentação dos circuitos internos e não para comunicação, logo a comunicação ocorre de forma idêntica a tag passiva.

REI (2010) apresenta ainda uma quarta classificação chamada de Semiativa, que tem como característica principal ficar desabilitada enquanto não recebe um sinal do leitor, isto é não está em funcionamento. Ao receber o sinal, o dispositivo RFID, também chamado de tag, opera da mesma forma que uma tag Ativa, como ocorre nos equipamentos utilizados em pedágios por exemplo.

SMITH (2005) lembra que embora diversas formas construtivas e tecnológicas sejam disponibilizadas aos usuários, alguns obstáculos estão no caminho da tecnologia RFID, dentre eles a popularidade do código de barras e o investimento necessário para substituir um modelo tecnológico vigente. Para superar estas dificuldades, GLOVER \&BHATT (2007) enfatizam a necessidade de integrar os novos projetos RFID com os sistemas de código de barras existentes. É importante frisar que a associação de tecnologias traz novos horizontes aplicativos e que tecnologias como: Telefonia $3 G$ e 4G, Bluetooth, associadas à tecnologia RFID tem futuro promissor.

As duas tecnologias têm o seu campo de aplicação e não são concorrentes. Pode-se observar na Tabela 2 diferenças entre elas, cabendo ao projetista aproveitar as características de cada uma delas ou ambas. 


\begin{tabular}{|lcc|}
\hline \multicolumn{1}{c}{ Característica } & RFID & Barras \\
\hline Resistência a deformações mecânicas & Alta & Baixa \\
\hline Formas construtivas & Variados & Etiquetas \\
\hline Leitura visual e alinhada & Não & Sim \\
\hline Vida Útil & Alta & Baixa \\
\hline Possibilidade de armazenar dados & Sim & Não \\
\hline Leitura simultânea & Sim & Não \\
\hline Funções Adicionais & Sim & Não \\
\hline Segurança da informação & Alta & Baixa \\
\hline Custo Inicial & Alto & Baixo \\
\hline Custo de reposição & Baixo & Alto \\
\hline Reutilização & Sim & Não \\
\hline
\end{tabular}

Tabela 2 - Comparativo RFID e Código de Barras - Glover \& Bhatt (2007)

Em 1994 uma evolução do Código de Barras foi criada e denominada de "Quick Response - QR CODE' (Resposta Rápida), que é a configuração do Código de Barras em duas dimensões. Esta nova proposta é associada a outras tecnologias e permite escanear o código e vinculá-lo a um texto e/ou "link", para consolidar a busca de informações.

A capacidade de armazenamento de informações é maior do que o Código de Barras tradicional, podendo ser de até 8 bits ou mais de 7.000 caracteres. A disponibilidade de softwares de leitura destes códigos em aparelhos celulares e similares tem difundido esta nova ferramenta. Por outro lado, a informação não pode ser dinâmica, com leitura e gravação de dados continuamente, o que ainda o " $Q R$ $C O D E$ " em desvantagens frente ao RFID num Processo Informado. Certamente esta tecnologia também terá seu papel no mercado, podendo ser consorciada a outras como o próprio RFID. A Figura 5 mostra exemplos destas etiquetas.

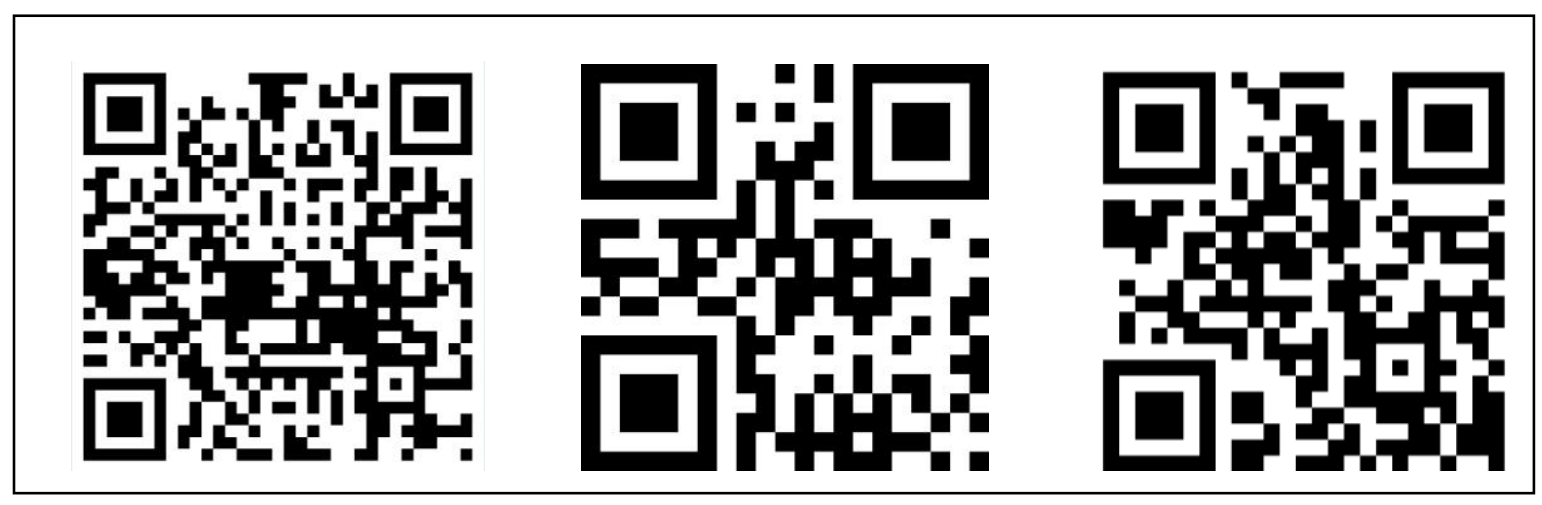

Figura 5 - Exemplos de QR- CODE 
Embora o RFID tenha sido introduzindo durante a segunda guerra somente no final dos anos 90 começou a ser aceito pelo mercado (DOLGUI e PROTH 2008), baseada três motivos principais:

$\checkmark \quad$ A possibilidade da incorporação da Identificação Eletrônica de Produto (EPC).

$\checkmark \quad$ O aumento da capacidade de armazenamento de dados.

$\checkmark \quad$ A diminuição dos custos unitários.

É aceito universalmente que um custo unitário de uma tag RFID precisa estar na casa de 0,05 Euros para tornar a aplicação da tecnologia viável economicamente a todos os segmentos, embora o tipo de "tag" influencie no custo, uma vez que as passivas são mais baratas e trazem limitações de memória e distância para leitura, enquanto as ativas com baterias são maiores e mais caras. SOON e GUTIÉRREZ (2008 p.89) afirmam que: "Se o custo da "tag" for superior a 5 centavos de dólar inviabiliza o controle no item", posicionamento que também é compartilhado por ZHU, MUCHOPADHYAY e KURATA (2012). Os autores ainda mencionam que existem dois extremos organizacionais, um com muita movimentação de produtos de baixo valor e o segundo de pouca movimentação de produtos com alto valor, certamente esta ultima categoria permite mais investimentos na aplicação da Tecnologia RFID.

$\mathrm{Na}$ atualidade a discussão do uso do RFID recai diretamente na definição dos custos de implantação, dado que "para atender ao impacto do RFID no chão de fábrica é preciso levantar o retorno do Investimento (ROI), abatendo o ganho de visibilidade e diminuição de custos com logística, do custo operacional" (EPC Global).

Para produtos de baixo ciclo de vida o uso do RFID é baseado em dois pontos ditos por KÄRKKÄIENN (2003 p. 529), primeiro perguntando qual a vantagem desta implementação comparado ao código de barras; e o segundo baseado no do custo do investimento. Na maioria dos casos a decisão é a favor da aplicação do RFID, principalmente pela redução dos estoques. 
Segundo GLOVER \& BHATT (2007), a utilização da tecnologia RFID traz vantagens sobre outras tecnologias, refletidas no custo do gerenciamento de um processo. Algumas destas vantagens são:

$\begin{array}{ll}\checkmark & \text { Não é necessário alinhamento; } \\ \checkmark & \text { Altas velocidades em controle de estoque: } \\ \checkmark & \text { Independência da forma do produto rastreado; } \\ \checkmark & \text { Permite diversos níveis de registro } \\ \checkmark & \text { Possibilita a regravação complementando dados armazenados. }\end{array}$

Os autores reconhecem 5 períodos distintos na história das implantações de Sistemas com Tecnologia RFID nas organizações, são elas:

$\checkmark \quad$ Período proprietário: Tem como principal característica a identificação pura do elemento utilizador.

$\checkmark$ Período de compatibilidade: Nesta fase grandes empresas incentivaram seus parceiros a fazerem uso da tecnologia, porém sem perceber as vantagens competitivas e a empresa patrocinadora busca a compatibilidade entre sistemas.

$\checkmark \quad$ Período Inicial de Uso do RFID: As empresas utilizam a tecnologia em seus processos, gerando dados e informações para gestão.

$\checkmark$ Período Avançado de uso do RFID: Corresponde ao compartilhamento de informações entre parceiros, portanto demandando infra-estrutura mais robusta e padrões mais rígidos.

$\checkmark$ Período da Internet das Coisas: É o período mais promissor no uso do RFID, pois permite que as informações estejam disponíveis na nuvem, possibilitando o reconhecimento instantâneo de todos os atributos de uma cadeia produtiva. Nesta, altos índices de segurança e privacidade deverão ser atendidos e todo produto terá uma única identidade digital.

Pode-se observar pelas aplicações no mercado que atualmente o quarto estágio é o que mais se enquadra, pois as parcerias estratégias de atendimento ao cliente assim o exigem. 
GLOVER e BHATT (2007) apresentam na Figura 6 o posicionamento da tecnologia RFID entre outras utilizadas para identificação e as aplicações que com ele já são realizadas.

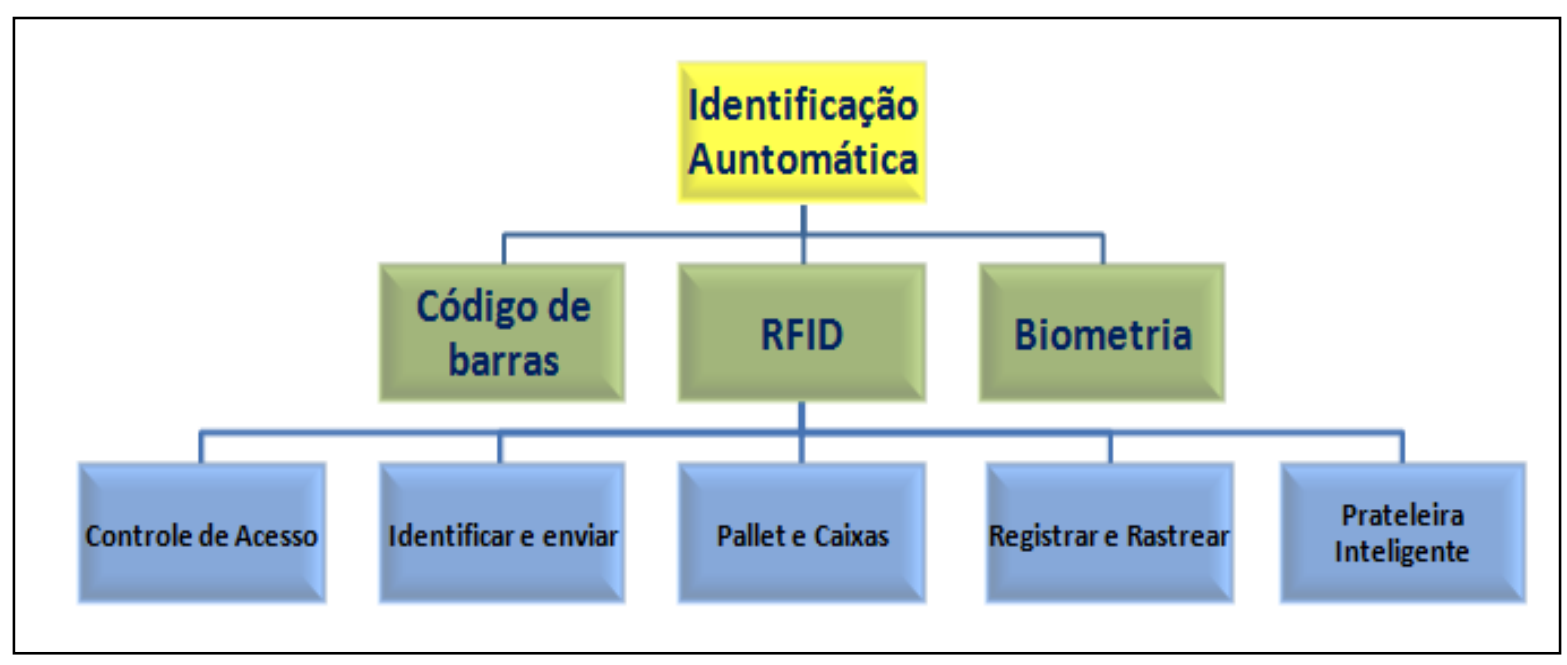

Figura 6 - Relacionamento entre aplicações do RFID - GLOVER \& BHATT (2007 pág 9)

Controle de Acesso: Esta aplicação é simples e somente controla acessos em áreas restritas, pela simplicidade tem fragilidade em processos que evitem falsificações ou de procedimentos de emergência.

$\checkmark \quad$ Identificar e Enviar: Nesta configuração, também simples, é possível relacionar o RFID a um determinado elemento físico, permitindo acompanhá-lo em uma cadeia. Esta configuração também tem pontos frágeis como: Custo, Isolamento, Falha no identificador, Impacto nos processo.

$\checkmark$ Registros em Pallets e Caixas: É uma aplicação comum onde se identifica uma caixa com um ou mais itens, mantendo-se o caráter de rastreamento. Também nesta aplicação são necessários cuidados com: Integridade do pallet ou caixa; Orientação do pallet; Conteúdos que interferem.

Prateleiras Inteligentes: Esta aplicação permite o controle do movimento do item controlando automaticamente estoques $e$ substituições, além de suas características próprias como, validade, preço, origem, etc. 
Nos casos apresentados as informações estão armazenadas num banco pertencente ao Sistema de Informações, e qualquer acesso a eles precisa obrigatoriamente passar por um protocolo de interação, o que muitas vezes inviabiliza a busca. Esta situação abre a possibilidade de um novo modelo aplicativo onde as informações acompanhem o item na memória do próprio RFID estabelecendo-se um Modelo Informado de Processo.

Em seus estudos SABBAGHI e VAIDYANATHAN (2008) preveem que o RFID fará parte de uma infraestrutura Universal que apoiará o comércio, a indústria e os serviços adicionando valor ao longo da Cadeia de Suprimentos e consequentemente melhorando a gestão dos negócios.

Novas aplicações com RFID devem ser precedidas de estudos e de um processo de design (como o que será proposto neste trabalho), que segundo GLOVER \& BHATT (2007) devem atender os tópicos:

$\checkmark \quad$ Avaliar se o processo trará melhorias após a implantação.

$\checkmark$ Considerar a relação de "custos $\boldsymbol{x}$ benefícios" da implantação

$\checkmark \quad$ Estruturar um projeto visionário e amplo, que permita o crescimento contínuo.

$\checkmark \quad$ Garantir ações flexíveis para amadurecimento do projeto.

$\checkmark$ Compartilhar com seus parceiros a nova tecnologia.

A Figura 7 mostrada por VINISCH,et all I(2009) indica que um processo de negócio pode ser dividido em dois sub-processos, Operacionais e Gerenciais, que podem ter Melhorias com o uso RFID, classificadas como:

Automáticas: As que acontecem em função de processos mais eficientes que geram: Redução de custos e Aumento da confiabilidade.

$\checkmark$ Informativas: Que aparecem pela otimização dos processos como: Respostas rápidas; Redução de desperdícios e Flexibilidade. 


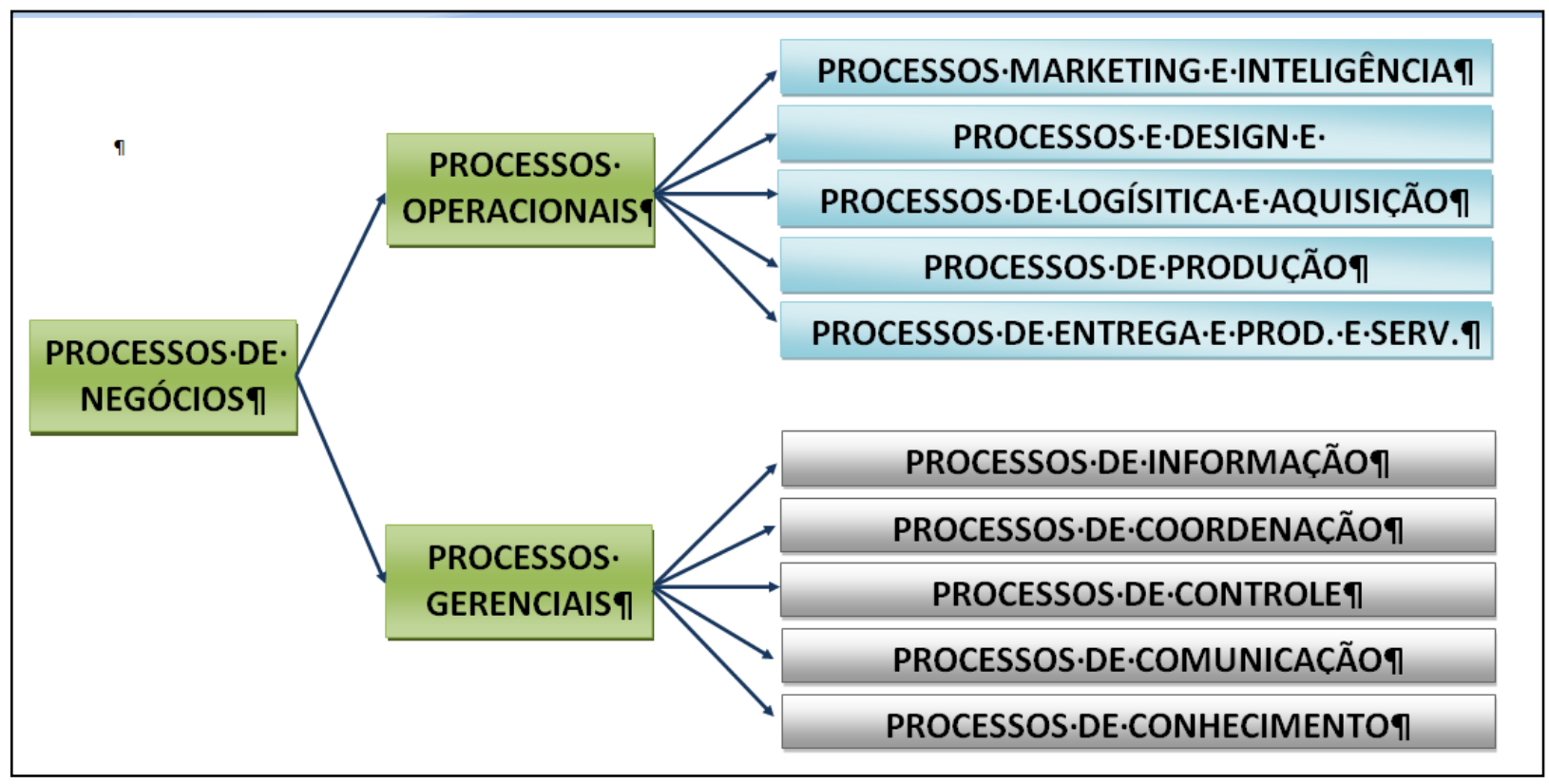

Figura 7 - Processos de negócio VINISCH, et all (2009 p. 1297)

\subsubsection{Aspectos técnicos do RFID.}

Como já mencionado a Tecnologia RFID ainda vem sendo subutilizada e entendida como uma ferramenta de uso específico para o rastreamento. SABBAGHI e VAIDYANATHAN (2008 p.80), dizem que "atualmente o RFID pode ser visto principalmente, como um aplicativo de rastreamento eficiente. No entanto os impactos serão maiores em novos aplicativos que se utilizem da INTELIGÊNCIA TECNOLÓGICA".

HAKIMI, MONTREUIL e RUIZ (2008) enfatizam que o uso da tecnologia RFID de forma pura e simples não traz ganhos ao Negócio, é fundamental que seu Modelo seja revisto e modernizado pelo uso da mesma. Segundo os autores a tecnologia RFID tende a se consolidar em novos projetos de Logística e "Supply Chain", pois as inovações tecnológicas oferecem ao dispositivo novas soluções a problemas até então não resolvidos, dos quais são exemplos:

A miniaturização dos componentes eletrônicos que possibilita a fabricação de "chips" de maior capacidade de memória com menor impacto nas dimensões da "tag". 
$\checkmark \quad$ Dispositivos inteligentes que permitem a estruturação de redes de alta velocidade com dispositivos RFID.

$\checkmark \quad$ O aumento da capacidade de processamento de servidores, cada vez mais potentes, associada a redes de banda larga de alta confiabilidade permite ao RFID uma aplicação "On-line".

$\checkmark$ Escopos dos projetos RFID diferenciados a partir da preocupação com a integração com os sistemas existentes.

A Figura 8 ilustra o novo posicionamento dos dispositivos RFID dentro da nuvem de informações, onde a possibilidade de novas aplicações é irrestrita, permitindo novos olhares para a "Supply Chain" até hoje não imaginadas, como é o caso do Agronegócio.

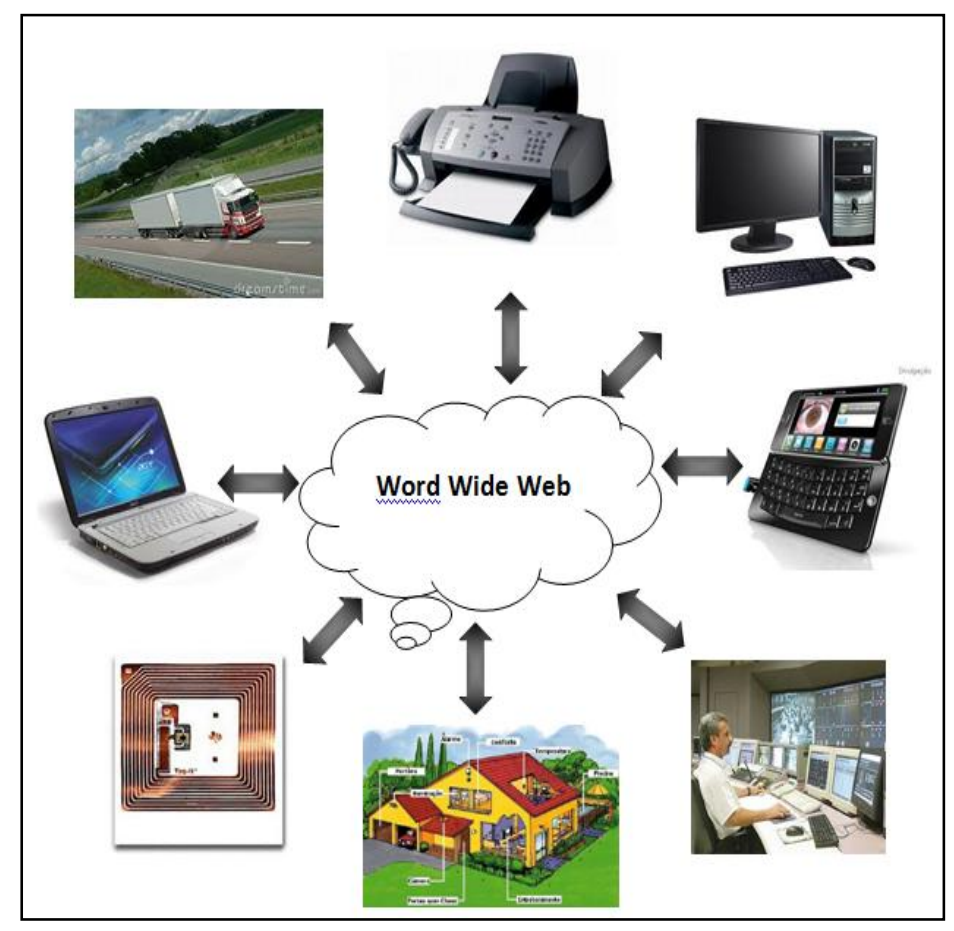

Figura 8 - Vida em Rede - Glover e Bhatt (2007 p. 21) 
Segundo DOLGUI E PROTH (2008) o RFID deve ser o sucessor tecnológico do Código de Barras, apresentando ainda duas grandes vantagens:

É possível atribuir identificação ao item, permitindo individualizar cada elemento de um universo similar.

$\checkmark \quad$ A facilidade de leitura e gravação que não precisa alinhamentos, logo gerando ganhos de escala.

O desenvolvimento de projetos com tecnologia RFID deve ter uma preocupação com as formas arquitetônicas dos sistemas que devem fazer parte do processo de design. Para tanto é preciso seguir uma rotina de execução recomendada, baseada nas seguintes etapas:

Codificação de RFID: É a etapa inicial de um projeto de implantação RFID e nela se define o escopo para a transformação da linguagem de máquina em linguagem dos usuários, ou seja, cria-se a identidade do RFID associada ao produto.

$\checkmark \quad$ Identificação dos RFID codificados: A utilização de dispositivos RFID em sistemas de "Supply Chain" está sujeita a falhas, sendo assim, um bom projeto deve considerar defeitos de fabricação, danos na instalação e o respectivo custo de reposição.

$\checkmark \quad$ Rastreamento da movimentação por meio de Identificadores: Os dados da movimentação de produtos podem ser levantados e monitorados, melhorando o desempenho da cadeia, são exemplos: quantidade, horário de chegada, horário de envio, responsabilidades, tempo de estocagem, atribuições, sanidade, etc. A importância do conhecimento destes dados definirá a forma distributiva dos leitores na planta, garantindo que as leituras realmente aconteçam.

$\checkmark \quad$ Integração dos dados ao negócio: Qualquer solução que utilize a tecnologia RFID, não pode estar focada somente em seus aspectos tecnológicos, é necessário que exista um protocolo de integração com os sistemas implantados. 
$\checkmark$ Produção de informações compartilhadas: As informações geradas a partir do RFID precisam estar disponíveis aos integrantes da Cadeia de Suprimentos gerando uma relação "Business to Business - B2B", entre os parceiros.

$\checkmark \quad$ Auto gerir-se de forma inteligentes: As demandas geradas a partir de um projeto utilizando RFID precisam ser rapidamente resolvidas, portanto a interação com outras ferramentas tecnológicas é vital, para possibilitar a inteligência na gestão de um processo informado.

SABBAGHI e VAIDYANATHAN (2008) propõem oito processos de Gestão que precisam ser monitorados e avaliados para garantir o sucesso de um projeto RFID, são eles:

$\begin{array}{ll}\checkmark & \text { Gestão da Relação com o Cliente } \\ \checkmark & \text { Gestão do Serviço ao Cliente } \\ \checkmark & \text { Gestão de Demanda } \\ \checkmark & \text { Gestão de Pedidos } \\ \checkmark & \text { Gestão do Fluxo de Fabricação } \\ \checkmark & \text { Gestão da Relação com Fornecedores } \\ \checkmark & \text { Gestão de Desenvolvimento de Produtos } \\ \checkmark & \text { Gestão da Devolução }\end{array}$

\subsubsection{Modelo básico de um Sistema RFID}

O projeto de um Sistema RFID é único e customizado para atender os "Business Process" da Organização. Para facilitar esta construção GLOVER \& BHATT (2007), propõem um esquema básico, ilustrado na Figura 9, a partir do qual se podem desenvolver os requisitos de cada caso a partir de seus principais componentes: Identificadores, Leitores, "Middleware". 


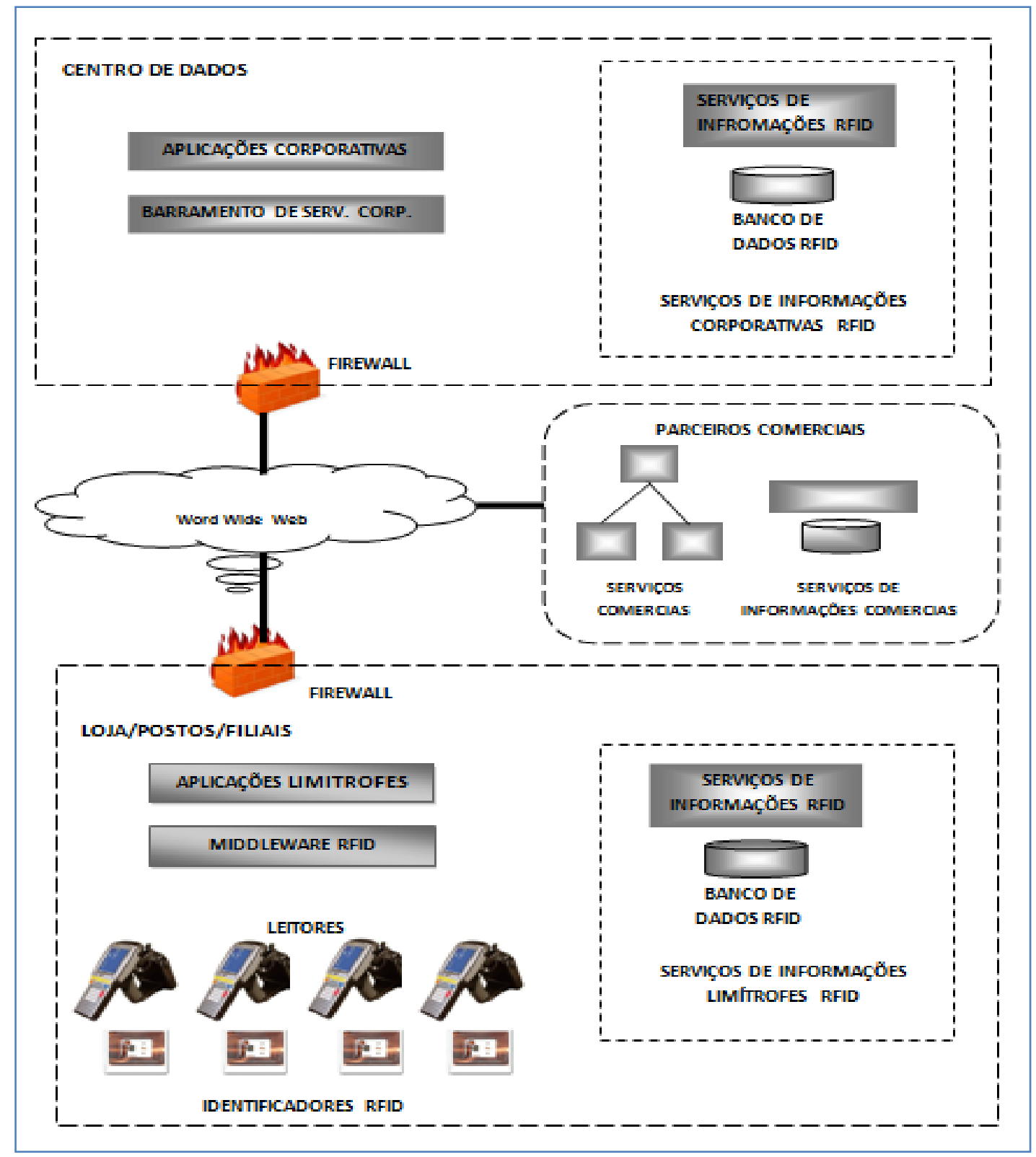

Figura 3 - Componentes básicos de um sistema RFID Glover \& Bhatt (2007 p.33)

GLOVER \& BHATT (2007) recomendam que se de atenção a determinados itens na elaboração de um Projeto Modelado com tecnologia RFID, dentre eles:

$\checkmark$ Privacidade e Segurança;

$\checkmark$ Desempenho;

$\checkmark$ Escalabilidade;

$\checkmark$ Maleabilidade;

$\checkmark \quad$ Extensibilidade e Capacidade de Manutenção; 
$\checkmark \quad$ Diretrizes de Arquitetura;

$\checkmark$ Começar com os Requisitos do Negócio;

$\checkmark \quad$ Avaliar a infra-estrutura existente

$\checkmark$ Processar os dados nos limites;

$\checkmark$ Buscar trabalhar níveis de rastreamento;

$\checkmark \quad$ Modelo de gestão do sistema;

$\checkmark$ Usar "Middleware" adequado

Segundo propõem SABBAGHI e VAIDYANATHAN (2008), cada Sistema RFID tem particularidades para operar satisfatoriamente dentro de um processo de negócio. Dependendo de sua aplicação aumenta a complexidade do desenvolvimento e implantação, porém três subsistemas básicos sempre estarão presentes na concepção, são eles:

$\checkmark \quad$ Sistema RFID - Que identifica os componentes;

$\checkmark \quad$ Sistema de Gestão - Que utiliza os dados coletados pelo RFID, para apoiar o negócio;

$\checkmark$ Gestão empresarial: Que organiza e compartilha informações com os parceiros da Cadeia.

\section{Identificadores}

Os identificadores RFID, comumente chamados de "tags", são elementos que precisam ser reconhecidos por um sistema de leitores, criando uma "conversação" entre dispositivos por meio de ondas de rádio freqüência, conforme Figura 10. 


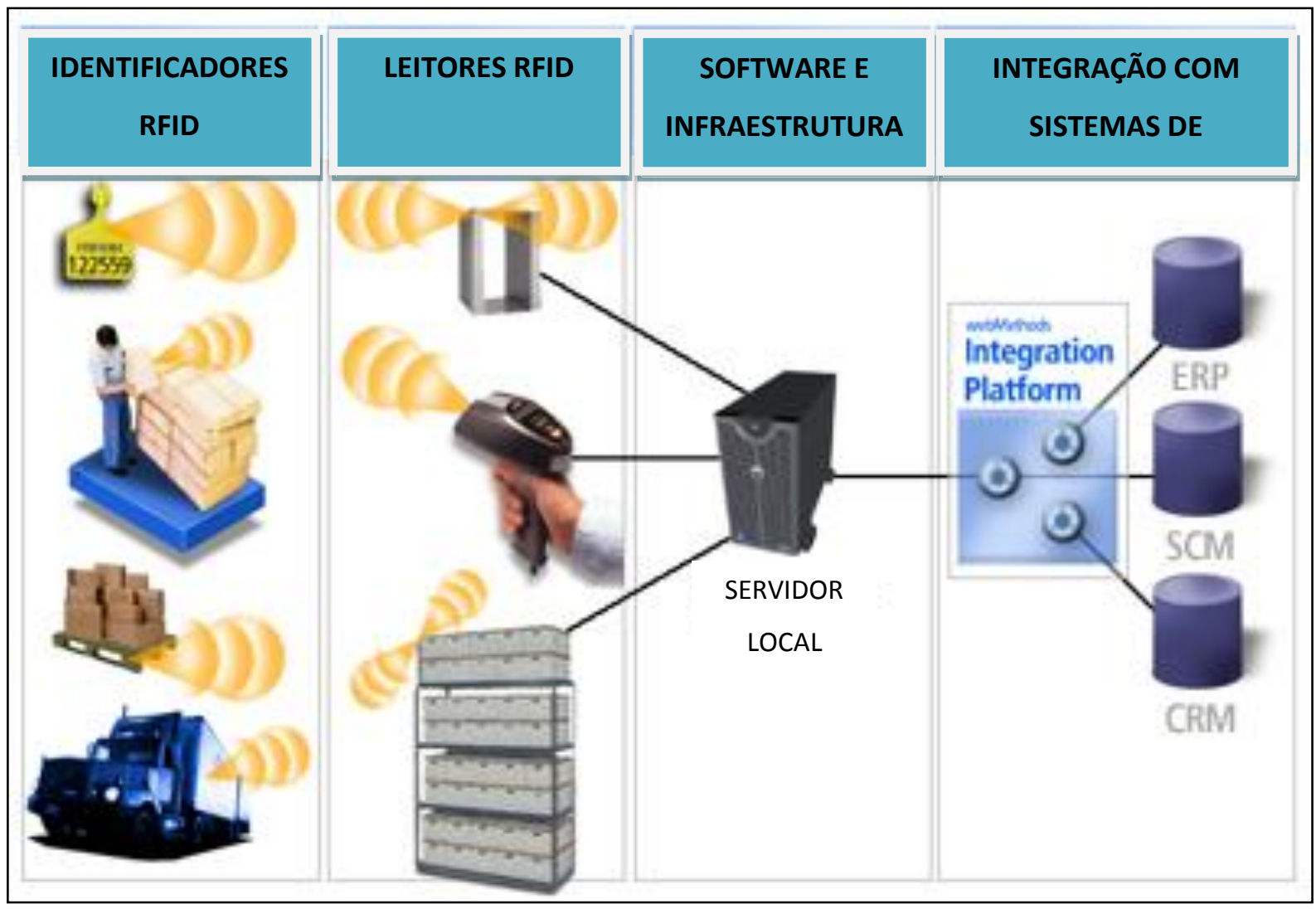

Figura 10 - Modelo de comunicação RFID http://www.jesic-tech.com/RFID.html

O mercado oferece diversas opções e tipos de configurações para Tags RFID, que por sua vez, permitem uma infinidade de aplicações, cabendo ao Projetista Desenvolvedor definir durante a elaboração do Projeto aquele que melhor atende as especificações. Segundo GLOVER \& BHATT (2007), podem ser definidas como características importantes:

$\checkmark$ Embalagem: Esta característica está relacionada com a forma de encapsulamento do RFID e sua respectiva forma de utilização. Atualmente podem-se encontrar Dispositivos em chaveiros, etiquetas, button, cartões, etc.

$\checkmark$ Acoplamento: Refere-se aos meios utilizados para estabelecer a conversação entre leitor e identificador, nele devem-se considerar a freqüência de comunicação, preço e interferência.

$\checkmark$ Energia: Vincula-se ao tipo de alimentação que os circuitos do RFID terão, classificando-o em Ativo, Passivo ou Semi-passivo. 
$\checkmark$ Capacidade de armazenamento de informações: A definição da capacidade de armazenamento de um Identificador depende da aplicação, podendo ser de 1 a dezenas de bites.

$\checkmark \quad$ Faixa de leitura;

$\checkmark$ Material da embalagem;

$\checkmark \quad$ Fatores de forma;

$\checkmark \quad$ Compatibilidade com Padrões e Custo

$\checkmark \quad$ Matar/Desabilitar;

$\checkmark$ Gravação única;

$\checkmark \quad$ Multiplicidade de gravações;

$\checkmark$ Resistência Mecânica;

$\checkmark$ Segurança avançada;

$\checkmark$ Compatibilidade.

$\checkmark \quad$ Freqüência

Dentre os fatores citados a Frequência tem papel decisivo na definição de todos os equipamentos, impactando de forma direta nos custos de implantação. A Figura 3 mostra as faixas de frequência RFID existentes e regulamentadas no Brasil.

\begin{tabular}{|c|l|l|l|l|}
\hline NOME & \multicolumn{1}{|c|}{$\begin{array}{c}\text { FAIXA DE } \\
\text { FREQUENCIA. }\end{array}$} & \multicolumn{1}{|c|}{ FREQUENCIAS ISM } & $\begin{array}{l}\text { DISTANCIA } \\
\text { AO LEITOR }\end{array}$ & APLICAÇÕES TíPICAS \\
\hline $\begin{array}{c}\text { Baixa } \\
\text { freqüência } \\
\text { (LF) }\end{array}$ & $30-300 \mathrm{kHz}$ & Menor $135 \mathrm{kHz}$ & $50 \mathrm{~cm}$ & $\begin{array}{l}\text { Identificação de animais } \\
\text { e leituras próximas com } \\
\text { alto conteúdo de água. }\end{array}$ \\
\hline $\begin{array}{c}\text { Alta } \\
\text { freqüência } \\
\text { (HF) }\end{array}$ & $3-300 \mathrm{MHz}$ & $\begin{array}{l}6.78 \mathrm{MHz}, 13,56 \mathrm{MHz}, \\
27.125 \mathrm{MHz}, 40.680 \mathrm{MHz}\end{array}$ & 3 metros & $\begin{array}{l}\text { Controle de acesso a } \\
\text { prédios }\end{array}$ \\
\hline $\begin{array}{c}\text { Ultra Alta } \\
\text { Freqüência } \\
\text { (UHF) }\end{array}$ & $300 \mathrm{MHz}-3 \mathrm{GHz}$ & $\begin{array}{l}433.920 \mathrm{MHz}, 869 \mathrm{MHz}, \\
915 \mathrm{MHz}\end{array}$ & 9 metros & Caixas e caixotes \\
\hline $\begin{array}{c}\text { Microondas } \\
\text { Maior que } 3 \mathrm{GHz}\end{array}$ & $\begin{array}{l}2,45 \mathrm{GHz}, 5,8 \mathrm{GHz}, 24.125 \\
\mathrm{GHz}\end{array}$ & $\begin{array}{c}\text { Mais de 10 } \\
\text { metros }\end{array}$ & Identificação de veículos \\
\hline
\end{tabular}

Tabela 2 - Faixas de Frequência do RFID - Glover \& Bhatt (2007)

Segundo GLOVER e BHATT (2007) a forma como o identificador e o leitor se relacionam entre si define o tipo acoplamento, que pode ser: 
Acoplamento difuso de retorno: Neste tipo de acoplamento o leitor envia um sinal ao identificador que reflete a onda com as informações a serem percebidas pelo leitor. A frequência nos dois sentidos é a mesma, logo a comunicação entre leitor e identificador não acontece simultaneamente.

$\checkmark$ Acoplamento indutivo: É um tipo comum de acoplamento para uso remoto, o leitor fornece energia de forma indutiva aos identificadores, que devolvem os dados da mesma forma, este acoplamento também é chamado de acoplamento de transformador, representado na Figura 11.

Acoplamento magnético: É um acoplamento muito semelhante ao acoplamento indutivo, porém a bobina do leitor é dividida em duas partes e reforçada por um núcleo de ferrite. A distância entre as bobinas fornece um acoplamento muito forte, muito comum em "smart cards".

Acoplamento capacitivo: É um acoplamento forte e normalmente é usado quando o identificador está junto com o leitor, da mesma forma que o acoplamento magnético é muito usado em "smart cards".

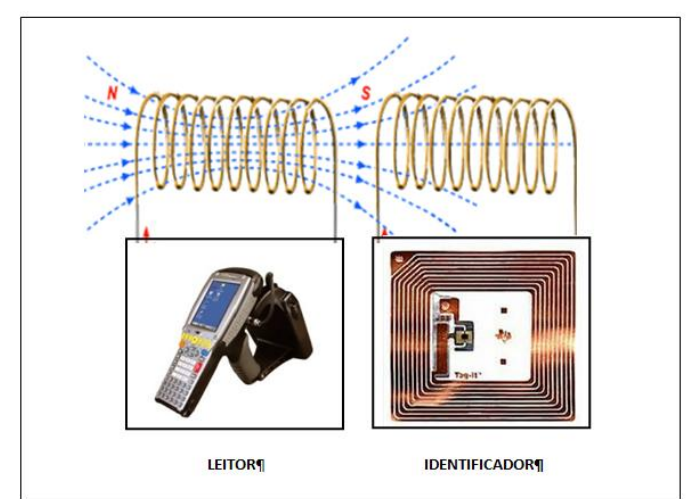

Figura 11 - Acoplamento indutivo GLOVER e BHATT (2007 p. 33) 
GLOVER E BHATT (2007) apresentam no Tabela 4 a classificação dos identificadores feita pela EPC Global, Inc, levando em consideração a forma de trabalho.

\begin{tabular}{|c|l|}
\hline CLASSE & \multicolumn{1}{|c|}{ DESCRIÇÃO } \\
\hline Classe 0 & Passivas, apenas de leitura \\
\hline Classe 0+ & Passiva, grava uma vez, mas usando protocolos da Classe 0 \\
\hline Classe I & Passiva, grava uma vez \\
\hline Classe II & Passiva, grava uma vez com extras como criptografia \\
\hline Classe III & Regravável, semi-passiva (chip com bateria, comunicações com energia do leitor \\
\hline Classe IV & $\begin{array}{l}\text { Regravável, ativa, identificadores "nos dois sentidos", que podem conversar com outros } \\
\text { identificadores, energizando suas próprias comunicações. }\end{array}$ \\
\hline Classe V & $\begin{array}{l}\text { Podem energizar e ler identificadores das Classes I, II e III e ler identificadores das Classes IV } \\
\text { e V, assim como atuar como identificador da Classe IV. }\end{array}$ \\
\hline
\end{tabular}

Tabela 3 - Classes de identificadores EPC GLOBAL - Glover \& Bhatt ( pág. 65 2007)

\section{Leitor RFID}

Um leitor tem a função de perceber a presença dos identificadores RFID nas proximidades, portanto segundo GLOVER \& BHATT (2007) o sistema lógico leitor terá quatro subsistemas representados na Figura 12.

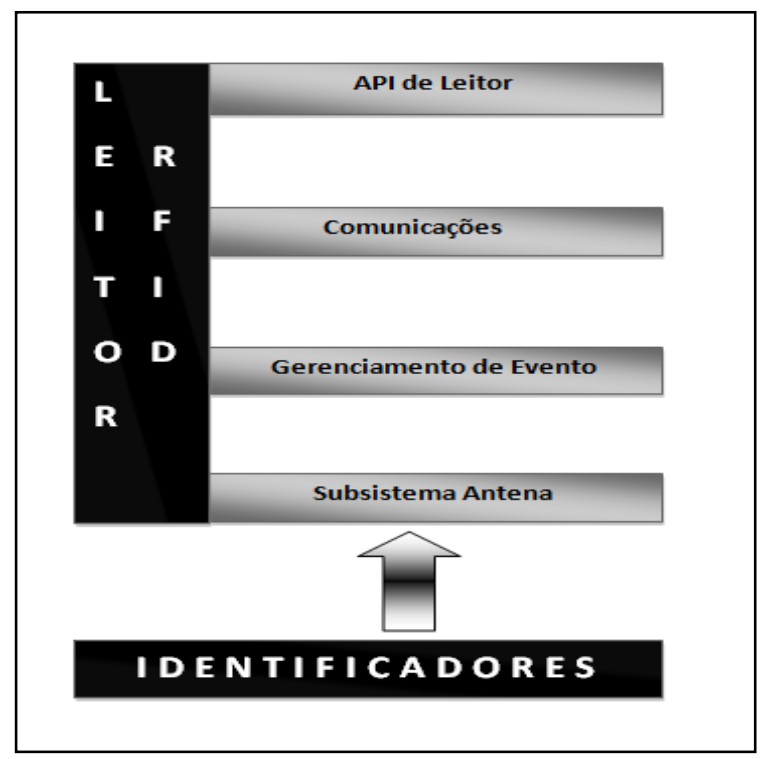

Figura 12 - Componentes lógicos de um leitor - GLOVER e BHATT (2007 p. 100) 
$\checkmark$ API ("Application Program Interface") - organiza as ferramentas de interface dos aplicativos com o leitor possibilitando sua configuração, monitoramento e gerenciamento.

$\checkmark$ Comunicação - operacionaliza a comunicação entre o leitor e o identificador independentemente do protocolo adotado, garantindo assim a conversação como o "Middleware".

$\checkmark$ Gerenciamento de Evento - Quando um leitor percebe um identificador em sua área de atuação, diz-se que ele esta observando, $e$ à medida que o mesmo reconhece a observação como única, passa a ser chamada de evento. Por sua vez não são todos os eventos que interessam, para tanto um subsistema faz esta avaliação.

$\checkmark \quad$ Antena - Este subsistema permite que o leitor se comunique com o identificador RFID, por meio de antenas, lógicas e interfaces. Quando se faz a seleção de leitores deve-se observar: a compatibilidade com todos os leitores; regulamentações de uso de telecomunicações e ambientes físicos sujeitos a interferências e danos físicos.

\section{“Middleware” RFID e Protocolos}

Um sistema conforme representado na Figura 10 (pág. 43) realiza milhares de leituras em pouco tempo, mas nem todas são importantes para a Gestão, portanto um filtro de informações precisa ser utilizado. Os filtros destas leituras são feitos por softwares especializados denominados de "Middleware" que padronizam a maneira de organizar as informações.

ADANCOVA e TOBES (2007) afirmam que as vantagens de um bom Sistema RFID estão em:

\footnotetext{
$\checkmark \quad$ Poder usar informações limpas, seguras e rápidas;

$\checkmark \quad$ Não ter necessidade de intervenção;

$\checkmark$ Leituras simultâneas de vários "tags";

$\checkmark$ Redução dos custos em função da redução de erros de informação.
} 
Os processos de comunicação são fundamentais para que um Sistema RFID tenha sucesso. Para tanto a interligação a redes de comunicação é indispensável. Desta forma, para que Identificadores, leitores e "Host" (Equipamentos com IP, ligados a rede), possam estabelecer uma conversação precisam seguir uma série de regras denominadas de PROTOCOLOS, que GLOVER e BHATT (2007 p. 69) definem como:

Um conjunto de regras formais definindo como transmitir dados, especialmente através de uma rede. Protocolos de baixo nível os padrões físicos e técnicos a serem observados, ordenamento de bits e bytes, a transmissão e detecção e correção de erros do fluxo de bits. Protocolos de alto nível lidam com a formatação de dados, incluindo a sintaxe de mensagens, o diálogo do terminal como o computador, conjuntos de caracteres, sequenciamento de mensagens, etc.

GLOVER e BHATT (2007) lembram que projetos que são desenvolvidos apropriando-se de novas tecnologias vão tendo conceitos consolidados durante sua realização e muitos problemas precisam ser resolvidos a partir de sua ocorrência, isto não é diferente para a tecnologia RFID. Felizmente para alguns destes problemas já existem soluções desenvolvidas que podem ser incorporadas a novos projetos, tais como: Isolamento, Anti-colisão e Identidade, o que respectivamente estão relacionados com: criar um fluxo de informações ordenadas, estabelecimento do tempo de conversação e a relação única do objeto com o identificador.

A comunicação entre Leitor e "Host" pode ser de duas categorias, Assíncrona e Síncrona. Na primeira a comunicação acontece quando existe uma mudança de estado do leitor e a segunda através de uma varredura periódica em que o leitor busca novas ocorrências em um dado intervalo de tempo. Porém os diversos protocolos criados geraram dificuldades de comunicação entre fornecedores diferentes de leitores e foi preciso se criar um protocolo geral pela EPC Global, assegurando o mínimo de funcionalidades e compatibilidade entre diferentes equipamentos. A proposta da EPC Global oferece três níveis de protocolo, conforme mostra a Figura 13, respectivamente: Camada do Leitor, Camada de Mensagem e Camada de Transporte. A primeira camada tem a finalidade de controle do conteúdo entre mensagens enviadas entre leitor e host, a segunda pelo gerenciamento da 
conexão, segurança, comandos, respostas e notas do leitor e terceira pela definição de serviços de suporte a rede.

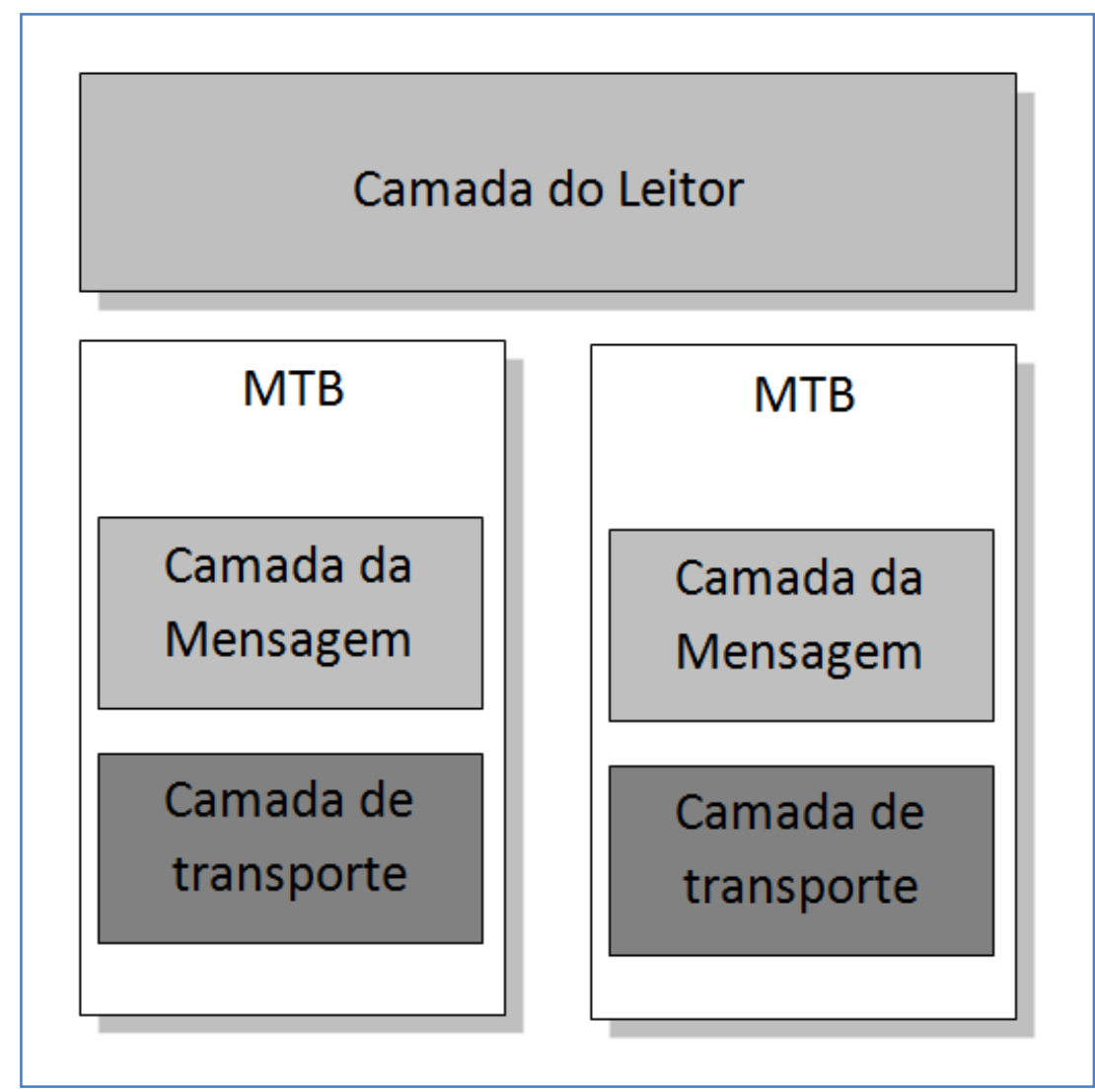

Figura 13 - Camadas do Protocolo de Leitor EPC Global - GLOVER e BHATT (2007 p. 115)

\subsection{4 - Orientações para implantar o RFID no SCM}

O RFID tem aplicações limitadas e setorizadas no mundo corporativo e ainda assim com poucas variações aplicativas, conforme resultado da pesquisa de ZHU, MUKHJOPADHYAY e KURATA (2012 p. 154)

Em pesquisa realizada na União Européia no ano de 2010 apenas $3 \%$ das empresas de logística estão desenvolvendo algum tipo de aplicação RFID, e que destas $56 \%$ o utilizam como controle de acesso, 29\% para controle de estoque, $24 \%$ com prevenção ao roubo, $21 \%$ para controle da manufatura. 
DOUG e PROTH (2008) recomendam os seguintes cuidados para iniciar um projeto com tecnologia RFID:

$\checkmark \quad$ Escolher a tecnologia apropriada para o caso;

$\checkmark$ Analisar profundamente $o$ problema a ser resolvido e suas conseqüências;

$\checkmark$ Compartilhar os Sistemas de RFID com os de TI;

$\checkmark \quad$ Estimar com pequena margem de erro o número de dados a serem envolvidos;

$\checkmark$ Buscar implantar o RFID ao nível do item, permitindo acompanhá-lo efetivamente ao longo da Cadeia.

Ainda segundo DOUG e PROTH (2008) o Escopo de um Projeto de Tecnologia RFID deve estar focado nas vantagens que ele pode oferecer a corporação, pois estas servirão de argumentos para garantir os investimentos necessários para aplicações em Supply Chain (SC), algumas vantagens já são comprovadas:

$\checkmark \quad$ A leitura de vários itens simultaneamente, o que permite acompanhar o desempenho da Cadeia em tempo real;

$\checkmark \quad$ O Aumento da segurança do produto principalmente se este for do segmento alimentício;

$\checkmark \quad$ A Redução de custos administrativos em função da simplificação dos processos da manufatura;

$\checkmark$ A Criação de um novo modelo de relacionamento com fornecedores e consumidores;

$\checkmark$ O Controle e redução de estoque;

$\checkmark$ O Controle de produtos em ambientes hostis; e

$\checkmark$ A Garantia da qualidade em toda cadeia produtiva.

BLECKER e HUANG (2008 p. 04) apresentam na Figura 14 um modelo com procedimentos para desenvolver um Projeto com RFID e o descritivo de suas respectivas fases, o que pode ser também seguido no $S$ 


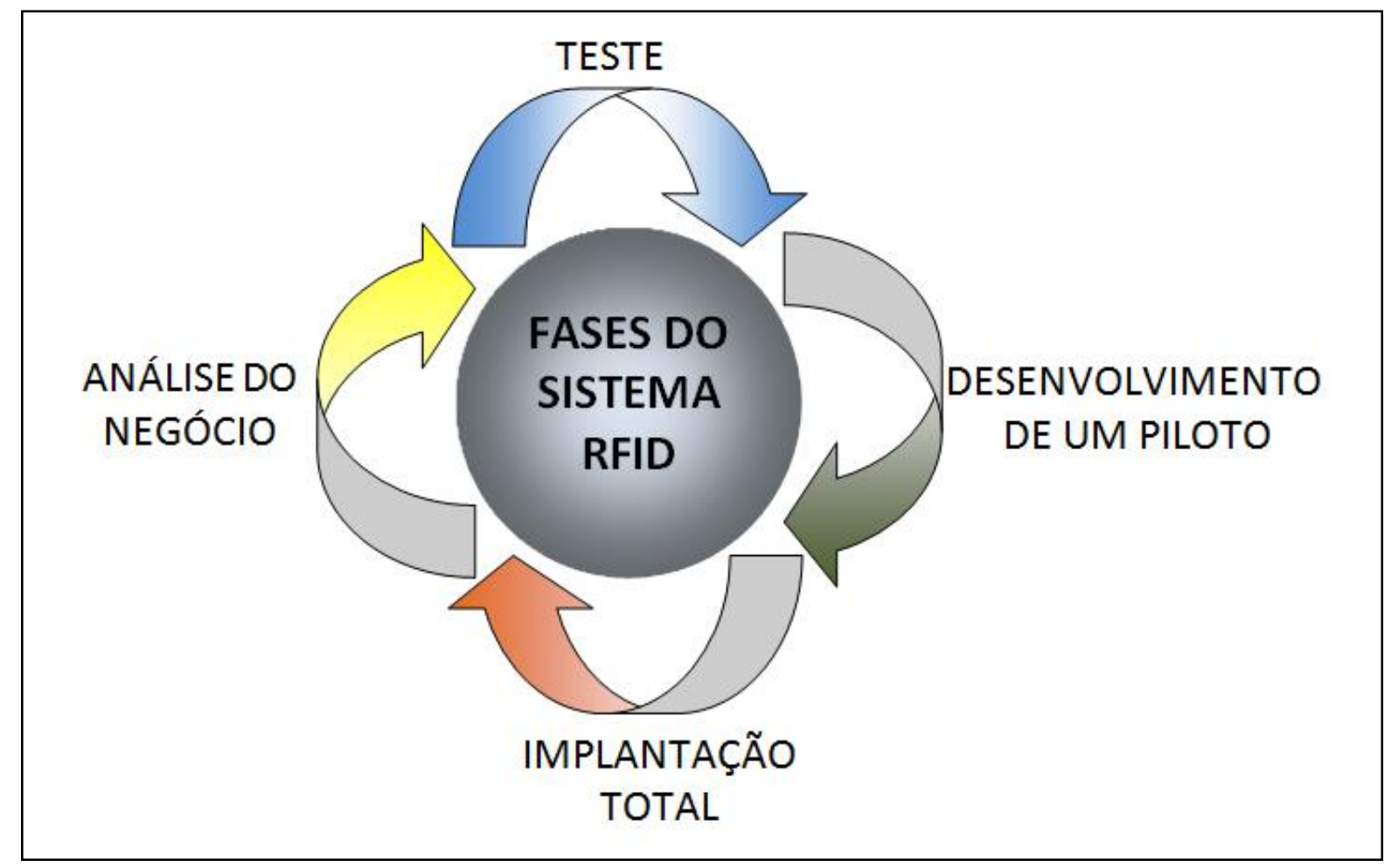

Figura 14 - Fases de implantação do RFID no SCM BLECKER e HUANG (2008 P. 04)

Análise do Negócio: Estuda o negócio e seus requisitos, determinando os envolvidos e suas expectativas. Esta fase é subdividida em:

- Análise do ambiente de negócio: Levanta os pontos fortes e fracos do projeto;

- Avaliação dos processos de Negócio existentes: Busca conhecer como funciona a organização;

- Definição do projeto: Define o escopo do projeto envolvendo todos os parceiros e interessados;

- Escolha do fornecedor: Levanta fornecedores confiáveis em todas as etapas do projeto.

- Análise Econômica: Determina a viabilidade econômica do projeto no curto, médio e longo prazo motivando a participação dos investidores. 
- Cenário alternativo: Realiza a análise de riscos determinando rotas alternativas caso problemas ocorram na implantação do projeto.

Testes: testes de laboratório são necessários para afinar os resultados evitando que falhas somente sejam perceptíveis durante a implantação.

$\checkmark \quad$ Implantação de Projeto Piloto: Acontece no ambiente real e permite ajustar antenas e leitores; compatibilidade com sistemas de TI; e treinar os usuários.

Implantação Completa: Pressupõe que o piloto funcionou e será incorporado ao projeto completo e que os problemas foram detectados e corrigidos.

\section{Dificuldades do RFID no SCM}

Toda Inovação Tecnológica encontra barreiras no início de seu ciclo de vida, embora o conceito de RFID não seja novo, suas aplicações são bastante recentes e segundo GROVER e BHATT enfrentam dificuldades com:

Normas e Padrões: Com o crescimento da Tecnologia RFID os governos estão criando regulamentações diversas, dentre elas as faixas de freqüência em que os dispositivos podem atuar. A dificuldade está justamente nos parâmetros destas regulamentações, que não são universais, dificultando a compatibilização de equipamentos.

Custos: $O$ custo de projetos que utilizam novas tecnologias muitas vezes é impeditivo da massificação do uso, porém o RFID tem tido redução drástica nos custos, mas ainda não alcançou valores ideais em função dos altos valores necessários para infra-estrutura e suporte.

$\checkmark$ Confiabilidade: $O$ ambiente exerce influência direta no desempenho dos dispositivos RFID e leituras podem não ser feitas, deixando o Sistema com pouca confiabilidade. A taxa de leitura deve ser o mais próximo possível de 100\%.

$\checkmark$ Privacidade: As informações contidas no RFID devem ser endereçadas as pessoas que dela façam uso, garantindo privacidade, 
sigilo e confidencialidade. Desta forma 0 uso de ferramentas apropriadas deve fazer parte deste sistema.

Segurança: A preocupação nesta abordagem está que as informações contidas no RFID sejam confiáveis e não passíveis de adulterações por Sistemas paralelos, ou seja, a fidedignidade da informação.

LU, HUANG e LI, (2011) afirmam que o mercado ainda apresenta preocupações com o RFID, principalmente com questões técnicas, de confiabilidade, custos e práticas éticas. Por outro lado, LI e DING (2007) contrapõem a afirmação mostrando que é possível aumentar a segurança nos Sistemas RFID com algum dos procedimentos:

$\checkmark \quad$ Matar a Tag: Consiste em desabilitá-la definitivamente na entrega;

$\checkmark \quad$ Tag bloqueio: Cria uma limitação de leitura em um ambiente;

$\checkmark \quad$ Criptografia: Consiste em ter informações codificadas;

$\checkmark \quad$ Senha: Faz a limitação de quem tem acesso as informações além de pseudônimos;

$\checkmark \quad$ Distâncias de leitura. Dificulta a leitura por dispositivos fora de área.

Contribuem com esta temática LI, GODON e VINISCH (2010), quando demonstram que existem muitas ferramentas disponíveis para aumentar o nível de segurança em Sistemas de TI, basta elaborar um projeto robusto e cuidadoso.

HESSEL et all (2009) afirma que analisar as vantagens de um sistema RFID, não pode ser feito exclusivamente usando o cálculo do Retorno do Investimento (ROI), pois muitos aspectos de sua utilização são intangíveis, sendo importante construir um robusto business case a partir de pilotos e provas.

\subsection{AGRONEGÓCIOS E SUPPLY CHAIN}

A história brasileira confunde-se com o agronegócio, mesmo antes de sua definição oficial e a exploração de madeira a partir do descobrimento deu início a este processo com uma sucessão de ciclos como o da borracha; da cana de açúcar; do café; e da agropecuária. 
A evolução dos processos primários conduziu naturalmente a constituição de organizações agroindústrias que fortalecem até hoje diversas cadeias produtivas. Afirma CONTINI (2012 p.01), que somente:

A partir dos anos 70 , o agronegócio brasileiro entra numa acelerada fase de modernização, com diversificação da produção, aumento da produção e da eficiência, notadamente da terra e da mão-de-obra. 0 aumento da eficiência da mão-de-obra está relacionado com a mecanização e a disponibilização de energia elétrica.

A pesquisa está cada vez mais presente nas diversas cadeias do agronegócio no intuito de diminuir custos e aumentar a qualidade de produtos, sendo assim novas variedades, novas formas de manejo de solo e novos produtos químicos têm colaborado para maior eficiência das cadeias do agronegócio. Por outro lado a garantia de qualidade exigida pelos clientes obriga cada vez mais a integração completa da Cadeia e CONTINI (2012 p.01), apresenta as diversas atividades econômicas ligadas ao Processo:

\footnotetext{
$\checkmark$ Insumos para a agricultura, como fertilizantes, defensivos, corretivos;

$\checkmark$ A produção agrícola, compreendendo lavouras, pecuária, florestas e extrativismo;

$\checkmark \quad$ A agroindustrialização dos produtos primários;

$\checkmark$ Transporte e comercialização de produtos primários e processados.
}

GUANZIROLI (2006 p.3) contextualiza de forma exata a profissionalização do campo e da agroindústria brasileira, quando descreve:

Nos últimos 20 anos, os níveis tecnológicos alcançados pelos produtores rurais brasileiros atingiram patamares expressivos que podem ser mensurados pelo aumento da produtividade no campo. Isso explica, por exemplo, o fato de o Brasil ter conseguido dobrar a produção de grãos para os atuais 100 milhões de toneladas, em relação à colheita de 50,8 milhões de toneladas obtida no início da década de 80, com a mesma área plantada. Este desempenho no campo só foi possível graças à utilização de insumos - basicamente sementes, adubo e agrotóxicos - de primeira linha disponíveis para o setor. Hoje o agronegócio, entendido como a soma dos setores produtivos com os de processamento do produto final e os de fabricação de insumos, responde por quase um terço do PIB do Brasil e por valor semelhante das exportações totais do país. 
GASQUES et all (2004) apresentam na Figura 15 um Modelo para o Sistema Agroindustrial brasileiro na forma de uma sequencia de processos que iniciam no produtor e terminam no consumidor. Nesta visão o processo não se restringe a produção no campo, mas passa pela industrialização e distribuição. A este conjunto de atividades denomina-se de Cadeia de Suprimentos do Agronegócio.

É importante lembrar que além das políticas macroeconômicas, das políticas setoriais e de evolução tecnologia, a organização do agronegócio tem sido um fator essencial para o seu sucesso, e o RFID pode cooperar significativamente para a sua eficiência e controle. Nesta óptica GASQUES et all (2004), apresentam alguns indicadores de desempenho do agronegócio:

\footnotetext{
$\checkmark \quad$ Participação no PIB;

$\checkmark$ Participação na balança comercial.

$\checkmark$ Produção agropecuária;

$\checkmark$ Venda de insumos;

$\checkmark \quad$ Interiorização, emprego e renda;

$\checkmark$ Posição no mercado mundial;

$\checkmark \quad$ Vantagem comparativa;

$\checkmark$ Relação de trocas;

$\checkmark$ Produtividade total dos fatores (PTF).
}

Dando continuidade a suas análises os autores ainda apresentam 3 fatores essenciais que explicam o sucesso do agronegócio brasileiro:

\footnotetext{
$\checkmark$ Pesquisa e Desenvolvimento;

$\checkmark$ Financiamento e

$\checkmark$ Organização do Agronegócio.
}

Destas constatações pode-se imaginar que é preciso uma ação para que os três fatores ocorram simultaneamente, ou seja, financiar a pesquisa para organizar a produção. 


\section{SISTEMA AGROINDUSTRIAL}

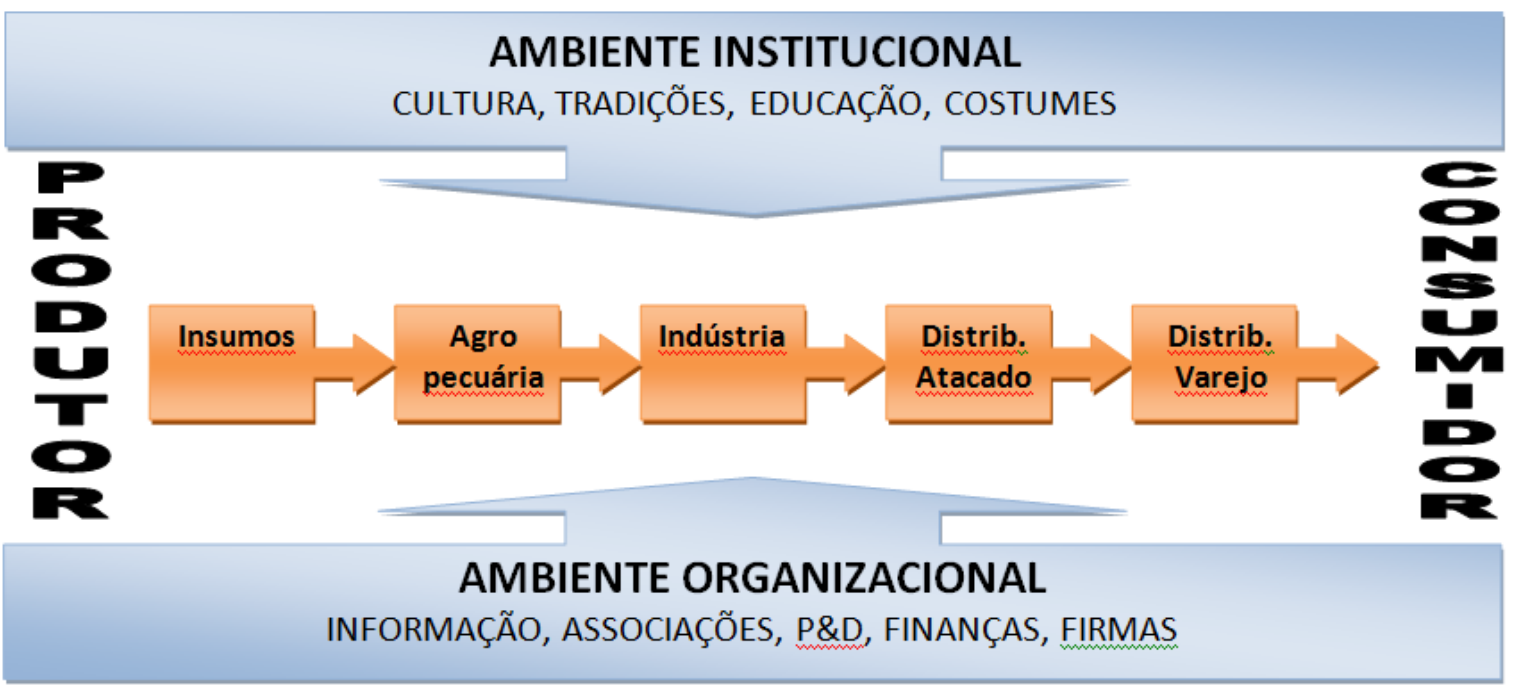

Figura 15 - Sistema Agroindustrial - GASQUES et all (2004 p.7)

GASQUES et all (2004) mostra na Figura 16 a representação do Agro cluster para o AGRONEGÓCIO os insumos que podem contribuir para a eficiência do setor bem como buscar vantagens competitivas e reciprocidade para os diversos atores envolvidos.

Apesar de todo sucesso do Agronegócio CONTINI (2012) mostra preocupação com os resultados cada vez mais portadores de recordes, pois seu conceito implica na existência de uma cadeia colaborativa e interdependente na busca de bons resultados. Entretanto, a manutenção de uma taxa de sucesso construída de forma participativa, demanda controles cada vez maiores dos processos parciais, que serão de difícil sustentação sem a implantação de um Processo Informado.

Nesta linha GUANZIROLI (2006) também mostra uma preocupação com o Agronegócio, primeiramente com a variação de preços no mercado externo e interno, uma vez que estes produtos são commodities e precisam ser competitivos com os concorrentes externos. A concorrência forte leva a uma busca pela redução de custos para a manutenção das margens de lucro, e desta forma a infra-estrutura de escoamento tem papel decisivo na composição dos preços, e esta é a segunda preocupação do autor, a infraestrutura. Neste contexto é esperado que existam 
muitas etapas a serem vencidas para garantir o sucesso da atividade e a Tecnologia será o grande diferencial das Cadeias de Suprimentos do Agronegócio.

\section{ELEMENTOS DOS AGRICLUSTERS: COMPETIÇAOO E COOPERAÇAOO}

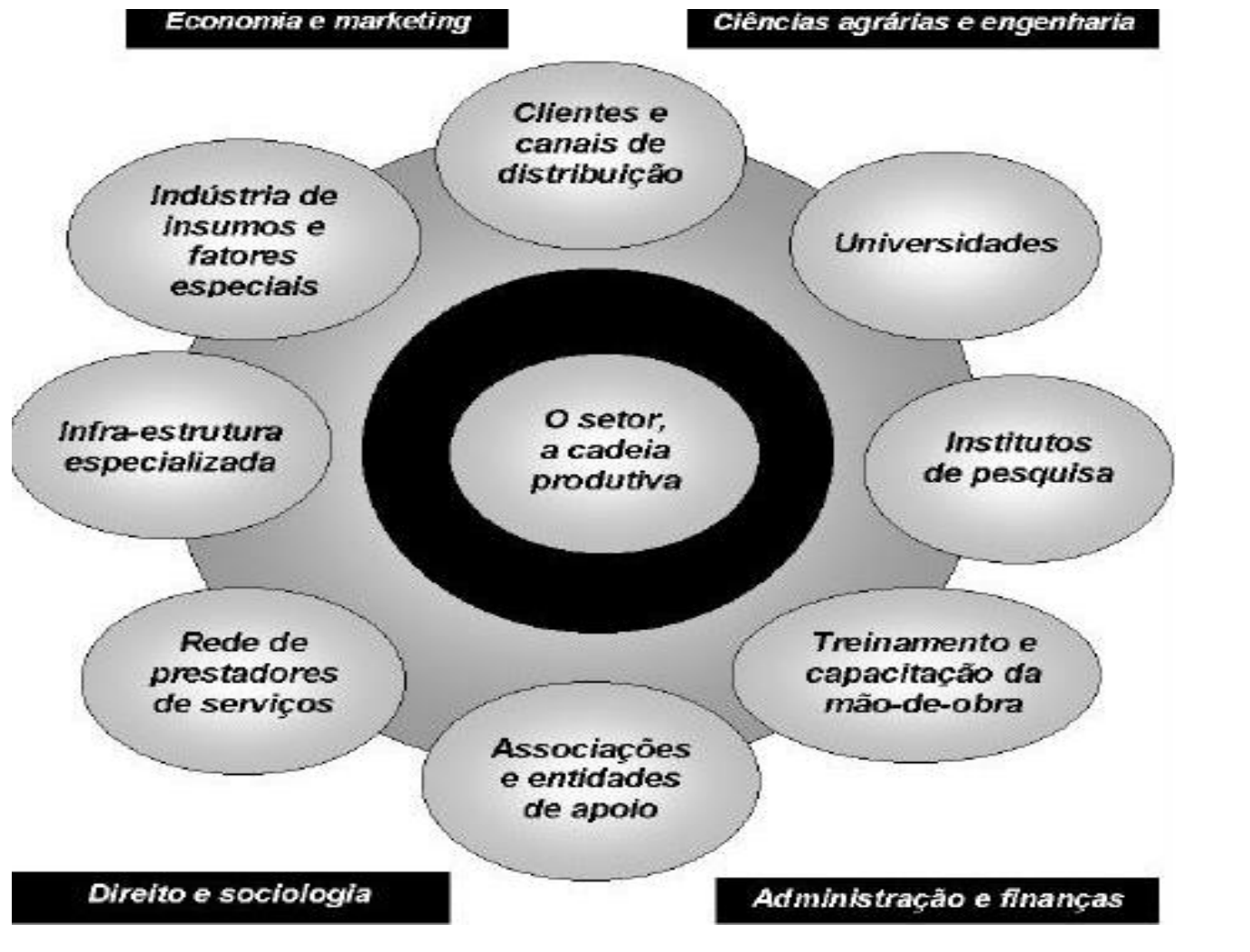

Figura 16 - Modelo de Agrocluster - GASQUES et all (2004 p.34)
A definição apresentada
por
IGLÉCIAS
(2007)
para o Agronegócio

extremamente completa, e pode ser a referência conceitual deste estudo quando diz:

O agronegócio, por tratar-se de um conjunto de atividades extremamente complexas e diversificadas, que abarcam extensas cadeias produtivas crescentemente globalizadas, relações comerciais internacionais e mercados financeiros mundiais, bem como as implicações de sua óbvia interação com o meio ambiente, está relacionado com uma enorme quantidade de atores. Dos governos que definem as diretrizes de política econômica à indústria e aos centros de pesquisa que desenvolvem novas tecnologias de produção no campo, dos movimentos sociais às corporações mundiais do setor, dos trabalhadores que emprega ao consumidor final que adquire seus produtos, dos governos estrangeiros que interpõem barreiras às organizações multilaterais, em que tais barreiras são questionadas, o agronegócio interage com uma infinidade de stakeholders, e de tão múltiplas interações depende, em grande medida, a sua própria viabilidade econômica. 
CONTINI (2012) mostra que a associação da agricultura e agroindústria produz impactos importantes na economia brasileira. Segundo o autor, a cada $R \$$ $1.000,00$ produzidos pela agropecuária existem outros $R \$ 5.636,00$ gerados em atividades posteriores à produção como: agroindústria, transporte e comercialização, o mesmo acontece antes da produção quando são criados outros $R \$ 623,00 \mathrm{em}$ atividades como: produção de máquinas e fertilizantes. Percebe-se, mais uma vez, que a atividade agropecuária, quando pensada como uma Cadeia tem alto potencial de desenvolvimento. Uma vantagem do Brasil, segundo o autor, comparativamente ao resto do mundo é sua extensão territorial, que permitirá no futuro conduzir de forma diferenciada a sua produção. Ainda nas observações do autor existem três fatores que interferem diretamente nos resultados do agronegócio:

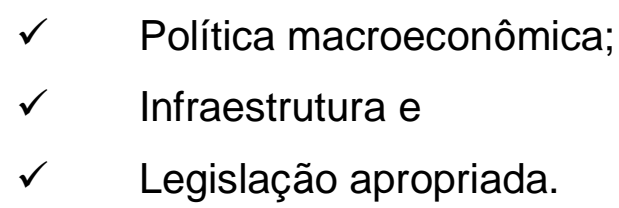

SILVA (2012) diz que os conceitos de Qualidade Total também se aplicam ao Agronegócio, porém estes são privilégios de grandes grupos industriais. Esta observação mostra que existe a necessidade de melhoria e inovação em grande parte deste segmento. CAIRES (2012) menciona que a dificuldade na "tomada de decisão" no agronegócio advém da dificuldade em absorver requisitos de qualidade e inovação, pois o setor é extremamente convencional.

GUILHOTO et all, (2006) lembra que outro fator relevante no agronegócio brasileiro é a participação da agricultura familiar, que além de ter um significativo poder de produção (diversificada) desempenha importante papel social. Apesar disto a agricultura familiar se apresenta de forma desorganizada e com futuro incerto, pois tem muita dificuldade em ter acesso a tecnologia de ponta, e conseqüentemente não tem como inserir precisão ao processo de produção agrícola, o que é um ponto importante para a evolução do setor. Sendo uma tecnologia escalável e também aplicável em pequeno porte, a inclusão do RFID é de fundamental importância para inserção da agricultura familiar na economia globalizada, por abrir a possibilidade de atribuir certificação de origem e qualidade aos produtos gerados por esta, através dos serviços de triagem e beneficiamento. 
Existem diversos insumos a serem utilizados em um processo de produção agrícola, e as sementes constituem os recursos essenciais que afetam tanto o grande produtor quanto a agricultura familiar. MARTIN, et all, ( 2007 p.123) lembram que:

\begin{abstract}
A semente é o principal insumo na implantação de uma cultura, além de representar baixo custo em relação ao custo total de produção, destacando-se como relevante fator para a garantia da produtividade das lavouras e para o resultado econômico da atividade agrícola.
\end{abstract}

HESSEL et all. (2009), comentam sobre a necessidade de melhorar o controle de qualidade na distribuição e venda de sementes através da tecnologia RFID, que segundo eles terá inúmeras novas aplicações nas cadeias de abastecimento, incluindo o rastreamento, controle e logística.

\title{
2.4 - O PAPEL DAS SEMENTES NO AGRONEGÓCIO
}

MARTIN et all (2007), lembra que as sementes precisam ser avaliadas após cada processo de beneficiamento, garantindo a qualidade do produto e identificando locais de "quebra do fluxo" ("deadlocks") para eliminá-los e assim atender a legislação que exige qualidade "superior a $\mathbf{8 0 \% " . ~}$

Vários fatores afetam a qualidade das sementes, um dos mais importantes é o ponto de maturação fisiológica, que quando é atingido garante maior potencial de germinação. Seguido deste fator vem a umidade contida na semente, pois além de perder qualidade pelo peso de água, necessitando de secagem, deixa a semente passiva de esmagamento. Desta forma toda vez que a umidade for superior a $16 \%$ recomenda-se a secagem artificial antes do armazenamento, trazendo estes valores a casa de $11 \%$. Em muitas regiões no Brasil a umidade relativa sofre variações enormes em poucos dias, portanto, o armazenamento de sementes, principalmente de milho, precisa acompanhamento especializado por parte dos produtores.

Entre os grãos produzidos no Brasil o MILHO é um dos mais importantes pelo papel central que desempenha em diversas cadeias do agronegócio. Porém, o armazenamento inadequado, a falta de tratamento e pouco monitoramento geram problemas para a manutenção da qualidade do grão. Segundo MARTIN et all (2007) 
o ataque de fungos, por armazenamento inadequado, leva a perdas da ordem de $20 \%$. Mesmo assim, GODOI (2008 p. 01) comenta que houve evolução da qualidade das sementes, quando diz:

A atual produção de sementes de milho híbrido é o resultado de aproximadamente 70 anos de avanços científicos e tecnológicos, desde o lançamento do primeiro híbrido comercial no Brasil, em 1939, até os dias de hoje, com o aparecimento dos primeiros híbridos geneticamente modificados, evidenciando o grande avanço da moderna agricultura brasileira.

A Qualidade Total nos processos do Agronegócio tem sido buscada frequentemente, porém o perfil dos atores do "Supply Chain" tem criado barreiras a inovações tecnológicas por pura desconfiança de seus resultados, reduzindo a competitividade nacional, conforme afirmam ARAÚJO, BARBAIS e SILVA (2004 p. 139):

Os clientes agrícolas são mais reservados e possuem certas tradições, desenvolvidos por herança. Exigem produtos e serviços de qualidade, com preços razoáveis; alguns reclamam, outros se calam, mas todos sempre desenvolvem uma imagem da empresa, positiva ou negativa.

A implantação de Sistemas RFID para criar um Processo Informado no agronegócio tem como meta alcançar a Qualidade Total da Cadeia de Suprimentos da Semente de Milho, pois esta tem boas chances de aceitar a inovação, porém o tema precisa ser abordado cientificamente, por meio de uma modelagem do processo, e as técnicas de Engenharia de Processos, "Workflow” e Engenharia de Serviços são aqui apresentados como a base desta abordagem.

\section{5 - A EVOLUÇÃO DO SETOR DE SERVIÇOS}

A economia tradicionalmente é dividida em três setores:

Primário: Relacionado com a produção de alimentos e outros produtos vindos do campo, através de cultivo programado ou com base em extrativismo, é caso da agricultura e pecuária, onde os produtos, na maior parte dos casos têm baixo valor agregado; 
$\checkmark$ Secundário: Está ligado à transformação e a manufatura, e deslanchou sua lucratividade e eficiência, comparativamente ao setor Primário, a partir da Revolução Industrial;

$\checkmark$ Terciário: está vinculado aos Serviços, ou a produtos que não possuem uma base material ou forma. Em alguns casos o serviço está associado à inserção ou venda de produtos do setor secundário e são chamados o "front end" da produção, tratando da comunicação com o consumidor.

O Setor de Serviços tem se tornado importante em todas as economias nacionais, pois são fontes importantes de emprego e renda, e mais recentemente adquiriram uma nova perspectiva com o crescimento em diversidade e volume em todo o mundo se tornando quase independente da produção industrial. Segundo SPOHRER et all (2007), o PIB dos Estados Unidos da América tem praticamente $80 \%$ de seus valores vinculados a Serviços.

Este novo cenário demonstra pesquisa sobre o desenvolvimento econômico precisam focar mais acentuadamente neste Setor com interesse na adaptação de Sistemas, Conceitos e Metodologias e posteriormente na integração dos serviços com a própria produção industrial (ou agrícola).

Sendo assim definir Serviço é fundamental para continuidade dos estudos. SPOHRER et all (2008) diz que "SERVIÇO é a aplicação de recursos para a satisfação de outros" ou na forma mais clássica é o trabalho realizado que não resulta necessariamente em um "BEM".

VARGO e AKAKA (2009) apresentam os fundamentos de Serviço Dominante e Bem Dominante para compor os novos setores econômicos, conceitos que também ilustrados por SPOHRER et all (2008):

Lógica do Bem dominante: Foi estruturada a partir de Smith no século XVIII, estando intimamente ligada a produção de bens duráveis na Revolução Industrial. Neste modelo o que tem valor é o produto acabado que atende ao consumidor. Tratado com indiferença o 
excedente destina-se à exportação para a geração de riqueza para as nações. $O$ valor do produto nesta lógica é o valor de troca, estimado com o necessário para a produção e Ainda os serviços são desvalorizados.

$\checkmark \quad$ Lógica do Serviço dominante: Esta forma de atendimento o cliente é integrante do processo e os bens são vistos como os canais para realização de um Serviço, nele existe a co-criação de valor onde todos os elementos de uma Cadeia contribuem para o atendimento de uma demanda. Na lógica do Serviço o valor do produto é relacionado com o valor de uso.

Um exemplo simples pode contribuir para o entendimento destas duas lógicas. Imagine-se que um consumidor precisa comprar um terno para ir a um casamento, na primeira opção ele vai a uma loja e compra algum que lhe sirva, a Lógica neste encaminhamento é do Bem Dominante. Por outro lado, se ele procura um alfaiate, esta se materializando a Lógica do Serviço, e o terno passa a ser uma forma de atender à demanda do serviço pelo profissional especializado em costura. Note que nesta fase o terno é produto de design e do trabalho o alfaiate em combinação direta (co-criação) com o consumidor (caso contrário a possibilidade de que o resultado final não agrade o cliente é muito elevada).

Um processo pode ser visto sob qualquer uma das lógicas, porém, cada vez mais, a Lógica dos Serviços Dominantes vem sendo praticada, pois ela permite gerar diferenciais competitivos no mercado cada vez mais competitivo e globalizado. SPOHRER (2008), citando (VARGO e LUSCH), propõe 10 premissas para se substituir a Lógica do Bem Dominante pela Lógica do Serviço Dominante:

$\checkmark \quad$ O Serviço deve ser dotado de habilidades e conhecimento para 0 benefício do cliente, o que é fundamental na relação de troca;

$\checkmark$ A troca produzida pelo Serviço evidencia a natureza deste, isto é, a base para a criação do serviço é a própria relação de troca;

$\checkmark \quad$ Os bens são mecanismos necessários (recursos) para a efetivação do Serviço;

$\checkmark \quad$ Os insumos (habilidades e conhecimento) são vantagens competitivas; 
$\checkmark \quad$ Todos os agentes econômicos envolvidos são considerados recursos do Serviço;

$\checkmark \quad$ O cliente é parceiro e participa na co-criação do Serviço;

$\checkmark$ A empresa não entrega valor e sim propõem um valor ao cliente;

$\checkmark \quad$ Existe a visão centrada no Serviço e na satisfação do cliente;

$\checkmark$ Todos os envolvidos no Sistema de Serviço são integradores do recurso;

$\checkmark \quad$ O Valor do serviço tem que passar pela anuência do beneficiado.

A discussão deste item é importante para a tese e para o estudo de caso em questão, uma vez que na produção de Sementes de Milho não existe transformação de Matéria Prima em Produto Transformado. Ou seja, quando a semente milho chega na Portaria da Empresa sabe-se que ela passará por um processo de seleção e tratamento, onde avaliará seu potencial produtivo. Porém sairá do processo ainda como semente de milho. Este relacionamento com o processo pode ser caracterizado como um Serviço feito ao cliente que deseja um determinado tipo de semente. Desta forma, prevalece a Lógica do Serviço Dominante.

\section{6 - PRINCÍPIOS DE PROCESSOS INFORMADOS}

O conceito de Processo Informado tem raiz na Manufatura Informada e normalmente está vinculado à transformação de produtos. TAVARES, BATALHA e SILVA (2000) a definem como sendo um Processo que utiliza o EPC (Código Eletrônico de Produto) para a identificação básica e uma porção extra de memória para a armazenagem de informação que flui e se modifica durante o processo. Nesta visão o Supply Chain (Cadeia de Suprimentos) é totalmente monitorado permitindo que informações sobre produtos (ou serviços) possam ser geradas, transmitidas, e analisadas em TEMPO REAL, permitindo também uma atuação imediata e precisa quando necessário. O diferencial estudado neste trabalho está nos registros guardados no sistema e também junto ao produto (item), comprovando a qualidade do Processo a qualquer momento. 
Para a implantação de um Processo Informado é necessário definir quais dados precisam ser monitorados continuamente e a partir desta definição integrar o projeto com as estratégias de mercado adotadas e com as exigências dos clientes. A Figura 17 ilustra o modelo apresentado por TAVARES e SILVA (2007) para um processo de produção de “blanks", denominado de MANUFATURA INFORMADA.

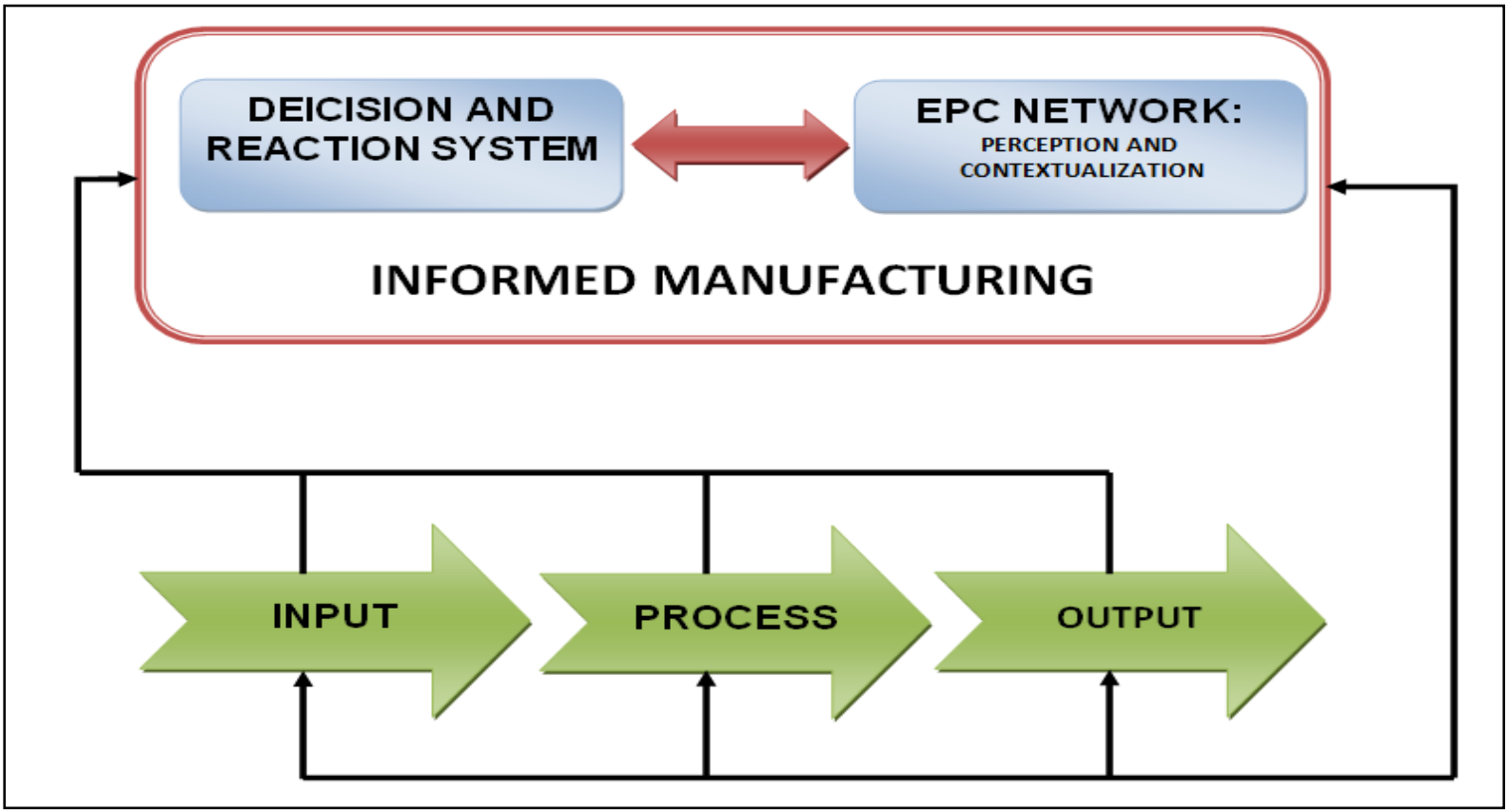

Figura 17- Modelo de Manufatura Informada - TAVARES e SILVA (2007)

A tecnologia RFID também se apresenta como uma solução tecnológica ideal para criar um Modelo Informado no Agronegócio. A Figura 18 ilustra uma aplicação tradicional como elemento que posiciona o item dentro do “Supply Chain”. Porém, a concepção deste sistema ainda permanece como uma substituição do código de barras, em que as informações ficam armazenadas num Banco de Dados na retaguarda, ou seja, junto ao produto só existe um código identificador do item, que quando acessado remete à informações codificadas e armazenadas no Banco de Dados. Esta estrutura, portanto, precisa também de suporte deu um sistema um sistema de comunicação robusto. 


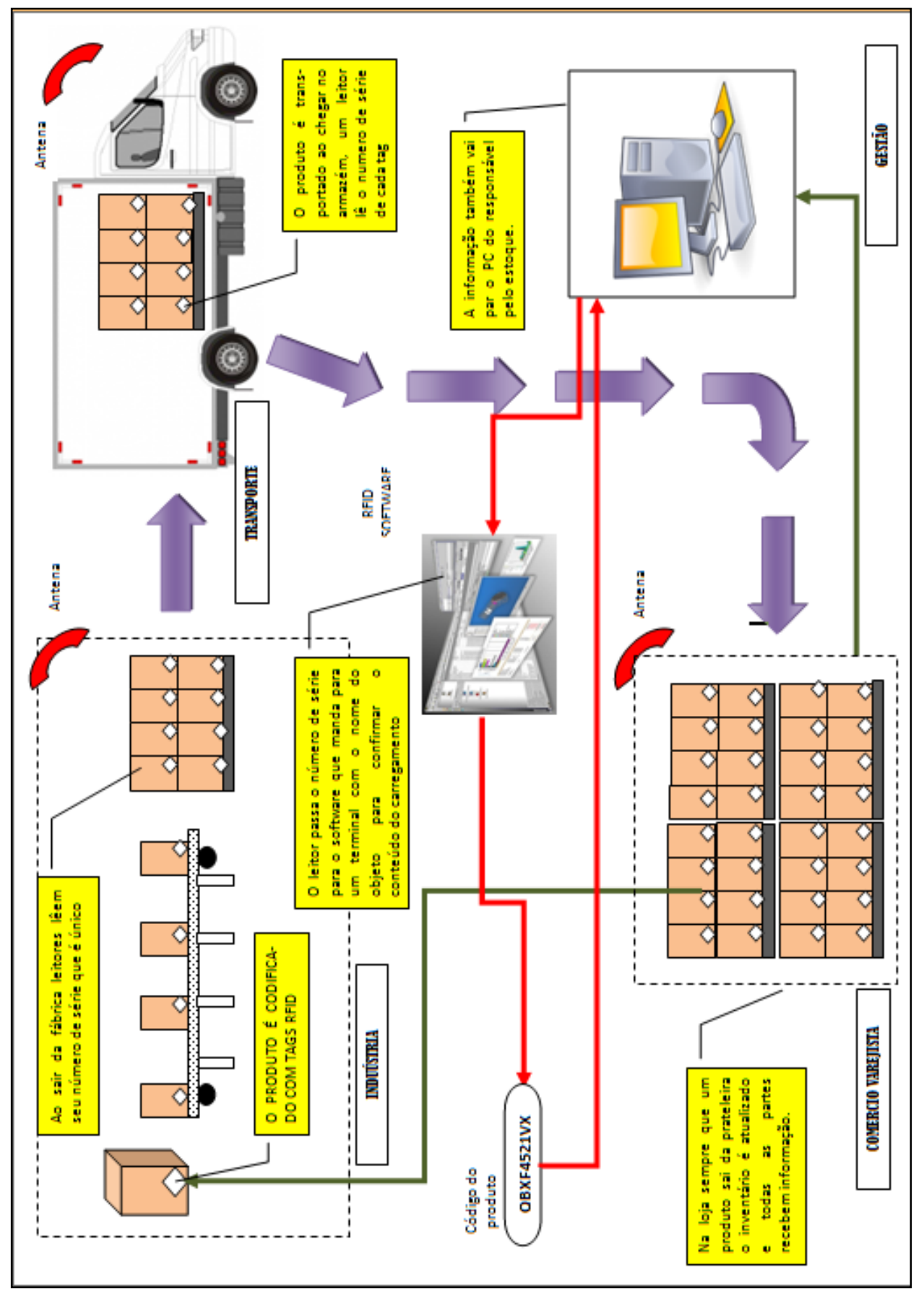

Figura 18 Adaptado - Uso de RFID - http://www.gta.ufrj.br/grad/ 
A proposta deste trabalho é representada na Figura 19, onde o RFID é utilizado para armazenar as informações relevantes do processo junto ao produto. Esta operação tem inicio com gravação dos códigos EPC no RFID, que recebe e fornece diversas informações do workflow da planta. A ilustração mostra que a comunicação da TAG com o sistema de TI é bilateral e ocorre continuamente durante as diversas etapas de um Processo e pode também ser vinculada a Sistemas digitais de comunicação como e Telefonia Móvel e Internet.

A proposta inovadora deste trabalho está na proposta de criação de um Método (baseado em estudo metodológico) para Implantar um Processo Informado no "Supply Chain" baseada no uso extensivo da Memória do Usuário do RFID.

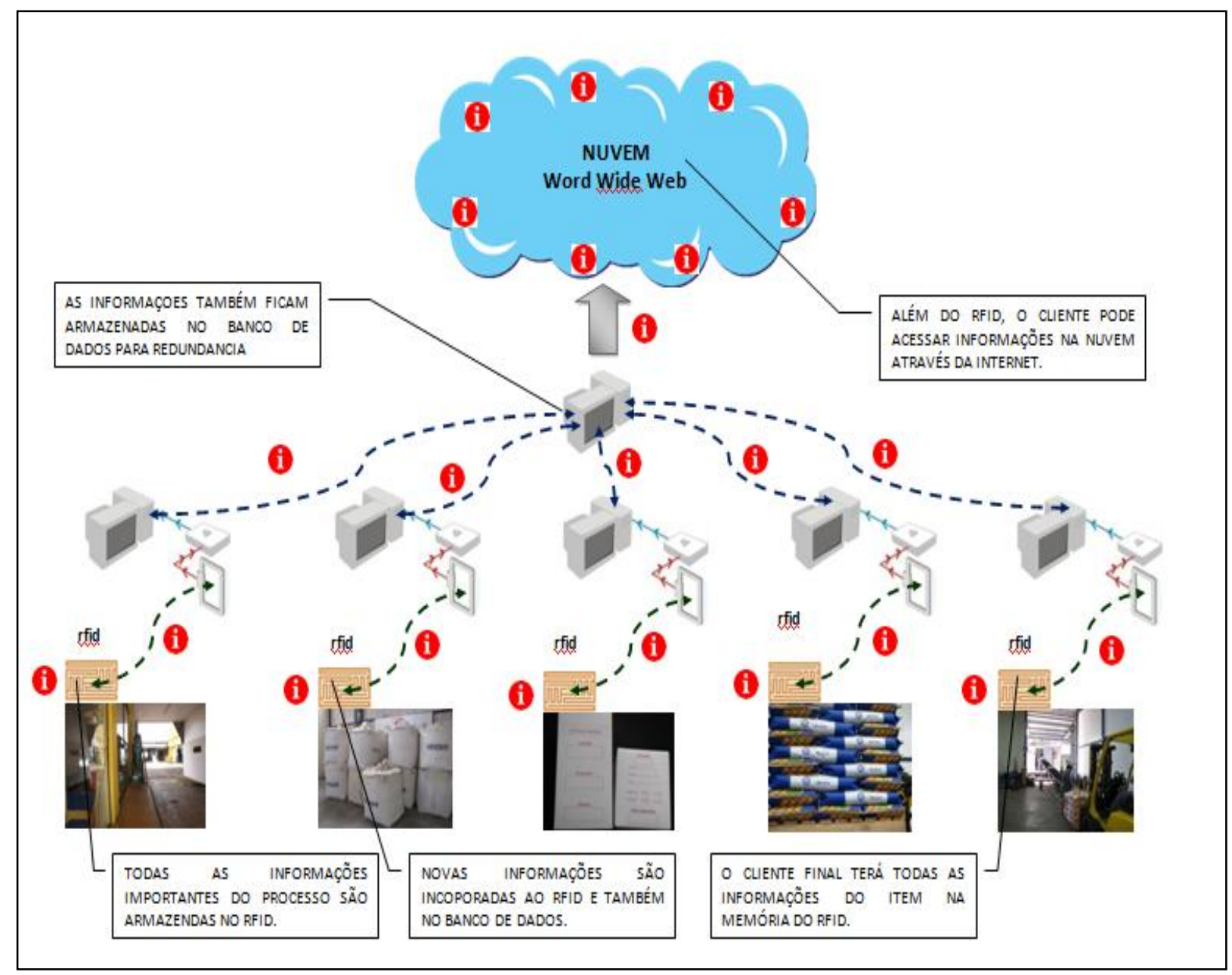

Figura 19 - RFID inserido na nuvem da internet - Próprio 
$\mathrm{Na}$ seção seguinte discutiremos a metodologia adotada para a elaboração das hipóteses deste trabalho, para sua validação, que se reflete no estudo de caso a ser apresentado.

\section{7 - "WORKFLOW MANAGEMENT"}

O termo "Workflow" é hoje um símbolo da evolução dos sistemas de informação da fase onde estes eram orientados a programa e dados para uma nova fase onde estes têm o seu desenvolvimento orientado a processos. Assim a WFMC (2009) (WorkFlow Management Coalition), define o conceito de Sistemas de Gerenciamento de Processos de Negócio como ferramentas que integram usuários e seus respectivos aplicativos computacionais para atender satisfatoriamente a um cliente, e que portanto tem todos os atributos de um sistema de serviço. Sendo assim, a Modelagem de um Processo precisa ser criteriosa e utilizar-se de todas as ferramentas disponíveis.

\subsection{1 - "Business Process" e "Workflow".}

Segundo AALST e VAN HEE (2002) os termos "Workflow" $\boldsymbol{e}$ "Busines Process", têm gerado algumas confusões no seu entendimento conceitual que precisam ser devidamente esclarecidas, para tanto os autores indicam a utilização das terminologias definidas pela WFMC ("WorkFlow Management Coalition”), como a maneira adequada para diminuir tais desencontros.

Ainda segundo AALST e STHAL (2011) um Processo de Negócio consiste de um conjunto de atividades interdependentes que é realizado no ambiente da Organização com ações coordenadas em conjunto para alcançar o objetivo do negócio. Cada processo de negócio é específico para uma única organização, mas pode prever o relacionamento com processos de outras empresas.

Por outro lado, seguindo a definição da WFMC (2009), "Workflow" "É a facilitação do entendimento do fluxo de trabalho computacionalmente para a automação de Processos de Negócio, no todo ou em parte dele." 
Uniformizando entendimentos definem-se como Processos o conjunto de tarefas realizadas por relações colaborativas entre funções hierárquicas da Organização. Duas motivações podem promover a atribuição do trabalho nas empresas, a primeira pela ordem direta das chefias e a segunda pela imposição do cliente. Cada vez mais estas duas formas de fomentar o trabalho estão sendo aproximadas, buscando uma relação proativa do tipo ganha-ganha, onde as chefias passam a serem interlocutores da produção com o cliente. À medida que novos atores são incorporados ao Processo mais complexas ficam as relações corporativas, portanto o conceito de Cadeia de Suprimentos demanda cada vez mais de Modelagem de Processos.

Outro elemento que deve estar presente na modelagem de um Processo é a Estrutura Organizacional da Empresa, que segundo AALST e VAN HEE (2002), são pouco exploradas pelas literaturas. O "Workflow" do Processo pode resolver esta questão, desde que seja montado com critérios exatos e comprovadamente conclusivos. Segundo os mesmos autores, existem três possíveis formas estruturais para uma Organização: Organização Hierárquica; Organização Matricial Organização em Rede

Segundo AALST e VAN HEE (2002) independente do nível de decisão de um Processo quatro etapas precisam ser vencidas e nelas podem ser utilizadas as mais variadas ferramentas na busca do Modelo ideal, tais como: Técnicas Matemáticas, Inteligência Artificial, etc. A Figura 20 permite visualizar estas fases, que devem ser consideradas na formulação de um Modelo. 


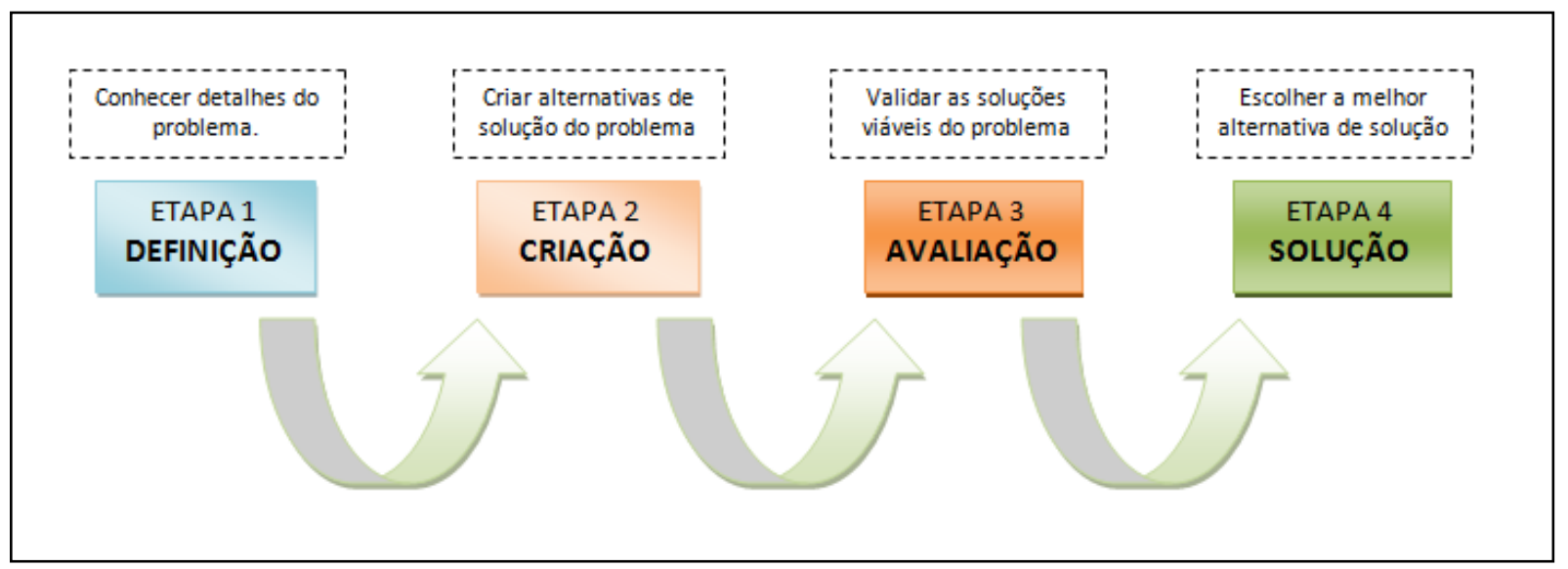

Figura 20 - Fases para Tomada de Decisão (Próprio)

Nos estudos e análises de Modelos as ferramentas computacionais têm desempenhado papel fundamental, pois permitem através de técnicas matemáticas acelerarem resultados para tomada de decisão e principalmente por permitirem simular os Processos sem a necessidade de correr riscos financeiros, humanos, e temporais. Desta forma, se ocorrer situações que necessitem correções, estas podem ser identificadas e corrigidas antes da operação real de um Sistema.

Segundo AALST e VAN HEE (2002) as ferramentas computacionais vem se tornando tão complexas que se transformam em Sistemas Especializados, como por exemplo: Sistemas de Registro, Sistemas de Gestão do Conhecimento, Sistemas de Automação e Controle, "Sistema de Workflow", etc. A associação de diversos Sistemas Computacionais gera então o que tradicionalmente é denominado de Sistema de Informação ou Tecnologia da Informação (TI).

A evolução histórica dos Sistemas de Gerenciamento de Negócios é mostrada por AALST e VAN HEE (2004), na Figura 21, quando enfatiza a existência de quatro camadas temporais e conceituais, que precisam ser conhecidas por que com eles trabalha. 


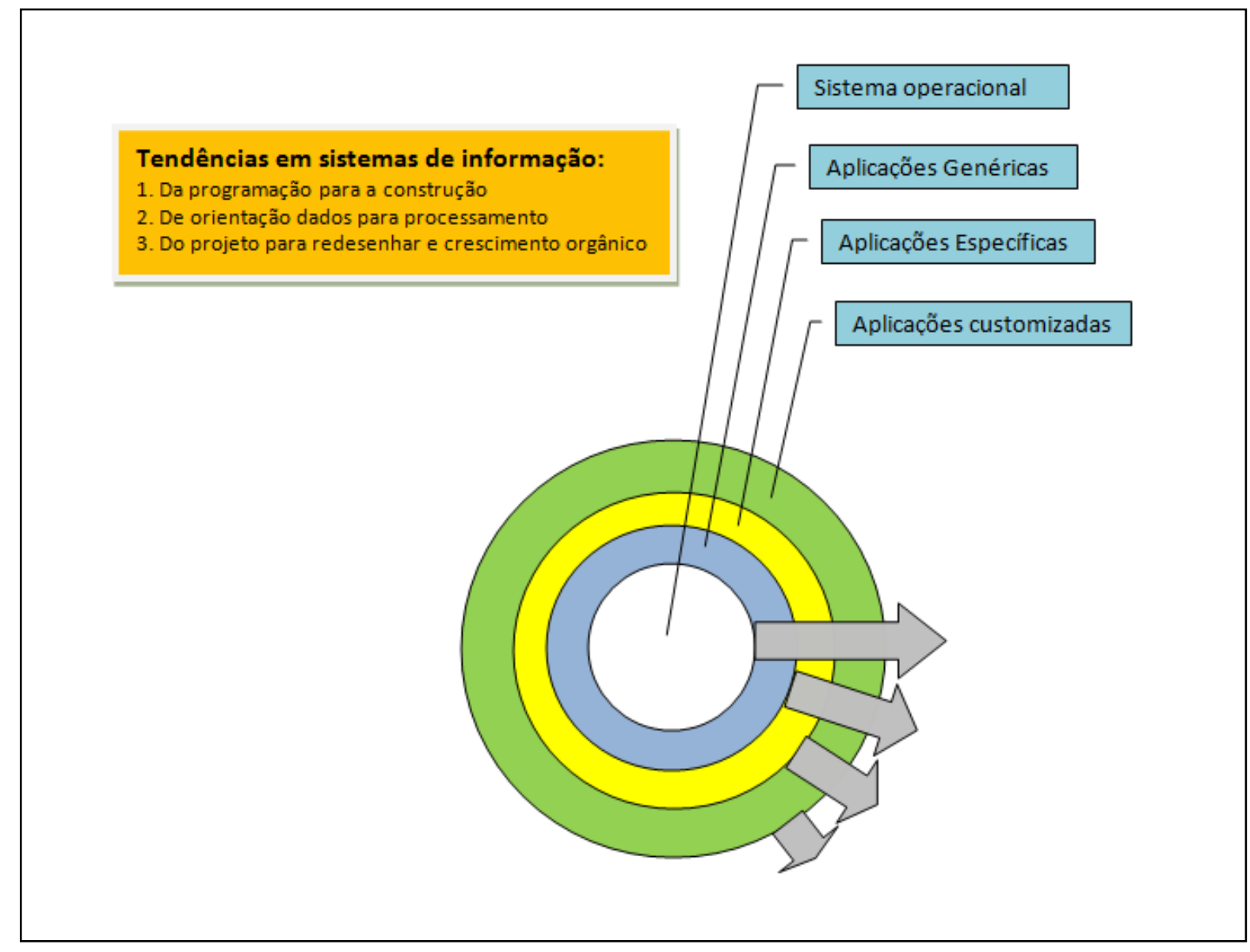

Figura 21 - Evolução dos Sistemas de Gerenciamento de Negócios - AALST e VAN LEE (2004)

Interpretando a Figura 21 o centro é constituído pelos sistemas de Operação que colocam o hardware em funcionamento, enquanto a segunda camada são os Sistemas de aplicações genéricas, que são usados por várias Organizações ou Setores, como exemplo, tem-se os Editores de Textos, as Planilhas etc. A terceira camada por sua vez é constituída por Sistemas que atendem segmentos organizacionais similares como logística, reserva de passagens, etc., finalmente o quarto nível destina-se a aplicações específicas e estruturadas na medida exata do Negócio da Organização.

Na década de 60 a segunda e a terceira camada não existiam e os Sistemas de Informação eram pobres e com recursos limitados, e mesmo assim desenvolvidos para soluções específicas dos clientes. A tendência atual, com o aumento de funcionalidades é que o círculo cresça para fora e que algumas destas possam até 
mudar de camada. Das observações mais importantes feitas nesta evolução tem-se que:

$\checkmark \quad$ A TI que era desenvolvedora de Software agora passa a oferecer Sistemas,

$\checkmark \quad$ Os Sistemas deixam de ser focados na tecnologia e passam a olhar com mais detalhes ao Modelo de Negócio, orientando-se aos Processos.

$\checkmark \quad$ Os Projetos são rigorosamente planejados e organizados, levando em consideração a possibilidade de seu crescimento.

Segundo a WFMC um Sistema de Gerenciamento de "Workflow" (SGWF) é "Um sistema que define, cria e gera a execução do “Workflow” através da utilização de software, sendo capaz de interpretar o processo e interagir com os participantes do fluxo de trabalho e, se necessário, recorrer ao uso da $\mathrm{TI}$, ferramentas e aplicativos." Desta forma, um Sistema de “Workflow” é indispensável para o desenvolvimento de um Modelo de Processo, pois a partir de sua utilização é possível "lidar" com todas as variâncias existentes no Caso Real. AALST e VAN HEE (2002) sugerem que entre o início e o término de um "Caso" existe um “Estado", que consiste de três elementos: Valores atribuídos, Condições e Conteúdo.

O "Workflow" de um Processo sempre terá, segundo: AALST e VAN HEE (2002), três dimensões que são representadas na Figura 22, e assim descritas:

A dimensão da Organização - Vinculada a regras e a organização das tarefas, explicitando condições, seqüências e interações.

$\checkmark$ A dimensão de Recurso - Vinculado com recursos envolvidos e formas de aporte para cumprimento das regras.

A dimensão do Processo - São definições do próprio caso, relacionado com o atendimento do desejado e de acordo com as demais dimensões. 


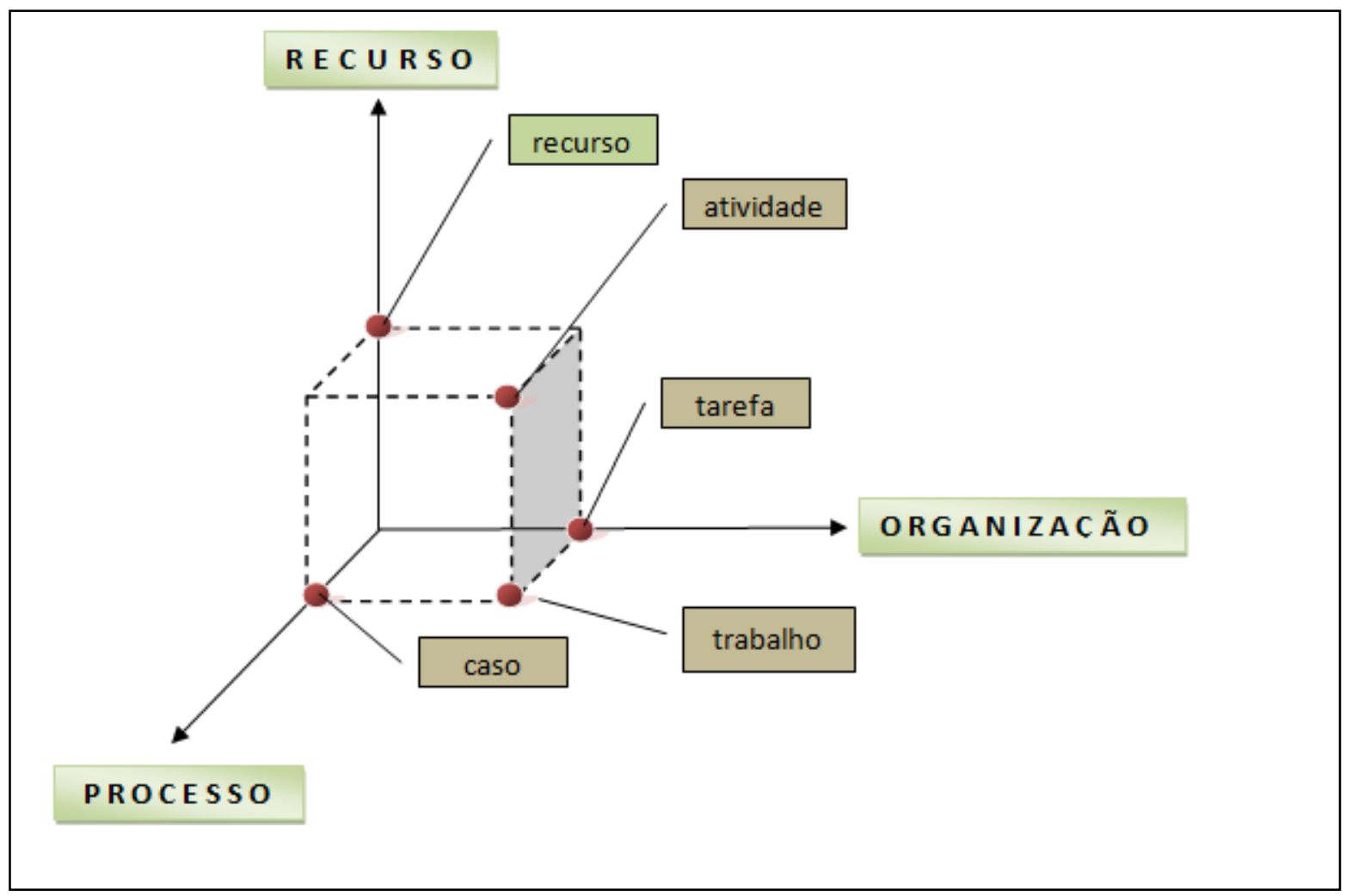

Figura 22 - Três dimensões do Workflow - (AALST 2004 pág. 8)

Assim sendo, inúmeras variáveis podem ser associadas ao caso gerando atributos que devem ser gerenciados e, portanto a capacidade de um Sistema de “Workflow”, simular a realidade e nela interferir para sua melhoria, é garantia de que o Modelo terá sucesso. Ainda segundo AALST e VAN HEE (2002), a Rede de Petri é uma ferramenta que apresenta duas características ideais para a Modelagem, o que a recomenda para casos como o estudado nesta tese, são elas:

$\checkmark$ A lógica estruturada desenvolvida com rigidez matemática busca eliminar incertezas e ambigüidades de uma observação, garantindo a fiel modelagem de um Processo, o que não ocorre em outras técnicas menos formais.

$\checkmark \quad$ O formalismo da ferramenta permite "questionar" o próprio Processo modelado, propondo correções e melhorias constantemente.

A Rede de Petri, portanto tem aplicabilidade em Modelagens de Processos de automação e controle, Estudo de desempenhos, Desenvolvimento de Protocolos, etc., itens que justificam seu estudo. 
O desenvolvimento desta Rede, que também é chamada de Rede de Transição, ocorreu em 1962 pelo estudioso Carl Adam Petri e tem como característica mais importante fornecer ao modelador uma configuração gráfica da modelagem, tornando-a mais visual, logo com facilidades para a interpretação.

Quando se utiliza a Rede de Petri para Modelagem de Processo, as vantagens da representação gráfica e da exatidão matemática são evidenciadas, principalmente em eventos de seqüência lógica que precisam tratamento computacional, chamados eventos discretos.

A estrutura da Rede de Petri é composta por três elementos básicos:

$\checkmark \quad$ Estados: São representados por um circulo que define um componente passivo do sistema.

$\checkmark$ Ações: Representadas por retângulo que indica um componente ativo do sistema, ou seja, eventos que modificam o Estado inicial do Sistema.

$\checkmark \quad$ Relação de Fluxo: Tem a representação de setas que especificam como ocorre a transformação de um Estado para outro através de uma ação.

A Figura 23 mostra a simplicidade dos diagramas obtidos a partir de Redes de Petri para Modelagem de Processo, que para o caso modela o registro da reclamação de um cliente em uma Organização, ambos fictícios. 


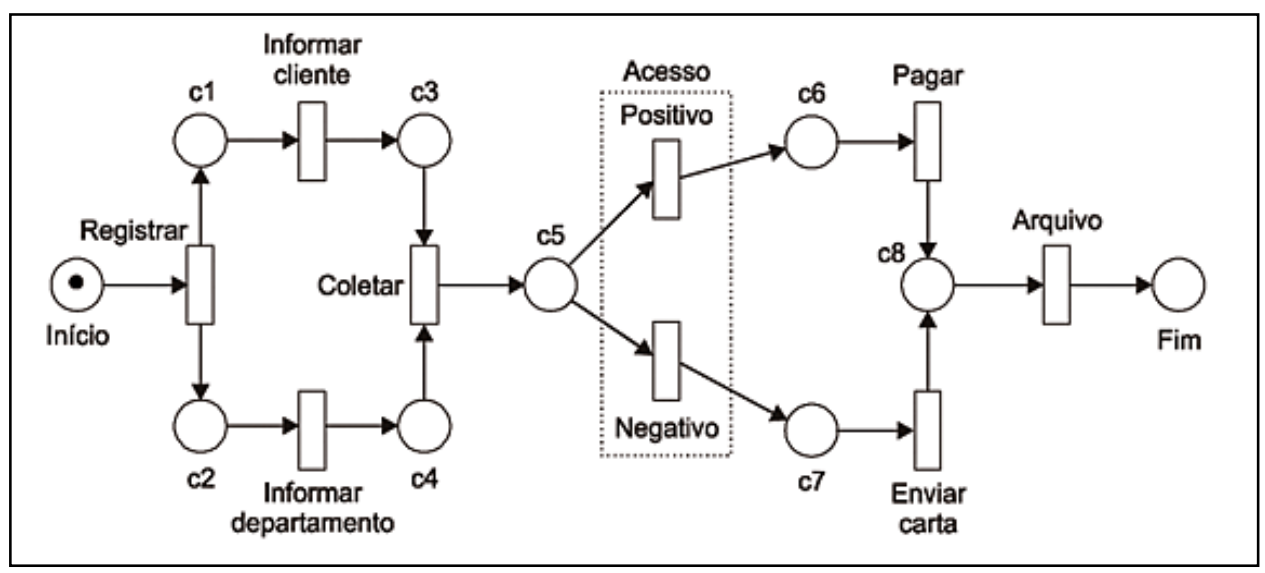

Figura 23 - Exemplo de Rede de Petri - AALST e HEE (2002 p.50)

Outra forma de modelagem chamada de WF-Nets, é estruturada obedecendo as três dimensões representadas na Figura 25, utilizando-se de representações de portas E e OU, que geram a indicação dos fluxos das tarefas de forma seqüencial, paralela, condicional ou interativa. Esta forma de modelagem é feita por software, que tem uma estrutura robusta baseada na Rede de Petri com e extremamente amigável ao usuário. Em síntese estas ferramentas dispensam o usuário de profundos conhecimentos em teorias matemáticas, por serem elaboradas para utilização intuitiva. Tabela 5 ilustra a simbologia utilizada nestes diagramas.

\begin{tabular}{|c|l|l|}
\hline Name: & \multicolumn{2}{|l|}{ Description: } \\
\hline XOR-Split & $\begin{array}{l}\text { The XOR-Split is used to trigger only one outgoing flow. It is best } \\
\text { used for automatically choosing between a number of possible } \\
\text { exclusive alternatives once a task completes. }\end{array}$ \\
\hline OR-Split & $\begin{array}{l}\text { The AND-Split is used to start a number of task instances simul- } \\
\text { taneously. It can be viewed as a specialisation of the OR-Split, } \\
\text { where work will be triggered to start on all outgoing flows. }\end{array}$ \\
\hline AND-Join & $\begin{array}{l}\text { The OR-Split is used to trigger some, but not necessarily all outgo- } \\
\text { ing flows to other tasks. It is best used when we won't know until } \\
\text { run-time exactly what concurrent resultant work can lead from } \\
\text { the completion of a task. }\end{array}$ \\
\hline XOR-Join & $\begin{array}{l}\text { A task with an AND-Join will wait to receive completed work } \\
\text { from all of its incoming flows before beginning. It is typically used } \\
\text { to synchronise pre-requisite activities that must be completed be- } \\
\text { fore some new piece of work may begin. }\end{array}$ \\
\hline OR-Join & $\begin{array}{l}\text { Once any work has completed on an incoming flow, a task with an } \\
\text { XOR-Join will be capable of beginning work. It is typically used to } \\
\text { allow new work to start so long as one of several different pieces } \\
\text { of earlier work have been completed. }\end{array}$ \\
\hline
\end{tabular}

Tabela 4 - Simbologia para WF-Nets 9YAWL User Manual 2.3 pág. 30 
Um exemplo da aplicação WF-Net é feita na Figura 24 e mostra o "Workflow" desenvolvido para Modelar o Processo de Reclamação de cliente em uma Organização.

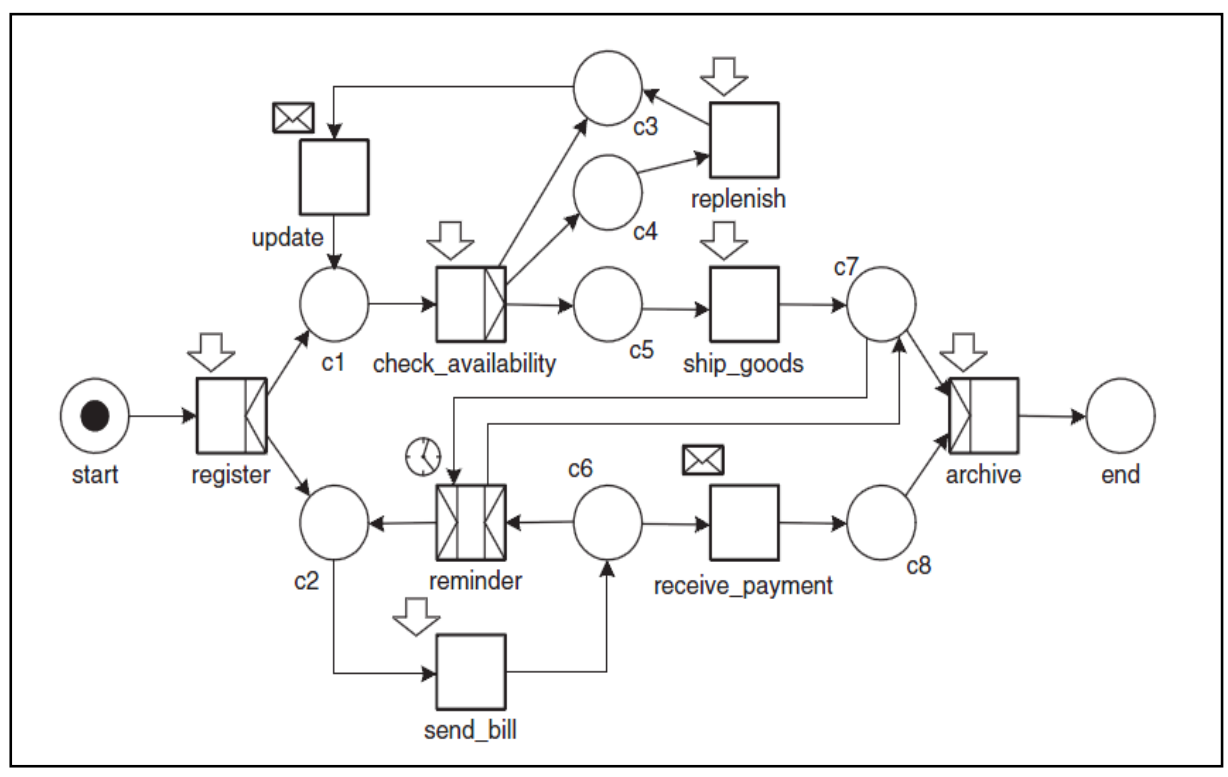

Figura 24 - - Exemplo Aplicativo WF-Nets (AALST 2004 pág. 14)

\subsection{2 - Ferramentas para Modelagem}

$\mathrm{Na}$ busca de criar um aplicativo que permitisse o desenvolvimento de Sistemas de "WorkFlow" estruturado numa Rede de Petri, Wil van der Aalst e Arturter Hofsted criaram no ano de 2002 a ferramenta conhecida como YAWL - "Yet Another Workflow Language" (2012), que é uma definida como uma WF-Nets. A facilidade oferecida pela ferramenta acelera o desenvolvimento de fluxos de trabalho trazendo consigo vantagens descritas no Manual do Usuário (YAWL "User Manual" 2.3), como:

$\checkmark \quad$ Oferecer suporte para desenvolvimento de controle de fluxos.

$\checkmark$ Capturar dados feitos em XML, XPETH E XQUERY.

$\checkmark$ Oferece suporte e recursos para captura de requerimentos.

$\checkmark$ Possui base sólida e formal eliminando informações dúbias e automatizando as verificações.

$\checkmark \quad$ Foi desenvolvida para ser um software aberto sem interesses comerciais e com qualidade para alcançar a utilização universal. 
$\checkmark \quad$ Tem ótima resolução gráfica oferecendo facilidades para manuseio do usuário.

$\checkmark$ Permite realizar alterações em função da evolução dos fluxos de trabalho, dando flexibilidade aos Modelos.

$\checkmark$ Tem uma estrutura intuitiva para facilitar a utilização.

$\checkmark \quad$ Oferece atualização fácil e permanente sem custos ao usuário.

$\checkmark \quad$ Facilita a criação de simulações de Processos.

Pelas considerações apresentadas a ferramenta YAWL é apropriada para se desenvolver a Modelagem de Processo Informado de "Supply Chain", proposto nesta Tese.

A Modelagem de um Processo Informado pode necessitar de mais de uma ferramenta, dependendo da etapa do seu desenvolvimento, portanto os diagramas UML podem ser muito úteis para capturar detalhes do negócio e iniciar o desenvolvimento de um novo projeto. Por este motivo a primeira etapa de capitulo 4, foram usados diagramas UML-“Use Case" para capturar requisitos importantes para a Modelagem.

A modelagem UML foi desenvolvida por Grady Booch, James Rumbaugh e Ivar Jacobson conhecidos como "os três amigos", dotados de grande conhecimento da área de modelagem orientada a objetos. Juntos criaram as três mais conceituadas metodologias até então conhecidas. Seqüencialmente, a UML foi criada como a ferramenta que se apropriou dos pontos positivos das linguagens existentes, criando mecanismos de padronização para a modelagem e tendo como características básicas: a facilidade de criação de um modelo, a exatidão do modelo frente à realidade modelada, e a possibilidade de atualização do modelo.

O surgimento da UML terminou com discussões existentes entre os estudiosos e desenvolvedores, criando uma condição de uniformidade de entendimento entre todos, sendo seus objetivos: a partir dos conceitos de orientação a objetos, modelar qualquer tipo de sistema, não somente de software; permitir que 
métodos usualmente conceituais possam ser executáveis; criar uma linguagem de modelagem que seja de fácil uso por homens e máquinas.

Segundo afirma VICENTE (2004), a UML é estruturada usando o conceito de orientação ao objeto (pessoa, produto, etc.) sendo considerada uma entidade autônoma que contém os próprios dados que são manipulados através de processos definidos para o próprio objeto.

A UML já é uma linguagem aceita internacionalmente para o desenvolvimento de software e, sendo de fácil aplicabilidade, tem sido fortemente utilizada para outras necessidades de modelagem oferecendo ao modelador consistência facilidade nos desenvolvimentos. 


\section{METODOLOGIA}

Esta pesquisa tem como objetivo o desenvolvimento de um Modelo de Processo Informado para o "Supply Chain" do Agronegócio. A tecnologia RFID será o grande diferencial desta proposta, através da qual as informações relevantes do Processo acompanharão o item (produto) permitindo o acesso a elas em qualquer tempo. Para que este modelo seja materializado é necessário avaliar a integração com Sistemas de Tl já implantados e também a capacidade de memória dos Tags, equipamentos RFID que hoje são utilizados para processos simples de rastreamento.

\subsection{MÉTODOS}

GIL (2002) classifica uma pesquisa em três categorias,

$\checkmark \quad$ Exploratória Utilizada quando se necessita uma investigação profunda de um tema desconhecido, desta forma o pesquisador pode aprofundar-se num tema que ainda não foi explorado. À medida que uma busca de informações é estabelecida e procura-se atender uma abordagem particular a pesquisa exploratória toma o caráter de um Estudo de Caso. Numa pesquisa exploratória ferramentas como a pesquisa bibliográfica e entrevistas podem ser aplicadas,

$\checkmark$ Descritiva, Tem o foco na observação e registro de um evento e é isenta de opiniões do pesquisador. Uma de suas características é a busca de "números" que demonstrem o comportamento do fenômeno observado. Esta pesquisa diferencia-se da primeira por que se tem o conhecimento prévio do evento pesquisado, o que se busca é ter novos olhares a uma mesma ocorrência.

$\checkmark$ Explicativa, É mais abrangente do que a pesquisa descritiva, pois também busca analisar e interpretar um evento, aprofundando os conhecimentos até então reconhecidos. Pelo caráter de aprofundamento embutido nesta pesquisa são normalmente necessários modelos de simulação da realidade, portanto a demanda de equipamentos e laboratórios é uma de suas características. 
Este estudo é classificado como uma Pesquisa Exploratória, pois em seu desenvolvimento buscou-se uma investigação profunda sobre formas de implantar um Processo Informado na Cadeia de Suprimentos do Agronegócio. Para que esta proposta fosse realizada estudos sobre Cadeia de Suprimentos, Agronegócio Tecnologia RFID e Modelagem de Processo precisaram ser aprofundados e relacionados para criar um novo paradigma sobre informações que acompanham o item (produto). A pesquisa exploratória dita que a revisão bibliográfica deve ser profunda e precisa embasar as propostas de novos desafios. Além da pesquisa bibliográfica, foram realizadas entrevistas com profissionais especializados das áreas do Agronegócio e de Sistemas RFID, para que assim fosse possível conceber um novo modelo que concentrasse temas tão diferenciados.

As pesquisas ainda podem ser classificadas como Quantitativas ou Qualitativas, a primeira é totalmente aberta, permitindo que a resposta a questões formuladas sejam conceituais e de cunho pessoal, a subjetividade está presente nas respostas deste tipo de pesquisa. Por sua vez, o segundo busca resultados comprovados que permitam tabulações na busca da interpretação dos eventos pesquisados. Ambas as pesquisas podem se utilizar de ferramenta como: Entrevista, Questionários, Relatórios ou Amostras.

Esta pesquisa mostra características Qualitativas e Quantitativas, pois muitos conceitos foram observados e redesenhados para a construção de um Modelo Informado de Processo do Supply Chain utilizando a Tecnologia RFID. As ferramentas utilizadas nesta pesquisa foram a entrevista desestruturada e semiestruturada, junto aos especialistas na produção de sementes de milho e da Tecnologia RFID. Em ambos os casos os primeiros encontros tiveram a finalidade de conhecer o tema abordado, tanto da produção das sementes quanto da Tecnologia, logo entrevistas desestruturadas, sequencialmente as entrevista foram semiestruturadas orientadas por questões pontuadas específicos e verbais. No caso da empresa produtora de Sementes as entrevistas foram sempre acompanhadas de visitas às instalações físicas permitindo assim conhecer detalhadamente o processo produtivo. MOREIRA (2006) complementa dizendo que a primeira etapa da pesquisa pode ser feita mediante entrevistas, que podem ser desestruturadas, semi- 
estruturadas ou não estruturadas e que a definição da qual deve ser aplicada cabe ao pesquisador, em função do que esta procurando nas respostas dos entrevistados.

As respostas obtidas nas atividades descritas no parágrafo anterior permitiram utilizar softwares especializados para construção de Modelos, dando a pesquisa caráter quantitativo $\mathrm{Na}$ primeira etapa foi usado o software chamado Enterprise Architect 9.2, disponibilizado junto ao D-Lab (Laboratório USP), para levantar atributos necessários através de Diagramas de Classe UML, em seguida tendo-os definidos e conhecendo os detalhes da Tecnologia RFID utilizou-se o software livre YAWL4 Study 2.3 para representar o Workflow utilizado para o Estudo de Caso, metodologia apropriada para este estudo.

O estudo buscou criar um Modelo de Processo Informado para uma Cadeia de Suprimentos ("Supply Chain") que fosse representativo para a economia brasileira, o que facilmente o conduziu ao Agronegócio. Neste segmento inúmero são as Cadeias disponíveis e a escolha muito diversificada, sendo assim, buscou-se uma que além de representativa posteriormente permitisse estender seus resultados as demais. Nesta perspectiva o Milho se evidencia, e foi escolhido também em função de suas margens de lucro viáveis para investimentos em tecnologia, segundo informações dos especialistas consultados. Para que o estudo vislumbrasse todas as nuances da Cadeia de Suprimentos do Milho particularizou-se a observação na produção de Sementes de Milho, que tem menor escala do que o grão comercial, mas apresenta exatamente o mesmo comportamento.

A produção da Semente de milho pode ser dividida em dois sub-processos básicos a Produção e o Beneficiamento, o primeiro acontece no campo e o segundo em ambiente fabril. O sub-processo Beneficiamento foi escolhido para concentrar o estudo, pois pode ser caracterizado como uma etapa de Manufatura / Serviço do "Supply Chain". Para obterem-se dados e experimentações realizou-se parte da pesquisa junto à empresa Limagrain Guerra, produtora de sementes de milho e respeitada em todo o território nacional, caracterizando um Estudo de Casos, que. Segundo GIL (2002) e MIGUEL (2007) é aplicado para que se 
aprofundar nos detalhes o que se busca no estudo da Cadeia de Suprimentos da Semente de Milho.

O uso de um Estudo de casos traz algumas vantagens e permite ao pesquisador teorizar e explicar fenômenos que outras formas de pesquisa não permitem. Reforçam esta posição LUDCKE E ANDRÉ (1986, p.18-19), ao afirmarem:

As características fundamentais do estudo de caso são as que visam a descoberta, a interpretação do contexto, retratam a realidade, usam variedade e fontes de informações, revelam experiências de vicárias e permitem generalizações naturalistas, representam pontos conflitantes numa visão social, utilizam uma forma mais acessível do que os outros relatórios de pesquisa.

\subsection{OBJETO DO ESTUDO}

Esta pesquisa foi definida como Exploratória embasada num Estudo de Caso, para desenvolvimento de um Modelo Informado de Processo da Cadeia de Suprimentos Agronegócio.

\subsection{TÉCNICAS E ESTRATÉGIAS}

A pesquisa na forma de um Estudo de Caso precisou ser planejada e contar com uma estratégia de desenvolvimento. Para tanto seguiu-se as seguintes etapas:

$\checkmark \quad$ Revisão bibliográfica: Etapa fundamental numa pesquisa Exploratória de um Estudo de Caso, para tanto se buscou o embasamento em itens até então independentes como: Tecnologia RFID, Supply Chain Management, Agronegócios, Modelagem de Negócios, "Workflow”.

$\checkmark$ Pesquisa de Campo: Definida a Cadeia de Suprimentos a ser modelada foi preciso conhecê-la, para tanto se visitou a empresa onde ser realizou o Estudo de Caso acompanhando todo o processo de beneficiamento (Manufatura / Serviços) das sementes de milho fazendo-se registros fotográficos e operacionais. 
$\checkmark \quad$ Entrevista com especialistas: Para se consolidar o entendimento do processo foram feitas entrevistas com os especialistas da empresa produtora de sementes e também de empresas detentoras do conhecimento da tecnologia RFID.

$\checkmark \quad$ Levantamento documental: Durante os procedimentos observaramse que inúmeros documentos são gerados durante o processo de beneficiamento, alguns por forma de organização da produção e outros por exigência legal, porém ambos precisam ser incorporados ao novo modelo. Para tanto foi preciso resgatá-los e analisá-los.

Modelagem do Processo: Para estudo do processo foi desenvolvido o modelo do processo utilizando diagramas UML- "Use Case".

$\checkmark \quad$ Desenvolvimento de um Modelo Teórico Após o Estudo do Estado da Arte do Processo de produção de Sementes de Milho, considerando determinações legais e de processo, elaborou-se o "Workflow" do Modelo Informado com a utilização da Tecnologia RFID.

Desenvolvimento de Modelo em Laboratório: Após realização do Workflow foi preciso simular um Modelo Informado para a Cadeia das Sementes de Milho e analisar suas respostas. Para tanto, desenvolveuse uma parceria com a empresa $3 \mathrm{M}$, para transferência de tecnologia, com uso de seus equipamentos.

Conclusões: Após a coleta de dados do Modelo de Laboratório (protótipo) foi feita análise dos resultados e consolida a viabilidade da proposta para aplicação em Cadeias de Suprimentos do Agronegócio, bem como sugestões de trabalhos futuros. 


\section{PROPOSTA DE PROCESSO INFORMADO E ESTUDO DE CASO.}

O objetivo desta Tese é propor um método para a Modelagem do Processo Informado de Supply Chain, baseado no uso de RFID, que permita ao cliente acessar o histórico de um item consumido ou adquirido, na busca pela garantia de origem e comprovação da qualidade. A utilização da Tecnologia RFID, através de Tags incorporados ao produto tem como inovação (em relação a outros trabalhos no mesmo tema) a utilização de maior espaço de memória, dentro do conceito de Memória Expandida. A Modelagem proposta utiliza ferramentas de $\mathrm{Tl}$, para a captura de todas as tarefas e atividades envolvidas e realizadas durante o "Workflow" (associado a um processo de negócios). Este estudo tem sua característica inédita justamente na utilização de ferramentas computacionais (sistemas de informação) para automatizar o monitoramento do "Workflow" com uma nova visão aplicativa da tecnologia RFID, isto é, que transcende o seu papel de instrumento de identificação. Como dito nos capítulos anteriores, esta abordagem é especialmente promissora quando usada para modelar sistemas de serviço - por completo ou serviços inseridos em um processo maior como manufatura ou agricultura de precisão.

Entretanto, como também comentado na introdução e no capítulo 2, processos que resultam em "Workflow" precisam ser modelados, tanto na sua sequência de ações e resultados, como na sua interação com o restante do sistema produtivo. E este processo se inicia com a eliciação e análise de requisitos impostos pelos atores envolvidos no sistema que se quer analisar, normalmente feita em linguagens específicas para este fim com os diagramas da UML ('Unified Modeling Language").

Entre os diagramas da UML o diagrama de caso de uso ("Use Case") é o mais usado na prática, especialmente para a análise de processos de negócio (de onde se vai retirar os processos de "Workflow" que foram objeto deste trabalho). Este tópico, apesar de muito importante para a aplicabilidade das propostas contidas neste trabalho não constitui contribuição acadêmica e, portanto vamos simplesmente utilizar uma ferramenta comercial de grande aceitação no mercado para esta fase do projeto. Neste caso, o software "ENTERPRISE ARCHITECT" é uma ótima opção 
inicial para construção do Modelo. Esta primeira etapa é obtida pela inserção de um tratamento mais formal para o "Supply Chain" (Dolgui e Proth, 2008), e promovendo soluções que permitam usufruir das vantagens tecnológicas dos dispositivos RFID. Um ponto importante neste processo é a abertura para o desenvolvimento de pesquisa acadêmica como um insumo ao agrocluster, através de convênio entre um fabricante do software, a empresa SparX da Austrália e o Design Lab (D-Lab), da Escola Politécnica da USP (contando ainda com o apoio da empresa 3M do Brasil). Note-se ainda que o referido software permite a análise requisitos por "viewpoints", contribuição de outras teses do D-Lab.

Portanto feita esta análise inicial dos requisitos é possível identificar os processos de "Workflow" que precisam ser modelados.

A ferramenta indicada para a modelagem de "Workflow" é o software YAML4Study, que implementa as "Wf-nets (workflow nets)", uma proposta de W. Van der Aalst, para uma representação de processos de workflow baseados em Redes de Petri "Place/Transition" (também já referenciada no capítulo 2). O processo proposto pressupõe a análise do "Workflow" e dos fluxos do Processo Informado, para identificar de "interação" com os dispositivos RFID, isto é, os pontos em que nova informação é inserida no sistema (e acoplada ao produto) e/ou os pontos em que informação precisa ser coletada destes dispositivos para reorientação do próprio fluxo ou para certificação de qualidade.

Na verdade, a proposta feita neste trabalho é factível para qualquer "Supply Chain" embora tenha sido escolhido como prova de conceito, testar a sua aplicabilidade prática na uma Cadeia do Agronegócio. A principal motivação desta escolha está no fato de que cresce continuamente os desenvolvimentos da agricultura de precisão, porém existe uma lacuna no acompanhamento, registro e comprovação das ocorrências na Cadeia. É ainda um caso típico de inserção de serviços no setor básico (primário) da economia que é a Agricultura, só que, com novas bases. Outro fator levado em consideração foi a importância do segmento para a economia e a ausência de projetos, estudos e desenvolvimentos específicos. 
A escolha de uma cadeia representativa do Agronegócio é fundamental para que futuramente se possam estender os resultados a todo este segmento. A grande maioria das Cadeias previamente observadas, como a do boi, por exemplo, têm grande potencial aplicativo, porém a sua composição é complexa e dotada de diversos atores do tipo "pessoa jurídica", que encapsulam a informação, dificultando a estruturação de um Modelo.

Outro agravante na escolha da cadeia é a margem de investimento oferecida pelo produto, pois também é preciso evidenciar a viabilidade econômica da proposta. Esta situação foi constatada para a Cadeia da Soja, que no momento tem estreitas margens de lucro, dado que, sendo uma "commodity", tem preço fixado no mercado internacional e não comportaria investimentos tecnológicos baseados em serviço.

Após diversas entrevistas com especialistas do Setor constatou-se que nas próximas safras o milho terá alta no mercado internacional, o que permitirá investimentos em novas tecnologias. Determinada a cadeia, verificou-se a possibilidade de segmentá-la ainda mais, sem que se perdesse a visão do "Supply Chain" ideal. A produção de Sementes de Milho surgiu naturalmente como a opção apropriada para o Estudo, e dentro desta cadeia, o processo de "industrialização" permite uma configuração ideal para se realizar um Estudo de Caso.

Definida esta premissa buscou-se uma empresa que aceitasse participar deste Estudo, abrindo detalhes de sua planta industrial, o que foi possível com a parceria da empresa Limagrain-Guerra do Brasil.

A etapa derradeira deste trabalho foi criar um protótipo em bancada que mostrasse os resultados obtidos de forma clara e em escala reduzida, pois toda lógica de uso de equipamentos RFID está voltada à identificação do item e não ao Processo Informado. Para tanto, a simulação foi feita com equipamentos existentes no mercado para utilização de controle de patrimônio de bibliotecas, emprestados pela $3 \mathrm{M}$ do Brasil, que para fins de conclusão deste trabalho fez um convênio informal com o D-Lab. 
Assim, o protótipo deve refletir o processo sintetizado pelo método proposto, que é sintetizado na Tabela 6

\begin{tabular}{|c|l|l|}
\hline Item & \multicolumn{1}{|c|}{ Atividade } & \multicolumn{1}{|c|}{ Objetivo } \\
\hline $\mathbf{0 1}$ & Buscar dados preliminares & $\begin{array}{l}\text { Esta etapa visa buscar dados que permitam alcançar o entendimento dos } \\
\text { processos vigentes na empresa. Para tanto é preciso adotar um } \\
\text { instrumento de pesquisa, que pode ser entrevistas abertas ou fechadas, } \\
\text { questionários, etc. }\end{array}$ \\
\hline $\mathbf{0 2}$ & Diagramar operações & $\begin{array}{l}\text { O entendimento dos processos precisa ser sistematizado de forma a não } \\
\text { deixar nenhum detalhe sem consideração, portanto a busca de } \\
\text { ferramentas apropriadas facilita a sistematização. Os diagramas UML } \\
\text { usados neste trabalho se mostraram adequados a esta fase. }\end{array}$ \\
\hline $\mathbf{0 3}$ & Modelar o processo & $\begin{array}{l}\text { Consolidado o entendimento dos processos é importante criar um modelo } \\
\text { que o represente exatamente como ele se desenvolve na realidade, } \\
\text { permitindo assim antecipar as condicionantes de operação. A utilização de } \\
\text { ferramentas apropriadas essencial, softwares que estejam } \\
\text { fundamentados em Redes de Petri são ideias. }\end{array}$ \\
\hline $\mathbf{0 5}$ & Desenvolver fornecedor & $\begin{array}{l}\text { Os equipamentos que serão utilizados em um protótipo devem ser dotados } \\
\text { de assistência dos fornecedores para conceber um projeto eficiente. Para } \\
\text { tanto o fornecedor deve ser um parceiro no projeto, comprometendo-se } \\
\text { com os resultados. }\end{array}$ \\
\hline $\mathbf{0 6}$ & Desenvolver software & $\begin{array}{l}\text { O software é componente fundamental para o sucesso do modelo, } \\
\text { portanto o seu desenvolvimento deve ser feito por profissionais } \\
\text { competentes, que integrem os fornecedores partir dos modelos feitos. }\end{array}$ \\
\hline $\mathbf{0 0}$ & Validar Modelo & $\begin{array}{l}\text { A lógica do modelo deve ser validada na aceitação dos requisitos } \\
\text { levantados, novamente uma entrevista com colaboradores da empresa no } \\
\text { intuito de afinar o projeto antes do desenvolvimento do protótipo. }\end{array}$ \\
\hline Implantar Protótipo & $\begin{array}{l}\text { Para que os recursos sejam bem utilizados a criação de Protótipos é } \\
\text { fundamental, pois permite em pequenas escalas levantar falhas } \\
\text { previamente a ocorrência. O protótipo, portanto evita prejuízos. }\end{array}$ \\
\hline
\end{tabular}

Tabela 6 - Sequência de procedimentos para estruturar um Modelo

No que se segue apresentaremos os detalhes do estudo de caso começando pelo processo de negócios e pela inserção no mercado da própria empresa escolhida. 


\subsection{HISTÓRICO DA EMPRESA LIMAGRAIN-GUERRA}

O Estudo de Caso foi feito em uma empresa tradicional que teve início em 1929, no interior do Rio Grande do Sul e foi transferida para Pato Branco no Estado do Paraná no ano de 1952. Nesta etapa a empresa era basicamente um empreendimento familiar do tipo armazéns de secos e molhados.

Em 1979 foi reestruturada mudando seu foco para o mercado agroindustrial, mais especificamente para a produção de sementes que no ano de 1992 foi impulsionado pela parceria com uma multinacional detentora da tecnologia de milho híbrido.

No final da década de 90 a empresa amplia seu potencial produtivo, inaugurando novas unidades de recebimento na região Sudoeste do Paraná, iniciando assim um processo de crescimento contínuo e estável.

Nesta trajetória em 2008 a empresa torna-se uma das maiores exportadoras de grãos do Estado do Paraná, entrando também para o segmento agroindustrial passando a produzir alimentos como biscoitos, macarrão, farinhas e outros, sempre mpliando a atuação na "Supply Chain" dos grãos que beneficiava, por exemplo, o trigo.

A empresa reestruturou seu modelo de gestão em 2011, criando o organograma apresentado na Figura 25. Estas modificações, que estão sendo promovidas na empresa nos últimos dois anos, buscam inovar o processo de produção de Sementes, no intuito de alcançar rapidamente $10 \%$ do Mercado Nacional de Sementes de Milho. Esta situação cria um ambiente favorável à realização do Estudo de Caso. 


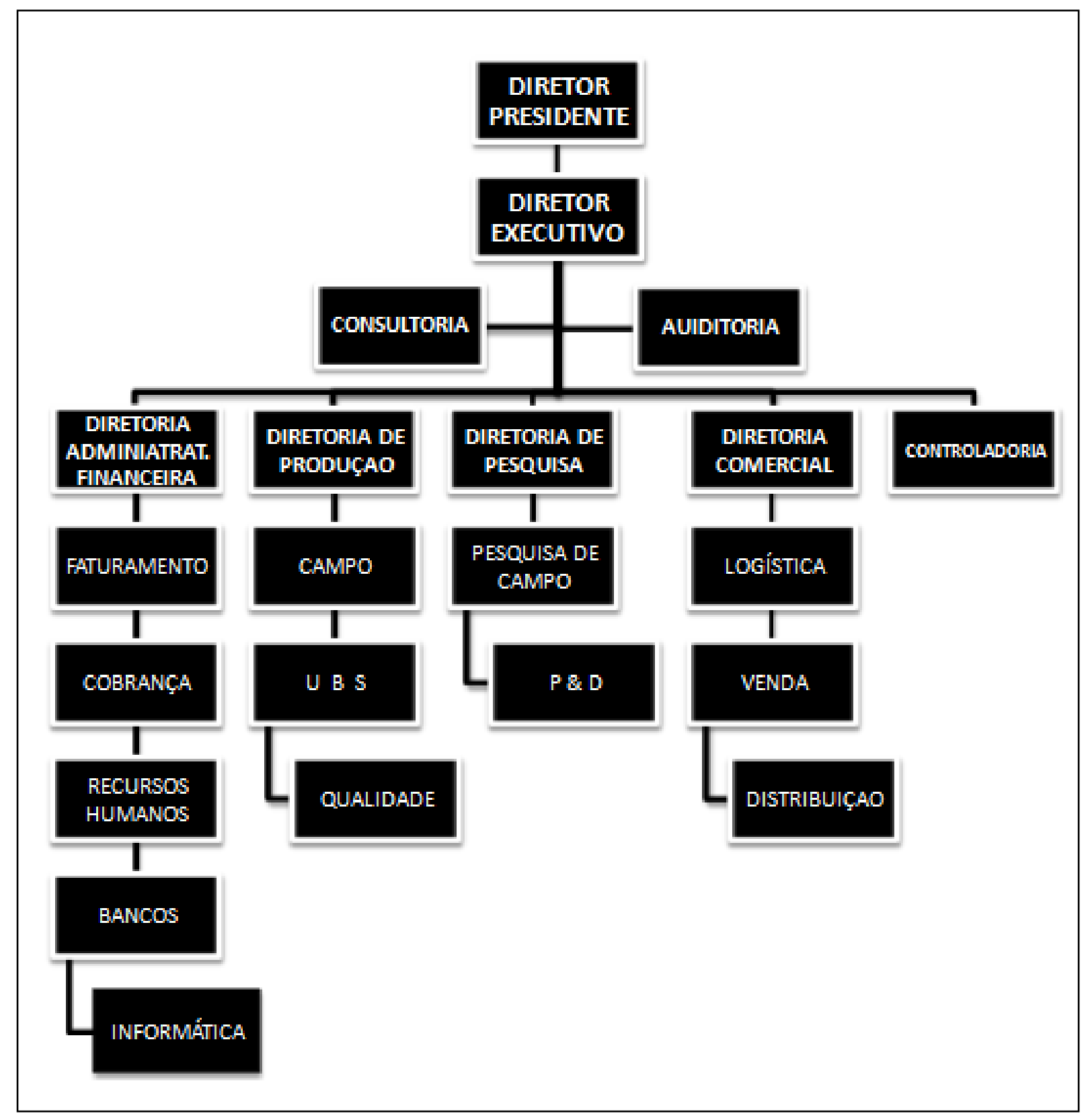

Figura 25 - Organograma Redefinido - Empresa 2011

\section{2 - CARACTERIZAÇÕES DA CADEIA DE SEMENTE DE MILHO}

Para desenvolver o Modelo de Processo para o "Supply Chain" do Milho foi preciso conhecer como esta se comporta, portanto, foram necessárias visitas, entrevistas e observações, processos característicos da fase de eliciação de requisitos clássicos. 


\subsubsection{Termos e Definições:}

As Cadeias de Suprimentos tem particularidades pertinentes ao tipo do produto e uma terminologia que precisa ser conhecida para compreender os detalhes do processo (em um processo equivalente à elaboração de glossário, que sucede à fase de eliciação de requisitos). Para o caso do milho os principais termos são:

$\checkmark \quad$ Bonecas polinizadas: São espigas de Milho que apresentam o cabelo seco ou secando, com coloração marrom.

$\checkmark$ Bonecas receptivas: São espigas de Milho que apresentam o cabelo exposto, fresco, úmido e receptivo ao pólen.

$\checkmark \quad$ Colheita: É a operação realizada no campo para retirar as sementes das linhas de fêmea, operação que pode ser feita manualmente ou mecanicamente, com uma colheitadeira de espigas.

$\checkmark$ Despendoamento: é uma operação manual/mecânica com o objetivo de retirar o pendão das plantas que compõem as linhas da fêmea.

$\checkmark$ Dobra manual: Quando as espigas atingem a maturação fisiológica dobra-se a planta no gomo imediatamente abaixo da espiga.

$\checkmark \quad$ Fêmea: É a linha de plantio que será despendoada e que receberá o pólen e será colhida para semente, designada também como progenitor feminino.

$\checkmark \quad$ Florescimento: É o estágio do campo de semente em que as plantas das linhas de fêmea apresentam $5 \%$ de estigmas maiores que $10 \mathrm{~mm}$.

$\checkmark \quad$ Híbrido Duplo: É o grão oriundo do cruzamento de 2 híbridos simples.

$\checkmark \quad$ Híbrido Simples: É o grão proveniente do cruzamento de 2 linhagens puras.

$\checkmark \quad$ Híbrido Triplo: É o grão com origem no cruzamento de 1 linhagem pura e 1 híbrido simples.

$\checkmark$ Isolamento: é a distância mínima em metros ou tempo mínimo em dias, necessário para que não ocorra polinização indesejada.

$\checkmark \quad$ Linhagem pura: É a denominação que se dá ao milho geneticamente puro e estável. 
$\checkmark \quad$ Macho: É a linha de plantio que fornecerá o pólen; também designado polinizador ou progenitor masculino.

$\checkmark \quad$ Maturação fisiológica: Ocorre quando as sementes apresentam a ponta do sabugo enegrecida e não circula seiva para as sementes.

$\checkmark$ Pendão polinizando: É denominado assim, pois o pendão fica exposto, com anteras à mostra e liberando pólen.

$\checkmark$ Polinização: É denominado como sendo o exato momento em que o grão de pólen se transfere do pendão para o cabelo.

$\checkmark$ Pré-florescimento: É o estágio do campo de sementes uma semana antes do florescimento.

$\checkmark$ "Split": É a diferença entre o plantio das linhas de Macho e das linhas de Fêmea.

$\checkmark$ Transporte: É a operação realizada que tem como objetivo levar a semente, a granel ou em espigas, até o local de secagem.

\subsubsection{Modelo SCM do Milho.}

A proposta de um Modelo Informado de Processo para o "Supply Chain" da Semente de Milho implicou em aprofundar o conhecimento de suas atividades. Para estruturar esta etapa foi necessário visitar o ambiente produtivo e observar suas particularidades registrando seus procedimentos. Em paralelo com as observações foram feitas entrevistas não estruturadas e semi-estruturadas no intuito de assimilar de forma mais consistente o que foi observado.

De posse das informações foi preciso usar de uma ferramenta que permitisse representar e estudar os requisitos necessários para o desenvolvimento do novo Modelo. A opção para a representação dos requisitos escolhida foi a linguagem UML, como já mencionado, uma vez que é totalmente aceita pelos estudiosos em Modelagem de Negócio. ASSIS e RODRIGUES(2003, p.91) afirma que a

UML é uma linguagem padrão utilizada para modelagem e projeto de sistemas, que permite demonstrar as funcionalidades do sistema proposto através da visualização, especificação, construção e demonstração de elementos de um software, utilizando conceitos próximos da realidade, para atendimento de analistas e usuários. 
Segundo afirma SALM JUNIOR (2003), a utilização de dois diagramas, dos diversos existentes na linguagem UML, já proporciona a captura de forma satisfatória dos processos de negócio, como no caso da Semente de Milho. Estes seriam: o Diagrama de "Use Case", para representar o Modelo, a partir do que já é feito atualmente, e o Diagrama de Estados (que pode também ser substituído pelas redes de Petri ou por uma rede Wf-net. Para utilização da UML, buscou-se o software chamado "ENTERPRISE ARCHITECT MODELING TOLL" -version 9.2, licenciado junto ao D-lab/USP. Esta opção segundo CANDIDO (2007 p.69) tem "como característica fundamental a visibilidade que a linguagem UML possui, portanto facilita sobremaneira a comunicação ente analistas do modelo e o cliente do sistema modelado.".

A Figura 26 mostra o diagrama "USE CASE", que permitiu reconhecer dois processos distintos na produção de Sementes de Milho, o primeiro chamado de PROCESSO DE CAMPO e o segundo de PROCESSO INDUSTRIAL. Cada um destes processos pode ser subdividido em sub-processos, a partir dos quais se desenhou o Modelo.

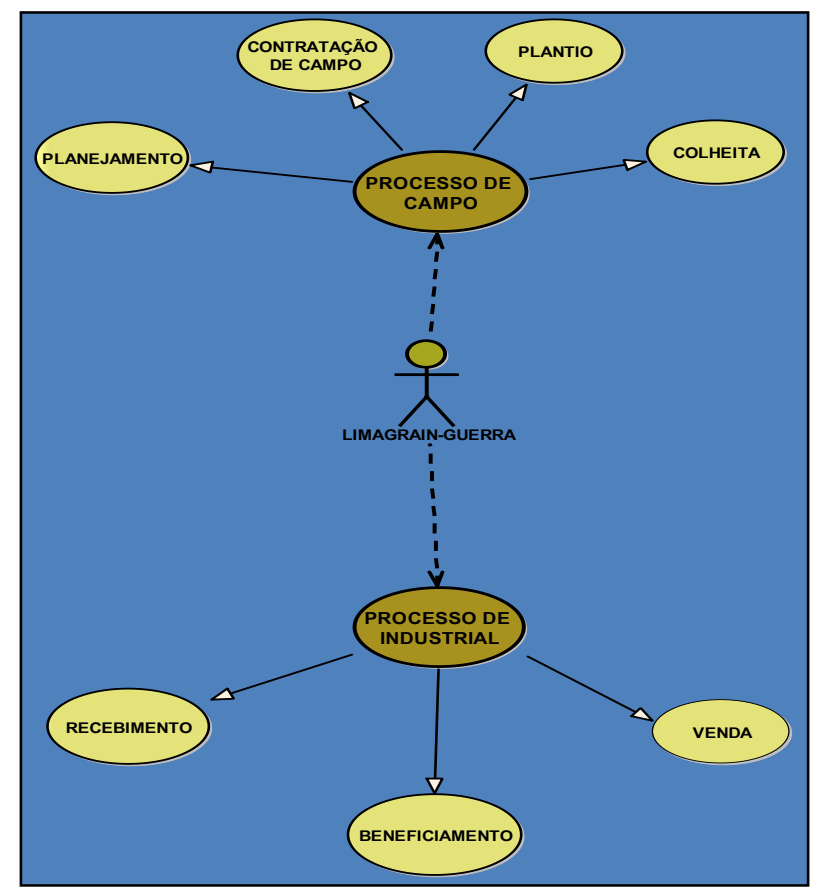

Figura 26 - Diagrama UML “Use Case” SCM do Milho - Própria 


\subsubsection{Processo de Campo}

O Processo de Campo pode ser definido como tudo o que acontece antes de uma carga de semente chegar à Portaria da empresa e diretamente vinculada com o "plantar e colher".

\section{Processo de Campo - Planejamento}

Como em qualquer atividade, o planejamento é a parte mais importante na Cadeia de Suprimentos da Semente de Milho para o atendimento de uma safra e normalmente acontece com 4 anos de antecedência das colheitas de grãos comerciais determinando inclusive as demandas de sementes genéticas junto às detentoras das variedades. A Figura 27 mostra o diagrama que permitiu definir 3 atividades importantes geradoras de informações para o Processo Informado.

$\checkmark \quad$ Definir Pontos de Venda: Visa determinar quais regiões do território

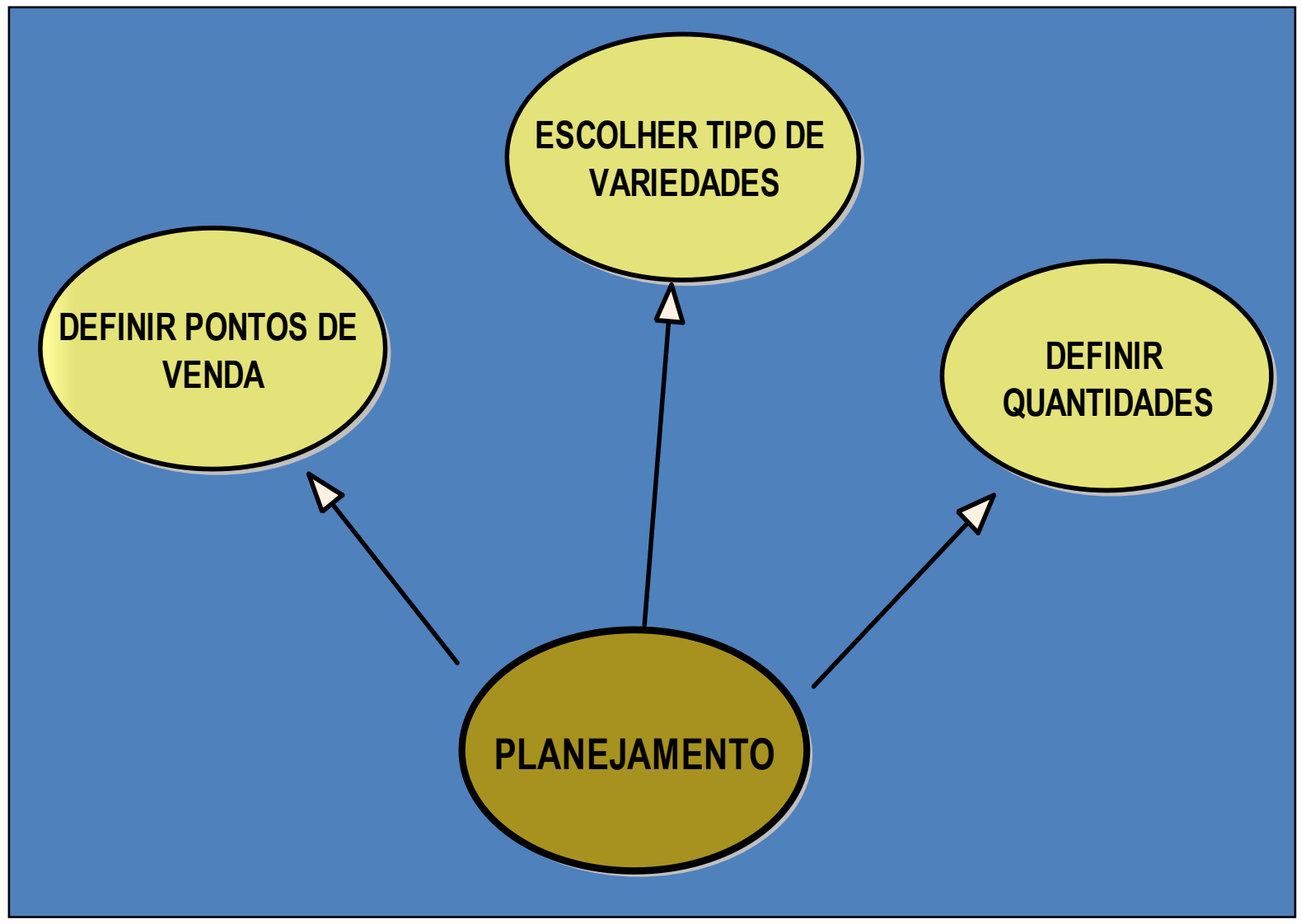

Figura 27 - Diagrama UML “Use Case” do Planejamento - Própria 
brasileiro serão atendidas na safra planejada.

$\checkmark \quad$ Escolher tipo de variedades: Definidas as regiões de vendas é preciso definir quais variedades são apropriadas para cada caso.

$\checkmark \quad$ Definir quantidade: Terminando as projeções deve-se determinar a quantidade de cada variedade deve ser produzida.

\section{Processo de Campo - Contratação de Campo}

A produção das sementes é orientada em todas as etapas para a garantia de qualidade. Para tanto os locais de plantio precisam ter registro e controle exatos, e o diagrama Use Case da Figura 28 identificou 4 tarefas a serem cumpridas rigorosamente:

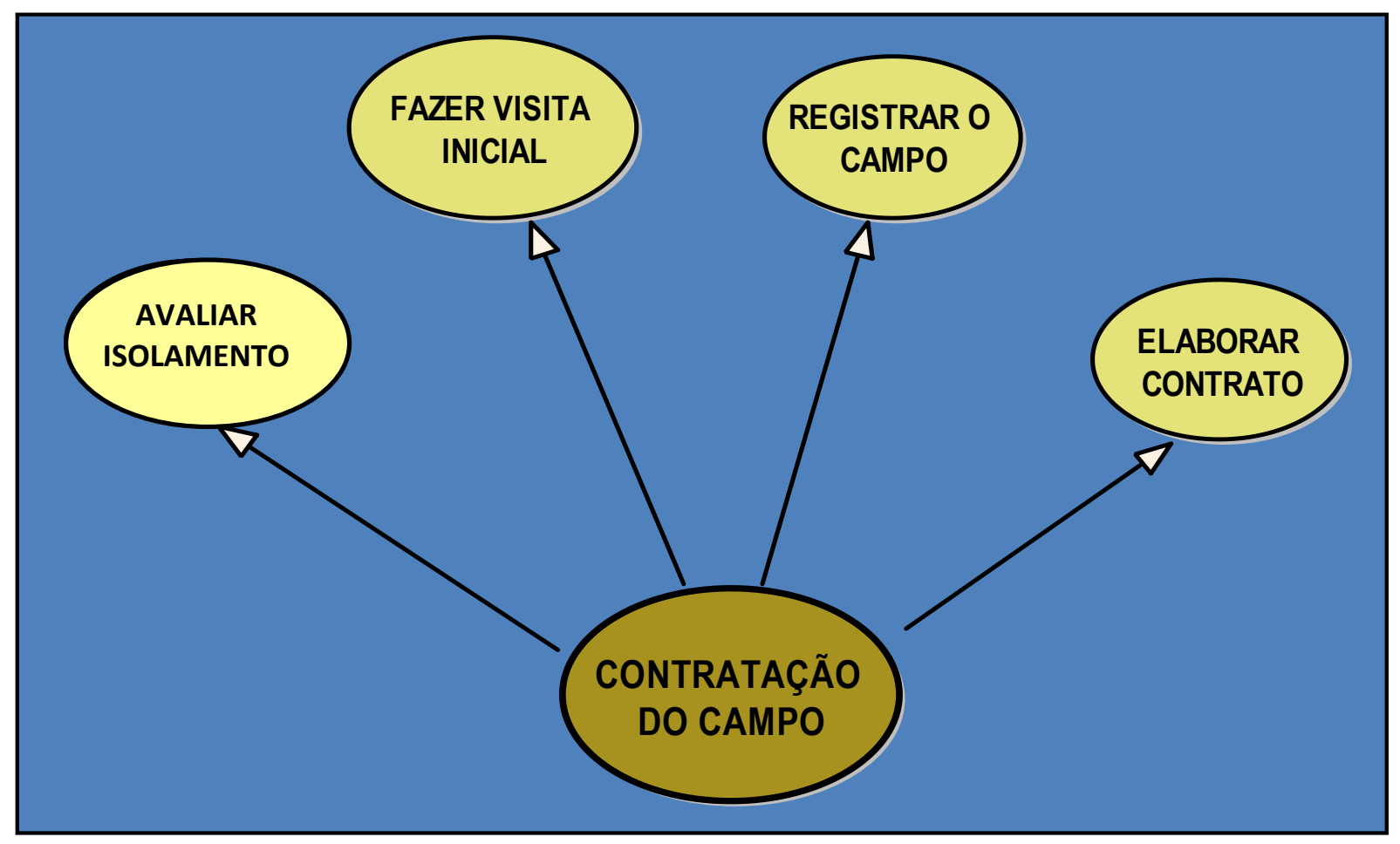

Figura 4 - Diagrama UML “Use Case” da Contratação do Campo - Própria 
$\checkmark \quad$ Avaliar o Isolamento: Observar a distância mínima entre o campo de produção de sementes e outra área de milho e/ou a diferença em dias entre o plantio de sementes e o plantio de outra área de milho.

$\checkmark \quad$ Fazer vistoria Inicial: Verificar as condições técnicas, econômicas, estruturais do produtor e de sua propriedade, para analisar a viabilidade da contratação de campo.

$\checkmark$ Registrar o Campo: O campo produtor de sementes deve ser registrado no Ministério da Agricultura e cabe a empresa obter o número do registro.

$\checkmark \quad$ Elaborar Contrato: Registrar documentalmente a relação empresa $\mathbf{x}$ produtor, dando normativas para obter-se sementes de qualidade $\mathrm{e}$ em quantidade.

\section{Processo de Campo - Plantio}

Definidas as variedades, quantidades, e locais efetiva-se a plantação das sementes genéticas para obtenção das sementes comerciais. Na Figura 290 Diagrama UML "Use Case" mostra as etapas do sub-processo.

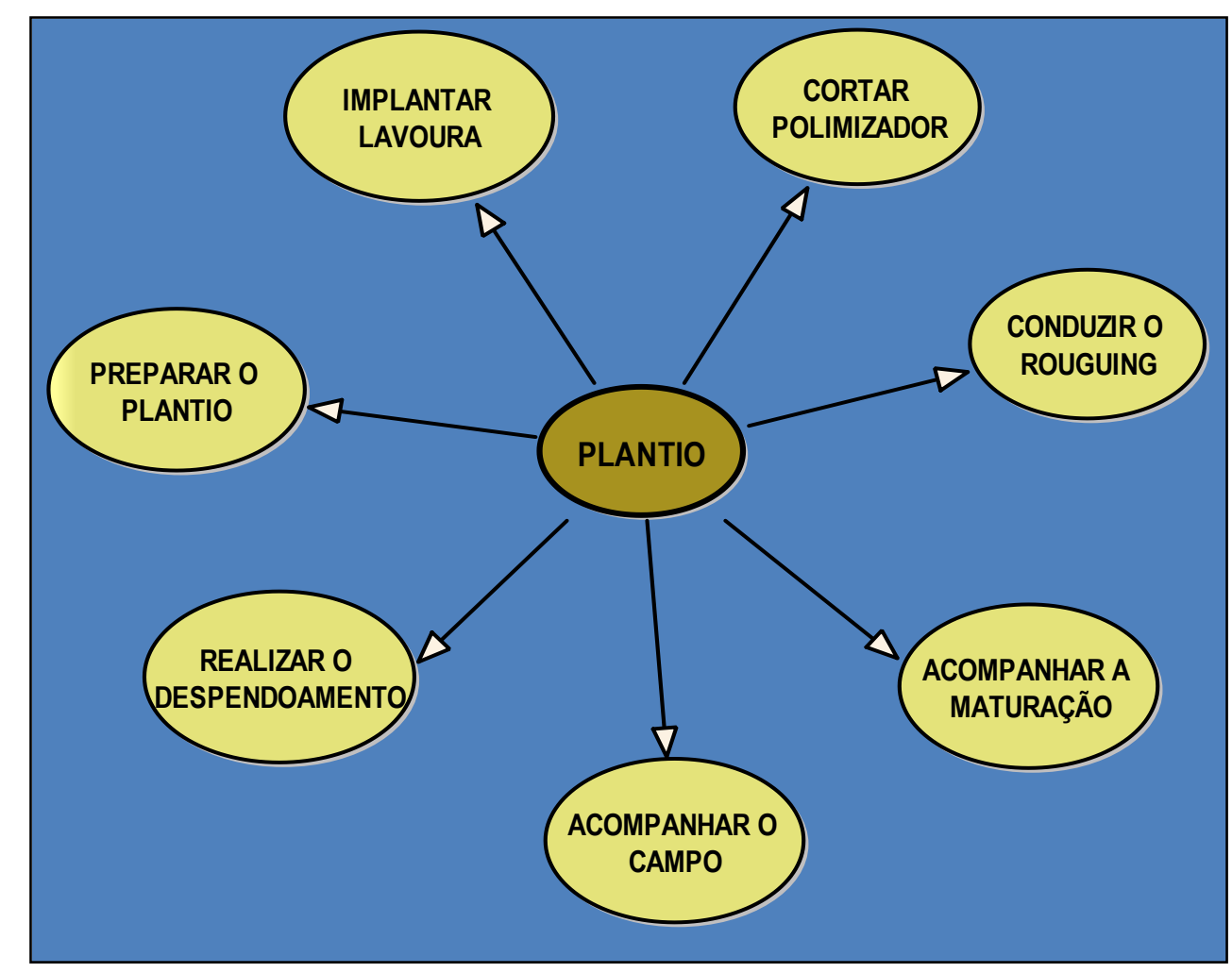

Figura 29 - Diagrama UML “Use Case” do Plantio - Própria 
$\checkmark \quad$ Preparar o plantio: O plantio não é um processo simples, é preciso cumprir uma série de cuidados com a fertilidade, com os implementos, com o isolamento, etc. Sendo assim o atendimento a estas premissas é pré-condição para o plantio.

$\checkmark \quad$ Implantar a Lavoura: É o sub-processo que coloca a semente na "terra" depois de todos os preparos terem sido feitos, seguindo sempre as orientações do Responsável Técnico de campo.

Cortar o Polimizador: Elimina as linhas do polinizador (macho), para evitar a contaminação das fileiras fêmeas durante a colheita.

$\checkmark$ Conduzir o "Roguing": Consiste em eliminar qualquer planta que possa causar contaminação comprometendo a qualidade.

$\checkmark \quad$ Realizar o Despendoamento (da Fêmea): Deve-se efetuar a retirada dos pendões de todas as plantas para não ocorrer auto-fecundação.

$\checkmark$ Acompanhar o Campo: Realizar visitas periódicas observando 0 desenvolvimento da plantação, ocorrências de pragas, crescimento e cuidados preventivos ou curativos quando necessários.

$\checkmark$ Acompanhar a Maturação (Fisiológica): verificar a densidade de plantio, o desenvolvimento vegetativo e maturação fisiológica. Em resumo, se analisa os aspectos de bom desenvolvimento da planta e a possibilidade de obter bons grãos. Quando necessárias medidas corretivas são prescritas.

\section{Processo de Campo - Colheita}

A colheita é um dos pontos críticos da produção, pois existem fatores que fogem ao domínio do produtor, como condições de clima, transporte, infra-estrutura de escoamento. O diagrama UML Use Case da Figura 30 ilustra os sub-processos levantados.

Preparar a colheita: A colheita precisa ser feita com precisão evitando perdas, quebras, maturação inadequada, etc., logo prepara-se a colheita, ajustando máquinas, escolhendo período e avaliando o clima. 


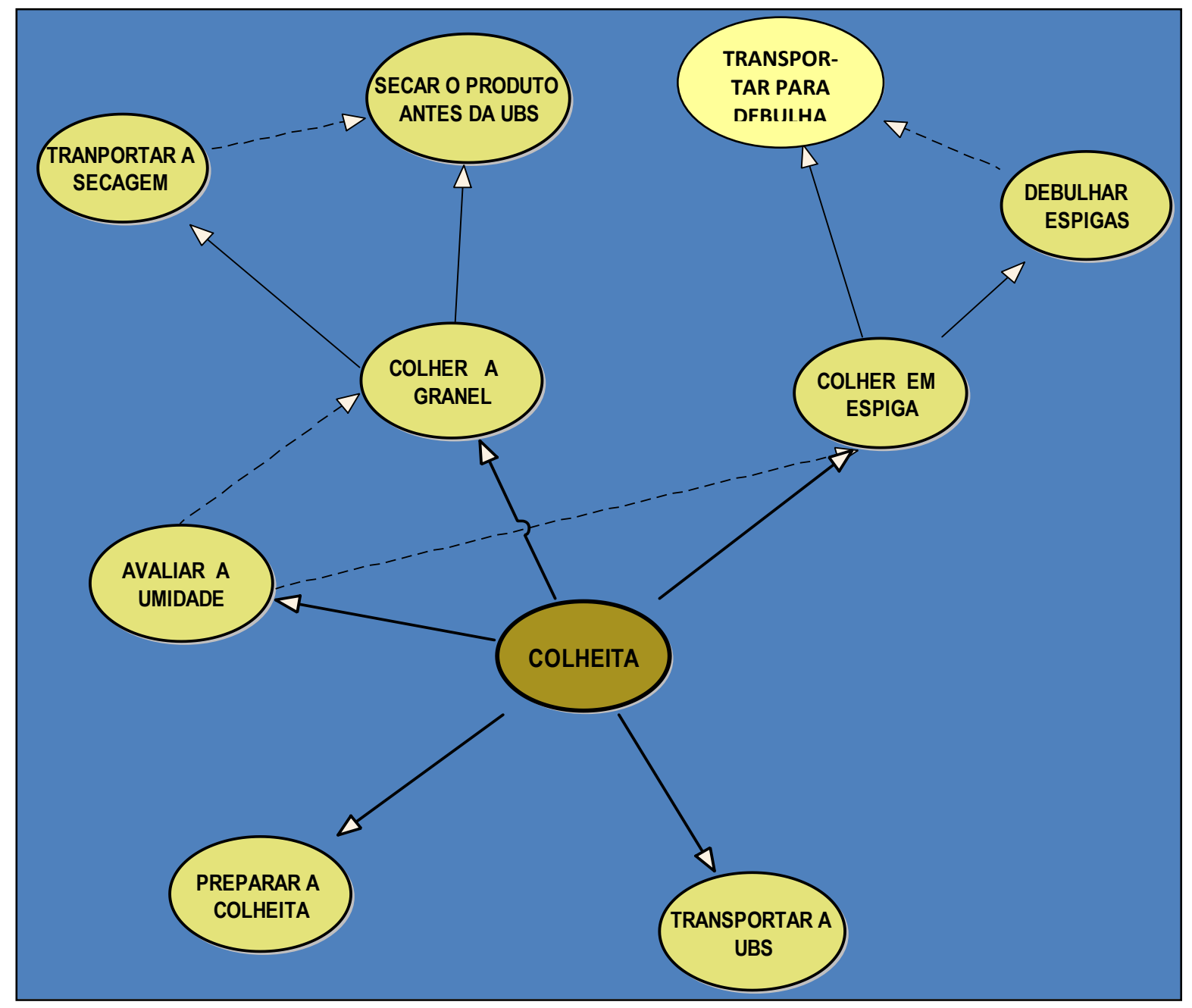

Figura 30 - Diagrama UML “Use Case” da Colheita - Própria

$\checkmark \quad$ Avaliar a Umidade: A umidade é fator determinante na qualidade do grão e o início de colheita do milho só é aconselhável com índice menor que $30 \%$.

$\checkmark \quad$ Colher a Granel: Esta forma de colheita é mais rápida, feita por meio de colheitadeiras, e somente são recomendadas quando o grão estiver com umidade entre 15 e $18 \%$.

$\checkmark$ Transportar a secagem: Destina-se a recolher e transportar até a Unidade de Beneficiamento de Sementes (UBS), as sementes de fêmeas. 
$\checkmark \quad$ Secar o produto antes da UBS: Deve ser feita antes de chegar a UBS em caso de estar fora dos do padrões mínimos desejados, portanto encaminhada à secadores de terceiros,

$\checkmark$ Colher em Espiga: Esta forma de colheita e feita manualmente, e recomendada quando a umidade esta entre $28 \%$ e $35 \%$. Nesta forma de colheita duas etapas são introduzidas:

- Transportar para Debulha: Neste caso o transporte é feito levando as espiga e deve evitar quebras.

- Debulhar Espigas: A debulha nada mais é do retirar os grãos da espiga, e quando não fori feita no campo, deverá ser feita por terceiros.

Este sub-processo de colheita em espigas é pouco utilizado, pois traz o aumento do tempo de trabalho.

$\checkmark$ Transportar à UBS: Visa recolher e transportar até a UBS, as sementes oriundas das linhas de fêmeas, buscando sempre manter a qualidade das mesmas. É importante que se faça o transporte em velocidade compatível, em média de $50 \mathrm{~km} / \mathrm{h}$, de maneira que o tempo de transporte entre colheita e UBS, não seja superior a 18 horas.

\subsubsection{Processo Industrial}

Foi a melhor forma de chamar o processo que acontece dentro das instalações da empresa produtora de semente, ou seja, da Portaria para dentro. Este Processo tradicionalmente visto como industrial pode ser visto também como um serviço de beneficiamento de grãos, ou seja, um misto "Manufatura / Serviços".

\section{Processo Industrial - Recebimento}

O recebimento dos grãos na UBS (Unidade de Beneficiamento de Sementes) dá início ao processo Industrial, conforme mostra o Diagrama UML Use Case da Figura 31. O recebimento por sua vez é composto por 3 sub-processos e 11 atividades. 


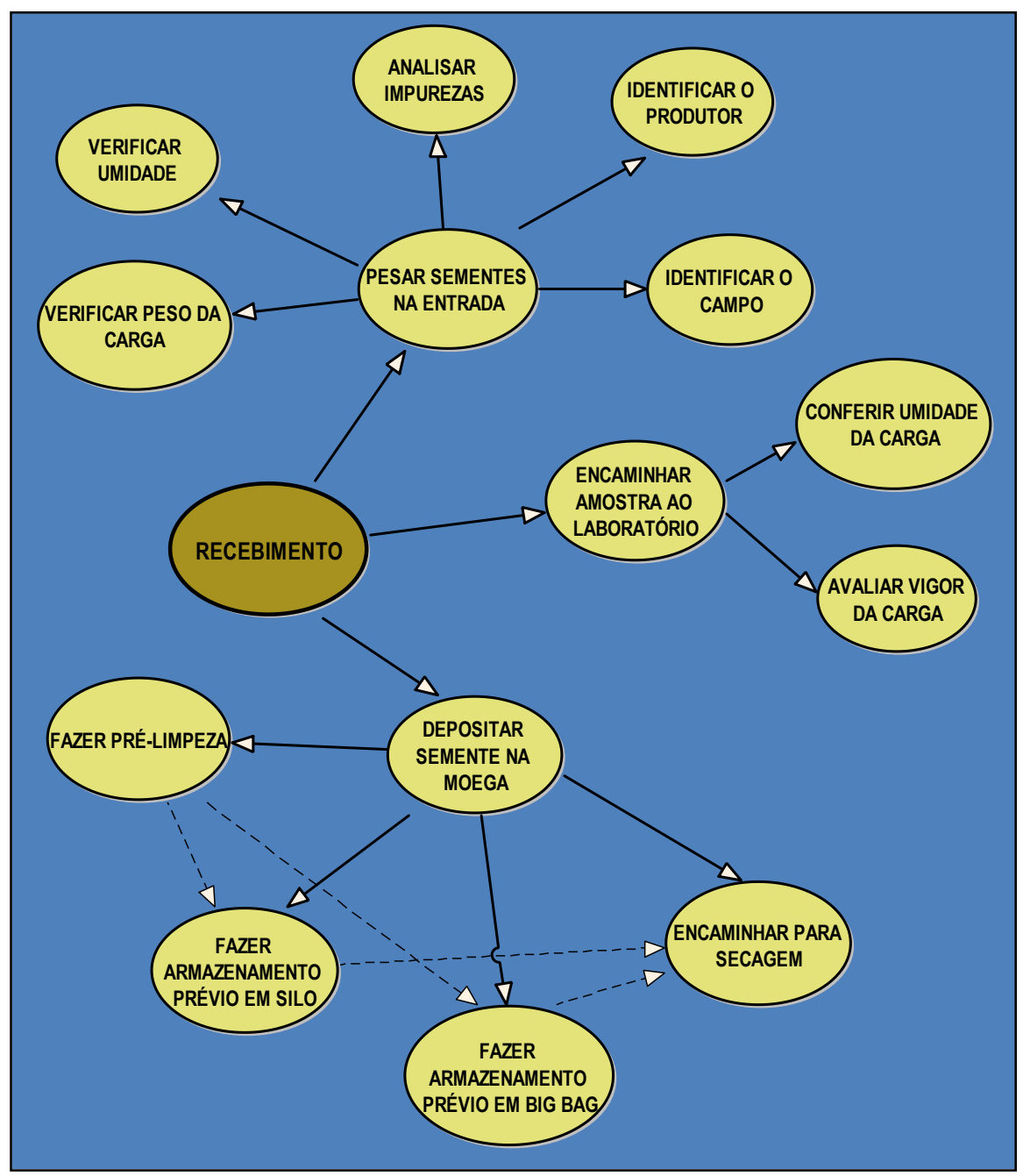

Figura 5 - Diagrama UML “Use Case” do Recebimento - Própria

Pesar Sementes na Entrada: Este sub-processo tem início quando uma carga de sementes chega à UBS posicionando-se sobre a balança e dados descritivos da carga passam a ser incorporados ao Sistema de Informações.

- Identificar o Campo: Esta informação já deve estar registrada no Sistema de Informações da empresa e refere-se ao registro do campo junto ao Ministério da Agricultura e no momento da chegada da carga deve ser confirmado. 
- Identificar o Produtor: Nesta atividade se identifica o produtor, Nota Fiscal, Tipo do Veículo de transporte, dados do Motorista, Tempo de Viagem.

- Verificar peso da carga: Com o caminhão sobre a balança é feito a pesagem com carga e posteriormente sem carga, para ter o valor bruto. Outros procedimentos são feitos em paralelo, tais como preenchimento do romaneio e retirada de amostras para ensaio.

- Verificar Umidade: O percentual ideal de umidade da semente é de $11 \%$. Para tanto valores diferentes são descontados para composição do peso líquido.

- Analisar Impurezas: Nesta atividade é avaliada a quantidade de terra, folhas, e outros detritos junto à carga em função da colheita. O percentual de impureza também e descontado na definição do peso líquido.

\section{Encaminhar Amostra ao Laboratório:}

- Conferir Umidade da Carga: Este processo é feito a partir da amostra para confirmar dados coletados e analisados durante o recebimento da carga. É feito nesta etapa somente em casos passíveis de descartes imediatos.

- Avaliar Vigor da Carga: O vigor determina a capacidade de uma semente germinar em condições desfavoráveis e é feito nesta fase somente quando a carga parece visualmente comprometida.

Depositar Semente na Moega: A moega é parte do Processo Industrial que coloca a semente em processamento, sendo etapas componentes desta fase:

- Fazer Pré-Limpeza: Quando se tiram da carga os restos de colheita, terra, pedras, galhos e insetos.

- Encaminhar para Secagem: Quando os grãos vêm com umidade diferenciada é preciso uniformizar o produto evitando o apodrecimento e diferenças de qualidade. 
- Fazer Armazenamento Prévio em Silo: Muitas vezes existe excesso de produto e é necessário armazená-los antes de iniciar o beneficiamento; uma das formas de armazenamento é em silos.

- Fazer Armazenamento Prévio em Big Bag: Esta forma de armazenamento ocorre de forma similar ao Silo, apenas utilizada quando os silos estiverem totalmente cheios ou com variedades diferentes de semente.

\section{Processo Industrial - Beneficiamento}

No sub-processo de Beneficiamento a semente bruta começa a transformarse em semente comercial garantida. Esta fase representa de forma completa todo 0 "Supply Chain" da Semente de Milho, motivo pelo qual, será abordada como elemento central do Estudo. O Diagrama "Use Case" representado na Figura 32, mostra as diversas atividades e sub-atividades envolvidas no Beneficiamento.

$\checkmark$ Enviar Produto á Maquina de Limpeza: A colheita feita mecanicamente traz consigo pedras, resíduos da planta, terra, que precisam ser separados dos grãos, portanto toda a carga passa por um processo de limpeza antes de chegar a torre.

$\checkmark \quad$ Enviar Produto à Torre: A maior parte do processo de preparo da semente ocorre neste equipamento que pode ser decomposto em atividades:

- Passar pela Mesa Dessimétrica: Tirar as sementes que tem baixa qualidade e resíduos pelo principio da separação de materiais de densidade diferentes pela movimentação de uma base comum.

- Selecionar Sementes por Tipos: Os grãos são diferentes em tamanho, espessura ou comprimento. A separação busca dar uniformidade por um sistema de "peneiramento" rotativo.

- Armazenar em Caixas de Classificação: Feita a separação dos grãos por tipos o final do desta etapa se faz pela armazenagem temporária dos grãos em caixas classificadas. 


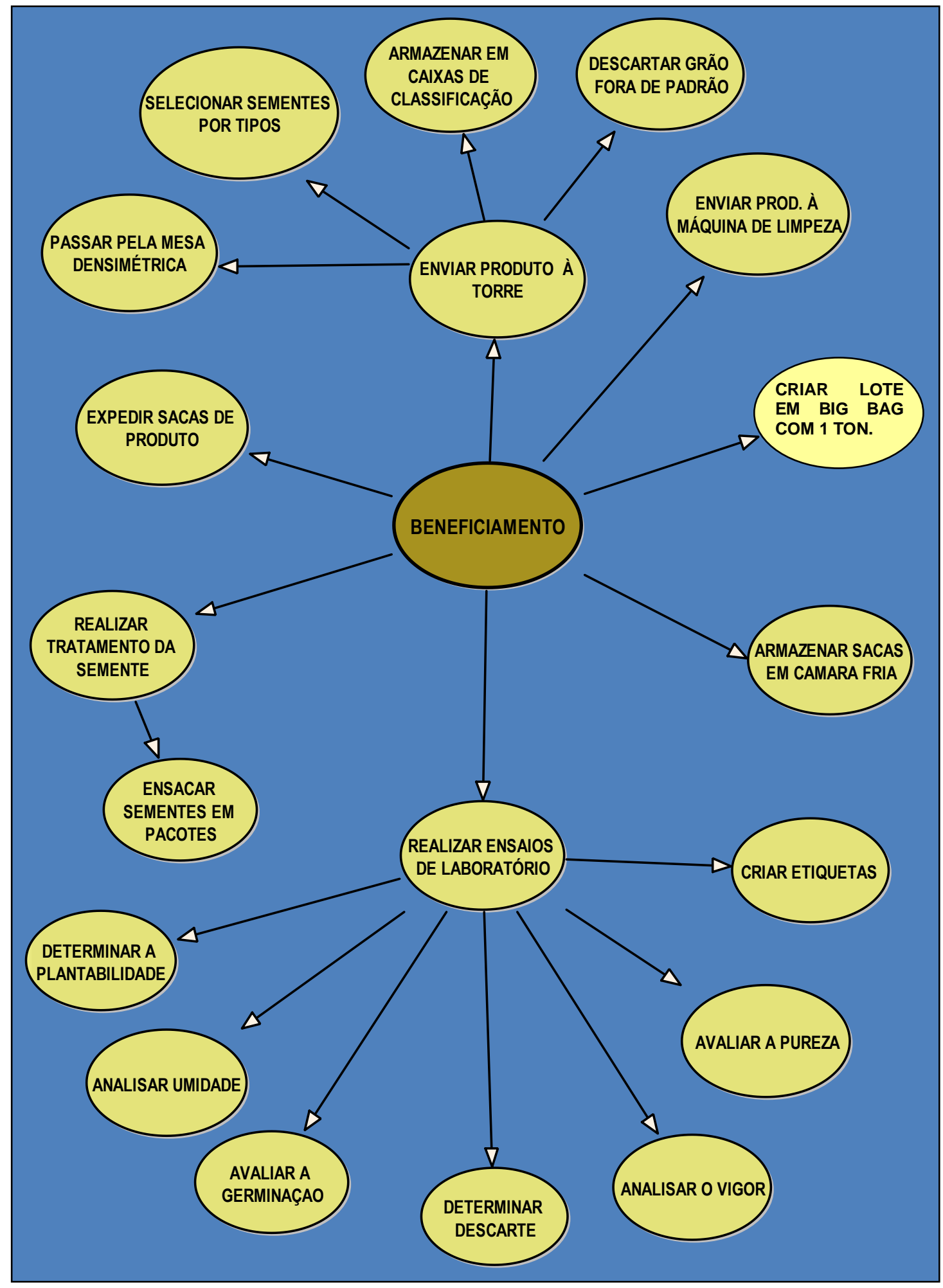

Figura 32 - Diagrama UML “Use Case” do Beneficiamento - Própria 
Descartar Grão fora de Padrão: Os grãos que não puderam ser classificados, por não atenderem nenhuma das especificações de venda serão descartados.

Criar Lote em "Big Bag" com 1 tonelada: A partir da descarga das caixas de classificação, que não podem ser feitas ao mesmo tempo, os grãos de sementes são armazenados em grandes sacolas, chamadas de "Big Bag", com capacidade para 1 tonelada. A cada conjunto de 14 unidades é formado um lote de produto, e os dados passam a acompanhar o produto mediante a colocação de etiqueta.

Realizar Ensaios de Laboratório: $O$ envio e guarda de amostras ao laboratório é uma forma de comprovar a qualidade das sementes, portanto feitas em todos os lotes produzidos. Neste sub-processo são feitas as seguintes atividades:

- Criar Etiquetas: Quando se inicia o ensacamento em "Big Bag", imediatamente se produzem etiquetas para identificá-lo e também as caixas de amostras que irão ao laboratório.

- Analisar Umidade: A umidade tem influência direta na perenidade da semente. É, portanto, um índice que precisa ser confirmado com o obtido na portaria.

- Avaliar a Germinação: É observado o comportamento da semente em condições favoráveis ao crescimento, determinando o percentual de sementes que vingam, jamais inferior a $85 \%$.

- Analisar o Vigor: O ensaio de vigor é semelhante ao da germinação, porém a semente é submetida a condições adversas, verificando-se também o percentual de sementes que vingam.

- Avaliar a Pureza: Determina se todas as sementes de um lote têm as mesmas características.

- Determinar Descarte: Quando um lote não atinge os índices desejados o laboratório determina o seu descarte. 
- Determinar a Plantabilidade: Este ensaio é feito no intuito de informar ao produtor quais tipos de implementos devem ser usados para obter maior rendimento no plantio

Realizar Tratamento da Semente: Quando as sementes são aprovadas nos ensaios de laboratório podem seguir no processo, passando a ser tratadas para imunizá-las contra pragas ou fungos.

- Ensacar Sementes em Pacotes: Ao término do tratamento as sementes serão ensacadas em pacotes de $20 \mathrm{~kg}, 60 \mathrm{~kg}$ ou 60.000 sementes, dependendo da programação de venda.

Armazenar sacas em Câmara Fria: As sacas identificadas podem ficar em armazéns ou na câmara fria a temperatura de 10 graus centigrados, dependendo do tempo de venda e envio ao cliente. O armazenamento em câmara fria pode ser feito por um ano, após este período os ensaios de laboratório precisam ser refeitos.

Expedir Sacas de Produtos: Com ordem da Diretoria Comercial a expedição é feita mediante emissão de nota fiscal, processo de logística, e outros dados.

\section{Processo Industrial - Venda}

A venda é ponto fundamental em qualquer modelo de negócio e também no Agronegócio principalmente se for entendido como um Serviço. O Diagrama "Use Case" da Figura 33 mostra quatro atividades deste sub-processo.

$\checkmark$ Providenciar Documentação: Dar agrupamento aos documentos gerados para comprovação da garantia da qualidade.

$\checkmark$ Autorizar Expedição: Quando a documentação estiver corretamente emitida o setor comercial autoriza a montagem da carga.

$\checkmark$ Organizar Logística: As vendas de sementes são extremamente diversificadas em quantidade, variedade e região de entrega, logo o "fazer chegar" é um complexo trabalho de logística vinculado à Diretoria Comercial. 
$\checkmark$ Pós Venda: Esta atividade é realizada pelos representantes e revendedores que devem obrigatoriamente acompanhar a safra, dando assistência técnica aos clientes e preparar a venda do ano seguinte.

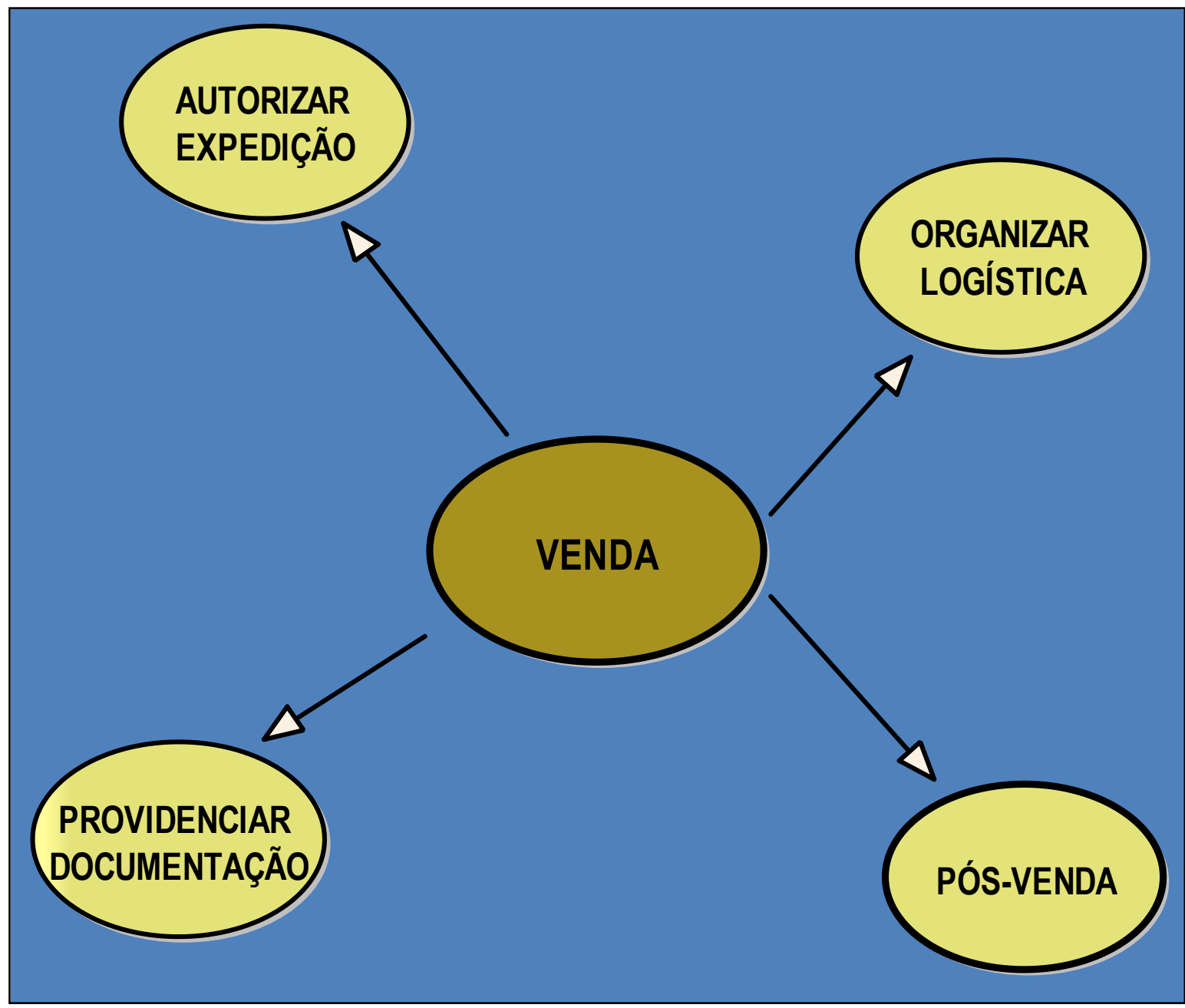

Figura 33 - Diagrama UML “Use Case” de Venda - Própria 


\subsection{ASPECTOS DA GESTÃO DA INFORMAÇÃO NO MODELO}

Os Diagramas UML - "Use Case" utilizados para a determinação dos requisitos do Modelo Informado de "Supply Chain" permitiram observar a necessidade de classificar três tipos de informações circulando pelo Processo de forma interdependente e hierárquica, definidas como:

\subsubsection{Informações Permanentes:}

Definiram-se como Informações Permanentes aquelas que são gravadas em um dispositivo RFID e nele permanecem inalteradas até o final do Processo. Nesta concepção, quando o dispositivo é lido cria um sistema redundante com um banco de dados externos, permitindo repassar a informação a outros dispositivos RFID numa relação chamada de Tags Mãe/Tag Filhas. A Figura 34 ilustra este tipo de fluxo de Informações, nela uma informação é gravada no RFID, e nele permanece sendo lida diversas vezes durante o processo, alimentando o banco de dados, confirmando a leitura, mas nunca sendo alterada.

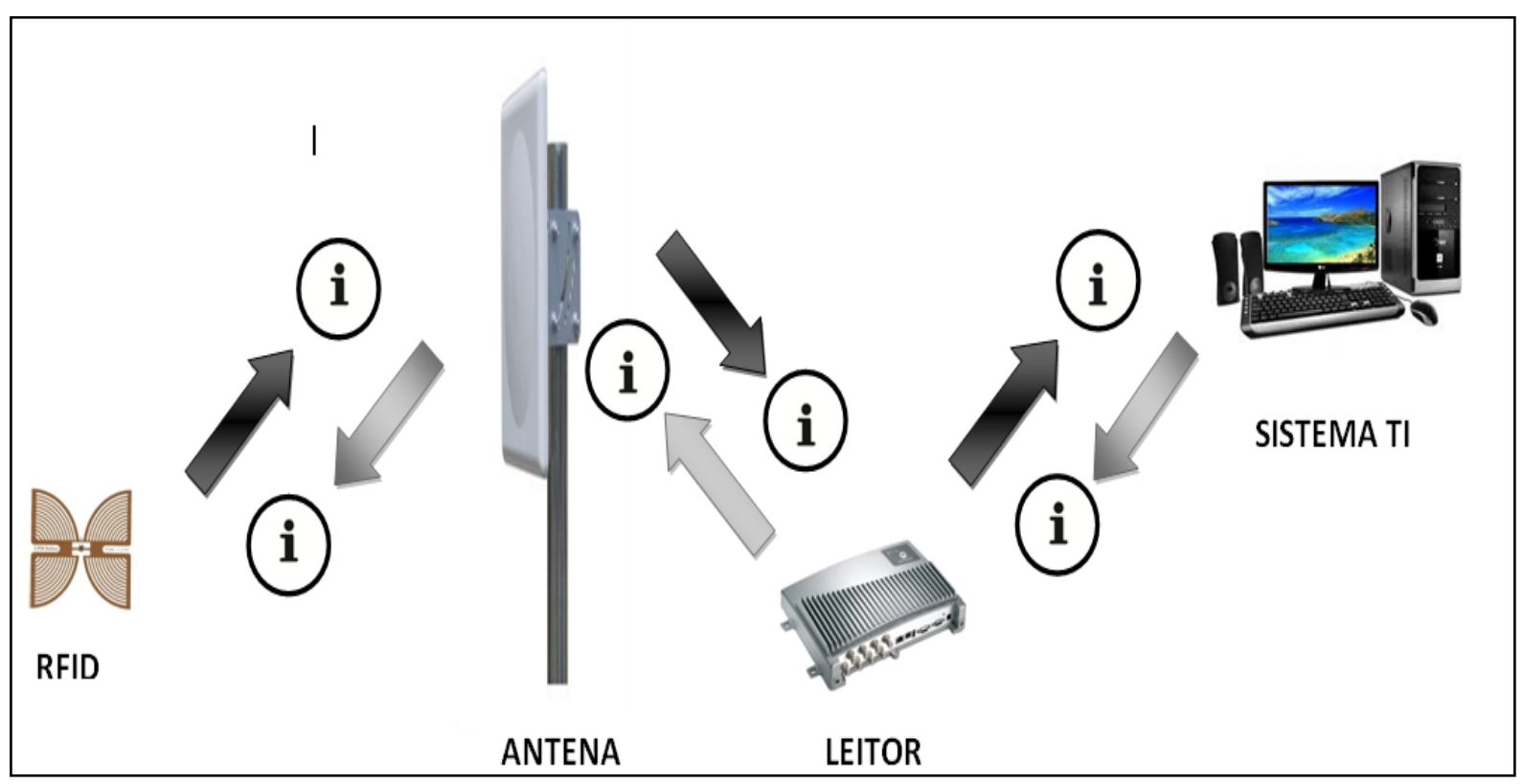

Figura 34 - Fluxo das Informações Permanentes 


\subsection{Informações Compostas:}

Denominou-se de Informações Compostas àquelas que têm origem na composição de um resultado pelas informações precedentes. Assim, varias informações lidas em um RFID são enviadas ao Banco de Dados e processadas, gerando uma única informação que é devolvida e gravada no RFID. A Figura 35 indica este fluxo, que pode ser aplicado a um processo, que durante seu desenvolvimento gera inúmeras informações que precisam ser controladas, porém no seu encerramento somente precisa ficar gravada a informação de que o processo ocorreu com sucesso. Evidentemente que as informações parciais devem ficar armazenadas em Banco de Dados para futuras comprovações em caso de necessidade.

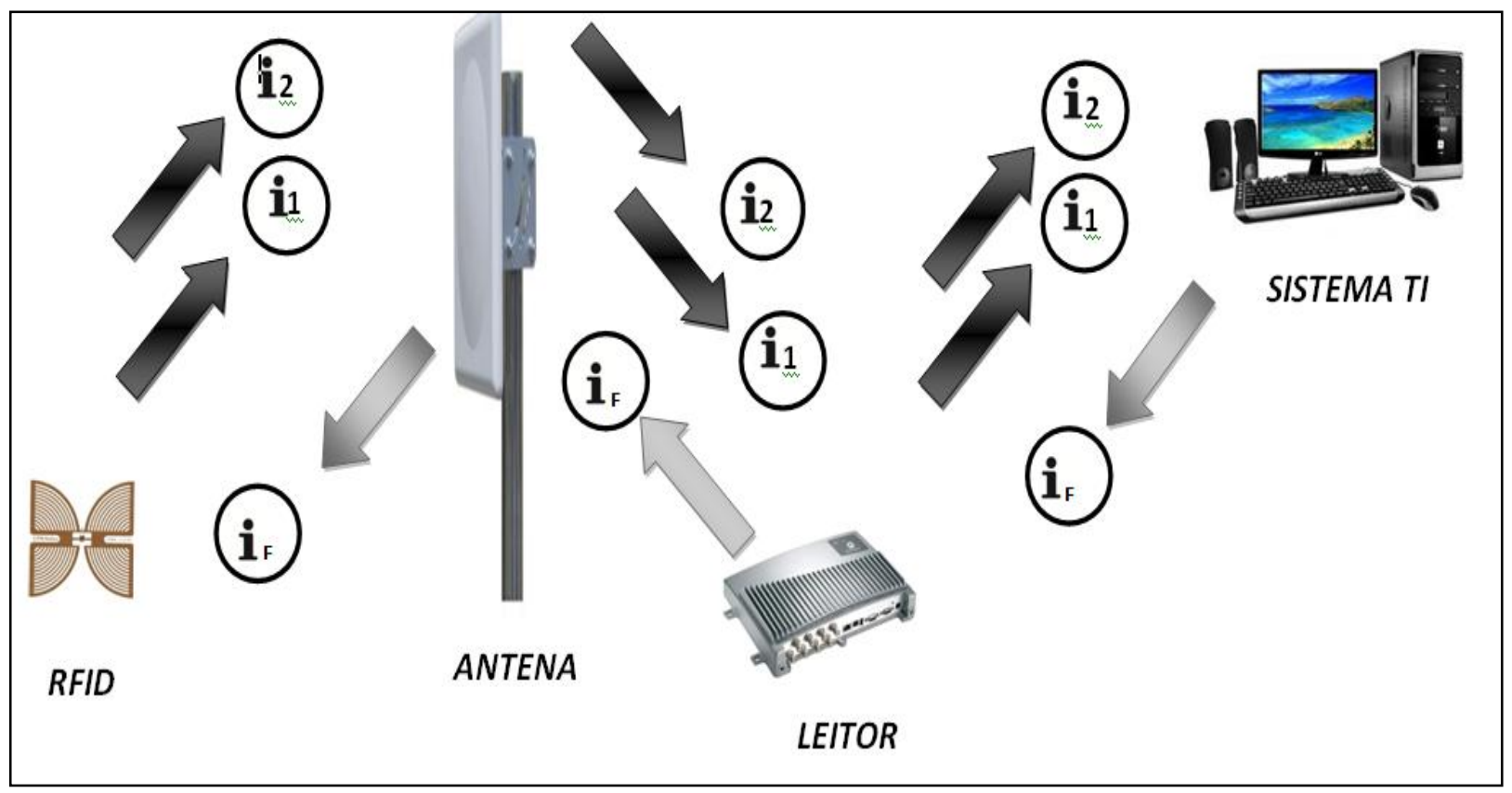

Figura 35 -- Fluxo das Informações Compostas 


\subsubsection{Informações Independentes:}

Finalmente atribuiu-se a denominação de Informações Independente àquelas que podem ser necessárias para estudos no processo, porém não são necessárias junto ao produto, logo devem ser armazenadas exclusivamente no banco de dados depois da realização de uma atividade monitorada. A Figura 36 indica a forma desta alternativa, em uma etapa de um processo, uma informação é gerada e armazenada no RFID, que no termino do processo envia a informação ao Banco de Dados, liberando sua memória, ou seja, o registro só permanece externo ao dispositivo.

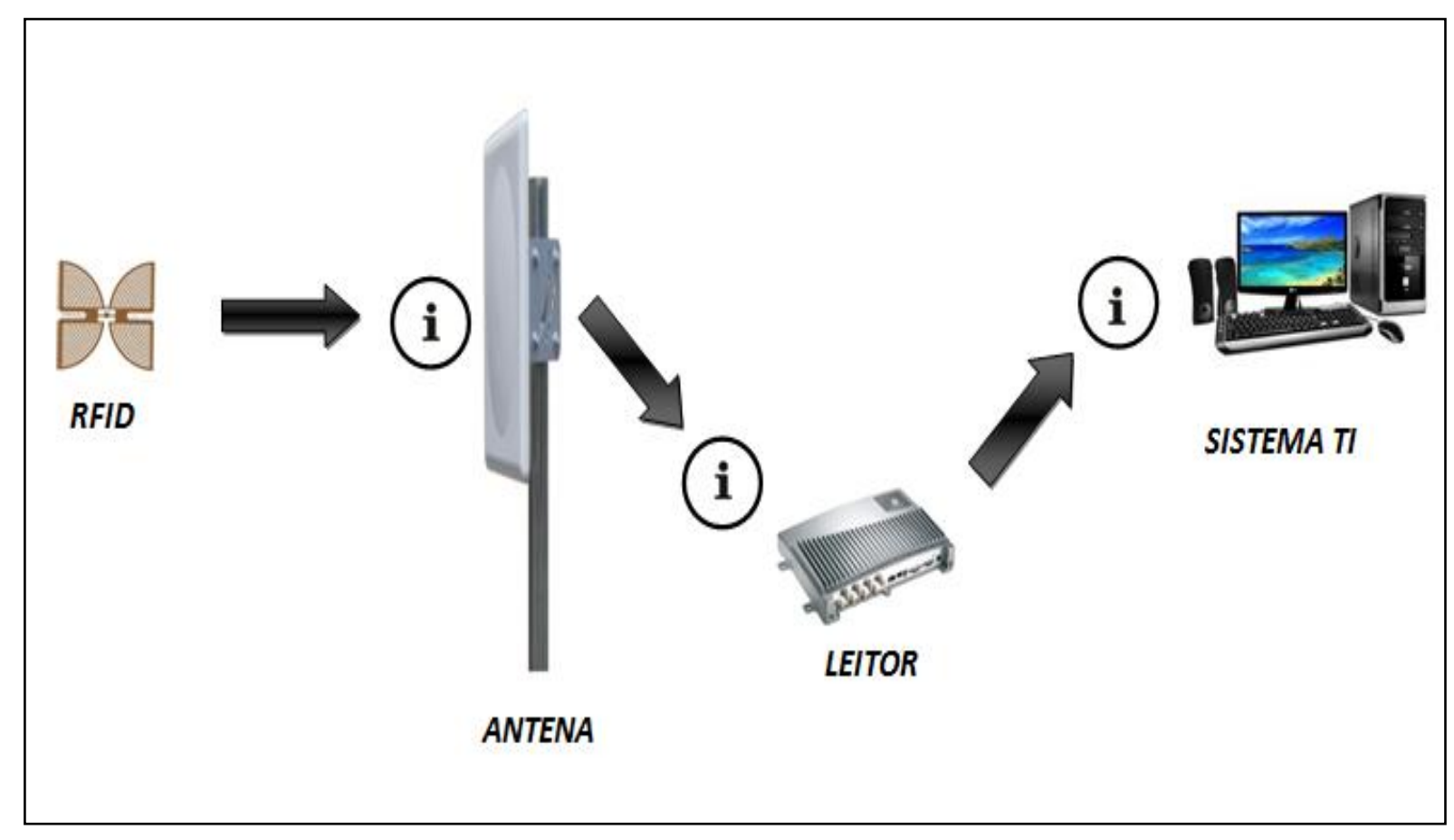

Figura 6 - Fluxo das Informações independentes

Os esquemas propostos são ilustrativos e fazem uso de antenas, leitores e TAG's RFID como elementos do Sistema Informado, porém a tecnologia existente de leitores/gravadores avulsos e portáteis pode otimizar a operação.

A utilização de equipamentos como o mostrado na Figura 37 permite eliminar antenas e leitores fixos ou reduzir o número de equipamentos necessários em um projeto, diminuindo os custos e melhorando o desempenho da aplicação. 


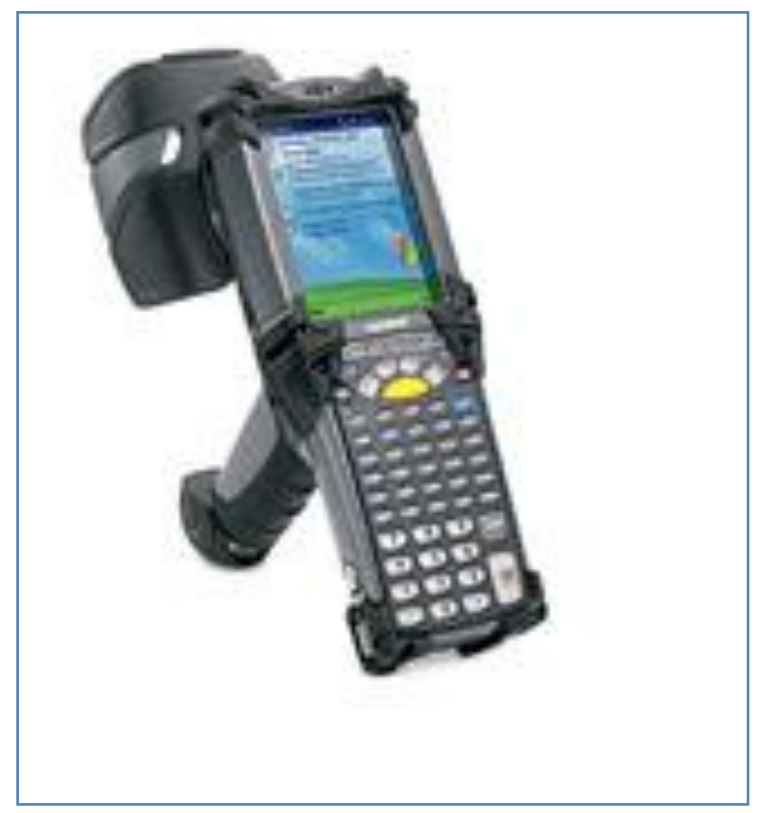

Figura 37 - Leitor/gravador Portátil

\subsection{4 - Modelo Funcional do Piloto}

A construção do Modelo levantou os movimentos da semente de milho na planta e determinou os pontos de coleta e incorporação de dados para o Sistema Informado com base no RFID.

- Trajeto de sementes a granel:

É a movimentação bruta que trata do grão em grande quantidade, sem nenhum processo de beneficiamento envolvido. Ocorre em caminhões que chegam a portaria e descarregam na Moega.

- Trajeto de Sementes em "Big Bag":

É uma etapa intermediária quando as sementes são selecionadas e separadas em "sacolões" de uma tonelada identificadas por etiquetas adesivas, chamadas de "Big Bag".

A cada conjunto de 14 "Big Bag's" define-se um LOTE de sementes.

- Trajeto de Sementes em Sacas: Este trajeto ocorre com a semente ensacada em pacotes de 20 ou $60 \mathrm{~kg}$ e está pronto para comercialização. Para facilidade na movimentação um conjunto de ate 80 pacotes são agrupados em palets, e distribuídos em armazéns ou câmaras frias, 
dependendo da data de expedição. A Figura 38 mostra como se concebeu os trajetos.

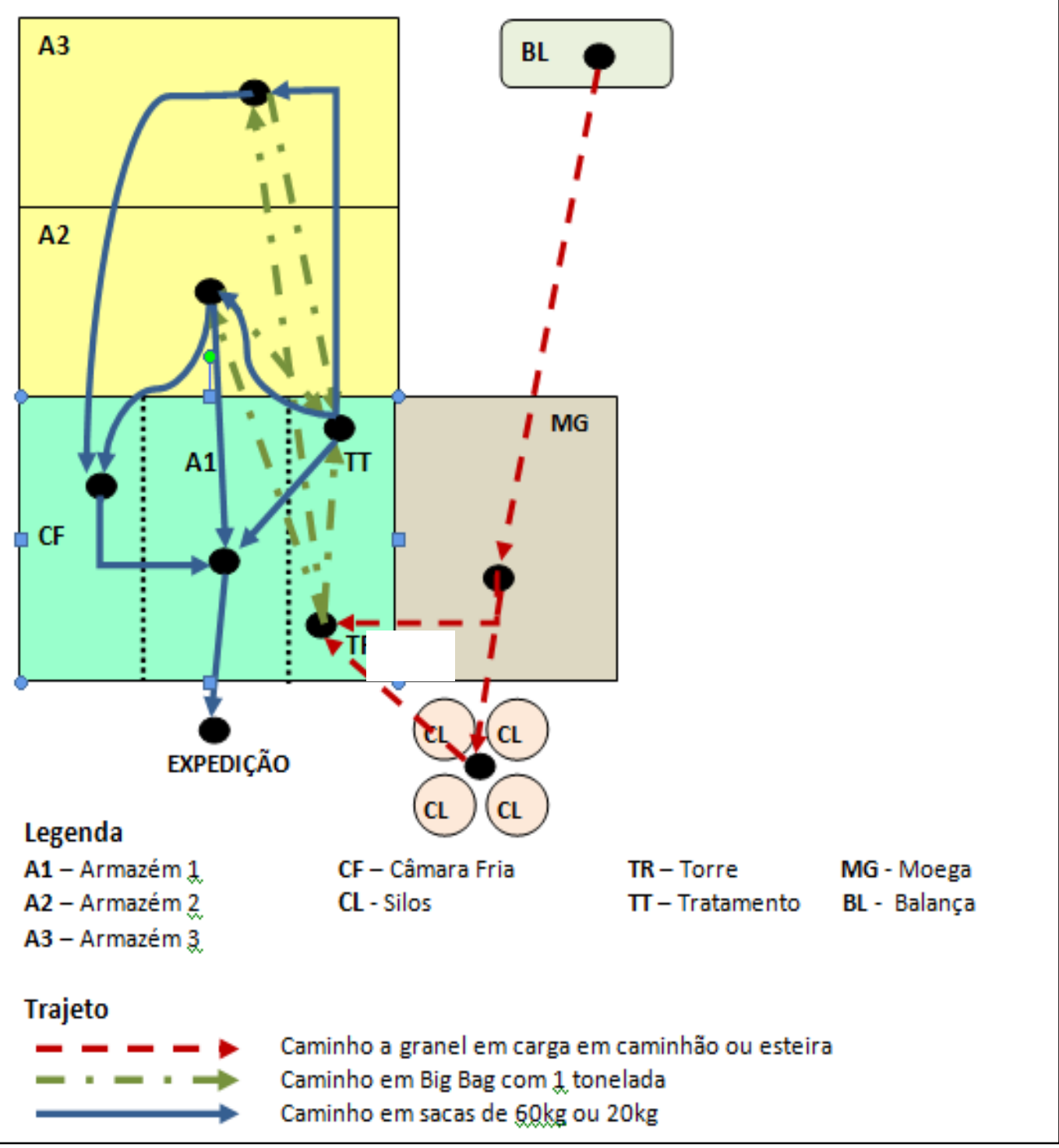

Figura 7 - Trajetórias da semente de milho - Próprio 
Os diagramas UML serviram de base para a construção do "Workflow" para o processo de produção de sementes. Este processo foi então modelado usando o ambiente "YAWL4Study-2.3".

O primeiro diagrama, chamado de "Workflow Master do Supply Chain" mostra as 10 grandes atividades do processo onde algumas delas podem ser decompostas em sub-atividades. Este modelo comprovou que a semente circula pela planta em três modos distintos:

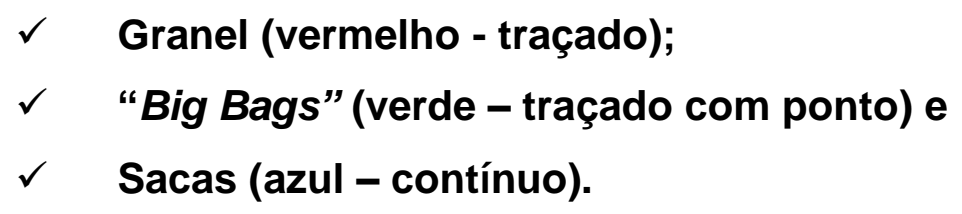

Para vincular cada forma de circulação às etapas do processo representou-se cada uma delas usando cores distintas pelas indicadas na Figura 39. É importante lembrar que o software utilizado tem em sua estrutura a utilização das Redes de Petri, permitindo ao usuário aplicá-lo sem aprofundar-se nas respectivas teorias do assunto, como por exemplo, as transições de estado.

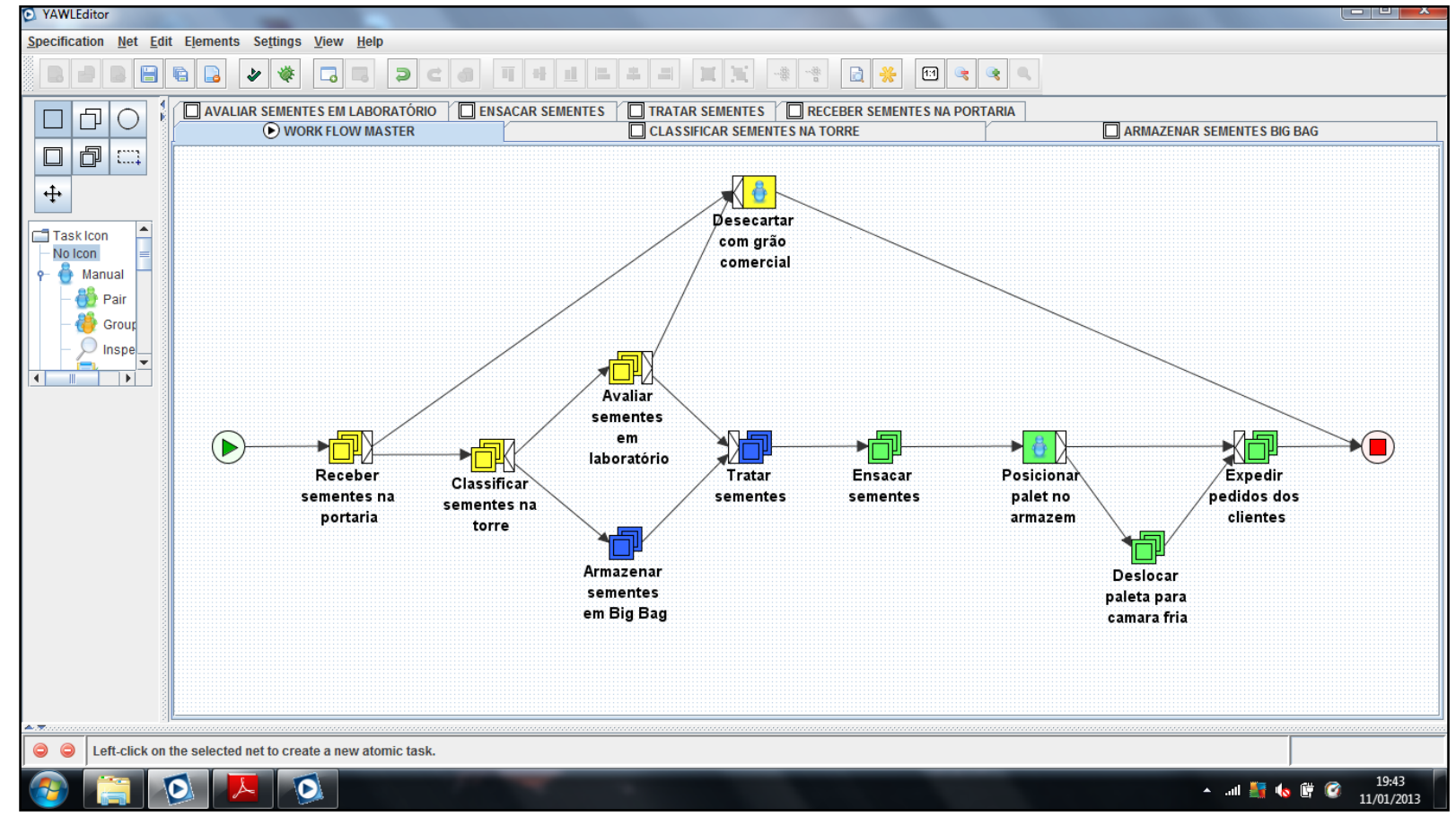

Figura 8 - "Workflow Master" do "Supply Chain" da Semente de Milho 


\section{$\checkmark$ Receber sementes na portaria}

Esta Etapa é composta por três linhas de trabalho, representadas na Figura 40, cada uma tendo dados que precisam ser incorporadas ao Sistema de Informações. As duas primeiras são constituídas por ações que precisam ser feitas durante a produção das sementes no Campo, portanto antes da chegada e sob os cuidados do Responsável Técnico da Empresa. Na proposta do piloto deste trabalho os dados serão levantados e coletados na Portaria, facilitando a simulação.

Quando a carga de sementes chega, dois ensaios são fundamentais: o ensaio de umidade, que no recebimento não pode ser superior a $11 \%$, e o de impurezas, que não deve ser superior a $2 \%$. Em ambos os casos os valores relativos às medições serão descontados para determinação do peso liquido da carga.

A última atividade desta etapa é a emissão de um romaneio que registra em papel os trabalhos realizados e autoriza a entrada do grão como semente ou como milho comercial.

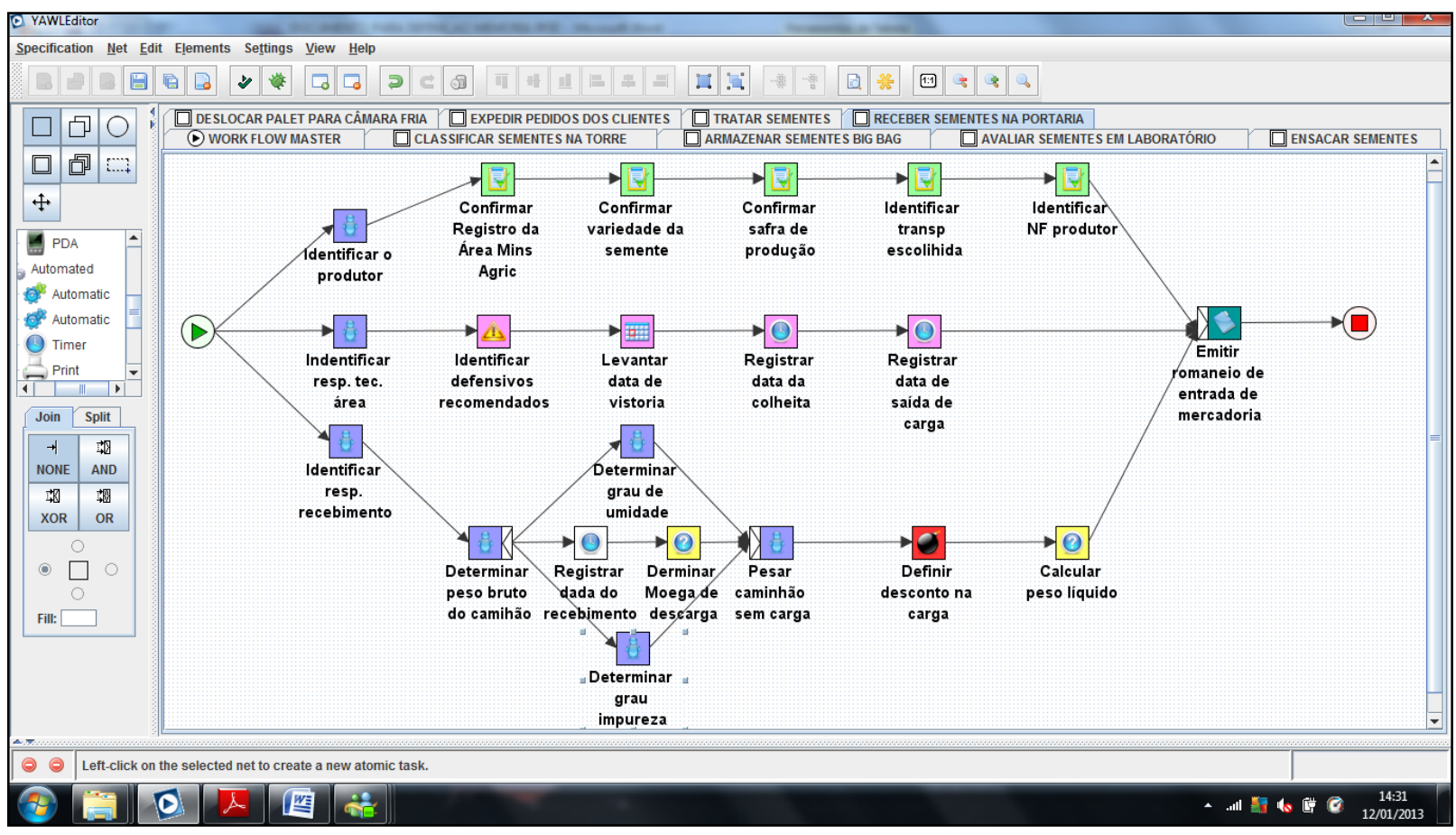

Figura 90 - "Workflow" Receber Sementes na Portaria 


\section{$\checkmark \quad$ Classificar sementes na Torre}

Terminado o Recebimento e uma vez que a carga seja aceita como semente, esta é encaminhada às Moegas para descarga. Neste ponto a carga entra no subprocesso de seleção na torre, que as separa em função de suas características dimensionais. Algumas vezes é preciso armazenamento em silos a espera do equipamento. A Figura 41 ilustra as atividades do sub-processo.

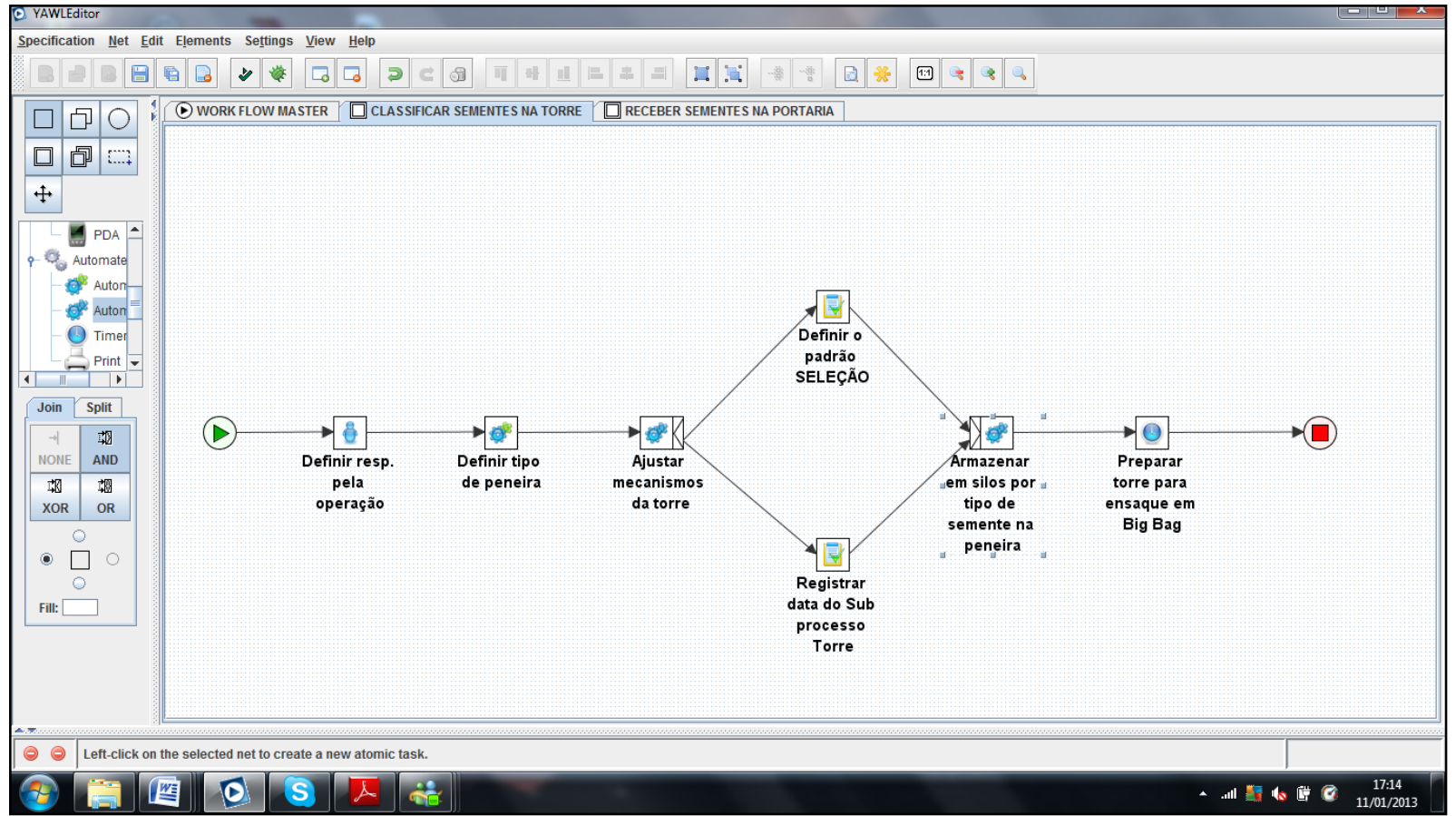

Figura 41 - "Workflow” Classificar Sementes na Torre

\section{Armazenar sementes em "Big Bag"}

Quando as sementes saem da Torre já estão classificadas conforme características físicas, por exemplo: Longa, Média, Curta, Redonda ou Espessa, e ficam armazenadas em pequenos depósitos até serem colocadas em grandes sacas com capacidade de 1 Tonelada, chamadas de "Big Bag". Ao conjunto de 14 "Big Bag's" se dá o nome de lote, que juntamente com demais especificações ficam adesivadas em cada um deles, processo que também deverá ser atendido por um dispositivo RFID. A Figura 42 mostra o "workflow" deste sub-processo, até a definição de onde ficarão armazenados nos Armazéns. 


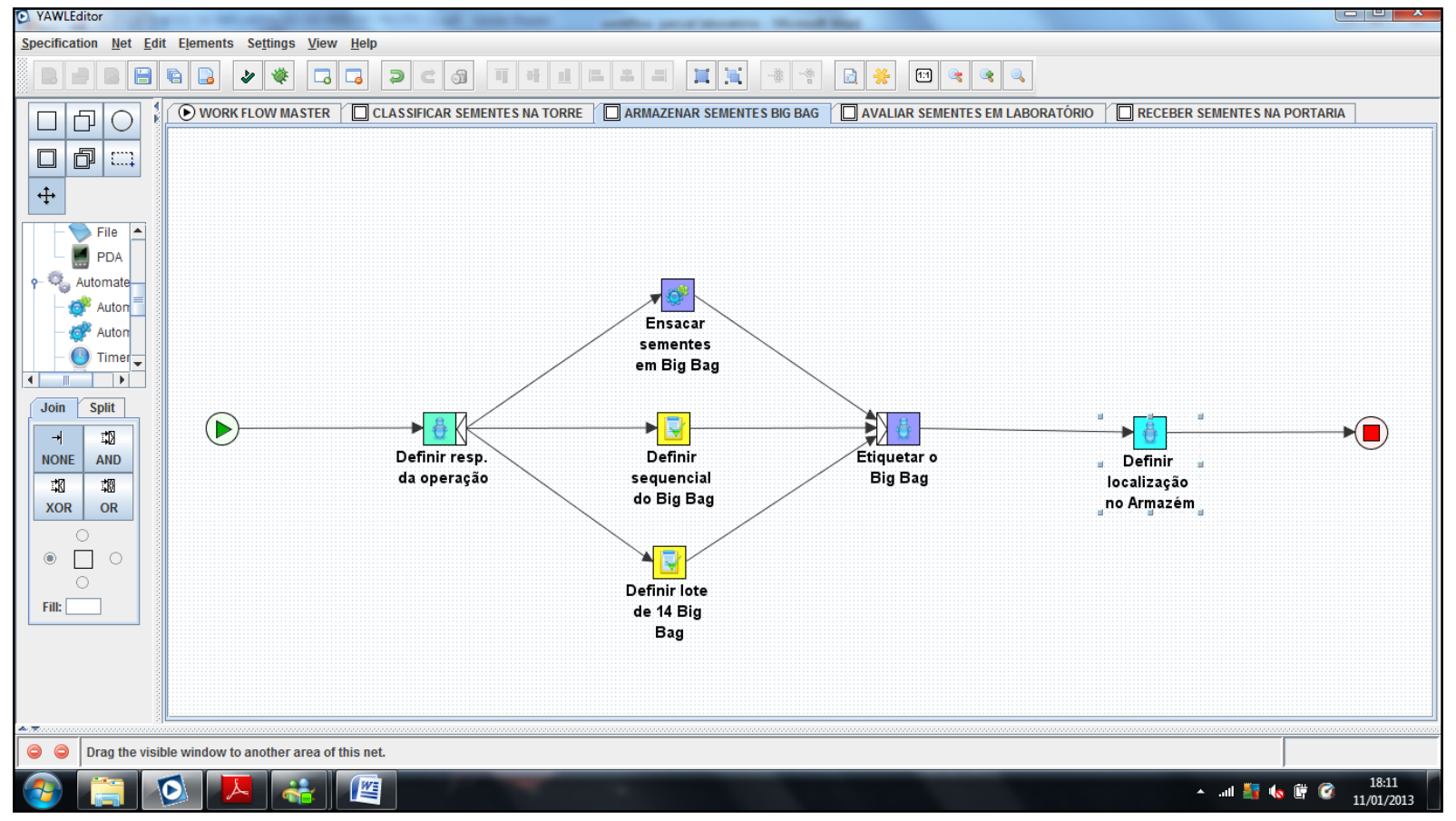

Figura 42 - “Workflow” de Armazenar Sementes em Big Bag

\section{Avaliar sementes em laboratório}

Ao mesmo tempo em que as sementes são armazenadas em "Big Bag's", amostras são enviadas para o laboratório para análise de qualidade com ensaios de vigor, germinação e umidade entre outros, conforme indicado na Figura 43.

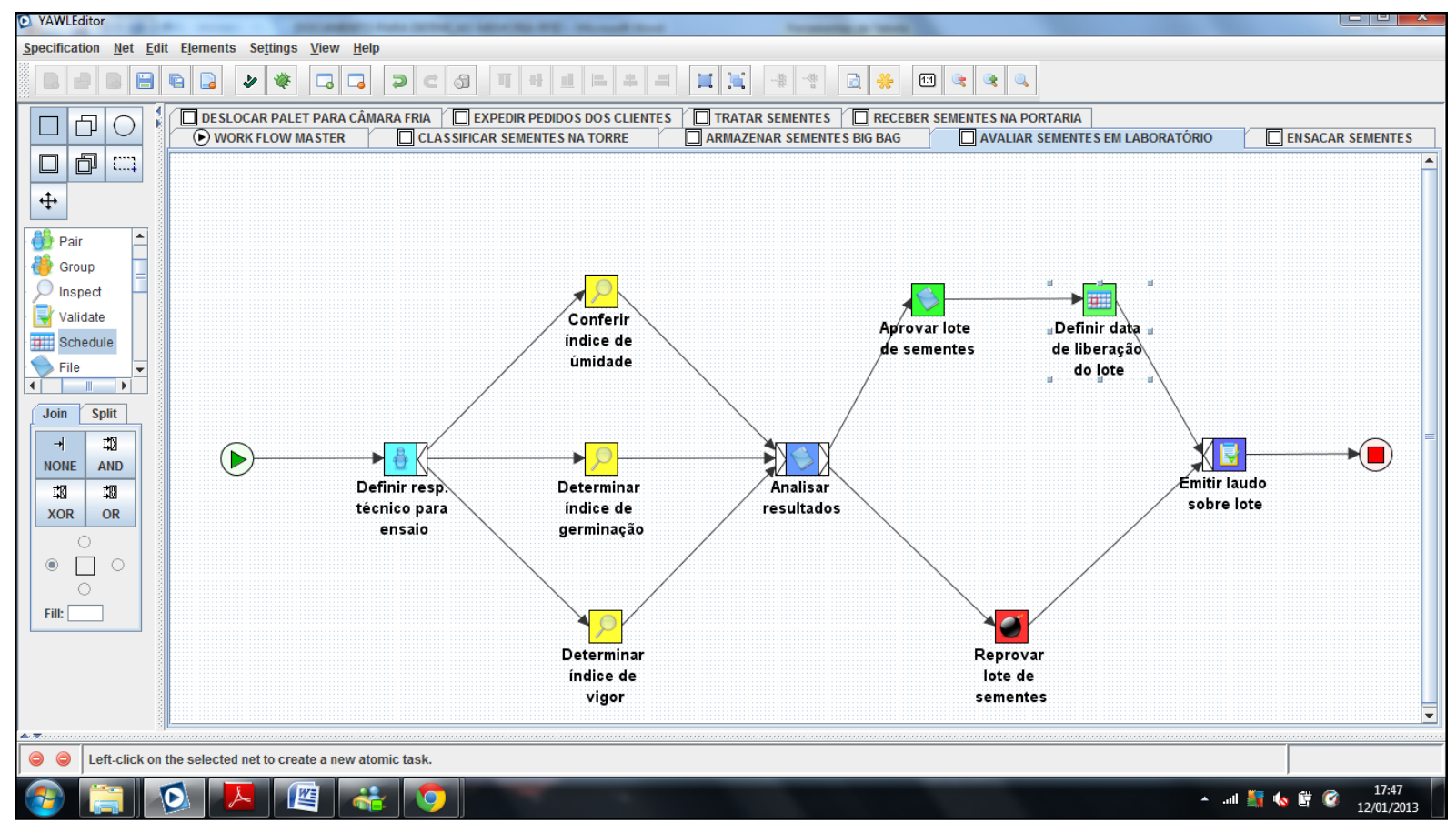

Figura 10 - “Workflow” de Avaliar Sementes em Laboratório 


\section{$\checkmark \quad$ Tratar sementes}

À medida que vendas ocorrem, os "Big Bag's" retornam dos armazéns e as sementes passam pelo tratamento contra fungos e insetos, garantindo a sua qualidade. Alguns dados desta fase devem ser incorporados ao RFID e a Figura 44 ilustra como se desenvolve este "Workflow" parcial.

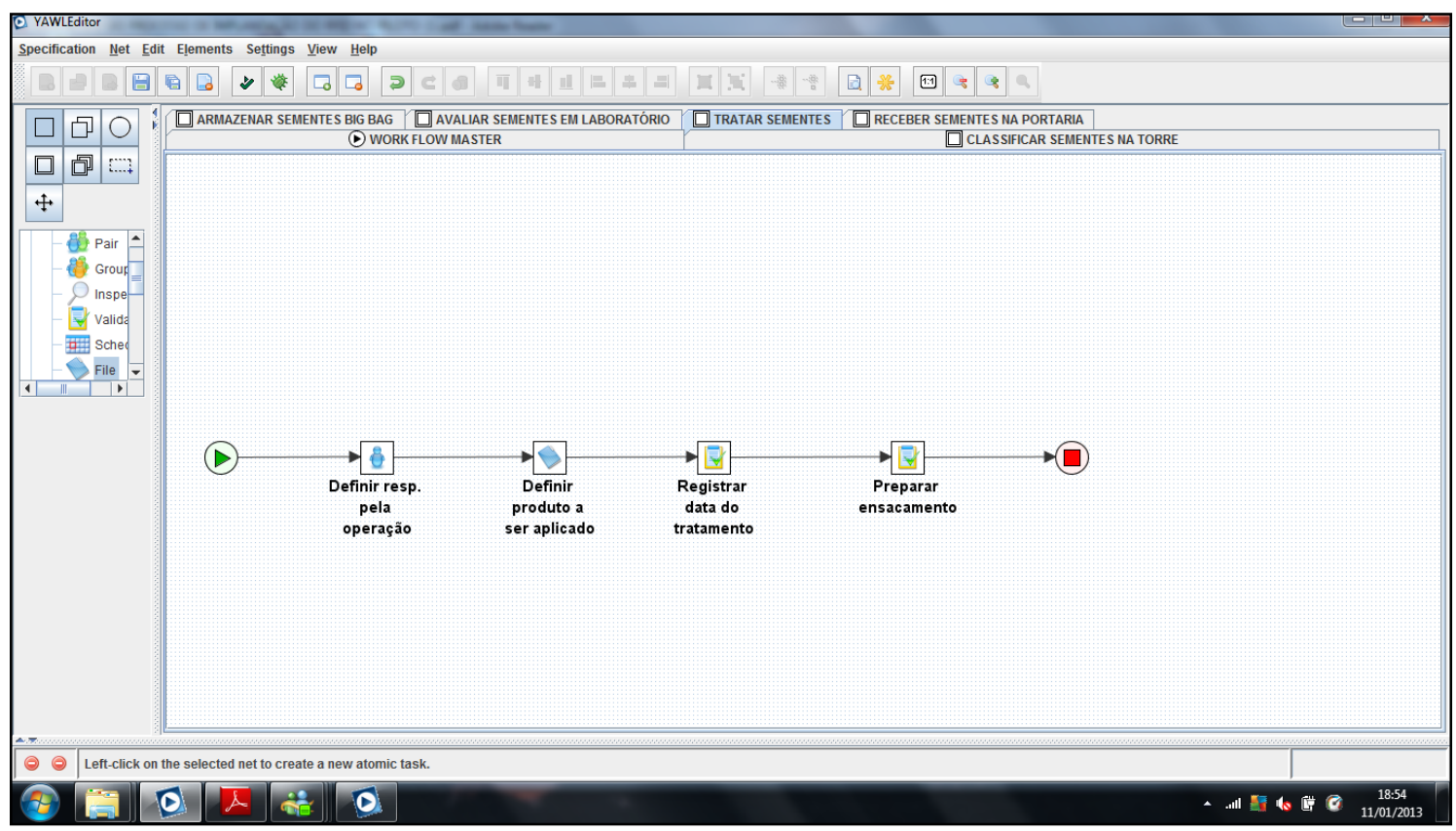

Figura 44 - “Workflow” de Tratar Sementes

\section{$\checkmark \quad$ Ensacar sementes}

Após o tratamento das sementes o processo segue com empacotamento, em sacas de $20 \mathrm{~kg}$ ou $60 \mathrm{~kg}$. Nesta fase os dados comerciais exigidos são fixados ao pacote por etiquetas adesivas. Em seguida os pacotes (80 unidades) são condicionados em palets para armazenamento

No Processo Informado proposto esta etapa será importante, pois se fixará a tag RFID na saca e a consequente transferência de dados, garantindo que a informação acompanhará 0 item até o cliente. A Figura 45 representa este subprocesso. 


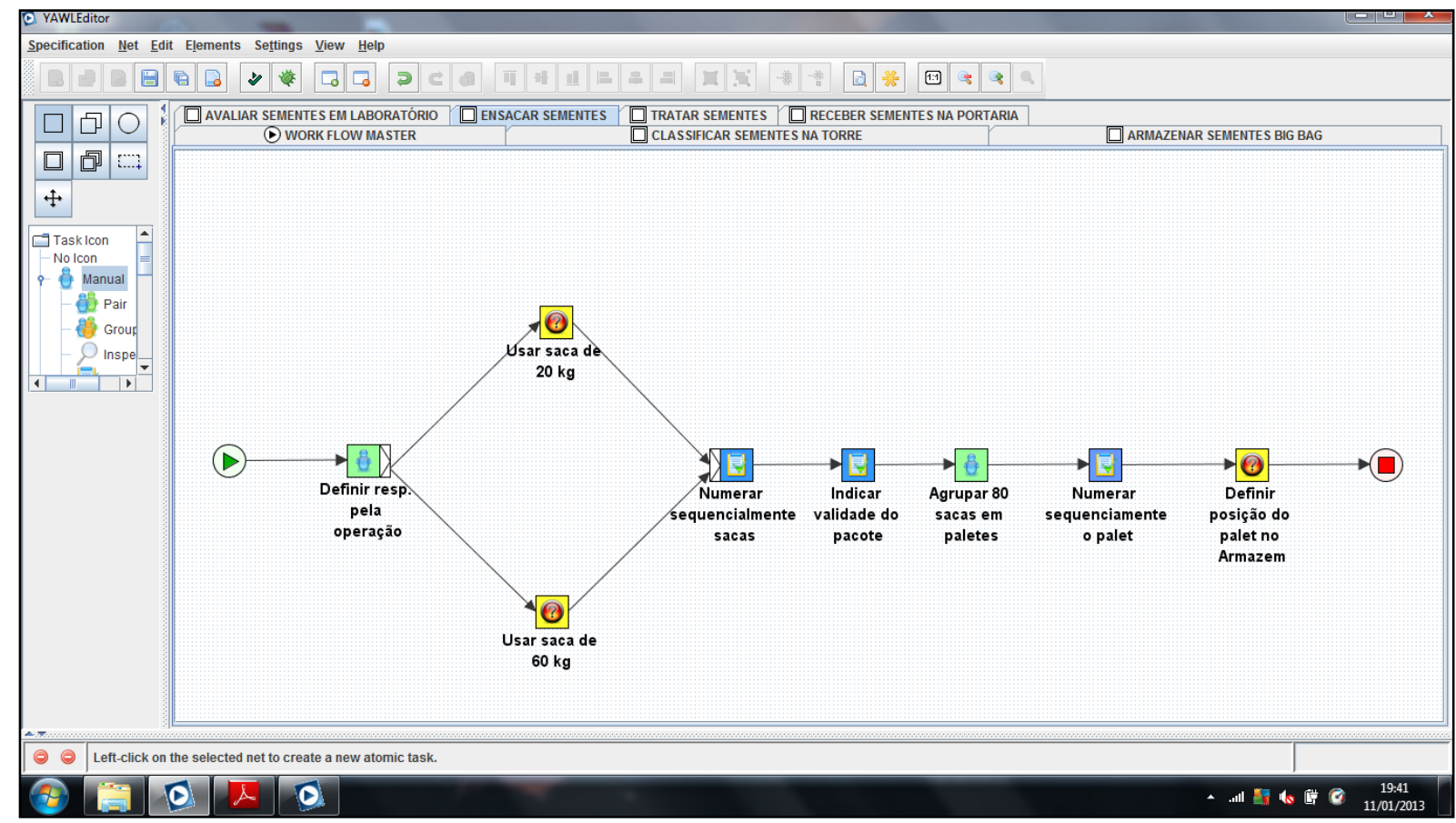

Figura 11 - “Workflow” de Ensacar Sementes

\section{$\checkmark \quad$ Deslocar Palet para Câmara Fria}

Esta atividade pode ser feita de duas formas, mas trata-se de armazenar as sacas embaladas no armazém se o embarque estiver próximo ou em câmara fria se estiver distante. A Figura 46 demonstra o fluxo desta fase.

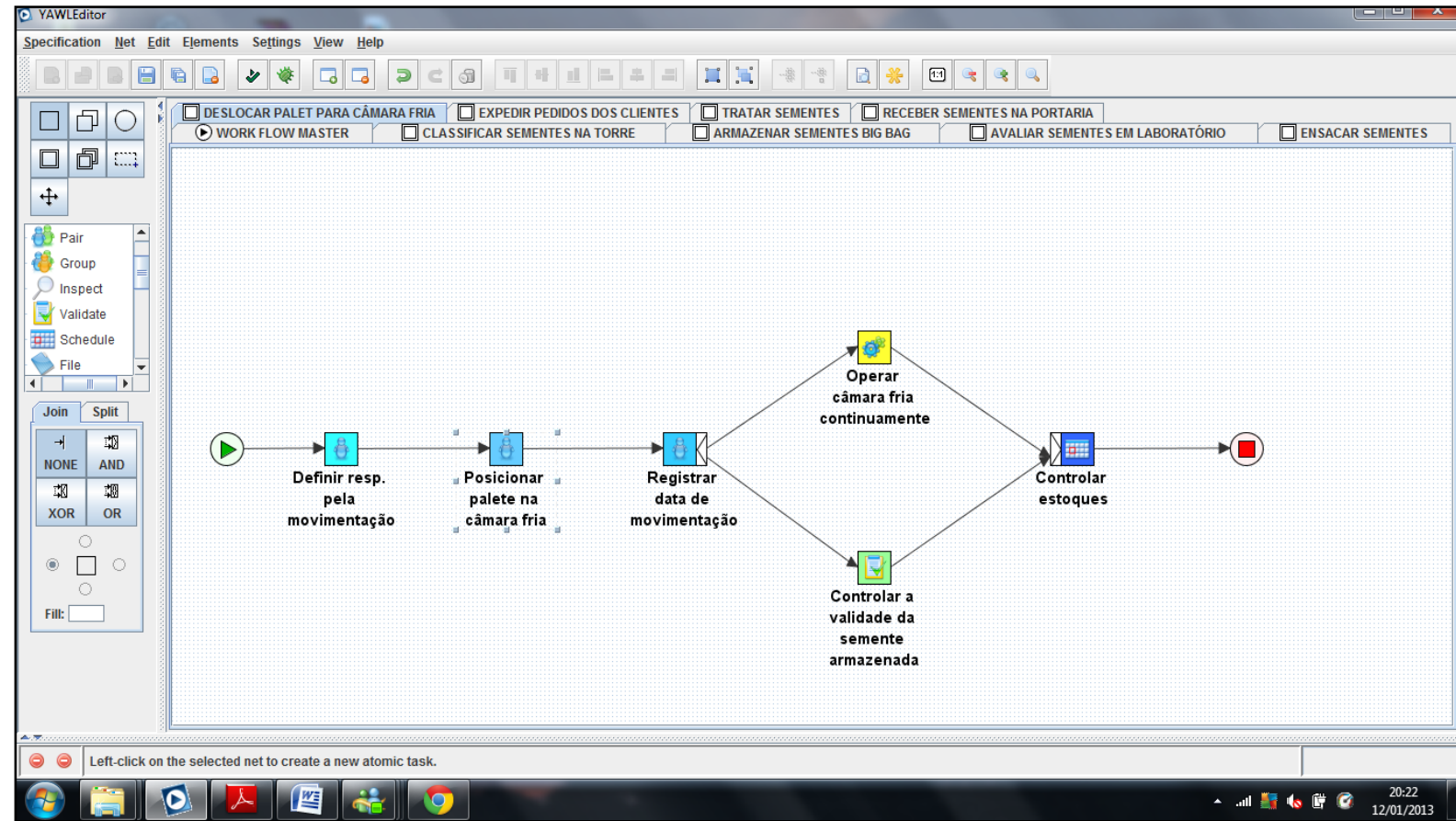

Figura 46 - "Workflow” de Deslocar Palet para Câmara Fria 


\section{$\checkmark \quad$ Expedir pedidos dos clientes}

Finalmente a última etapa do processo é expedição de sacas para os clientes, onde cargas são formadas seguindo uma logística de entrega. Nessa fase serão incorporados os dados finais nas "Tags". A Figura 47 ilustra os itens que compõem a expedição.

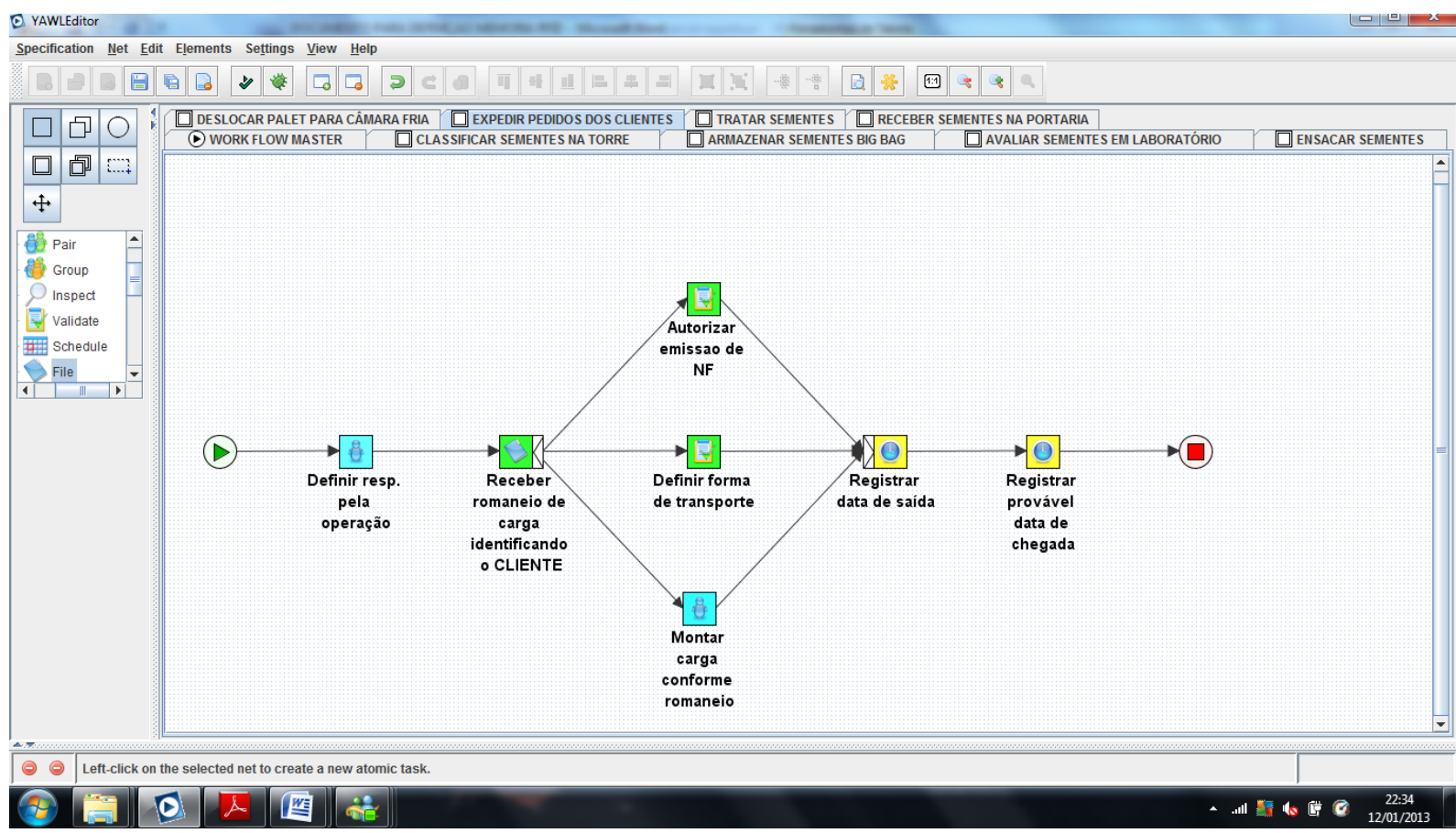

Figura 47 - Workflow da Expedição aos Clientes

\subsection{5 - Especificação do Projeto Piloto}

A aplicabilidade de um Processo Informado para o "Supply Chain" do Milho será ilustrada através de uma montagem Piloto, onde se procurou determinar os pontos críticos que deveriam ser ratificados pela implantação.

\section{Detalhamento para Especificação das "Tag's"}

Após a especificação e análise de requisitos, seguida da modelagem dos processos e identificação dos pontos de interação, é preciso modelar a informação com respeito à quantidade de caracteres e formato. Este processo resultou nos Quadros 7,8 e 9 que mostram a necessidade de memória dos Tag's RFID para o Processo Informado. 


\begin{tabular}{|c|c|c|c|c|}
\hline \multicolumn{5}{|c|}{ ETAPA ONDE AS SEMENTES CIRCULAM A GRANEL } \\
\hline $\begin{array}{l}\text { OCORRÊNCIA DA } \\
\text { INFORMAÇÃO }\end{array}$ & DESCRITIVO & $\begin{array}{c}\text { CARACTERES } \\
\text { RELACIONADOS }\end{array}$ & $\begin{array}{l}\text { EXEMPLO DE } \\
\text { INFORMAÇÃO }\end{array}$ & OCUPAÇÃO DE MEMÓRIA \\
\hline \multirow{11}{*}{ CAMPO } & Identificar o produtor & De 0 a 15 & José A. Silva & $5 * 15=75$ bits \\
\hline & Confirmar registro no Min. da Agricultura & De 0 a 15 & 065 & 5 bits \\
\hline & Confirmar variedade da semente & De 10 a 15 & SG 6030YG & 15 bits \\
\hline & Confirmar a safra da produção & 9. & $2012 / 2013$ & 25 bits \\
\hline & Identificar transp. escolhida & De 0 a 15 & Iguaçu transp. & $5 * 15=75$ bits \\
\hline & Identificar NF do Produtor & 6 & 564 & 10bits \\
\hline & Identificar o ress. Técnico da Area. & De 0 a 15 & Pedro Antunes & $5^{*} 15=75$ bits \\
\hline & \begin{tabular}{|l|} 
Identificar defensivos recomendados \\
\end{tabular} & De 0 a 30 & Calcário/Bassagran & $5 * 30=150$ bits \\
\hline & \begin{tabular}{|l|} 
Levantar data da vistoria \\
\end{tabular} & De 0 a 15 & Aprovado & $5^{*} 10=50$ bits \\
\hline & Registrar data da colheita & 10 & $04 / 03 / 2012$ & 25 bits \\
\hline & Registrar data saída da carga & 10 & $07 / 03 / 2012$ & 25 bits \\
\hline \multirow{8}{*}{ PORTARIA } & Identificar resp. recebimento & De 0 a 15 & Antonio Soares & 15 bits \\
\hline & Determinar peso bruto do caminhão & 8 & $12.000 \mathrm{~kg}$ & 15 bits \\
\hline & \begin{tabular}{|l|} 
Determinar grau de umidade \\
\end{tabular} & 5 & $10 \%$ & 10 bits \\
\hline & Registrar data do recebimento & 10 & $08 / 03 / 2012$ & 25 bits \\
\hline & \begin{tabular}{|l} 
Determinar Moega de descarga \\
\end{tabular} & 2 & 04 & 5 bits \\
\hline & \begin{tabular}{|l|} 
Determinar grau impureza \\
\end{tabular} & 5 & $2 \%$ & 10bits \\
\hline & Definir desconto na carga & 8 & $12 \%$ & 10bits \\
\hline & Calcular o peso líquido & 8 & $10.560 \mathrm{~kg}$ & 15 bits \\
\hline \multicolumn{4}{|c|}{ PARCIAL 1} & 525 bits \\
\hline
\end{tabular}

Tabela 7 - Estudo da Capacidade de Memória na fase Granel - Próprio

\section{ETAPA ONDE AS SEMENTES CIRCULAM EM BIG BAG}

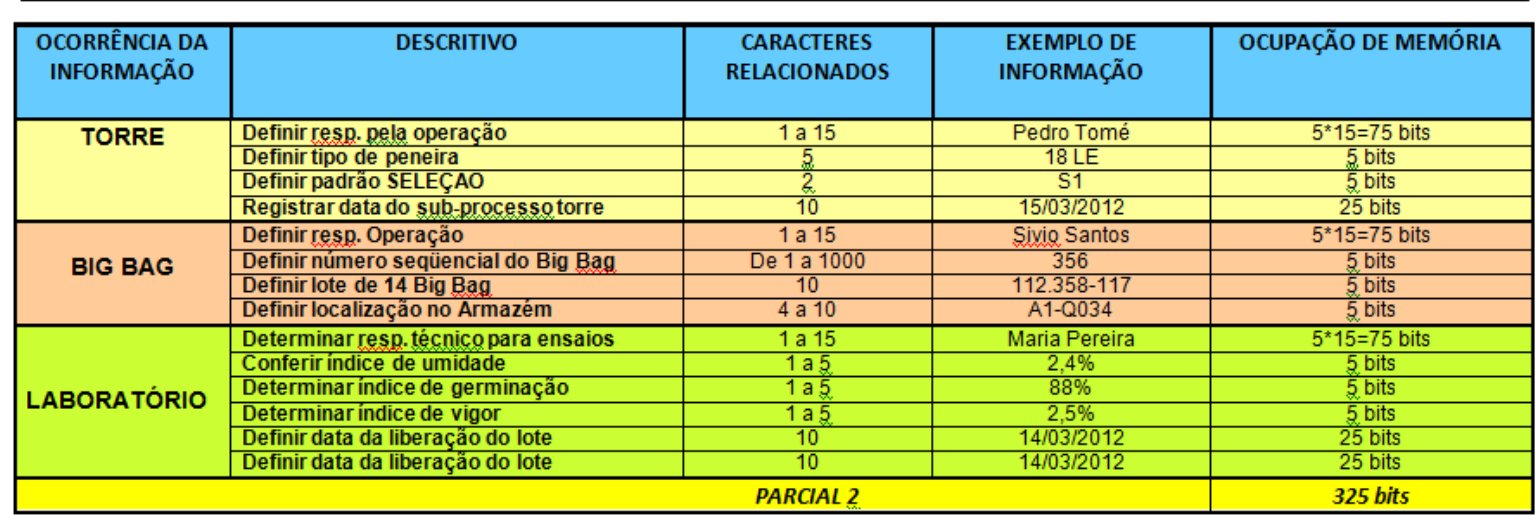

Tabela 8 - Estudo da Capacidade de Memória na fase Big Bag - Próprio

\begin{tabular}{|c|c|c|c|c|}
\hline \multicolumn{5}{|c|}{ ETAPA ONDE AS SEMENTES CIRCULAM EM SACAS } \\
\hline $\begin{array}{l}\text { OCORRÊNCIA DA } \\
\text { INFORMAÇÃOO }\end{array}$ & DESCRITIVO & $\begin{array}{l}\text { CARACTERES } \\
\text { RELACIONADOS }\end{array}$ & $\begin{array}{l}\text { EXEMPLO DE } \\
\text { INFORMAÇÃOO }\end{array}$ & OCUPAÇÃO DE MEMÓRIA \\
\hline TRATAMENTO & $\begin{array}{l}\text { Definir resp. pela operação } \\
\text { Definir produto a ser aplicado } \\
\text { Registrar data do tratamento }\end{array}$ & $\begin{array}{c}\frac{1 \text { a } 15}{\text { De } 10 \text { a } 30} \\
10\end{array}$ & $\begin{array}{c}\text { Pedro Tomé } \\
\text { Conservante } \mathrm{x} \\
30 / 03 / 2012\end{array}$ & $\begin{array}{c}5^{*} 15=75 \text { bits } \\
5^{\star} 30=150 \text { bits } \\
25 \text { bits }\end{array}$ \\
\hline \multirow{3}{*}{$\begin{array}{l}\text { PACOTE } \\
\text { (PALET) }\end{array}$} & $\begin{array}{l}\text { Definir resp. pela operação } \\
\text { Definir o peso de cada (60kg ou } 20 \mathrm{~kg} \text { ) } \\
\text { Numerar seqüencialmente as sacas }\end{array}$ & $\begin{array}{c}1 \text { a } 15 \\
\frac{7}{D e 1} \text { a } 400.000\end{array}$ & $\begin{array}{c}\text { Pedro Tomé } \\
60,12 \mathrm{~kg} \\
1236\end{array}$ & $\begin{array}{c}\frac{5 * 15=75 \text { bits }}{5 \text { bits }} \\
5 \text { bits }\end{array}$ \\
\hline & $\begin{array}{l}\text { Indicar validade do pacote } \\
\text { Numerar seqüencialmente os palets. }\end{array}$ & $\begin{array}{c}10 \\
1 \mathrm{a} 10.000 \\
\end{array}$ & $\frac{30 / 03 / 2013}{126}$ & 25 bits \\
\hline & Definir posiçáo do Palet no Armazém & 4 a 10 & $\mathrm{~A} 3-\mathrm{Q} 045$ & 5 bits \\
\hline CÂMARA FRIA & $\begin{array}{l}\text { Definir resp pela movimentação } \\
\text { Posicionar Palet na Câmara Fria } \\
\text { Registrar data de movimentação }\end{array}$ & $\frac{1 \text { a } 15}{4 \text { a } 10}$ & $\begin{array}{c}\text { FELIPE MELLO } \\
\text { CF-143 } \\
10 / 10 / 2012\end{array}$ & $\begin{array}{c}\frac{5 * 15=75 \text { bits }}{5 \text { bis }} \\
25 \text { bits }\end{array}$ \\
\hline \multirow{3}{*}{ EXPEDIÇÄO } & $\begin{array}{l}\text { Definir resp. pela operação } \\
\text { Receber romaneio de Carga identificando } \\
\text { CLIENTE }\end{array}$ & $\begin{array}{l}\text { a } 15 \\
1 \text { a } 15 \\
\end{array}$ & $\begin{array}{l}\text { FELIPE MELLO } \\
\text { AGRICOLA SUL }\end{array}$ & $\begin{array}{l}5^{*} 15=75 \text { bits } \\
5^{*} 15=75 \text { bits }\end{array}$ \\
\hline & $\begin{array}{l}\text { Autorizar emissäo de NF } \\
\text { Definir forma de transporte }\end{array}$ & $\frac{1 a 5}{\operatorname{De} 0 \text { a } 15}$ & $\frac{567-G}{1 \text { quacu transp }}$ & $\frac{5, \text { bits }}{5^{*} 15=75 \text { bits }}$ \\
\hline & $\begin{array}{l}\text { Registrar data de saida } \\
\text { Regiatrar provaveldata de chegada }\end{array}$ & 10 & $\frac{1210 / 2012}{22 / 10 / 2012}$ & $\frac{25 \text { bits }}{25 \text { bits }}$ \\
\hline \multicolumn{4}{|c|}{ PARCIAL 3} & 620 bits \\
\hline & PARCIAL $1+$ & PARCIAL $2+$ & PARCIAL $3=$ & 1420 bits \\
\hline
\end{tabular}

Tabela 9 - Estudo da Capacidade de Memória na fase Sacas - Próprio 
Os três quadros elaborados visam determinar qual a capacidade de memória que deve ser disponibilizada para o usuário. Ou seja, o segmento que permitirá a consolidação de um Processo Informado. Desta forma, o Código Eletrônico de Produto (EPC), estará vinculado ao seu BANCO DE MEMÓRIA, e não é considerado nas tabelas anteriores.

Levando em consideração o tipo de movimentação de sementes que ocorre dentro da planta industrial e também o tipo de informações necessárias para acompanhamento do item e consolidação do Modelo Informado, três pontos de interação estratégicos foram selecionados para a implantação no piloto.

\section{$\checkmark \quad$ RFID NÍVEL 1 - PRODUÇÃo (movimentação Granel)}

Neste nível os Tag's (RFID), recebem as primeiras informações sobre a semente e estas são relacionadas com o campo de produção e movimentação a granel.

Em uma implantação REAL os dados de campo seriam incorporados a um sistema de TI, ao longo do tempo entre plantio e colheita. Este procedimento pode ser feito mediante a alimentação do Banco de Dados por meio de Internet, ou equipamentos de telefonia, através der um protocolo de acesso. Os responsáveis destas informações serão no futuro o produtor das sementes e também o responsável técnico pela área.

A transferência de dados oriundos do campo para a "Tag" RFld de entrada é feita quando a carga chega à portaria para um processo de recebimento e conferencia de qualidade do produto (dado que não se trabalha com qualidade assegurada - ainda - no agronegócio).

No Projeto Piloto estes dados foram incorporados no ponto que representa a Portaria juntamente com os dados de amostragem da qualidade. São exemplos das informações:

- Registro do Campo no Ministério da Agricultura;

- Identificação do Produtor;

- Identificação do Responsável Técnico;

- Acompanhamentos;

- Transporte 
A primeira etapa do processo ocorre quando a semente circula a granel pela planta industrial e vincula dados da produção da carga recebida ao tag. Esta tag por sua vez acompanha o produto até que ele deixe a torre, e seja armazenado em "Big Bag's" de uma tonelada. Por definição o conjunto de 14 "Big Bag's compõe um lote

sendo assim as informações armazenadas deve ser divididas entre novos "tag's". Sendo assim, quando este evento ocorre tem-se uma "TAG MÃE" gerando 14 “TAG'S" FILHAS, uma para cada Big Bag que compõem o Lote.

\section{RFID NÍVEL 2 - INDUSTRIALIZAÇÃO}

Este nível do RFID tem como característica a coleta de dados de produção que acontecem no equipamento denominado de "TORRE". Este equipamento é composto por um conjunto de esteiras e peneiras que permite a classificação das sementes em função de suas características físicas.

Neste ponto do processo os dados que acompanhavam o produto a granel são acrescidos de características físicas da semente, mediante a composição dentre as seguintes classificações.

$$
\begin{aligned}
& \text { L = Longa; } \\
& \text { M = Média; } \\
& \text { C = Curta; } \\
& \mathbf{R}=\text { Redonda; } \\
& \text { E = Espessa }
\end{aligned}
$$

Esta classificada é padronizada e exigida pelo mercado, podendo ser individualizada ou composta, como exemplo: uma semente classificada como ME tem tamanho Médio e é Espessa.

Também nesta fase do processo amostras das sementes são enviadas ao laboratório para análise de Grau de Umidade, Germinação e Vigor, de cada Lote. Estes ensaios são feitos em canteiros simulando uma plantação real e passam a ser a garantia de qualidade.

Como existe uma diferença temporal entre a seleção das sementes e a realização dos ensaios em Laboratório, estas são colocadas em grandes sacas com capacidade para 1 tonelada, chamados de "Big Bag", quando deixam a Torre. 
Além dos dados transferidos pela "Tag" Mãe a cada "Tag" Filha fixadas nos "Big Bag's", serão incorporadas informações adicionadas como: as informações físicas da semente e a respectiva identificação seqüencial.

É importante que os dados estejam também armazenados no Sistema de Informação, para que a redundância de segurança as informações em caso de algum problema com as "Tag's".

No momento em que os ensaios laboratoriais comprovarem a qualidade da semente esta estará liberada o tratamento e ensacamento.

\section{$\checkmark$ RFID NÍVEL 3 - ARMAZENAMENTO E EXPEDIÇÃO}

Neste terceiro nível tem-se a liberação dos Lotes pelo Laboratório e consequentemente os "Big Bag's" são desmanchados para realização do tratamento químico. Este trabalho é feito em uma torre onde é se pulveriza quimicamente os grãos que são imediatamente armazenados em sacas de 20 ou $60 \mathrm{~kg}$.

Neste momento, uma "tag" RFID deve ser fixada a cada uma das sacas e todas as informações contidas nos Big Bag devem ser transferidas a elas, acrescidas: dos dados de Laboratório; dos dados de Tratamento e numeração sequencial de saca.

Mais uma vez, ter-se-á uma situação de "TAG MÃE", que pertence ao "Big Bag", neste caso, gerando informações para diversas "TAGS FILHAS", pertencentes a cada saca produzida.

Após o completar o ensacamento é preciso armazenar as sacas existindo duas opções de destinação dependendo da programação de vendas: Armazém ou Câmara Fria. Para facilitar à movimentação as sacas são agrupadas em "palets" com aproximadamente 80 unidades, que passam as ser movimentados por empilhadeiras.

Em função do grande número de palets o armazenamento é feito dividindo o ambiente em quadras, com os "palets" podendo ter uma identificação RFID independente para facilitar processo de inventário.

$\mathrm{Na}$ Figura 49 apresenta-se o conceito de Estações de interação, que são locais na planta onde existirão equipamentos para leitura ou gravação das "Tag's" RFID. As Fotos 1, 3, 6, 10 (Identificadas em contorno amarelo.), mostram os pontos onde estas estações devem ser instaladas. 
Outro ponto relevante é reconhecer que a proposta de um Sistema Informado requer ampliação de Memória do "Tag", o que o diferenciará dos equipamentos convencionais, e principalmente do Código de Barras.

A memória de um RFID é dividida em 4 blocos, cada um com uma semântica específica, onde o bloco 3, quando existe, é destinado a usos definidos pelo usuário, até então, com pouca capacidade de armazenamento, conforme indica Figura 48.

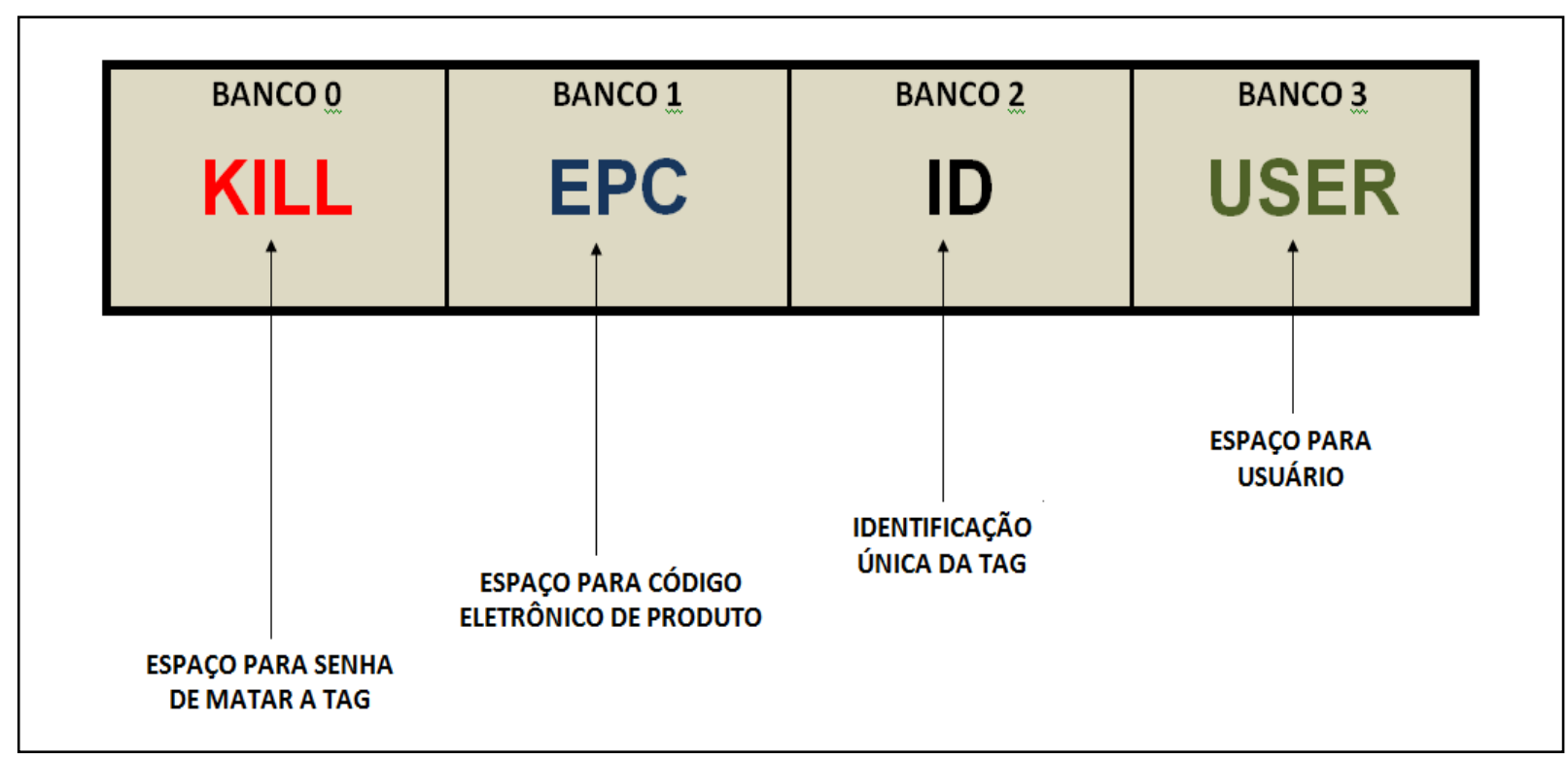

Figura 48- Estrutura da Memória de um Tag RFID.

Em resumo o aumento da capacidade de memória do Banco "3-USER" é condição indispensável para projetos de Sistemas Informados com RFID. Neste caso especifico não será possível na situação real uma memória inferior a 1500 bits. 


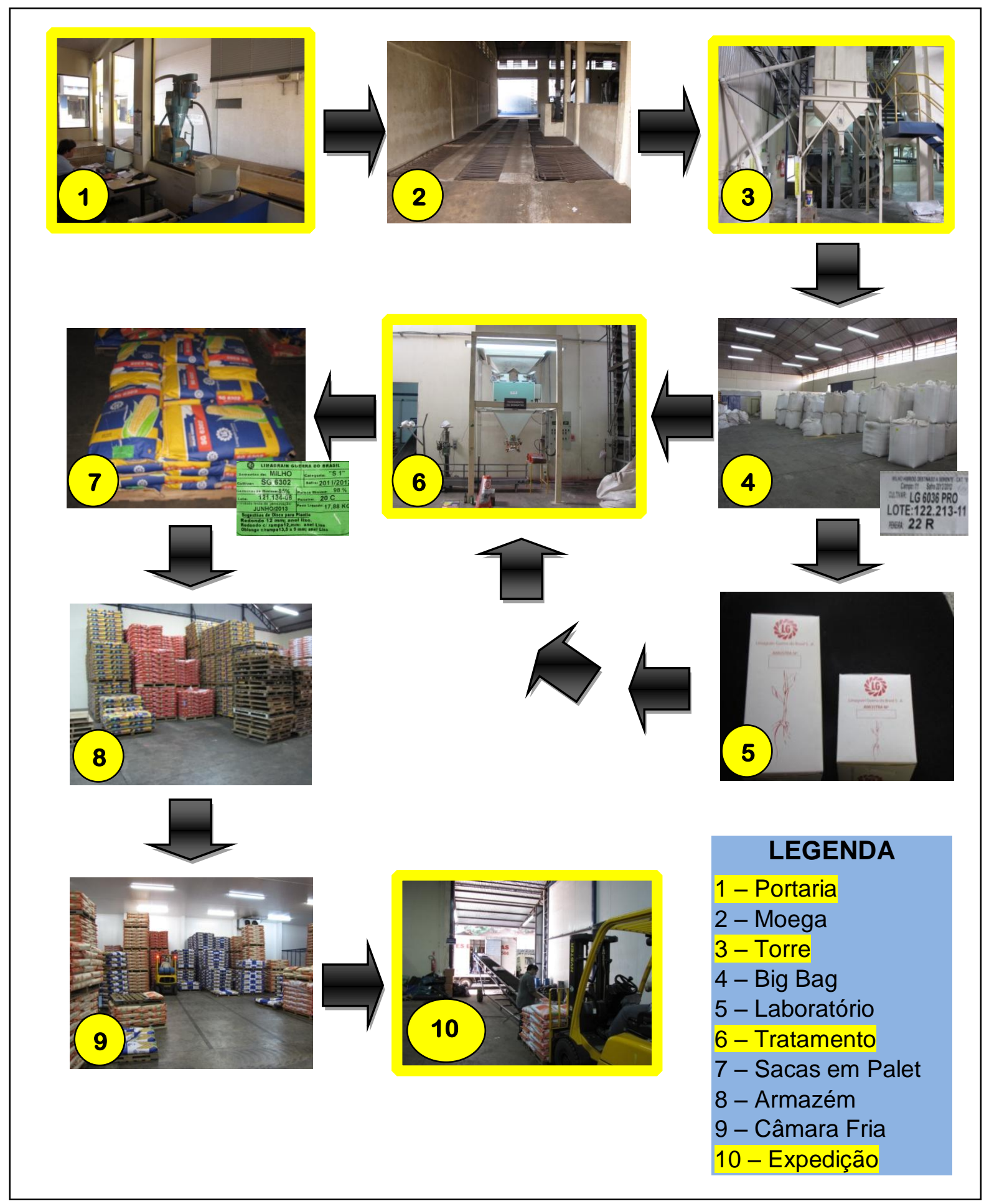

Figura 49 - Posicionamento de Estações de Conversação RFID 


\section{Detalhamento para Especificação das Estações de conversação.}

$\checkmark \quad$ Portaria: Este é o ponto onde a Semente de Milho entra no Processo Informado da Planta, portanto a Estação de Conversação da Portaria será responsável pela coleta de dados do Campo e Entrada, e por registrá-los no Sistema e também no RFID de Nível 1. A estação neste ponto deverá ser composta por um computador, um leitor gravador portátil de estiquetas RFID, com um software amigável de interação. A Figura 50 mostra um local destinado a função, enquanto as Figuras 51 e 52 mostram a telas de registro de dados para o Sistema e Relatórios

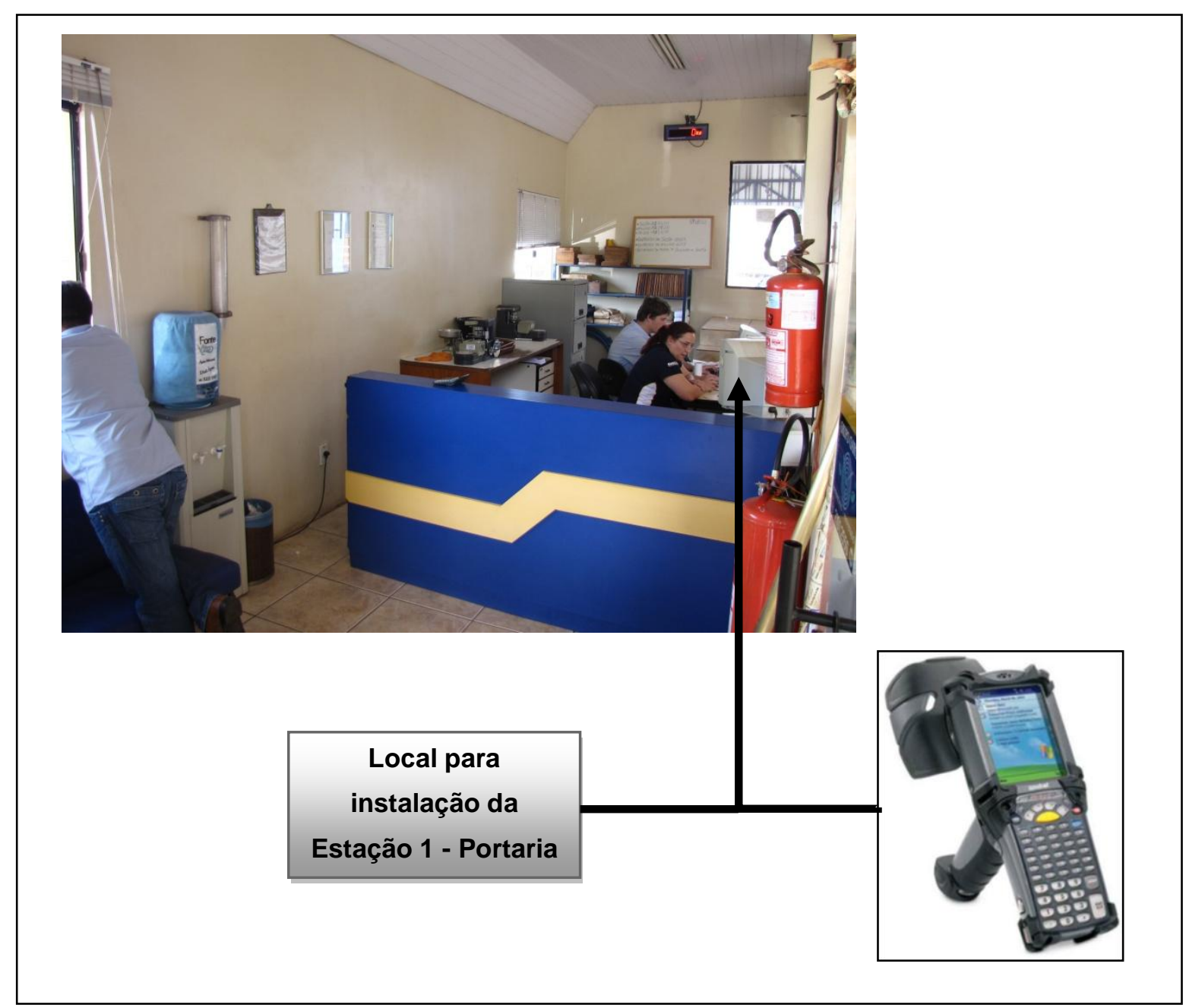

Figura 50- Estação Leitor / Gravador RFID na Portaria 


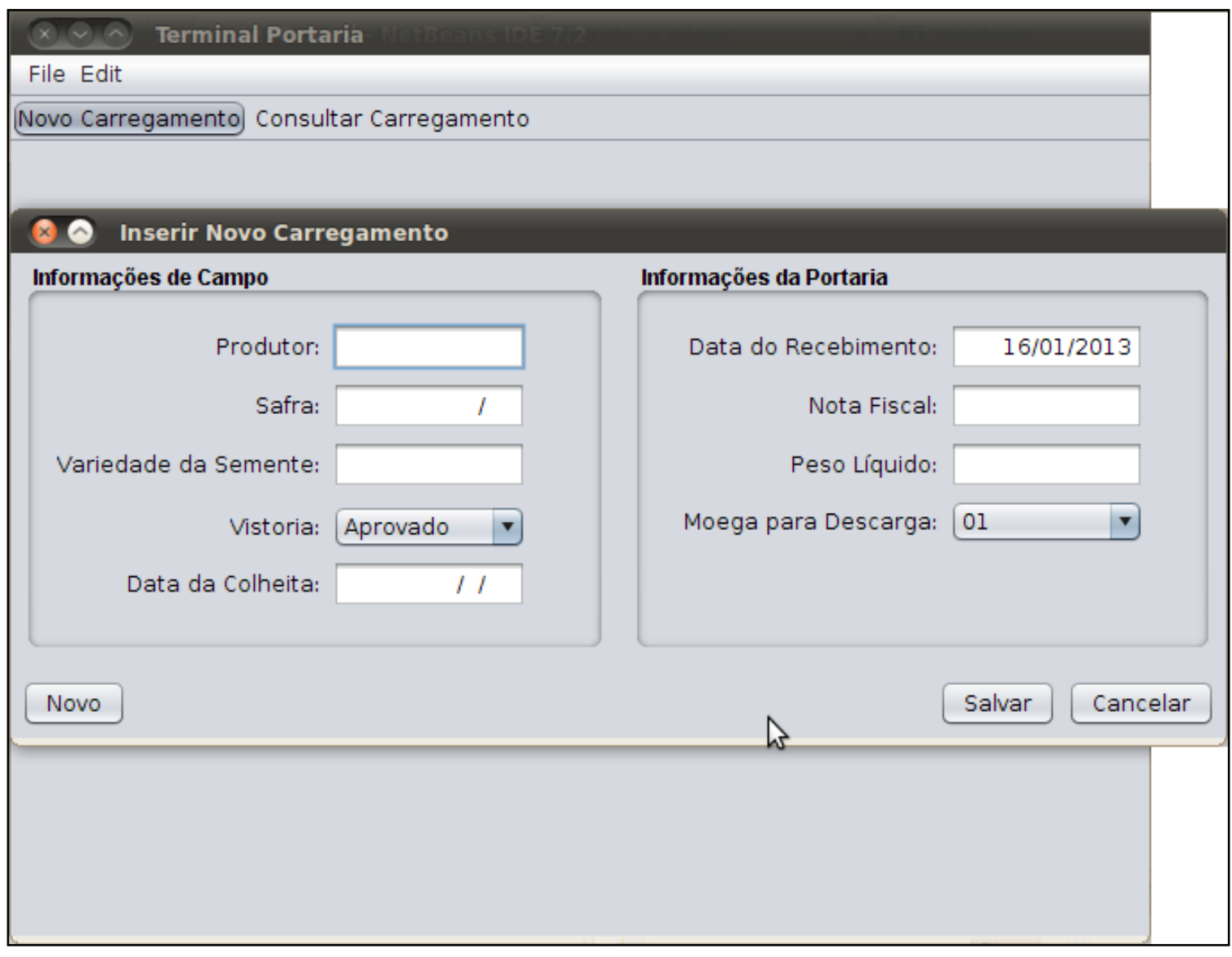

Figura 12 - Tela de gravação de dados

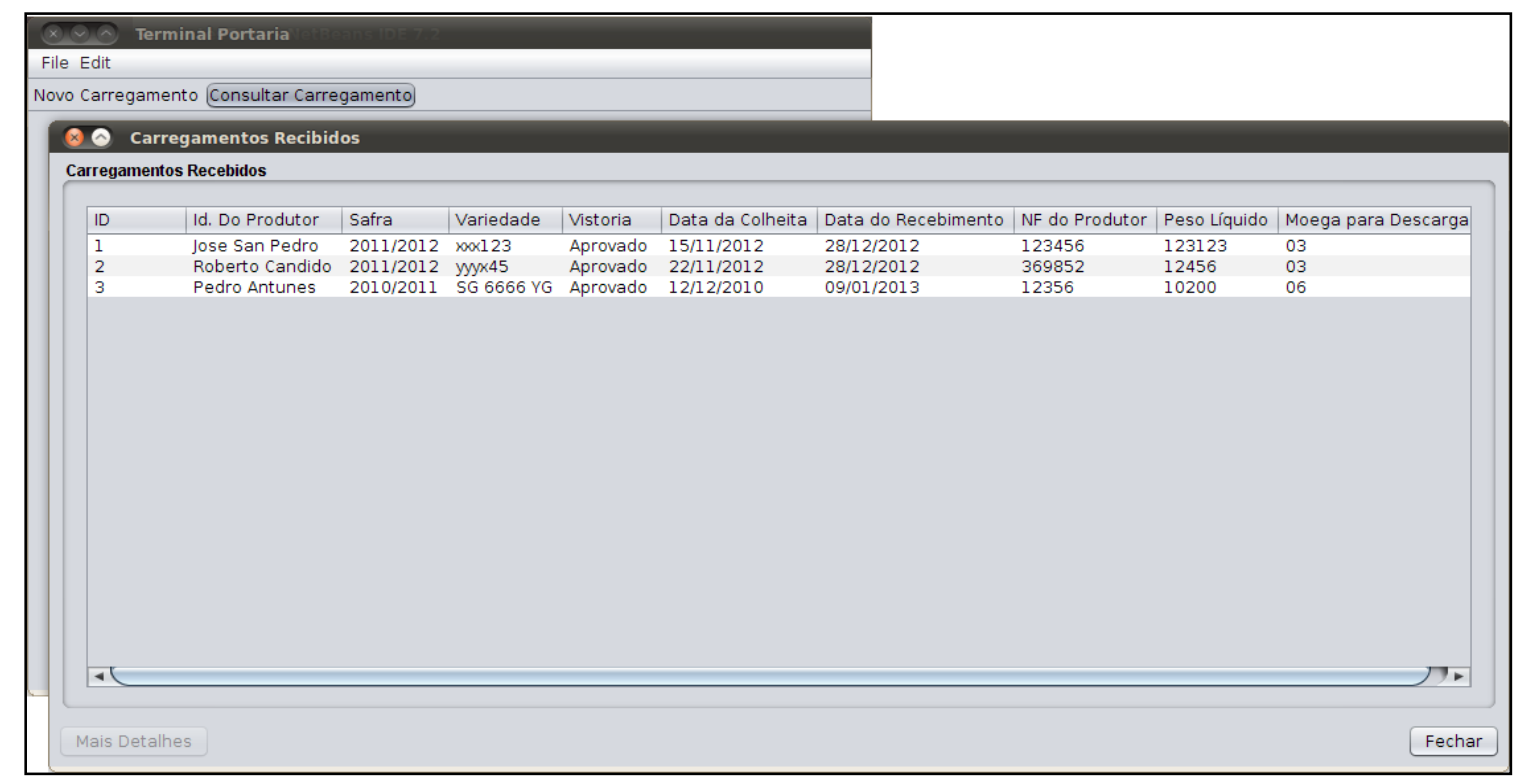

Figura 52 - Tela de Relatório de Recebimento 
$\checkmark$ Torre de Classificação e Tratamento: A segunda Estação será posicionada de forma a atender a torre de Seleção e também a de Tratamento, permitindo otimizar investimentos. A figura 53 mostra que os dois equipamentos estão proximos e permitem esta opção.

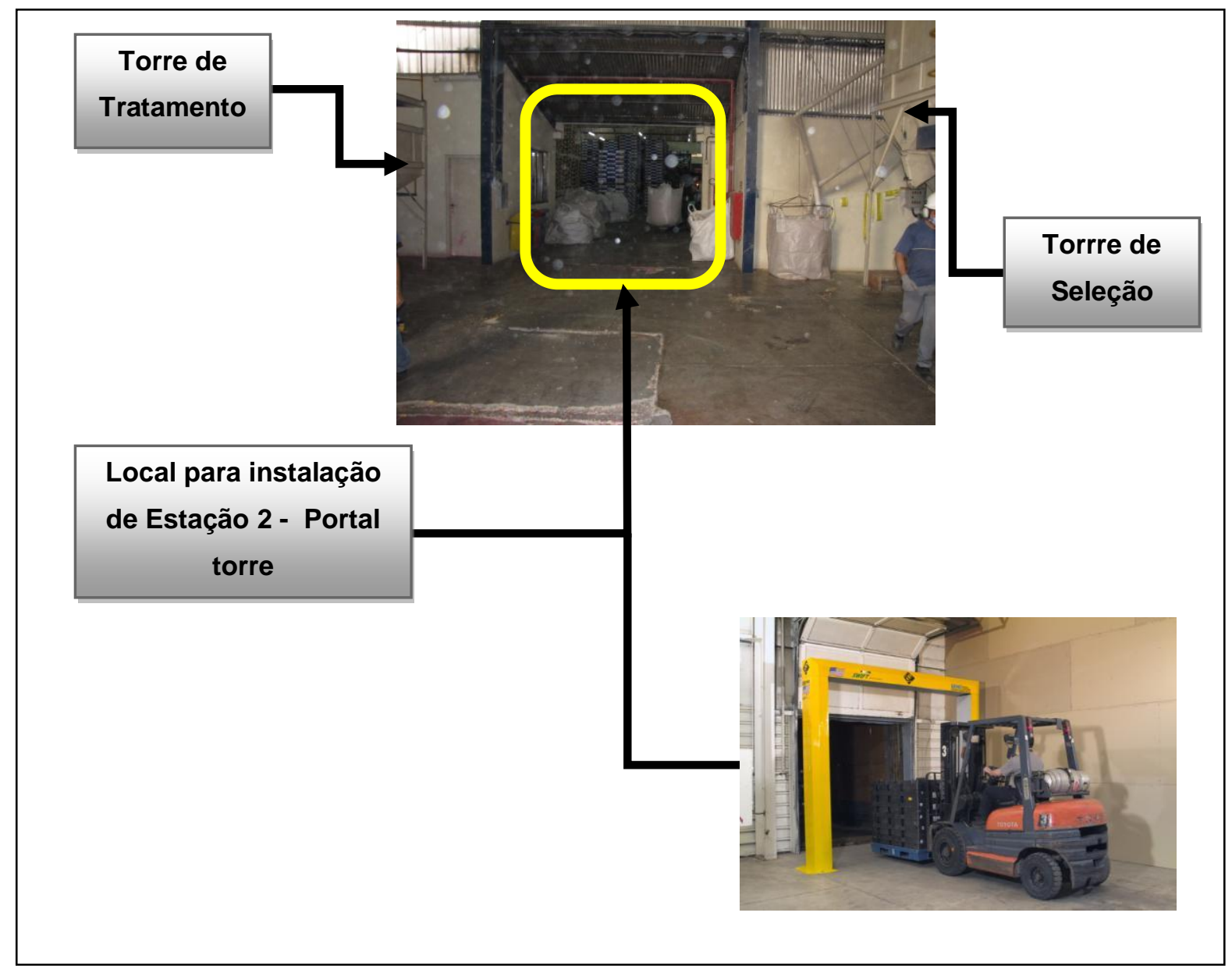

Figura 53 - Estação 2 para Torre Seletiva e de Tratamento

A forma de portal com antenas permite que o deslocamento que ocorre em seus domínios de atuação sejam percebidos e se estabeleça uma "conversa" com o Sistema Informado, lendo e gravando informações no RFID. Esta estação terá um portal, um computador e um leitor gravador de RFID, associado a um software amigavel para interação. As Figura 54, 55, 56 mostram as telas de registro na saída da Torre, para o Big Bag e também após o tratamento no instante de ensacamento das sementes. 


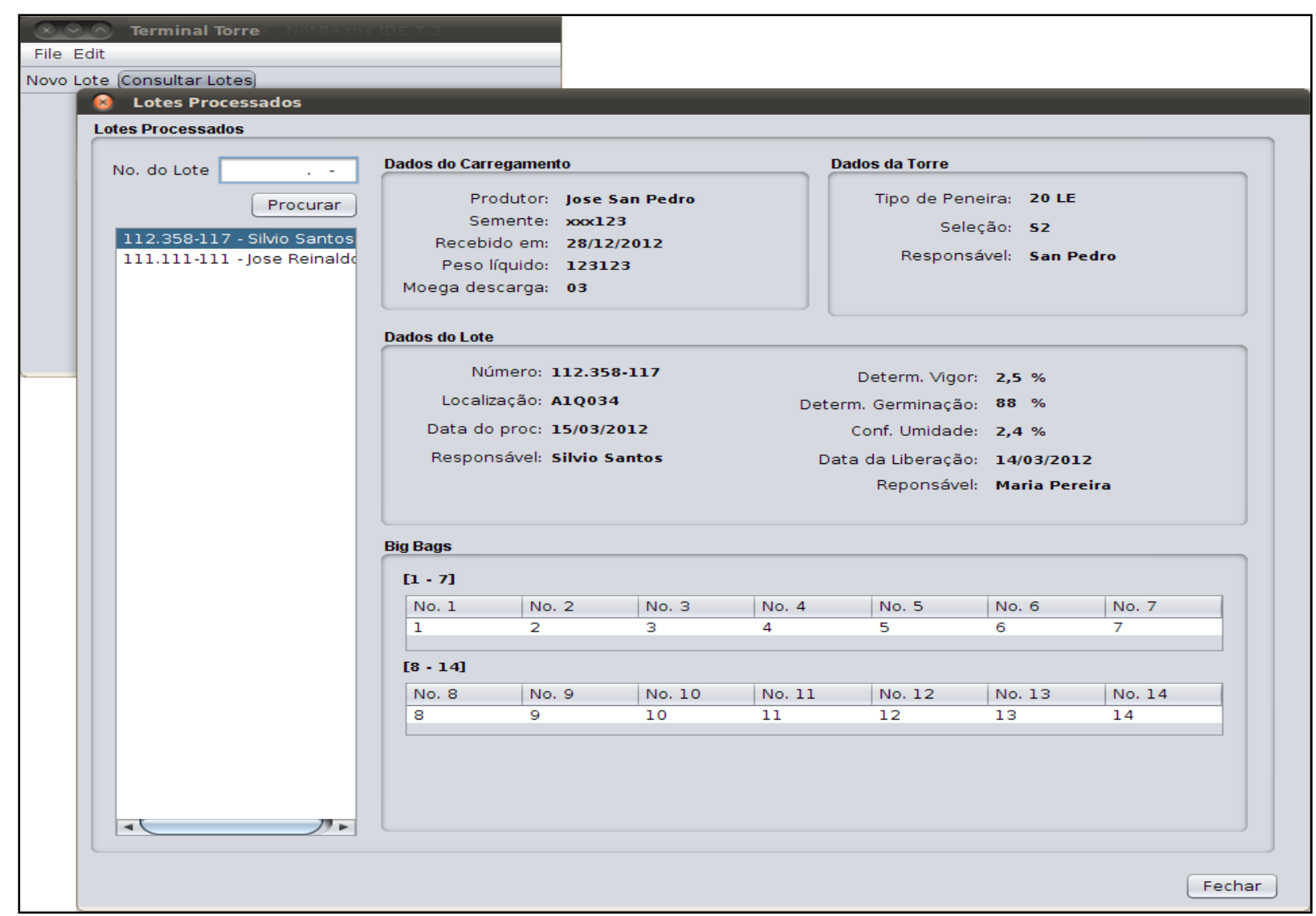

Figura 54 - Tela de Gravação de dados na Torre

\begin{tabular}{|l}
\hline File Edit \\
Novo Palet Consultar Palets
\end{tabular}

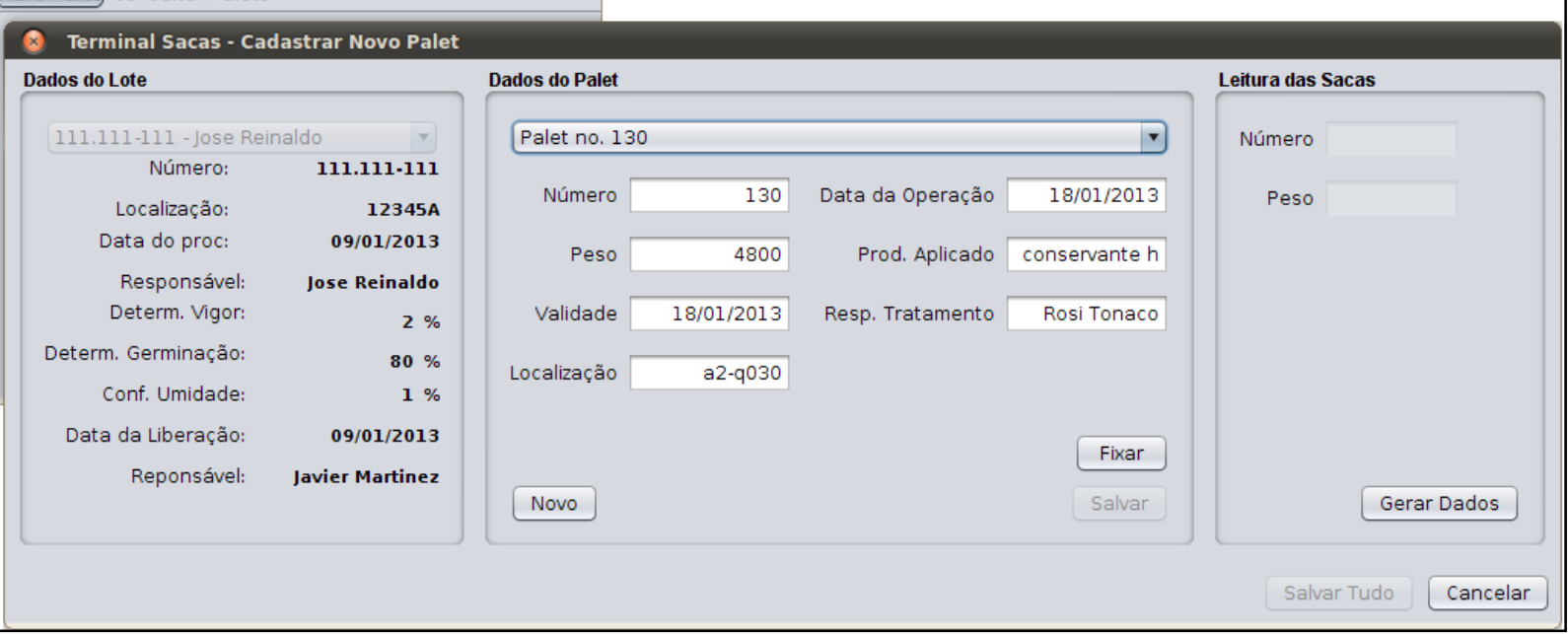

Figura 55 - Tela de Gravação no Tratamento 


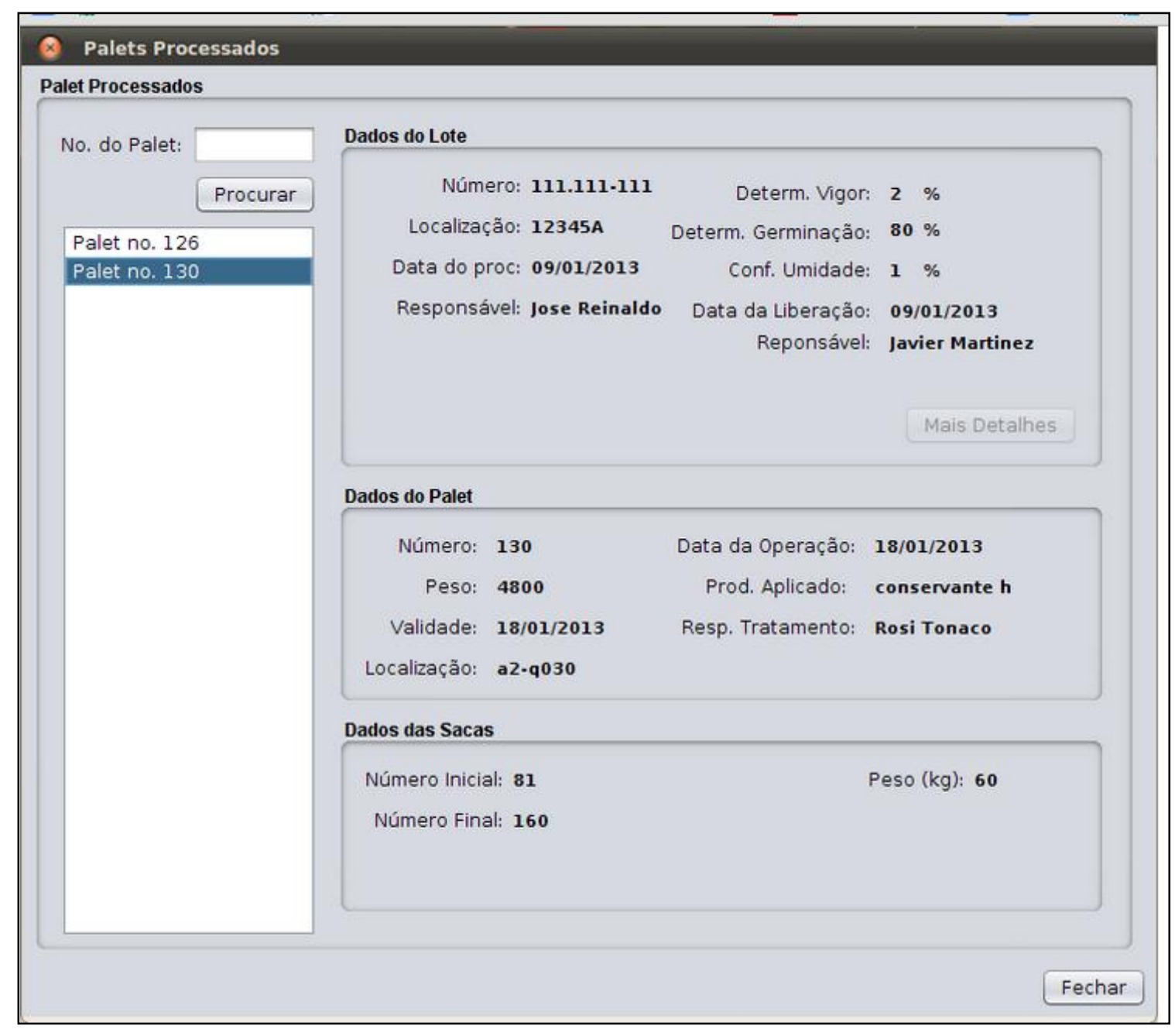

Figura 56 - Estação 2 para Controle de Paletes

$\checkmark$ Expedição: A Estação de número 3 será instalada para consolidar o Processo Informado no "Supply Chain" do Milho na Esteira de carga de caminhoes. Neste ponto os dados do cliente se incoporam ao Sistema e também à Tag RFID. A Figura 57 ilustra o modelo com antenas laterais. Nesta etapa também existe interação com o operador que faz diversas inserções ao Sistema e ao RFID. Sendo assim, ela será composta por um computador, antenas fixadas em pedestal disposto lateralmente à esteira, leitores RFID e o software que nesta etapa terá como tela o mostrado nas Figura 58. 


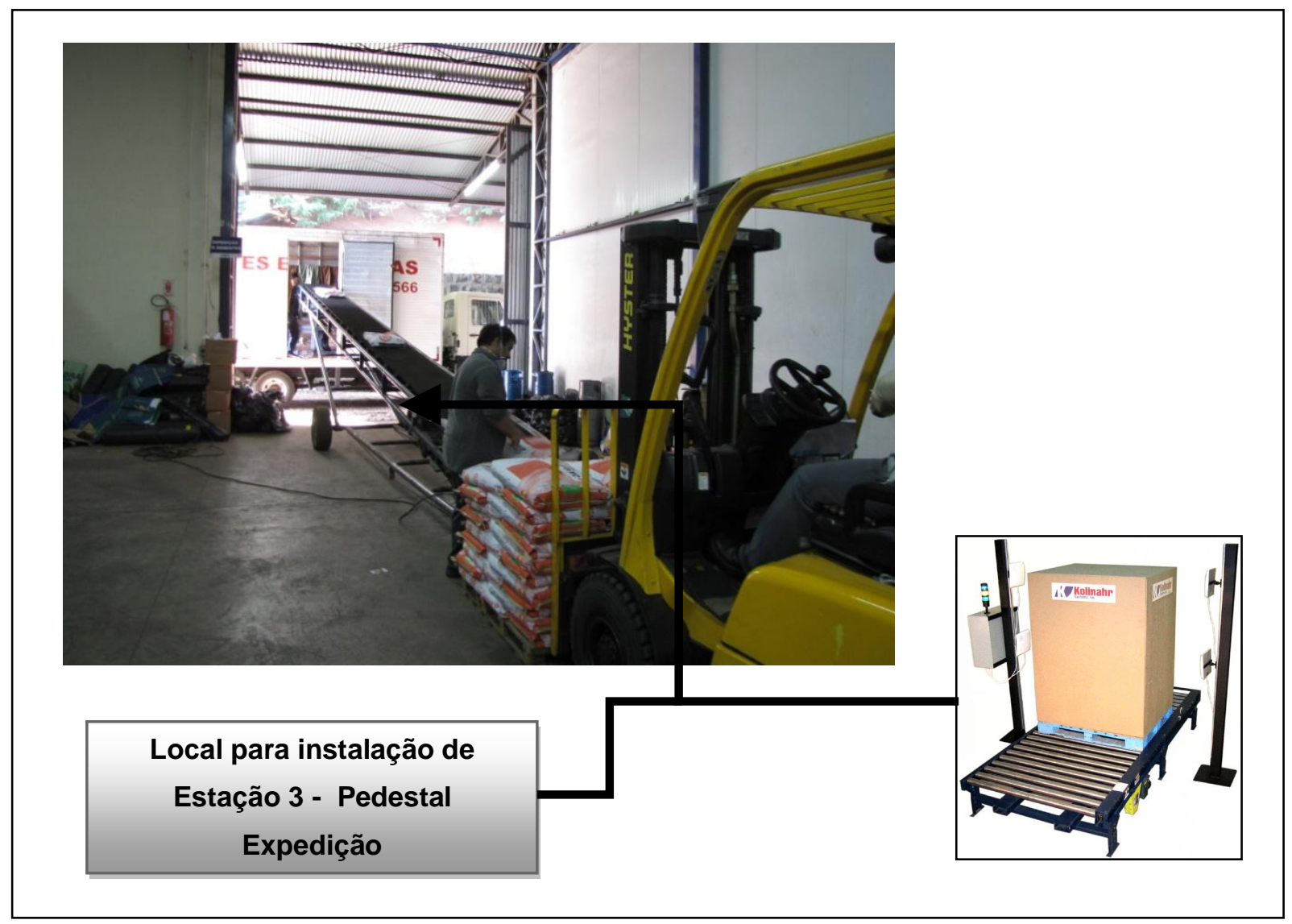

Figura 13 - Tela de Gravação para Ensacamento e Colocação em Palets

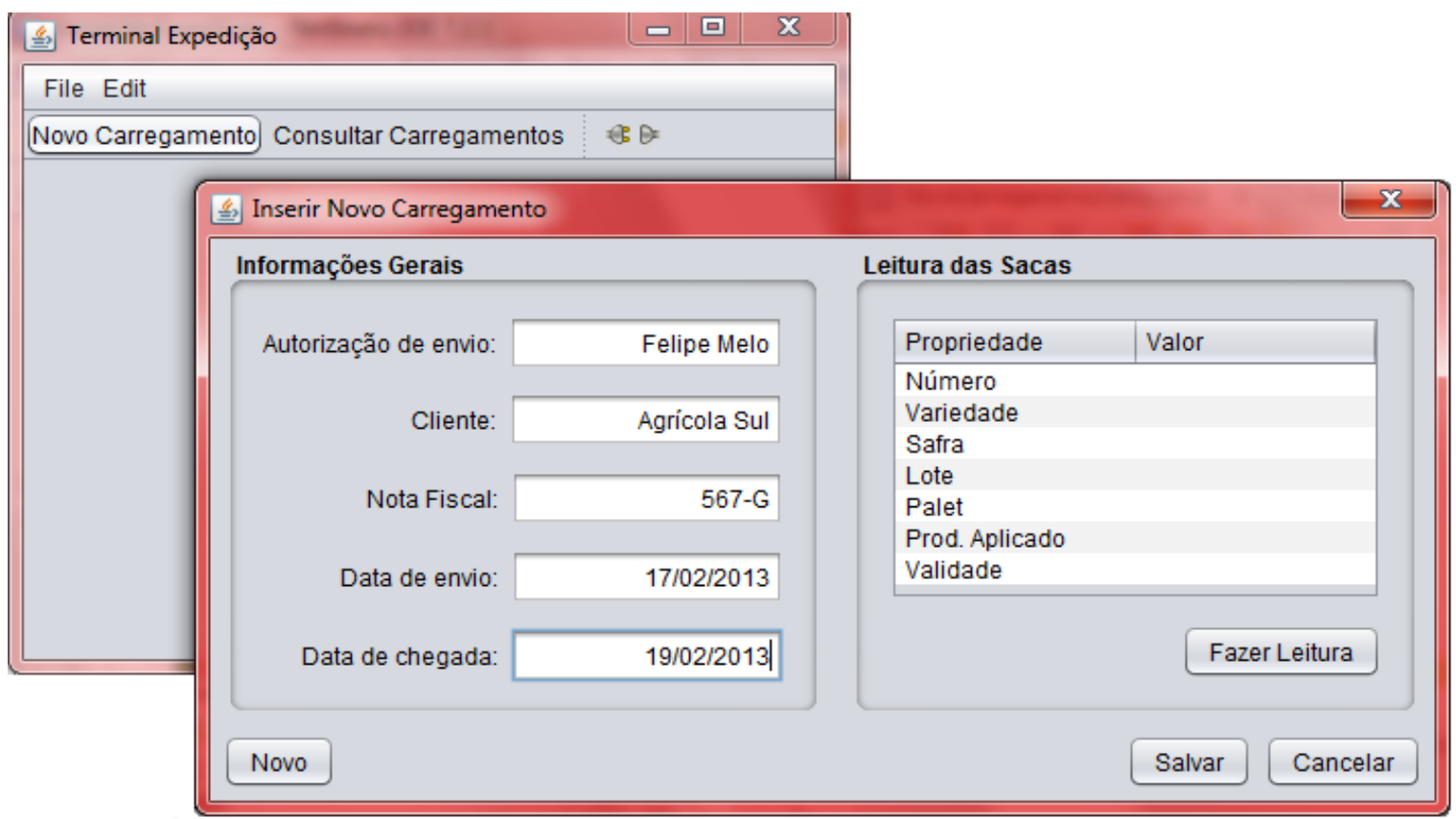

Figura 14 - Tela de Gravação na expedição 
A Estação 3 portanto é a responsável pelo encerramento do Processo Informado na Planta, e consolida todos os dados que vão acompanhar a saca de Semente de Milho. Depois da transposição desta Estação já será possível efetuar a Leitura de todos os dados que acompanham o item, basta que a saca seja submetida a uma antena ou um leitor manual. O resultado da leitura é mostrado na tela gerada na Figura 59

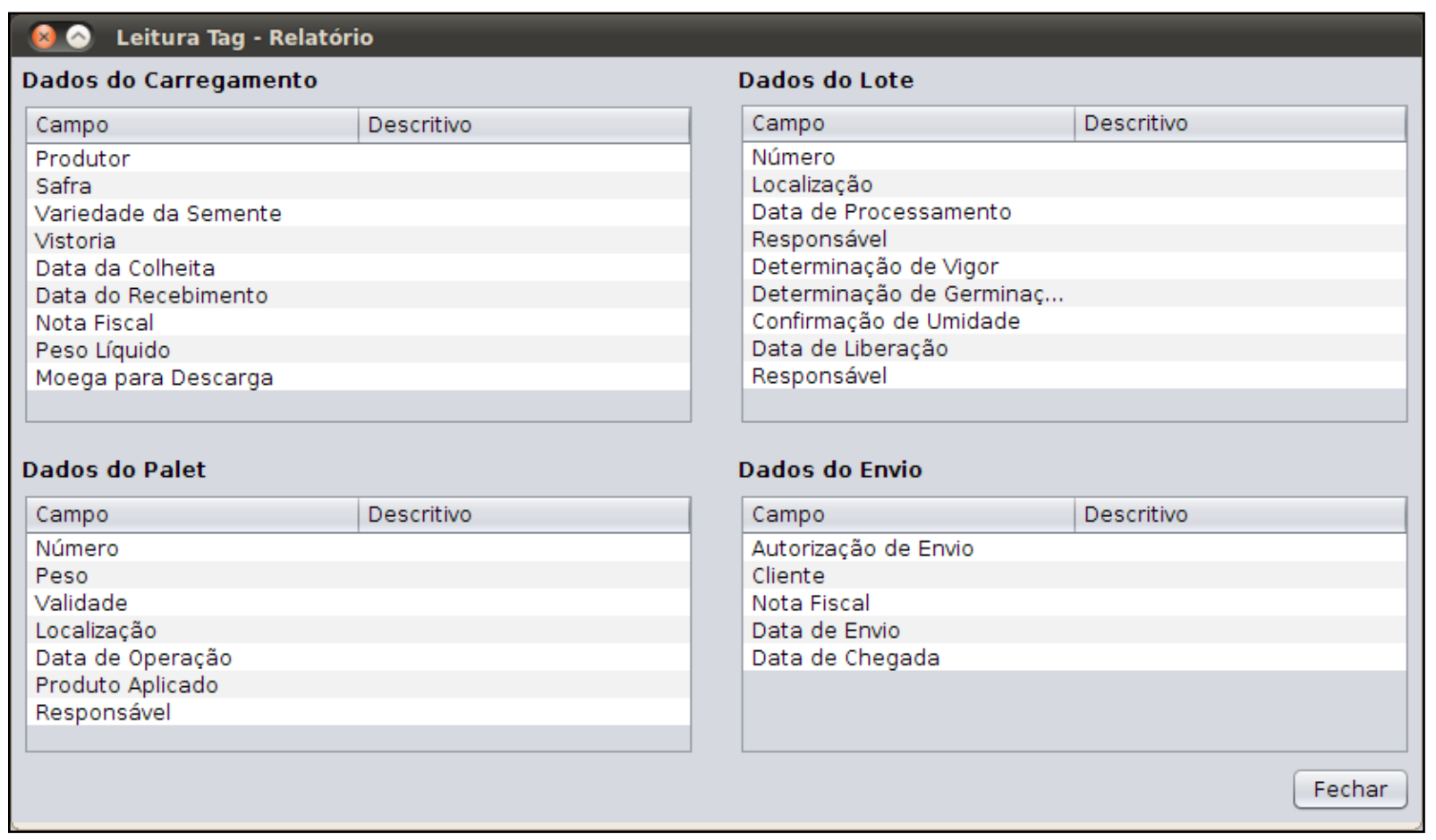

Figura 59- Tela de leitura do RFID junto a saca de sementes

\subsection{CONSIDERAÇÕES FINAIS:}

Neste capítulo apresentou-se a proposta defendida nesta tese, que teve como objetivo a criação de uma Metodologia para a implantação de um Processo Informado no "Supply Chain" do Agronegócio. Para efetivação da proposta dois conceitos foram trabalhados de forma complementar e assim dar sustentação ao estudo, são eles: A tecnologia RFID, Workflow e a Lógica do Serviço Dominante. Finalmente para aglutinarem-se conceitos, até então difusos, foi necessário utilizarse de ferramentas computacionais disponíveis no mercado, como Enterprise Architect 9.2 e YAWL4 Study 2.3. 
A escolha do agronegócio foi justificada pela sua importância econômica e para tanto a busca de um "Supply Chain" representativo do segmento levou a escolha da produção de sementes de milho. Para tanto, foi estudado e redesenhado o Modelo de Negócio de uma empresa Produtora de Sementes.

Os pontos de interação foram identificados e devidamente mapeados na planta baixa da empresa, e que estão apresentadas na seqüência de fotos da Figura 49 da página 124. Entretanto o que temos de resultado neste capítulo é a especificação (expressa até de maneira informal para melhor entendimento, mas passível de ter uma representação mais disciplinada no Enterprise Architecture).

A simulação através da elaboração de um Piloto foi ponto fundamental para validar a proposta, porém a inexistência de equipamentos com características que o projeto demandava foram desafios vencidos, através da Parceria com a empresa 3M do Brasil. Desta forma, com "tag's", leitores, antenas e softwares cedidos pela empresa foi possível comprovar o funcionamento do modelo criado neste trabalho.

A proposta de um novo equipamento para este fim está fora do escopo deste trabalho, mas uma dúvida ficou no ar sobre uma possível adaptação de equipamentos já existentes e também uma necessidade de validar, ou pelo menos confirmar a viabilidade do método com os equipamentos disponibilizados pela $3 \mathrm{M}$ do Brasil. 


\section{RESULTADOS}

\section{1 - CRIAÇÃO DE UM PROTÓTIPO:}

A elaboração de um protótipo permite ao pesquisador estudar um caso real a partir de uma montagem em bancada e utilizando-se de equipamentos disponíveis no mercado. A partir desta montagem é possível simular situações de operação determinando os pontos críticos e levantando falhas de projeto antes de sua implantação definitiva. Esta forma de trabalho traz as vantagens de se conhecer o Processo antecipadamente, evitando assim desperdícios de recursos em caso de correções ou alterações da concepção original.

Nesta óptica, a realização desta pesquisa realizou uma busca no Mercado por componentes que permitissem a Montagem do Protótipo de um Sistema Informado, busca esta que imediatamente mostrou a concentração de aplicações das "Tags" RFID em sistemas que se apresentam como uma evolução linear do código de barras - restrito, portanto à função de identificação - e com limitações de uso pela falta de maior capacidade de memória disponível ao usuário.

Outro ponto observado foi a indisponibilidade do Mercado para desenvolvimento de novas pesquisas e aplicações dos dispositivos RFID, preferindo por tanto concentrar esforços em aplicações tradicionais de posicionamento do item. Como conseqüência desta forma de trabalho poucas empresas desenvolvem parcerias com Centros de Pesquisa buscando ampliar seu mercado potencial através da Inovação Tecnológica. Como conseqüência imediata desta postura comercial a definição de equipamentos que pudessem ser aplicados no Protótipo foi extremamente prolongada.

Esta conjuntura levou a busca de uma parceria com empresas que tivessem um forte apelo pela Inovação Tecnológica e praticassem em seu cotidiano a Pesquisa, o Desenvolvimento e a Inovação (P\&D\&I). O resultado desta busca foi encontrar na Empresa $3 \mathrm{M}$ a parceira que no momento da pesquisa tinha condições de dar suporte técnico para o desenvolvimento de um produto concebido sob a óptica do Processo Informado.

A linha de produtos que utiliza a tecnologia RFID na empresa 3M está voltada para processos de controle de acervo de biblioteca, portanto equipamentos de pequeno porte e de uso bastante específico. Esta situação é desafiadora, pois as 
propostas aplicativas deste Estudo são conceitualmente opostas ao produto comercial da empresa. Por outro lado a comprovação dos resultados esperados mostrou que o Modelo Informado proposto pode revolucionar o "Supply Chain".

\title{
5.2 - ESCOLHA DE COMPONENTES PARA PROTÓTIPO:
}

Antena: É o dispositivo de pequeno porte mostrado na Figura 60, que trabalha com leituras de "Tag's" RFID (HF) fazendo leituras de pequenas distâncias. Na aplicação comercial os "Tag's" são fixados dentro dos livros para controle de empréstimos e devoluções pelos usuários. Nesta forma de trabalho a necessidade de pessoas para operação é inevitável, pois a tarefa é feita em balcões de atendimento onde os livros são passados manualmente pela antena para reconhecimento..

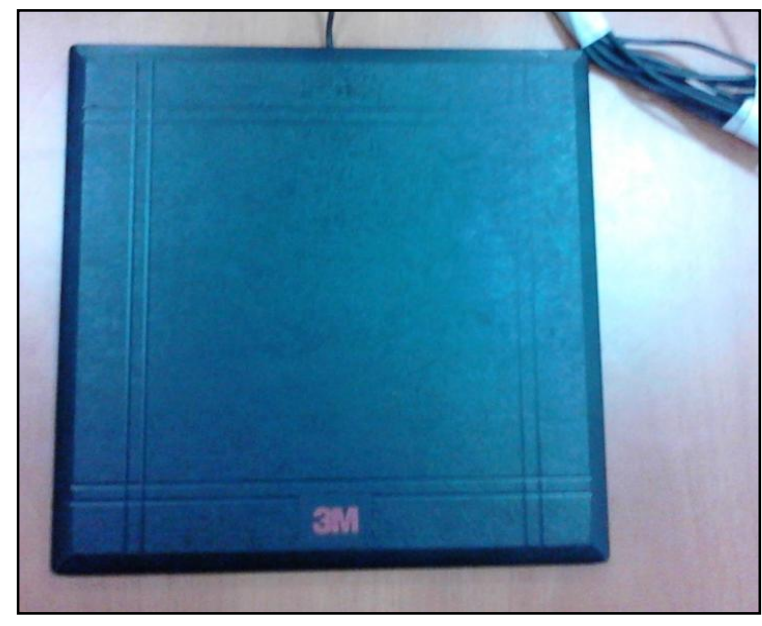

\author{
Dimensões \\ Pad: $28,5 \mathrm{~cm} \times 28,5 \mathrm{~cm} \times 1,0 \mathrm{~cm}$ \\ Leitor: $16 \mathrm{~cm} \times 10 \mathrm{~cm} \times 3 \mathrm{~cm}$ \\ Requisitos elétricos \\ Leitor: $100 / 120$ ou $200 / 240$ VAC \\ $50-60 \mathrm{~Hz}$ \\ $5.0 / 2.5 \mathrm{~A}$ \\ Peso (aproximado) \\ Pad e leitor: $1 \mathrm{Kg}$ \\ Software é fornecido pela 3M
}

Figura 60 - Antena em forma de Pad 3M

Leitor / Gravador: Está mostrado na Figura 61 e realiza a Leitura e Gravação das tarefas de empréstimo e devolução de livros no Sistema de Bibliotecas 3M. Nos projetos de controle de biblioteca o Leitor / Gravador tem um papel simplificado de reconhecer o item, cujos dados encontram-se registrados em Banco de Dados. Esta característica de informações armazenadas em Banco de Dados é que se buscou alterar, fazendo-as acompanhar o item, caracterizando, portanto um Sistema Informado. Para que o Protótipo fosse concretizado foram necessários que protocolos de equipamentos fossem abertos e chaves 
de programas e interfaces fornecidas e muitas destas liberações tiveram que ser obtidas diretamente com centros de pesquisa da empresa no EUA.

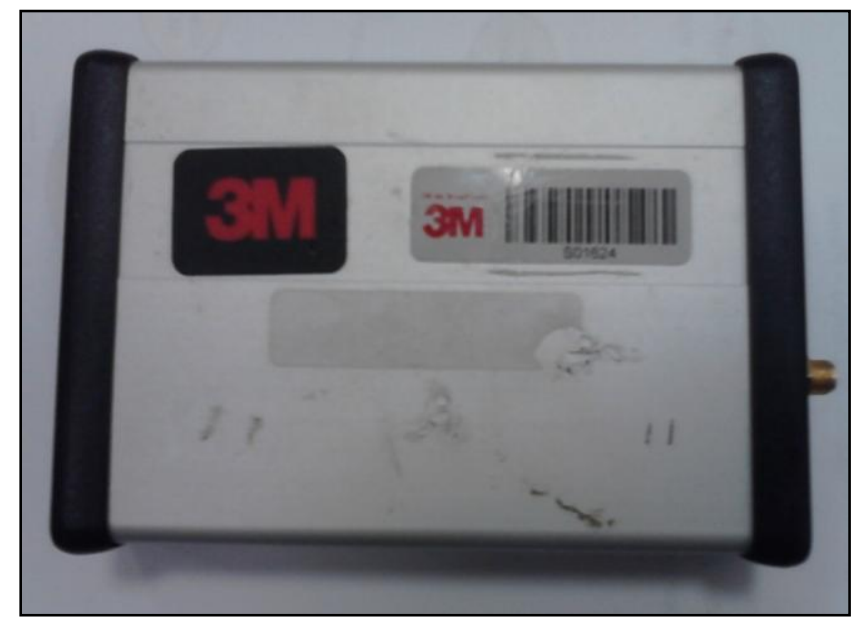

Dimensões

Largura: $14,22 \mathrm{~cm}$

Profundidade: $12,7 \mathrm{~cm}$

Altura: $2,54 \mathrm{~cm}$

Peso $103,2 \mathrm{~g}$

Ambiente

Intervalo de temperatura

típica de ambiente:

$50^{\circ} \mathrm{F}$ a $104^{\circ} \mathrm{F}\left(10^{\circ} \mathrm{C}\right.$ a 40

$\left.{ }^{\circ} \mathrm{C}\right)$

Umidade: $0 \%$ a $85 \% \mathrm{RH}$, sem condensação

Elétrica 12 VDC, 0,3A

Figura 15 - Leitor / Gravador 3M

$\checkmark$ Tag RFID - Para desenvolvimento do Protótipo serão utilizadas "Tag's" comerciais utilizadas no Sistema de Biblioteca da $3 \mathrm{M}$ e mostradas na Figura 62 com suas principais características. Esta "Tag" tem capacidade de $2 \mathrm{kbites}$, porém existe um bloqueio de parte dela no intuito de limitar a aplicação aos projetos comerciais da empresa.

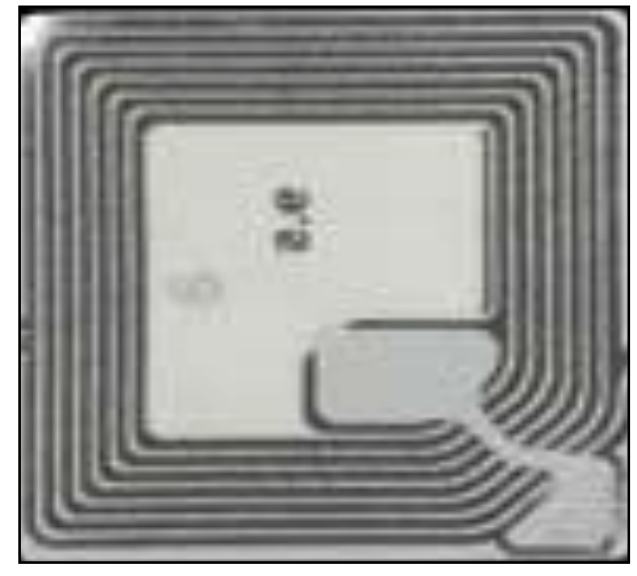

Figura 62 - Exemplo de tag adesiva 3M

\section{Desempenho}

Identifica e rastreia itens;

Armazena informações seguras;

Simplifica a classificação e o inventário; e Detectada pelo Sistema de Detecção RFID;

Regravável

Informações podem ser atualizadas; Chip de memória armazena as informações do item.

\section{Rápido processamento}

Não é requerido posicionamento preciso;

Itens identificados rapidamente.

Etiqueta para identificação e rastreamento.

Proporciona segurança do item.

Dimensões $5 \times 5 \mathrm{~cm}$ 
$\checkmark$ "Middleware" - A efetiva interação entre os dispositivos do Protótipo Modelado só ocorre quando existirem protocolos de comunicação estabelecidos por softwares definidos e estruturados para esta função. Para o Estudo de Caso deste trabalho foi fornecido pela empresa 3M o módulo "3M Enhaced Pad Staff Worstation", que é o encarregado de fazer a interface com o hardware (Leitor/Gravador e Pad) e também fornecer um conjunto de bibliotecas que permitem ao usuário desenvolver aplicações para interagir com o hardware, conforme mostrado na Figura 63. A utilização deste módulo implicou em disponibilização de chaves para ativação do aplicativo, envio de documentações, e autorizações de uso. Além dos aplicativos fornecidos pela Empresa e prévia autorização para usá-los em uma pesquisa acadêmica e não comercial, foram desenvolvidos dois outros módulos utilizando a linguagem JAVA no laboratório D-Lab. A função destes módulos foi permitir a integração do Sistema da $3 \mathrm{M}$ com o banco de dados "MySQL" onde foram armazenadas todas as informações geradas no Processo Informado. $O$ primeiro módulo permite gravar as informações obtidas na Simulação do Processo Informado no banco de dados e o segundo módulo é o encarregado de fazer a leitura/gravação das informações nas "Tag's". É importante lembrar que para a criação do Protótipo e Simulação do Processo Informado foram utilizados "Tag's" comerciais com pouca memória disponível ao usuário, o que determinou a alternativa de gravá-las como índices das tabelas correspondentes armazenadas no banco de dados. Esta opção foi de extrema importância, pois permitiu validar o Processo e comprovar a necessidade de expansão de Memória das Tags. Para completar a simulação do Protótipo foi utilizado um banco de dados do tipo "MySQL", que confere ao Sistema a capacidade de armazenar as informações de forma redundante, evitando dessa forma perda definitiva de dados uma vez que, estarão armazenados em dois locais, nas "Tag's" e nele próprio. No Anexo 1 apresenta-se parte dos fontes do programa produzido para a tese. Lembrando que alguns deles não podem se publicados, por serem proprietários. 


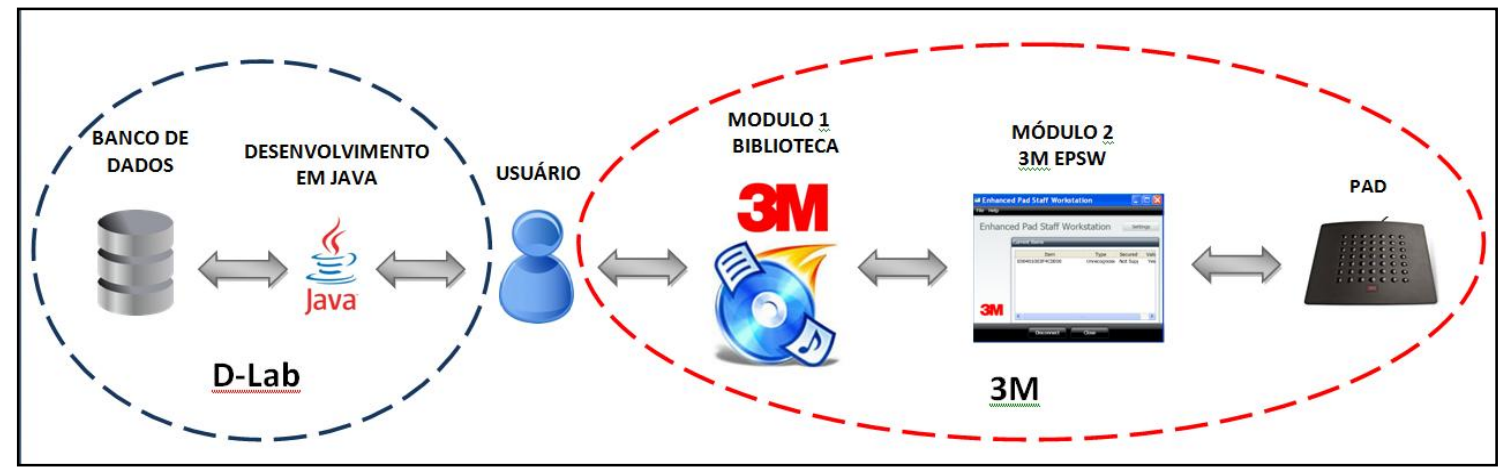

Figura 63 - Arquitetura do Sistema

\section{3 - CONFIGURÇÃO SIMULADA DE ESTAÇÃO}

A Empresa 3M, colaborando com o estudo disponibilizou para montagem do Protótipo os equipamentos descritos no item 5.2 deste trabalho. Evidentemente que um protótipo não é a reprodução de um evento em escala reduzida, mas sim um modelo físico que permite estudá-los em situações que possam reproduzir a realidade. Desta forma, quando os componentes são agrupados e ligados com mostra a Figura 64 se cria uma Estação de Interação que se transformou no Protótipo de um Modelo Informado para o Agronegócio.

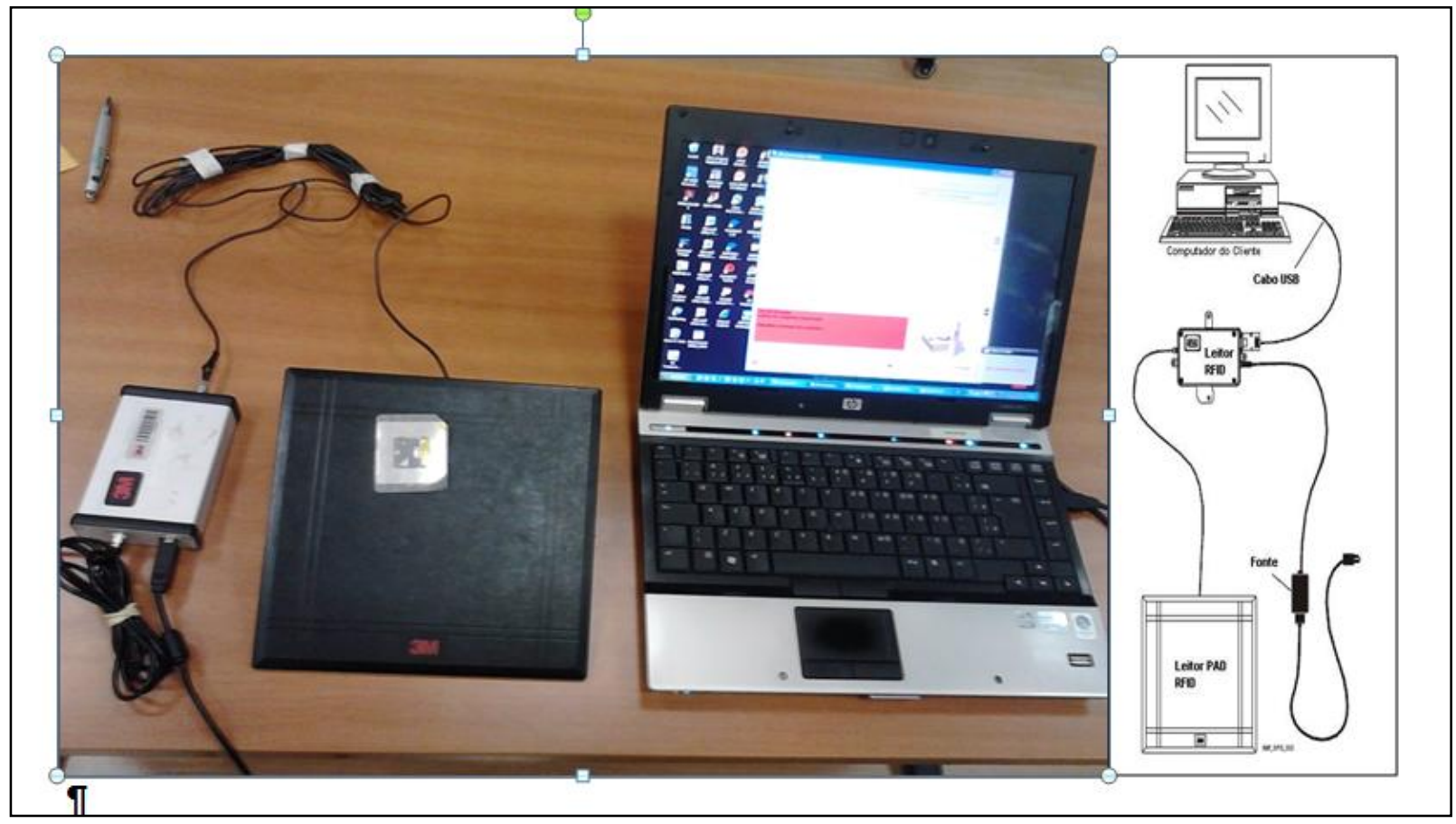

Figura 16 - Modelo Protótipo de Sistema Informado do Agronegócio 
A Figura 65, já apresentada na página 120, mostra os quatro pontos do Processo Informado que geram informações que precisam ser reproduzidas pelo Protótipo, pois é neles que ocorrerão as interações com troca de informação. Logo a questão nesta parte do Estudo é mostrar a correspondência entre os pontos especificados para o processo informado do milho no beneficiamento e o protótipo.

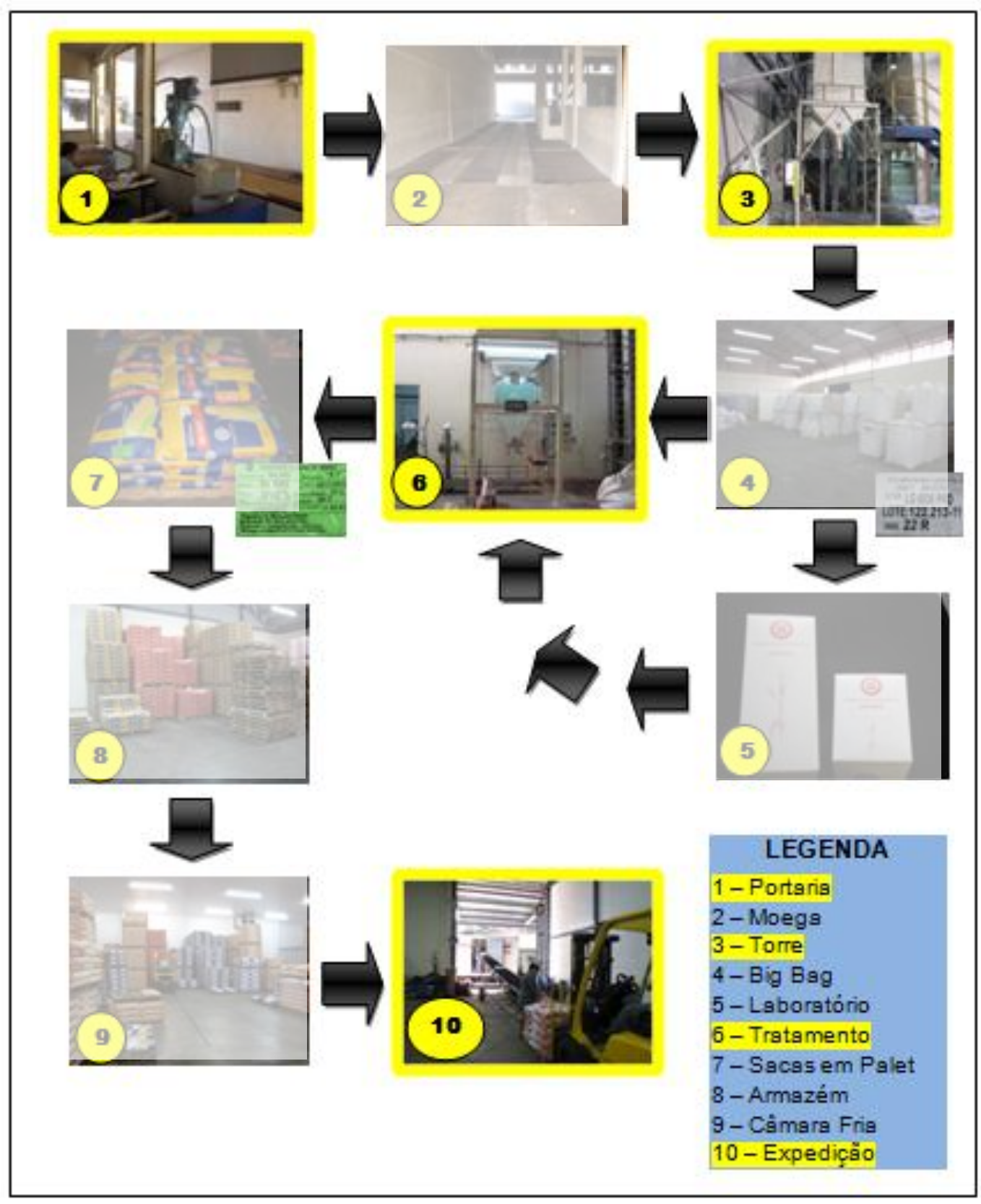

Figura 17 - Pontos para Conversação - Leitura e Gravação de Tags 
Para demonstração do protótipo as quatro estações de conversação (leitura/gravação) serão feitas num mesmo equipamento, uma vez que foi possível através do software diferenciar a operação de cada uma delas. A inexistência de equipamentos suficientes para simular as quatro estações de Leitura e Gravação das "Tags" foi a justificativa desta escolha, portanto estas tarefas serão simulados por um único conjunto antena e leitor / gravador incorporado ao Protótipo, conforme a Figura 64 da página 139.

Embora o Processo Informado deva ser feito na totalidade do Supply Chain, neste trabalho concentramos numa etapa representativa que da Portaria (Foto 1 da Figura 65) para dentro da empresa. Esta opção de trabalho foi adotada em função de que a totalidade de um processo de produção de sementes leva no mínimo 4 (quatro) anos, desde a produção da semente genética pelos detentores da variedade até o produtor do grão comercial. Certamente este período inviabilizaria a realização de nosso trabalho, logo a segmentação da do Supply Chain foi inevitável e necessária. Desta forma para o modelo os dados de Campo serão incorporados ao Sistema e às Tags a partir do recebimento neste ponto ${ }^{2}$.

Nesta estruturação os dados de campo e as condições de chegada da carga serão gravadas simultaneamente na "Tag" por meio de um Gravador/Leitor Manual, que se torna mais prático o operador de balança lotado na Portaria. Depois de gerada esta acompanha a carga em seu descarregamento e ingresso no processo de seleção. São exemplos dos dados nela gravados nesta etapa a Umidade do milho no momento do recebimento, o grau de impurezas da carga, o produtor responsável, etc.

A simulação desta etapa do processo foi feita com uma carga fictícia chegando à Portaria, quando imediatamente se abre uma tela com solicitação de dados que devem ser preenchidos e incorporados ao sistema e simultaneamente a gravação da "Tag" pela passagem no Pad 3M. Nesta operação ficam nela

\footnotetext{
2 Em um processo estendido as informações coletadas e acrescentadas na fase de Campo deveriam vir já acondicionadas em um tag, que só receberia dados adicionais na chegada à empresa de beneficiamento da semente.
} 
registrados diversos dados como: nome do produtor, transportador, umidade, e demais itens já mostrados anteriormente.

Para consolidar a aplicação cada tabela registrada corresponde a um código que a referencia no Banco de Dados, esta opção de desenvolvimento foi feita em função da limitação da memória dos dispositivos utilizados no protótipo. Porém, na configuração real, todas as linhas da tabela corresponderão a um índice, gerando a gravação de cada um dos campos no Sistema e também no "Tag".

Depois que o produto está no processo, passa por um equipamento chamado de Torre de Classificação (Foto 3 da Figura 65), quando as sementes são separadas por tamanho e espessura e posteriormente armazenadas em "Big Bag's" com capacidade para 1 tonelada, formando um Lote quando atingirem 14 unidades. Nesta fase existe uma mudança na forma de condução das sementes, e novas características são observadas, portanto, novos dados que precisam ser gravados, porém agora acompanhando os "Big Bag's". É perceptível que uma carga de sementes gera diversos "Big Bag's", que precisam ser identificados individualmente, ou seja, os dados que acompanhavam a carga precisam ser replicados a cada um, acrescidos de novos dados gerados na Torre, tais como: espessura, tamanho, Lote, etc. Em resumo, neste ponto. a "Tag" vinda com a carga toma a característica de "mãe" gerando então "Tag's" filhas com os novos dados.

Em função do exposto, a sugestão feita é de implantar a segunda Estação de gravação/leitura neste ponto, optando pela estrutura em forma de portal, pois em função do layout da empresa, também atenderá também a etapa seguinte, o tratamento das sementes, conforme ilustrada na Figura 65.

A simulação desta etapa do processo é feita de forma similar a descrita para a entrada dos produtos, ou seja, através da passagem pelo Pad 3M. A simulação é feita inicialmente com o reconhecimento da "Tag" que acompanha a carga, caracterizada como "mãe" e a gravação das "filhas" que representam o acompanhamento dos "Big Bag's", que após fechados são guardados em locais identificados nos armazéns 
$\mathrm{Na}$ sequência a próxima etapa do processo que gera novos dados é a torre de tratamento, (vista na Foto 6 da Figura 65), quando os “Big Bag's" são removidos dos armazéns e desmanchados para que as sementes recebam tratamentos químicos que evitem apodrecimento e ataque de pragas.

Ao término do tratamento as sementes devem ser ensacadas em pacotes comerciais de $20 \mathrm{~kg}$ ou $60 \mathrm{~kg}$ e fechadas por meio de costuras. Entende-se que neste ponto as novas "Tag's" devem ser fixadas fisicamente nas sacas e receberem inicialmente as informações contidas nos "Big Bag's" desmanchados. Neste ponto do processo as "Tag's" fixas nos "Bib Bag's" trocam de função e assumem o caráter de mãe, enquanto as fixas nas sacas tornam-se filhas, que recebem o complemento de informações referentes ao tratamento recebido pelas sementes, tais como: tipo de tratamento, número da saca, responsável pela operação, dentre outros já especificados.

Terminado o ensacamento e transferências dos dados os pacotes devem ser deslocam para o Armazém ou para Câmara Fria, até o momento de serem enviados aos clientes. No caso real, este bloco de novas informações será gravado pelo Portal RFID, que também foi utilizado para registro dos Produtos saídos da Torre de Classificação e condicionados nos "Big Bag's". Mais uma vez os dados devem ser inseridos no Sistema com o uso de um computador, que oferece diretamente na tela campos a serem preenchidos pelo operador. A operação de armazenamento das sacas é feita com o agrupamento de aproximadamente 80 unidades em "palets", que também é passível de fornecer dados para o processo.

Na simulação desta Etapa o Pad 3M fará também a vez do Portal RFID, primeiramente identificando o "Big Bag's" através de uma "Tag" mãe. Na seqüência utilizou-se outras três "Tag's" fixas em caixas simulando os pacotes comerciais de $60 \mathrm{~kg}$, que assumiram o papel de "filhas" e acrescidas dos dados referentes ao fechamento do pacote.

A quarta estação de leitura / gravação opera durante a expedição das sacas de sementes de milho (Foto 10 da Figura 65) pela esteira de carregamento de caminhões. Nesta etapa as sacas comerciais são retiradas do armazém ou da 
Câmara Fria, identificadas pela respectiva "Tag" e recebem a gravação de novos dados, tais como: transportador, cliente, data da saída etc. Esta conversação será feita utilizando-se de antenas fixas em pedestais laterais a esteira.

Novamente o Pad 3M foi usado para simular a realidade conforme é mostrado na Figura 65. A passagem da do pacote que simula uma saca de sementes, primeiramente permite o seu reconhecimento e em seguida faz a gravação de novos dados, que foram incorporados ao sistema mediante o preenchimento de uma tabela lida na tela de um computador.

A comprovação final de que o modelo proposto é factível também foi simulado usando o Pad 3M, criando, portanto uma situação equivalente ao recebimento das sacas de semente por um cliente. Este procedimento foi feito passando o pacote quer representa a saca de semente e vendo o relatório gerado em forma de tabela. Este relatório foi concebido com interface amigável ao usuário, permitindo que facilmente tenha a certeza da qualidade do produto.

$\mathrm{Na}$ prática esta etapa é feita no momento do recebimento das sacas de sementes pelo cliente, que deverá ter uma forma de leitura dos Tags. A evolução tecnológica permite que o usuário tenha diversas alternativas de acesso, dede leitores manuais, uso de antenas ou aparelhos celulares capacitados a esta atividade.

A Figura 66 representa de forma ilustrada como acontece a criação das "Tag's" Filhas, de forma que a informação possa ser distribuída e compartilhada entre todos os membros do "Supply Chain".

É importante lembrar que esta Tese propôs criar uma metodologia de Modelagem de um Processo de Supply Chain Informado para o Agronegócio utilizando-se para isto diversos conceitos que até então eram distintos. A dispersão de conceitos associada ao segmento escolhido para estudo certamente trazem pontos de CRITICIDADE, ou seja, pontos que estão sujeitos a falhas e consequentemente comprometerem o processo. No protótipo a criticidade está na transposição de dados de processo utilizando-se da intervenção e digitação de 
operadores. Certamente no nível de protótipo esta situação é aceitável, até porque, existirá a redundância com os procedimentos que são praticados na atualidade, tais como: utilização de código de barras e relatórios gerenciais. Sendo assim, em novas etapas de trabalho serão observados detalhamentos de integração com Processos de Automação, Processos de Controle e Sistemas de Informações Gerenciais.

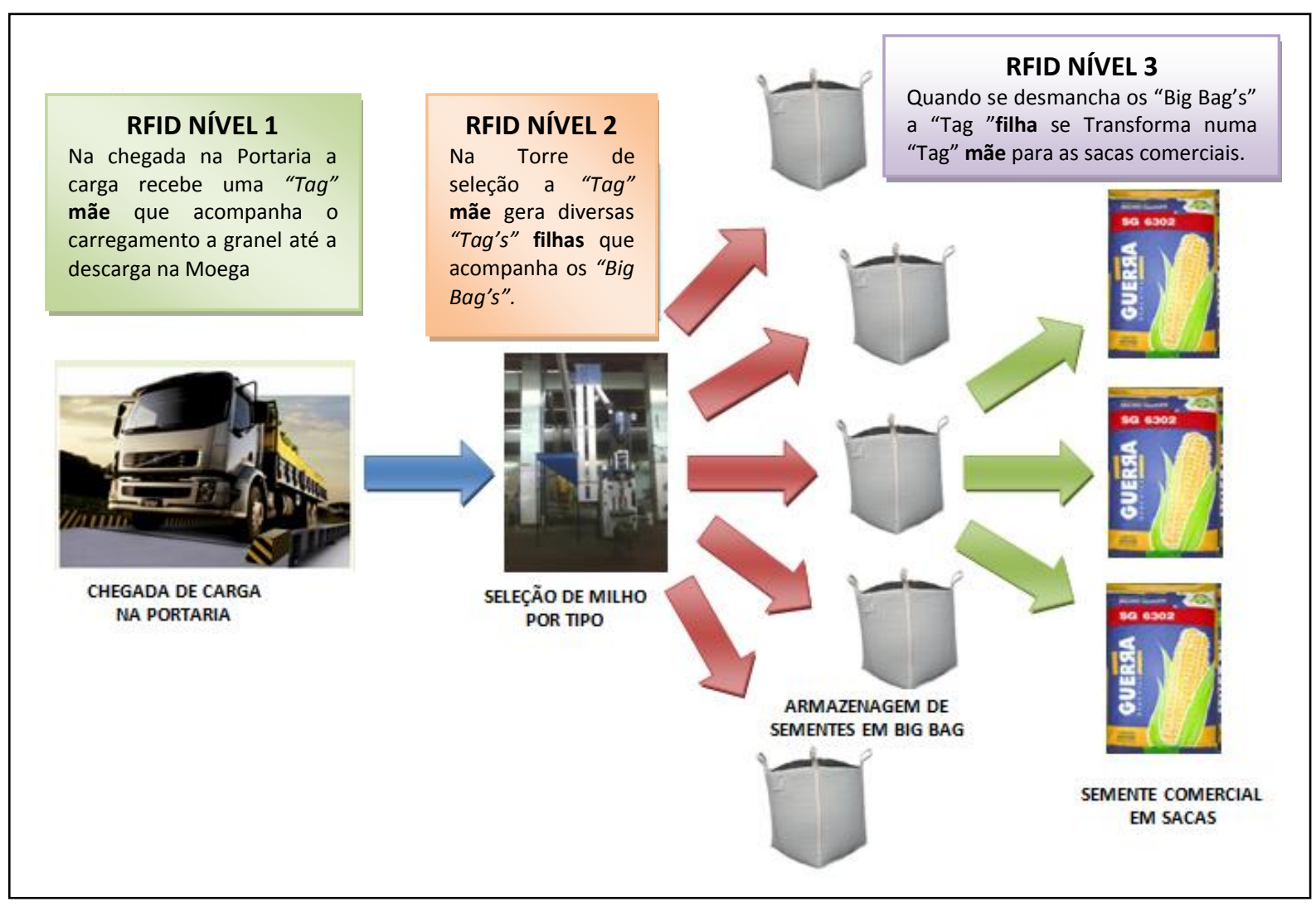

Figura 66 - Dinâmica de Troca de Informações

\section{4 - PERCEPÇÂO DE INVESTIMENTO:}

Esta tese não desenvolveu um estudo da viabilidade econômica da aplicação de um Sistema Informado para o Supply Chain do Agronegócio, uma vez que sua abordagem foi focada na concepção da Metodologia, porém é possível levantar a ordem de valor para um investimento nesta implantação. Na intenção de quantificar valores existem intangíveis, tais como: Garantia da qualidade na ponta, Certificação de Origem, Exigência de mercados especiais, etc., que precisam ser aprofundados rigorosamente. Mesmo assim, a Quadro 9 ilustra diversos custos, que permitem estimar o custo de instalação, sem considerar o custo com desenvolvimento e integração de sistemas. 


\begin{tabular}{|c|c|c|}
\hline EQUIPAMENTO & CARACTERÍSTICAS & FAIXA DE PREÇO \\
\hline \multirow[t]{5}{*}{ TAG RFID } & ETIQUETA ADESIVA HF LEITURA ATE $30 \mathrm{CM}$ & USȘ 0,50 a US\$̦ 1,50 \\
\hline & ETIQUETA ENCAPSULADA EM TECIDO PARA COSTURA HF LEITURA ATE $30 \mathrm{cM}$ & US\$\$ 0,50 a US\$ 1,50 \\
\hline & ETIQUETA ADESIVA UHF LEITURA ATE 5 METROS & US\$̦ 0,30 a US\$\$ 0,60 \\
\hline & ETIQUETA ENCAPSULADA EM TECIDO PARA COSTURA UHF LEITURA ATE $5 \mathrm{M}$ & US\$\$ 0,30 a US\$ 2,50 \\
\hline & TAGS RFID RIGIDOS HF OU UHF & US\$ 1,00 a US\$ 5,50 \\
\hline \multirow[t]{3}{*}{ ANTENAS RFID } & ANTENAS PARA LEITURA PARA LEITURA DE RFID HF ATE $30 \mathrm{CM}$ & USȘ 50,00 a USȘ 450,00 \\
\hline & ANTENAS PARA LEITURA PARA LEITURA DE RFID UHF ATE $5 \mathrm{M}$ & US\$ 195,00 a US\$ 800,00 \\
\hline & PORTAIS DE LEITURAS DE RFID UHF ATE 5M & US\$ $5.500,00$ a US\$\$ $12.000,00$ \\
\hline \multirow[t]{4}{*}{ LEITORES RFID } & LEITOR/GRAVADOR DE PROXIMIDADE/BANCADA HF COM ANTENA EMBUTIDA & US\$̦ 95,00 a US\$̦ 250,00 \\
\hline & LEITORE/GRAVADOR DE BANCADA PARA ANTENAS HF COM 2 SAIDAS & US\$\$ 120,00 a US\$ 350,00 \\
\hline & LEITORES/GRAVADOR DE BANCADA PARA ANTENAS UHF COM 1,2 OU 4 SAIDAS & US\$̦ $1.500,00$ a US\$\$ $4.500,00$ \\
\hline & IMPRESSORAS RFID HF OU UHF & US\$̦ 5.500,00 a US\$̦ $8.000,00$ \\
\hline \multirow[t]{2}{*}{ LEITORES MANUAIS } & LEITOR/GRAVADOR MANUAL DE RFID HF E CODIGO DE BARRAS & US\$\$ 250,00 a US\$̦ $1.500,00$ \\
\hline & LEITOR/GRAVADOR MANUAL DE RFID UHF E CODIGO DE BARRAS & USȘ 3.000,00 a US\$̦ 5.500,00 \\
\hline \multirow[t]{4}{*}{ INFRAESTRUTURA } & TERMINAIS / COMPUTADORES VEICULARES TOUCHSCREEN & US\$ $4.500,00$ a US\$̦ $10.000,00$ \\
\hline & SOFTWARE SDKS PARA LEITORES HF & US\$̦ 0,00 a US\$̦ $1.500,00$ \\
\hline & CABOS RF PARA ANTENAS RFID & US\$̦ 4,50 a US\$ 10,00 p/ Mt \\
\hline & MIDDLEWARES & US\$̦ 400,00 a US\$̦ 8.000,00 p/ CNPJ \\
\hline
\end{tabular}

Tabela 10 - Custo estimativo de equipamentos - Próprio

A instalação de um Protótipo conforme o desenvolvido neste trabalho demandaria os seguintes itens:

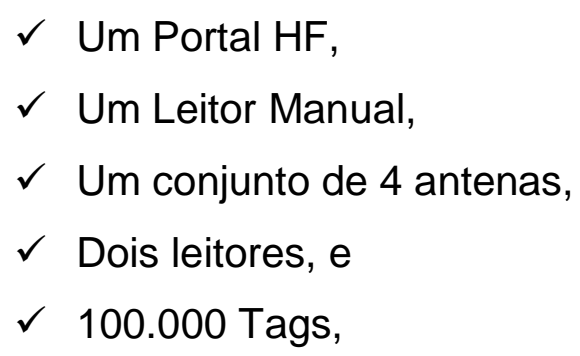

Agrupando os custos dos itens individuais chegou-se a um estimativo orientativo no montante de aproximadamente US\$80.000,00, que sem rigores de análise equivalem a $R \$ 200.000,00$

Supondo que em uma safra sejam comercializadas 100.000 sacas de sementes com "Tag's" RFID, a custo médio $R \$ 150,00$, serão gerados $R \$$ 15.000.000,00, em faturamento. De forma simples um investimento na ordem de $1,33 \%$ do faturamento anual pode viabilizar um diferencial competitivo perante a concorrência, tornando-se viável economicamente e comercialmente. 


\section{5 - RECOMENDAÇÕES:}

Uma parte da contribuição desta tese para àqueles que desejam prosseguir nos estudos de Modelos Informados no Supply Chain, com a utilização da Tecnologia RFID está descrita nas recomendações que são listadas abaixo:

\section{Difundir a cultura do RFID}

A tecnologia RFID, embora antiga, tem aplicações muito recentes e inovadoras no controle de Processos e vem sendo aplicada erroneamente como uma sucessora do Código de Barras. Desta forma, é importante que a empresa tenha um política de difusão da tecnologia entre seus colaboradores, fornecedores e clientes, demonstrando os impactos positivos sobre os seus resultados. Esta ação pode ser feita internamente com reuniões internas, divulgação em boletins e murais e pequenos cursos àqueles que terão uso direto desta nova tecnologia.

Por outro lado, a parceria com fornecedores é fundamental para que qualquer projeto que trate de Supply Chain tenha sucesso, desta forma, é preciso que sejam firmados acordos e contratos de colaboração e resultados. É importante, portanto, que a empresa, que está atuando com incentivadora do uso desta nova tecnologia, seja a fornecedora de dados, informações, regras e orientações para o fortalecimento conjunto.

Fechando a linha do Supply Chain o cliente deve estar diretamente envolvido nos processos de Inovação, sendo importante ouvi-lo em suas demandas para que a nova tecnologia possa contribuir diretamente no atendimento de suas expectativas. Sendo assim, cabe a empresa apresentar-lhe os novos rumos desenvolvidos e os ganhos que the serão oferecidos. Uma boa estratégia é a realização de eventos de divulgação, tais como encontros, feiras e reuniões de equipes técnicas.

\section{Capacitar colaboradores}

Antes da adoção de uma nova tecnologia é preciso formar um grupo de especialistas dentro da organização, com conhecimentos suficientes para poder operar equipamentos, realizar ajustes, fornecer assistência técnica para fornecedores e clientes, auxiliar na implantação do novo processo, etc.

Esta demanda exige que antes da implantação de um novo processo com nova tecnologia, exista um plano de capacitação de colaboradores, que vejam também nesta implantação uma possibilidade de crescimento profissional. 
Desta forma, é preciso que o departamento de recursos humanos da empresa desenvolva um programa da capacitação, com cursos, treinamentos, estágios e visitas a aplicações similares. Depois de que um grupo tenha domínio da tecnologia ai sim pode iniciar a sua implantação, pois é fundamental que conhecedores do dia a dia da empresa participem e descrevam quais as formas de trabalho que acontecem na planta, e como estas devem ser consideradas na implantação.

\section{$\checkmark \quad$ Estabelecer compromisso de parceria}

Imediatamente após a sensibilização de fornecedores da importância da nova tecnologia para o "Supply Chain" deve ser estabelecida a definição de papeis nos desenvolvimentos quais são os compromissos cada membro. De forma sequencial estabelecer um projeto conjunto que seja estratégico para consolidar o modelo de trabalho adotado.

Para fechamento dos compromissos de parcerias é necessário que a empresa estabeleça oficialmente os contratos entre os integrantes, deixando explícitos os direitos e deveres de cada.

\section{$\checkmark \quad$ Criar um vínculo de cooperação para o P\&D\&I}

A inovação em processos, produtos e serviços não ocorre de forma voluntária, as organizações precisam criar políticas de Pesquisa, Desenvolvimento e Inovação, de acordo com sua estrutura. Desta forma, a aplicação de um Processo Informado no Supply Chain do Agronegócio é estar na vanguarda no momento. Porém, a partir da publicidade do evento a aplicação será universalizada e a vanguarda diminuída. Sendo assim, uma vez criada uma posição diferenciada no mercado a organização deve buscar em Centros de Pesquisas, Universidades e até mesmo com fornecedores, criar um mecanismo de geração permanente de P\&D\&l.

\section{$\checkmark \quad$ Avaliar a legislação}

A própria característica de criar um novo processo com a inclusão de uma nova tecnologia, como esta proposto neste trabalho, remete a uma profunda análise dos aspectos legais envolvidos. Nesta situação, em paralelo ao desenvolvimento deverá se buscar informações sobre leis que cercam a aplicação, normas técnicas e inclusive a necessidade de novos regimentos. No caso específico do RFID aplicado ao Agronegócio de imediato a busca de informações, em fontes do Ministério da agricultura, ANVISA, ABNT, Ministério de Telecomunicações, é recomendado. 


\section{$\checkmark \quad$ Avaliação prévia de projeto}

O projeto elaborado deve ser minuciosamente avaliado. Além da estrutura técnica específica para o RFID, é preciso para observação de detalhes de instalação que podem comprometer o desempenho dos equipamentos. É fundamental verificar se existem coberturas metálicas, reservatórios de água, Antenas de telecomunicação, etc.

\section{$\checkmark \quad$ Integração de Sistemas}

Cada vez mais as organizações lançam mãos de sistemas de automação e controle que permitam gerenciar os processos de maneira a deixá-los mais rápidos, seguros, maleáveis, e facilitem as tomadas de decisão. A grande questão está em como integrar todos os sistemas existentes numa organização, permitindo que todos tirem proveitos dos dados gerados. Sendo assim, é recomendável que já durante a fase de iniciação de um Projeto com RFID, gerando um Sistema Informado se preveja a forma de integrá-los aos outros sistemas, precisando, portanto, estreito relacionamento com as empresas fornecedoras destes serviços. 


\section{6 - CONCLUSÕES E TRABALHOS FUTUROS:}

Uma das conclusões do presente trabalho é que existem inúmeras oportunidades de pesquisa e desenvolvimento de processos de automação para o Agronegócio envolvendo a tecnologia RFID e também processos informados. Portanto, esta proposta ratifica a hipótese levantada por TAVARES, BATALHA e SILVA (2000) e TAVARES E SILVA. (2007) de que um processo informado traz vantagens competitivas seja, aplicado a fabricação de "blanks", na fabricação de automóveis ou em um processo de inversão do controle de qualidade, do produto final para o processo de fabricação (ou ainda em um processo de alta granularidade, como seria a agricultura familiar se inserida no processo pela automação dos serviços).

No caso presente, uma hipótese similar foi aplicada a um processo produtivo baseado em serviços para o segmento do agronegócio, cujo design deve seguir a linha conceitual da Engenharia de Serviços lançada por Oliveira e Silva (2011).

O caráter inovador da proposta está em ter um processo baseado em serviços e ao mesmo tempo em processos informados, uma integração que leva a vários problemas no processo de design, que envolve "workflow management", "servisse design", além dos problemas inerentes à alocação de recursos e sequenciamento de processos. Este fato levou a um estudo mais detalhado da fase inicial de levantamento e análise de requisitos.

As razões para isso são simples: métodos baseados em serviço são fortemente dependentes da fase de requisitos (Oliveira e Silva, 2011), assim, não é razoável tentar uma abordagem formal dos dados de forma antecipada, uma vez que é amplamente conhecido que a fase inicial de projeto, notadamente a fase de eliciação e análise de requisitos não pode ser formalizada. Ainda assim, mantivemos o processo canônico (semi-formal) baseado em UML e na fase de análise de requisitos uma representação baseada em "Workflow" nets, que por sua vez são baseadas em Redes de Petri. Portanto antes de chegar a uma especificação, o método passa por uma antecipação da representação formal como esperado de qualquer proposta moderna em "Engineering Design.

Portanto restaria mostrar que este método poderia de fato ser aplicado na prática a um processo de grande importância e impacto econômico (além de poder 
ser aplicado com recursos de hardware e software disponíveis no mercado). Isto foi colocado no estudo de caso, onde o alvo foi o agronegócio, e em especial o beneficiamento de sementes. A cadeia da semente de milho só veio a comprovar que este campo é vasto e receptivo e que este trabalho trouxe contribuições para a ciência do gerenciamento de processos, tais como:

A utilização de softwares de Modelagem com uso liberado, que permite desenhar com exatidão processos de negócio, desmistificando sua complexidade operacional. Além da simplicidade de utilização estes softwares têm baixos custos, o que torna atraente um desenvolvimento com profundidade de detalhes, consequentemente minimizando falhas na implantação.

$\checkmark \quad$ O desenvolvimento de um software de uso específico para no Modelo Informado do "Supply Chain" da semente de Milho, feito na linguagem Java, que pode facilmente ser adequado a outras variedades do agronegócio como Soja, Trigo, Carne e Leite. (Anexo 1)

O desenvolvimento de um método (a a análise do seu contexto metodológico) para estruturar modelos Informados, que pode ser adotada para qualquer "Supply Chain" que incorpore a tecnologia RFID informado como estratégia competitiva,

$\checkmark \quad$ Disponibilizar um Modelo de Gerenciamento de projeto que pode ser incorporado a qualquer "Supply Chain" de "commodities" do agronegócio, no intuito de quebrar a fragilidade dos produtos brasileiros no mercado internacional, quando sujeitos a comprovação de qualidade e atendimento a regras fitossanitárias.

$\checkmark \quad$ Abrir a perspectiva de ter um Modelo de Gestão robusto para a Agricultura Familiar, que no Brasil representa mais de $80 \%$ das propriedades estruturados no modelo Informado do "Supply Chain" a atuarem em Cadeias Produtivas nobres, como a do vinho, ou até o milho, e oferecer certificação de origem (qualidade assegurada). Este foi um resultado suplementar do trabalho que não foi direcionado a este ramo de aplicação inicialmente.

$\checkmark$ Possibilitar o desenvolvimento de aplicações diferenciadas com tecnologias complementares como exemplo, monitoração e controle de 
temperatura de armazenamento e logística de distribuição, com um Modelo Informado para o "Supply Chain".

Demonstrar que o desenvolvimento de novos mercados para a Tecnologia RFID depende da ampliação da Memória do Usuário, que incentivem as empresas a investir em P\&D\&I.

A partir do Modelo Informado e da tecnologia "RFID" Criar a necessidade de novas proposições para adequação de legislações Federais, Estaduais e Municipais, que oportunizem o uso da tecnologia RFID, como diferencial competitivo dos produtos brasileiros no Mercado Internacional, sendo inclusive um indutor de exportações de novos produtos.

Vários dos tópicos mencionados acima foram resultados suplementares, isto é, não faziam parte de metodologia adotada inicialmente que era focada em ter um desenvolvimento inédito, mas prático e com fundamentação teórica em processos e métodos já existentes, para os processos informados com dados distribuídos entre "host items" e em bancos de dados, gerando artefatos automatizados para garantir a procedência e qualidade de produtos e insumos. A inserção de uma "prova de conceito" visava atribuir aplicabilidade e acabou por gerar alguns sub-produtos interessantes no estudo da área de aplicação: a agricultura de precisão.

O trabalho também mostrou que existem ainda vários pontos não explorados e alvo de novos estudos, para integrar o leque de conhecimento necessário para garantir eficiência a investimentos em sistemas informados em várias áreas e em especial no Agronegócio:

$\checkmark$ Desenvolvimento de um Modelo Informado que acompanhe a produção de grãos e sementes no campo, associando-o a Sistemas de Agricultura de Precisão.

$\checkmark$ Desenvolver um Sistema Informado de Pós-venda de sementes, que permita ter o acompanhamento do produto até 0 recebimento de cargas em pontos de exportação. 
$\checkmark$ Desenvolvimento de Sistemas Informados em Cadeias complexas do agronegócio que permitam o consumidor final, de produtos industrializados, acessar informações do Supply Chain do produto como a carne bovina, por exemplo.

$\checkmark$ Desenvolvimento de aplicativos especializados a equipamentos de telefonia móvel, que permitam acesso simplificado de dados armazenados em dispositivos RFID, de um Sistema Informado.

$\checkmark$ Apropriar o Modelo Informado com Tecnologia RFID a outras formas de Gerenciamento, que necessitem acompanhamentos sistemáticos, armazenamento de dados, certificação de processos, garantia de qualidade, como Sistemas de Manutenção com alta confiabilidade.

Portanto, perspectiva é a extensão do atual método para serviços mais dependentes de recursos e produtos (que é por exemplo o caso da manufatura), ou a transformação do atual sistema de informação resultante deste método em um sistema supervisório inteligente, abrindo a perspectiva de uso governamental em várias cadeias onde se pretenda ter uma avaliação de qualidade dos produtos (carne, vacinas, etc.). Outro tópico importante é a inclusão do tempo como parâmetro ou variável do modelo, dado que este é um dado importante para a agricultura de precisão. 


\section{REFERÊNCIAS}

ADANCOVA, P.; TOBES, Z; METRA BLANSCO, BLANSKO - UHF RFID Technology and Applications - Radioelektronika, $200717^{\text {th }}$ International Conference 24-25 abril $2007-$ pg 1 a 5 - E-ISBN: 1-4244-0822-9 - Digital Object Identifier: 10.1109/ RADIOELEK.2007.371705 - Disponível em: - http://ieeexplore.ieee.org/ xpl/mostRecentlssue.jsp?punumber=4234163 - Acesso em 10 mar 2011.

AALST, WIL M. P. van der - Business Process Management Demystified: A Tutorial on Models, Systems and Standards forWorkflow Management - Business Process Management Demystified - J. Desel, W. Reisig, and G. Rozenberg (Eds.): ACPN 2003, LNCS 3098, pp. 1-65, 2004._c Springer-Verlag Berlin Heidelberg 2004 - Disponível em: http://link.springer.com/chapter/10.1007\%2F978-3-540-27755-2_1?LI=true Acesso em 10.12.2012

AALST, WIL M.P van der e STAHL, CRISTIAN - Modeling business a petri net oriented approach - MIT 2011 - disponível em http://books.google.com.br/books?id=0-qXzSgow0C\&printsec=frontcover\&dq=modeling+business+process+a+petri+net+orientede+ approach\&hl=pt-BR\&sa=X\&ei=Zp8zUaS0Msbw0QGe1oCgBA\&ved=0CD4Q6AEwAA\#v= onepage\&q=modeling\%20business $\% 20$ process $\% 20 a \% 20$ petri\%20net\%20orientede\%20app roach\&f=false - Acesso em 10.01.2013

AALST, WIL M. P. van der e HEE, KEES VAN - Workflow management - Models, Methods and Systems 2002 - ISBN 0-262-01189-1 - Disponível em http://books.google.com.br/books?id=O1xW1_Za-I0C\&printsec=frontcover\&dq=workflow+ management+models, + methods+and+systems\&hl=pt-BR\&sa $=X \& e i=2 a A z U f i B O Y b h 0 w G d j 4$ CwBQ\&ved=0CDUQ6AEwAA - Acesso em 12.01.2013

ARAUJO, GERALDINO CARNEIRO DE; BARBAIS, JOVENA RUFINO; SILVA, ROBERTO PEREIRA DA - Satisfação dos Clientes dos Agronegócios - Econ. Pesqui .. Araçatuba, $v, 6 . \quad n, 6, \quad p, \quad 123$ 142, mar. 2004 - Disponível em http://www.feata.edu.br/downloads/revistas/economiaepesquisa/v6_artigo07_satisfacao.pdf Acesso em 30 julho 2012.

ASSIS, LIVIO SILVA DE; RODRIGUES, JURANDIR V. - Modelagem orientada a objetos de um Sistema de Vendas de um empresa de representações comerciais - Monografia (Especialista em Informática Industrial) - Faculdade de Engenharia - Universidade Estadual Paulista Campus de Guaratinguetá - 2003

ASSUMPÇAO, MARIA RITA PONTES - Reflexão para Gestão Tecnológica em Cadeia de Suprimentos - GESTÃO \& PRODUÇÃO, v.10, n.3, p.345-361, dez. 2003. Disponível em: http://www.scielo.br/scielo.php?pid=S0104-530X2003000300009\& script=sci_arttext Acesso em 10 nov 2011.

BLECKER, THORSTEN e HUANG, GERGE Q. - RFID in Operations and Supply Chain Management - Research and Appications - Berlin - Erich Schmidt GmbH \& Co - 2008 ISSN 1863 - 3390 - ISBN 9783503100880 - Disponível em http://www.traserproject.eu/documents/Book_sample.pdf - Acesso em 30 julho 2012

CAIRES, J.C. - Vendendo para o Agronegócio. Agronline.com.br. Disponível em: <http://www.agronline.com.br/artigos/artigo.php?id=311 >. Acesso em: 30 de janeiro de 2012. 
CANDIDO, ROBERTO - Escritório de Gerenciamento de Projeto (PMO) como Estratégia de Customização de Soluções na Indústria Eletroeletrônica - Dissertação de Mestrado - Escola Politécnica da Universidade de São Paulo - Departamento de Engenharia Naval e Oceânica - 2007 - São Paulo

CONTINI, E. - Dinamismo do agronegócio brasileiro. Agronline.com.br. Disponível em: <http://www.agronline.com.br/artigos/artigo.php?id=22>. Acesso em: 30 de janeiro de 2012.

DOLGUI, ALEXANDRE e PROTH, JEAN-MARIE - RFID Technology in Supply Chain Management: State of the art and perspectives - World Congress The International Federation of Automatic Control Seoul, Korea, July 6-11, 2008 - Disponível em: http://www.nt.ntnu.no/users/skoge/prost/proceedings/fac2008 /data/papers/1399.pdf Acesso em 20 dez 2011.

ENTERPRISE ARCHITECT MODELING TOLL VERSION 9.2 - Sparx Systems Pty Ltda www.spartxsystems.com - Acesso em 20 julho 2012.

EPC GLOBAL U.S - Benefits of RFID-Enabled Supply Chain - RFID4u The Global hub for RFID Training - Disponível em http://www.rfid4u.com/ downloads/Benefits\%20of\%20RFID-Enabled\%20Supply\%20Chain.pdf - Acesso em 20 de nov 2011

FELÍCIO, PEDRO EDUARDO DE - Rastreabilidade Aplicada a Carne Bovina - In: MATTOS, W.R.S. et al. (Ed.). A produção animal na visão dos brasileiros. Piracicaba: FEALQ, 2001. p.294-301.

FIGUEIREDO, KLEBER e ARKADER, REBECCA - Da Distribuição Física ao Supply Chain Management: $O$ Pensamento, $O$ Ensino e as Necessidades de Capacitação em Logística - Revista Tecnologísitica - 1988 - Disponível em: http://scholar.google.com.br/scholar?hl=en\&q=DA+DISTRIBUl\%C3\%87\%C3\%83O+F\%C3\% 8DSICA+AO+SUPPLY+CHAIN+MANAGEMENT\%3A+O+PENSAMENTO $\% 2 \mathrm{C}+\mathrm{O}+\mathrm{ENSINO}+$ $\mathrm{E}+\mathrm{AS}+\mathrm{NECESSIDADES}+\mathrm{DE}+\mathrm{CAPACITA} \% \mathrm{C3} \% 87 \% \mathrm{C} 3 \% 83 \mathrm{O}+\mathrm{EM}+\mathrm{LOG} \% \mathrm{C} 3 \% 8 \mathrm{DSTICA} \& \mathrm{~b}$ tn $\mathrm{G}=\&$ as_sdt $=1 \% 2 \mathrm{C} 5 \&$ as_sdtp $=-$ Acesso em 18 nov 2012

GASQUES, JOSE GARCIA; REZENDE, GERVÁSIO CASTRO DE; VERDE, CARLOS MONTEIRO VILLA; SALERNO, MARIO SERGIO; CONCEIÇAO, JÚNIA CRISTINA P.R. DA; CARVALHO, JOÃO CARLOS DE SOUZA - Desempenho e Crescimento do Agronegócio no Brasil - Instituto de Pesquisa Econômica Aplicada - Ipea 2004 Texto para discussão No 1009 - ISSN 1415-4765 - Disponível em: www.ipea.gov.br Acesso em 08.12.2011.

GIL, ANTONIO CARLOS - Como elaborar projetos de pesquisa - 4 ed - São Paulo: Atlas, 2002 - ISBN 85-224-3169-8.

GLOVER, BILL e BHATT HIMANSHU - Fundamentos de RFID - Rio de Janeiro - Alta books 2007.

GODOI, RUBENS ERIC ZANOLELLO GODOI - Produção de Sementes de Milho Hibrido - Revista SEED NEWS - set/out 2008 - ano XII b.5 - Disponível em: http://www.seednews.inf.br/portugues/seed125/artigocapa125.shtml - Acesso em 03.04.2012. 
GOMES, CARLOS FRANCISCO SIMÒES - Gestão da Cadeia de Suprimentos integrada a Tecnologia da Informação - São Paulo - Pioneira Thopson Learning - 2004 - Disponível em http://books.google.com.br - Acesso em 30 agosto 2012.

GUANZIROLI, CARLOS ENRIQUE - Agronegócio no Brasil: perspectivas e limitações Universidade Federal Fluminense - textos para discussão - UFF/ECONOMIA - TD 186 Abril/2006 - Disponível em: www.uff.br/econ/download/tds/UFF_TD186.pdf - Acesso em 12 jan 2011.

GUILHOTO, JOAQUIM J. M; SILVEIRA, FERNANDO G.; ICHIHARA, SILVIO M. AZZONI, CARLOS R. - A importância do agronegócio familiar no Brasil - RER, Rio de Janeiro, vol. 44, no 03, p. 355-382, jul/set 2006 - Impressa em setembro 2006 -

HAKIMI,DRISS; MONTREUIL, BENOIT e RUIZ, ANGEL - Impacts of RFID Deployment on Real Time Management of Retail Stores - Proceedings of the 17th World Congress The International Federation of Automatic Control Seoul, Korea, July 6-11, 2008 - Disponível em: http://www.nt.ntnu.no/users/skoge/prost/proceedings/ ifac2008/data/papers/3641.pdf - Acesso em 12 nov 2010

HESSEL , FERNANDO et all - Implantando RFID na cadeia de negócios: tecnologia a Serviço da Exelencia / org. Fabiano et all - Porto Alegree: EDIPUCRS, 2009 - ISBN 978-85-7430-897-5

HOLWEG, MATTHIAS; HOLMSTROM, JAN; SMAROS JOHANNA - Supply Chain Collaboration: Making Sense of the Strategy Continuum - International Journal of Logistics Management, $\mathrm{O}$ Vol,. 16 Iss: 2, pp.237 - 256 Disponível em: http://www.sciencedirect.com/science/article/pii/S026323730500023X - Acesso em 18 dez 2011.

IGLÉCIAS, WAGNER - O Empresário do Agronegócio no Brasil Ação Coletiva e Formas de Atuação Política- As Batalhas do Açucar e do Algodão na OMC - Rev. Sociologia Política, Curitiba, 28, p. 75-97, jun. 2007 - Disponível em http://www.scielo.br/pdf/rsocp/n28/a06n28.pdf. Acesso em 24 março 2012.

KÄRKKÄIENN, MIKKO - Increasing Efficience in the Supply Chain for short shelf life goods using RFID tagging - International Journal of Retali \& Distribution Management Disponível em http://www.emeraldinsight.com/journals.htm? articleid=857441\&show=abstract - Acesso em 20 dez 2011

FIGUEIREDO, Kleber e ARKADER, Rebecca. Da Distribuição Física ao Supply Chain Management: o Pensamento, o Ensino e as Necessidades de Capitação em Logística. Revista Tecnologística. Ano IV - no 33. www.cel.coppead.ufrj.br/fr-capac.htm. Agosto/88.

LEE, DONGMYUNG e PARK, JINWCO - RFID based Traceabilitty in the supply chain Industrial Management e Data systems p 713 -725 - Vol 108 n. 62008 - Disponível www emeraaldingsight.com/0263-5577 - Acesso em 10.10.2011.

LARA, JORGE ANTONIO FERREIRA DE; SOARES, ADRIANA LOURENÇO Rastreabilidade da carne bovina: uma exigencia para a segurança alimentar Seminário de Ciências Agrárias, Londrina v.24, n.1, p. 143-148, jan jun. 2003 
LI, SUHONG; GODON, DANIELLE e VISICH, JOHN K. - An exploratory study of RFID implementation in the supply chain - Management Research Review Vol. 33 No. 10, 2010 pp. 1005-1015 \# Emerald Group Publishing Limited 2040-8269 DOI 10.1108/01409171011084003; Disponível em http://www.emeraldinsight.com/ journals.htm?articleid=1885773\&show=abstract - Acesso em 03 de nov 2011

LI, YINGJIU e DING, XUHUA - Protecting RFID Communications in Supply Chains World Congress The International Federation of Automatic Control Seoul, 234 - 241 - Korea, July, 2008 - Disponível em: http://dl.acm.org/citation.cfm?id=1229318 - Acesso em 12 out 2011

LU, WEISHENGE; HUANG, GEORGE Q. e LI, HENG - Scenarios for applying RFID technology in construction project management - Automation in Construction 20 (2011) 101-106 - Disponível http://www.sciencedirect.com/ science/article/pii/S0926580510001366 - Acesso em 05.dez.2011.

LUDKE, Menga; ANDRE, Marli E. D. A - Pesquisa em Educação: Abordagens Qualitativas - São Paulo: E.P.U. 1986. ISBN 88512030703.

MARTIN, THOMAS NEWTON; TOMAZELLA, ANDRE LUIS; CICERO, SILVIO MOURE; NETO, DURVAL DOURADO; FAVARIN, JOSÉ LAÉRCIO; JUNIOR, PEDRO ABEL VIEIRA. - Questões Relevantes na Produção de sementes de milho - Primeira Parte. Revista da FZVA. Uruguaiana, v.14, n.1, p. 119-138. 2007 - Disponível em: http://revistaseletronicas.pucrs.br/ojs/index.php/fzva/article /viewFile/2483/1942 - Acesso em 10 out 2011.

MIGUEL, PAULO AUGUSTO CALICHICK - Estudo de Caso na Engenharia da produção: Estruturação e Recomendações para sua condução - Revista Produção ISSN 0102 6513 - v.17, n.1, p. 226-219 , janeiro abril 2007 -acesso em 14.08.2007 no endereço http://www.scielo.com.br/pdf/v17n1/14pdf.

MOREIRA, HERIVELTO - Metodologia da pesquisa para o professor pesquisado / Herivelto Moreira, Luiz Gonzaga Caleffe - Rio de Janeiro:- DP\&A 2006 - ISBN 85-740-3108.

NETO, FRANCISCO FERRAES; JUNIOR, MAURICIO KUEHNE - Logística Empresarial.COLEÇÃO GESTAO EMPRESARIAL - 2008 Disponível em: http://www.ebah.com.br/logistica empresarial-pdf-a5197.html ou http://www.pb.utfpr. edu.br/daysebatistus/Texto_1.PDF - Acesso em 01 de jun. 2011.

NETO, RENATA VALESKA DO NASCIMENTO; OLIVEIRA, JOSE RICARDO ABREU DE e GHINATO, PAULO - Supply Chain Management Aplicação e Ferramentas - XXII Encontro Nacional de Engenharia de Produção Curitiba - PR, 23 a 25 de outubro de 2002 Disponível em http://www.abepro.org.br/biblioteca/ENEGEP2002_TR11_0851.pdf - Acesso em 16 nov 2011

PORTAL BRASILEIRO DO SUPPLY CHAAIN - Supply Chain Online Perguntas Frequentes - Disponível em: http://www.supplychainonline.com.br/modules.php? name=FAQ\&myfaq=yes\&id_cat=1\&categories=Introdu\%E7\%E30+ao+Supply+Chain+Manag ement - Acesso em 10 nov 2011

QUEIROZ, I. A. e CRUZ, M. M. C. - Estado da Arte Sobre Supply Chain Management. In: XIX ENCONTRO NACIONAL DE ENGENHARIA DE PRODUÇÃO, 1999, Rio de Janeiro. 
Anais...Rio de Janeiro: Universidade Federal do Rio de Janeiro, 1999. Disponível em: http://www.abepro.org.br/biblioteca/ENEGEP1999_A0416.PDF - Acesso em 01 dez 2012.

REI, JOSE - RFID versus Código de barras da Produção a Grande Distribuição Disserta de Mestrado em Engenharia Eletrotécnica e de Computadores - Junho 2010 Faculdade de Engenharia da Universidade do Porto - Disponível em www.páginas.fe.up.pt Acesso 03.11.2012

SABBAGHI, ASGHAR e VAIDYANATHAN, GANESCH - Effectiveness and efficiency of RFID technology in Supply Chain Management: Strategic values and Challenges Journal of Theoretical and Applied Electronic Commerce Research ISSN 0718-1876 Electronic Version VOL 3 / ISSUE 2 / AUGUST 2008 / 71-81 @ 2008 Universidad de Talca - Chile - Disponível em: http://www.scielo.cl/scielo.php ?script=sci_arttext\&pid=S071818762008000100007\&lng=en\&nrm=iso\&ignore=.html - Acesso em 3 de nov 2001.

SALM JUNIOR, JOSÉ FRANCISCO - Extensão da UML para descrever processos de Negócio - Dissertação (Mestre em Engenharia de Produção) - Departamento de Eng. de Produção e Sistemas - Universidade Federal de Santa Catarina - Florianópolis 2003.

SILVA, JOSÉ EDUARDO FERREIRA DA SILVA - Qualidade Total no Agronegócio. Agronline.com.br. Disponível em: <http://www.agronline.com.br /artigos/artigo.php?id=183>. Acesso em: 30 de janeiro de 2012

SMITH, ALLAN D. - Exploring radio frequency identification technology and its impact on business systems - Year: 2005 Volume: 13 Issue:1Page:16 - 28 ISSN:0968-5227 DOI: 10.1108/09685220510582647.- Disponível em http://assets.leeds2.emeraldinsight.com/Insight/viewContentltem.do?contentType=Article\&hd Action=Inkhtml\&contentld=1463654\&dType=SUB\&history=false - Acesso em 13 jun 2011

SOON, CHIN-BOO; GUTIÉRREZ JAIRO A. - Effects of the RFID Mandate on Supply Chain Management - Journal of Theoretical and Applied Electronic Commerce Research ISSN 0718-1876 Electronic Version VOL 3 / ISSUE 1 / APRIL 2008 / 81-91 (C 2008 Universidad de Talca - Chile - Disponível em: http://dl.acm.org/ citation.cfm? $\mathrm{id}=1365656.1365665$ - Acesso em 15.07.2011

SPOHRER, JIN; MAGLIO P. PAUL; BAILEY, JOHN; GRUH, DANIEL - Steps Toward a Science of Service Systems - Authorized licensed use limited to: UNIVERSIDADE DE SAO PAULO. Downloaded on June 25, 2009 at 10:01 from IEEE Xplore. Restrictions apply Acesso em 29.06.2012.

SPOHRER, JIN; VARGO, STEPHEN L.; CASWELL, NATHAN; MAGLIO, PAUL P.- The Service System is the Basic Abstraction of Service Science - Proceedings of the 41st Hawaii International Conference on System Sciences - 2008 - Disponível em: http://ieeexplore.ieee.org/xpl/login.jsp?tp=\&arnumber=4438807\&url=http\%3A\%2F\%2Fieeexp lore.ieee.org\%2Fxpls\%2Fabs_all.jsp\%3Farnumber\%3D4438807 - Acesso em 19.06.2012.

TAVARES, J.J.P.Z.S., BATALHA, G.F., SILVA, J.R. - Formalization of the Information System of Material Management for a Case Study: Tailored Welded Blank Manufacturing $-8^{\text {th }}$ Int. Conference in Metal Forming, Krakovia, 2000.

TAVARES, J.J.P.Z.S e SILVA, J.R - Improving Auto id Value Generation with Informed Process based on Petri nets $19^{\text {th }}$ Int Conference of Production Research- Chile 2007. 
YAWL4 STYDY 2.3 - YAWL - User Manual - 2004-2012 The YAWL Foundation Disponivel em http://www.yawlfoundation.org/ - Acesso em 15.07.2012

VARGO e AKAKA. - Service-Dominant Logic as a Foundation for Service Science: Clarifications - Service Science 1(1), pp. 32-41, $\square 2009$ SSG - Disponível em: http://servsci.journal.informs.org/content/1/1/32.short - Acesso em 25.07.2012.

VICENTE, LEONARDO SILVA SCIAMMARELLO - Modelagem de Processo e linguagem de Modelagem Unvicada: Uma Análise Crítica - Dissertação (Mestre em Engenharia) COPPE - Universidade Federal do Rio de Janeiro - Rio de Janeiro 2004.

VINISCH, JOHN K.; LI, SUHONG; KHUMAWALA, BASHEER; REYES, PEDRO M. Empirical evidence of RFID impacts on supply chain performance - International Journal of Operations \& Production Management Vol. 29 No. 12, 2009 pp. 1290-1315 - Disponível em: http://www.emeraldinsight.com/journals.htm?articleid=1826846\&show =abstract Acesso em 04 jan 2012

WANG, LUNG-CHUANG; LIN, YU-CHENG; LIN, PAO H. - Dynamic mobile RFID-based supply chain control and management system in construction - ADVANCED ENGINEERING INFORMATICS 21 (2007) 377-390 - Received 4 September 2006; accepted 6 September 2006; Disponível em http://www.sciencedirect.com/science/article/pii/S1474034606000528 - Acesso em 02 de nov. 2011.

WLMC Work Management Coalition - The workflow reference Model - Document Number TC00-1003 - by David Hollingsworh - Disponível em www.wfmc.org/index.php?option=com_docman\&itemid=73 - Adicionado em 19/01/1995 e mododificada em 16/04/2009 - Acesso em 28/11/2012.

ZHU, XIAOWEI; MUKHOPADHYAY, SAMAR K. e KURATA, HISASHI - A review of RFID technology and its managerial applications in different industries - Eng. Technol. Manage. 29 (2012) 152-167 - Disponível em: http://www.sciencedirect.com /science/article/pii/S092347481100049X - Acesso em 12.dez.2011 
ANEXO 1

FONTES DO PROGRAMA DESENVOLVIDO PARA O ESTUDO DE CASO 


\section{Módulo Granel}

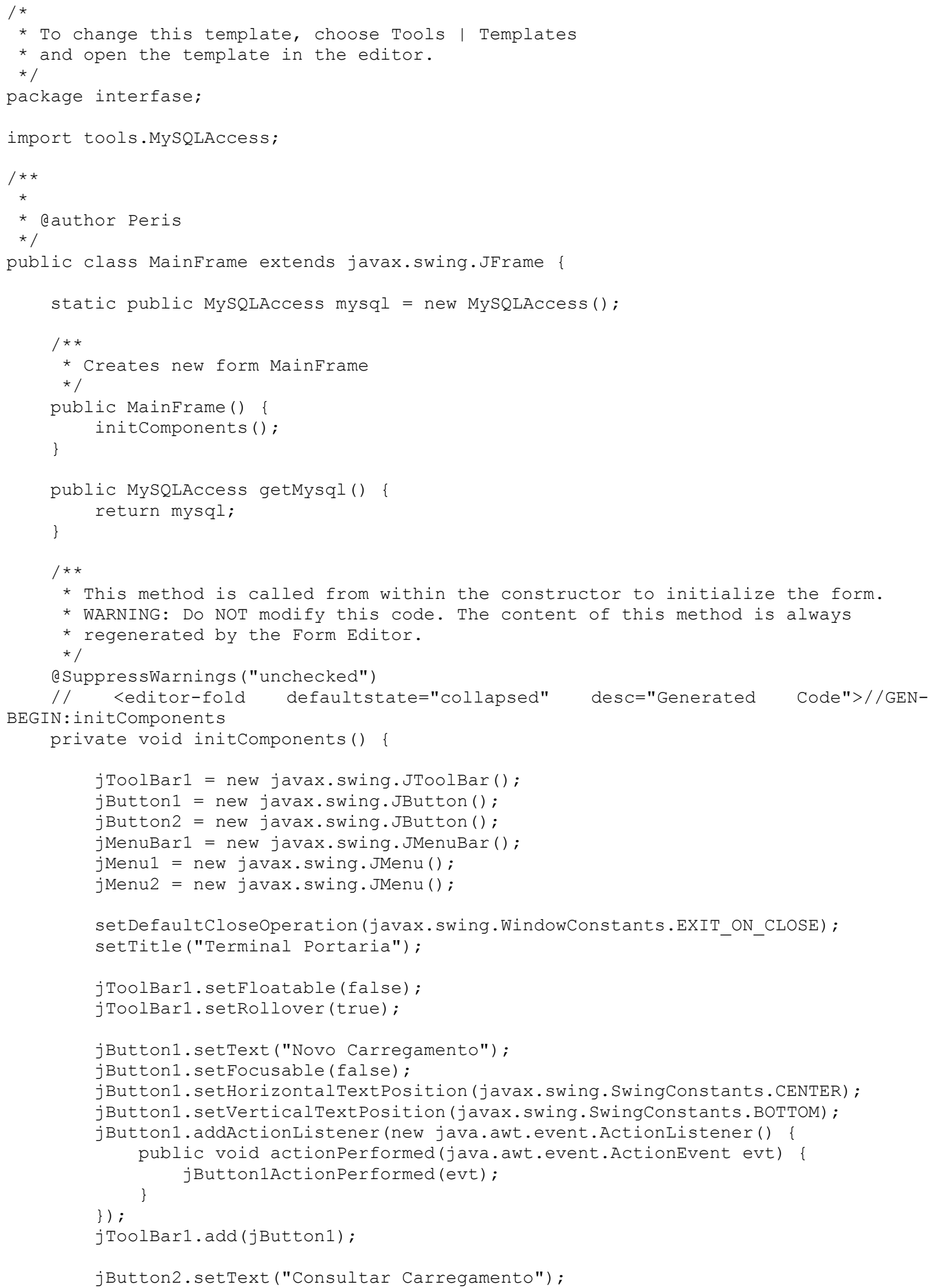


jButton2. setFocusable (false);

jButton2. setHorizontalTextPosition (javax. swing. SwingConstants.CENTER);

jButton2. setVerticalTextPosition (javax.swing. SwingConstants.BOTTOM);

jButton2.addActionListener(new java.awt.event. ActionListener() \{ public void actionPerformed(java.awt.event. ActionEvent evt) \{ jButton2ActionPerformed (evt);

\});

jToolBar1.add (jButton2);

jMenul.setText ("File");

jMenuBar1.add (jMenu1);

jMenu2.setText ("Edit");

jMenuBar1.add (jMenu2);

setJMenuBar (jMenuBar1);

javax.swing.GroupLayout

layout

new

javax.swing. Grouplayout (getContentPane ());

getContentPane(). setLayout (layout);

layout.setHorizontalGroup (

layout.createParallelGroup (javax.swing. GroupLayout. Alignment. LEADING)

Short.MAX_VALUE)

addComponent (jToolBar1, javax.swing.GroupLayout.DEFAULT SIZE,

) ;

layout.setVerticalGroup (

layout.createParallelGroup (javax.swing.GroupLayout. Alignment. LEADING)

. addGroup (layout.createSequentialGroup () . addComponent (jToolBarl,

25, javax.swing.GroupLayout.PREFERRED_SIZE)

javax.swing.GroupLayout.PREFERRED_SIZE,

)

$\operatorname{pack}()$;

\}// </editor-fold>//GEN-END:initComponents

private void jButtonlActionPerformed(java.awt.event.ActionEvent evt) \{//GENFIRST:event jButton1ActionPerformed

NovoCarregamentoDialog

novoCarregmentoDialog

new

NovoCarregamentoDialog (this, true);

novoCarregmentoDialog.setLocationRelativeTo (this);

novoCarregmentoDialog.setVisible (true);

\}//GEN-LAST:event_jButton1ActionPerformed

private void jButton2ActionPerformed(java.awt.event. ActionEvent evt) \{//GENFIRST:event_jButton2ActionPerformed

RelätorioCarregamentoDialog relatorioCarregamentoDialog = new

RelatorioCarregamentoDialog(this, true);

relatorioCarregamentoDialog.setLocationRelativeTo(this)

relatorioCarregamentoDialog.setVisible(true);

\}//GEN-LAST:event_jButton2ActionPerformed

$1 * *$

* eparam args the command line arguments

* 1

public static void main(String args[]) (

/* Set the Nimbus look and feel */

//<editor-fold defaultstate="collapsed" desc=" Look and feel setting code (optional) ">

/* If Nimbus (introduced in Java $\mathrm{SE}$ 6) is not available, stay with the default look and feel.

* For

details

see

http://download.oracle.com/javase/tutorial/uiswing/lookandfeel/plaf.html

* /

$\operatorname{try}\{$ 
if ("Nimbus".equals (info.getName()) ) \{

javax.swing. UIManager.setLookAndFeel (info.getClassName ()) ; break;

\}

\}

\} catch (ClassNotFoundException ex) \{

java.util.logging. Logger.getLogger (MainFrame.class.getName ()). log (java.util.logging .Level.SEVERE, null, ex);

\} catch (InstantiationException ex) \{

java.util.logging.Logger.getLogger (MainFrame.class.getName()). log (java.util.logging .Level.SEVERE, null, ex);

\} catch (IllegalAccessException ex) \{

java.util.logging. Logger.getLogger (MainFrame.class.getName ()) .log (java.util.logging .Level.SEVERE, null, ex);

\} catch (javax.swing. UnsupportedLookAndFeelException ex) \{

java.util.logging. Logger.getLogger (MainFrame.class.getName ()).log (java.util.logging .Level.SEVERE, null, ex);

\}

$/ /</$ editor-fold $>$

/* Create and display the form */

java.awt.EventQueue.invokeLater(new Runnable() \{ public void run() \{ new Mainframe().setVisible(true); \}

\});

\}

// Variables declaration - do not modify//GEN-BEGIN:variables

private javax.swing.JButton jButton1;

private javax.swing.JButton jButton2;

private javax.swing. JMenu jMenu1;

private javax.swing. JMenu jMenu2;

private javax.swing. JMenuBar jMenuBar1;

private javax.swing. JToolBar jToolBarl;

// End of variables declaration//GEN-END:variables

\}

1

* To change this template, choose Tools I Templates

* and open the template in the editor.

$\star /$

package interfase;

import java.text.ParseException;

import java.util.logging.Level;

import java.util.logging.Logger;

import javax.swing. JFormattedTextField;

import javax.swing. JoptionPane;

import javax.swing.text. DefaultFormatterFactory;

import javax.swing.text.MaskFormatter;

import org.joda.time.LocalDate;

import tools.Utilities;

$1 * *$

* Qauthor Peris

* 1

public class NovoCarregamentoDialog extends javax.swing.JDialog \{

$$
/ * *
$$




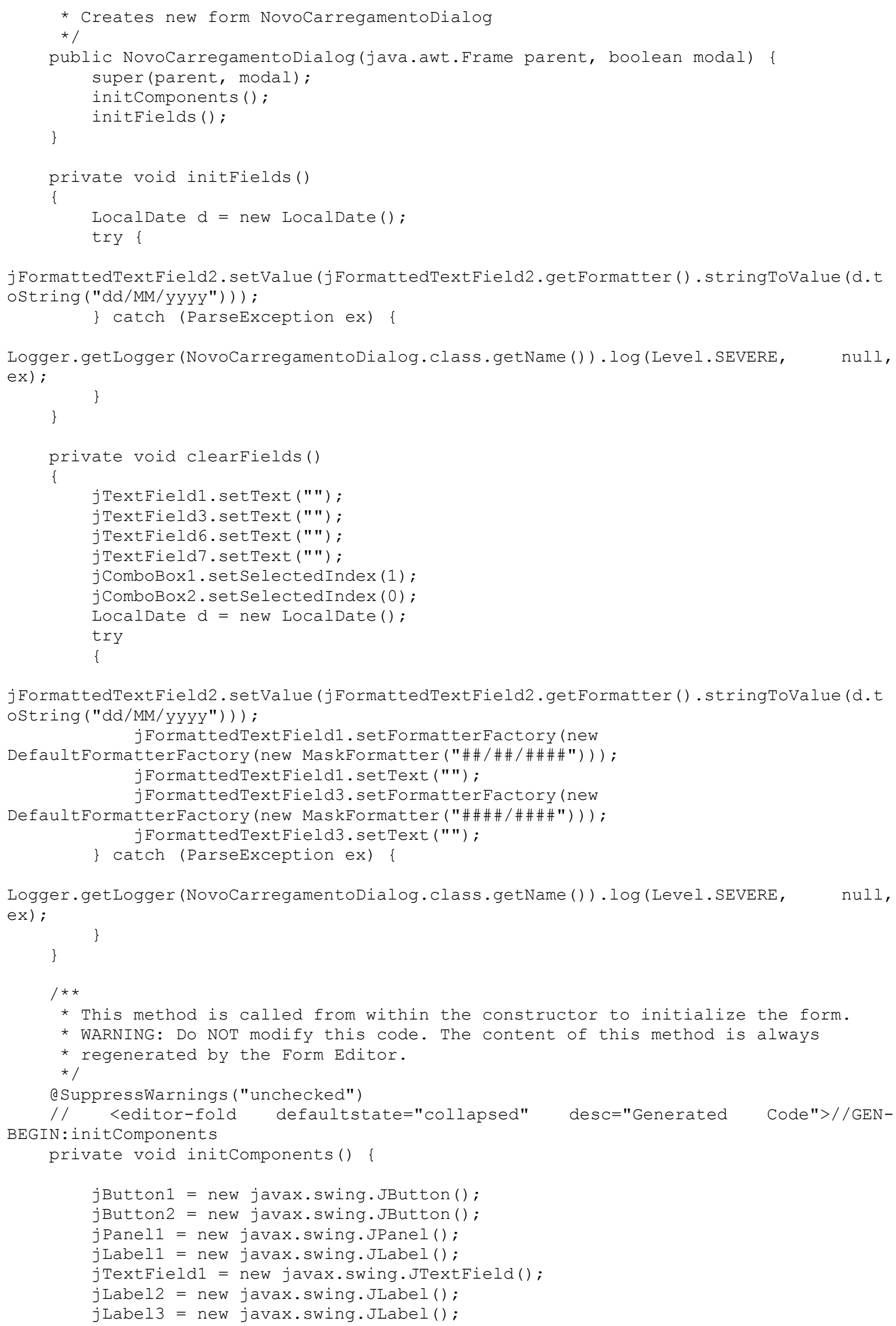




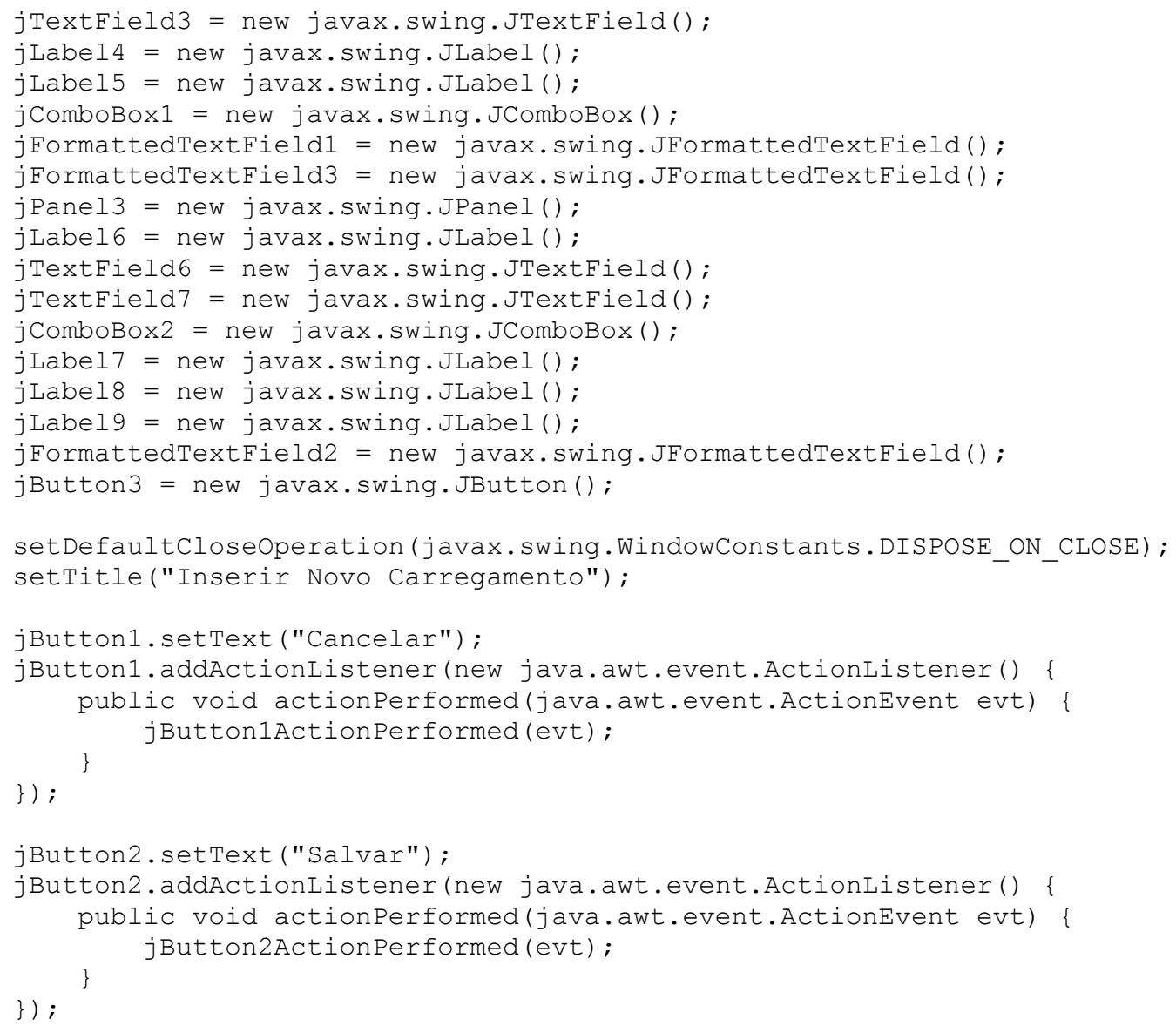

jPanel1.setBorder (javax.swing.BorderFactory.createTitledBorder (null, "Informa ̃̃̊̃ues de Campo", javax.swing.border.TitledBorder.DEFAULT_JUSTIFICATION, javax.swing.border.TitledBorder.DEFAULT POSITION, new java.awt.Font("Arial", 1, 12)) ); // NOI18N

jLabel1. setText ("Produtor:");

jTextFieldl.setHorizontalAlignment (javax.swing.JTextField.RIGHT);

jLabel2.setText ("Safra:");

jLabel3. setText("Variedade da Semente:");

jTextField3. setHorizontalAlignment (javax.swing.JTextField.RIGHT);

jLabel4.setText ("Vistoria:");

jLabel5. setText ("Data da Colheita:");

jComboBoxl.setModel (new javax.swing. DefaultComboBoxModel (new String[] "Reprovado", "Aprovado" \})) ;

jComboBoxl.setSelectedIndex (1);

try \{

jFormattedTextField1. setFormatterFactory (new

javax.swing.text. DefaultFormatterFactory (new

javax.swing.text.MaskFormatter("\#\#/\#\#/\#\#\#\#")));

\} catch (java.text.ParseException ex) \{ ex.printStackTrace ();

jFormattedTextField1.setHorizontalAlignment (javax.swing.JTextField.RIGHT); 
try

jFormattedTextField3. setFormatterFactory (new

javax.swing.text.DefaultFormatterFactory (new

javax.swing.text.MaskFormatter("\#\#\#\#/\#\#\#\#")));

\} catch (java.text.ParseException ex) \{ ex.printStackTrace();

jFormattedTextField3. setHorizontalAlignment (javax.swing.JTextField.RIGHT);

javax.swing.Grouplayout

jPanel1Layout

new

javax.swing.GroupLayout (jPanel1);

jPanel1. setLayout (jPanel1Layout)

jPanellLayout. setHorizontalGroup(

jPanellLayout.createParallelGroup (javax.swing.GroupLayout.Alignment.LEADING)

. addGroup (jPanel1 Layout. createSequentialGroup ()

. addContainerGap ()

.addGroup (jPanellLayout.createParallelGroup (javax.swing.GroupLayout.Alignment. LEADI NG)

. addGroup (jPanell Layout. createsequentialGroup ()

.addGap (0, 0, Short.MAX VALUE)

.addGroup (jPanellLayout.createParallelGroup (javax.swing.GroupLayout. Alignment. LEADI NG)

$$
\text { . addComponent ( jLabel2, }
$$

javax.swing.GroupLayout.Alignment.TRAILING)

- addComponent (jLabel1,

javax.swing.GroupLayout.Alignment.TRAILING))

.addPreferredGap (javax.swing. LayoutStyle. ComponentPlacement.RELATED)

.addGroup (jPanellLayout.createParallelGroup (javax.swing.GroupLayout.Alignment. LEADI NG)

$$
\text { . addComponent (jTextField1, }
$$

javax.swing.GroupLayout.Alignment.TRAILING, javax.swing.GroupLayout.PREFERRED_SIZE, 109, javax.swing.GroupLayout.PREFERRED SIZE)

. addComponent (jFormattedTextField3,

javax.swing.GroupLayout.Alignment.TRAILING, javax.swing.GroupLayout.PREFERRED SIZE, 109, javax.swing.GroupLayout.PREFERRED_SIZE))) . addGroup (jPanel1Lāyout. createSequentialGroup ()

. addGroup (jPanel1Layout. createParallelGroup (javax.swing. GroupLayout. Alignment. TRAIL ING)

$$
\begin{aligned}
& \text { - addComponent (jLabel3) } \\
& \text { - addComponent (jLabel 5) } \\
& \text { - addComponent (jLabel 4)) }
\end{aligned}
$$

.addPreferredGap (javax.swing. LayoutStyle.ComponentPlacement.RELATED)

.addGroup (jPanellLayout. createParallelGroup (javax.swing.GroupLayout.Alignment. LEADI NG)

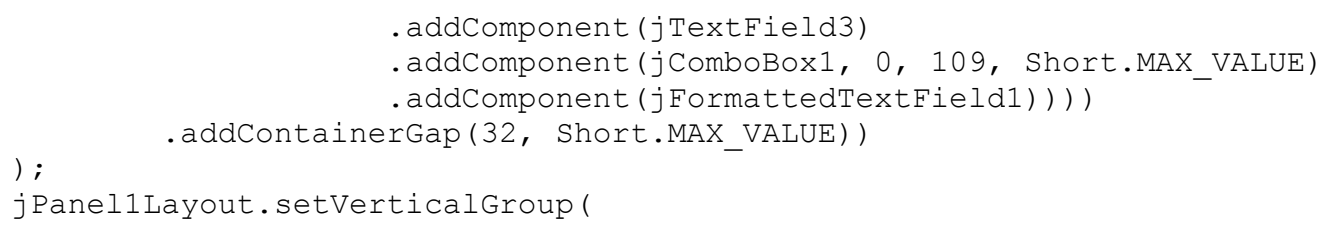

jPanellLayout.createParallelGroup (javax.swing.GroupLayout.Alignment. LEADING) . addGroup (jPanel1 Layout. createSequentialGroup () - addContainerGap ()

.addGroup (jPanel1Layout. createParallelGroup (javax.swing.GroupLayout. Alignment. BASEL INE)

$$
\text { . addComponent (jLabel1) }
$$


- addComponent (jTextField1,

javax.swing. GroupLayout. PREFERRED SIZE,

javax.swing.GroupLayout.DEFAULT_SIZE, javax.swing.GroupLayout.PREFERRED_SIZE))

. addPreferredGap (javax.swing. LayoutStyle.ComponentPlacement.RELATED)

. addGroup (jPanel1Layout. createParallelGroup (javax. swing. GroupLayout.Alignment. BASEL INE)

- addComponent (jLabel2)

- addComponent (jFormattedTextField3,

javax.swing.GroupLayout.PREFERRED_SIZE,

javax.swing.GroupLayout.DEFAULT_SIZE, javax.swing.GroupLayout.PREFERRED_SIZE))

. addPreferredGap (javax.swing. Layoutstyle.ComponentPlacement.RELATED)

. addGroup (jPanel1Layout. createParallelGroup (javax.swing. GroupLayout. Alignment. BASEL INE)

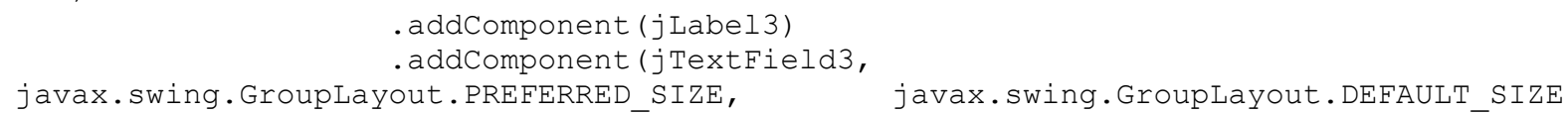
javax.swing.GroupLayout.PREFERRED_SIZE))

$$
\text { . } \operatorname{addGap}(9,9,9)
$$

.addGroup (jPanel1Layout. createParallelGroup (javax.swing. GroupLayout. Alignment.BASEL INE )

$$
\text { - addComponent ( jLabel 4) }
$$

javax.swing. GroupLayout. PREFERRED SIZE,

javax.swing. GroupLayout.PREFERRED_SIZE))

javax.swing.GroupLayout.DEFAULT SIZE,

.addPreferredGap (javax.swing. LayoutStyle.ComponentPlacement.RELATED)

.addGroup (jPanel1Layout. createParallelGroup (javax.swing. GroupLayout.Alignment. BASEI INE)

$$
\text { - addComponent (jLabe15) }
$$

- addComponent (jFormattedTextField1,

javax.swing.Grouplayout.PREFERRED_SIZE,

javax.swing.GroupLayout.PREFERRED_SIZE))

javax.swing. GroupLayout.DEFAULT SIZE,

. addContainerGap ( $\overline{1} 4$, Short.MAX_VALUE))

) ;

jPanel3. setBorder (javax.swing.BorderFactory.createTitledBorder(null,

"Informa ̃̃̊̃̃ues da Portaria", javax.swing.border.TitledBorder.DEFAULT JUSTIFICATION, javax.swing.border.TitledBorder.DEFAULT POSITION, new java.awt.Font("Arial", 1 , 12)) ; // NOI18N

jLabel6. setText ("Data do Recebimento:");

jTextField6. setHorizontalAlignment (javax.swing.JTextField.RIGHT) ;

jTextField7. setHorizontalAlignment (javax.swing.JTextField.RIGHT);

jComboBox2. setModel (new javax.swing. DefaultComboBoxModel (new String[] \{ "01", "02", "03", "04", "05", "06", "07", "08", "09", "10" \}));

jLabel7. setText ("Nota Fiscal:") ;

jLabe18. setText ("Peso LÃquido:") ;

jLabe19. setText ("Moega para Descarga:");

try

jFormattedTextField2. setFormatterFactory (new

javax.swing.text. DefaultFormatterFactory (new

javax.swing.text.MaskFormatter("\#\#/\#\#/\#\#\#\#"))) ;

\} catch (java.text.ParseException ex) \{ 
jPanel3Layout. createParallelGroup (javax.swing.GroupLayout.Alignment. LEADING) . addGroup (jPanel3Layout. createsequentialGroup () . $\operatorname{addGap}(16,16,16)$

. addGroup (jPanel3Layout. createParallelGroup (javax.swing. GroupLayout. Alignment. TRAIL ING)

$$
\begin{aligned}
& \text {. addComponent ( jLabel } 6 \text { ) } \\
& \text {. addComponent ( jLabel } 7 \text { ) } \\
& \text {. addComponent ( jLabel } 8 \text { ) } \\
& \text {. addComponent (jLabel } 1 \text { )) }
\end{aligned}
$$

.addPreferredGap (javax.swing. Layoutstyle.ComponentPlacement.RELATED)

-addGroup (jPanel3Layout. createParallelGroup (javax.swing. GroupLayout. Alignment. LEADI NG, false)

$$
\text { - addComponent (jComboBox2, }
$$

jPanel3Layout. createParallelGroup (javax.swing.GroupLayout.Alignment. LEADING) - addGroup (jPanel3Layout. createsequentialGroup () - addContainerGap ()

.addGroup (jPanel3Layout. createParallelGroup (javax.swing. GroupLayout. Alignment. BASEL INE)

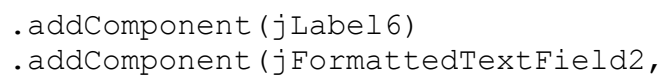


INE)

. addComponent (jComboBox2,

javax.swing.GroupLayout.PREFERRED_SIZE,

javax.swing.GroupLayout.DEFAULT_SIZE,

javax.swing. GroupLayout. PREFERRED SIZE)

. addComponent (jLabel9))

Short.MAX_VALUE))

.addContainerGap (javax.swing.Grouplayout.DEFAULT SIZE,

)

jButton 3 . setText ("Novo");

jButton3.addActionListener(new java.awt.event.ActionListener() \{ public void actionPerformed(java.awt.event.ActionEvent evt) \{ jButton3ActionPerformed (evt);

\}

\});

javax.swing.Grouplayout

layout

new

javax.swing.Grouplayout (getContentPane ());

getContentPane(). setLayout (layout);

layout.setHorizontalGroup (

layout.createParallelGroup (javax.swing.GroupLayout.Alignment. LEADING)

. addGroup (layout.createSequentialGroup () - addContainerGap ()

.addGroup (layout.createParallelGroup (javax.swing.GroupLayout.Alignment. TRAILING, false)

$$
\text { . addGroup (layout. createSequentialGroup() }
$$
. addComponent (jButton3)

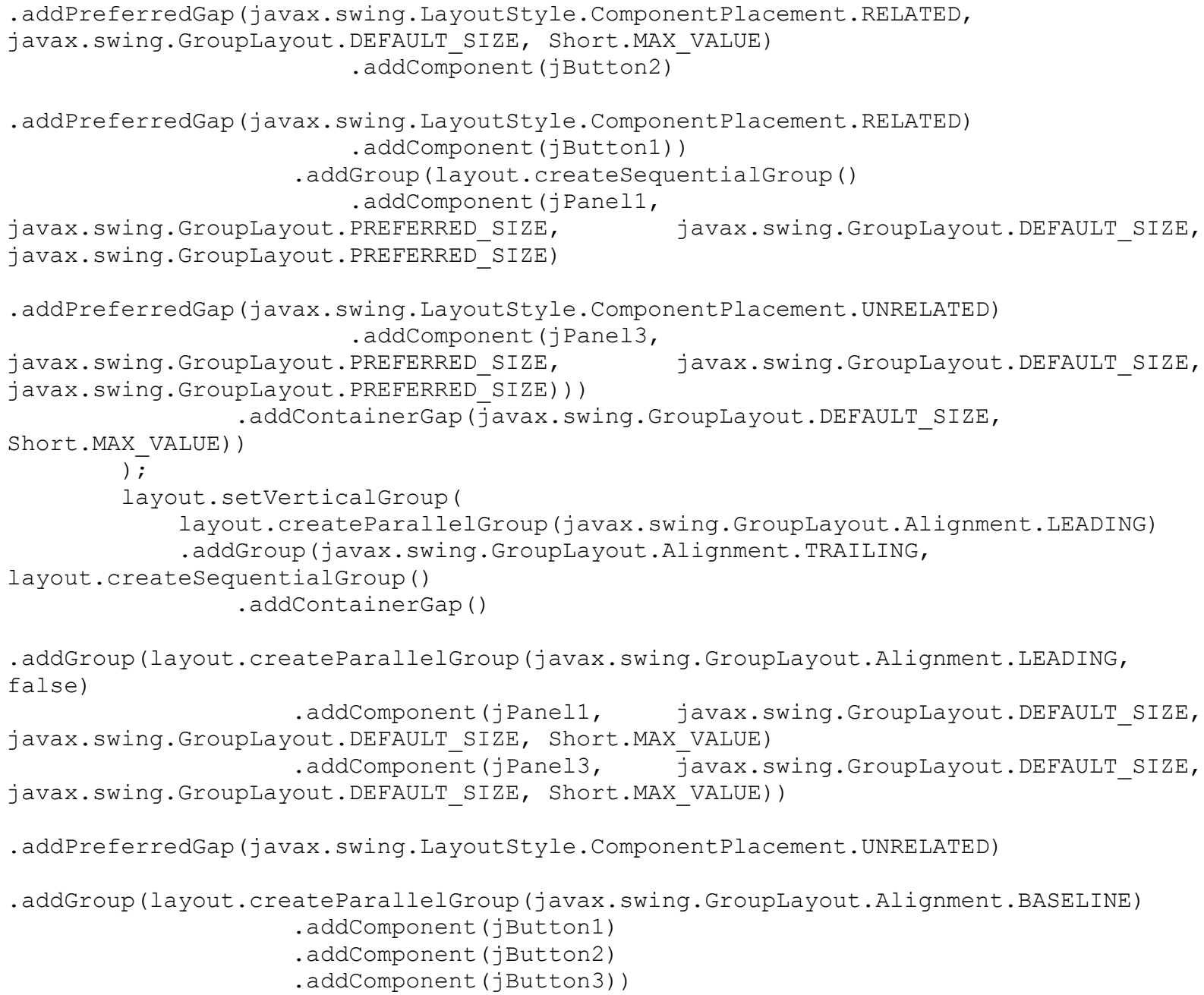


Short.MAX VALUE))

.addContainerGap (javax.swing.GroupLayout.DEFAULT_SIZE,

);

$\operatorname{pack}() ;$

\}// </editor-fold>//GEN-END:initComponents

private void jButtonlActionPerformed(java.awt.event.ActionEvent evt) \{//GENFIRST:event_jButton1ActionPerformed

this.dispose ();

\}//GEN-LAST: event jButton1ActionPerformed

private void jButton2ActionPerformed(java.awt.event. ActionEvent evt) \{//GENFIRST:event_jButton2ActionPerformed

String[] parametros = new String[9];

parametros $[0]=$ jTextFieldl.getText ();

parametros $[1]=$ jFormattedTextField3.getText () ;

parametros $[2]=j$ TextField3.getText ()$;$

parametros[3] = String.valueof (jComboBoxl.getSelectedIndex());

parametros [4] = jFormattedTextField1.getText();

parametros [5] = jFormattedTextField2.getText();

parametros $[6]=j$ TextField6.getText () ;

parametros [7] = jTextField7.getText ();

parametros $[8]=$ jComboBox 2 .getSelectedItem().toString ();

boolean result $=$ MainFrame.mysql.criarNovoCarregamento(parametros);

if (result)

\{

\}

else

\{

JOptionPane.showMessageDialog(this,

"Aconteceu um erro na hora de gravar os dados

no banco",

"Novo Carregamento - Erro",

\}

JOptionPane.ERROR MESSAGE);

\}//GEN-LAST:event_jButton2ActionPerformed

private void jButton3ActionPerformed(java.awt.event.ActionEvent evt) \{//GENFIRST:event_jButton3ActionPerformed

clearfields ();

\}//GEN-LAST: event_jButton3ActionPerformed

// Variables declaration - do not modify//GEN-BEGIN:variables

private javax.swing.JButton jButton1;

private javax.swing. JButton jButton2;

private javax.swing.JButton jButton3;

private javax.swing.JComboBox jComboBoxl;

private javax.swing. JComboBox jComboBox2;

private javax.swing.JFormattedTextField jFormattedTextField1;

private javax.swing. JFormattedTextField jFormattedTextField2;

private javax.swing.JFormattedTextField jFormattedTextField3;

private javax.swing. JLabel jLabel1;

private javax.swing. JLabel jLabel2;

private javax.swing. JLabel jLabel3;

private javax.swing. JLabel jLabel4;

private javax.swing. JLabel jLabel5;

private javax.swing. JLabel jLabel6;

private javax.swing. JLabel jLabel7;

private javax.swing. JLabel jLabel8;

private javax.swing. JLabel jLabel9;

private javax.swing. JPanel jPanel1;

private javax.swing. JPanel jPanel3;

private javax.swing.JTextField jTextFieldl; 


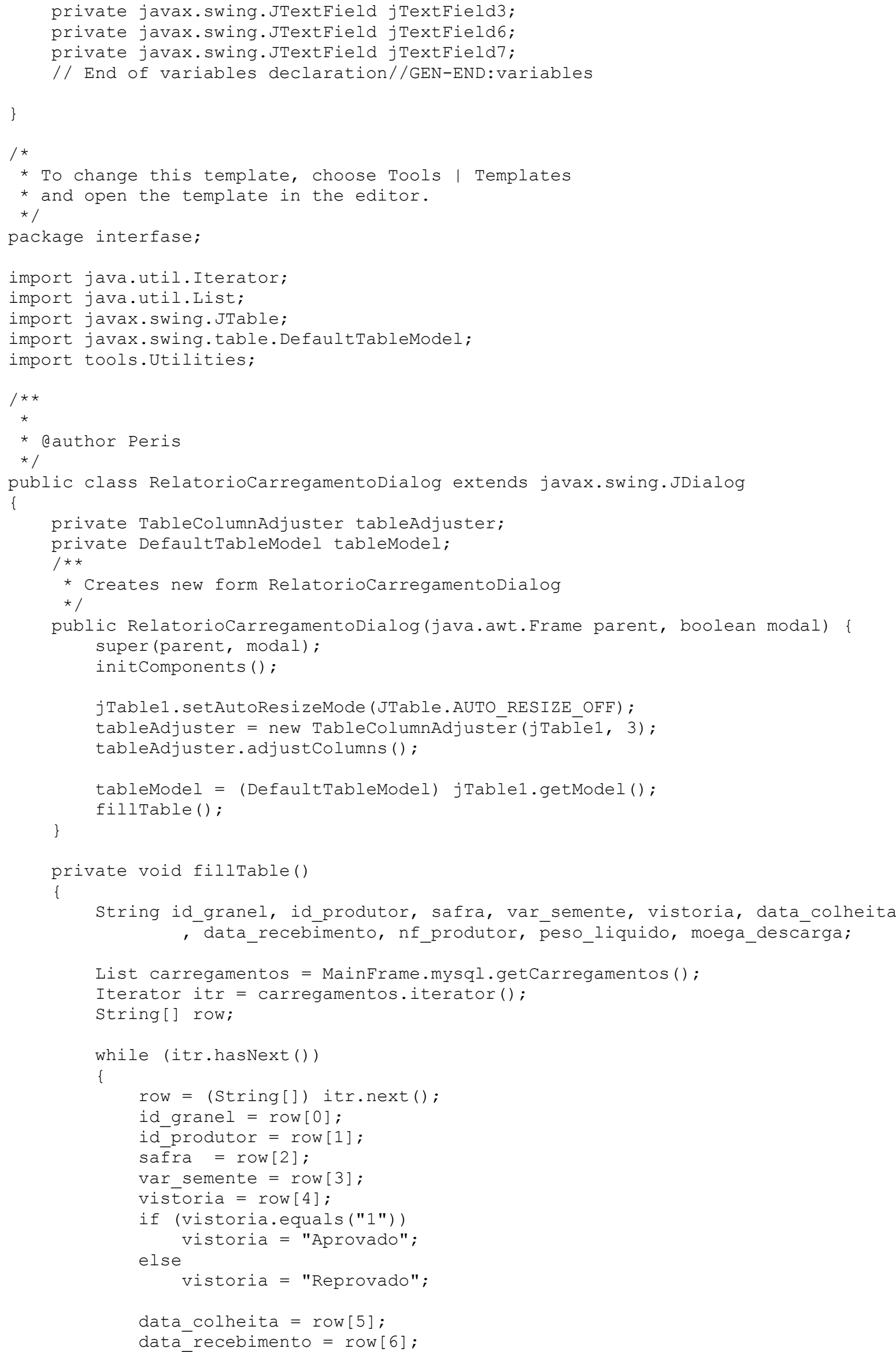




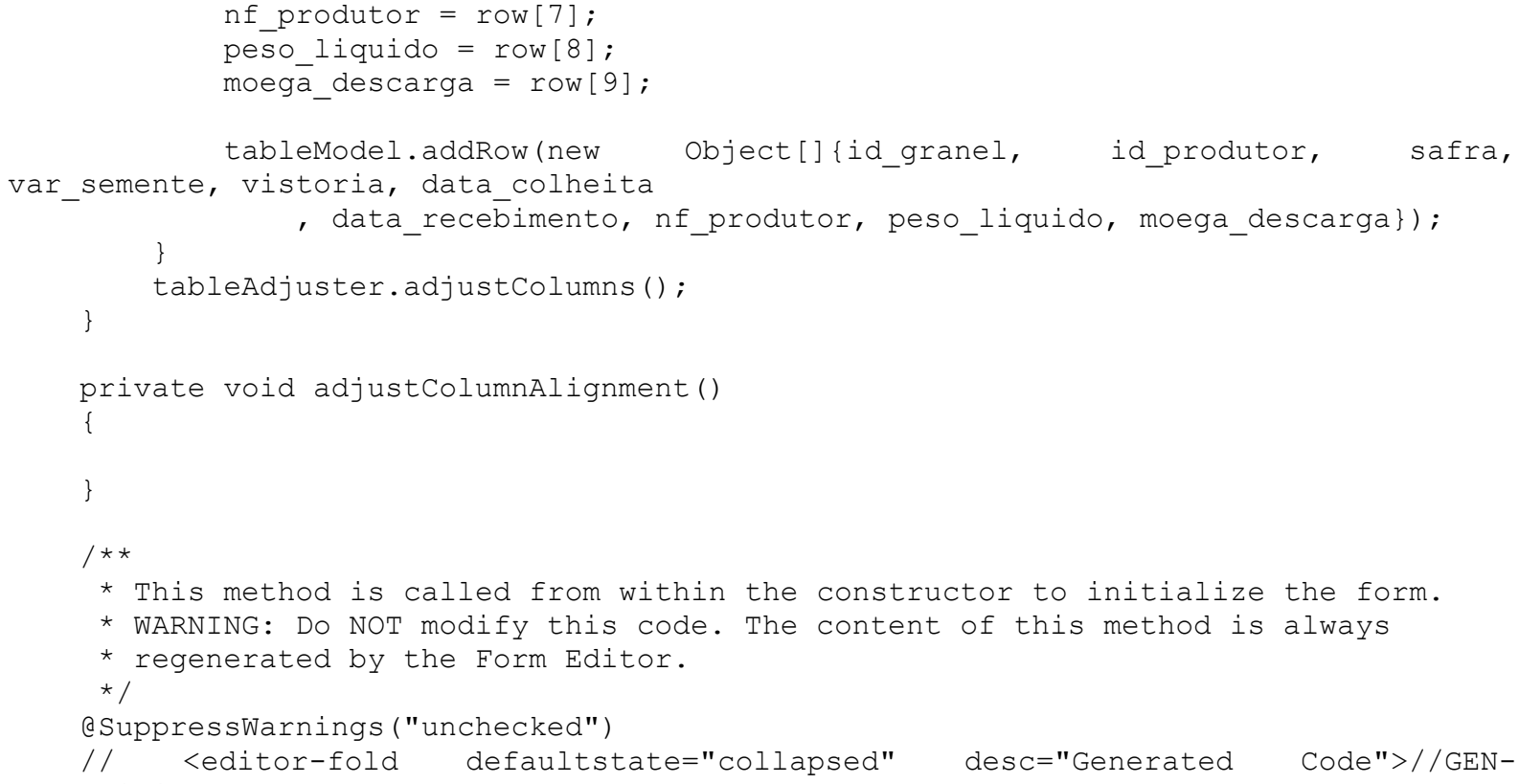

jPanel1.setBorder (javax.swing.BorderFactory.createTitledBorder(null, "Carregamentos Recebidos", javax.swing.border.TitledBorder.DEFAULT JUSTIFICATION, javax.swing.border.TitledBorder.DEFAULT_POSITION, new java.awt.Font("Arial", 1, 12)) ) / // NOI18N

jTablel.setModel (new javax.swing.table. DefaultTableModel ( new Object [] [] \{

\} ， 


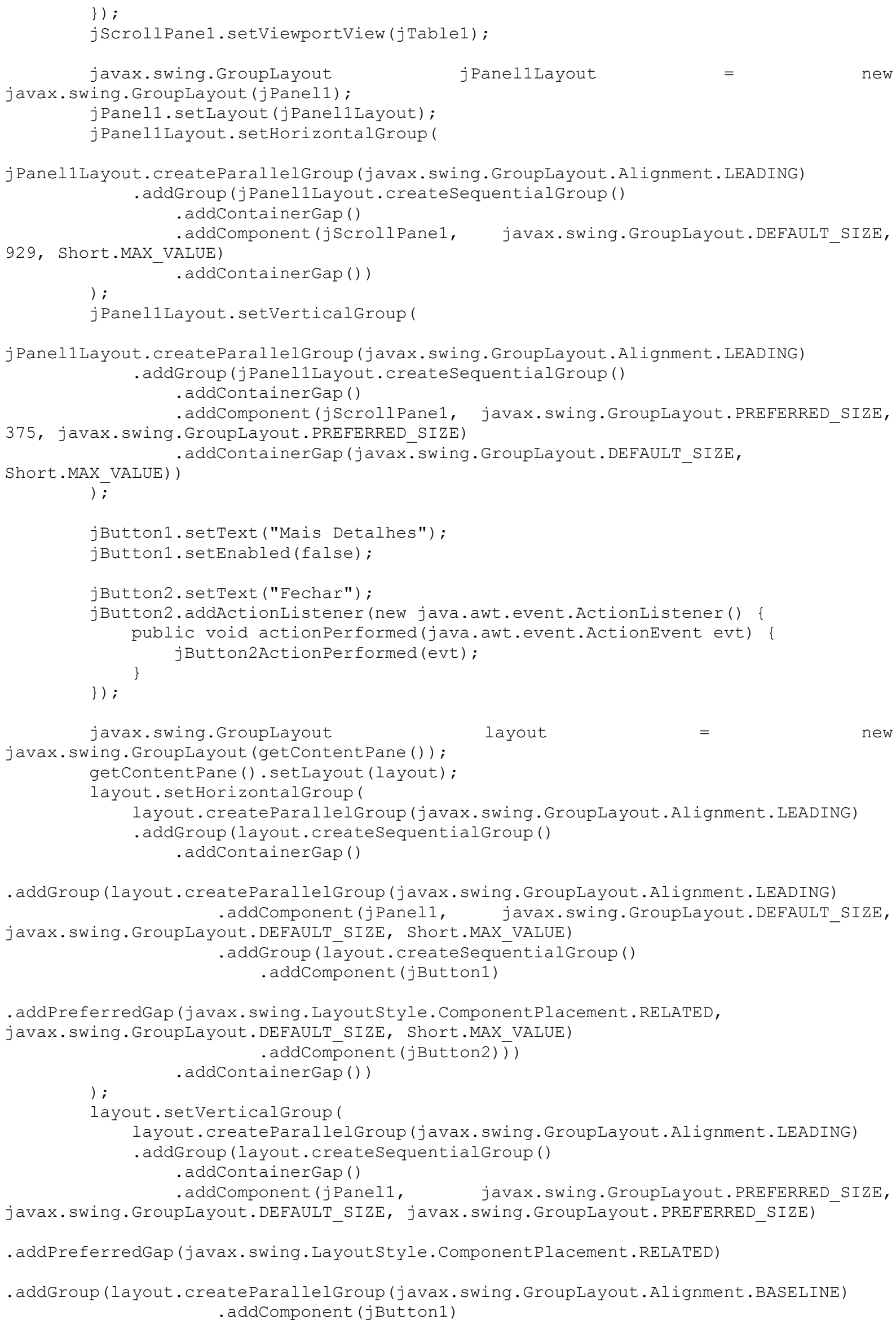


. addComponent (jButton2))

.addContainerGap (javax.swing.GroupLayout.DEFAULT_SIZE,

Short.MAX VALUE))

)

$\operatorname{pack}() ;$

\}// </editor-fold>//GEN-END:initComponents

private void jButton2ActionPerformed(java.awt.event.ActionEvent evt) \{//GENFIRST:event_jButton2ActionPerformed

dispose ();

\}//GEN-LAST:event_jButton2ActionPerformed

private void jTablelMouseClicked(java.awt.event.MouseEvent evt) \{//GENFIRST:event_jTable1MouseClicked

//Utilities.consoleout("mouse clicked...");

jButton1. setEnabled (true);

\}//GEN-LAST:event_jTable1MouseClicked

// Variables declaration - do not modify//GEN-BEGIN:variables

private javax.swing. JButton jButton1;

private javax.swing. JButton jButton2;

private javax.swing. JPanel jPanell;

private javax.swing. JScrollPane jScrollPanel;

private javax.swing.JTable jTablel;

// End of variables declaration//GEN-END:variables

\}

$/ *$

* To change this template, choose Tools | Templates

* and open the template in the editor.

$*$ /

package tools;

import java.sql. Connection;

import java.sql. DriverManager;

import java.sql. PreparedStatement;

import java.sql. Resultset;

import java.sql.SQLException;

import java.sql. Statement;

import java.util.ArrayList;

import java.util.List;

import java.util.logging.Level;

import java.util.logging.Logger;

import javax.swing.JoptionPane;

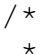

* eauthor sanpedro

*/

public class MysqLAccess \{

private string database = "sementes";

private String db user $=" \star \star \star \star * "$;

private string db user pass $=" * * * * "$;

private String db_server $=" * * * * * "$;

private string query;

private Connection connect $=$ null;

private statement statement = null;

private PreparedStatement preparedStatement = null;

private Resultset resultset = null;

private java.awt. Frame parent;

public MySQLAccess() \{

this.connect (); 


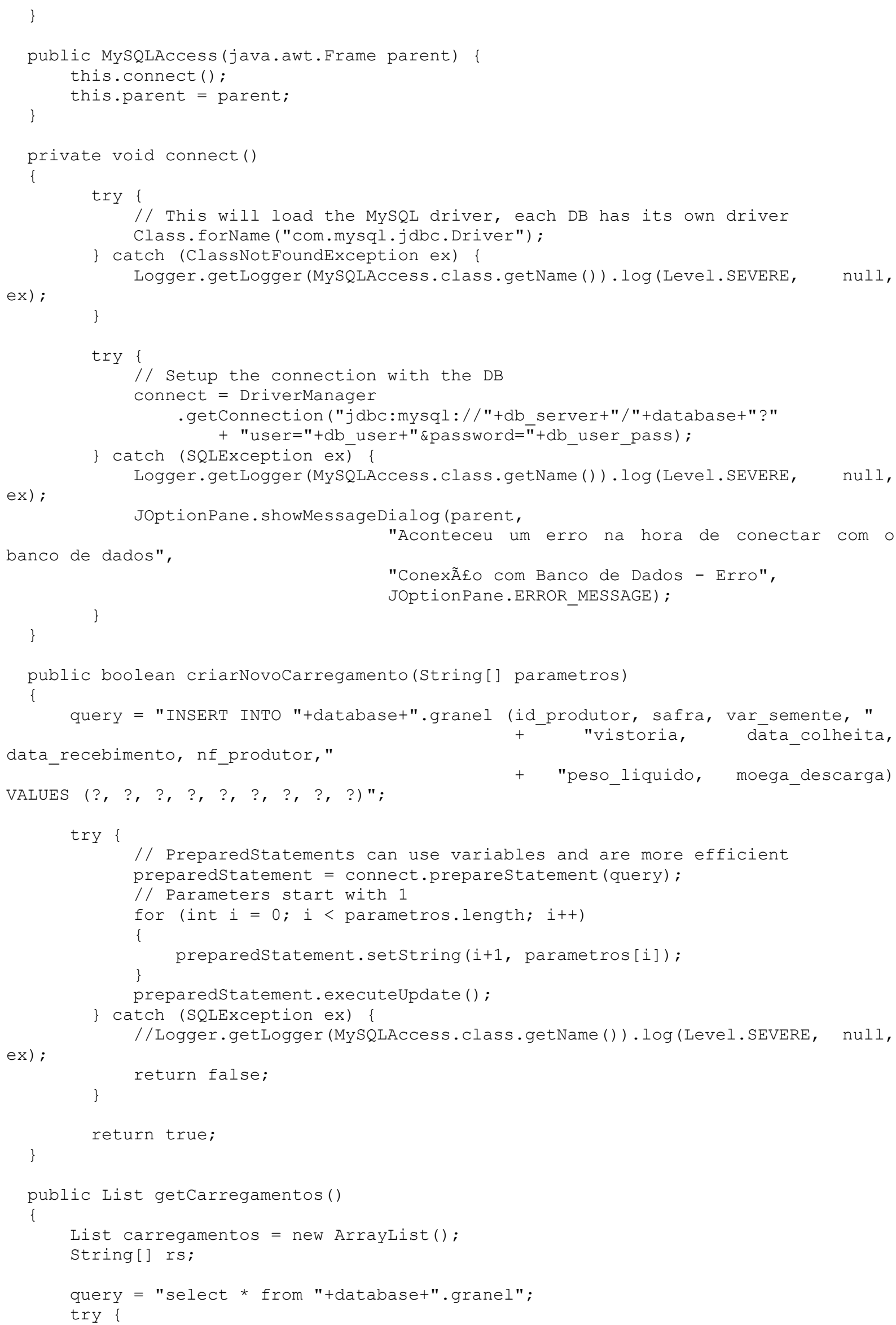




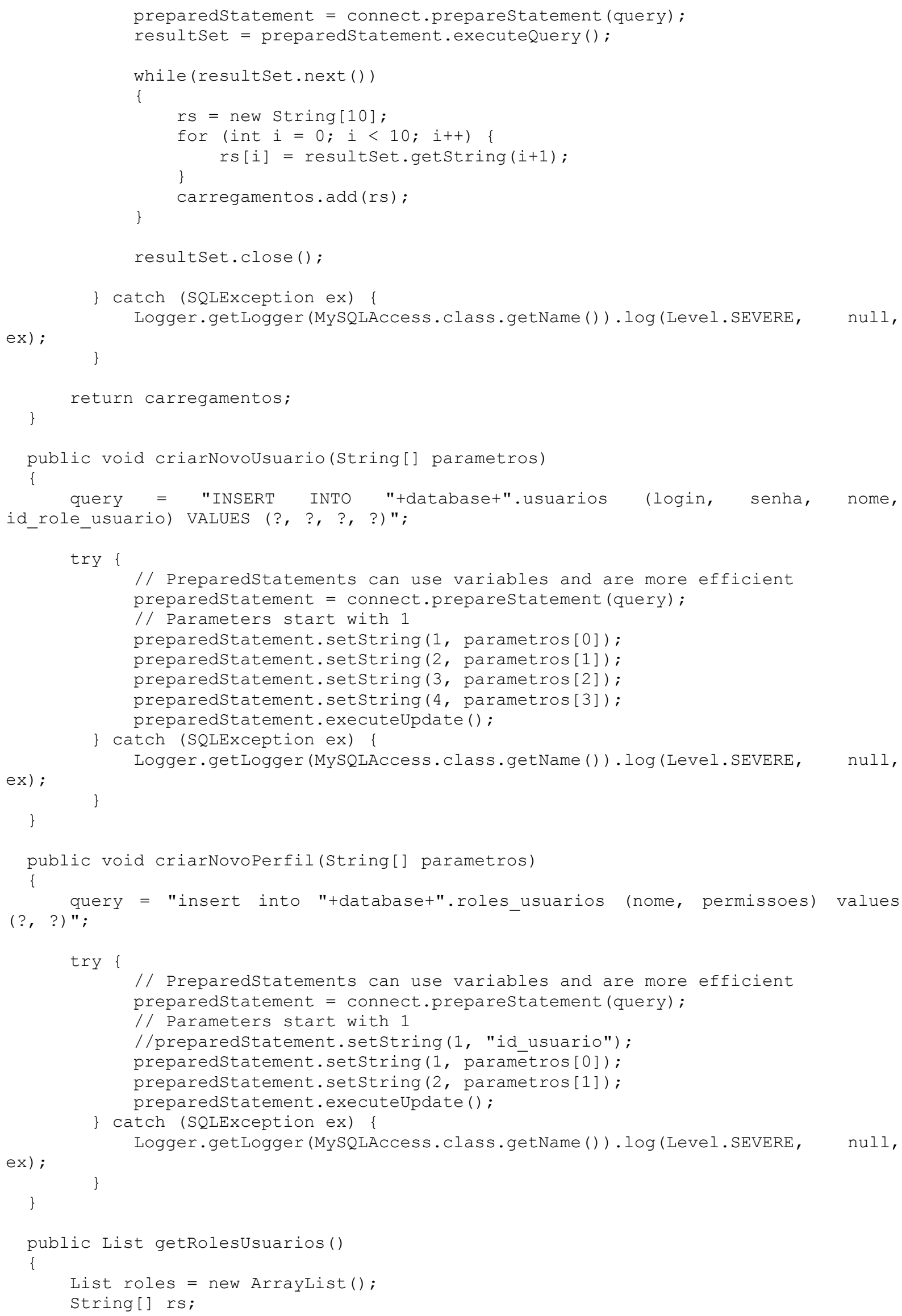




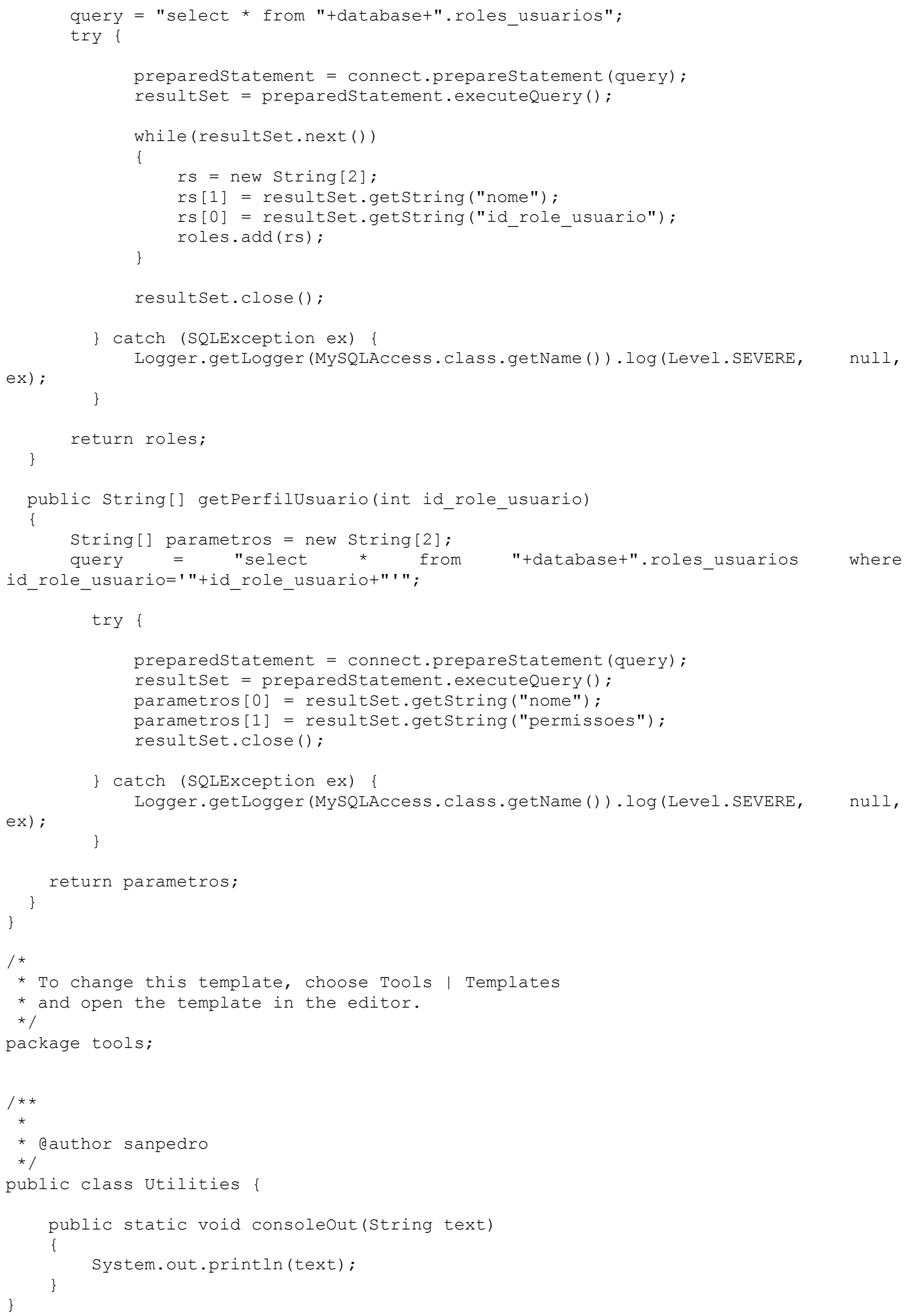




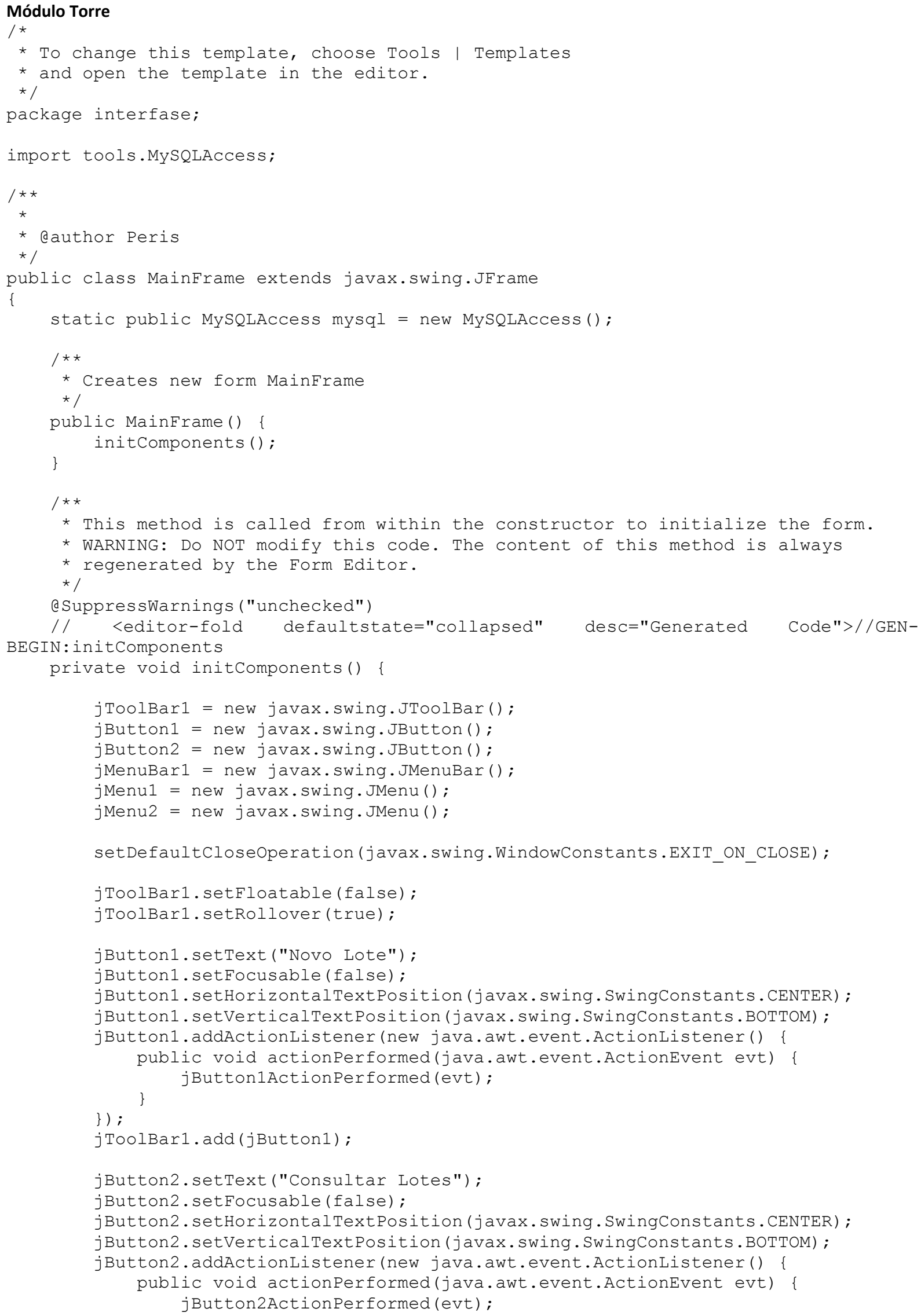




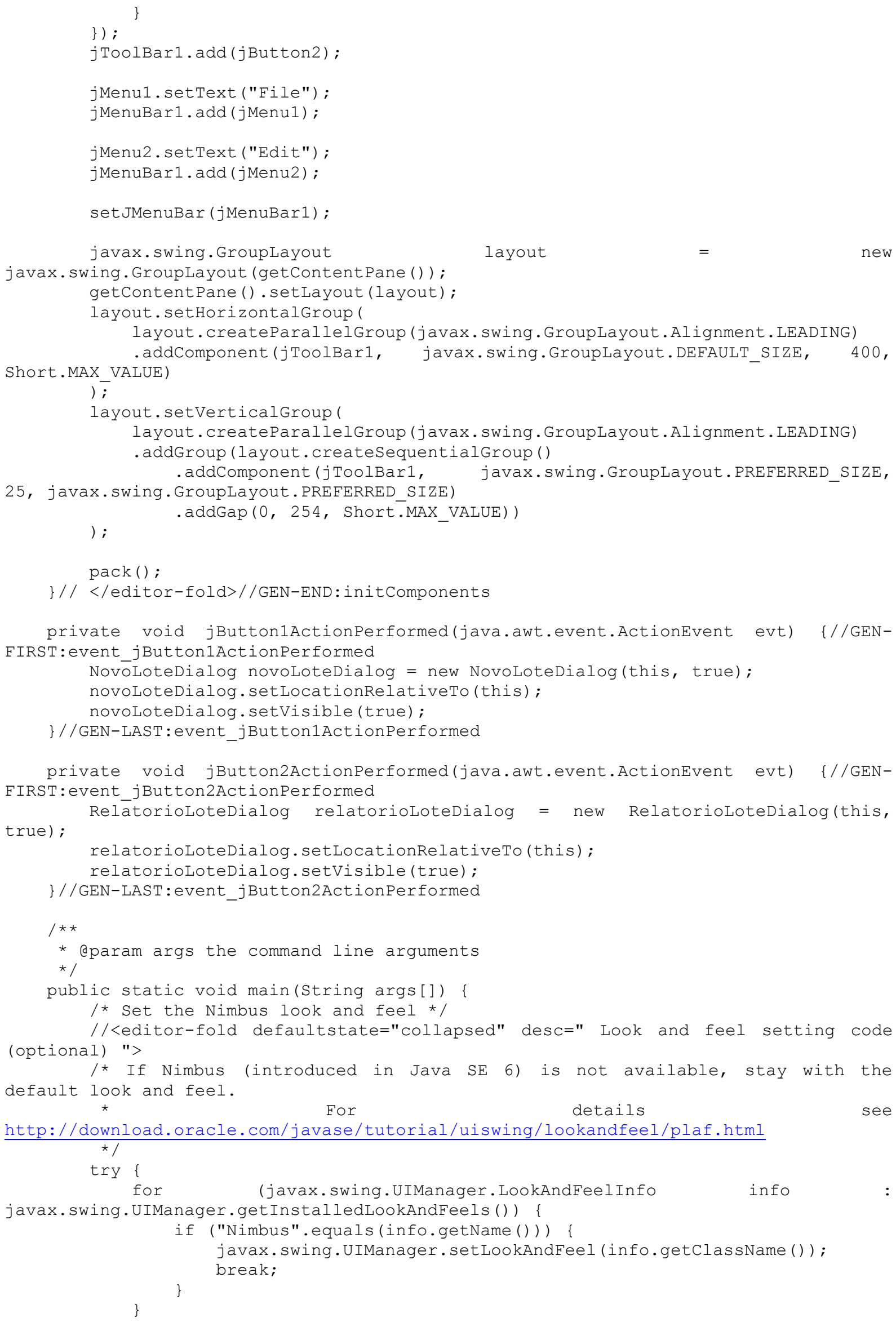

private void jButtonlActionPerformed(java.awt.event.ActionEvent evt) \{//GENFIRST:event jButton1ActionPerformed

NovoLoteDialog novoLoteDialog = new NovoLoteDialog(this, true);

novoLoteDialog.setLocationRelativeTo(this);

novoLoteDialog.setVisible (true);

\}//GEN-LAST:event_jButton1ActionPerformed

private void jButton2ActionPerformed(java.awt.event. ActionEvent evt) \{//GENFIRST: event jButton2ActionPerformed

Relatoriolotedialog relatoriolotedialog = new Relatoriolotedialog(this, true);

relatorioLoteDialog.setLocationRelativeTo(this);

relatorioLoteDialog.setVisible (true);

\}//GEN-LAST:event_jButton2ActionPerformed

$1 * *$

* eparam args the command line arguments

*/ 
\} catch (ClassNotFoundException ex) \{

java.util.logging. Logger.getLogger (MainFrame.class.getName ()) . log (java.util.logging .Level.SEVERE, null, ex);

\} catch (InstantiationException ex) \{

java.util.logging. Logger.getLogger (MainFrame.class.getName ()) . log (java.util.logging .Level.SEVERE, null, ex);

\} catch (IllegalAccessException ex) \{

java.util.logging.Logger.getLogger (MainFrame.class.getName ()).log (java.util.logging .Level.SEVERE, null, ex);

\} catch (javax.swing. UnsupportedLookAndFeelException ex) \{

java.util.logging. Logger.getLogger (MainFrame.class.getName ()) . log (java.util.logging .Level.SEVERE, null, ex);

\}

$/ /</$ editor-fold $>$

/* Create and display the form */

java.awt. EventQueue.invokeLater (new Runnable() \{ public void run() ( new MainFrame(). setVisible(true);

) ;

\}

// Variables declaration - do not modify//GEN-BEGIN:variables

private javax.swing. JButton jButton1;

private javax.swing. JButton jButton2;

private javax.swing. JMenu jMenul;

private javax.swing. JMenu jMenu2;

private javax.swing. JMenuBar jMenuBarl;

private javax.swing. JToolBar jToolBarl;

// End of variables declaration//GEN-END:variables

\}

/*

* To change this template, choose Tools I Templates

* and open the template in the editor.

* 1

package interfase;

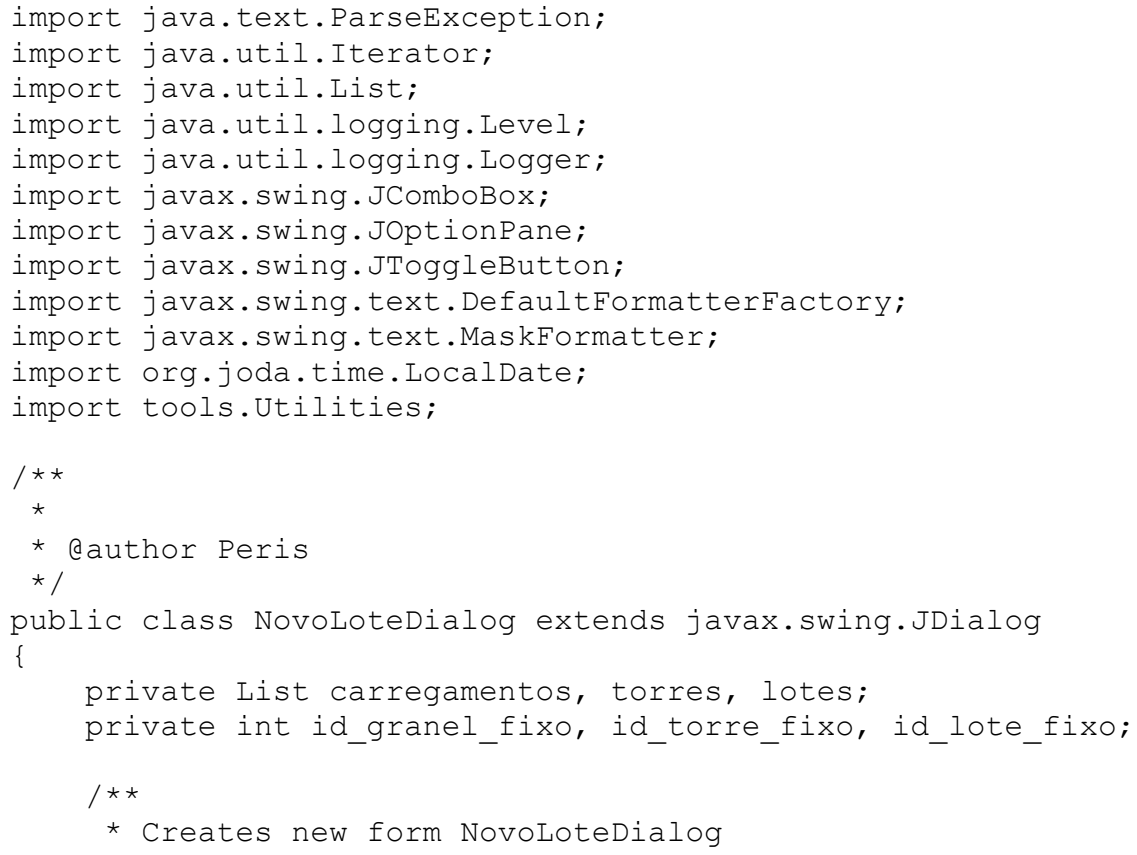




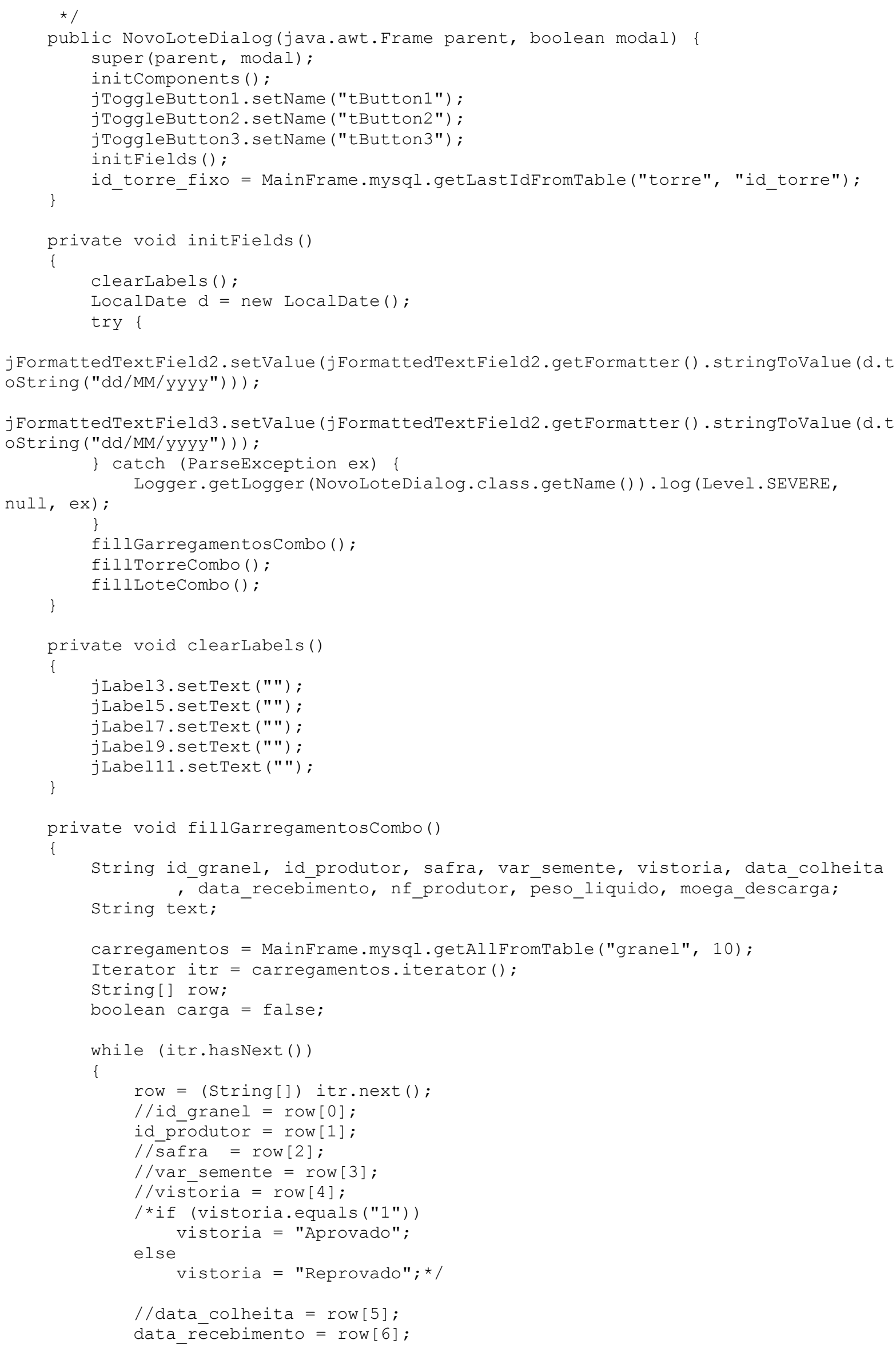




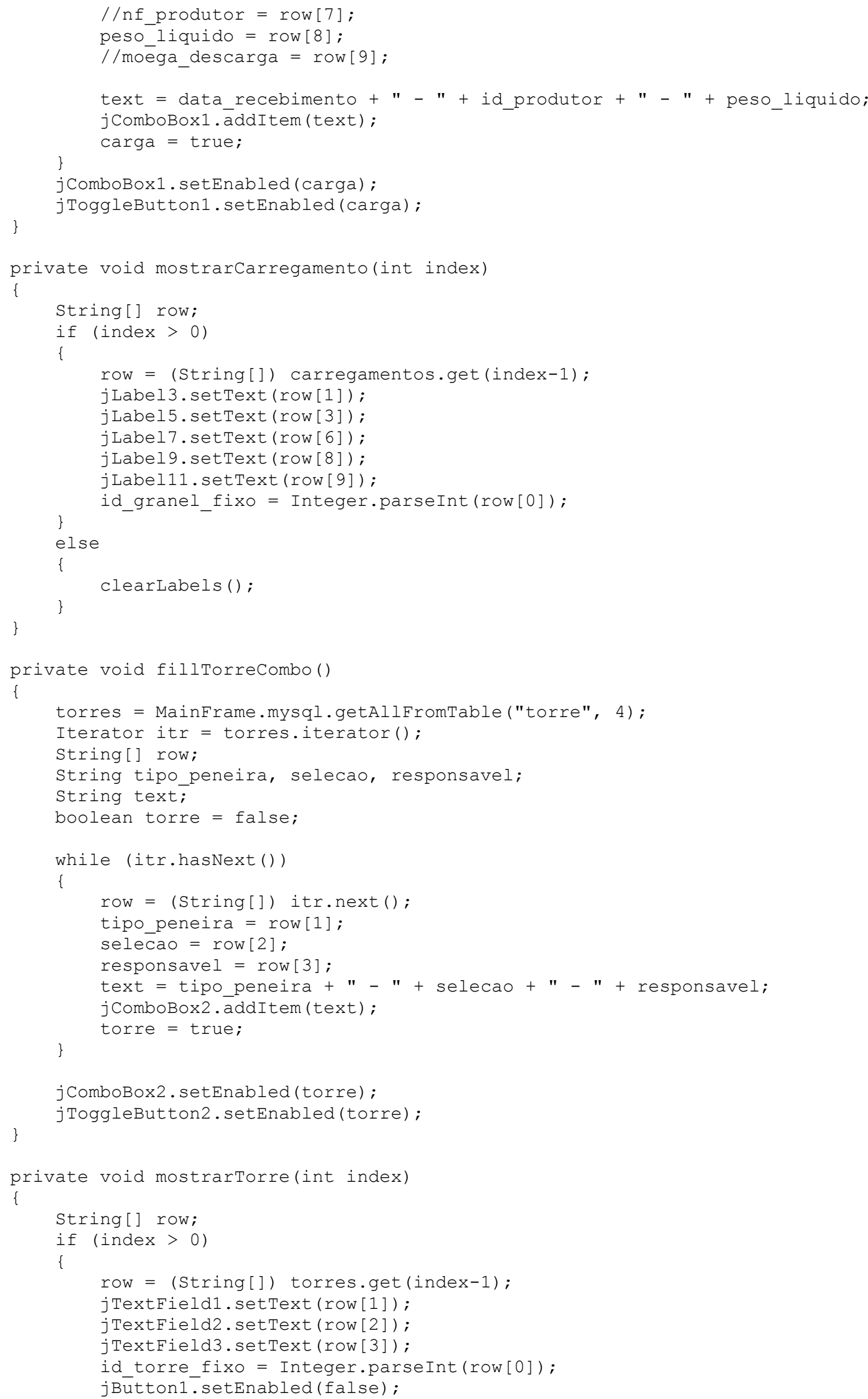




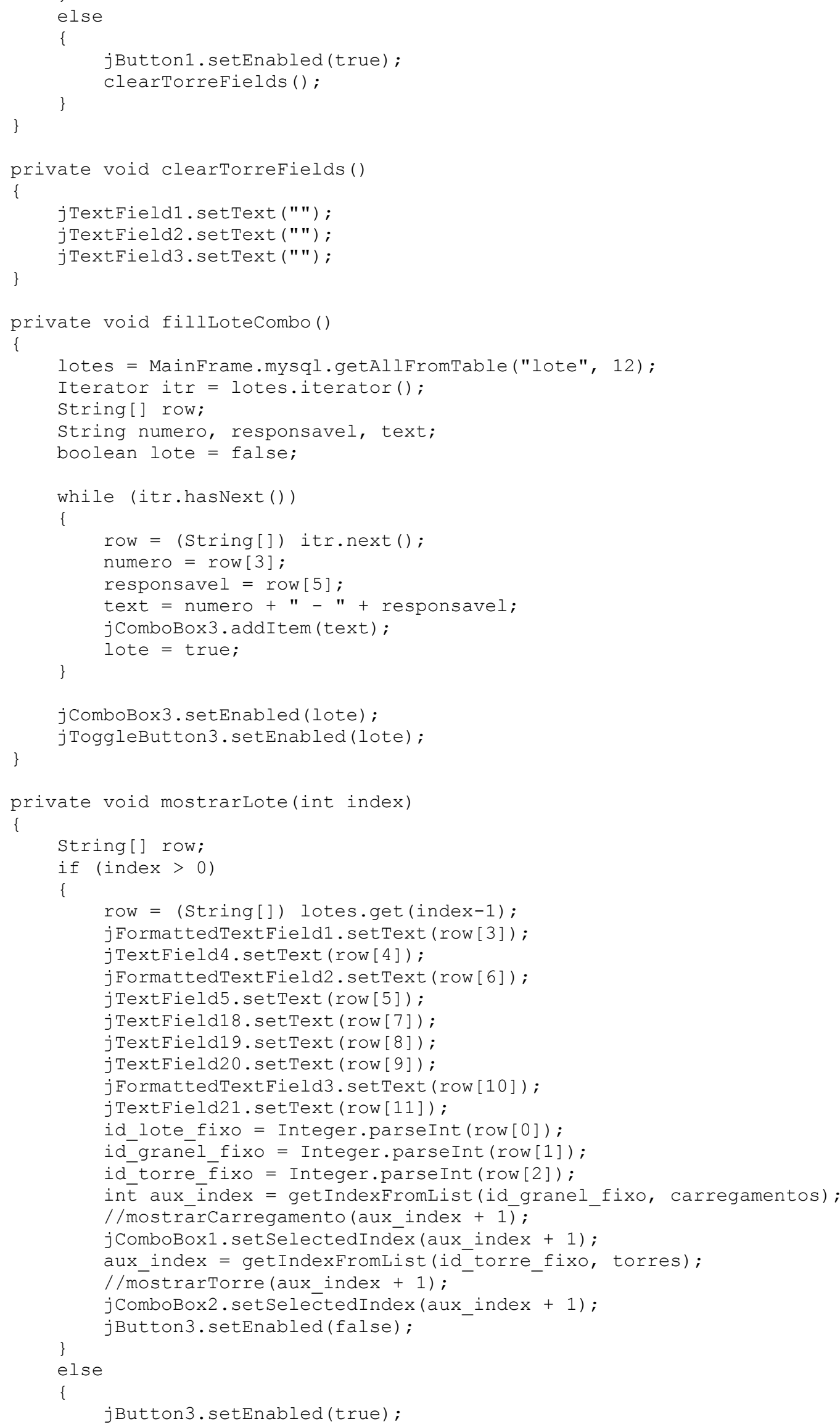




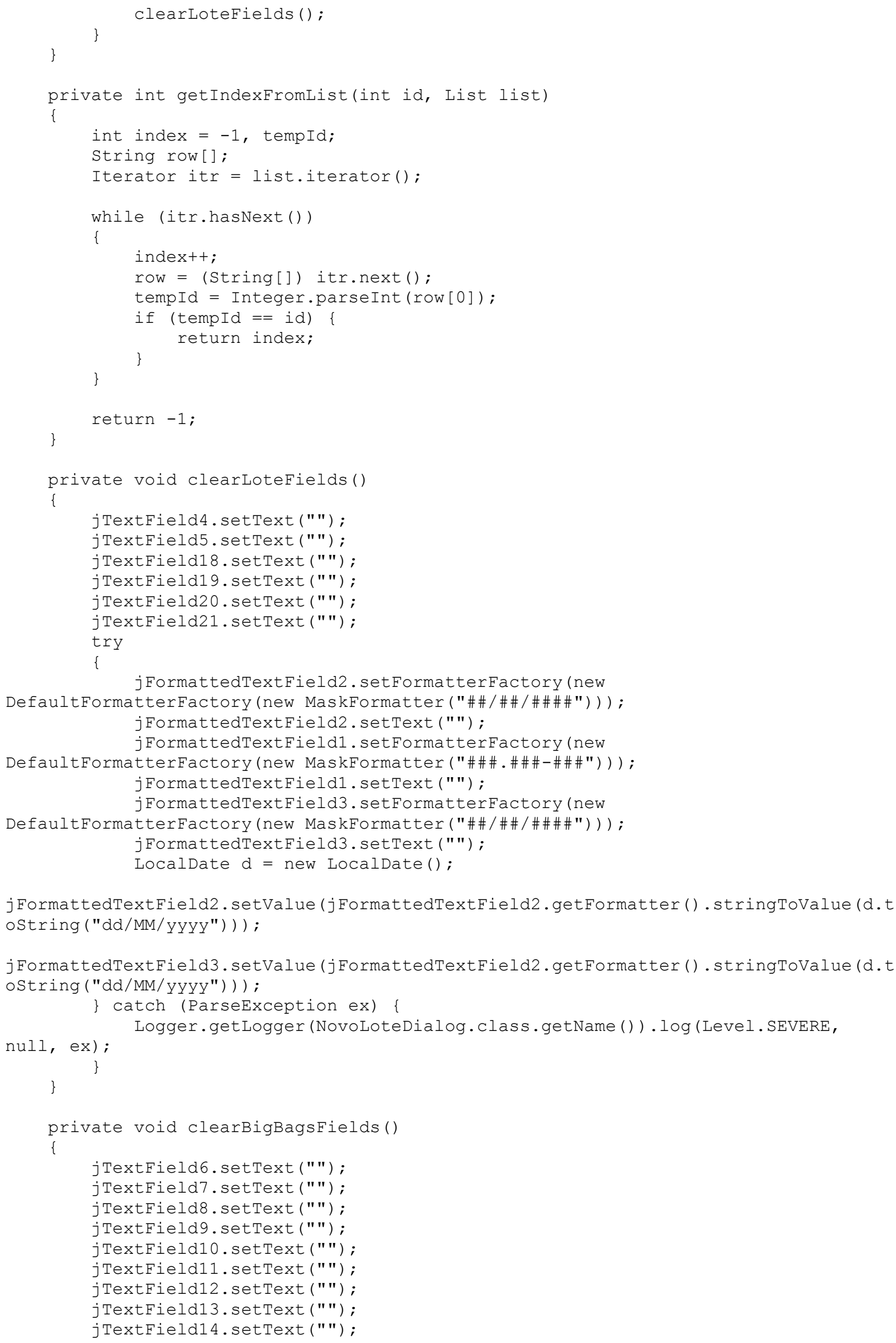


jTextField15. setText ("");

jTextField16. setText ("");

jTextField17. setText ("");

jTextField22. setText ("");

jTextField23. setText ("");

private void updateToggleButtonstatus(JToggleButton toggleButton, JComboBox comboBox

if (toggleButton.isselected())

toggleButton. setText ("Liberar") ;

comboBox. setEnabled (false);

if (toggleButton.getName().equals ("tButton2")) \{

jButtonl. setEnabled (false);

if (toggleButton.getName().equals("tButton3")) \{

jButton3. setEnabled (false);

\}

else

\{

toggleButton. setText ("Fixar") ;

comboBox. setEnabled (true);

if (toggleButton.getName () .equals ("tButton2"))

jButton1. setEnabled (true);

if (toggleButton.getName ().equals ("tButton3"))

/ /

/ / jButton3. setEnabled (true);

/**

* This method is called from within the constructor to initialize the form.

* WARNING: Do NOT modify this code. The content of this method is always

* regenerated by the Form Editor.

* 1

QSuppressWarnings ("unchecked")

// <editor-fold defaultstate="collapsed" desc="Generated Code">//GENBEGIN: initComponents

private void initComponents() \{

jPanel1 = new javax.swing.JPanel ();

jComboBox1 = new javax.swing. JComboBox();

jLabel2 = new javax.swing.JLabel ();

jLabel3 = new javax.swing.JLabel ();

jLabel4 = new javax.swing.JLabel ();

jLabel5 = new javax.swing.JLabel ();

jLabel 6 = new javax.swing.JLabel ();

jLabel 7 = new javax.swing.JLabel ();

jLabel8 = new javax.swing.JLabel ();

jLabel9 = new javax.swing.JLabel ();

jLabel10 = new javax.swing.JLabel ();

jLabel11 = new javax.swing. JLabel ();

jToggleButton 1 = new javax.swing.JToggleButton();

jPanel2 = new javax.swing.JPanel();

jComboBox2 = new javax.swing.JComboBox();

jLabel1 = new javax.swing.JLabel ();

jTextField1 = new javax.swing.JTextField();

jLabel12 = new javax.swing.JLabel ();

jTextField2 = new javax.swing.JTextField();

jLabel13 = new javax.swing.JLabel ();

jTextField3 = new javax.swing. JTextField();

jButton 1 = new javax.swing. JButton();

jToggleButton2 = new javax.swing. JToggleButton();

jButton2 = new javax.swing.JButton();

jPanel3 = new javax.swing.JPanel(); 
jComboBox3 = new javax.swing.JComboBox();

jLabel14 = new javax.swing.JLabel ();

jFormattedTextField1 = new javax.swing.JFormattedTextField();

jLabel15 = new javax.swing. JLabel ();

jTextField4 = new javax.swing.JTextField();

jLabel16 = new javax.swing.JLabel ();

jFormattedTextField2 = new javax.swing.JFormattedTextField();

jLabel17 = new javax.swing.JLabel ();

jTextField5 = new javax.swing.JTextField();

jToggleButton 3 = new javax.swing.JToggleButton();

jButton3 = new javax.swing.JButton();

jButton 4 = new javax.swing.JButton();

jLabel34 = new javax.swing.JLabel ();

jLabel31 = new javax.swing.JLabel ();

jLabel39 = new javax. swing. JLabel ();

jLabel33 = new javax.swing.JLabel ();

jTextField18 = new javax.swing.JTextField();

jLabel38 = new javax.swing.JLabel ();

jTextField19 = new javax.swing.JTextField ();

jTextField21 = new javax.swing.JTextField();

jLabel30 = new javax.swing.JLabel ();

jLabel32 = new javax.swing. JLabel ();

jFormattedTextField3 = new javax.swing.JFormattedTextField();

jLabel37 = new javax.swing.JLabel ();

jTextField20 = new javax.swing.JTextField();

jPanel4 = new javax.swing.JPanel();

jTextField6 = new javax.swing.JTextField();

jTextField7 = new javax.swing.JTextField();

jTextField8 = new javax.swing.JTextField();

jTextField9 = new javax.swing.JTextField();

jTextField10 = new javax.swing.JTextField();

jTextField1 = new javax.swing.JTextField();

jTextField12 = new javax.swing.JTextField();

jTextField13 = new javax.swing.JTextField();

jTextField14 = new javax.swing. JTextField();

jTextField15 = new javax.swing.JTextField();

jTextField16 = new javax.swing.JTextField();

jTextField17 = new javax.swing.JTextField();

jLabel18 = new javax.swing.JLabel ();

jLabel19 = new javax.swing.JLabel ();

jLabel20 = new javax.swing.JLabel();

jLabel21 = new javax.swing. JLabel ();

jLabel22 = new javax.swing.JLabel ();

jLabel23 = new javax.swing.JLabel ();

jLabel24 = new javax.swing.JLabel ();

jLabel25 = new javax.swing. JLabel ();

jLabel26 = new javax.swing.JLabel ();

jLabel27 = new javax.swing.JLabel ();

jLabel28 = new javax.swing.JLabel ();

jLabel29 = new javax.swing.JLabel ();

jLabel35 = new javax.swing. JLabel ();

jTextField22 = new javax.swing.JTextField();

jLabel36 = new javax.swing.JLabel ();

jTextField23 = new javax.swing.JTextField();

jButton 9 = new javax.swing. JButton();

jButton 7 new javax.swing.JButton();

jButton 5 = new javax.swing.JButton();

jButton 6 = new javax.swing. JButton();

setDefaultCloseoperation (javax.swing.WindowConstants.DISPOSE_ON_CLOSE); setTitle("Processar Novo Lote");

setResizable (false);

do

jPanel1.setBorder(javax.swing.BorderFactory.createTitledBorder(null, "Dados Carregamento", javax.swing.border.TitledBorder.DEFAULT_JUSTIFICATION, javax.swing.border.TitledBorder.DEFAULT_POSITION, new java.awt.Font("Arial", 1, 
12))); // NOI18N

jComboBoxl.setModel (new javax.swing. DefaultComboBoxModel (new String[] "Selecione o carregamento" \}));

jComboBox1.addItemListener(new java.awt. event.ItemListener() \{ public void itemstatechanged(java.awt.event. ItemEvent evt) \{ \} jComboBoxlItemstateChanged (evt);

\});

jLabel2. setText ("Produtor:");

jLabel3.setFont (new java.awt.Font("Tahoma", 1, 11)); // NOI18N jLabel3. setText ("jLabel3");

jLabel4.setText ("Semente:");

jLabe15. setFont (new java.awt.Font("Tahoma", 1, 11)); // NOI18N jLabe15. setText ("jLabel5");

jLabel6.setText ("Recebido em:");

jLabel7. setFont (new java.awt.Font("Tahoma", 1, 11)); // NOI18N jLabe17.setText ("jLabel7");

jLabel8. setText ("Peso lÃquido:") ;

jLabel9. setFont (new java.awt.Font ("Tahoma", 1, 11)); // NOI18N

jLabe19.setText ("jLabe19");

jLabel10. setText ("Moega descarga:");

jLabel11.setFont (new java.awt.Font("Tahoma", 1, 11)); // NOI18N

jLabel11. setText ("jLabel11");

jToggleButton1.setText ("Fixar");

jToggleButton1.addMouseListener (new java.awt.event.MouseAdapter() public void mouseClicked (java.awt.event.MouseEvent evt) \{ jToggleButton1MouseClicked (evt);

\});

javax.swing. GroupLayout jPanel1Layout

new javax.swing. GroupLayout ( jPanel1);

jPanel1. setLayout (jPanell Layout);

jPanellLayout.setHorizontalGroup(

jPanel1Layout.createParallelGroup (javax.swing.GroupLayout.Alignment. LEADING) . addGroup (jPanell Layout.createSequentialGroup () - addContainerGap ()

.addGroup (jPanellLayout.createParallelGroup (javax.swing.GroupLayout.Alignment. LEADI NG)

$$
\text { - addGroup (jPanel1Layout. createSequentialGroup () }
$$

. addGroup (jPanel1Layout. createParallelGroup (javax.swing. GroupLayout. Alignment. TRAIL ING)

$$
\begin{aligned}
& \text {. addComponent (jLabel2) } \\
& \text { - addComponent (jLabel4) } \\
& \text { - addComponent (jLabel6) } \\
& \text { - addComponent (jLabel 8) } \\
& \text { - addComponent (jLabel10)) }
\end{aligned}
$$

.addPreferredGap (javax.swing.LayoutStyle.ComponentPlacement.RELATED)

.addGroup (jPanellLayout.createParallelGroup (javax.swing.GroupLayout. Alignment. LEADI 
NG)

$$
\begin{gathered}
\text {. addComponent (jLabel5) } \\
\text {. addComponent (jLabel3) } \\
\text {. addComponent (jLabel } 7) \\
\text {. addComponent (jLabel9) } \\
\text {. addComponent (jLabel11)) } \\
\text {. addGap (0, 0, Short.MAX_VALUE)) }
\end{gathered}
$$

.addGroup (javax.swing.GroupL̄ayout.Alignment.TRAILING,

jPanel1Layout.createSequentialGroup ()

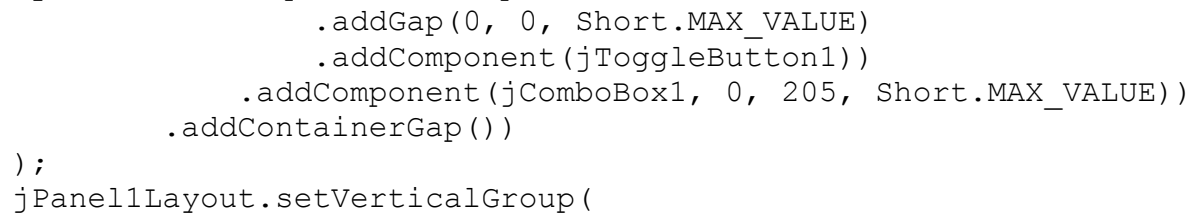
INE)

$$
\begin{aligned}
& \text {. addComponent (jLabel10) } \\
& \text {. addComponent (jLabel11)) }
\end{aligned}
$$

.addPreferredGap (javax.swing.LayoutStyle.ComponentPlacement.RELATED, javax.swing.GroupLayout.DEFAULT_SIZE, Short.MAX_VALUE)

$$
\text { - addComponent (j'̄oggleButton1) }
$$

) ; - addContainerGap ())

jPanel2.setBorder (javax.swing.BorderFactory.createTitledBorder(null, "Dados da Torre", javax.swing.border.TitledBorder.DEFAULT_JUSTIFICATION, javax.swing.border.TitledBorder.DEFAULT_POSITION, new java.awt.Font("Arial", 1, 
12))); // NOI18N

jComboBox2. setModel (new javax.swing. DefaultComboBoxModel (new String[]

"Selecionar a torre" \})):

jComboBox2.addItemListener(new java.awt.event.ItemListener() \{

public void itemStateChanged(java.awt.event.ItemEvent evt) \{ jComboBox2ItemstateChanged (evt);

\});

jLabel1.setText("Tipo de Peneira");

jTextFieldl.setHorizontalAlignment (javax.swing.JTextField.TRAILING) ;

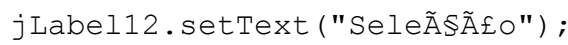

jTextField2. setHorizontalAlignment (javax.swing.JTextField.TRAILING);

jLabel13.setText ("Respons $\tilde{A}_{i}$ vel") ;

jTextField3. setHorizontalAlignment (javax.swing.JTextField.TRAILING);

jButton1. setText ("Salvar");

jButton1.addActionListener(new java.awt.event.ActionListener() \{ public void actionPerformed(java.awt.event. ActionEvent evt) \{ jButtonlActionPerformed (evt); \}

\});

jToggleButton2.setText ("Fixar");

jToggleButton2.addActionListener(new java.awt.event.ActionListener() \{ public void actionPerformed (java.awt. event. ActionEvent evt) \{ \} jToggleButton2ActionPerformed (evt);

\});

jButton2. setText ("Nova") ;

jButton2.addActionListener(new java.awt.event. ActionListener() \{ public void actionPerformed(java.awt.event. ActionEvent evt) \{ \} jButton2ActionPerformed (evt);

\});

javax.swing.GroupLayout

javax.swing.GroupLayout (jPanel2);

jPanel2. setLayout (jPanel2Layout);

jPanel2Layout. setHorizontalGroup (

jPanel2Layout.createParallelGroup (javax.swing.GroupLayout. Alignment. LEADING) . addGroup (jPanel2 Layout. createSequentialGroup () . addContainerGap ()

.addGroup (jPanel2Layout. createParallelGroup (javax.swing. GroupLayout. Alignment. LEADI NG)

.addComponent (jComboBox2, 0, 217, Short.MAX_VALUE)

. addGroup (jPanel2Layout. createSequentialGroüp ()

.addGroup (jPanel2Layout. createParallelGroup (javax.swing. GroupLayout. Alignment. TRAIL ING)

$$
\begin{aligned}
& \text {. addComponent (jLabel12) } \\
& \text {. addComponent (jLabel1) } \\
& \text {. addComponent (jLabel13)) }
\end{aligned}
$$

.addPreferredGap (javax.swing.LayoutStyle.ComponentPlacement.RELATED)

.addGroup (jPanel2Layout. createParallelGroup (javax. swing. GroupLayout. Alignment. LEADI 
NG)

addComponent (jTextField1)

. addComponent (jTextField2)

. addComponent (jTextField3)))

. addGroup (javax.swing.GroupLayout.Alignment. TRAILING,

jPanel2Layout.createSequentialGroup ()

. $\operatorname{addGap}(0,0$, Short.MAX_VALUE)

. addComponent (jToggleButton2,

javax.swing.GroupLayout.PREFERRED_SIZE,

63,

javax.swing.Grouplayout.PREFERRED_SIZE))

.addGroup (javax.swing.GroupLayout.Alignment. TRAILING,

jPanel2Layout.createSequentialGroup () - addComponent (jButton2,

javax.swing.GroupLayout.PREFERRED_SIZE, 63, javax.swing.GroupLayout.PREFERRED_SIZE)

.addPreferredGap (javax.swing. LayoutStyle.ComponentPlacement.RELATED,

javax.swing.GroupLayout.DEFAULT SIZE, Short.MAX VALUE)

. addContainerGap ()

)$;$

jPanel2Layout.setVerticalGroup (

jPanel2Layout.createParallelGroup (javax.swing.Grouplayout.Alignment.LEADING)

. addGroup (jPanel2 Layout. createSequentialGroup ()

. addContainerGap ()

.addComponent (jComboBox2, javax.swing.GroupLayout. PREFERRED SIZE,

javax.swing.GroupLayout.DEFAULT_SIZE, javax.swing.GroupLayout.PREFERRED_SIZE)

.addPreferredGap (javax.swing. LayoutStyle.ComponentPlacement. UNRELATED)

.addGroup (jPanel2Layout.createParallelGroup (javax.swing. GroupLayout. Alignment. BASEL INE)

. addComponent (jLabel1)

. addComponent (jTextField1,

javax.swing. Grouplayout. PREFERRED SIZE,

javax.swing.GroupLayout.PREFERRED_SIZE))

javax.swing.GroupLayout.DEFAULT_SIZE,

.addPreferredGap (javax.swing. LayoutStyle.ComponentPlacement. UNRELATED)

.addGroup (jPanel2Layout.createParallelGroup (javax.swing. GroupLayout. Alignment. BASEL INE)

. addComponent (jLabel12)

. addComponent (jTextField2

javax.swing. Grouplayout. PREFERRED SIZE,

javax.swing.GroupLayout.DEFAULT SIZE,

javax.swing.GroupLayout.PREFERRED_SIZE))

.addPreferredGap (javax.swing. LayoutStyle.ComponentPlacement. UNRELATED)

.addGroup (jPanel2Layout.createParallelGroup (javax.swing.GroupLayout. Alignment. BASEL INE)

. addComponent (jLabel13)

. addComponent (jTextField3,

javax.swing. Grouplayout. PREFERRED SIZE,

javax.swing.GroupLayout.DEFAULT_SIZE, javax.swing.GroupLayout.PREFERRED_SIZE))

.addPreferredGap (javax.swing.LayoutStyle.ComponentPlacement.RELATED, javax.swing.GroupLayout.DEFAULT_SIZE, Short.MAX_VALUE)

.addGroup (jPanel2Layout. createParallelGroup (javax.swing.GroupLayout. Alignment. BASEL INE)

- addComponent (jButton1)

. addComponent (jButton2))

.addPreferredGap (javax.swing. LayoutStyle.ComponentPlacement.RELATED)

- addComponent (jToggleButton2)

-addContainerGap ()) 
jPanel3. setBorder (javax.swing.BorderFactory.createTitledBorder (null, "Dados javax.swing.border.TitledBorder.DEFAULT_JUSTIFICATION, javax.swing.border.TitledBorder.DEFAULT_POSITION, new java.awt.Font("Arial", 1, 12))); // NOI18N

jComboBox3.setModel (new javax.swing. DefaultComboBoxModel (new String[] "Selecione o lote" \}));

jComboBox3.addItemListener(new java.awt.event.ItemListener() \{ public void itemstateChanged(java.awt.event.ItemEvent evt) \{ jComboBox3ItemstateChanged (evt);

\}); \}

\section{jLabel14. setText ( "NÃ ${ }^{\circ}$ mero") ;}

try \{ jFormattedTextField1.setFormatterFactory (new javax.swing.text. DefaultFormatterFactory (new javax.swing.text.MaskFormatter("\#\#\#.\#\#\#-\#\#\#")));

\} catch (java.text.ParseException ex) \{ ex.printStackTrace ();

\}

jFormattedTextFieldl.setHorizontalAlignment (javax.swing.JTextField.TRAILING);

jLabel15. setText ("Localizã̃ß̃̃£o") ;

jTextField4.setHorizontalAlignment (javax.swing.JTextField.TRAILING) ;

jLabel16.setText ("Data do proc.");

try \{ jFormattedTextField2. setFormatterFactory (new

javax.swing.text. DefaultFormatterFactory (new javax.swing.text.MaskFormatter("\#\#/\#\#/\#\#\#\#"))) ;

\} catch (java.text.ParseException ex) \{ ex.printStackTrace ();

\}

jFormattedTextField2. setHorizontalAlignment (javax.swing. JTextField.TRAILING);

jLabel17. setText ("Respons $\left.\tilde{A}_{i} v e l "\right) ;$

jTextField5. setHorizontalAlignment (javax.swing.JTextField.TRAILING);

jToggleButton3.setText ("Fixar");

jToggleButton3.addActionListener (new java.awt.event.ActionListener() \{ public void actionPerformed(java.awt.event. ActionEvent evt) \{ jToggleButton3ActionPerformed (evt);

\});

jButton3. setText ("Salvar");

jButton3.addActionListener(new java.awt.event. ActionListener() \{ public void actionPerformed(java.awt.event. ActionEvent evt) \{ \} jButton3ActionPerformed (evt);

\});

jButton 4 . setText ("Novo");

jButton4.addActionListener(new java.awt.event.ActionListener() \{ public void actionPerformed(java.awt.event. ActionEvent evt) \{ jButton4ActionPerformed (evt) ; 
\});

jLabel34. setText ("Repons $\tilde{A}_{i}$ vel") ;

jLabel31. setText ("Det. Germinã̃ßñ£o") ;

jLabe139. setText ("응") ;

jLabel33.setText ("Data da Liberã̃ß̃̃£o") ;

jTextField18.setHorizontalAlignment (javax.swing.JTextField.TRAILING);

jLabe138. setText ("응") ;

jTextField19. setHorizontalAlignment (javax.swing.JTextField.TRAILING) ;

jTextField21. setHorizontalAlignment (javax.swing.JTextField.TRAILING);

jLabe130. setText ("Det. Vigor");

jLabel32. setText ("Conf. Umidade") ;

try \{

jFormattedTextField3. setFormatterFactory (new

javax.swing.text.DefaultFormatterFactory (new

javax.swing.text.MaskFormatter("\#\#/\#\#/\#\#\#\#"))) ;

\} catch (java.text.ParseException ex) \{ ex.printStackTrace ();

\}

jFormattedTextField3.setHorizontalAlignment (javax.swing.JTextField.TRAILING);

jLabe137. setText ("응") ;

jTextField20.setHorizontalAlignment (javax.swing.JTextField.TRAILING)；

javax.swing.GroupLayout

jPanel 3Layout

new

javax.swing.Grouplayout (jPanel3);

jPanel3. setLayout (jPanel3Layout);

jPanel3Layout.setHorizontalGroup(

jPanel3Layout.createParallelGroup (javax.swing. GroupLayout. Alignment. LEADING) - addGroup (jPanel3Layout. createSequentialGroup () . addContainerGap ()

.addGroup (jPanel3Layout. createParallelGroup (javax.swing. GroupLayout.Alignment. LEADI NG)

$$
\text { . addComponent (jComboBox3, }
$$

javax.swing.GroupLayout.DEFAULT_SIZE, Short.MAX_VALUE)

0, .addGroup (javax.swing.GroupLayout.Alignment.TRAILING, jPanel3Layout.createSequentialGroup ()

. addComponent (jButton4, javax.swing.GroupLayout.PREFERRED_SIZE, 63, javax.swing.GroupLayout.PREFERRED_SIZE)

.addPreferredGap (javax.swing.LayoutStyle.ComponentPlacement.RELATED, javax.swing.GroupLayout.DEFAULT_SIZE, Short.MAX_VALUE)

.addGroup (jPanel 3Layout.createParallelGroup (javax.swing.Grouplayout. Alignment. LEADI NG, false)

. addComponent (jButton3,

javax.swing.GroupLayout.DEFAULT_SIZE, 71, Short.MAX_VALUE)

. ad̄ Component (jToggleButton3,

javax.swing.GroupLayout.DEFAULT_SIZE, javax.swing.GroupLayout.DEFAULT_SIZE, Short.MAX VALUE) ))

. addGroup (jPanel3Layout. createSequentialGroup () 
.addGroup (jPanel3Layout. createParallelGroup (javax.swing.GroupLayout.Alignment. TRAIL ING)

. addGroup (jPanel3Layout. createSequentialGroup ()

.addGroup (jPanel3Layout. createParallelGroup (javax.swing. GroupLayout. Alignment. TRAIL ING)

$$
\begin{aligned}
& \text {. addComponent (jLabel16) } \\
& \text {. addComponent (jLabel15) } \\
& \text {. addComponent (jLabel14) } \\
& \text {. addComponent (jLabel17)) }
\end{aligned}
$$

.addPreferredGap (javax.swing. LayoutStyle.ComponentPlacement.RELATED)

.addGroup (jPanel 3Layout. createParallelGroup (javax.swing. GroupLayout. Alignment. LEADI NG, false)

. addComponent (jFormattedTextField1,

javax.swing.GroupLayout.DEFAULT SIZE, 136, Short.MAX VALUE)

. addComponent (jTexextField4)

. addComponent (jFormattedTextField2)

. addComponent (jTextField5))

. addGap $(18,18,18)$

. addGroup (jPanel3Layout. createParallelGroup (javax.swing. GroupLayout. Alignment. TRAIL ING)

$$
\begin{gathered}
\text {. addComponent (jLabel32) } \\
\text {. addComponent (jLabel33) } \\
\text {. addComponent (jLabel 31) } \\
\text {. addComponent (jLabel30)) } \\
\text {. addComponent (jLabel34)) }
\end{gathered}
$$

.addPreferredGap (javax.swing.LayoutStyle.ComponentPlacement.RELATED)

.addGroup (jPanel3Layout.createParallelGroup (javax.swing. GroupLayout. Alignment.TRAIL ING)

$$
\begin{aligned}
& \text {. addGroup (jPanel3Layout. createSequentialGroup () } \\
& \text {. addComponent (jTextField18) }
\end{aligned}
$$

.addPreferredGap (javax.swing. LayoutStyle.ComponentPlacement.RELATED)

. addComponent (jLabe138))

. addGroup (jPanel3Layout. createSequentialGroup ()

.addGroup (jPanel3Layout. createParallelGroup (javax.swing.GroupLayout.Alignment. LEADI NG)

$$
\begin{aligned}
& \text {. addComponent (jTextField19) } \\
& \text {. addComponent (jTextField20)) }
\end{aligned}
$$

.addPreferredGap (javax.swing. LayoutStyle.ComponentPlacement.RELATED)

.addGroup (jPanel3Layout.createParallelGroup (javax.swing.GroupLayout. Alignment. LEADI NG)

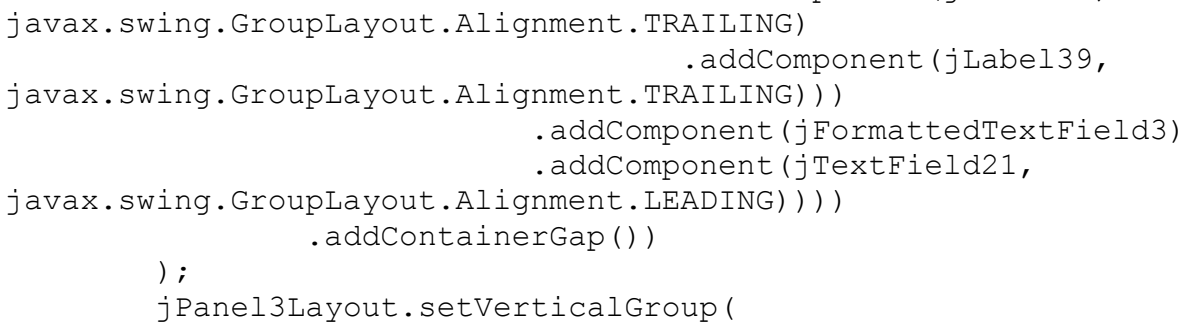

jPanel3Layout.createParallelGroup (javax.swing. GroupLayout.Alignment. LEADING) . addGroup (jPanel3Layout. createSequentialGroup () . addContainerGap ()

.addComponent (jComboBox3, javax.swing.Grouplayout.PREFERRED_SIZE, javax.swing.GroupLayout.DEFAULT_SIZE, javax.swing.GroupLayout.PREFERRED_SIZE) 
.addPreferredGap (javax.swing. Layoutstyle.ComponentPlacement.UNRELATED)

. addGroup (jPanel3Layout. createParallelGroup (javax.swing. GroupLayout. Alignment. LEADI NG)

-addGroup (jPanel 3Layout. createsequentialGroup ()

.addGroup (jPanel3Layout. createParallelGroup (javax.swing. GroupLayout. Alignment. LEADI NG)

.addGroup (jPanel 3Layout. createParallelGroup (javax.swing. GroupLayout. Alignment. BASEL INE)

- addComponent (jLabel14)

- addComponent (jFormattedTextField1,

javax.swing.GroupLayout.PREFERRED_SIZE, javax.swing.GroupLayout.DEFAULT_SIZE, javax.swing.Grouplayout.PREFERRED_SIZE))

- addCómponent (jLabe130,

javax.swing. GroupLayout. Alignment. TRAILING) )

.addPreferredGap (javax.swing. Layoutstyle.ComponentPlacement.UNRELATED)

.addGroup (jPanel3Layout. createParallelGroup (javax.swing. GroupLayout. Alignment.BASEL INE)

- addComponent (jLabe115)

- addComponent (jTextField4,

javax.swing.GroupLayout.PREFERRED_SIZE,

javax.swing. GroupLayout. PREFERRED SIZE)

- addCōmponent (jLabe131)

. addComponent (jTextField19,

javax.swing. GroupLayout. PREFERRED SIZE,

javax.swing. GroupLayout. PREFERRED SIZE)

javax.swing.GroupLayout.DEFAULT_SIZE,

. addComponent (jLabel37))

. addPreferredGap (javax.swing. Layoutstyle. ComponentPlacement. UNRELATED)

. addGroup (jPanel3Layout. createParallelGroup (javax.swing. GroupLayout. Alignment. BASEL INE)

- addComponent (jLabe116)

. addComponent (jFormattedTextField2,

javax.swing.GroupLayout.PREFERRED_SIZE, javax.swing.GroupLayout.DEFAULT_SIZE, javax.swing. GroupLayout.PREFERRED SIZE)

- addCōmponent (jLabe132)

- addComponent (jTextField20,

javax.swing.GroupLayout.PREFERRED_SIZE,

javax.swing. GroupLayout. PREFERRED_SIZE)

javax.swing. GroupLayout.DEFAULT SIZE, . addCómponent (jLabe139)))

.addGroup (jPanel3Layout. createParallelGroup (javax.swing. GroupLayout. Alignment. BASEL INE)

addComponent (jTextField18,

javax.swing.GroupLayout.PREFERRED_SIZE, javax.swing.GroupLayout.DEFAULT_SIZE, javax.swing.GroupLayout.PREFERRED_SIZE) . addComponent (jLabel38)))

.addPreferredGap (javax.swing. Layoutstyle. ComponentPlacement. UNRELATED)

. addGroup (jPanel3Layout. createParallelGroup (javax.swing. GroupLayout. Alignment. LEADI NG)

.addGroup (jPanel3Layout. createParallelGroup (javax.swing. GroupLayout. Alignment. BASEL INE)

- addComponent ( jLabe117)

- addComponent (jTextField5,

javax.swing. GroupLayout. PREFERRED SIZE,

javax.swing. GroupLayout.PREFERRED_SIZE)

javax.swing. GroupLayout.DEFAULT_SIZE,

. addComponent (jLabel33)) 
- addGroup (jPanel3Layout. createsequentialGroup () . addComponent (jFormattedTextField3,

javax.swing.GroupLayout.PREFERRED_SIZE javax.swing.GroupLayout.DEFAULT_SIZE, javax.swing.GroupLayout.PREFERRED_SIZE)

.addPreferredGap (javax.swing. Layoutstyle.ComponentPlacement.RELATED)

. addGroup (jPanel3Layout. createParallelGroup (javax.swing. GroupLayout. Alignment. BASEL INE)

. addComponent ( jLabe134)

- addComponent (jTextField21,

javax.swing.GroupLayout.PREFERRED_SIZE, javax.swing.GroupLayout.DEFAULT_SIZE, javax.swing. GroupLayout.PREFERRED_SIZE))))

. addPreferredGap (javax. swing. Layoutstyle. ComponentPlacement.RELATED, Short.MAX VALUE)

.addGroup (jPanel3Layout. createParallelGroup (javax.swing. GroupLayout.Alignment. BASEL INE)

$$
\text { - addComponent (jButton3) }
$$

- addComponent (jButton4))

. addPreferredGap (javax.swing. Layoutstyle. ComponentPlacement. RELATED)

. addComponent (jToggleButton3)

) ;

- addContainerGap ())

jPanel4.setBorder(javax.swing.BorderFactory.createTitledBorder(null, "Big Bags", javax.swing.border.TitledBorder.DEFAULT_JUSTIFICATION, javax.swing.border.TitledBorder.DEFAULT_POSITION, new java.awt.Font("Arial", 1 , 12) ) ) ; / / NOI18N

jTextField6. setHorizontalAlignment (javax.swing. JTextField.TRAILING); jTextField7. setHorizontalAlignment (javax.swing. JTextField. TRAILING); jTextField8. setHorizontalAlignment (javax.swing. JTextField.TRAILING); jTextField9. setHorizontalAlignment (javax.swing. JTextField.TRAILING); jTextField10. setHorizontalAlignment (javax.swing.JTextField. TRAILING); jTextField11. setHorizontalAlignment (javax.swing.JTextField. TRAILING) ; jTextField12. setHorizontalAlignment (javax.swing.JTextField. TRAILING) ; jTextField13. setHorizontalAlignment (javax.swing.JTextField. TRAILING) ; jTextField14. setHorizontalAlignment (javax.swing.JTextField. TRAILING) ; jTextField15. setHorizontalAlignment (javax.swing.JTextField. TRAILING) ; jTextField16. setHorizontalAlignment (javax.swing.JTextField.TRAILING) ; jTextField17. setHorizontalAlignment (javax.swing. JTextField. TRAILING) ; jLabel18. setText ("No. 1");

jLabel19. setText ("No. 2");

jLabel20. setText ("No. 3") ;

jLabel21. setText ("No. 4") ;

jLabe122. setText ("No. 5") ; 


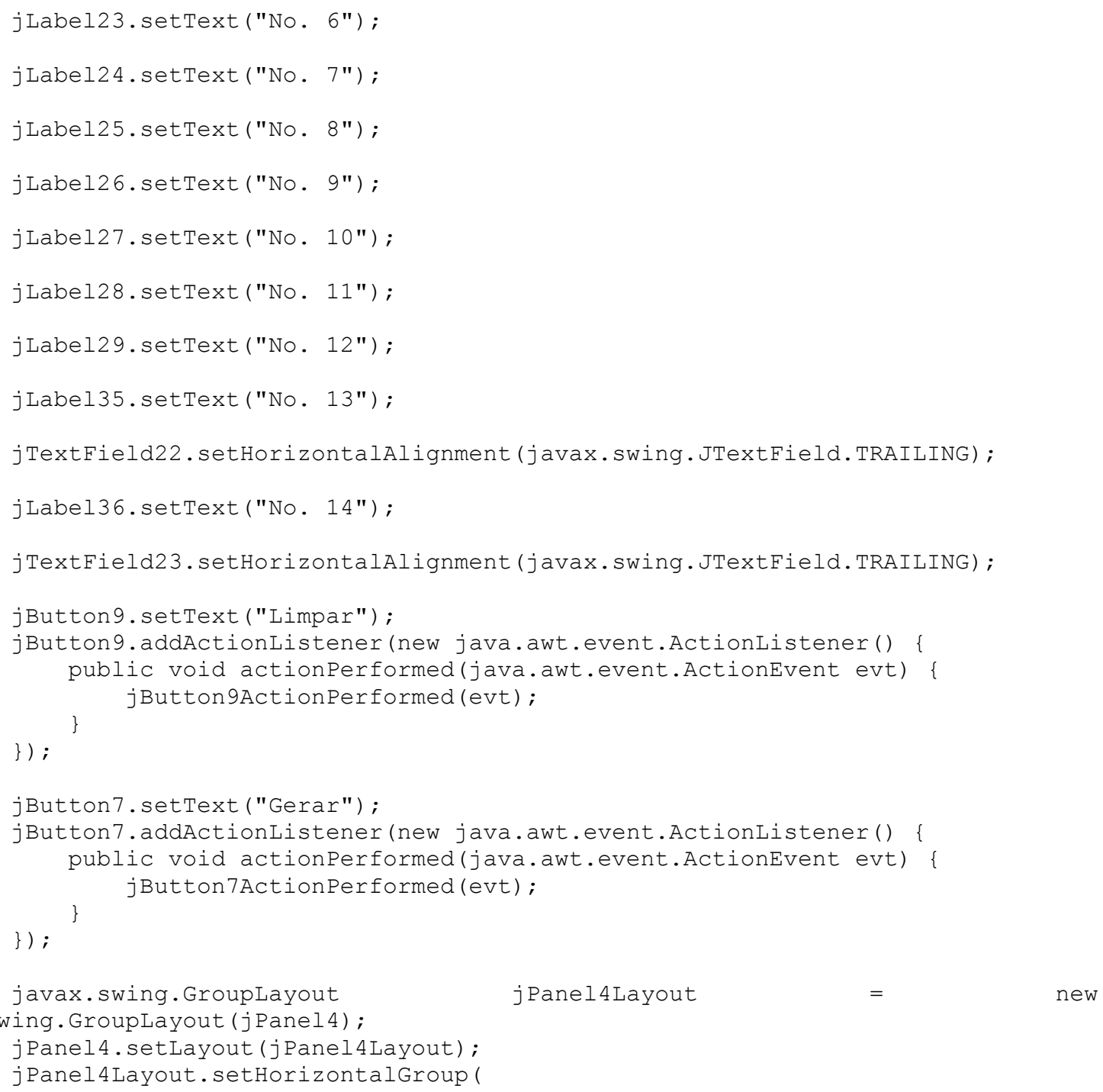

jPanel4 Layout.createParallelGroup (javax.swing.GroupLayout.Alignment. LEADING) . addGroup (jPanel 4 Layout. createSequentialGroup () - addContainerGap ( )

. addGroup (jPanel 4Layout. createParallelGroup (javax.swing. GroupLayout. Alignment. TRAIL ING, false)

. addGroup (javax.swing.GroupLayout.Alignment. LEADING,

jPanel 4 Layout. createsequentialGroup () - addComponent (jLabel25)

. addPreferredGap (javax.swing. Layoutstyle. ComponentPlacement. RELATED) - addComponent (jTextField13))

. addGroup (javax.swing.GroupLayout.Alignment. LEADING, jPanel 4 Layout. createsequentialGroup () - addComponent (jLabe118)

. addPreferredGap (javax.swing. Layoutstyle.ComponentPlacement.RELATED) . addComponent (jTextField6,

javax.swing.Grouplayout.PREFERRED_SIZE, javax.swing.GroupLayout.PREFERRED_SIZE)) )

. addPreferredGap (javax.swing. Layoutstyle. ComponentPlacement. UNRELATED)

-addGroup (jPanel 4Layout. createParallelGroup (javax.swing. GroupLayout. Alignment. LEADI NG, false) 
. addGroup (jPanel 4 Layout. createSequentialGroup () . addComponent (jLabel19)

.addPreferredGap (javax.swing. LayoutStyle.ComponentPlacement.RELATED) . addComponent (jTextField7,

javax.swing. GroupLayout. PREFERRED SIZE,

javax.swing.GroupLayout.PREFERRED_SIZE)) . addGroup (jPanel 4 Layout. createSequentialGroup () . addComponent (jLabel26)

.addPreferredGap (javax.swing. LayoutStyle. ComponentPlacement.RELATED) . addComponent (jTextField14)))

.addPreferredGap (javax.swing. LayoutStyle. ComponentPlacement. UNRELATED)

.addGroup (jPanel 4Layout.createParallelGroup (javax.swing.GroupLayout.Alignment. LEADI NG)

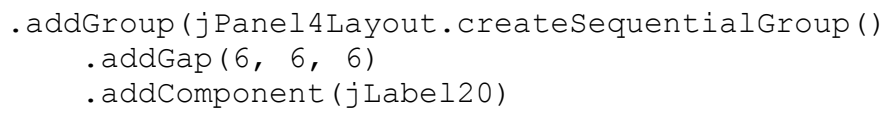

.addPreferredGap (javax.swing. LayoutStyle.ComponentPlacement. UNRELATED)

. addGroup (jPanel 4 Layout. createParallelGroup (javax.swing.GroupLayout. Alignment. LEADI NG)

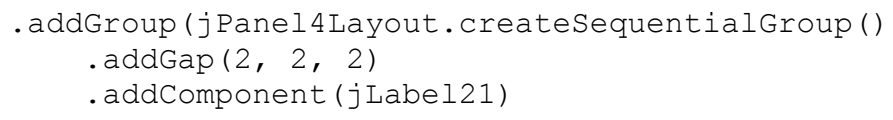
NG)

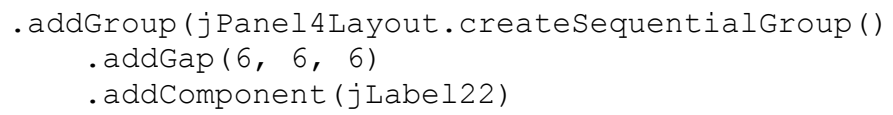


jPanel 4layout. createsequentialGroup () . addComponent (jLabe129)

. addPreferredGap (javax.swing. Layoutstyle.ComponentPlacement.RELATED) - addComponent (jTextField17,

javax.swing. GroupLayout. PREFERRED SIZE,

62 ,

javax.swing.GroupLayout.PREFERRED_SIZE)))

.addGroup (jPanel 4Layout. createParallelGroup (javax.swing. GroupLayout. Alignment. LEADI NG)

. addGroup (javax.swing. GroupLayout. Alignment. TRAILING,

jPanel 4 Layout. createsequentialGroup ( )

. $\operatorname{addGap}(16,16,16)$

. addComponent (jLabe135)

-addPreferredGap (javax.swing. Layoutstyle. ComponentPlacement. RELATED)

- addComponent (jTextField22,

javax.swing.GroupLayout.PREFERRED_SIZE,

javax.swing. Grouplayout. PREFERRED SIZE))

- addGroup (jPañel 4 Layout. createsequentialGroup ()

- $\operatorname{addGap}(18,18,18)$

. addComponent (jLabe123)

.addPreferredGap (javax.swing. LayoutStyle. ComponentPlacement. UNRELATED) . addComponent (jTextField11,

javax.swing. GroupLayout. PREFERRED SIZE,

70

javax.swing.GroupLayout.PREFERRED_SIZE)))

. $\operatorname{addGap}(13,13,1 \overline{3})$

.addGroup (jPanel4Layout. createParallelGroup (javax.swing. GroupLayout. Alignment. TRAIL ING)

- addGroup (jPanel 4 Layout. createSequentialGroup () - addComponent ( jLabe124)

.addPreferredGap (javax.swing. Layoutstyle. ComponentPlacement. UNRELATED) - addComponent (jTextField12,

javax.swing. GroupLayout. PREFERRED SIZE,

javax.swing.GroupLayout.PREFERRED_SIZE))

66 ,

. addGroup (jPañel4 Layout. createSequentialGroup () - addComponent (jLabel36)

.addPreferredGap (javax.swing. Layoutstyle.ComponentPlacement. UNRELATED) . addComponent (jTextField23,

javax.swing. GroupLayout. PREFERRED SIZE,

65,

javax.swing.GroupLayout.PREFERRED_SIZE)))

. addPreferredGap (javax. swing. Layoutstyle. ComponentPlacement.RELATED,

Short. MAX VALUE)

.addGroup (jPanel 4Layout. createParallelGroup (javax.swing. GroupLayout.Alignment. LEADI NG, false)

-addComponent (jButton9, javax.swing.GroupLayout.DEFAULT_SIZE, javax.swing.GroupLayout.DEFAULT SIZE, Short.MAX VALUE)

.addComponentt (jButton7, javax.swing.GroupLayout.DEFAULT_SIZE, javax.swing.Grouplayout.DEFAULT SIZE, Short.MAX VALUE))

) ;

- addContainerGap̄ ( )

jPanel4Layout. setVerticalGroup (

jPanel4 Layout. createParallelGroup (javax.swing.GroupLayout.Alignment. LEADING)

. addGroup (jPanel 4 Layout. createsequentialGroup ()

. addGroup (jPanel 4 Layout. createParallelGroup (javax.swing.GroupLayout. Alignment. LEADI NG)

. addGroup (jPanel 4 Layout. createSequentialGroup ()

- addContainerGap () 
.addGroup (jPanel 4Layout.createParallelGroup (javax.swing.GroupLayout.Alignment. BASEL INE)

. addComponent ( $j$ TextField6,

javax.swing.GroupLayout.PREFERRED_SIZE,

javax.swing.GroupLayout.DEFAULT_SIZE,

javax.swing. GroupLayout. PREFERRED SIZE)

. addComponent ( jLabel18)

. addComponent (jTextField7

javax.swing.GroupLayout.PREFERRED_SIZE, javax.swing.GroupLayout.DEFAULT_SIZE, javax.swing.GroupLayout.PREFERRED SIZE)

- addCömponent (jLabel19)

. addComponent (jTextField8,

javax.swing.GroupLayout.PREFERRED_SIZE, javax.swing.GroupLayout.DEFAULT_SIZE,

javax.swing.GroupLayout. PREFERRED SIZE)

. addComponent (jLabel20)

. addComponent (jTextField9,

javax.swing.GroupLayout.PREFERRED SIZE,

javax.swing.GroupLayout.PREFERRED_SIZE)

. addComponent (jLabel21)

. addComponent (jTextField10,

javax.swing.Grouplayout. PREFERRED SIZE,

javax.swing.GroupLayout.DEFAULT_SIZE,

javax.swing. GroupLayout. PREFERRED SIZE)

- addComponent (jLabel22)

. addComponent ( $j$ TextField11,

javax.swing.GroupLayout.PREFERRED_SIZE

javax.swing.GroupLayout.DEFAULT_SIZE,

javax.swing.Grouplayout. PREFERRED SIZE)

. addComponent (jLabel23)

. addComponent (jTextField12,

javax.swing.GroupLayout.PREFERRED_SIZE,

javax.swing.GroupLayout.DEFAULT_SIZE,

javax.swing.Grouplayout. PREFERRED SIZE)

. addCōomponent (jLabel24)))

. addComponent (jButton 7))

. addGap $(18,18,18)$

.addGroup (jPanel 4Layout.createParallelGroup (javax.swing. GroupLayout.Alignment. BASEL INE)

.addComponent (jTextField13,

javax.swing.Grouplayout.PREFERRED_SIZE,

javax.swing.GroupLayout.DEFAULT_SIZE, javax.swing. GroupLayout. PREFERRED SIZE)

. addComponent (jLabel25)

. addComponent (jTextField14,

javax.swing.GroupLayout.PREFERRED_SIZE,

javax.swing.GroupLayout.DEFAULT_SIZE,

javax.swing.GroupLayout.PREFERRED SIZE)

. addComponent ( $j$ Label26)

. addComponent (jTextField15,

javax.swing. Grouplayout. PREFERRED SIZE,

javax.swing.GroupLayout.PREFERRED SIZE)

. addComponent (jLabel27)

. addComponent ( jLabel28)

. addComponent (jTextField17,

javax.swing.GroupLayout.PREFERRED_SIZE,

javax.swing.GroupLayout.DEFAULT_SIZE, javax.swing. GroupLayout. PREFERRED SIZE)

. addComponent (jLabel29)

. addComponent (jTextField16,

javax.swing.GroupLayout.PREFERRED_SIZE,

javax.swing.GroupLayout.PREFERRED_SIZE)

. addComponent (jLabe135)

. addComponent (jLabe136)

. addComponent (jTextField23,

javax.swing.GroupLayout.PREFERRED_SIZE,

javax.swing.GroupLayout.DEFAULT_SIZE,

javax.swing.GroupLayout.PREFERRED_SIZE)

. addComponent (jTextField22,

javax.swing.GroupLayout.PREFERRED_SIZE, javax.swing.GroupLayout.DEFAULT_SIZE,

javax.swing. GroupLayout. PREFERRED SIZE)

. addComponent (jButton9))

.addContainerGap (javax.swing.GroupLayout. DEFAULT SIZE, 


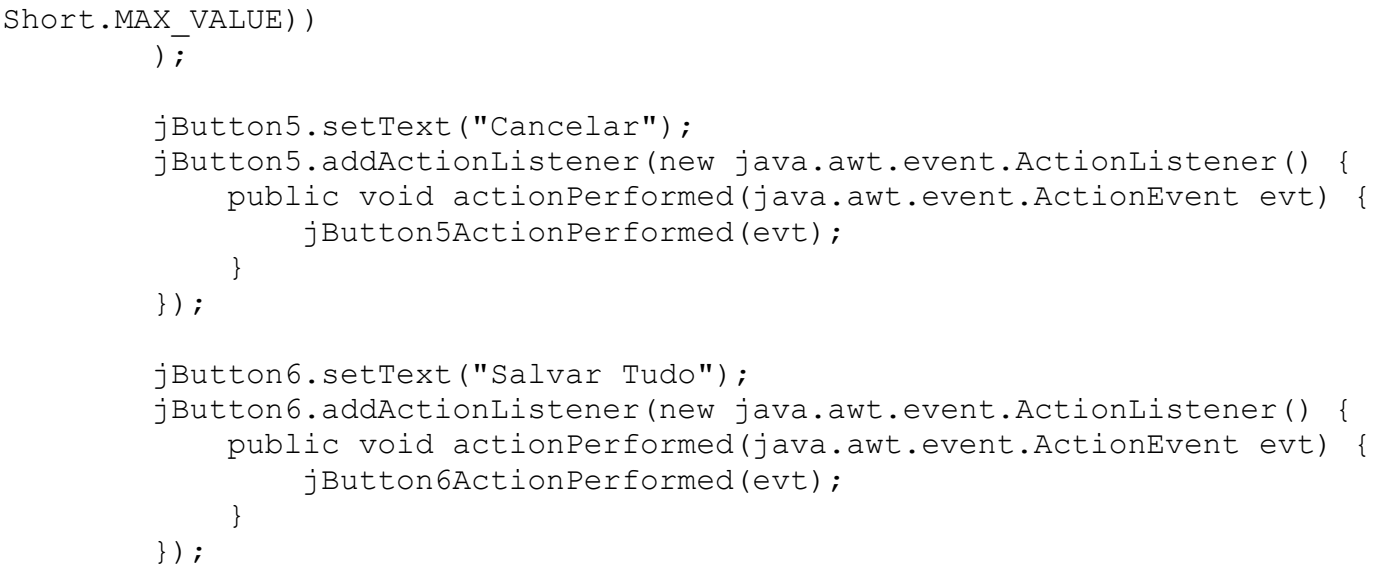


.addGroup (layout.createParallelGroup (javax.swing.GroupLayout.Alignment.BASELINE) . addComponent (jButton5) . addComponent (jButton6))

) ; - addContainerGap ()

$\operatorname{pack}() ;$

\}// </editor-fold>//GEN-END:initComponents

private void jToggleButton2ActionPerformed(java.awt.event.ActionEvent evt) $\{/ /$ GEN-FIRST:event jToggleButton2ActionPerformed updateToggleButtonStatus (jToggleButton2, jComboBox2);

\}//GEN-LAST: event_jToggleButton2ActionPerformed

private void jButton5ActionPerformed(java.awt.event.ActionEvent evt) \{//GENFIRST: event jButton5ActionPerformed

dispose ();

\}//GEN-LAST: event_jButton5ActionPerformed

private void jComboBoxlItemStatechanged(java.awt.event. ItemEvent evt) \{//GENFIRST:event_jComboBoxlitemstateChanged mostrarCarregamento (jComboBoxl.getSelectedIndex ()) ;

\}//GEN-LAST: event_jComboBoxlItemStateChanged

private void jToggleButton1MouseClicked(java.awt.event.MouseEvent evt) \{//GENFIRST:event_jToggleButtonlMouseClicked updateToggleButtonstatus (jToggleButton1, jComboBox1);

\}//GEN-LAST:event_jToggleButton1MouseClicked

private void jComboBox2ItemStateChanged(java.awt.event.ItemEvent evt) \{//GENFIRST: event jComboBox2ItemStatechanged mostrarTorre (jComboBox2.getSelectedIndex ());

\}//GEN-LAST:event_jComboBox2ItemStateChanged

private void jButtonlActionPerformed(java.awt.event.ActionEvent evt) \{//GENFIRST: event jButton1ActionPerformed

// SALVAR TORRE

String[] parametros = new String[3];

parametros $[0]=j$ TextFieldl.getText () ;

parametros $[1]=$ jTextField2.getText ()

parametros $[2]=j$ TextField3.getText ()$;$

boolean result $=$ Mainframe.mysql. insertRowInTable ("torre", parametros); id torre fixo = Mainframe.mysql.getLastIdFromTable("torre", "id torre"); Utílities.s.consoleout("lastID = "+id_torre_fixo);

if (result)

\{

\}

jToggleButton2. setEnabled (result);

else

\{

JoptionPane.showMessageDialog(this,

"Aconteceu um erro na hora de gravar os dados

no banco",

"Nova Torre - Erro",

JOptionPane.ERROR_MESSAGE);

\}

\}//GEN-LAST: event_jButton1ActionPerformed

private void jButton2ActionPerformed(java.awt.event.ActionEvent evt) \{//GEN- 
FIRST: event jButton2ActionPerformed

clearTorreFields ();

jButton1. setEnabled (true);

jComboBox2. setSelectedIndex (0);

\}//GEN-LAST:event_jButton2ActionPerformed

private void jButton3ActionPerformed(java.awt.event. ActionEvent evt) \{//GENFIRST:event jButton3ActionPerformed

// SALVAR LOTE

String[] parametros = new String[11];

parametros $[0]=$ String.valueof(id_granel_fixo);

parametros[1] = String.valueof(id torre_fixo);

parametros [2] = jFormattedTextFiēldl.geEtText ();

parametros [3] = jTextField4.getText();

parametros $[4]=j$ TextField5.getText ();

parametros [5] = jFormattedTextField2.getText();

parametros $[6]=j$ TextField18.getText ();

parametros $[7]=$ jTextField19.getText ()$;$

parametros $[8]=j$ TextField20.getText () ;

parametros $[9]=$ jFormattedTextField3.getText () ;

parametros $[10]=$ jTextField21.getText();

boolean result = MainFrame.mysql.insertRowInTable("lote", parametros);

id_lote fixo = MainFrame.mysql.getLastIdFromTable ("lote", "id_lote");

Utilitiés.consoleout("lastID = "+id_lote_fixo);

if (result)

\{

\}

jToggleButton2. setEnabled (result) ;

else

\{

JoptionPane.showMessageDialog (this,

"Aconteceu um erro na hora de gravar os dados

no banco",

"Novo Lote - Erro",

JOptionPane.ERROR_MESSAGE);

\}

\}//GEN-LAST: event_jButton3ActionPerformed

private void jButton4ActionPerformed(java.awt.event.ActionEvent evt) \{//GENFIRST:event jButton4ActionPerformed

clearLotefields ();

jButton3. setEnabled (true);

jComboBox3. setSelectedIndex (0);

\}//GEN-LAST:event_jButton4ActionPerformed

private void jComboBox3ItemStateChanged(java.awt.event.ItemEvent evt) \{//GENFIRST: event jComboBox3ItemStatechanged

mostrarLote (jComboBox3.getSelectedIndex ());

\}//GEN-LAST:event_jComboBox3ItemStateChanged

private void jToggleButton3ActionPerformed(java.awt.event.ActionEvent evt) \{//GEN-FIRST: event_jToggleButton3ActionPerformed

updateToggleButtonStatus (jToggleButton3, jComboBox3);

\}//GEN-LAST: event_jToggleButton3ActionPerformed

private void jButton9ActionPerformed(java.awt.event. ActionEvent evt) \{//GENFIRST:event_jButton9ActionPerformed

clearBigBagsFields ();

\}//GEN-LAST: event_jButton9ActionPerformed

private void jButton6ActionPerformed(java.awt.event.ActionEvent evt) \{//GENFIRST:event_jButton6ActionPerformed

// SALVAR BIG BAGS

String[] parametros = new String[14];

parametros $[0]=$ jTextField6.getText () ; 


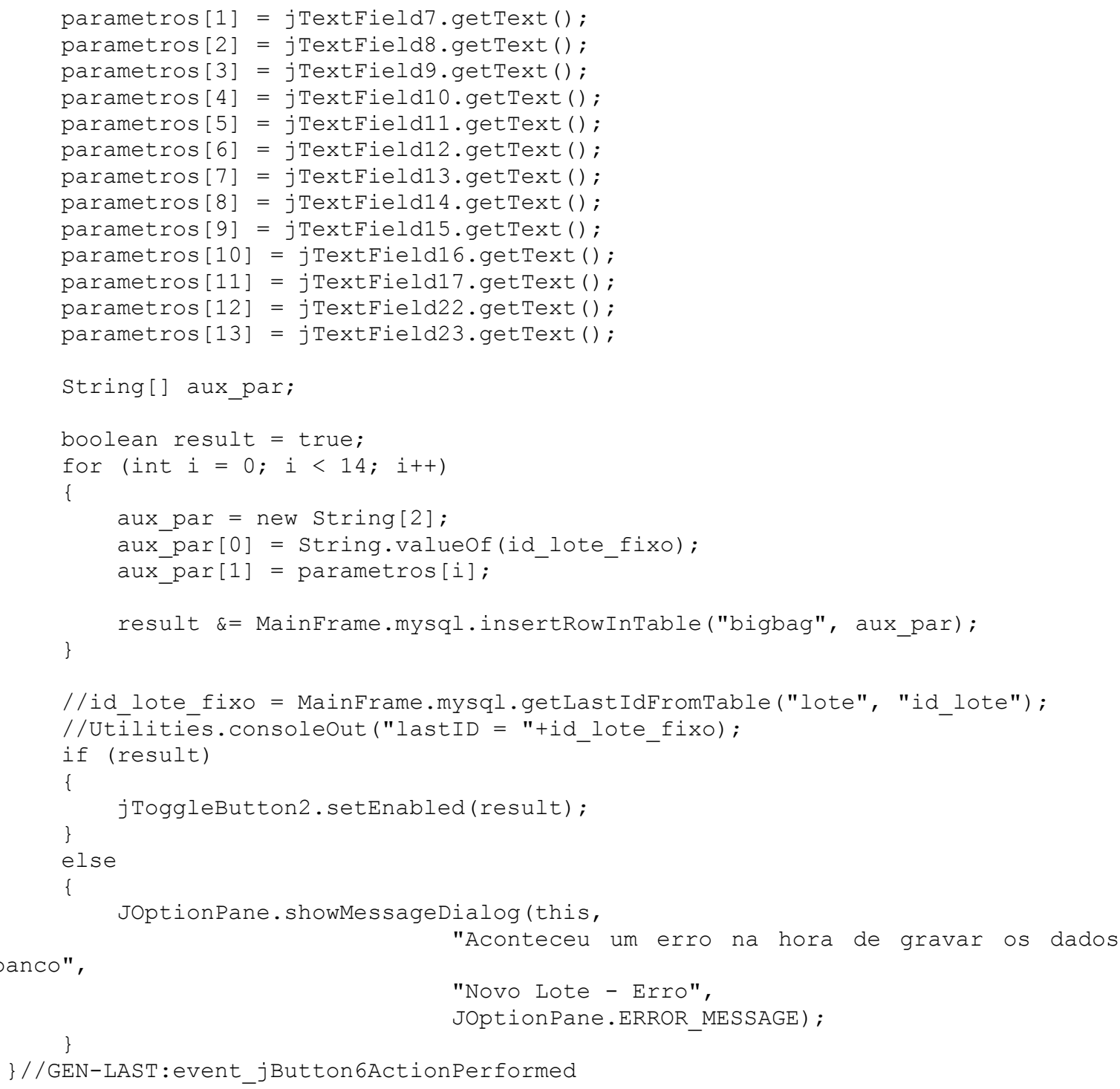


private javax.swing. JButton jButton2;

private javax.swing. JButton jButton3;

private javax.swing. JButton jButton 4 ;

private javax.swing. JButton jButton5;

private javax.swing.JButton jButton6;

private javax.swing. JButton jButton 7 ;

private javax.swing. JButton jButton9;

private javax.swing. JComboBox jComboBox1;

private javax.swing.JComboBox jComboBox2;

private javax.swing. JComboBox jComboBox3;

private javax.swing. JFormattedTextField jFormattedTextField1;

private javax.swing. JFormattedTextField jFormattedTextField2;

private javax.swing. JFormattedTextField jFormattedTextField3;

private javax.swing. JLabel jLabel1;

private javax.swing. JLabel jLabel10;

private javax.swing. JLabel jLabel11;

private javax.swing. JLabel jLabel12;

private javax.swing. JLabel jLabel13;

private javax.swing. JLabel jLabel14;

private javax.swing. JLabel jLabel15;

private javax.swing.JLabel jLabel16;

private javax.swing. JLabel jLabel17;

private javax.swing. JLabel jLabel18;

private javax.swing. JLabel jLabel19;

private javax.swing. JLabel jLabel2;

private javax.swing. JLabel jLabel20;

private javax.swing. JLabel jLabel21;

private javax.swing. JLabel jLabel22;

private javax.swing. JLabel jLabel23;

private javax.swing. JLabel jLabel24;

private javax.swing.JLabel jLabel25;

private javax.swing.JLabel jLabel26;

private javax.swing. JLabel jLabe127;

private javax.swing. JLabel jLabel28;

private javax.swing. JLabel jLabe129;

private javax.swing.JLabel jLabel3;

private javax.swing. JLabel jLabel30;

private javax.swing. JLabel jLabel31;

private javax.swing. JLabel jLabel32;

private javax.swing.JLabel jLabel33;

private javax.swing. JLabel jLabel34;

private javax.swing. JLabel jLabel35;

private javax.swing.JLabel jLabel36;

private javax.swing. JLabel jLabe137;

private javax.swing. JLabel jLabel38;

private javax.swing. JLabel jLabel39;

private javax.swing.JLabel jLabel4;

private javax.swing.JLabel jLabel5;

private javax.swing.JLabel jLabel6;

private javax.swing.JLabel jLabe17;

private javax.swing.JLabel jLabel8;

private javax.swing. JLabel jLabel9;

private javax.swing. JPanel jPanel1;

private javax.swing.JPanel jPanel2;

private javax.swing.JPanel jPanel3;

private javax.swing.JPanel jPanel4;

private javax.swing. JTextField jTextFieldi;

private javax.swing.JTextField jTextField10;

private javax.swing.JTextField jTextField11;

private javax.swing. JTextField jTextField12;

private javax.swing. JTextField jTextField13;

private javax.swing. JTextField jTextField14;

private javax.swing.JTextField jTextField15;

private javax.swing.JTextField jTextField16;

private javax.swing.JTextField jTextField17;

private javax.swing.JTextField jTextField18; 


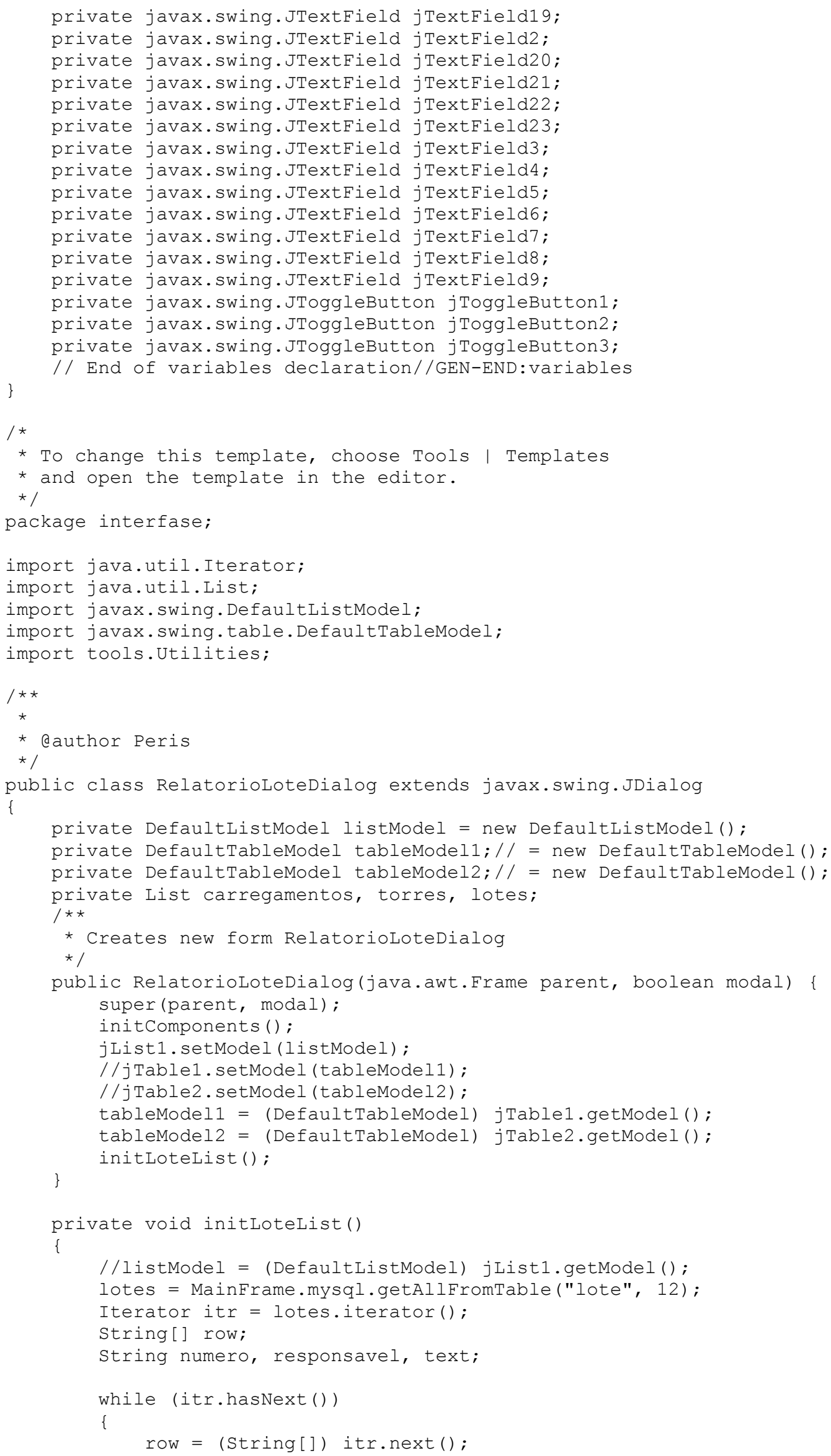




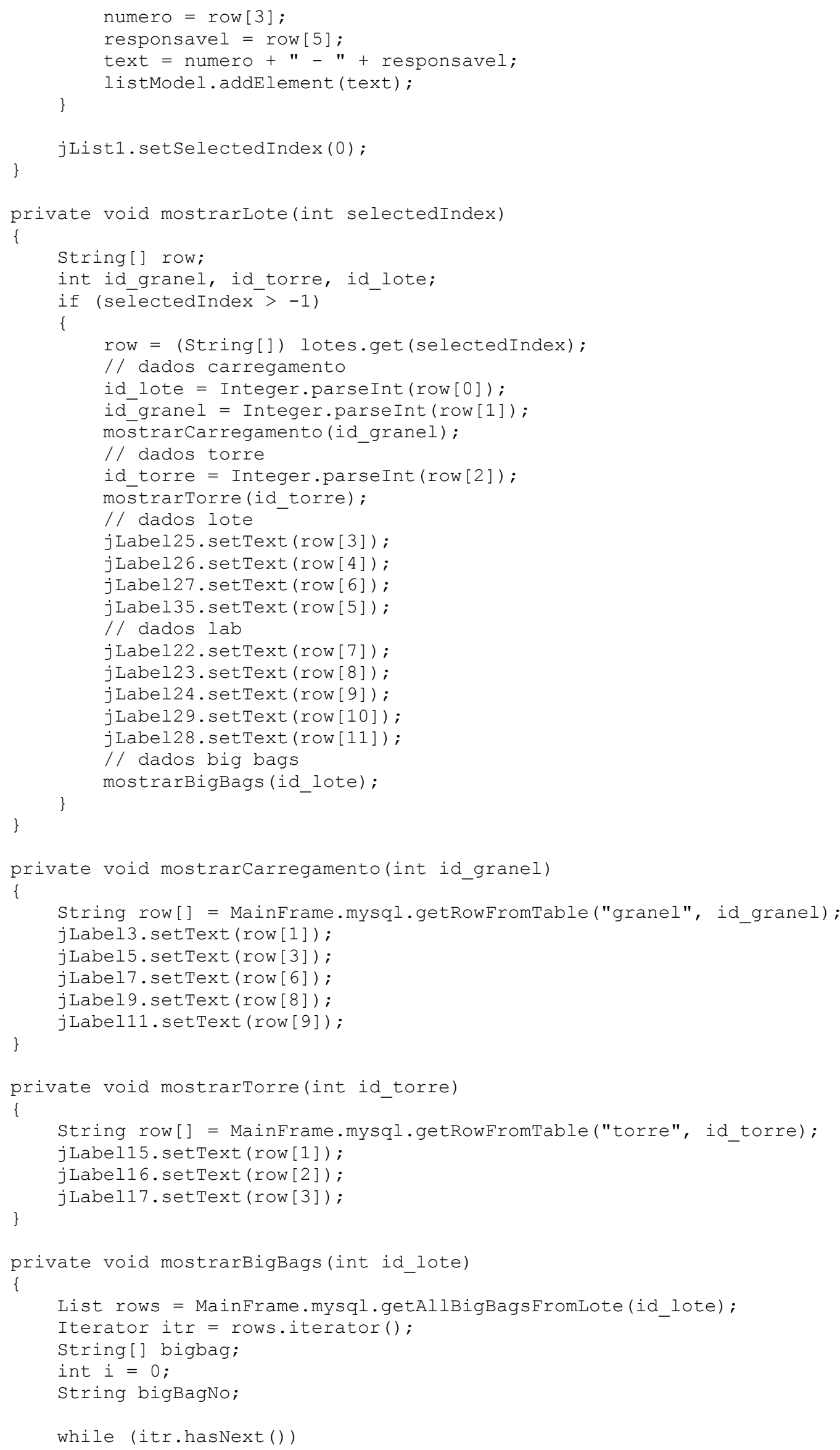


bigbag $=($ String []$)$ itr.next () ;

bigBagNo = bigbag[2];

if $(i<7) \quad\{$

tableModel1. setValueAt (bigBagNo, 0, i);

\}

else \{

\}

tableMode12. setValueAt (bigBagNo, 0, i-7);

$i++$;

\}

$1 * *$

* This method is called from within the constructor to initialize the form.

* WARNING: Do NOT modify this code. The content of this method is always

* regenerated by the Form Editor.

*

@SuppressWarnings ("unchecked")

// <editor-fold defaultstate="collapsed" desc="Generated Code" $>/ /$ GENBEGIN: initComponents

private void initComponents()

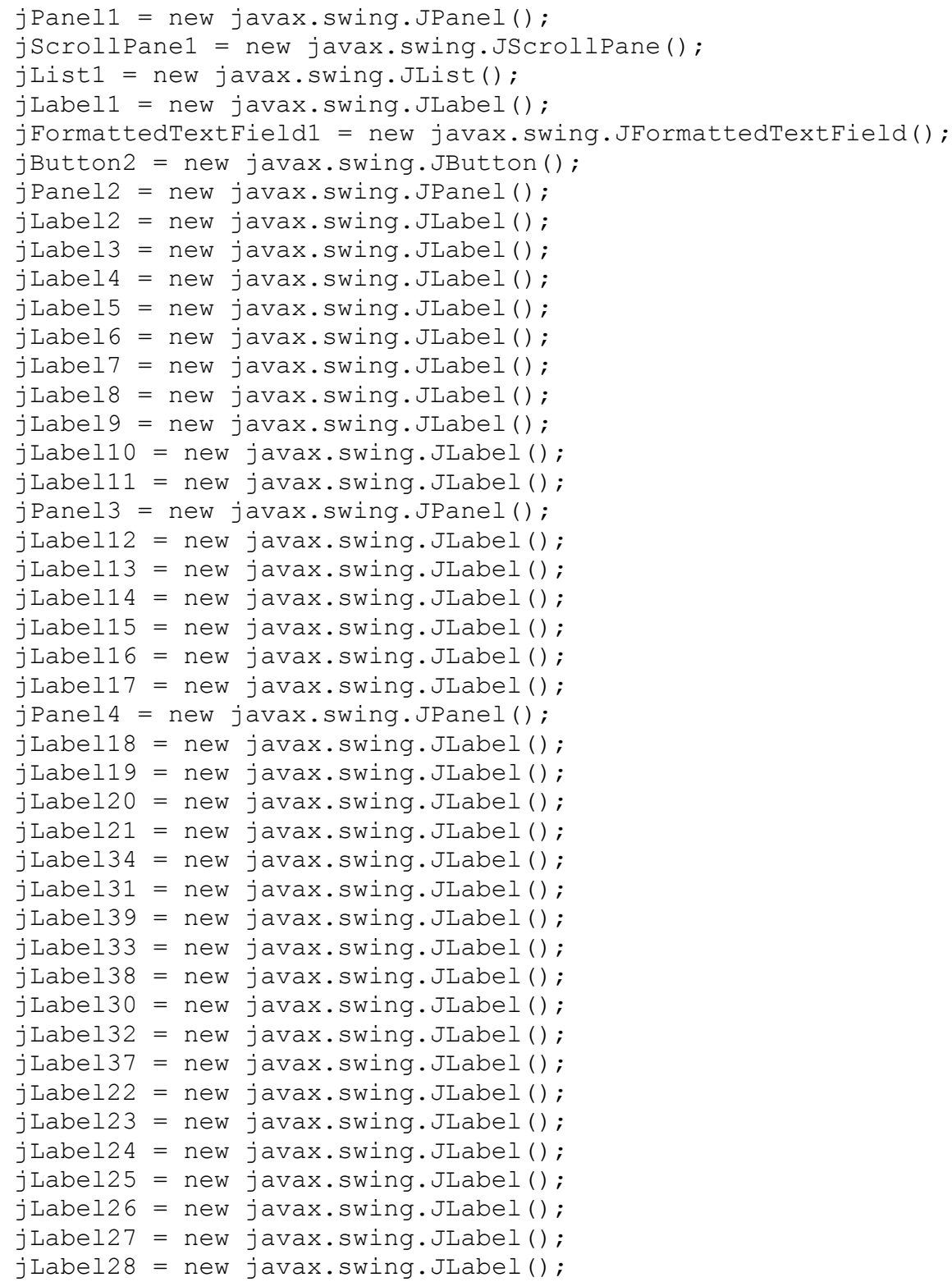




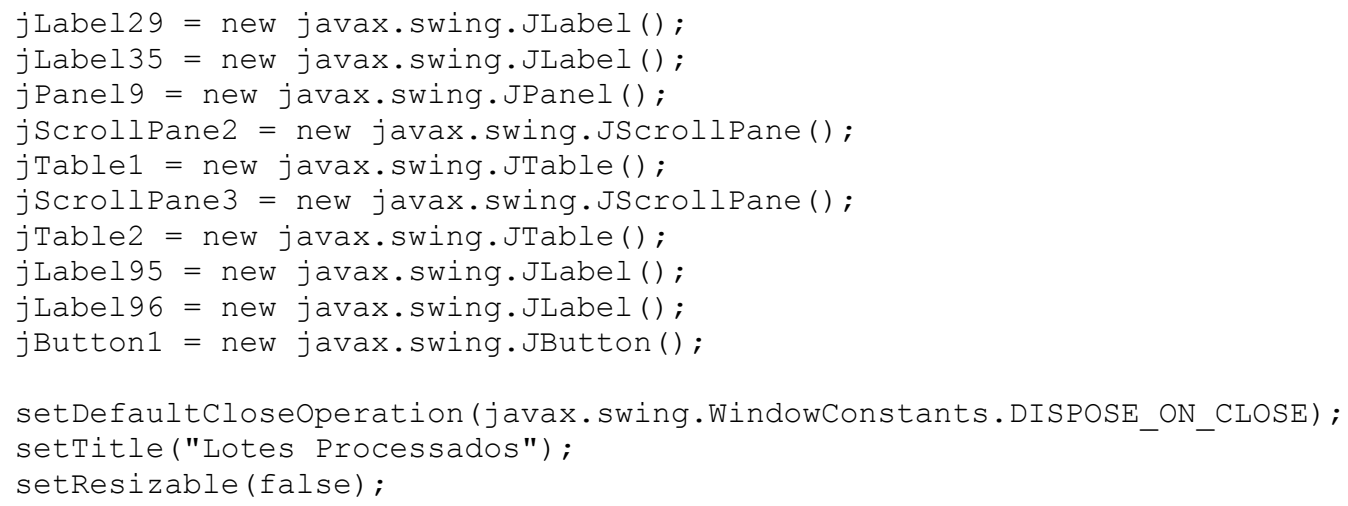

jPanel1.setBorder(javax.swing.BorderFactory.createTitledBorder(null, "Lotes Processados" javax.swing.border.TitledBorder.DEFAULT JUSTIFICATION, javax.swing.border.TitledBorder.DEFAULT_POSITION, new java.awt.Font("Arial", 1, 12)) ); // NOI18N

jList1.setSelectionMode (javax.swing.ListSelectionModel.SINGLE_SELECTION);

jList1.addListSelectionListener (new

javax.swing.event. ListSelectionListener() \{ public void valueChanged(javax.swing.event. ListSelectionEvent evt) \{ \} jList1ValueChanged (evt);

\});

jScrollPane1.setViewportView(jList1);

jLabel1.setText ("No. do Lote");

try \{

jFormattedTextField1. setFormatterFactory (new

javax.swing. text. DefaultFormatterFactory (new

javax.swing.text.MaskFormatter("\#\#\#.\#\#\#-\#\#\#")));

\} catch (java.text.ParseException ex) \{ ex.printStackTrace ();

\}

jFormattedTextField1.setHorizontalAlignment (javax.swing. JTextField.TRAILING);

jButton2. setText ("Procurar");

jPanel2.setBorder(javax.swing.BorderFactory.createTitledBorder(null, "Dados do Carregamento", javax.swing.border.TitledBorder.DEFAULT_JUSTIFICATION, javax.swing.border.TitledBorder.DEFAULT_POSITION, new java.awt.Font("Arial", 1, 12))); // NOI18N

jLabel2. setText ("Produtor:");

jLabe13. setFont (new java.awt.Font("Tahoma", 1, 11)); // NOI18N jLabel3. setText ("jLabel3");

jLabel4. setText ("Semente:");

jLabe15. setFont (new java.awt.Font("Tahoma", 1, 11)); // NOI18N jLabel5. setText ("jLabel5");

jLabel6.setText ("Recebido em:");

jLabe17.setFont (new java.awt.Font("Tahoma", 1, 11)); // NOI18N

jLabe17. setText ("jLabel7");

jLabel8.setText ("Peso IÃquido:");

jLabe19. setFont (new java.awt.Font ("Tahoma", 1, 11)); // NOI18N 
jLabel9. setText ("jLabel9");

jLabe110. setText ("Moega descarga:") ;

jLabel11. setFont (new java.awt.Font("Tahoma", 1, 11)) ; // NOI18N

jLabel11. setText ("jLabel11");

javax.swing.GroupLayout

jPane12Layout

new javax.swing. Grouplayout (jPanel2);

jPanel2. setLayout (jPanel2Layout) ;

jPanel2Layout. setHorizontalGroup(

jPanel2Layout. createParallelGroup (javax.swing.GroupLayout.Alignment. LEADING) . addGroup (jPanel2Layout. createSequentialGroup () - addContainerGap ( )

. addGroup (jPanel2Layout. createParallelGroup (javax.swing. GroupLayout. Alignment. TRAIL ING)

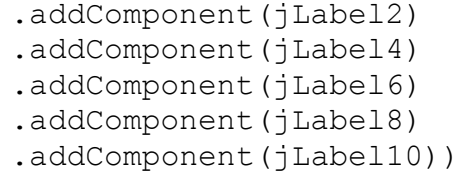

.addPreferredGap (javax.swing. LayoutStyle.ComponentPlacement.UNRELATED)

.addGroup (jPanel2Layout. createParallelGroup (javax.swing. GroupLayout.Alignment. LEADI NG)

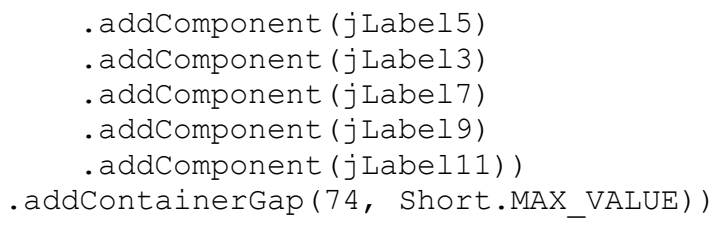

jPanel2Layout. createParallelGroup (javax.swing.GroupLayout.Alignment.LEADING) - addGroup (jPanel2 Layout. createSequentialGroup () - addContainerGap ( )

.addGroup (jPanel2Layout. createParallelGroup (javax.swing. GroupLayout.Alignment.BASEL INE)

$$
\begin{aligned}
& \text { - addComponent (jLabe 12) } \\
& \text { - addComponent (jLabel 3)) }
\end{aligned}
$$

.addPreferredGap (javax.swing.LayoutStyle.ComponentPlacement.RELATED)

.addGroup (jPanel2Layout. createParallelGroup (javax.swing.GroupLayout.Alignment.BASEL INE)

$$
\text { - addComponent (jLabel4) }
$$$$
\text { . addComponent (jLabel5)) }
$$

.addPreferredGap (javax.swing. LayoutStyle.ComponentPlacement.RELATED)

. addGroup (jPanel2Layout. createParallelGroup (javax.swing. GroupLayout. Alignment. BASEL INE)

$$
\begin{aligned}
& \text { - addComponent (jLabel 6) } \\
& \text { - addComponent (jLabel 7)) }
\end{aligned}
$$

.addPreferredGap (javax.swing. LayoutStyle.ComponentPlacement.RELATED)

. addGroup (jPanel2Layout. createParallelGroup (javax.swing. GroupLayout. Alignment. BASEL INE)

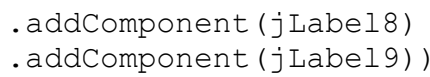


.addPreferredGap (javax.swing. Layoutstyle.ComponentPlacement.RELATED)

.addGroup (jPanel2Layout.createParallelGroup (javax.swing.GroupLayout. Alignment. BASEL INE)

. addComponent ( $j$ Label10)

. addComponent (jLabel11))

Short.MAX_VALUE))

.addContainerGap (javax.swing.GroupLayout.DEFAULT SIZE,

)$;$

da

jPanel3. setBorder (javax.swing.BorderFactory.createTitledBorder(null, "Dados javax.swing.border.TitledBorder.DEFAULT JUSTIFICATION, javax.swing.border.TitledBorder.DEFAULT_POSITION, new java.awt.Font("Arial", 1, 12)) ); // NOI18N

jLabel12. setText("Tipo de Peneira:");

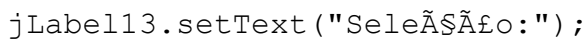

jLabel14. setText ("Respons $\tilde{A}_{i}$ vel:" ) ;

jLabel15. setFont (new java.awt.Font("Tahoma", 1, 11)) ; // NOI18N

jLabel15. setText ("jLabe115");

jLabel16. setFont (new java.awt.Font("Tahoma", 1, 11)) ; // NOI18N

jLabel16. setText ("jLabel16");

jLabe117. setFont (new java.awt.Font("Tahoma", 1, 11)) ; // NOI18N

jLabel17. setText ("jLabe117");

javax.swing. GroupLayout

jPane13Layout

new javax.swing. Grouplayout (jPanel3);

jPane13. set Layout (jPanel3Layout);

jPanel3Layout. setHorizontalGroup(

jPanel3Layout. createParallelGroup (javax.swing.GroupLayout.Alignment. LEADING) . addGroup (jPanel3Layout. createsequentialGroup () . $\operatorname{addGap}(25,25,25)$

.addGroup (jPanel3Layout. createParallelGroup (javax.swing. GroupLayout.Alignment. TRAIL ING)

$$
\begin{aligned}
& \text {. addComponent (jLabel13) } \\
& \text { - addComponent (jLabel12) } \\
& \text {. addComponent (jLabel14)) }
\end{aligned}
$$

.addPreferredGap (javax.swing. LayoutStyle. ComponentPlacement. UNRELATED)

.addGroup (jPanel 3Layout. createParallelGroup (javax.swing. GroupLayout. Alignment. LEADI NG)

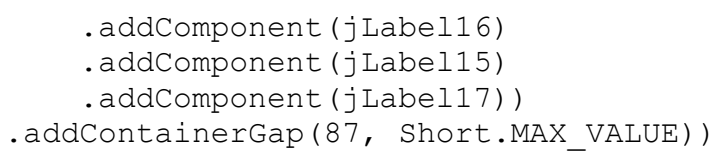

jPanel3Layout. createParallelGroup (javax.swing.GroupLayout.Alignment. LEADING) . addGroup (jPanel3Layout. createSequentialGroup () - addContainerGap ()

.addGroup (jPanel3Layout. createParallelGroup (javax.swing. GroupLayout.Alignment. LEADI NG)

. addComponent (j Label15)

- addGroup (jPanel3Layout. createSequentialGroup ()

. addComponent (jLabel12) 
.addPreferredGap (javax.swing. LayoutStyle. ComponentPlacement. UNRELATED)

.addGroup (jPanel 3Layout.createParallelGroup (javax.swing. GroupLayout. Alignment. BASEL INE)

$$
\begin{aligned}
& \text {. addComponent (jLabel13) } \\
& \text {. addComponent (jLabel16)) }
\end{aligned}
$$

.addPreferredGap (javax.swing. Layout.Style.ComponentPlacement. UNRELATED)

.addGroup (jPanel 3Layout.createParallelGroup (javax.swing. GroupLayout. Alignment. BASEL INE)

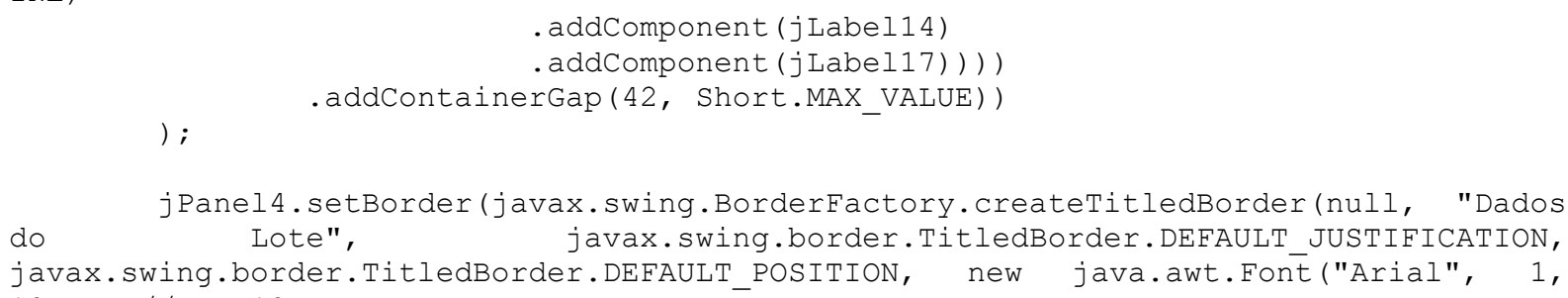


jLabe127. setFont (new java.awt.Font("Tahoma", 1, 11)) ; // NOI18N

jLabe127. setText ("jLabe127");

jLabe128. setFont (new java.awt.Font("Tahoma", 1, 11)) ; // NOI18N

jLabe128. setText ("jLabe128");

jLabe129. setFont (new java.awt.Font("Tahoma", 1, 11)) ; // NOI18N

jLabe129. setText ("jLabe129");

jLabe135. setFont (new java.awt.Font("Tahoma", 1, 11)) ; // NOI18N

jLabel35. setText ("jLabel35");

javax.swing. Grouplayout

jPanel 4Layout

new javax.swing. GroupLayout (jPanel4);

jPanel4. set Layout (jPanel4 Layout);

jPanel4 Layout. setHorizontalGroup (

jPanel 4 Layout. createParallelGroup (javax.swing.GroupLayout.Alignment. LEADING) . addGroup (jPanel 4 Layout. createSequentialGroup ()

$\cdot \operatorname{addGap}(24,24,24)$

. addGroup (jPanel 4Layout. createParallelGroup (javax.swing. GroupLayout. Alignment. TRAIL ING)

$$
\begin{aligned}
& \text {. addComponent ( j Label20) } \\
& \text { - addComponent ( j Label19) } \\
& \text { - addComponent ( j Label18) } \\
& \text {. addComponent (j Label21)) }
\end{aligned}
$$

.addPreferredGap (javax.swing.LayoutStyle.ComponentPlacement.RELATED)

.addGroup (jPanel 4 Layout. createParallelGroup (javax.swing.GroupLayout.Alignment.LEADI NG)

$$
\begin{aligned}
& \text {. addComponent (jLabel26) } \\
& \text { - addComponent (jLabel25) } \\
& \text {. addComponent (jLabel27) } \\
& \text {. addComponent (jLabel35)) } \\
& \text {. addGap (101, } 101,101)
\end{aligned}
$$

.addGroup (jPanel 4Layout. createParallelGroup (javax.swing. GroupLayout. Alignment. TRAIL ING)

. addGroup (javax.swing.GroupLayout.Alignment. LEADING,

jPanel 4 Layout. createsequentialGroup ()

. addGroup (j Panel 4 Layout. createParallelGroup (javax.swing. GroupLayout. Alignment. TRAII ING)

$$
\begin{aligned}
& \text {. addComponent (jLabel30) } \\
& \text {. addComponent (jLabel32) } \\
& \text {. addComponent (jLabel31)) }
\end{aligned}
$$

.addPreferredGap (javax.swing. Layoutstyle.ComponentPlacement. UNRELATED)

.addGroup (jPanel4Layout. createParallelGroup (javax.swing. GroupLayout. Alignment. LEADI NG)

$$
\begin{aligned}
& \text {. addComponent ( jLabe 123) } \\
& \text {. addComponent ( jLabe 122) } \\
& \text {. addComponent (jLabel24)) }
\end{aligned}
$$

. addPreferredGap (javax.swing. Layoutstyle.ComponentPlacement.RELATED)

.addGroup (jPanel 4Layout. createParallelGroup (javax.swing. GroupLayout. Alignment. TRAIL ING)

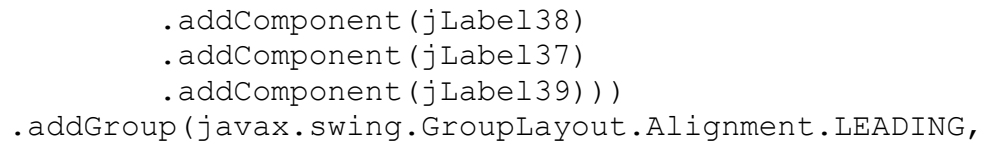


jPanel 4layout. createsequentialGroup ()

$$
\text { - } \operatorname{addGap}(14,14,14)
$$

. addGroup (jPanel 4Layout. createParallelGroup (javax.swing. GroupLayout.Alignment. TRAIL ING)

$$
\begin{aligned}
& \text { - addComponent (jLabel33) } \\
& \text {. addComponent (jLabel34)) }
\end{aligned}
$$

. addPreferredGap (javax.swing. Layoutstyle.ComponentPlacement. UNRELATED)

.addGroup (jPanel4Layout. createParallelGroup (javax.swing. GroupLayout.Alignment. LEADI NG)

$$
\begin{aligned}
& \text { - addComponent (jLabel29) } \\
& \text {. addComponent (jLabel28)))) }
\end{aligned}
$$

) ;

jPanel4Layout. setVerticalGroup (

jPanel4 Layout. createParallelGroup (javax.swing.GroupLayout.Alignment.LEADING) . addGroup (jPanel4 Layout. createSequentialGroup ()

.addGroup (jPanel4Layout. createParallelGroup (javax.swing. GroupLayout.Alignment. LEADI NG)

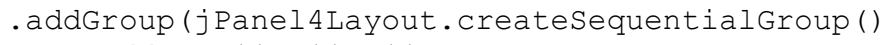

.addGroup (jPanel4Layout. createParallelGroup (javax.swing. GroupLayout.Alignment. LEADI NG)

.addGroup (jPanel 4Layout. createParallelGroup (javax.swing.GroupLayout.Alignment.BASEL INE )

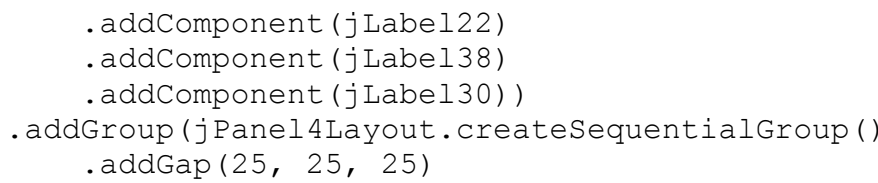

.addGroup (jPanel 4Layout. createParallelGroup (javax.swing. GroupLayout. Alignment. TRAIL ING)

. addGroup (jPanel 4 Layout. createSequentialGroup ()

. addGroup (jPanel 4Layout. createParallelGroup (javax.swing. GroupLayout. Alignment. BASEL INE)

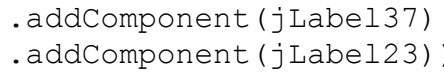

.addPreferredGap (javax.swing.Layoutstyle.ComponentPlacement.UNRELATED)

. addGroup (jPanel4 Layout. createParallelGroup (javax.swing. GroupLayout. Alignment. BASEL INE)

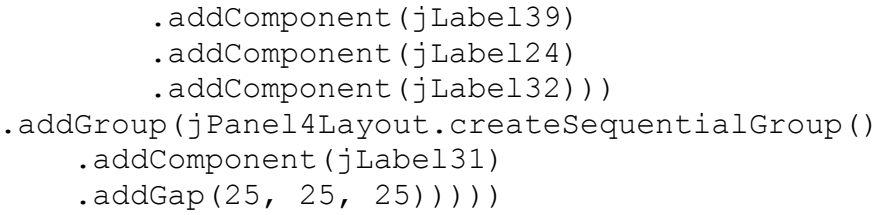

.addPreferredGap (javax.swing. Layoutstyle.ComponentPlacement. UNRELATED)

.addGroup (jPanel 4Layout. createParallelGroup (javax.swing. GroupLayout.Alignment. BASEL INE)

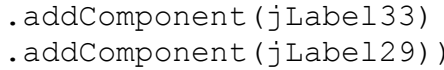

. addPreferredGap (javax.swing. Layoutstyle. ComponentPlacement.RELATED, 
.addGroup (jPanel 4Layout.createParallelGroup (javax.swing.Grouplayout. Alignment. BASEL INE)

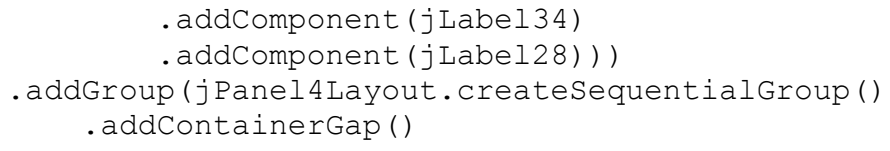

.addGroup (jPanel 4Layout.createParallelGroup (javax.swing.GroupLayout. Alignment. BASEL INE)

$$
\begin{aligned}
& \text {. addComponent (jLabel18) } \\
& \text {. addComponent (jLabel25)) }
\end{aligned}
$$

.addPreferredGap (javax.swing. LayoutStyle.ComponentPlacement. UNRELATED)

.addGroup (jPanel 4 Layout. createParallelGroup (javax.swing. GroupLayout. Alignment. BASEL INE)

$$
\begin{aligned}
& \text {. addComponent (jLabel19) } \\
& \text {. addComponent (jLabel26)) }
\end{aligned}
$$

.addPreferredGap (javax.swing. LayoutStyle. ComponentPlacement. UNRELATED)

.addGroup (jPanel 4Layout. createParallelGroup (javax.swing.GroupLayout. Alignment. BASEL INE)

$$
\begin{aligned}
& \text {. addComponent (jLabel20) } \\
& \text {. addComponent (jLabel27)) }
\end{aligned}
$$

.addPreferredGap (javax.swing. LayoutStyle. ComponentPlacement. UNRELATED)

.addGroup (jPanel 4Layout. createParallelGroup (javax.swing. GroupLayout. Alignment. BASEL INE)

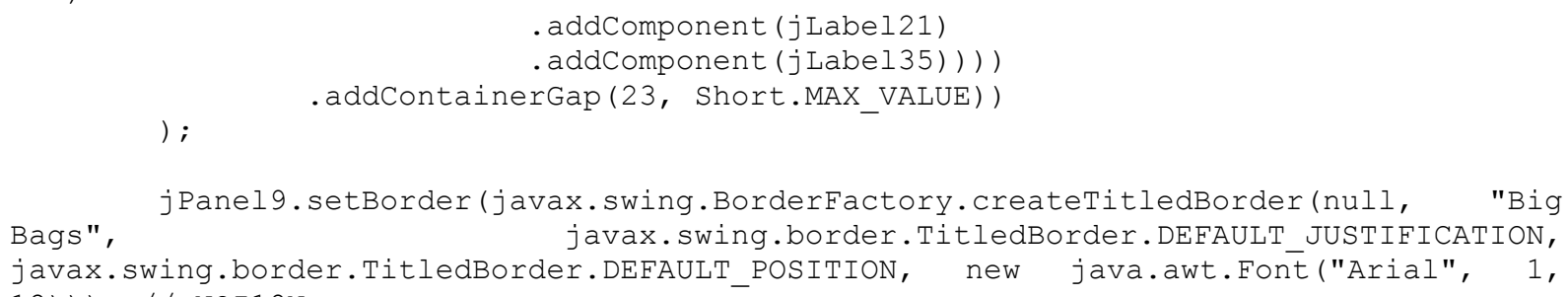




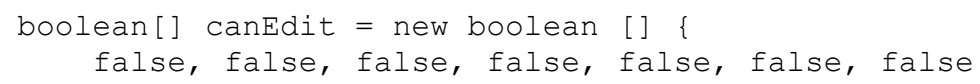

jPanel 9Layout.createParallelGroup (javax.swing. GroupLayout.Alignment. LEADING) - addGroup (jPanel 9Layout. createSequentialGroup () - addContainerGap ( )

.addGroup (jPanel9Layout. createParallelGroup (javax.swing. GroupLayout. Alignment. LEADI NG)

$$
\text { - addComponent (jScrollPane3) }
$$

javax.swing.Grouplayout.Alignment.TRAILING) . addGroup (jPanel9Layout. createsequentialGroup ()

.addGroup (jPanel 9Layout. createParallelGroup (javax.swing. GroupLayout.Alignment. LEADI NG)

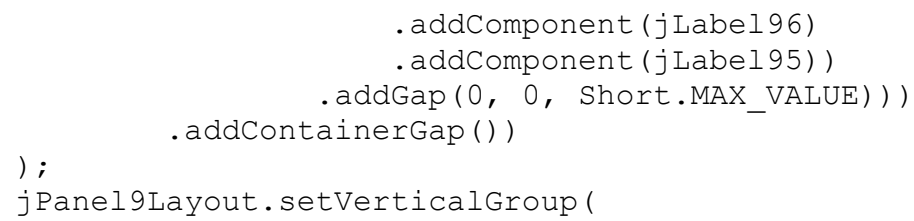

jPanel 9Layout. createParallelGroup (javax.swing.GroupLayout.Alignment. LEADING) . addGroup (jPanel 9Layout. createSequentialGroup () 
. addGroup (jPanel1Layout. createSequentialGroup ()

.addContainerGap ()

.addGroup (jPanellLayout.createParallelGroup (javax.swing.GroupLayout. Alignment. TRAIL ING, false)

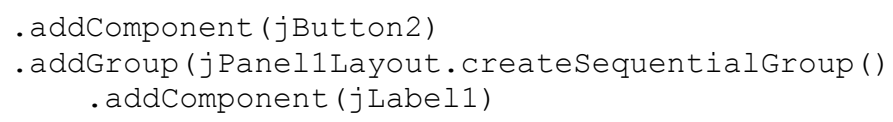

.addGroup (jPanellLayout.createParallelGroup (javax.swing.Grouplayout. Alignment. LEADI NG)

$$
\text { . addGroup (jPanel1Layout. createSequentialGroup () }
$$

.addGroup (jPanel1Layout. createParallelGroup (javax.swing. GroupLayout. Alignment. BASEL INE)

- addComponent (jLabel1)

. addComponent (jFormattedTextField1,

javax.swing. Grouplayout. PREFERRED SIZE,

javax.swing.GroupLayout.PREFERRED_SIZE)) javax.swing.GroupLayout.DEFAULT_SIZE,

.addPreferredGap (javax.swing. Layoutstyle.ComponentPlacement.RELATED) . addComponent (jButton2)

.addPreferredGap (javax.swing. LayoutStyle.ComponentPlacement.RELATED) . addComponent (jScrollPane1))

. addGroup (jPanel1Layout. createSequentialGroup ()

.addGroup (jPanellLayout.createParallelGroup (javax.swing.Grouplayout. Alignment. LEADI NG, false)

- addComponent (jPanel2,

javax.swing.GroupLayout.PREFERRED_SIZE,

javax.swing.GroupLayout.DEFAULT_SIZE, 


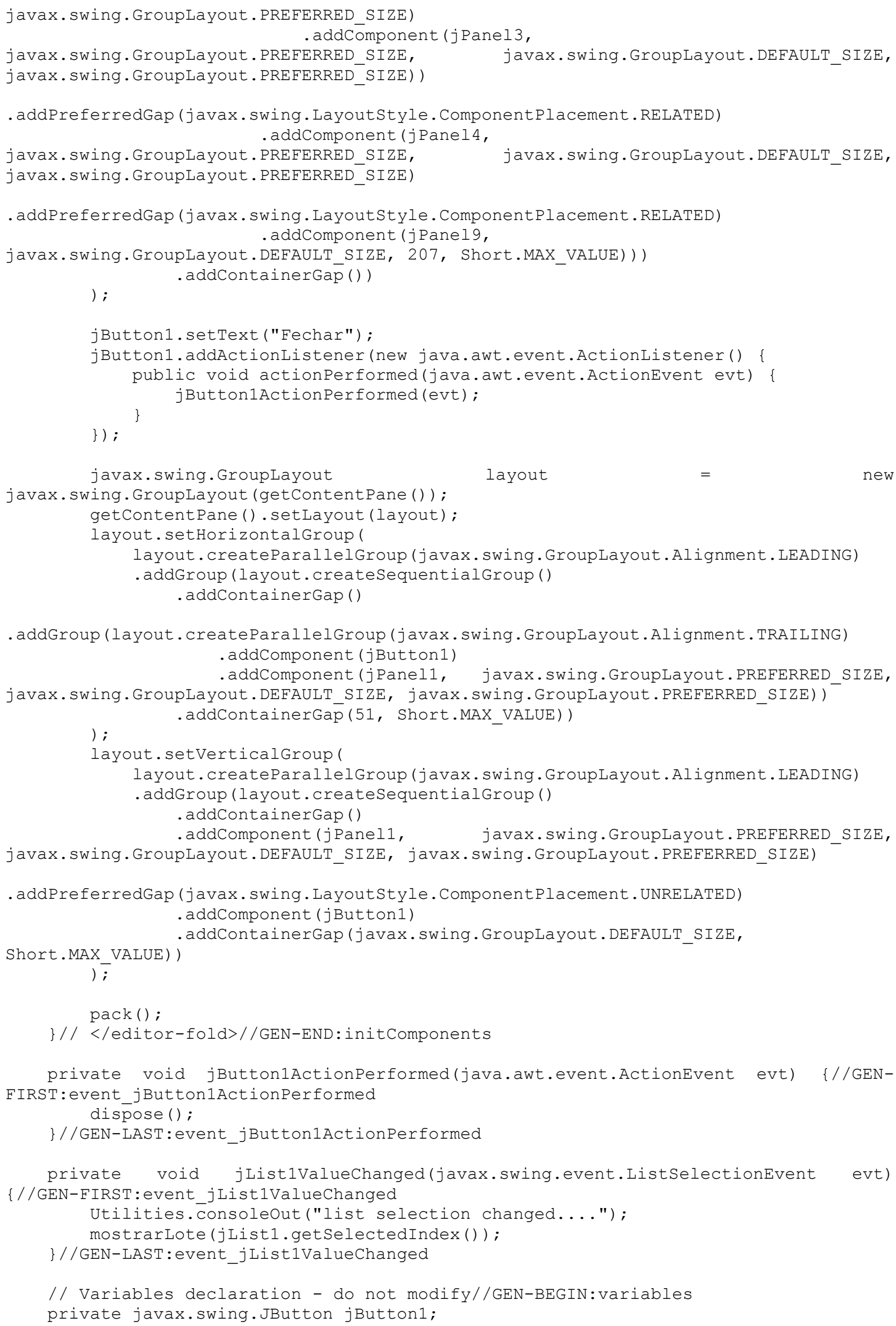


private javax.swing. JButton jButton2;

private javax.swing. JFormattedTextField jFormattedTextField1;

private javax.swing. JLabel jLabel1;

private javax.swing. JLabel jLabel10;

private javax.swing. JLabel jLabel11;

private javax.swing. JLabel jLabel12;

private javax.swing. JLabel jLabel13;

private javax.swing. JLabel jLabel14;

private javax.swing. JLabel jLabel15;

private javax.swing. JLabel jLabel16;

private javax.swing. JLabel jLabel17;

private javax.swing. JLabel jLabel18;

private javax.swing. JLabel jLabel19;

private javax.swing. JLabel jLabel2;

private javax.swing. JLabel jLabel20;

private javax.swing. JLabel jLabel21;

private javax.swing. JLabel jLabel22;

private javax.swing. JLabel jLabe123;

private javax.swing. JLabel jLabel24;

private javax.swing. JLabel jLabel25;

private javax.swing. JLabel jLabel26;

private javax.swing. JLabel jLabe127;

private javax.swing. JLabel jLabel28;

private javax.swing. JLabel jLabe129;

private javax.swing. JLabel jLabel3;

private javax.swing. JLabel jLabel30;

private javax.swing. JLabel jLabel31;

private javax.swing. JLabel jLabe132;

private javax.swing. JLabel jLabel33;

private javax.swing. JLabel jLabe134;

private javax.swing. JLabel jLabe135;

private javax.swing. JLabel jLabel37;

private javax.swing. JLabel jLabe138;

private javax.swing. JLabel jLabe139;

private javax.swing.JLabel jLabel4;

private javax.swing.JLabel jLabel5;

private javax.swing.JLabel jLabel6;

private javax.swing.JLabel jLabel7;

private javax.swing. JLabel jLabel8;

private javax.swing. JLabel jLabel9;

private javax.swing. JLabel jLabe195;

private javax.swing. JLabel jLabel96;

private javax.swing. JList jList1;

private javax.swing. JPanel jPanell;

private javax.swing. JPanel jPanel2;

private javax.swing. JPanel jPanel3;

private javax.swing.JPanel jPanel4;

private javax.swing. JPanel jPanel9;

private javax.swing. JScrollPane jScrollPanel;

private javax.swing. JScrollPane jScrollPane2;

private javax.swing. JScrollPane jScrollPane3;

private javax.swing.JTable jTablel;

private javax.swing. JTable jTable2;

// End of variables declaration//GEN-END:variables

/*

* To change this template, choose Tools | Templates

* and open the template in the editor.

*/

package tools;

import java.sql.Connection;

import java.sql. DriverManager;

import java.sql.PreparedStatement;

import java.sql.Resultset; 


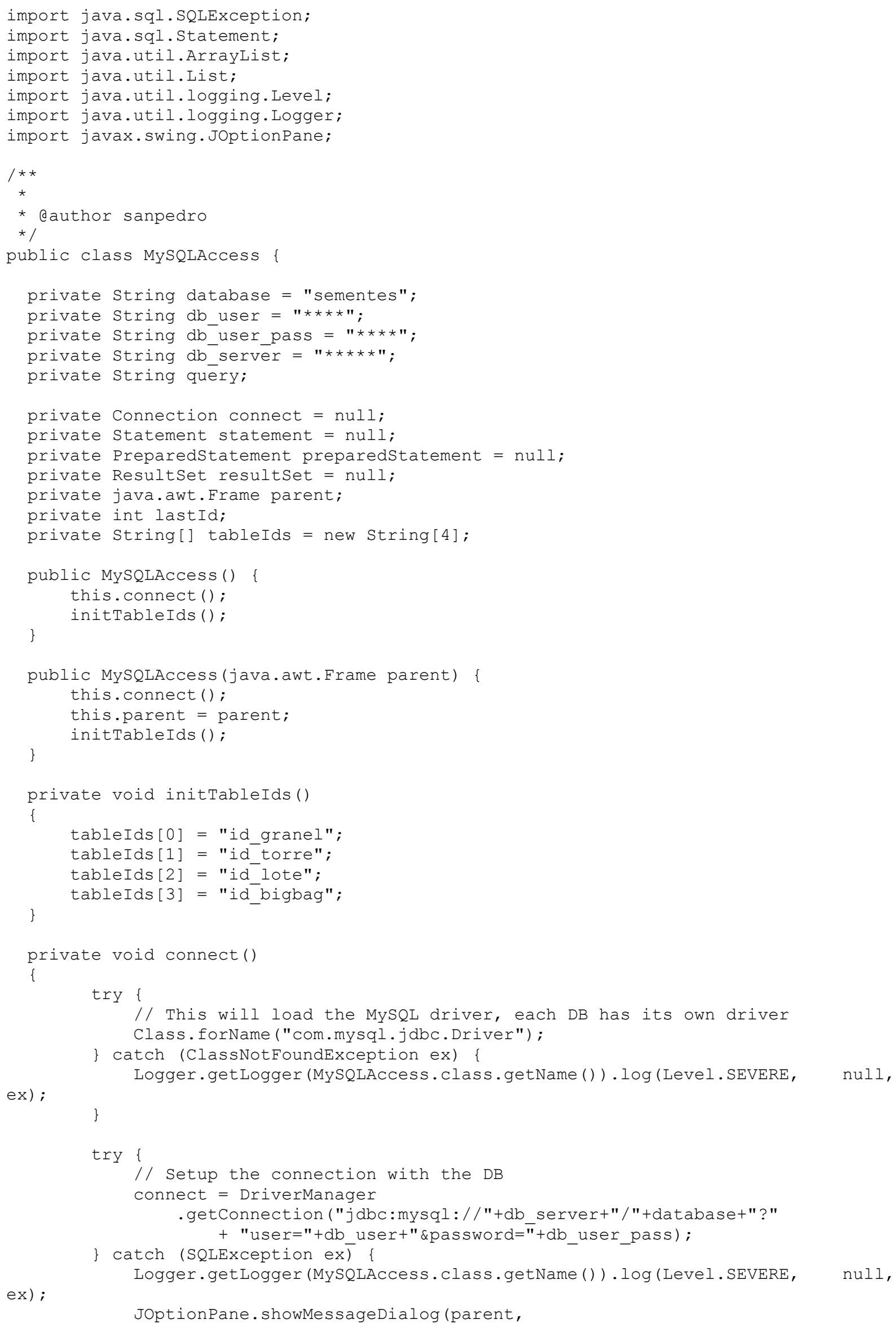




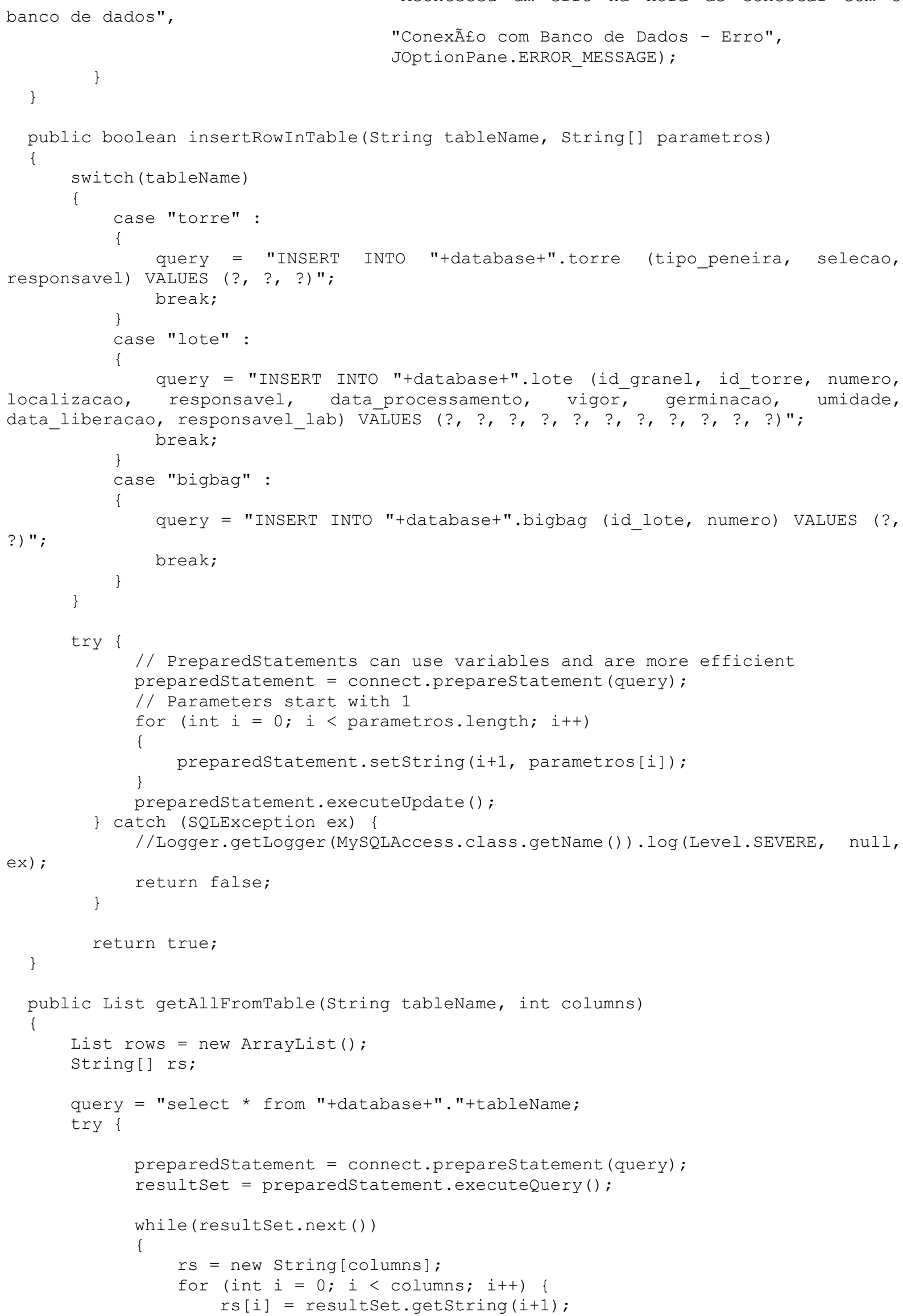




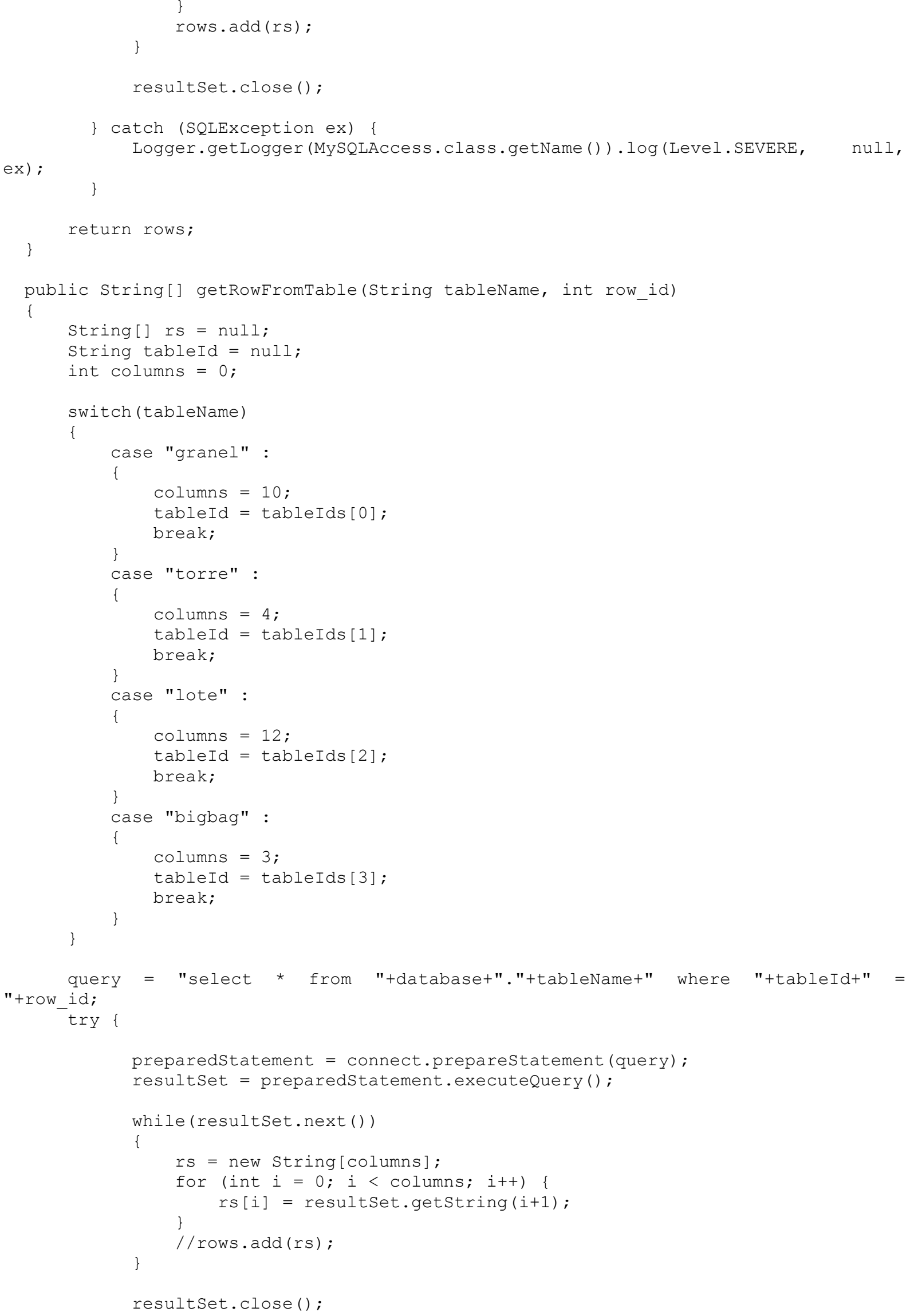




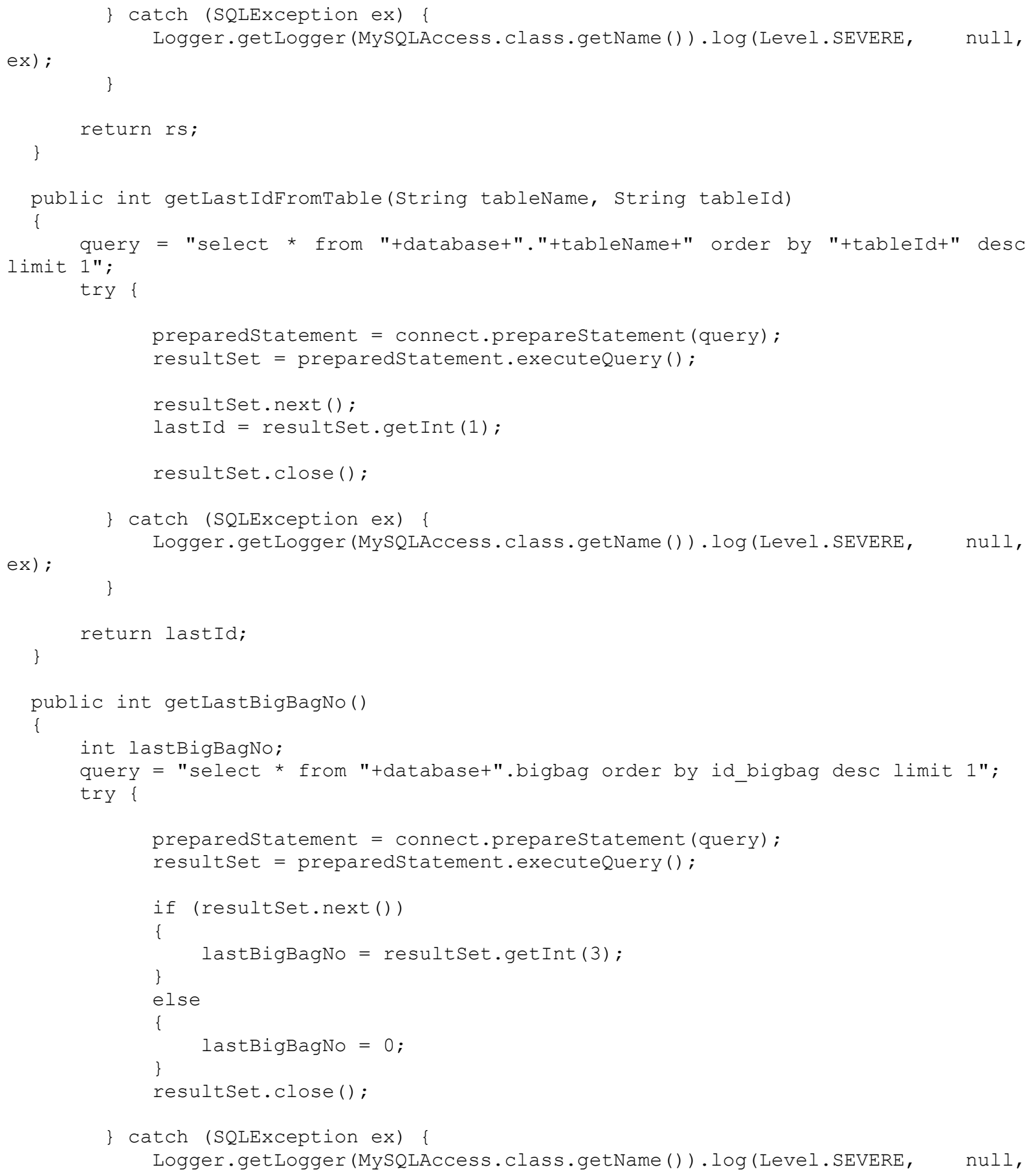




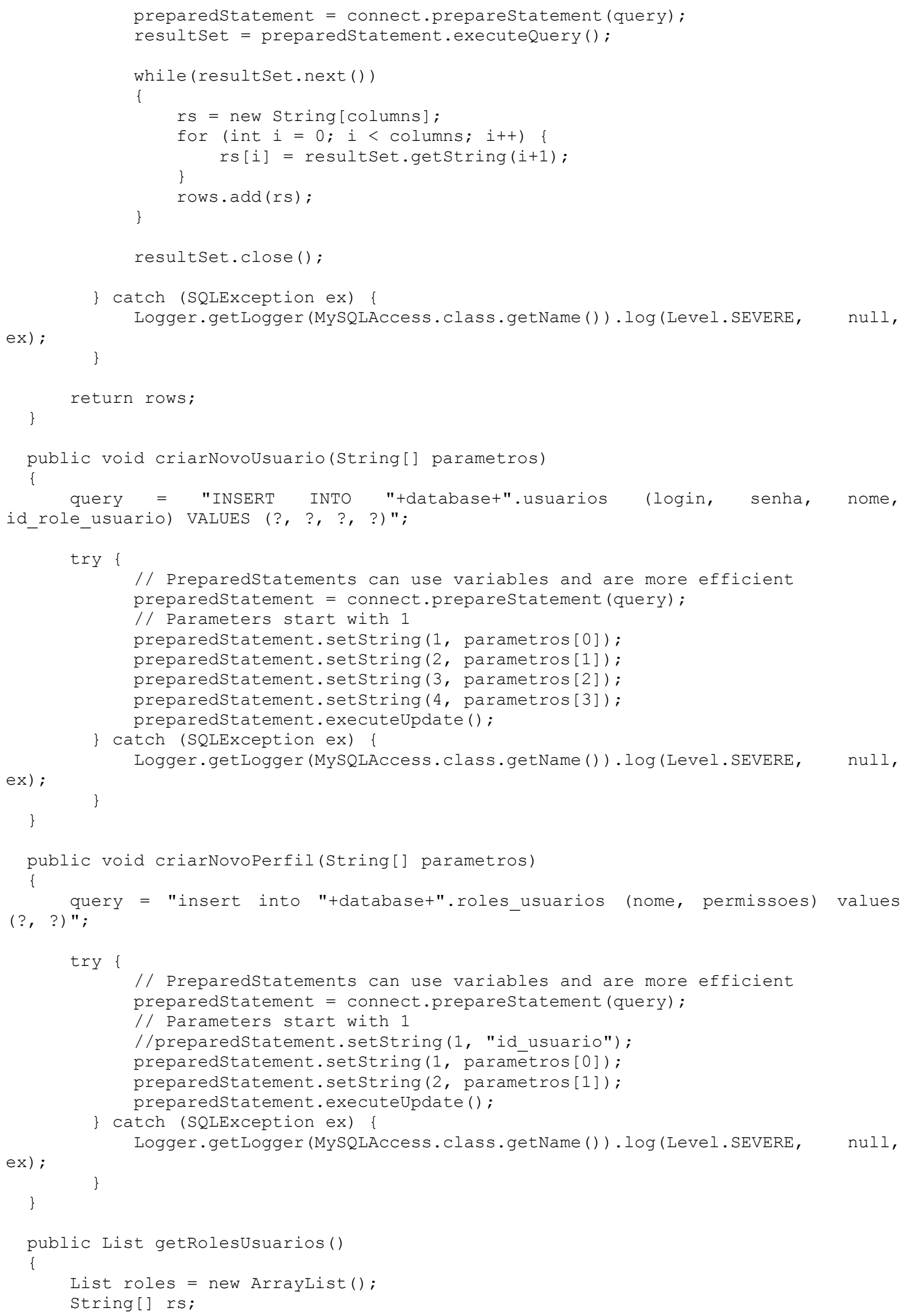




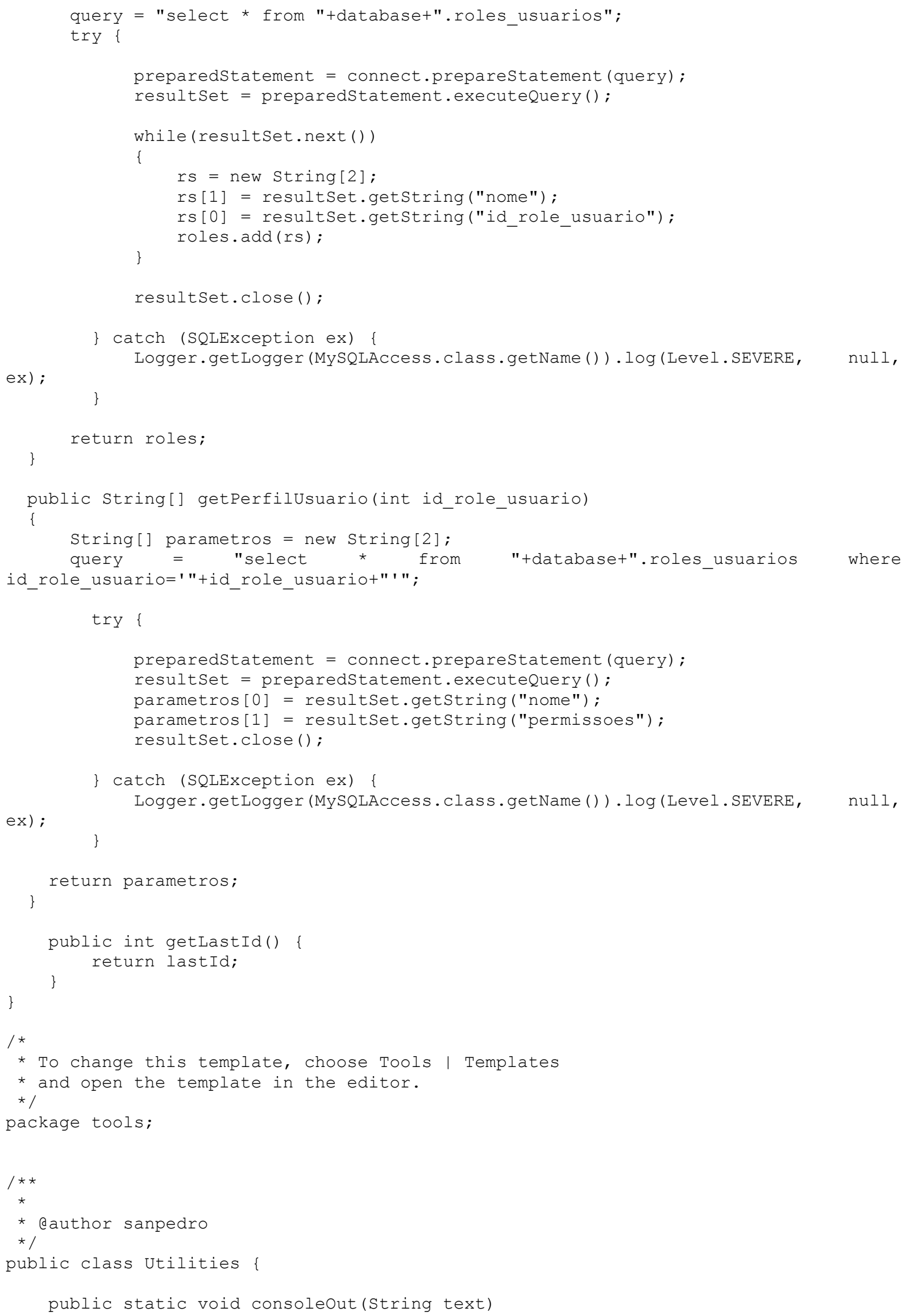




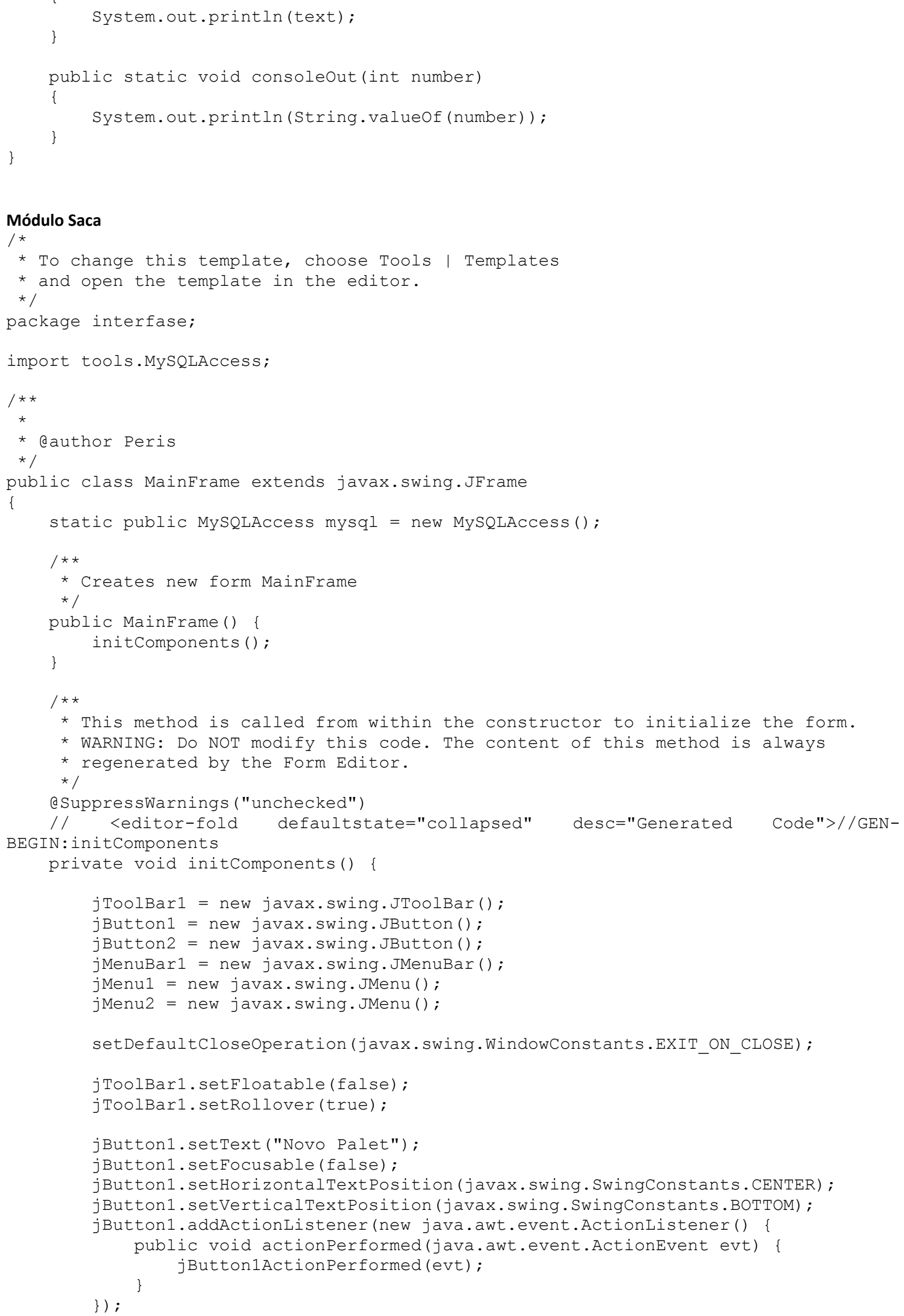


jToolBar1.add (jButton1);

jButton2. setText ("Consultar Palets");

jButton2. setFocusable (false);

jButton2. setHorizontalTextPosition (javax.swing. SwingConstants.CENTER);

jButton2. setVerticalTextPosition (javax.swing. SwingConstants.BOTTOM);

jButton2.addActionListener(new java.awt.event.ActionListener() \{ public void actionPerformed(java.awt.event. ActionEvent evt) \{ jButton2ActionPerformed (evt);

\});

jToolBar1.add (jButton2);

jMenu1.setText ("File");

jMenuBar1.add (jMenu1);

jMenu2.setText ("Edit");

jMenuBar1.add (jMenu2);

setJMenuBar (jMenuBar1);

javax.swing. GroupLayout

javax.swing.GroupLayout (getContentPane ()) ;

getContentPane(). setLayout (layout);

layout.setHorizontalGroup (

layout.createParallelGroup (javax.swing. Grouplayout. Alignment. LEADING) Short.MAX VALUE)

.addComponent (jToolBar1, javax.swing.Grouplayout.DEFAULT_SIZE, 400

);

layout.setVerticalGroup (

layout.createParallelGroup (javax.swing.GroupLayout. Alignment. LEADING)

- addGroup (layout. createSequentialGroup() .addComponent (jToolBar1, javax.swing.GroupLayout.PREFERRED_SIZE,

25, javax.swing.GroupLayout.PREFERRED_SIZE)

)$;$

.addGap (0, 254, Short.MAX_VALUE))

pack ();

\}// </editor-fold>//GEN-END: initComponents

private void jButtonlActionPerformed(java.awt.event.ActionEvent evt) \{//GENFIRST: event jButton1ActionPerformed

NovoPaletDialog novoloteDialog = new NovoPaletDialog(this, true);

novoLoteDialog.setLocationRelativeTo(this);

novoLoteDialog.setVisible (true);

\}//GEN-LAST: event jButton1ActionPerformed

private void jButton2ActionPerformed(java.awt.event.ActionEvent evt) \{//GENFIRST:event_jButton2ActionPerformed

RelatoriopaletDialog relatorioLoteDialog = new RelatoriopaletDialog(this, true)；

relatorioLoteDialog.setLocationRelativeTo (this);

relatorioLoteDialog.setVisible(true);

\}//GEN-LAST:event_jButton2ActionPerformed

$1 * *$

* eparam args the command line arguments

* 1

public static void main(String args[]) (

/* Set the Nimbus look and feel */

//<editor-fold defaultstate="collapsed" desc=" Look and feel setting code (optional) ">

/* If Nimbus (introduced in Java $\mathrm{SE}$ 6) is not available, stay with the default look and feel.
For
details

see

http://download.oracle.com/javase/tutorial/uiswing/lookandfeel/plaf.html 


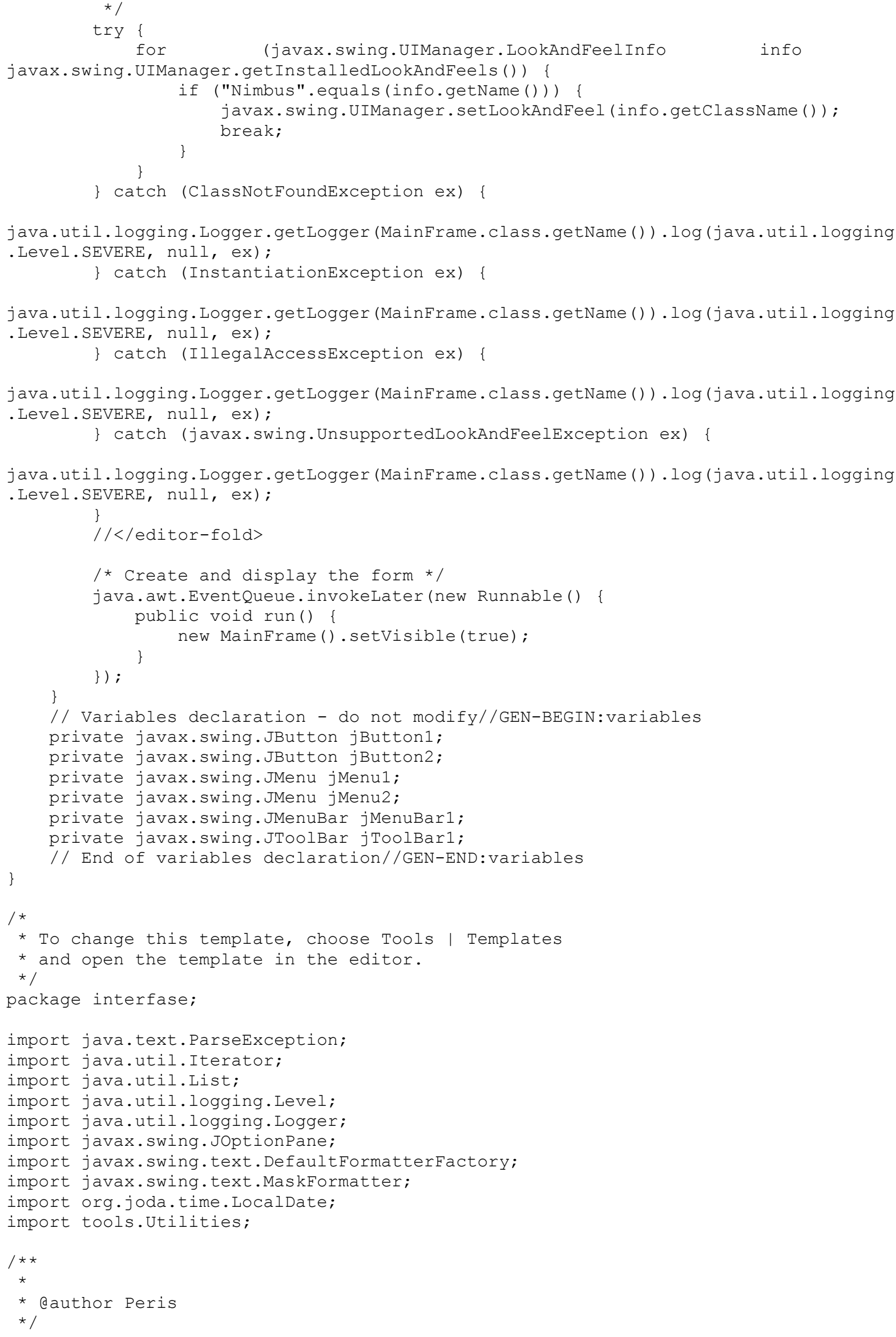


public class NovoPaletDialog extends javax.swing.JDialog

\{

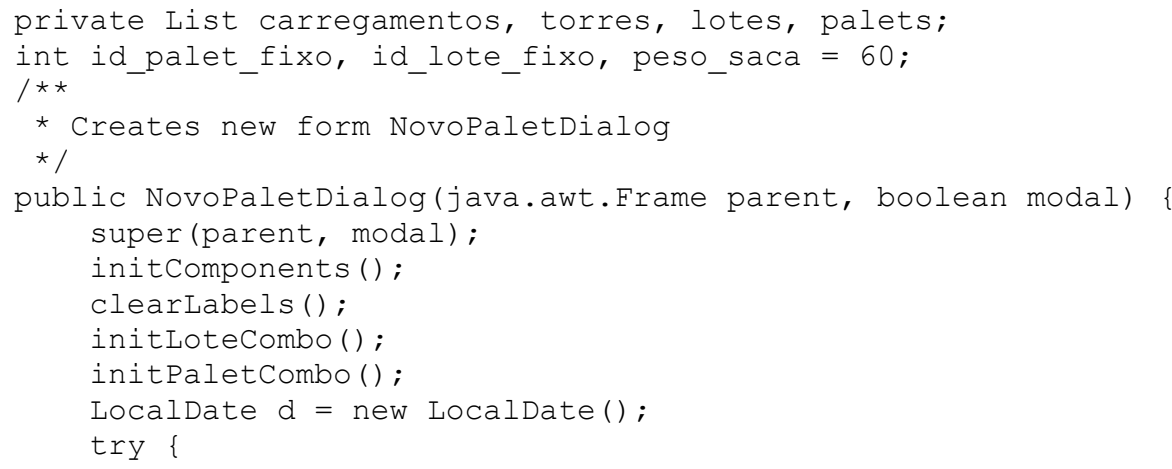




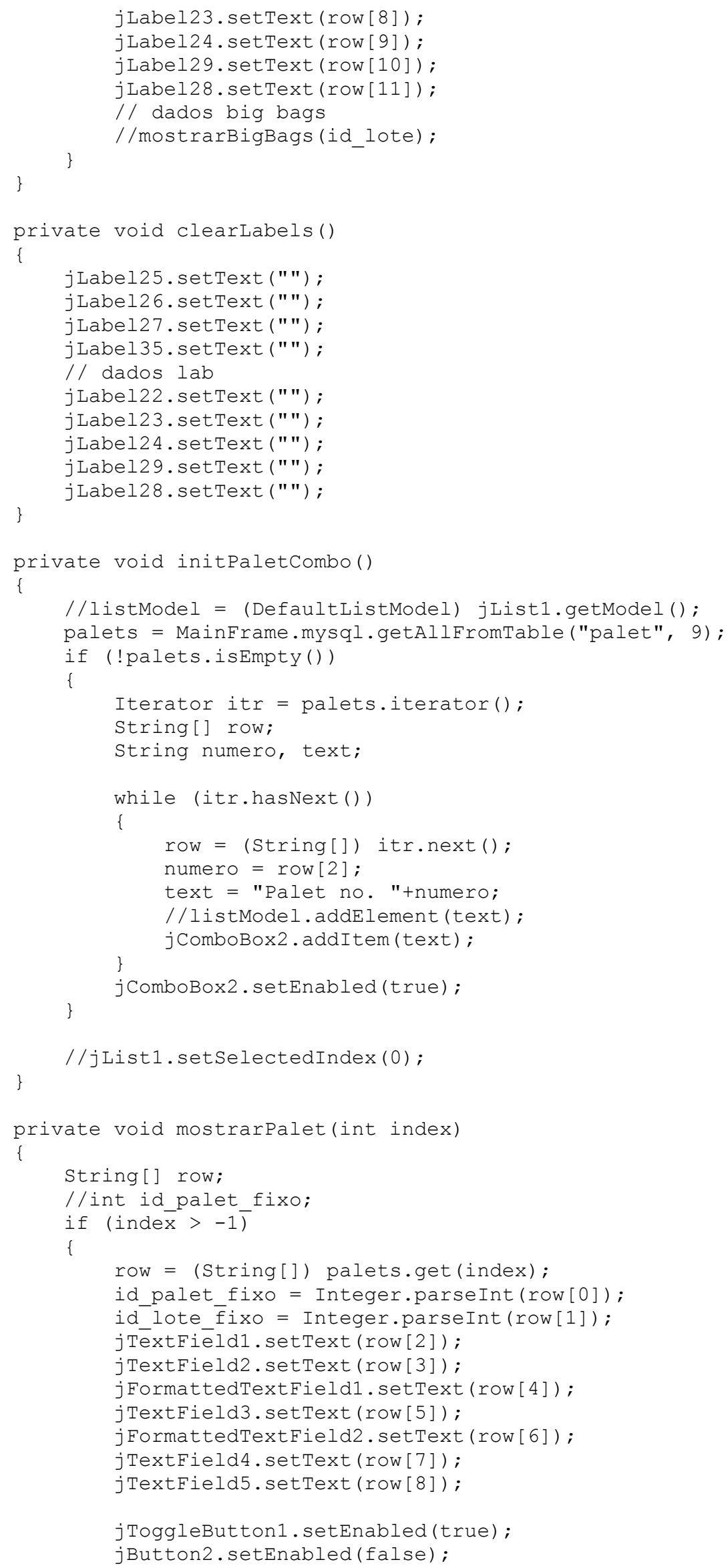




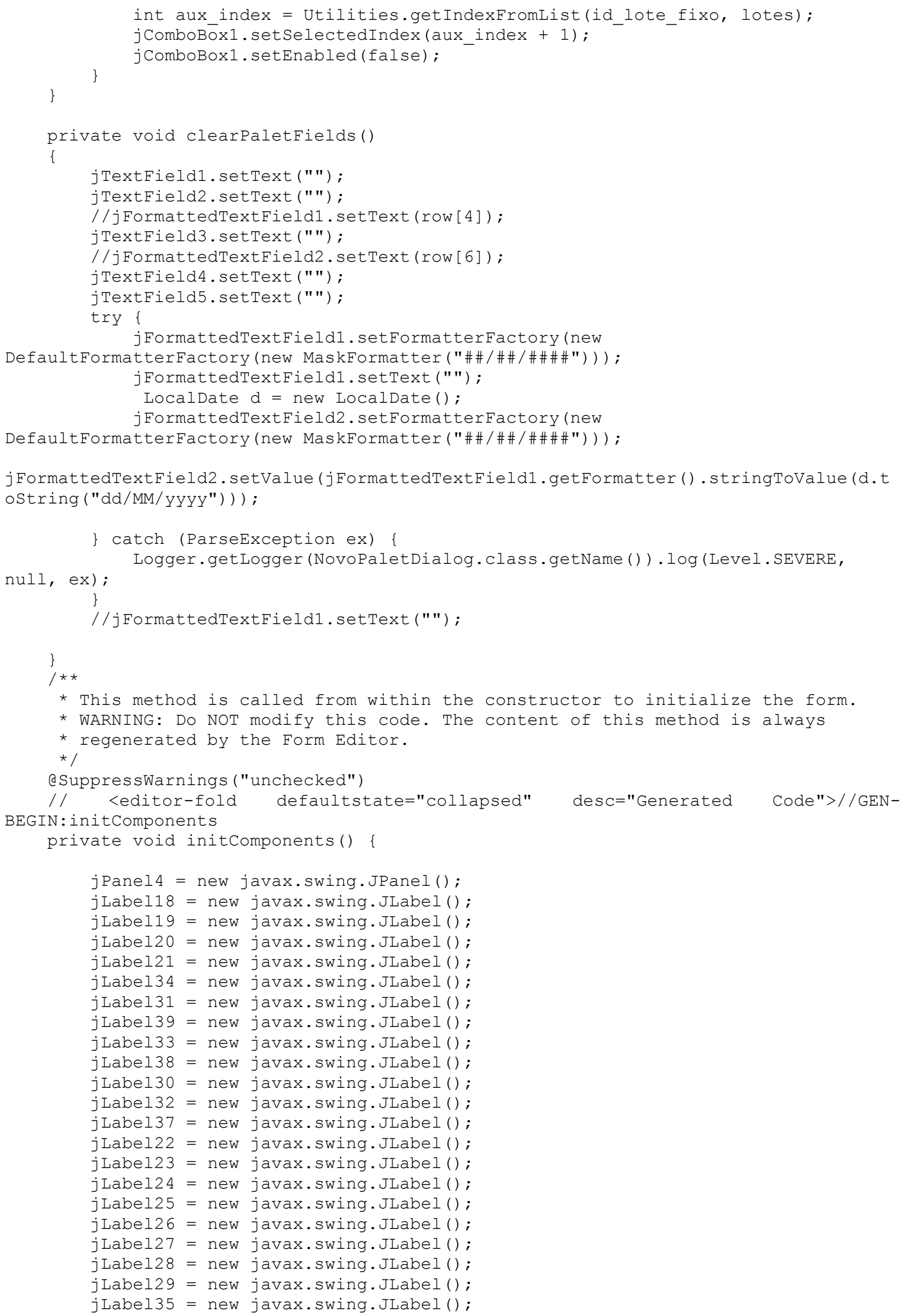


jComboBox1 = new javax.swing.JComboBox();

jPanell = new javax.swing.JPanel ();

jComboBox2 = new javax.swing.JComboBox();

jLabel1 = new javax.swing.JLabel ();

jTextFieldl = new javax.swing.JTextField();

jLabel2 = new javax.swing.JLabel ();

jLabel3 = new javax.swing.JLabel ();

jLabel4 = new javax.swing.JLabel ();

jTextField2 = new javax.swing.JTextField();

jTextField3 = new javax.swing.JTextField();

jFormattedTextFieldl = new javax.swing. JFormattedTextField();

jLabel5 = new javax.swing.JLabel ();

jLabel6 = new javax.swing.JLabel ();

jLabel7 = new javax.swing.JLabel ();

jFormattedTextField2 = new javax.swing. JFormattedTextField();

jTextField4 = new javax.swing.JTextField();

jTextField5 = new javax.swing.JTextField();

jButton 1 = new javax. swing. JButton();

jButton2 = new javax.swing.JButton();

jToggleButton 1 = new javax.swing. JToggleButton();

jPanel2 = new javax.swing.JPanel();

jLabel8 = new javax.swing.JLabel ();

jLabel9 = new javax.swing.JLabel ();

jTextField6 = new javax.swing.JTextField();

jTextField7 = new javax.swing.JTextField();

jButton 6 = new javax.swing.JButton();

jButton 4 = new javax.swing. JButton();

jButton 5 new javax.swing. JButton();

setDefaultCloseoperation (javax.swing.WindowConstants.DISPOSE_ON_CLOSE);

setTitle("Terminal Sacas - Cadastrar Novo Palet");

setResizable (false);

do

jPanel4.setBorder(javax.swing.BorderFactory.createTitledBorder(null, "Dados Lote", javax.swing.border.TitledBorder.DEFAULT JUSTIFICATION, javax.swing.border.TitledBorder.DEFAULT_POSITION, new java.awt.Font("Arial", 1, 12)) ); // NOI18N

jLabel18. setText ( "NÃ ${ }^{\circ}$ mero:") ;

jLabel19. setText ("Localizã̃§Ã£o:") ;

jLabel20.setText ("Data do proc:");

jLabel21.setText ("Respons $\left.\tilde{A}_{i} v e l: "\right)$;

jLabel34.setText ("Repons $\left.\tilde{A}_{i} v e l: "\right)$;

jLabel31. setText ("Determ. Germinã̃̊̃̃£o:") ;

jLabe139. setFont (new java.awt.Font("Tahoma", 1, 11)); // NOI18N

jLabel39. setText ("응);

jLabe133. setText ("Data da Liberã̃§̃̃£o:") ;

jLabel38. setFont (new java.awt.Font("Tahoma", 1, 11)); // NOI18N

jLabe138. setText ("응);

jLabel30. setText("Determ. Vigor:");

jLabel32. setText ("Conf. Umidade:");

jLabel37. setFont (new java.awt.Font("Tahoma", 1, 11)) ; // NOI18N

jLabel37. setText ("응");

jLabel22.setFont (new java.awt.Font("Tahoma", 1, 11)); // NOI18N 
jLabel22. setHorizontalAlignment (javax.swing. SwingConstants.TRAILING);

jLabel22. setText ("jLabel22");

jLabel23. setFont (new java.awt.Font("Tahoma", 1, 11)) ; // NOI18N

jLabel23. setHorizontalAlignment (javax.swing. SwingConstants.TRAILING) ;

jLabe123. setText ("jLabe123");

jLabel24.setFont (new java.awt.Font("Tahoma", 1, 11)); // NOI18N

jLabel24. setHorizontalAlignment (javax.swing. SwingConstants.TRAILING);

jLabel24. setText ("jLabe124");

jLabe125. setFont (new java.awt.Font("Tahoma", 1, 11)); // NOI18N

jLabe125. setText ("jLabel25");

jLabe126. setFont (new java.awt.Font("Tahoma", 1, 11)); // NOI18N

jLabel26.setText ("jLabel26");

jLabe127. setFont (new java.awt.Font("Tahoma", 1, 11)); // NOI18N

jLabel27. setText ("jLabe127");

jLabel28. setFont (new java.awt.Font("Tahoma", 1, 11)); // NOI18N

jLabel28. setText ("jLabel28");

jLabe129.setFont (new java.awt.Font("Tahoma", 1, 11)); // NOI18N

jLabel29. setText ("jLabel29");

jLabe135.setFont (new java.awt.Font("Tahoma", 1, 11)); // NOI18N

jLabel35. setText ("jLabe135");

jComboBoxl.setModel (new javax.swing. DefaultComboBoxModel (new String[]

"Selecione o lote" \}));

jComboBox1.addItemListener(new java.awt.event.ItemListener() public void itemstatechanged(java.awt.event. ItemEvent evt) \{ jComboBoxlitemstatechanged (evt); \}

\});

javax.swing.GroupLayout

jPanel 4Layout

new

javax.swing. GroupLayout (jPanel4);

jPanel4. setLayout (jPanel 4 Layout);

jPanel4 Layout. setHorizontalGroup(

jPanel 4 Layout.createParallelGroup (javax.swing.GroupLayout.Alignment. LEADING) . addGroup (jPanel 4 Layout. createSequentialGroup () . addContainerGap ()

.addGroup (jPanel 4Layout.createParallelGroup (javax.swing.GroupLayout.Alignment.LEADI NG)

$$
\text { . addGroup (jPanel } 4 \text { Layout. createSequentialGroup () }
$$

.addGroup (jPanel 4Layout. createParallelGroup (javax.swing. GroupLayout. Alignment. LEADI NG)

. addGroup (jPanel 4 Layout. createSequentialGroup ()

$$
\text { . } \operatorname{addGap}(36,36,36)
$$

.addGroup (jPanel 4 Layout.createParallelGroup (javax.swing.GroupLayout. Alignment. TRAIL ING)

. addComponent (jLabel18)))
. addComponent (jLabel32,

. addComponent (jLabel20)

- addComponent (jLabel19)

javax.swing.GroupLayout.Alignment.TRAILING)

. addComponent (j Label33,

javax.swing.GroupLayout. Alignment. TRAILING)

. addComponent (j Label34,

javax.swing.Grouplayout.Alignment. TRAILING) 


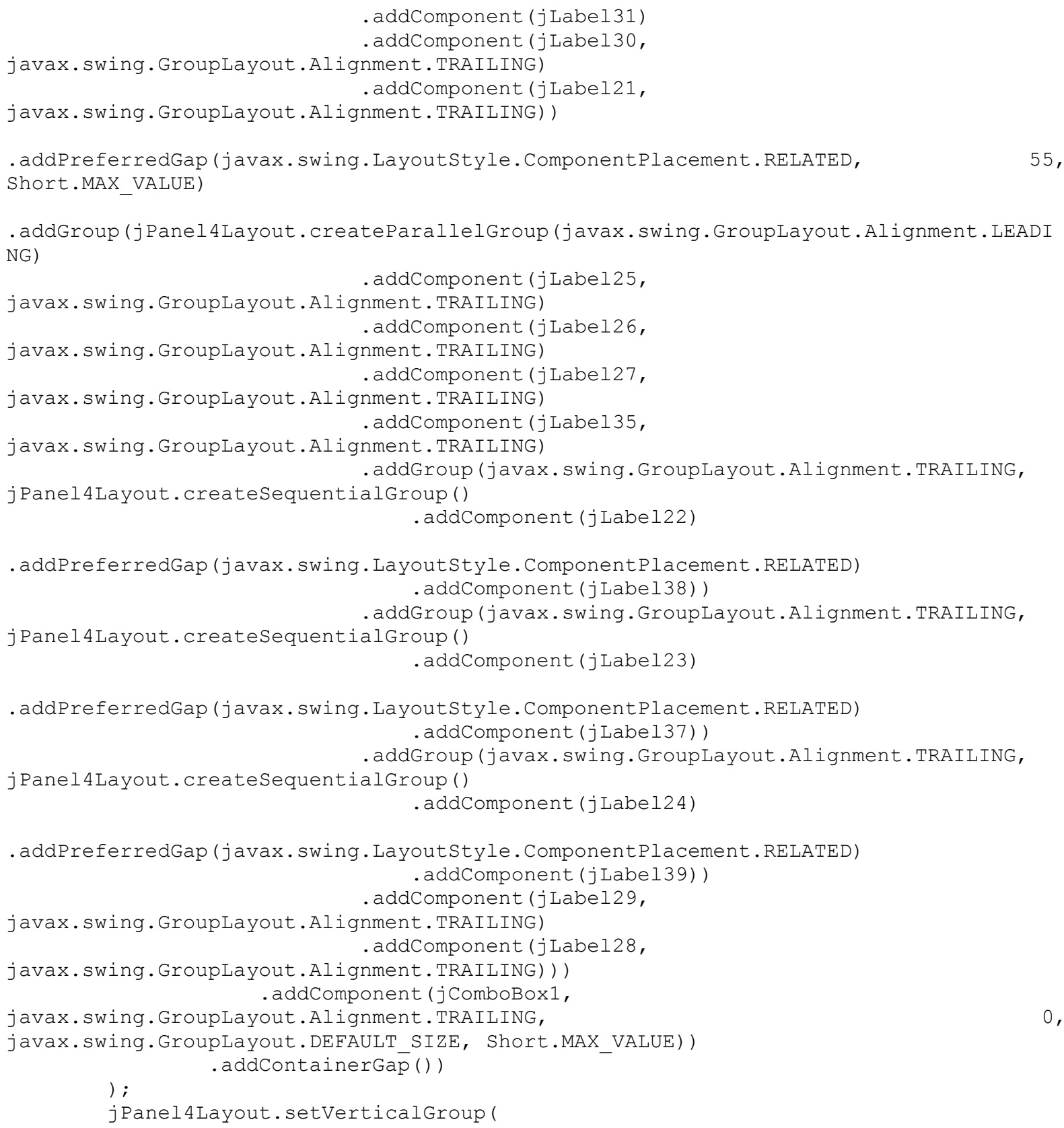
NG)

$$
\text { . addGroup (jPanel Layout. createsequentialGroup () }
$$

.addGroup (jPanel 4 Layout.createParallelGroup (javax.swing.GroupLayout. Alignment.BASEL INE)

$$
\begin{aligned}
& \text {. addComponent (jLabel18) } \\
& \text {. addComponent (jLabel25)) }
\end{aligned}
$$

.addPreferredGap (javax.swing. LayoutStyle.ComponentPlacement. UNRELATED) 
.addGroup (jPanel 4Layout. createParallelGroup (javax.swing.GroupLayout. Alignment. BASEL INE)

$$
\begin{aligned}
& \text { - addComponent (jLabel19) } \\
& \text {. addComponent (jLabel26)) }
\end{aligned}
$$

.addPreferredGap (javax.swing. LayoutStyle.ComponentPlacement.RELATED)

.addGroup (jPanel 4 Layout. createParallelGroup (javax.swing. GroupLayout. Alignment. BASEL INE)

$$
\begin{aligned}
& \text { - addComponent (jLabel20) } \\
& \text {. addComponent (jLabel27)) }
\end{aligned}
$$

.addPreferredGap (javax.swing. LayoutStyle.ComponentPlacement. UNRELATED)

.addGroup (jPanel 4 Layout. createParallelGroup (javax.swing. GroupLayout. Alignment. BASEL INE)

$$
\begin{aligned}
& \text {. addComponent (jLabel21) } \\
& \text {. addComponent (jLabel35)) }
\end{aligned}
$$

.addPreferredGap (javax.swing. Layoutstyle.ComponentPlacement. UNRELATED)

.addGroup (jPanel 4Layout.createParallelGroup (javax.swing.GroupLayout. Alignment. BASEL INE)

$$
\begin{aligned}
& \text {. addComponent (jLabe138) } \\
& \text {. addComponent (jLabel22)) }
\end{aligned}
$$

.addPreferredGap (javax.swing. Layoutstyle.ComponentPlacement. UNRELATED)

.addGroup (jPanel 4Layout.createParallelGroup (javax.swing.GroupLayout. Alignment. BASEL INE)

$$
\begin{gathered}
\text {.addComponent (jLabel 37) } \\
\text {. addComponent (jLabel23))) } \\
\text {. addGroup (jPanel 4 Layout. createSequentialGroup () }
\end{gathered}
$$$$
\text { . addGap (95, 95, 95) }
$$$$
\text { . addComponent ( jLabe130) }
$$

.addPreferredGap (javax.swing. Layout.Style.ComponentPlacement. UNRELATED) . addComponent (jLabel31)

.addPreferredGap (javax.swing. Layoutstyle.ComponentPlacement. UNRELATED)

.addGroup (jPanel 4Layout.createParallelGroup (javax.swing.GroupLayout. Alignment. BASEL INE)

$$
\begin{aligned}
& \text {. addComponent (jLabel24) } \\
& \text {. addComponent (jLabel32) } \\
& \text {. addComponent (jLabel39) }
\end{aligned}
$$

.addPreferredGap (javax.swing.LayoutStyle.ComponentPlacement. UNRELATED)

.addGroup (jPanel 4Layout. createParallelGroup (javax.swing.GroupLayout.Alignment. BASEL INE)

$$
\begin{aligned}
& \text {. addComponent (jLabel29) } \\
& \text {. addComponent (jLabel33)) }
\end{aligned}
$$

.addPreferredGap (javax.swing. LayoutStyle.ComponentPlacement. UNRELATED)

.addGroup (jPanel 4Layout. createParallelGroup (javax.swing.GroupLayout. Alignment. BASEL INE)

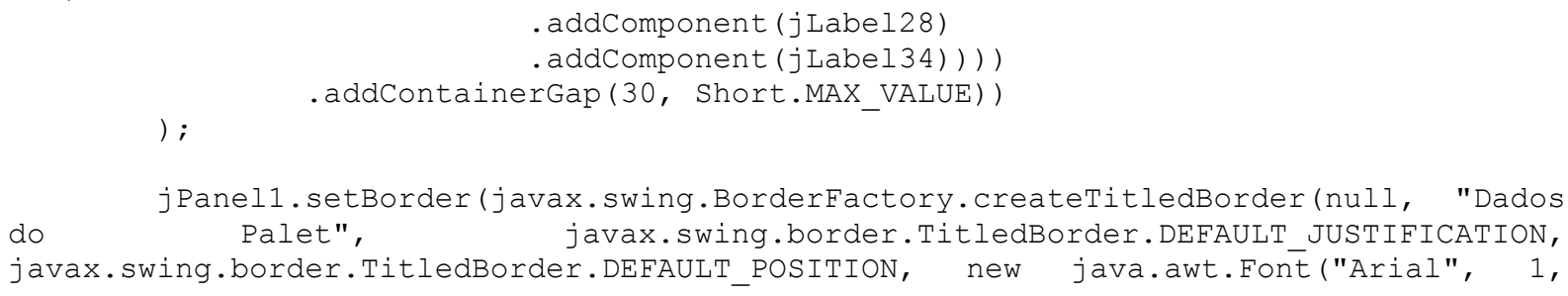


12))); // NOI18N

jComboBox2.setModel (new javax.swing. DefaultComboBoxModel (new String[] "Selecione o palet" \}));

jComboBox2. setEnabled (false);

jComboBox2.addItemListener(new java.awt.event.ItemListener() \{ public void itemstatechanged(java.awt.event.ItemEvent evt) \{ jComboBox2ItemStateChanged (evt);

\}); \}

jLabel1.setText ( "NÃ ${ }^{\circ}$ mero") ;

jTextField1.setHorizontalAlignment (javax.swing.JTextField.TRAILING) ;

jLabel2.setText ("Peso");

jLabe13. setText ("Validade") ;

jLabel4 . setText ("Localizã̃̊̃̃£o") ;

jTextField2.setHorizontalAlignment (javax.swing.JTextField.TRAILING) ;

jTextField3.setHorizontalAlignment (javax.swing.JTextField.TRAILING) ;

$\operatorname{try}\{$

jFormattedTextField1.setFormatterFactory (new

javax.swing.text. DefaultFormatterFactory (new

javax.swing.text.MaskFormatter("\#\#/\#\#/\#\#\#\#")));

\} catch (java.text.ParseException ex) \{

\}

ex.printstackTrace();

jFormattedTextFieldl.setHorizontalAlignment (javax.swing. JTextField.TRAILING);

jLabel5.setText ("Data da Operã̃ßñ£o");

jLabel6. setText ("Prod. Aplicado") ;

jLabe17. setText ("Resp. Tratamento");

try \{

jFormattedTextField2. setFormatterFactory (new

javax.swing.text. DefaultFormatterFactory (new

javax.swing.text.MaskFormatter("\#\#/\#\#/\#\#\#\#")));

\} catch (java.text.ParseException ex) \{

\}

ex.printStackTrace();

jFormattedTextField2. setHorizontalAlignment (javax.swing.JTextField.TRAILING) ;

jTextField4. setHorizontalAlignment (javax.swing.JTextField.TRAILING) ;

jTextField5.setHorizontalAlignment (javax.swing.JTextField.TRAILING) ;

jButton 1. setText ("Novo");

jButton1.addActionListener(new java.awt.event. ActionListener() \{ public void actionPerformed(java.awt.event. ActionEvent evt) \{ jButton1ActionPerformed (evt);

\}); \}

jButton2. setText ("Salvar");

jButton2.addActionListener(new java.awt.event.ActionListener() \{ public void actionPerformed(java.awt.event. ActionEvent evt) \{ jButton2ActionPerformed (evt); 
63, javax.swing.GroupLayout.PREFERRED_SIZE))

- addContainerGap ())

)$;$

jPanellLayout. setVerticalGroup (

jPanel1Layout.createParallelGroup (javax.swing.GroupLayout.Alignment.LEADING)

. addGroup (jPanell Layout. createSequentialGroup () . addContainerGap ()

.addComponent (jComboBox2, javax.swing.GroupLayout.PREFERRED_SIZE,

javax.swing.GroupLayout.DEFAULT_SIZE, javax.swing.GroupLayout.PREFERRED_SIZE)

.addPreferredGap (javax.swing. Layout.Style. ComponentPlacement. UNRELATED)

.addGroup (j PanellLayout. createParallelGroup (javax.swing. GroupLayout. Alignment. BASEL INE)

. addComponent (jLabel1)

. addComponent (jTextField1

javax.swing.GroupLayout.PREFERRED_SIZE,

javax.swing.GroupLayout.DEFAULT_SIZE,

javax.swing. GroupLayout. PREFERRED SIZE)

. addComponent (jLabel5)

. addComponent (jFormattedTextField2,

javax.swing.GroupLayout.PREFERRED_SIZE, javax.swing.GroupLayout.DEFAULT_SIZE, javax.swing.GroupLayout.PREFERRED_SIZE))

.addPreferredGap (javax.swing. LayoutStyle.ComponentPlacement. UNRELATED)

.addGroup (jPanellLayout.createParallelGroup (javax.swing.GroupLayout. Alignment. BASEL INE)

. addComponent (jLabel2)

. addComponent (jTextField2,

javax.swing. GroupLayout. PREFERRED SIZE,

javax.swing.GroupLayout.DEFAULT_SIZE,

javax.swing.GroupLayout.PREFERRED SIZE)

. addComponent (jLabel 6)

. addComponent (jTextField4,

javax.swing.Grouplayout. PREFERRED SIZE,

javax.swing.GroupLayout.PREFERRED_SIZE))

javax.swing.GroupLayout. DEFAULT SIZE,

.addPreferredGap (javax.swing. LayoutStyle.ComponentPlacement. UNRELATED)

.addGroup (jPanellLayout.createParallelGroup (javax.swing. GroupLayout. Alignment. BASEL INE)

. addComponent (jLabel3)

- addComponent (jFormattedTextField1,

javax.swing.Grouplayout. PREFERRED SIZE,

javax.swing.GroupLayout.DEFAULT SIZE,

javax.swing.GroupLayout.PREFERRED_SIZE)

. addComponent (jLabel 7)

. addComponent (jTextField5,

javax.swing. GroupLayout. PREFERRED SIZE,

javax.swing.GroupLayout.PREFERRED_SIZE))

javax.swing.GroupLayout.DEFAULT SIZE,

.addPreferredGap (javax.swing. Layoutstyle.ComponentPlacement. UNRELATED)

.addGroup (jPanel1Layout. createParallelGroup (javax.swing. GroupLayout. Alignment. BASEL INE)

. addComponent (jLabel 4 )

. addComponent (jTextField3,

javax.swing.GroupLayout.PREFERRED SIZE,

javax.swing.GroupLayout.PREFERRED_SIZE))

.addPreferredGap (javax.swing. LayoutStyle.ComponentPlacement.RELATED,

javax.swing.GroupLayout.DEFAULT_SIZE, Short.MAX_VALUE)

. addComponent (jT̄oggleButton 1 )

.addPreferredGap (javax.swing. LayoutStyle.ComponentPlacement.RELATED)

.addGroup (jPanellLayout. createParallelGroup (javax.swing. GroupLayout. Alignment. BASEL 
INE)

addComponent (jButton1)

. addComponent (jButton2))

. addContainerGap ())

);

jPanel2.setBorder(javax.swing.BorderFactory.createTitledBorder(null,

"Leitura das Sacas", javax.swing.border.TitledBorder.DEFAULT JUSTIFICATION, javax.swing.border.TitledBorder.DEFAULT_POSITION, new java.awt.Font("Arial", 1, 12))); // NOI18N

jLabel8. setText ("NÃ ${ }^{\circ}$ mero") ;

jLabe19. setText ("Peso");

jTextField6.setEnabled(false);

jTextField7.setEnabled(false);

jButton6. setText ("Gerar Dados");

jButton6.addActionListener(new java.awt.event.ActionListener() \{ public void actionPerformed(java.awt.event. ActionEvent evt) \{ jButton6ActionPerformed (evt); \}

\});

javax.swing. GroupLayout

jPanel2Layout

new

javax.swing. GroupLayout (jPanel2);

jPanel2.setLayout (jPanel2Layout);

jPanel2Layout.setHorizontalGroup(

jPanel2Layout.createParallelGroup (javax.swing.GroupLayout.Alignment. LEADING)

. addGroup (jPanel2Layout. createSequentialGroup ()

. addContainerGap ()

.addGroup (jPanel2Layout. createParallelGroup (javax.swing.GroupLayout.Alignment. TRAIL ING)

. addComponent (jLabel8)

. addComponent (jLabel9))

.addPreferredGap (javax.swing. LayoutStyle.ComponentPlacement.RELATED)

. addGroup (jPanel2Layout. createParallelGroup (javax.swing. GroupLayout. Alignment. LEADI NG, false)

. addComponent (jTextField6)

. addComponent (jTextField7,

javax.swing.GroupLayout.DEFAULT_SIZE, 90, Short.MAX_VALUE))

Short.MAX_VALUE))

.addContainerGap (javax.swing.GroupLayout.DEFAULT_SIZE,

.addGroup (javax.swing.GroupLayout.Alignment.TRAILING,

jPanel2Layout.createSequentialGroup ()

.addContainerGap (84, Short.MAX_VALUE)

. addComponent (jButton6)

- addContainerGap ())

);

jPanel2Layout.setVerticalGroup (

jPanel2Layout.createParallelGroup (javax.swing.GroupLayout. Alignment. LEADING) . addGroup (jPanel2 Layout. createSequentialGroup () . addContainerGap ()

.addGroup (jPanel2 Layout. createParallelGroup (javax.swing.GroupLayout. Alignment.BASEL INE)

. addComponent ( $j$ Label 8)

. addComponent (jTextField6,

javax.swing.GroupLayout. PREFERRED SIZE,

javax.swing.GroupLayout.DEFAULT_SIZE, 
javax.swing.GroupLayout.PREFERRED_SIZE))

.addPreferredGap (javax.swing. Layoutstyle.ComponentPlacement. UNRELATED)

.addGroup (jPanel2Layout. createParallelGroup (javax.swing. GroupLayout.Alignment. BASEL INE)

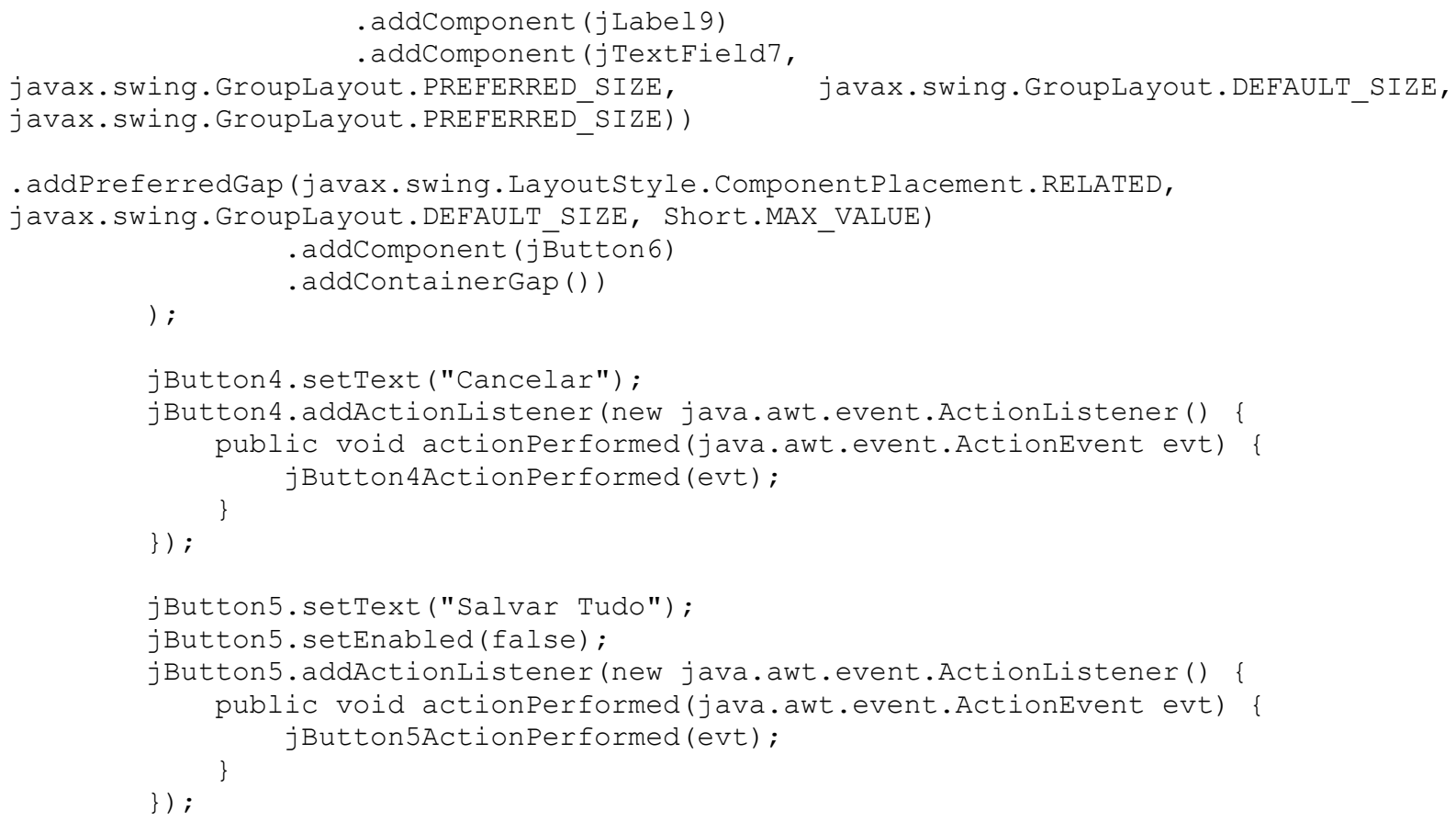




\section{- addContainerGap ( )}

.addGroup (layout. createParallelGroup (javax.swing.GroupLayout.Alignment. LEADING, false)

-addComponent (jPanel1, javax.swing.GroupLayout.DEFAULT_SIZE, javax.swing.GroupLayout.DEFAULT SIZE, short.MAX VALUE)

-addComponent (jPanel4, javax.swing.GroupLayout.DEFAULT_SIZE, javax.swing.GroupLayout.DEFAULT_SIZE, Short.MAX VALUE)

.addComponeñt (jPanel2, j̄avax.swing.Grouplayout.DEFAULT_SIZE,

javax.swing.GroupLayout.DEFAULT_SIZE, Short.MAX_VALUE))

.addPreferredGap (javax.swing. Layoutstyle.ComponentPlacement. UNRELATED)

. addGroup (layout. createParallelGroup (javax.swing.GroupLayout.Alignment.BASELINE)

. addComponent (jButton 4)

- addComponent (jButton5))

Short.MAX_VALUE))

. addContainerGap (javax.swing. GroupLayout. DEFAULT SIZE,

$\bar{i}$

pack () ;

\}// </editor-fold>//GEN-END: initComponents

private void jButton4ActionPerformed(java.awt.event.ActionEvent evt) \{//GENFIRST:event_jButton4ActionPerformed

dispose ();

\}//GEN-LAST:event_jButton4ActionPerformed

private void jComboBoxlItemStateChanged(java.awt.event.ItemEvent evt) \{//GENFIRST:event jComboBoxlItemstatechanged

int index = jComboBoxl.getSelectedIndex ();

mostrarLote (index - 1);

\}//GEN-LAST:event_jComboBox1ItemstateChanged

private void jButton2ActionPerformed(java.awt.event.ActionEvent evt) \{//GENFIRST:event_jButton2ActionPerformed

// SALVAR PALET

String[] parametros = new String[8];

parametros [0] = String.valueof(id_lote_fixo);

parametros [1] = jTextField1.getText();

parametros [2] = jTextField2.getText ();

parametros [3] = jFormattedTextFieldl.getText ();

parametros [4] = jTextField3.getText ();

parametros [5] = jFormattedTextField2.getText ();

parametros [6] = jTextField4.getText ();

parametros $[7]=$ jTextField5.getText ();

boolean result = MainFrame.mysql.insertRowInTable ("palet", parametros); id_palet_fixo = MainFrame.mysql.getLastIdFromTable("palet", "id_palet"); Utilities.consoleout("lastID = "+id_palet_fixo);

if (result)

\{

jToggleButton1. setEnabled (result);

\}

else

\{

JoptionPane. showMessageDialog (this,

"Aconteceu um erro na hora de gravar os dados

no banco",

"Nova Torre - Erro",

JoptionPane.ERROR_MESSAGE);

\}

\}//GEN-LAST:event_jButton2ActionPerformed

private void jComboBox2ItemstateChanged(java.awt.event.ItemEvent evt) \{//GENFIRST:event_jComboBox2Itemstatechanged 
int index $=$ jComboBox2.getSelectedIndex ();

mostrarPalet (index - 1);

\}//GEN-LAST:event_jComboBox2ItemStateChanged

private void jButtonlActionPerformed(java.awt.event.ActionEvent evt) \{//GENFIRST:event jButton1ActionPerformed

jComboBox2. setSelectedIndex (0);

clearPaletFields ():

jButton2. setEnabled (true);

jToggleButton1. setEnabled (true);

jComboBoxl.setEnabled (true);

jComboBoxl. setSelectedIndex (0);

clearLabels ();

\}//GEN-LAST:event_jButton1ActionPerformed

private void jButton6ActionPerformed(java.awt.event.ActionEvent evt) \{//GENFIRST: event jButton6ActionPerformed

// GERAR NO. DE SACAS CONSECUTIVAMENTE

// E SALVAR SACAS NO BD

int lastSacaNo = MainFrame.mysql.getLastSacaNo();

lastSacaNo++;

String[] aux par

boolean result $=$ true;

for (int $i=0 ; i<80 ; i++)$

aux_par = new String[3];

aux par[0] = String.valueof (id palet fixo);

aux_par $[1]=$ String.valueof (lastSacaN̄o)

aux par $[2]$ = String.valueof (peso saca);

result \&= MainFrame.mysql.insertRowInTable("saca", aux_par);

last SacaNo++;

//id_lote_fixo = MainFrame.mysql.getLastIdFromTable("lote", "id_lote");

//Utilities.consoleout("lastID = "+id lote fixo);

if (result)

jButton 6. setEnabled (false);

else

\{

JoptionPane.showMessageDialog(this,

"Aconteceu um erro na hora de gravar os dados

no banco",

"Novas Sacas - Erro",

JOptionPane.ERROR_MESSAGE);

\}//GEN-LAST:event jButton6ActionPerformed

private void jButton5ActionPerformed(java.awt.event.ActionEvent evt) \{//GENFIRST:event jButton5ActionPerformed

// // SALVAR SACAS

// String[] aux_par;

//

// boolean result $=$ true;

$/ /$ for (int $i=0 ; i<14 ; i++$ )

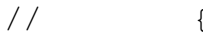

//

//

aux_par = new String[2];

aux_par[0] = String.valueof(id_lote_fixo);

aux par $[1]=$ parametros [i]

result \&= MainFrame.mysql.insertRowInTable("bigbag", aux par); 


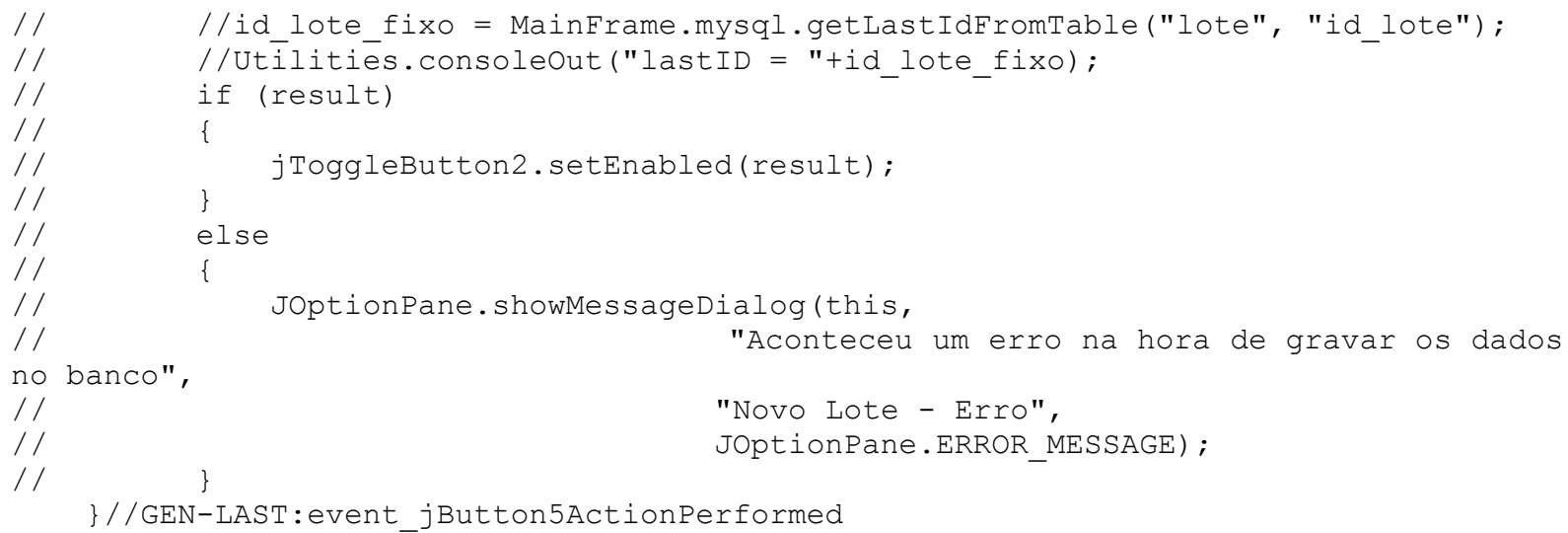

// Variables declaration - do not modify//GEN-BEGIN:variables private javax.swing. JButton jButton1; private javax.swing.JButton jButton2; private javax.swing. JButton jButton 4 ; private javax.swing. JButton jButton5; private javax.swing. JButton jButton6; private javax.swing. JComboBox jComboBox1; private javax.swing. JComboBox jComboBox2; private javax.swing.JFormattedTextField jFormattedTextField1; private javax.swing.JFormattedTextField jFormattedTextField2; private javax.swing. JLabel jLabel1; private javax.swing. JLabel jLabel18; private javax.swing. JLabel jLabel19; private javax.swing. JLabel jLabel2; private javax.swing. JLabel jLabel20; private javax.swing. JLabel jLabel21; private javax.swing. JLabel jLabel22; private javax.swing. JLabel jLabel23; private javax.swing. JLabel jLabe124; private javax.swing. JLabel jLabe125; private javax.swing. JLabel jLabel26; private javax.swing. JLabel jLabe127; private javax.swing. JLabel jLabel28; private javax.swing. JLabel jLabel29; private javax.swing. JLabel jLabel3; private javax.swing. JLabel jLabel30; private javax.swing. JLabel jLabel31; private javax.swing. JLabel jLabel32; private javax.swing. JLabel jLabe133; private javax.swing. JLabel jLabel34; private javax.swing. JLabel jLabel35; private javax.swing. JLabel jLabel37; private javax.swing. JLabel jLabe138; private javax.swing. JLabel jLabel39; private javax.swing. JLabel jLabel4; private javax.swing. JLabel jLabe15; private javax.swing. JLabel jLabel6; private javax.swing. JLabel jLabel7; private javax.swing. JLabel jLabel8; private javax.swing. JLabel jLabel9; private javax.swing.JPanel jPanell; private javax.swing.JPanel jPanel2; private javax.swing. JPanel jPanel4; private javax.swing. JTextField jTextField1; private javax.swing.JTextField jTextField2; private javax.swing. JTextField jTextField3; private javax.swing. JTextField jTextField4; private javax.swing. JTextField jTextField5; private javax.swing. JTextField jTextField6; private javax.swing.JTextField jTextField7; 


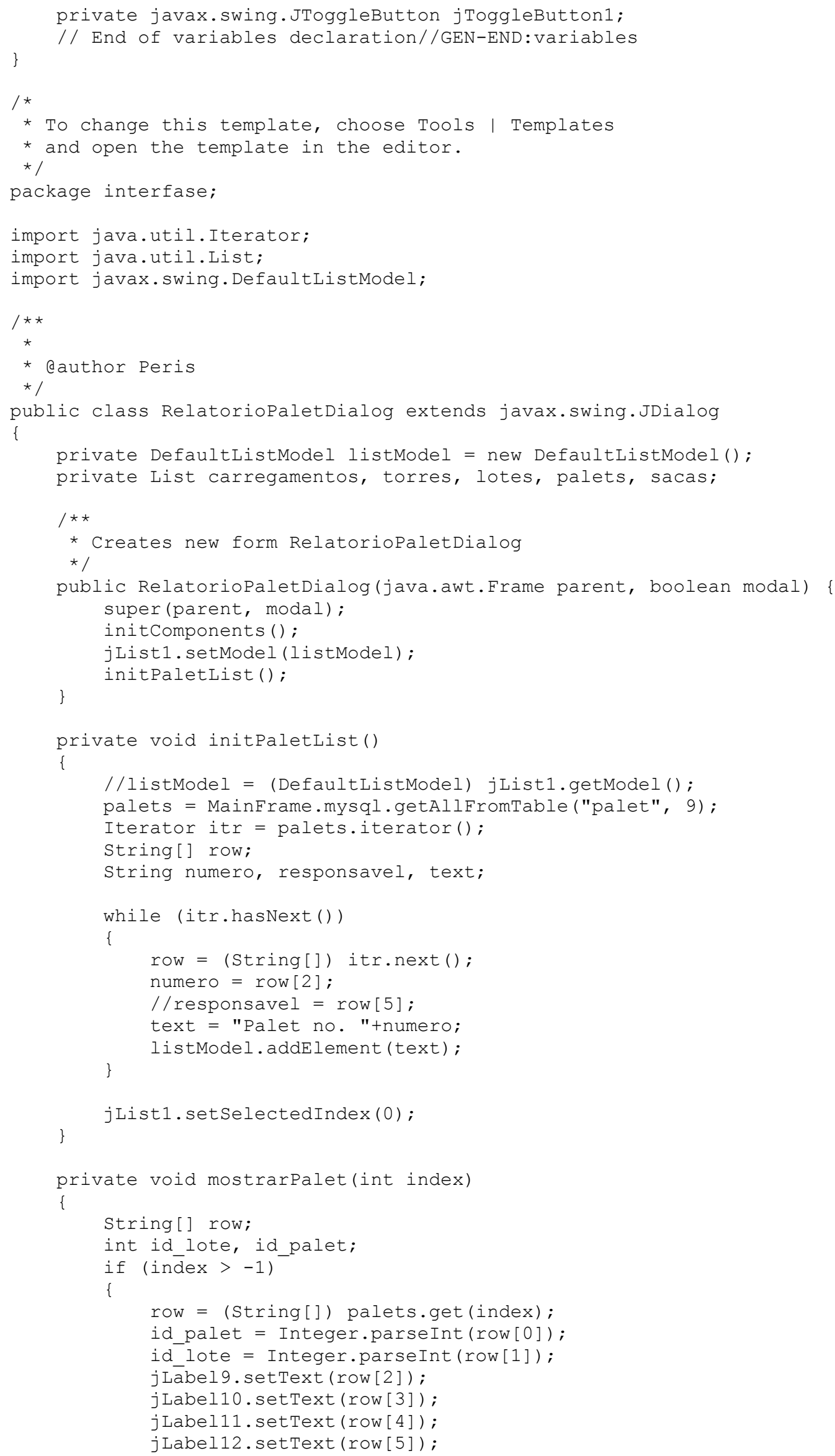




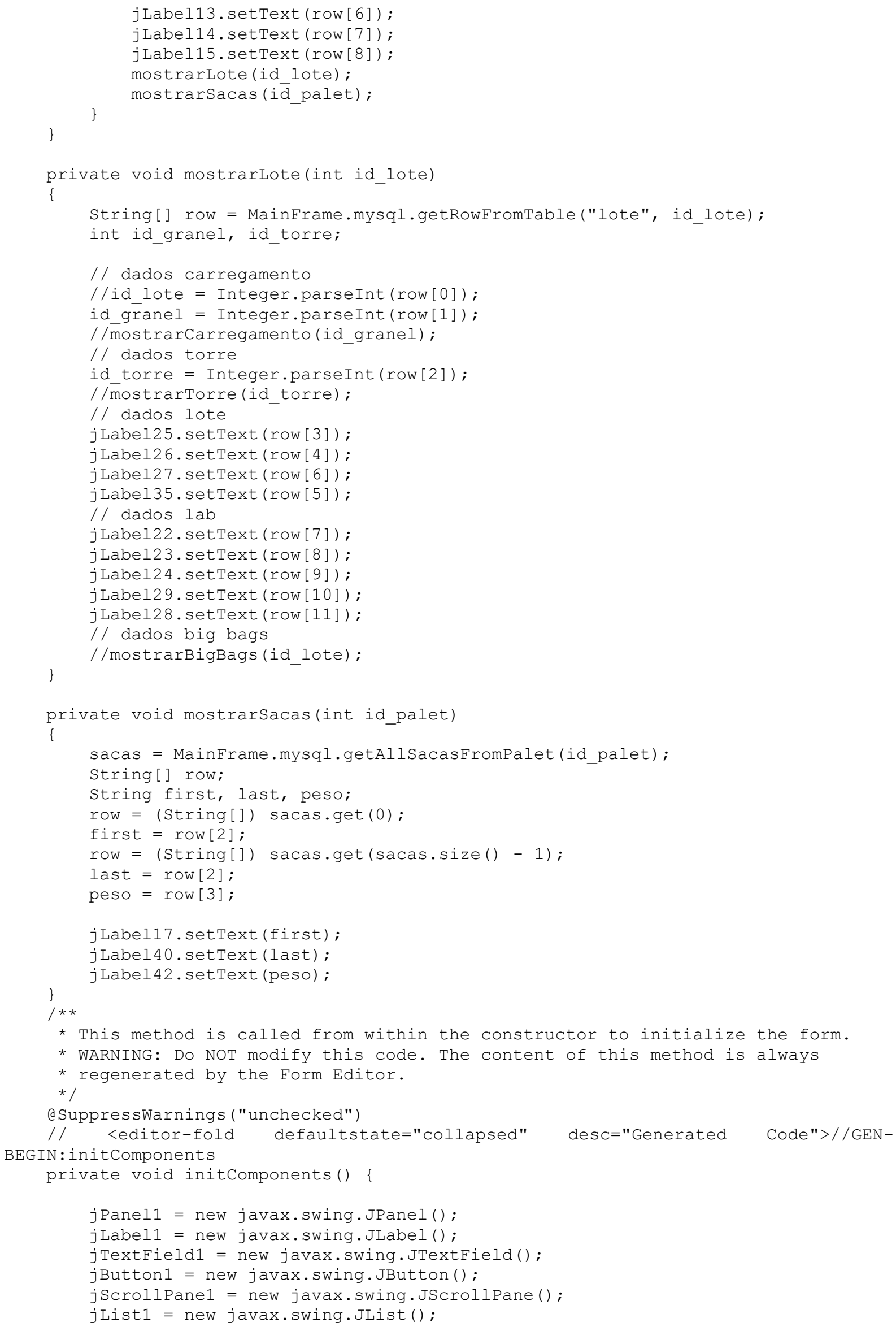


jPanel4 = new javax.swing.JPanel ();

jLabel18 = new javax.swing.JLabel();

jLabel19 = new javax.swing. JLabel ();

jLabel20 = new javax.swing. JLabel ();

jLabel21 = new javax.swing.JLabel ();

jLabel34 = new javax.swing.JLabel ();

jLabel31 = new javax.swing.JLabel ();

jLabel39 = new javax.swing.JLabel ();

jLabel33 = new javax.swing.JLabel ();

jLabel38 = new javax.swing.JLabel ();

jLabel30 = new javax.swing.JLabel ();

jLabel32 = new javax.swing.JLabel();

jLabel37 = new javax.swing. JLabel ();

jLabel22 = new javax.swing.JLabel ();

jLabel23 = new javax.swing. JLabel ();

jLabel24 = new javax.swing.JLabel ();

jLabel25 = new javax.swing.JLabel ();

jLabel26 = new javax.swing.JLabel ();

jLabel27 = new javax.swing.JLabel ();

jLabel28 = new javax.swing.JLabel ();

jLabel29 = new javax.swing.JLabel ();

jLabe135 = new javax.swing. JLabel ();

jButton 4 = new javax.swing.JButton();

jPanel2 = new javax.swing.JPanel();

jLabel2 = new javax.swing.JLabel ();

jLabel3 = new javax.swing.JLabel ();

jLabel4 = new javax.swing.JLabel ();

jLabel5 = new javax.swing.JLabel ();

jLabel6 = new javax.swing.JLabel ();

jLabel7 = new javax.swing.JLabel ();

jLabel8 = new javax.swing.JLabel();

jLabel9 = new javax.swing.JLabel ();

jLabel10 = new javax.swing.JLabel ();

jLabel11 = new javax.swing.JLabel ();

jLabel12 = new javax.swing.JLabel ();

jLabel13 = new javax.swing.JLabel ();

jLabel14 = new javax.swing.JLabel ();

jLabel15 = new javax.swing.JLabel ();

jPanel3 = new javax.swing.JPanel ();

jLabel16 = new javax.swing.JLabel ();

jLabel17 = new javax.swing.JLabel ();

jLabel36 = new javax.swing. JLabel();

jLabel40 = new javax.swing.JLabel ();

jLabel41 = new javax.swing.JLabel ();

jLabel42 = new javax.swing.JLabel ();

jButton2 = new javax. swing. JButton();

setDefaultCloseOperation(javax.swing.WindowConstants.DISPOSE ON CLOSE); setTitle("Palets Processados");

setResizable (false);

jPanel1.setBorder(javax.swing.BorderFactory.createTitledBorder(null, "Palet Processados", javax.swing.border. TitledBorder.DEFAULT JUSTIFICATION, javax.swing.border.TitledBorder.DEFAULT_POSITION, new java.awt.Font("Arial", 1, 12))); // NOI18N

jLabel1.setText("No. do Palet:");

jButton1.setText ("Procurar");

jList1.addListSelectionListener (new javax.swing.event.ListSelectionListener() \{ public void valueChanged(javax.swing.event.ListselectionEvent evt) jList1ValueChanged (evt);

\}) ; 
jScrollPane1. setViewportView (jList1);

do

jPanel4. setBorder(javax.swing.BorderFactory.createTitledBorder(null, "Dados Lote", javax.swing.border.TitledBorder.DEFAULT_JUSTIFICATION, javax.swing.border.TitledBorder.DEFAULT_POSITION, new java.awt.Font("Arial", 1 , 12)) ) / / NOI18N

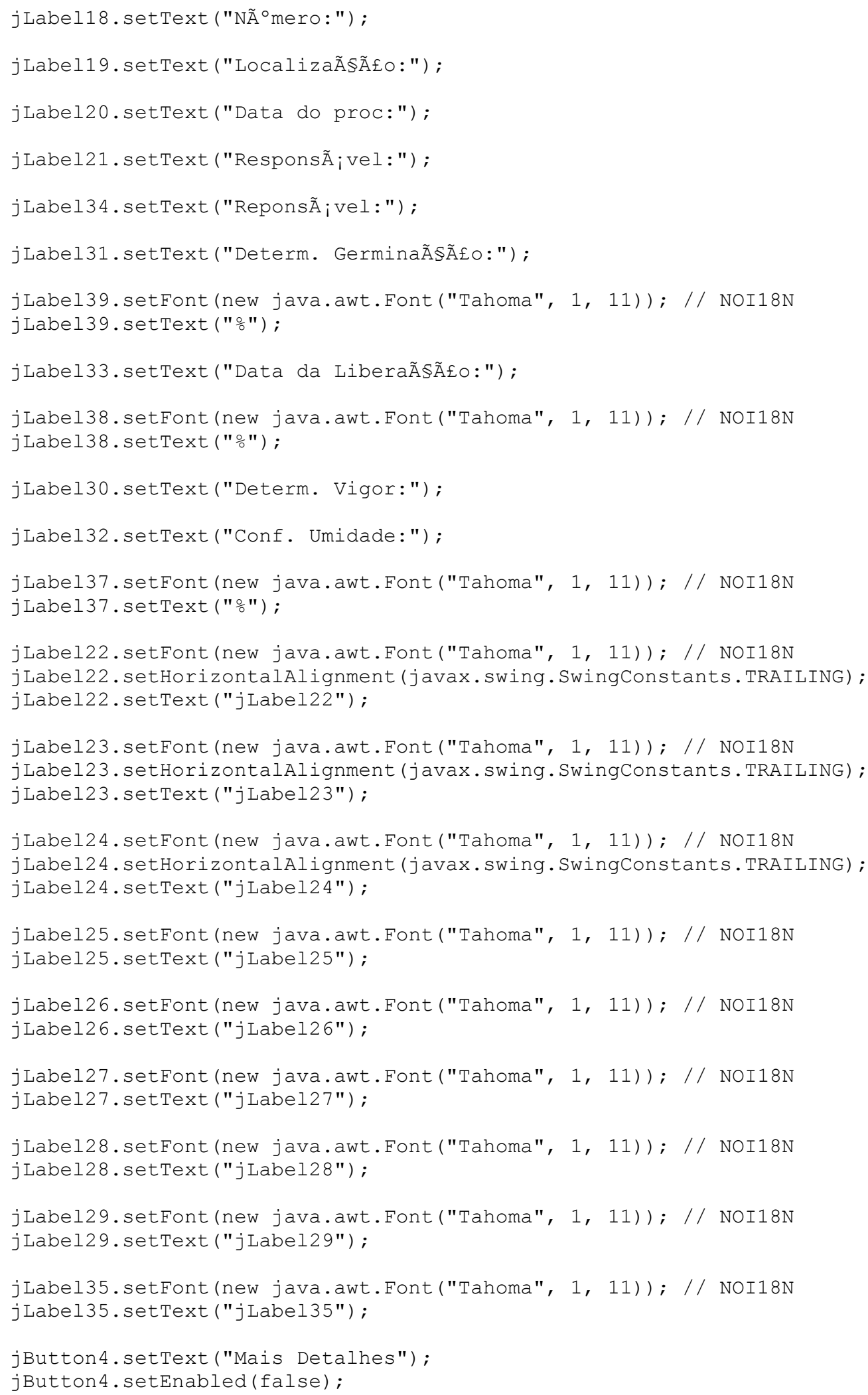


javax.swing.GroupLayout

javax.swing.GroupLayout (jPanel4);

jPanel4.setLayout (jPanel4 Layout);

jPanel4 Layout. setHorizontalGroup (

jPanel 4 Layout.createParallelGroup (javax.swing. GroupLayout. Alignment. LEADING)

- addGroup (jPanel 4 Layout. createSequential Group ()

. addGap $(24,24,24)$

.addGroup (jPanel 4Layout. createParallelGroup (javax.swing.GroupLayout.Alignment. TRAII ING)

$$
\begin{aligned}
& \text {. addComponent (jLabel20) } \\
& \text {. addComponent (jLabel19) } \\
& \text {. addComponent (jLabel18) } \\
& \text {. addComponent (jLabel21)) }
\end{aligned}
$$

.addPreferredGap (javax.swing. LayoutStyle.ComponentPlacement.RELATED)

.addGroup (jPanel 4Layout. createParallelGroup (javax.swing.GroupLayout. Alignment. LEADI NG)

$$
\begin{aligned}
& \text {. addComponent (jLabe 126) } \\
& \text {. addComponent (jLabel25) } \\
& \text {. addComponent (jLabel27) } \\
& \text {. addComponent (j Label35) }
\end{aligned}
$$

.addPreferredGap (javax.swing. LayoutStyle.ComponentPlacement.RELATED, javax.swing.GroupLayout.DEFAULT_SIZE, Short.MAX_VALUE)

.addGroup (jPanel 4Layout.createParallelGroup (javax.swing.GroupLayout.Alignment. TRAIL ING)

.addGroup (javax.swing.GroupLayout.Alignment. LEADING, jPanel 4 Layout.createSequentialGroup ()

$$
\text { . } \operatorname{addGap}(14,14,14)
$$

. addGroup (jPanel 4Layout. createParallelGroup (javax.swing.GroupLayout. Alignment. TRAIL ING)

$$
\begin{aligned}
& \text {. addComponent (jLabel33) } \\
& \text {. addComponent (jLabel34)) }
\end{aligned}
$$

.addPreferredGap (javax.swing. LayoutStyle.ComponentPlacement. UNRELATED)

. addGroup (jPanel 4 Layout. createParallel Group (javax.swing. GroupLayout. Alignment. LEADI NG)

$$
\text { - addComponent (jLabel29) }
$$

.addGroup (javax.swing.GroupLayout.Alignment.LEADING,

jPanel 4 Layout.createSequentialGroup ()

.addGroup (jPanel 4Layout. createParallelGroup (javax.swing.GroupLayout.Alignment.TRAIL ING)

$$
\begin{aligned}
& \text {. addComponent (jLabel30) } \\
& \text {. addComponent (jLabel32) } \\
& \text {. addComponent (jLabel31)) }
\end{aligned}
$$

.addPreferredGap (javax.swing. Layout.Style.ComponentPlacement. UNRELATED)

.addGroup (jPanel 4Layout. createParallelGroup (javax.swing.GroupLayout. Alignment. LEADI NG)

$$
\begin{aligned}
& \text {. addComponent (jLabel23) } \\
& \text {. addComponent (jLabel22) } \\
& \text {. addComponent (jLabel24)) }
\end{aligned}
$$

.addPreferredGap (javax.swing.Layoutstyle.ComponentPlacement.RELATED)

.addGroup (jPanel 4Layout.createParallelGroup (javax.swing.GroupLayout.Alignment.TRAIL 
ING)

\author{
. addComponent (jLabe138) \\ - addComponent (jLabel37) \\ . addComponent (jLabel39)))) \\ . addGap $(35,35,35))$ \\ . addGroup (javax.swing.GroupLayout.Alignment. TRAILING,
}

jPanel 4 Layout.createSequentialGroup ()

Short.MAX_VALUE) -addContainerGap (javax.swing.GroupLayout. DEFAULT SIZE,

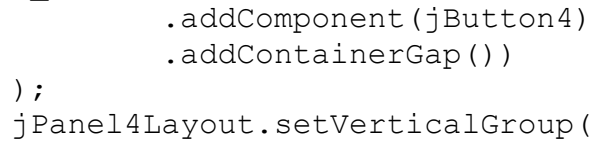

jPanel 4 Layout.createParallelGroup (javax.swing.GroupLayout.Alignment. LEADING) . addGroup (jPanel 4 Layout. createSequentialGroup ()

.addGroup (jPanel 4Layout. createParallelGroup (javax.swing.GroupLayout. Alignment. LEADI NG)

$$
\begin{aligned}
& \text {. addGroup (jPanel } 4 \text { Layout. createSequentialGroup () } \\
& \text {. addGap }(11,11,11)
\end{aligned}
$$

.addGroup (jPanel 4Layout.createParallelGroup (javax.swing.GroupLayout. Alignment. LEADI NG)

.addGroup (jPanel 4Layout. createParallelGroup (javax.swing.GroupLayout.Alignment. BASEL INE)

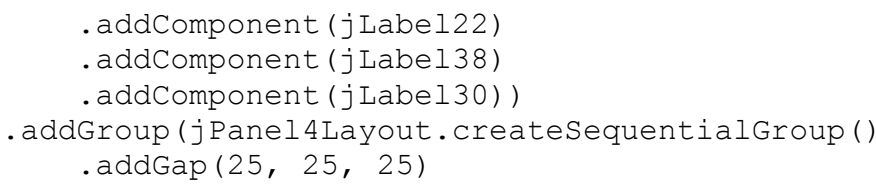

.addGroup (jPanel 4 Layout. createParallelGroup (javax.swing. GroupLayout. Alignment. TRAIL ING)

$$
\text { . addGroup (jPanel } 4 \text { Layout. createSequentialGroup () }
$$

.addGroup (jPanel 4Layout.createParallelGroup (javax.swing.Grouplayout. Alignment. BASEL INE)

$$
\text { - addComponent (jLabel37) }
$$$$
\text { . addComponent (jLabel23)) }
$$

.addPreferredGap (javax.swing. Layoutstyle.ComponentPlacement. UNRELATED)

.addGroup (jPanel 4Layout. createParallelGroup (javax.swing.GroupLayout. Alignment. BASEL INE)

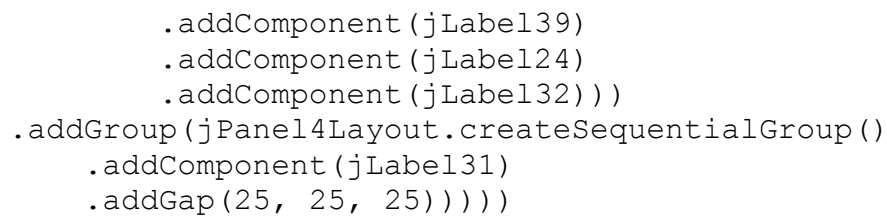

.addPreferredGap (javax.swing. Layoutstyle.ComponentPlacement. UNRELATED)

. addGroup (jPanel 4Layout. createParallelGroup (javax.swing. GroupLayout. Alignment. BASEL INE)

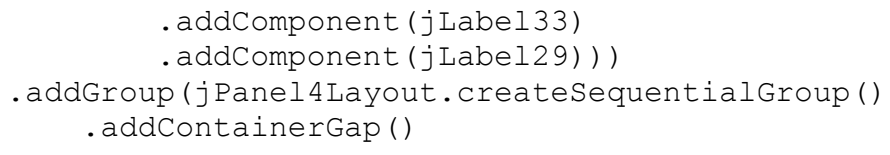

. addGroup (jPanel 4 Layout. createParallelGroup (javax.swing.GroupLayout. Alignment. BASEL INE)

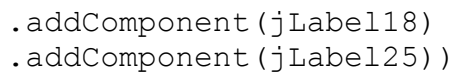


.addPreferredGap (javax.swing. Layout.Style. ComponentPlacement. UNRELATED)

.addGroup (jPanel 4Layout.createParallelGroup (javax.swing.GroupLayout. Alignment.BASEL INE)

$$
\begin{aligned}
& \text {. addComponent (jLabel19) } \\
& \text {. addComponent (jLabel26)) }
\end{aligned}
$$

.addPreferredGap (javax.swing. Layout.Style.ComponentPlacement. UNRELATED)

.addGroup (jPanel 4Layout.createParallelGroup (javax.swing. GroupLayout. Alignment. BASEL INE)

$$
\begin{aligned}
& \text { - addComponent (jLabel20) } \\
& \text {. addComponent (jLabel27)) }
\end{aligned}
$$

.addPreferredGap (javax.swing. Layoutstyle.ComponentPlacement. UNRELATED)

.addGroup (jPanel 4Layout.createParallelGroup (javax.swing.Grouplayout. Alignment. BASEL INE)

$$
\begin{aligned}
& \text {. addComponent (jLabel21) } \\
& \text {. addComponent (jLabel35)))) }
\end{aligned}
$$

.addPreferredGap (javax.swing. LayoutStyle.ComponentPlacement.RELATED)

.addGroup (jPanel 4Layout.createParallelGroup (javax.swing.GroupLayout. Alignment. BASEL INE)

$$
\begin{aligned}
& \text {. addComponent (jLabel 34) } \\
& \text {. addComponent (jLabel28)) }
\end{aligned}
$$

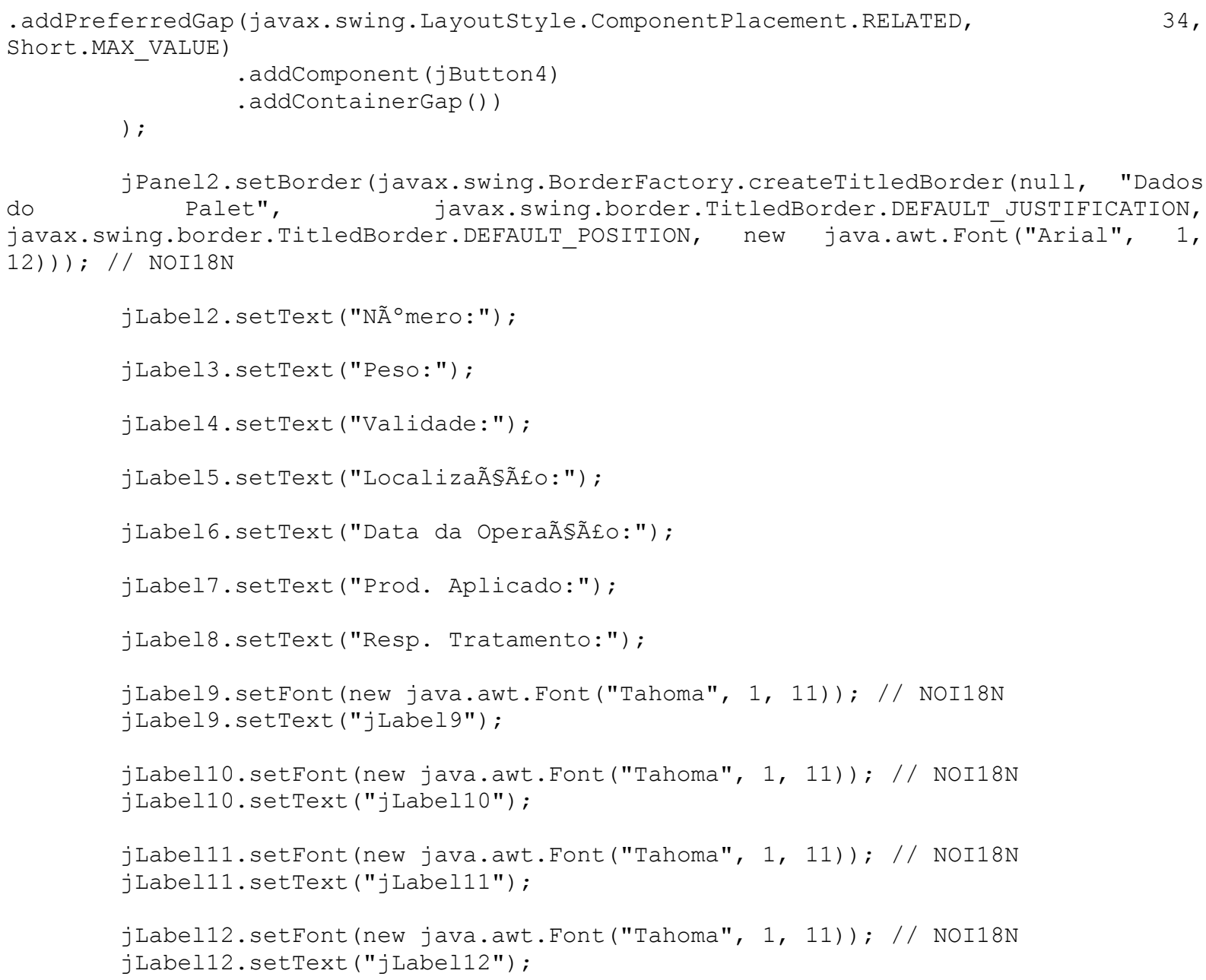


jLabel13. setFont (new java.awt.Font("Tahoma", 1, 11)); // NOI18N

jLabel13. setText ("jLabe113");

jLabel14.setFont (new java.awt.Font("Tahoma", 1, 11)); // NOI18N

jLabel14.setText ("jLabel14");

jLabel15. setFont (new java.awt.Font("Tahoma", 1, 11)); // NOI18N

jLabel15. setText ("jLabe115");

javax.swing.GroupLayout

jPanel2Layout

new javax.swing.GroupLayout ( jPanel2);

jPanel2. setLayout (jPanel2Layout);

jPanel2Layout. setHorizontalGroup(

jPanel2Layout. createParallelGroup (javax.swing.GroupLayout. Alignment. LEADING) . addGroup (jPanel2Layout. createSequentialGroup () . addContainerGap ()

.addGroup (jPanel2Layout.createParallelGroup (javax.swing. GroupLayout.Alignment. TRAIL ING)

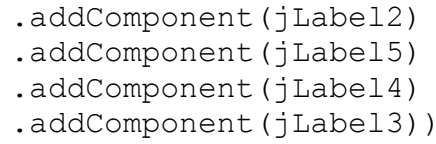

.addPreferredGap (javax.swing. LayoutStyle.ComponentPlacement. UNRELATED)

.addGroup (jPanel2Layout.createParallelGroup (javax.swing.GroupLayout. Alignment.LEADI NG)

. addGroup (jPanel2Layout. createSequentialGroup ()

. addComponent (jLabel12)

Short.MAX VALUE))

.addContainerGap (javax.swing.GroupLayout.DEFAULT_SIZE,

. addGroup (jPanel2Layout. createSequentialGroup ()

. addGroup (jPanel2Layout. createParallelGroup (javax.swing. GroupLayout. Alignment. TRAIL ING)

javax.swing.GroupLayout.Alignment.LEADING)

javax.swing.GroupLayout.Alignment.LEADING)

. addComponent (jLabel11,

javax.swing.GroupLayout.Alignment.LEADING) )

$$
\text { . addComponent (jLabel10, }
$$

.addPreferredGap (javax.swing. LayoutStyle.ComponentPlacement.RELATED,

javax.swing.GroupLayout.DEFAULT_SIZE, Short.MAX_VALUE)

.addGroup (jPanel2Layout. createParallelGroup (javax.swing.GroupLayout.Alignment. TRAIL ING)

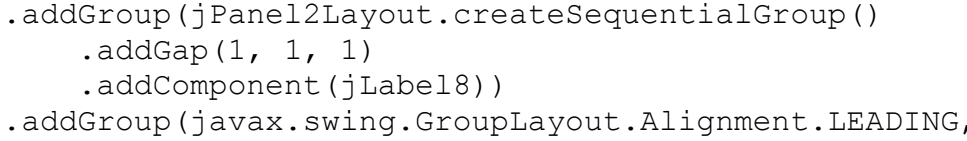

javax.swing. GroupLayout.Alignment. LEADING))

.addPreferredGap (javax.swing. Layoutstyle.ComponentPlacement. UNRELATED)

.addGroup (jPanel2Layout.createParallelGroup (javax.swing.GroupLayout.Alignment. LEADI NG)

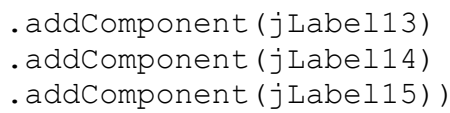


jPanel3Layout.setHorizontalGroup (

jPanel3Layout. createParallelGroup (javax.swing.GroupLayout. Alignment. LEADING) . addGroup (jPanel3Layout. createSequentialGroup () . addContainerGap ()

.addGroup (jPanel 3Layout.createParallelGroup (javax.swing.GroupLayout. Alignment. TRAIL ING)

- addGroup (jPanel3Layout. createSequentialGroup ()

.addGap (0, 1, Short.MAX VALUE)

. addComponent (jLabel36)

.addPreferredGap (javax.swing. LayoutStyle.ComponentPlacement. UNRELATED)

- addComponent ( $j$ Label 40 )

. $\operatorname{addGap}(266,266,266))$

. addGroup (jPanel3Layout. createSequentialGroup ()

. addComponent (jLabel16)

.addPreferredGap (javax.swing. LayoutStyle.ComponentPlacement.RELATED) . addComponent ( jLabel17)

.addPreferredGap (javax.swing. LayoutStyle.ComponentPlacement.RELATED, javax.swing.GroupLayout.DEFAULT_SIZE, Short.MAX_VALUE)

. addComponent (jLabel41)

.addPreferredGap (javax.swing. LayoutStyle.ComponentPlacement.RELATED)

. addComponent (jLabel 42)

. $\operatorname{addGap}(59,59,59))))$

) ;

jPanel3Layout.setVerticalGroup (

jPanel3Layout.createParallelGroup (javax.swing.GroupLayout.Alignment. LEADING)

. addGroup (jPanel3Layout. createSequentialGroup ()

. addContainerGap ()

. addGroup (jPanel3Layout. createParallelGroup (javax.swing. GroupLayout. Alignment. BASEL INE)

$$
\begin{aligned}
& \text {. addComponent (jLabel16) } \\
& \text {. addComponent (jLabel17) } \\
& \text {. addComponent (jLabel 41) } \\
& \text {. addComponent (jLabel 42)) }
\end{aligned}
$$

.addPreferredGap (javax.swing. LayoutStyle.ComponentPlacement. UNRELATED)

. addGroup (jPanel 3Layout. createParallelGroup (javax.swing.GroupLayout. Alignment. BASEL INE)

. addComponent (jLabe136)

. addComponent ( $j$ Label 40$)$ )

.addContainerGap (43, Short.MAX_VALUE))

) ;

javax.swing.GroupLayout

jPanellLayout

new

javax.swing. GroupLayout (jPanel1);

jPanel1. setLayout (jPanel1Layout);

jPanellLayout. setHorizontalGroup(

jPanel1Layout.createParallelGroup (javax.swing.GroupLayout.Alignment.LEADING) . addGroup (jPanell Layout. createSequentialGroup ()

. addContainerGap ()

.addGroup (jPanellLayout. createParallelGroup (javax.swing. GroupLayout. Alignment. TRAIL ING, false)

- addComponent (jButton1)

. addGroup (javax.swing.GroupLayout.Alignment. LEADING,

jPanell Layout.createSequentialGroup ()

. addComponent (jLabel1) 
.addPreferredGap (javax.swing. Layoutstyle.ComponentPlacement.RELATED) - addComponent (jTextField1))

- addComponent (jScrollpane1,

javax.swing.GroupLayout.Alignment.LEADING, javax.swing.GroupLayout.PREFERRED_SIZE, 170, javax.swing.GroupLayout.PREFERRED_SIZE))

.addPreferredGap (javax.swing. Layoutstyle.ComponentPlacement. UNRELATED)

.addGroup (jPanel1Layout. createParallelGroup (javax.swing. GroupLayout. Alignment. LEADI NG, false)

-addComponent (jPanel2, javax.swing.GroupLayout.DEFAULT_SIZE, javax.swing.GroupLayout.DEFAULT_SIZE, Short.MAX VALUE)

.addComponent (jPanel4, javax.swing.GroupLayout.DEFAULT_SIZE, javax.swing.GroupLayout.DEFAULT_SIZE, short.MAX VALUE)

.addComponeñt (jPanel3, javax.swing.GroupLayout.DEFAULT_SIZE, javax.swing.GroupLayout.DEFAULT_SIZE, Short.MAX VALUE))

- addContainerGap ( ) )

jPanel1Layout. setVerticalGroup(

jPanel1 Layout. createParallelGroup (javax.swing. GroupLayout.Alignment. LEADING)

. addGroup (jPanel1 Layout. createSequentialGroup ()

- addContainerGap ()

.addGroup (jPanel1Layout. createParallelGroup (javax.swing. GroupLayout. Alignment. LEADI NG)

- addGroup (jPanel1Layout. createsequentialGroup () - addComponent ( jPanel4,

javax.swing.GroupLayout.PREFERRED_SIZE,

javax.swing. GroupLayout. PREFERRED_SIZE)

javax.swing.GroupLayout.DEFAULT_SIZE,

. addPreferredGap (javax. swing. Layoutstyle. ComponentPlacement. RELATED)

- addComponent (jPanel2,

javax.swing. GroupLayout.PREFERRED SIZE,

javax.swing.GroupLayout.PREFERRED_SIZE)

. addPreferredGap (javax.swing. Layoutstyle.ComponentPlacement.RELATED)

- addComponent (jPanel3,

javax.swing.GroupLayout.PREFERRED_SIZE,

javax.swing.GroupLayout.DEFAULT_SIZE,

javax.swing.GroupLayout.PREFERRED_SIZE)

. addPreferredGap (javax.swing. Layoutstyle. ComponentPlacement.RELATED,

11 , Short.MAX_VALUE))

- addGroup (jPanel1 Layout. createsequentialGroup ()

.addGroup (jPanel1Layout. createParallelGroup (javax.swing. GroupLayout. Alignment.BASEL INE)

- addComponent ( jLabel1)

- addComponent (jTextField1,

javax.swing.GroupLayout.PREFERRED_SIZE, javax.swing.GroupLayout.DEFAULT_SIZE, javax.swing.GroupLayout.PREFERRED_SIZE))

.addPreferredGap (javax.swing. Layoutstyle.ComponentPlacement.RELATED)

- addComponent (jButton1)

.addPreferredGap (javax.swing. Layoutstyle. ComponentPlacement.RELATED) - addComponent (jScrollPane1)))

) ;

- addContainerGap ( )

jButton2. setText ("Fechar");

jButton2.addActionListener(new java.awt.event.ActionListener() \{

public void actionPerformed(java.awt.event. ActionEvent evt) \{

jButton2ActionPerformed (evt); 
\})；

javax.swing.Grouplayout

layout

new

javax.swing. Grouplayout (getContentPane ());

getContentPane(). setLayout (layout);

layout.setHorizontalGroup (

layout.createParallelGroup (javax.swing. GroupLayout. Alignment. LEADING)

.addGroup (layout.createSequentialGroup ()

- addContainerGap ()

. addComponent (jPanel1,

javax.swing.GroupLayout.PREFERRED_SIZE,

javax.swing.GroupLayout.DEFAULT_SIZE, javax.swing.GroupLayout.PREFERRED_SIZE)

. addContainerGap (41, Short.MAX VALUE) )

.addGroup (javax.swing.GroupLayout. $\bar{A} l i g n m e n t . T R A I L I N G$,

layout.createSequentialGroup ()

Short.MAX_VALUE) .addContainerGap (javax.swing.GroupLayout.DEFAULT_SIZE,

. addComponent (jButton2)

. addContainerGap ())

) ;

layout. setVerticalGroup (

layout.createParallelGroup (javax.swing.GroupLayout.Alignment. LEADING)

. addGroup (layout.createSequentialGroup ()

- addContainerGap ()

.addComponent (jPanel1, javax.swing.Grouplayout.PREFERRED SIZE,

javax.swing.GroupLayout.DEFAULT_SIZE, javax.swing.GroupLayout.PREFERRED_SIZE)

.addPreferredGap (javax.swing.LayoutStyle.ComponentPlacement.RELATED,

javax.swing.GroupLayout.DEFAULT SIZE, Short.MAX VALUE)

. addComponent ( $j \bar{B}$ utton2)

- addContainerGap ()

) ;

$\operatorname{pack}() ;$

\}// </editor-fold>//GEN-END:initComponents

private void jListlValueChanged(javax.swing.event. ListselectionEvent evt)

$\{/ /$ GEN-FIRST: event jList1ValueChanged

// MOSTRAR PALET

int index $=$ jList 1. getSelectedIndex ();

if $($ index $>-1) \quad\{$

mostrarPalet (index);

\}

\}//GEN-LAST:event_jList1ValueChanged

private void jButton2ActionPerformed(java.awt.event.ActionEvent evt) \{//GENFIRST:event_jButton2ActionPerformed

dispose ();

\}//GEN-LAST: event jButton2ActionPerformed

// Variables declaration - do not modify//GEN-BEGIN:variables

private javax.swing.JButton jButton1;

private javax.swing. JButton jButton2;

private javax.swing. JButton jButton 4

private javax.swing. JLabel jLabel1;

private javax.swing. JLabel jLabel10;

private javax.swing. JLabel jLabel11;

private javax.swing. JLabel jLabel12;

private javax.swing. JLabel jLabel13;

private javax.swing. JLabel jLabel14;

private javax.swing. JLabel jLabel15;

private javax.swing. JLabel jLabel16;

private javax.swing. JLabel jLabel17;

private javax.swing. JLabel jLabel18;

private javax.swing. JLabel jLabel19;

private javax.swing. JLabel jLabel2;

private javax.swing. JLabel jLabel20; 


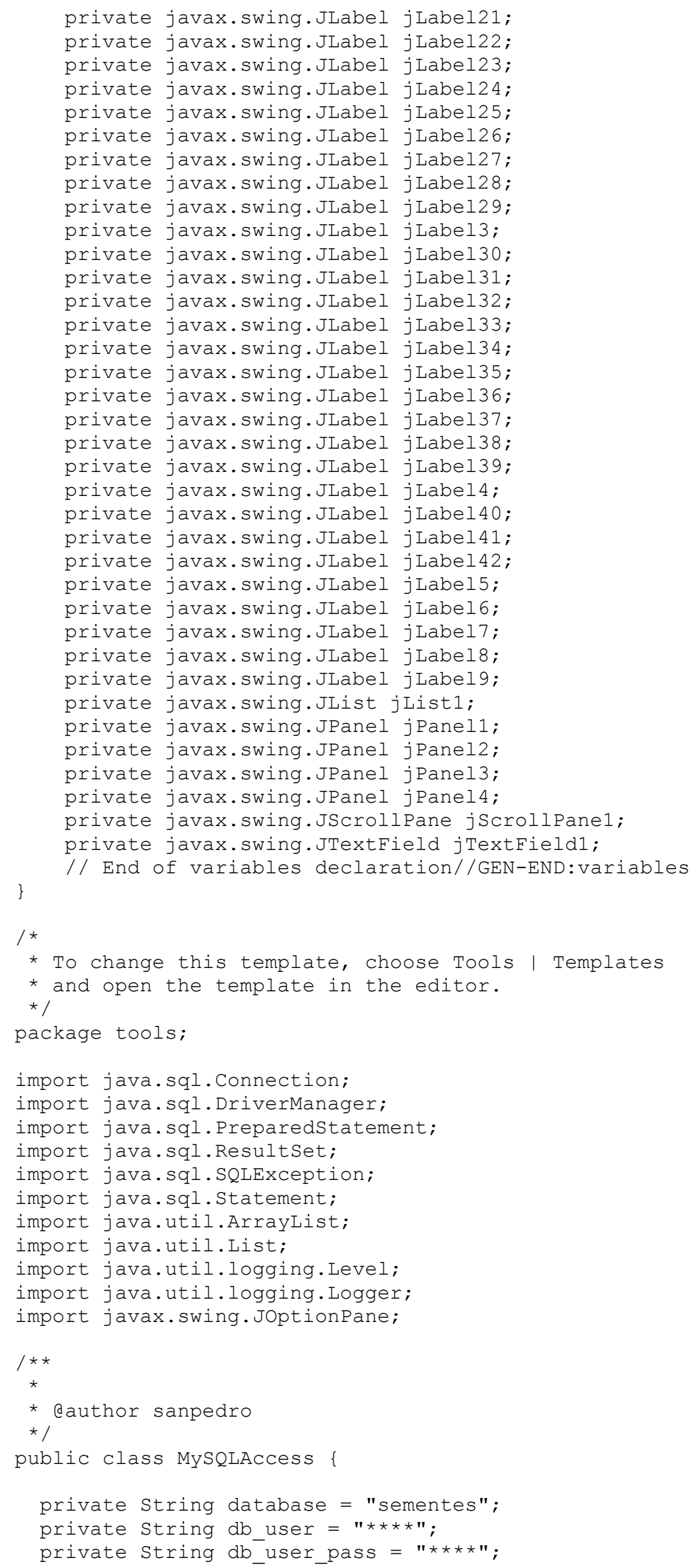

private javax.swing.JLabel jLabel21;

private javax.swing. JLabel jLabel32;

private javax.swing.JLabel jLabel33;

private javax.swing. JLabel jLabe134;

private javax.swing.JLabel jLabel35;

private javax.swing. JLabel jLabel36;

private javax.swing. JLabel jLabel39;

private javax.swing. JLabel jLabel4;

private javax.swing. JLabel jLabel40;

private javax.swing. JLabel jLabel41;

private javax.swing. JLabel jLabel42;

private javax.swing. JPanel jPanel1;

private javax.swing.JPanel jPanel2;

ivate javax.swing. JPanel jPanel3;

private javax.swing. JScrollPane jScrollPanel;

private javax.swing. JTextField jTextFieldl;

// End of variables declaration//GEN-END:variables

/*

Templates

and open the template in the editor.

import java.sql. DriverManager

import java.sql.PreparedStatement;

import java.sql.Resultset

import java.sql.SQLException; 


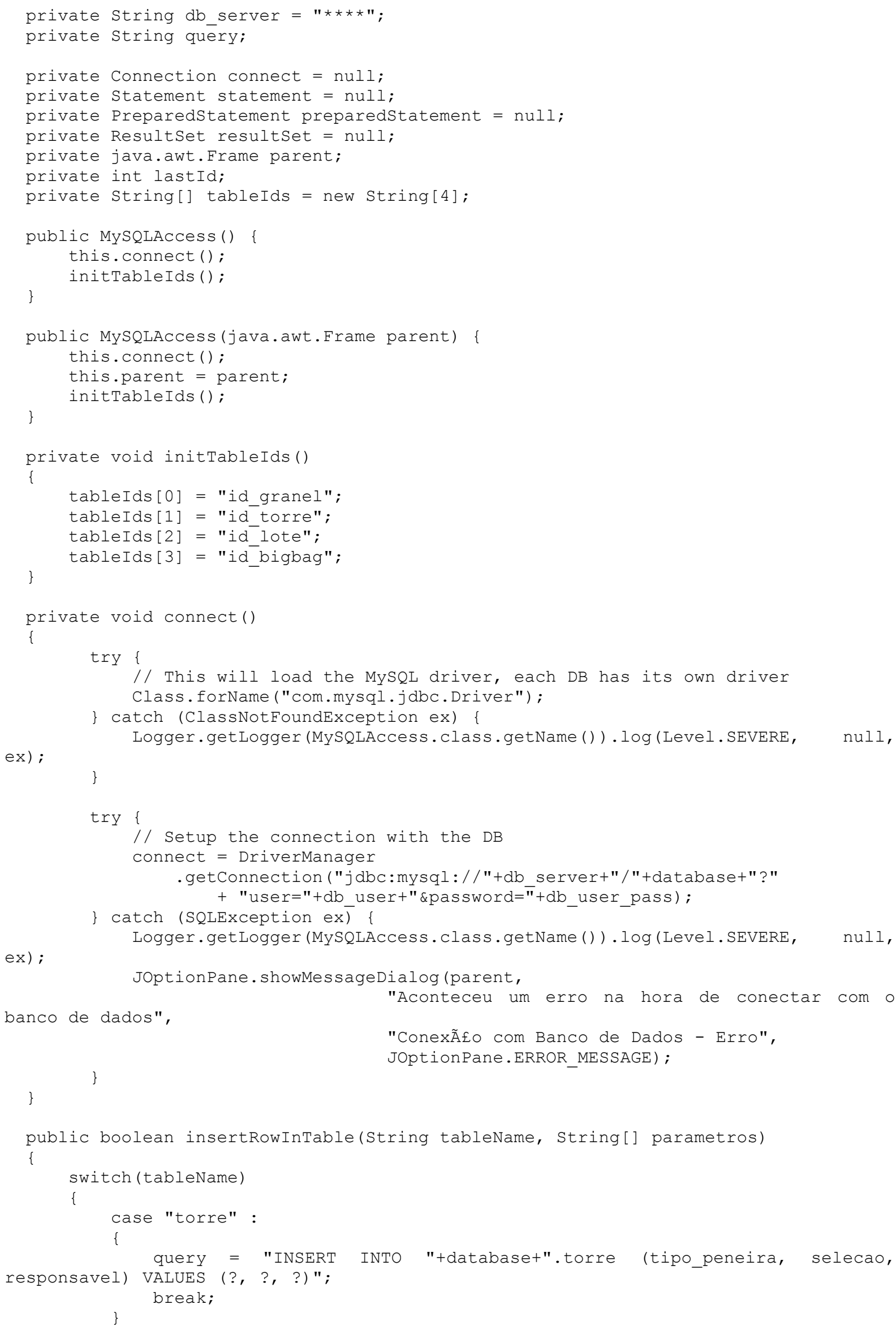




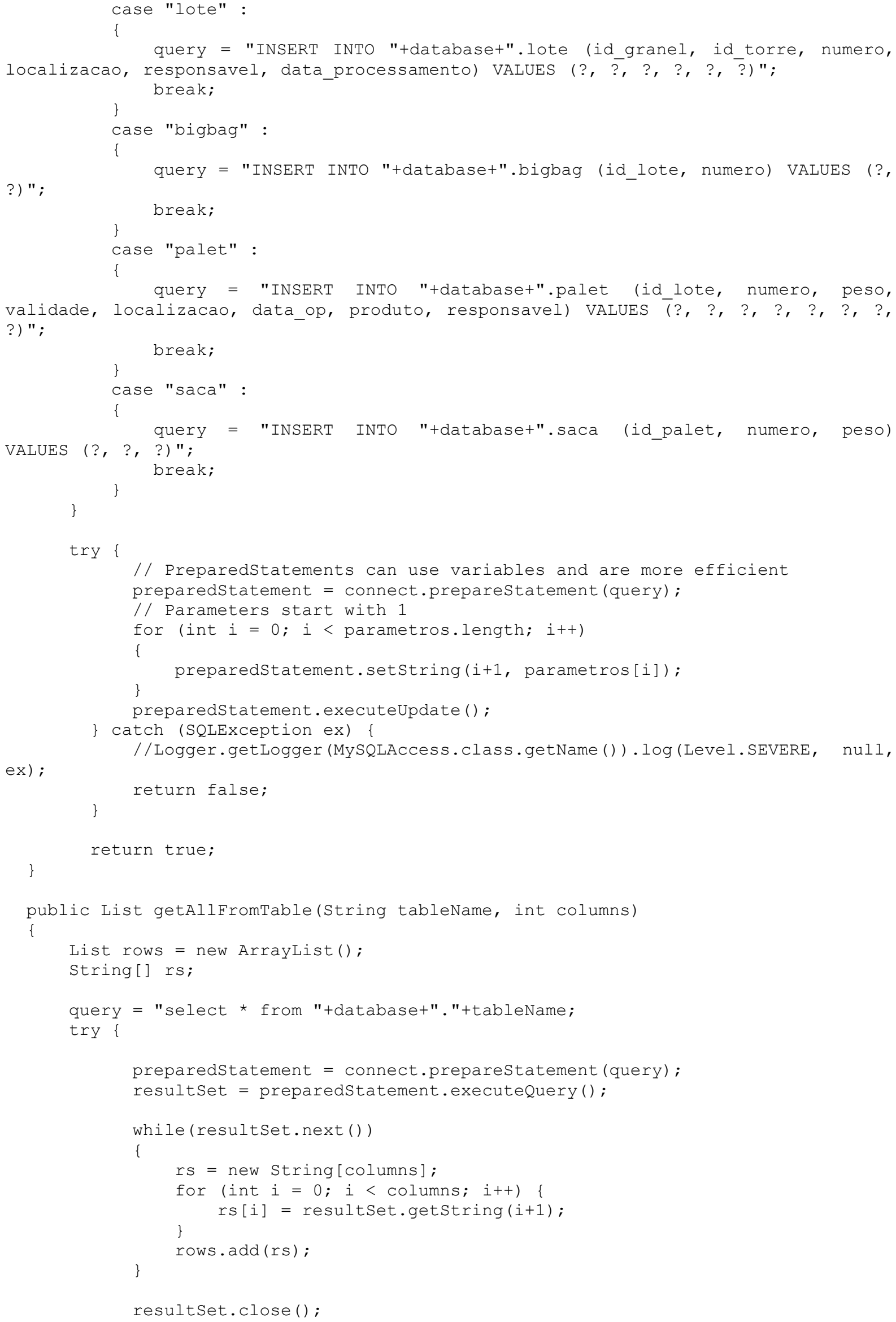




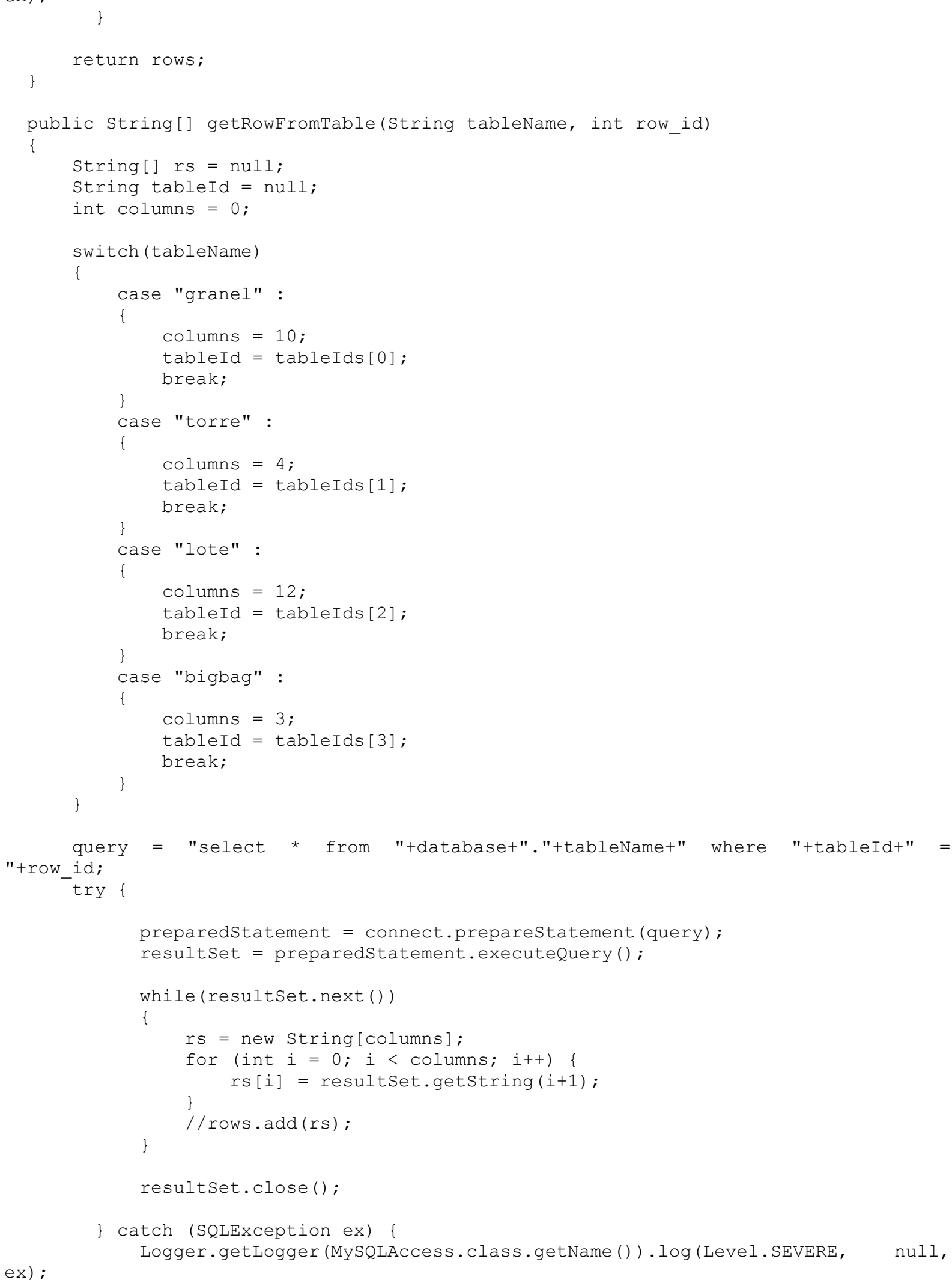




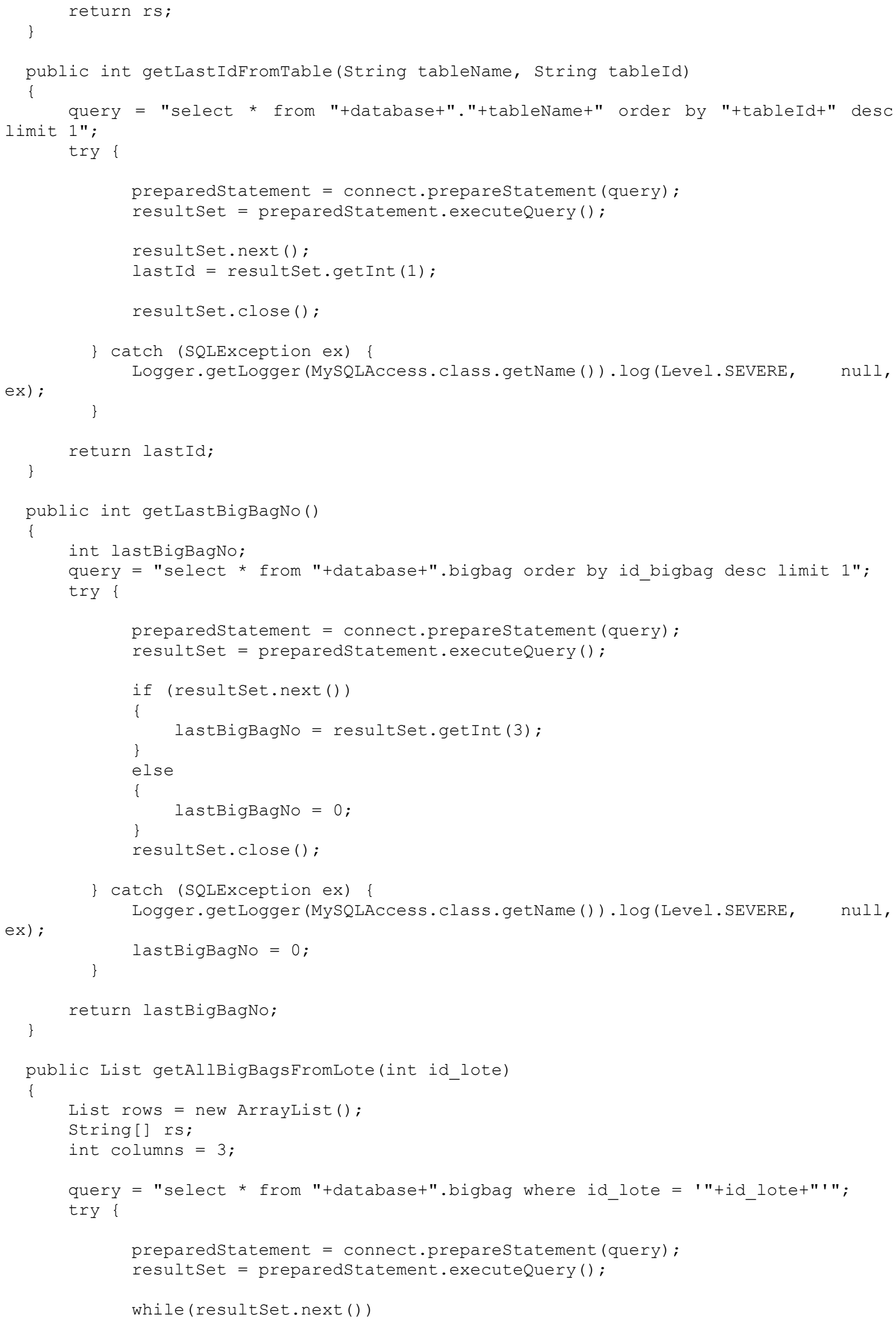




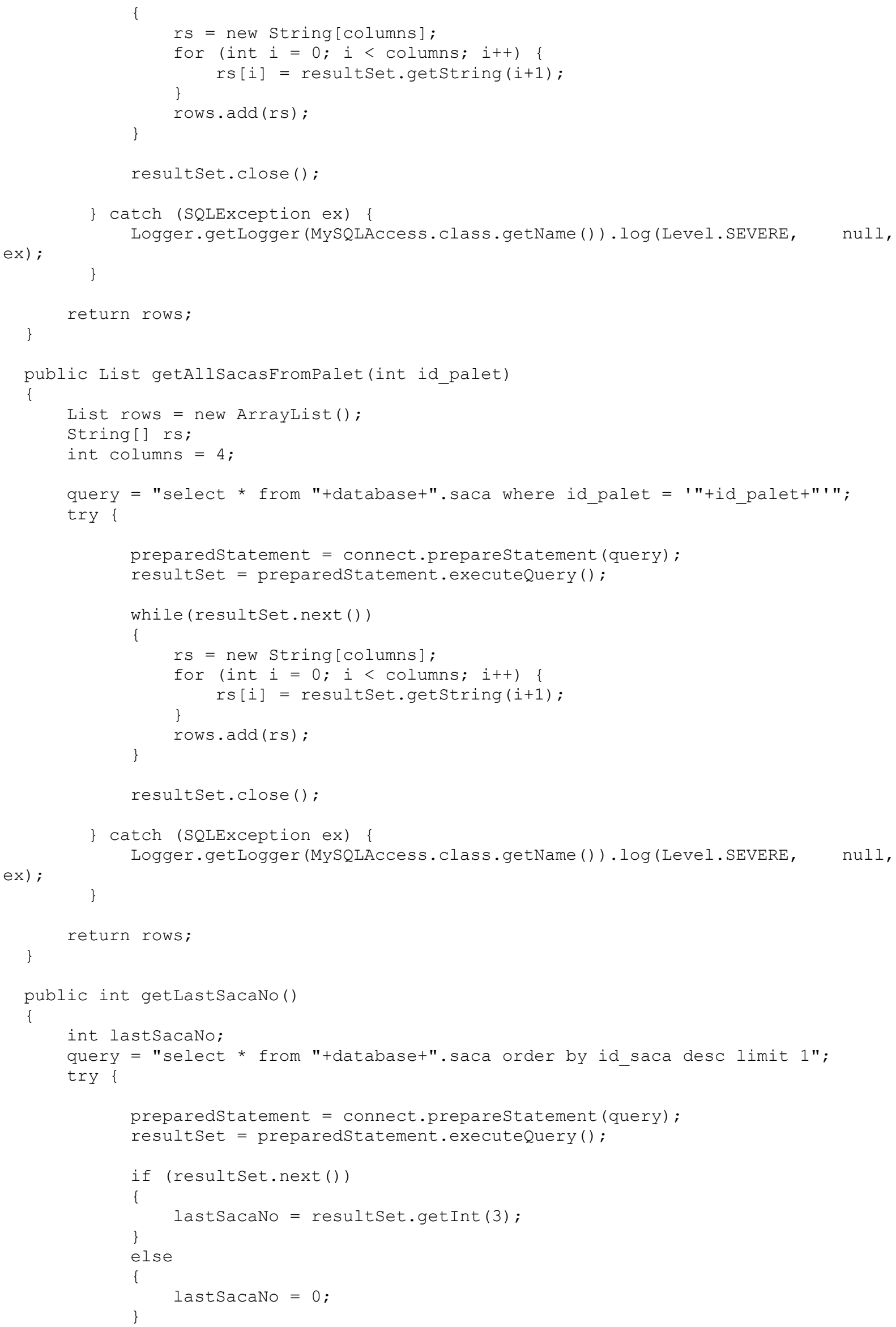




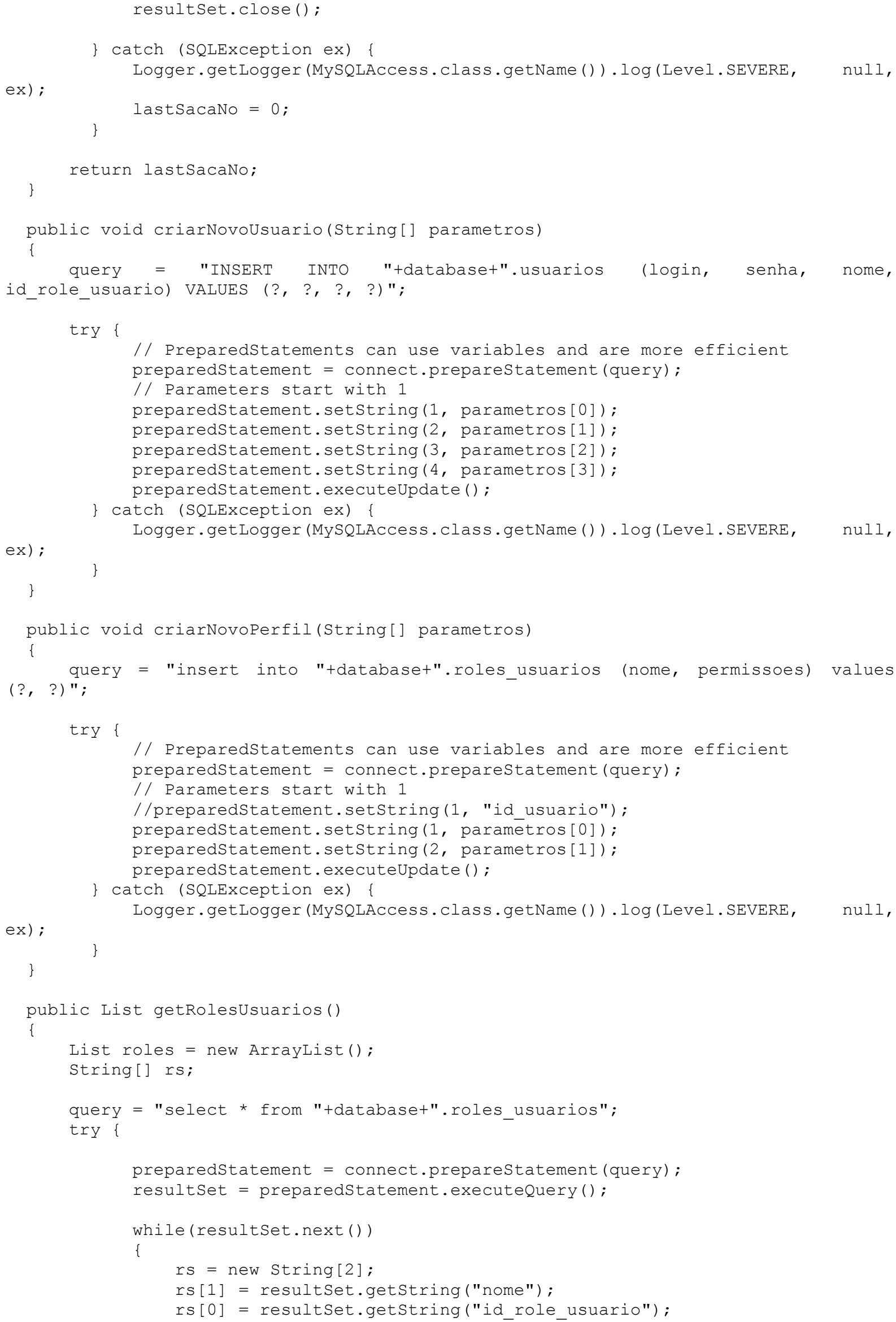




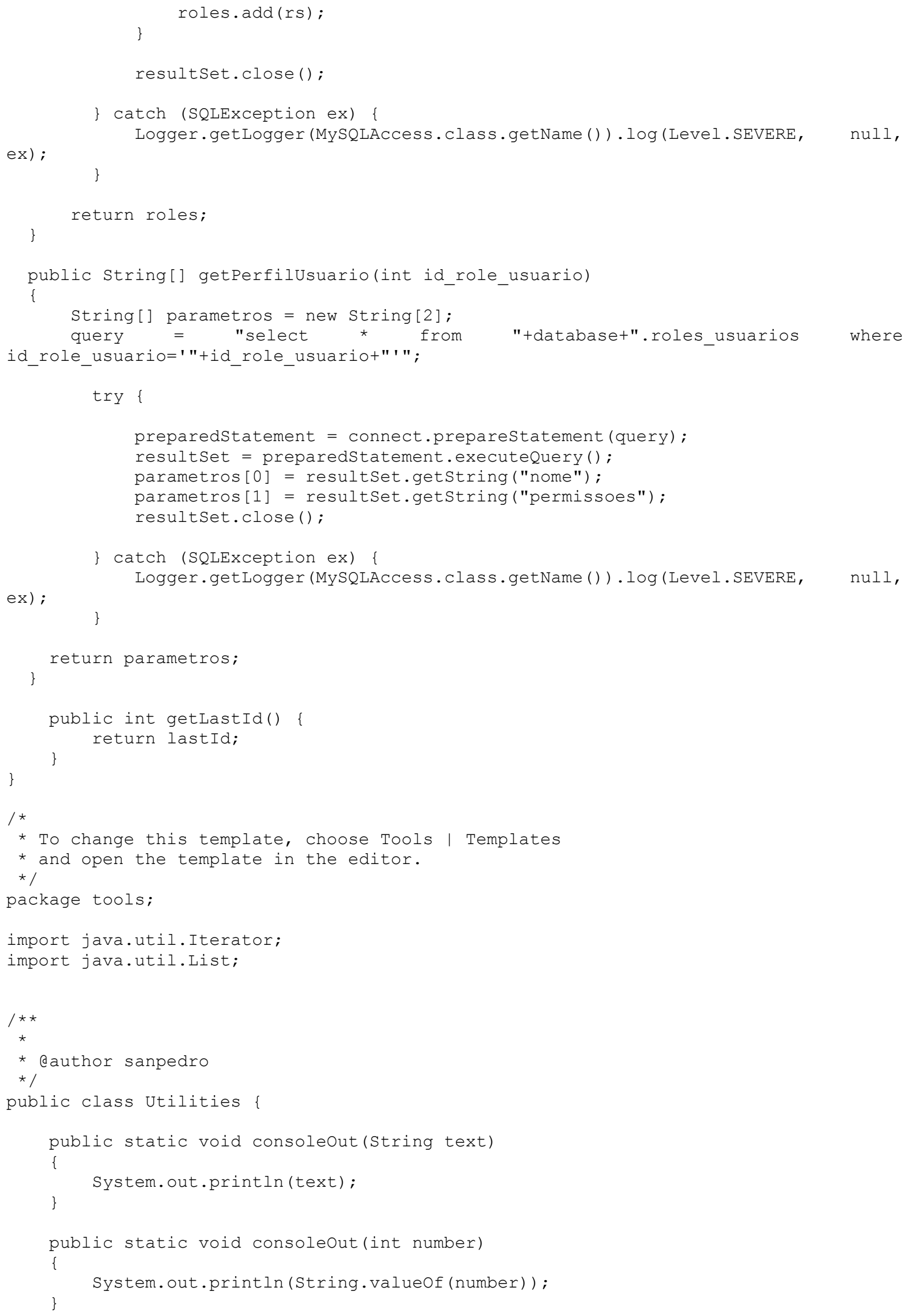




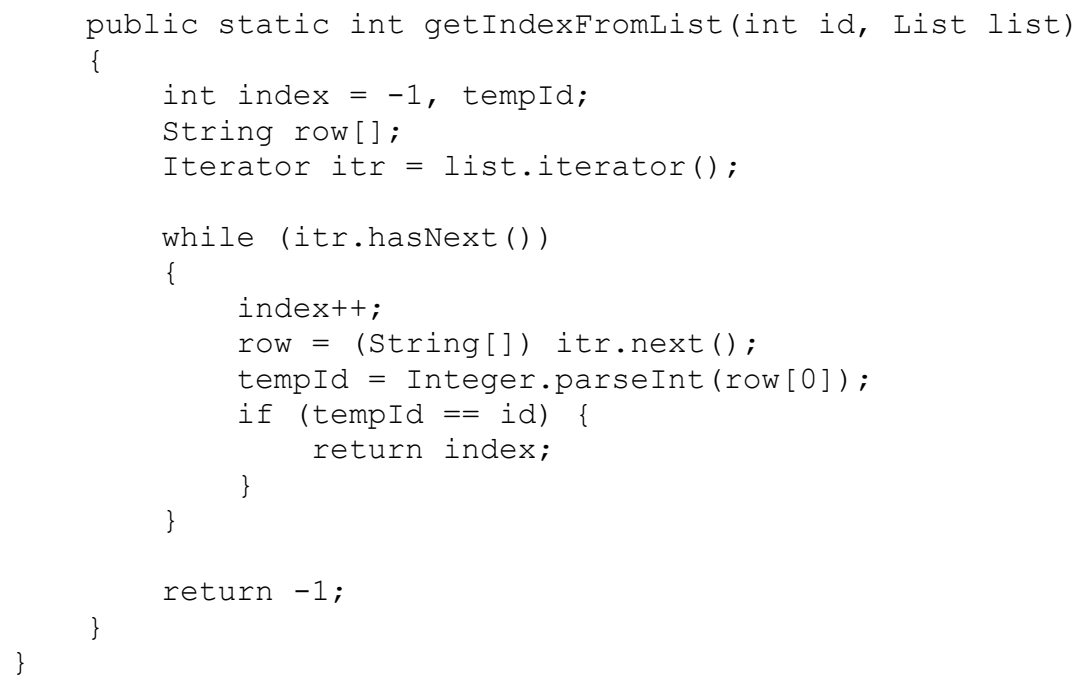

\section{Módulo Expedição}

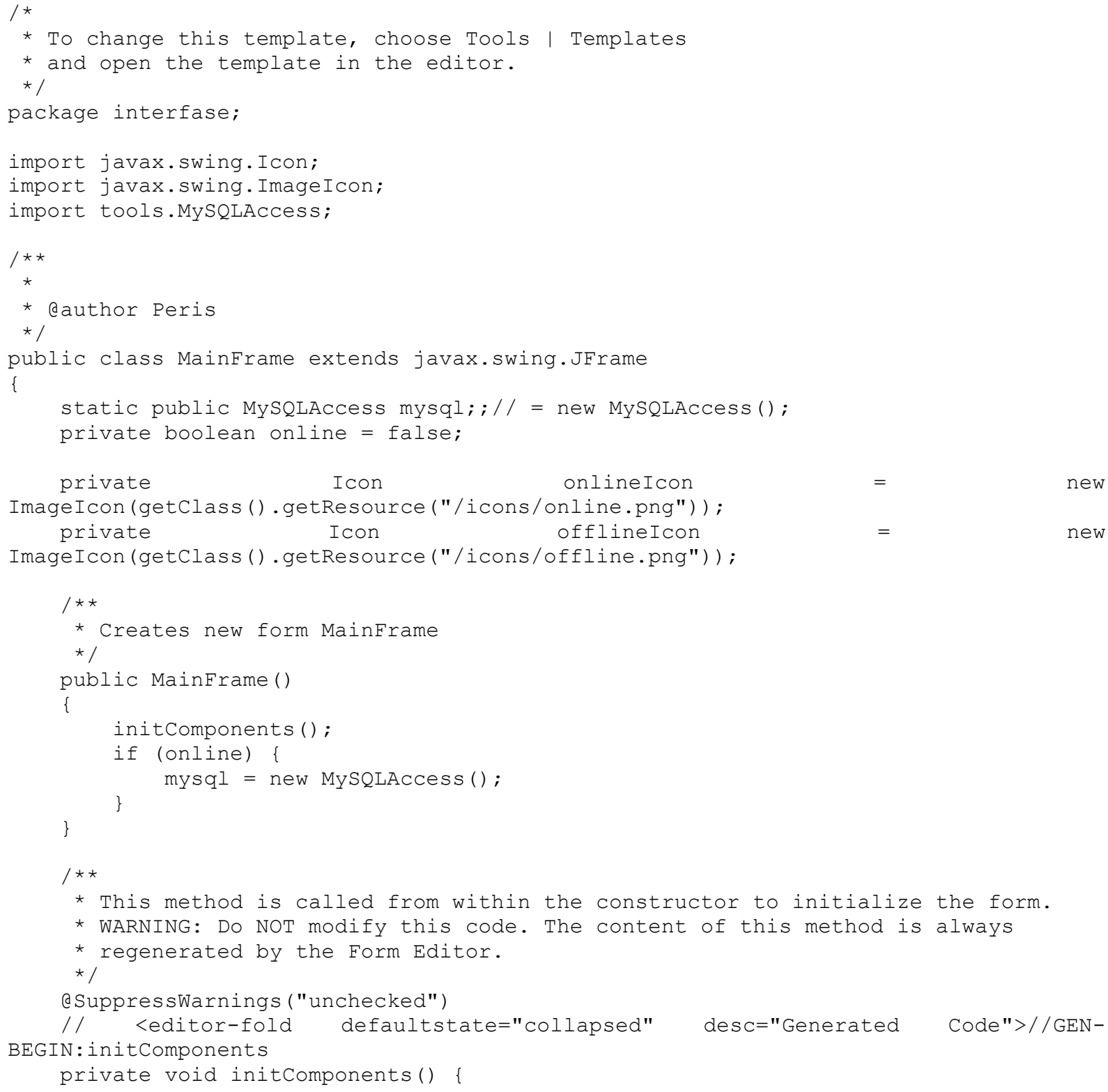


jToolBarl = new javax.swing.JToolBar();

jButton 1 = new javax.swing. JButton();

jButton2 = new javax.swing. JButton();

jSeparatorl = new javax.swing.JToolBar.Separator();

jButton $5=$ new javax.swing. JButton();

jMenuBar1 = new javax.swing. JMenuBar();

jMenul = new javax.swing.JMenu();

jMenu2 = new javax.swing.JMenu();

setDefaultCloseoperation (javax.swing.WindowConstants.EXIT_ON_CLOSE); setTitle("Terminal Expedi ̃̃ß̃̃£o");

jToolBarl.setFloatable (false);

jToolBarl.setRollover (true);

jButton1. setText ("Novo Carregamento");

jButton1. setFocusable (false);

jButton1. setHorizontalTextPosition (javax.swing. SwingConstants.CENTER);

jButton1.setVerticalTextPosition (javax.swing. SwingConstants.BOTTOM);

jButton1.addActionListener(new java.awt.event.ActionListener() \{ public void actionPerformed(java.awt.event. ActionEvent evt) \{ jButton1ActionPerformed (evt); \}

\});

jToolBar1.add (jButton1);

jButton2.setText ("Consultar Carregamentos")

jButton2. setFocusable (false);

jButton2. setHorizontalTextPosition (javax.swing. SwingConstants.CENTER);

jButton2. setVerticalTextPosition (javax.swing. SwingConstants.BOTTOM);

jButton2.addActionListener(new java.awt.event.ActionListener() \{ public void actionPerformed(java.awt.event. ActionEvent evt) \{ jButton2ActionPerformed (evt); \}

\});

jToolBar1.add (jButton2);

jToolBar1.add (jSeparator1);

jButton5. setIcon (new

javax.swing. ImageIcon(getClass().getResource("/icons/offline.png"))); // NOI18N

jButton5. setToolTipText("Working on-line");

jButton5. setFocusable (false);

jButton5. setHorizontalTextPosition (javax.swing. SwingConstants.CENTER);

jButton5. setVerticalTextPosition (javax.swing. SwingConstants.BOTTOM);

jButton5.addActionListener(new java.awt.event. ActionListener() \{ public void actionPerformed(java.awt.event. ActionEvent evt) \{ \} jButton5ActionPerformed (evt) ;

\}) ;

jToolBar1.add (jButton5);

jMenul.setText ("File");

jMenuBar1.add (jMenu1);

jMenu2.setText ("Edit");

jMenuBar1.add (jMenu2);

set JMenuBar (jMenuBar1);

javax.swing. GroupLayout

layout

$=$

new

javax.swing. Grouplayout (getContentPane ()) ;

getContentPane (). setLayout (layout);

layout.setHorizontalGroup (

layout.createParallelGroup (javax.swing. GroupLayout. Alignment. LEADING)

.addComponent(jToolBar1, javax.swing.GroupLayout.DEFAULT_SIZE, 
layout.setVerticalGroup (

layout.createParallelGroup (javax.swing.GroupLayout.Alignment. LEADING)

. addGroup (layout.createSequentialGroup () .addComponent (jToolBar1, javax.swing.GroupLayout.PREFERRED_SIZE,

25, javax.swing.GroupLayout.PREFERRED_SIZE)

) ; .addGap (0, 254, Short.MAX_VALUE))

$\operatorname{pack}() ;$

\}// </editor-fold>//GEN-END:initComponents

private void jButton1ActionPerformed(java.awt.event.ActionEvent evt) \{//GENFIRST: event_jButton1ActionPerformed

NovoCarregamentoDialog novoLotedialog = new NovoCarregamentoDialog(this, true);

novoLoteDialog.setLocationRelativeTo(this);

novoLoteDialog.setVisible (true);

\}//GEN-LAST: event_jButton1ActionPerformed

private void jButton2ActionPerformed(java.awt.event.ActionEvent evt) \{//GENFIRST: event jButton2ActionPerformed

// RelatoriopaletDialog relatorioLoteDialog = new RelatoriopaletDialog(this, true);

// relatorioLoteDialog.setLocationRelativeTo(this);

// relatorioLoteDialog.setVisible (true);

\}//GEN-LAST: event_jButton2ActionPerformed

private void jButton5ActionPerformed(java.awt.event.ActionEvent evt) \{//GENFIRST: event jButton5ActionPerformed

if (online)

\{

online $=$ false;

jButton5. setIcon (offlineIcon);

jButton5. setToolTipText ("Working off-line");

$/ /$ mysql = new MysQLAccess ();

else

\{

online = true;

jButton5. setIcon(onlineIcon);

jButton5. setToolTipText("Working on-line");

\}

mysql = new MySQLAccess ();

\}//GEN-LAST:event jButton5ActionPerformed

$1 * *$

* eparam args the command line arguments

* 1

public static void main(String args[]) \{

/* Set the Nimbus look and feel * /

//<editor-fold defaultstate="collapsed" desc=" Look and feel setting code (optional) ">

/* If Nimbus (introduced in Java SE 6) is not available, stay with the default look and feel.

* For details

$\frac{\text { http://download.oracle.com/javase/tutorial/uiswing/lookandfeel/plaf.html }}{* \text { / }}$

try

for

(javax.swing.UIManager. LookAndFeel Info

info

javax.swing. UIManager.getInstalledLookAndFeels()) \{

if ("Nimbus".equals (info.getName()) ) \{

javax.swing. UIManager.setLookAndFeel (info.getClassName ()) ; break;

\} 


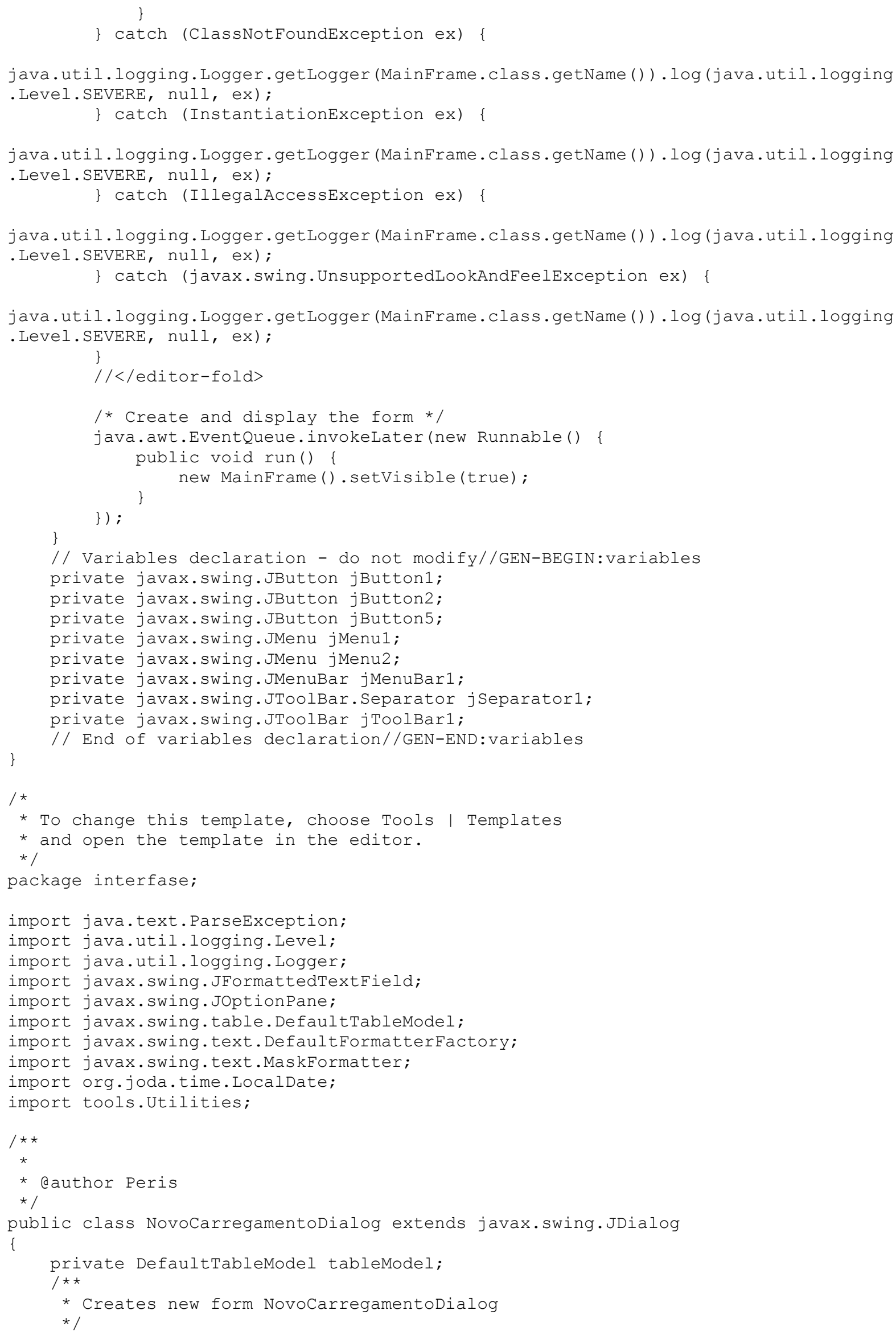




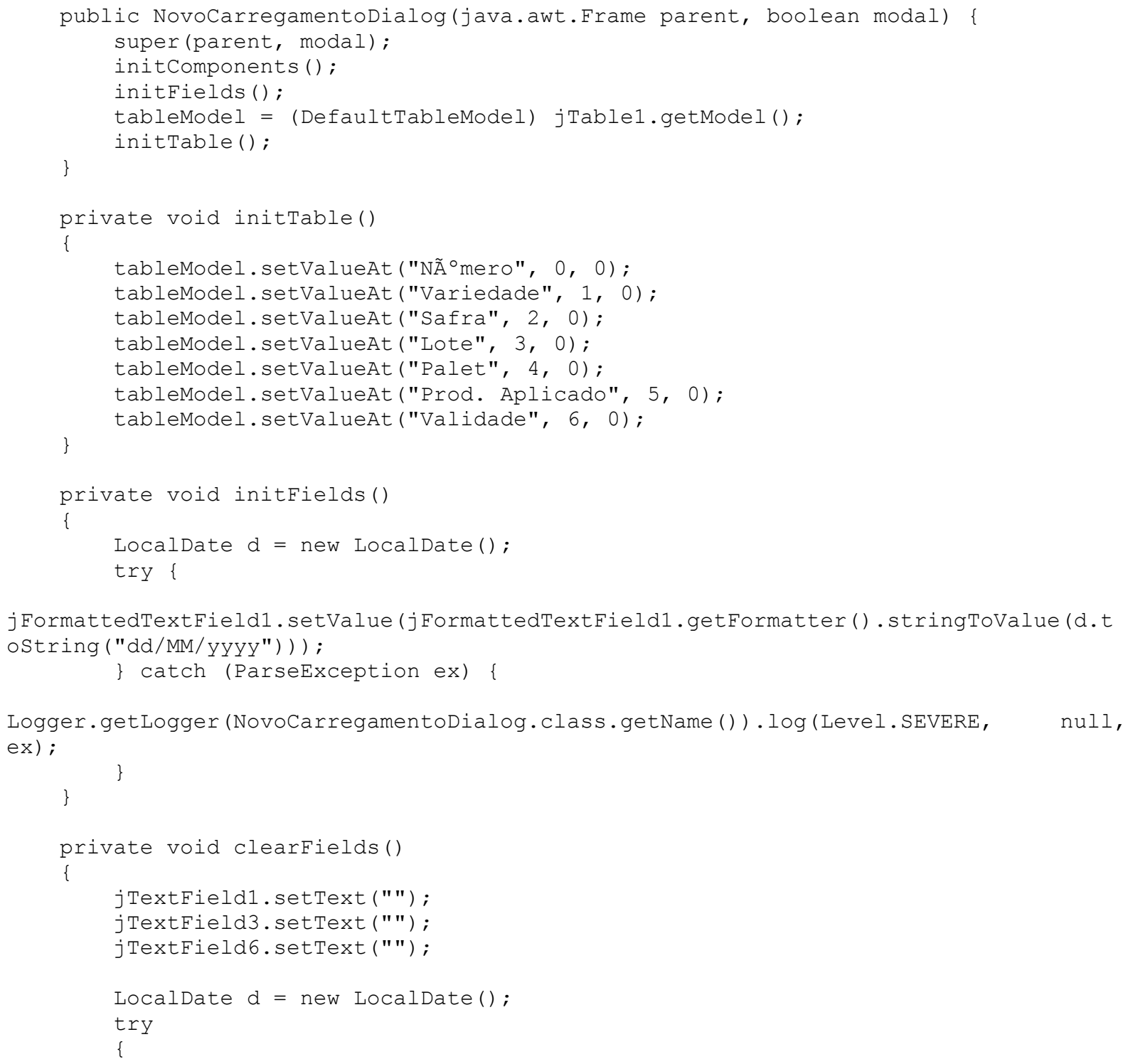

Logger.getLogger (NovoCarregamentoDialog.class.getName()) .log(Level.SEVERE, null, ex); 


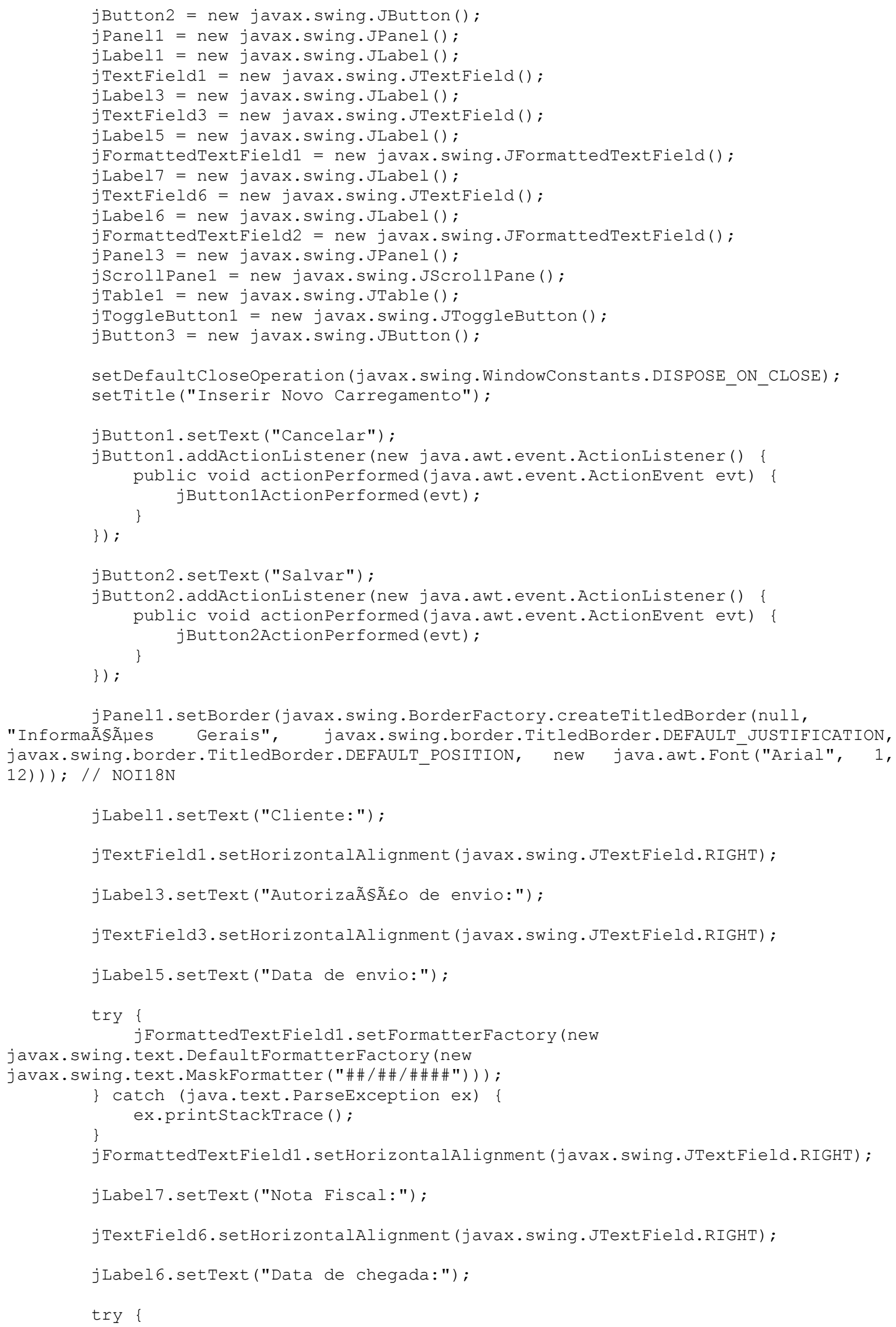

jPanell. setBorder (javax.swing. BorderFactory. createTitledBorder (null, "Informã̃ß̃ues Gerais", javax.swing.border.TitledBorder.DEFAULT_JUSTIFICATION, javax.swing.border.TitledBorder.DEFAULT_POSITION, new java.awt.Font("Arial", 1,

jLabel1.setText ("Cliente:");

jTextField1.setHorizontalAlignment (javax.swing.JTextField.RIGHT);

jLabel3.setText ("Autorizã̃ß̃̃£o de envio:");

jTextField3.setHorizontalAlignment (javax.swing.JTextField.RIGHT);

jLabel5.setText ("Data de envio:");

try \{ jFormattedTextField1. setFormatterFactory (new javax.swing.text. DefaultFormatterFactory (new 12)) ); // NOI18N 
jFormattedTextField2. setFormatterFactory (new

javax.swing. text. DefaultFormatterFactory (new

javax.swing.text.MaskFormatter("\#\#/\#\#/\#\#\#\#")));

\} catch (java.text.ParseException ex) \{

\}

ex.printstackTrace ();

jFormattedTextField2. setHorizontalAlignment (javax.swing.JTextField.RIGHT);

javax.swing. GroupLayout

jPanel1Layout

new

javax.swing. Grouplayout (jPanel1);

jPanel1. set Layout (jPanel1Layout);

jPanellLayout. setHorizontalGroup (

jPanel1 Layout. createParallelGroup (javax.swing.GroupLayout.Alignment. LEADING)

. addGroup (jPanel1 Layout. createsequentialGroup ()

- addContainerGap ()

.addGroup (jPanel1Layout. createParallelGroup (javax.swing. GroupLayout. Alignment. LEADI NG)

. addGroup (javax.swing.GroupLayout.Alignment.TRAILING,

jPanel1Layout.createsequentialGroup ()

.addGroup (jPanel1Layout. createParallelGroup (javax.swing. GroupLayout.Alignment. TRAIL ING)

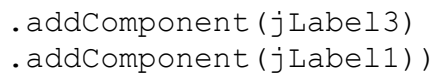

. addPreferredGap (javax. swing. Layoutstyle. ComponentPlacement. RELATED)

.addGroup (jPanel1Layout. createParallelGroup (javax.swing. GroupLayout. Alignment. LEADI NG)

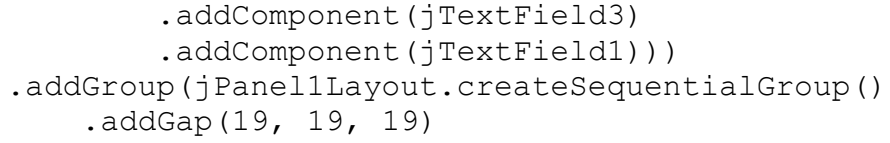

.addGroup (jPanel1 Layout. createParallelGroup (javax.swing. GroupLayout.Alignment. TRAIL ING)

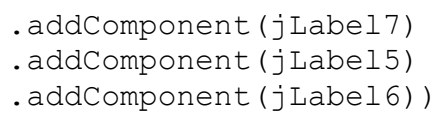

. addPreferredGap (javax.swing. Layoutstyle.ComponentPlacement.RELATED)

.addGroup (jPanel1Layout. createParallelGroup (javax.swing. GroupLayout. Alignment. LEADI NG)

- addComponent (jFormattedTextField2,

javax.swing. GroupLayout.DEFAULT SIZE, 135, Short.MAX VALUE)

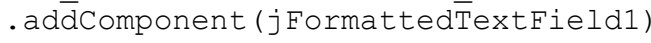

. addComponent (jTextField6))))

)

- addContainerGap ())

jPanel1Layout. setVerticalGroup(

jPanell Layout. createParallelGroup (javax.swing.GroupLayout.Alignment. LEADING) . addGroup (jPanel1Layout. createsequentialGroup () - addContainerGap ( )

.addGroup (jPanel1Layout. createParallelGroup (javax.swing. GroupLayout. Alignment.BASEL INE)

- addComponent ( jLabel3)

- addComponent (jTextField3,

javax.swing.GroupLayout. PREFERRED_SIZE,

javax.swing. GroupLayout. PREFERRED SIZE))

javax.swing.GroupLayout.DEFAULT_SIZE,

. $\operatorname{addGap}(11,11,1 \overline{1})$ 
.addGroup (jPanellLayout.createParallelGroup (javax.swing.Grouplayout. Alignment. BASEL INE)

- addComponent (jTextField1,

javax.swing. GroupLayout. PREFERRED SIZE,

javax.swing.GroupLayout.DEFAULT SIZE,

javax.swing.GroupLayout.PREEERRED_SIZE)

. addComponent $(j L$ Label1))

.addPreferredGap (javax.swing. LayoutStyle.ComponentPlacement. UNRELATED)

.addGroup (jPanellLayout. createParallelGroup (javax.swing.GroupLayout.Alignment. BASEL INE)

. addComponent (jTextField6,

javax.swing.GroupLayout.PREFERRED SIZE,

javax.swing.GroupLayout.DEFAULT_SIZE,

javax.swing.GroupLayout.PREEERRED_SIZE)

. addComponent (jLabe17))

.addPreferredGap (javax.swing. LayoutStyle. ComponentPlacement. UNRELATED)

.addGroup (jPanel1Layout. createParallelGroup (javax.swing.GroupLayout. Alignment. BASEL INE)

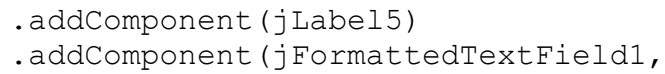

jPanel3. setBorder (javax.swing.BorderFactory.createTitledBorder (null, "Leitura das Sacas", javax.swing.border.TitledBorder.DEFAULT_JUSTIFICATION, javax.swing.border.TitledBorder.DEFAULT_POSITION, new java.awt.Font("Arial", 1, 12)) ); // NOI18N

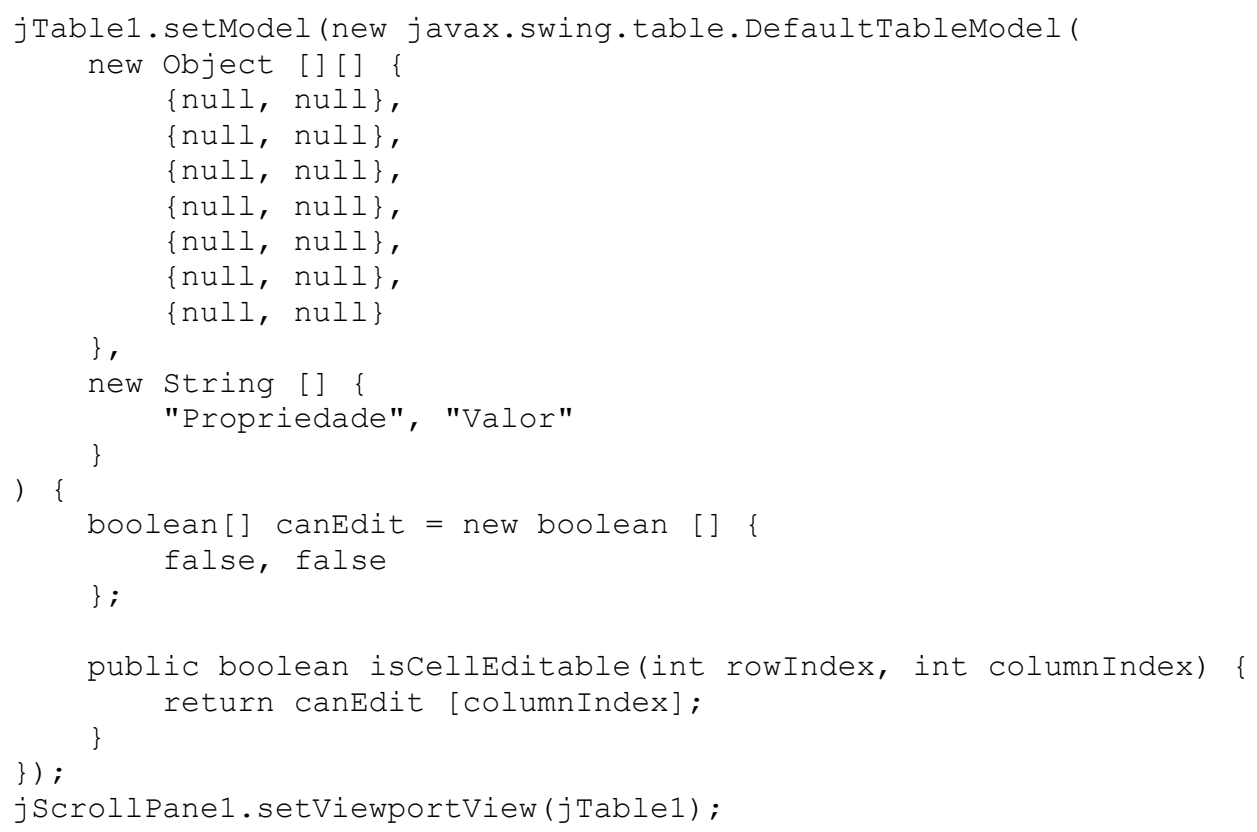




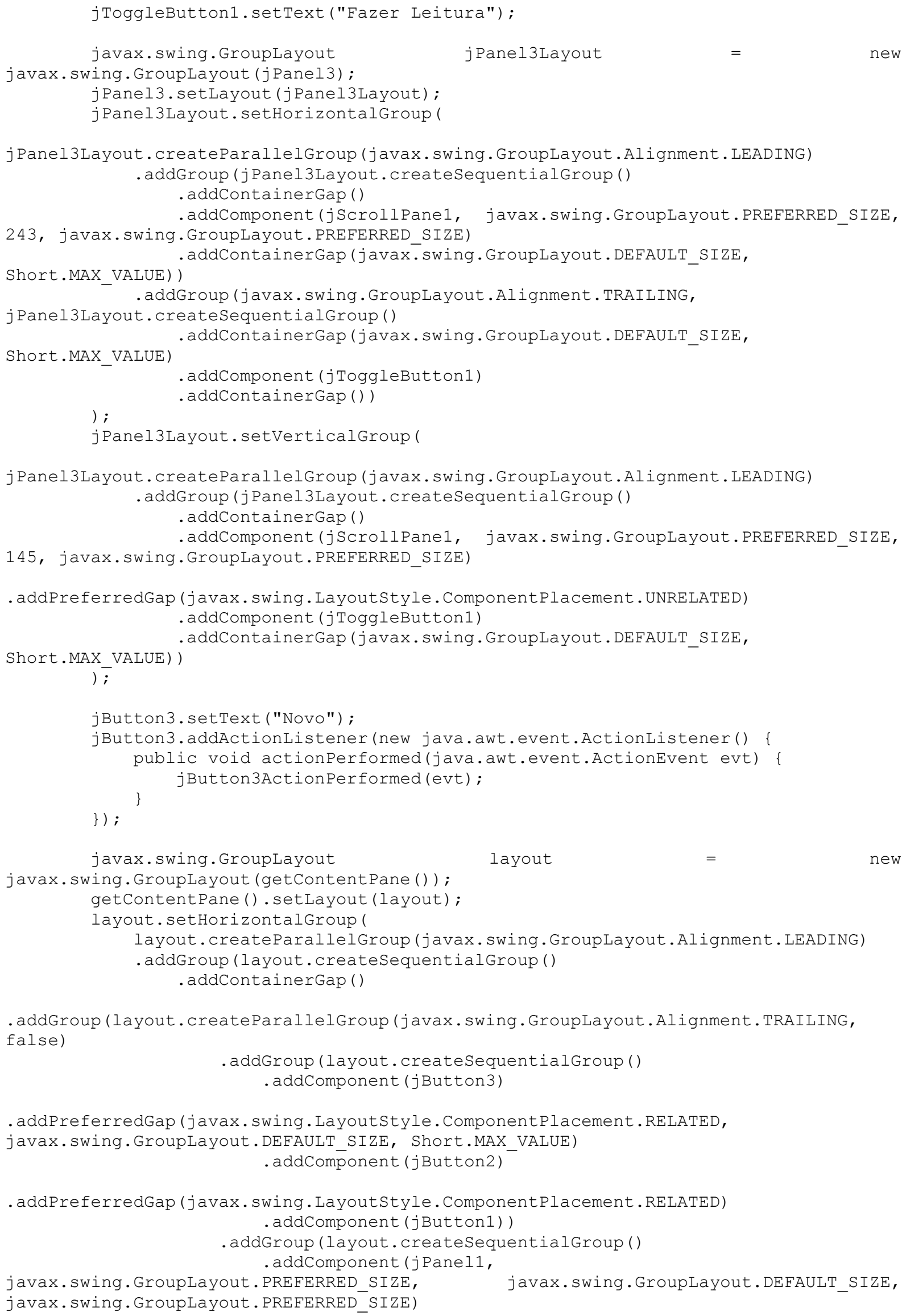




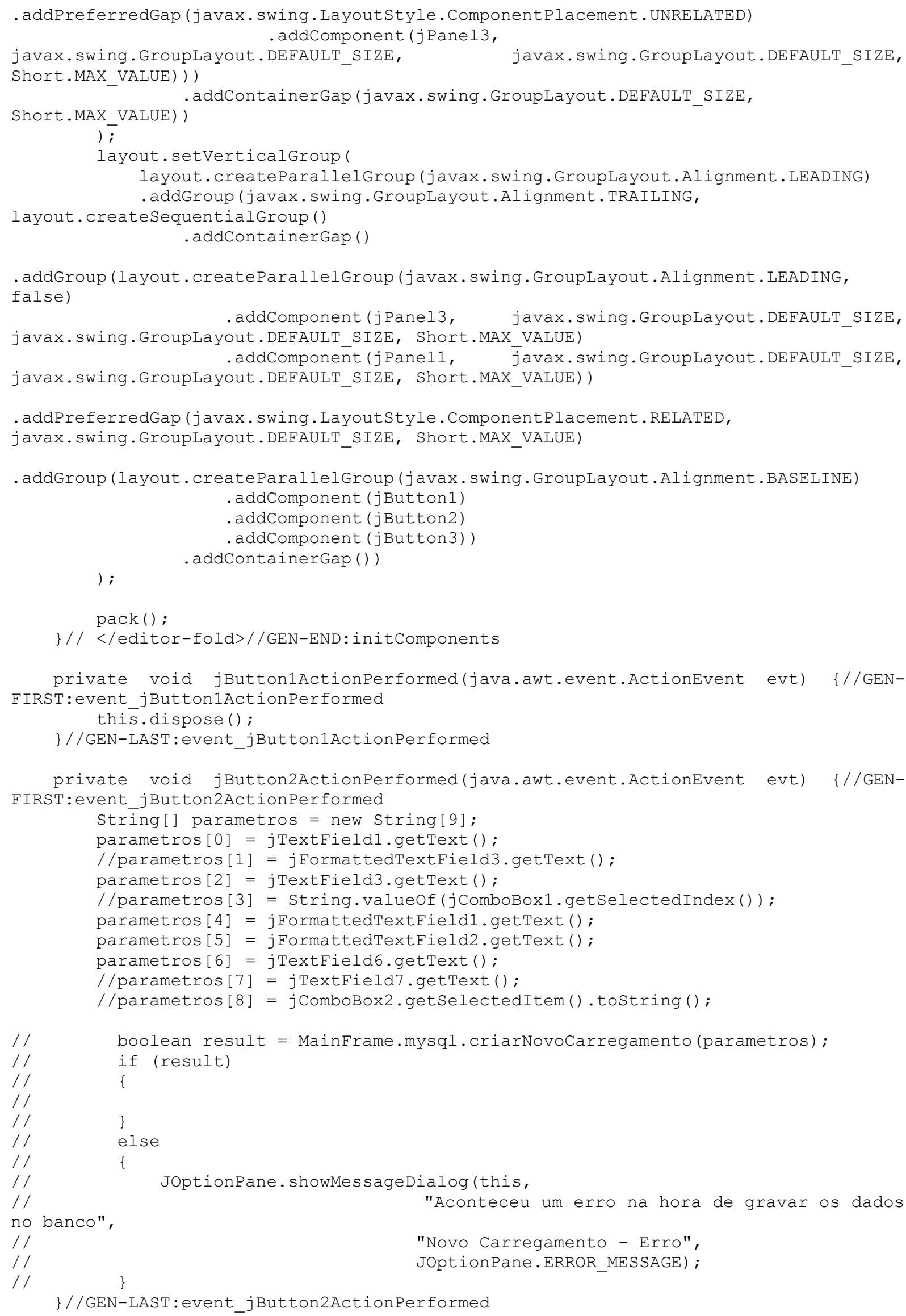

private void jButtonlActionPerformed(java.awt.event.ActionEvent evt) \{//GENFIRST:event_jButton1ActionPerformed

this.dispose ();

\}//GEN-LAST: event_jButton1ActionPerformed

private void jButton2ActionPerformed(java.awt.event.ActionEvent evt) \{//GENFIRST: event jButton2ActionPerformed

String[] parametros = new String[9]; parametros $[0]=j$ TextFieldl.getText () ;

$/ /$ parametros $[1]=j$ FormattedTextField3.getText (); parametros $[2]=$ jTextField3.getText (); 
private void jButton3ActionPerformed(java.awt.event. ActionEvent evt) \{//GENFIRST:event_jButton3ActionPerformed

clearfields ();

\}//GEN-LAST: event_jButton3ActionPerformed

// Variables declaration - do not modify//GEN-BEGIN:variables private javax.swing. JButton jButton1; private javax.swing. JButton jButton2; private javax.swing. JButton jButton3; private javax.swing.JFormattedTextField jFormattedTextField1; private javax.swing. JFormattedTextField jFormattedTextField2; private javax.swing. JLabel jLabel1; private javax.swing. JLabel jLabel3; private javax.swing. JLabel jLabel5; private javax.swing. JLabel jLabel6; private javax.swing. JLabel jLabel7; private javax.swing.JPanel jPanell; private javax.swing. JPanel jPanel3; private javax.swing. JScrollPane jScrollpanel; private javax.swing. JTable jTablel; private javax.swing.JTextField jTextField1; private javax.swing.JTextField jTextField3; private javax.swing.JTextField jTextField6; private javax.swing.JToggleButton jToggleButton1; // End of variables declaration//GEN-END:variables

$1 *$

* To change this template, choose Tools I Templates

* and open the template in the editor.

$*$ /

package tools;

import java.sql. Connection;

import java.sql. DriverManager;

import java.sql. PreparedStatement;

import java.sql. Resultset;

import java.sql.SQLException;

import java.sql. Statement;

import java.util.ArrayList;

import java.util.List;

import java.util.logging.Level;

import java.util.logging.Logger;

import javax.swing. JoptionPane;

/*

* eauthor sanpedro

* $/$

public class MySQLAccess \{

private string database = "sementes";

private string db_user $=" \star \star \star \star * "$;

private String db user_pass $=" * \star \star \star * "$;

private string db_server $=" \star \star \star * * "$;

private string query;

private Connection connect $=$ null;

private statement statement = null;

private PreparedStatement preparedStatement = null;

private Resultset resultset = null;

private java.awt. Frame parent;

private int lastId;

private string[] tableIds = new String[4]; 


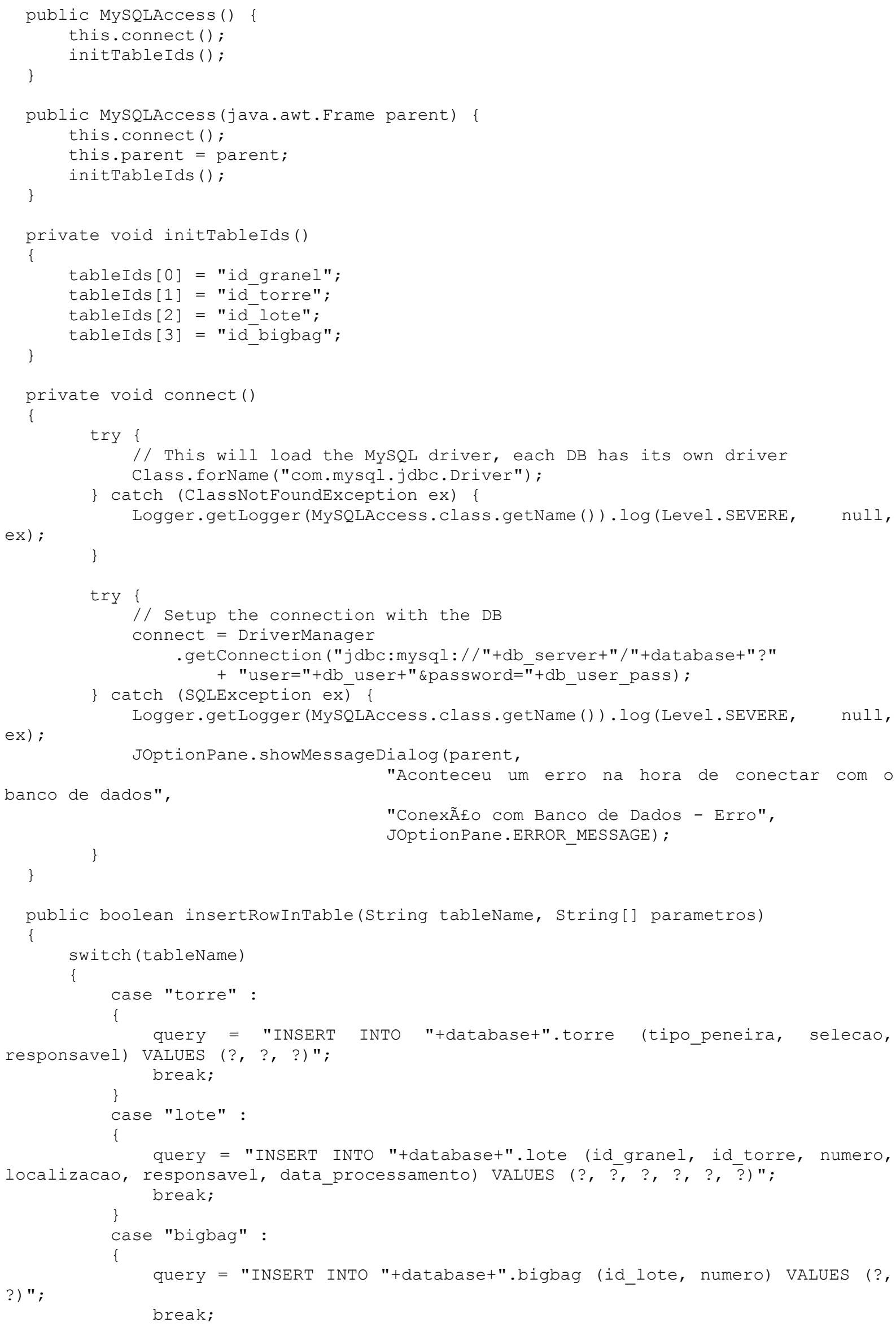


\} case "palet" :

\{

query = "INSERT INTO "+database+".palet (id lote, numero, peso, validade, localizacao, data_op, produto, responsavel) VALUES (?, ?, ?, ?, ?, ?, ? ?) " ;

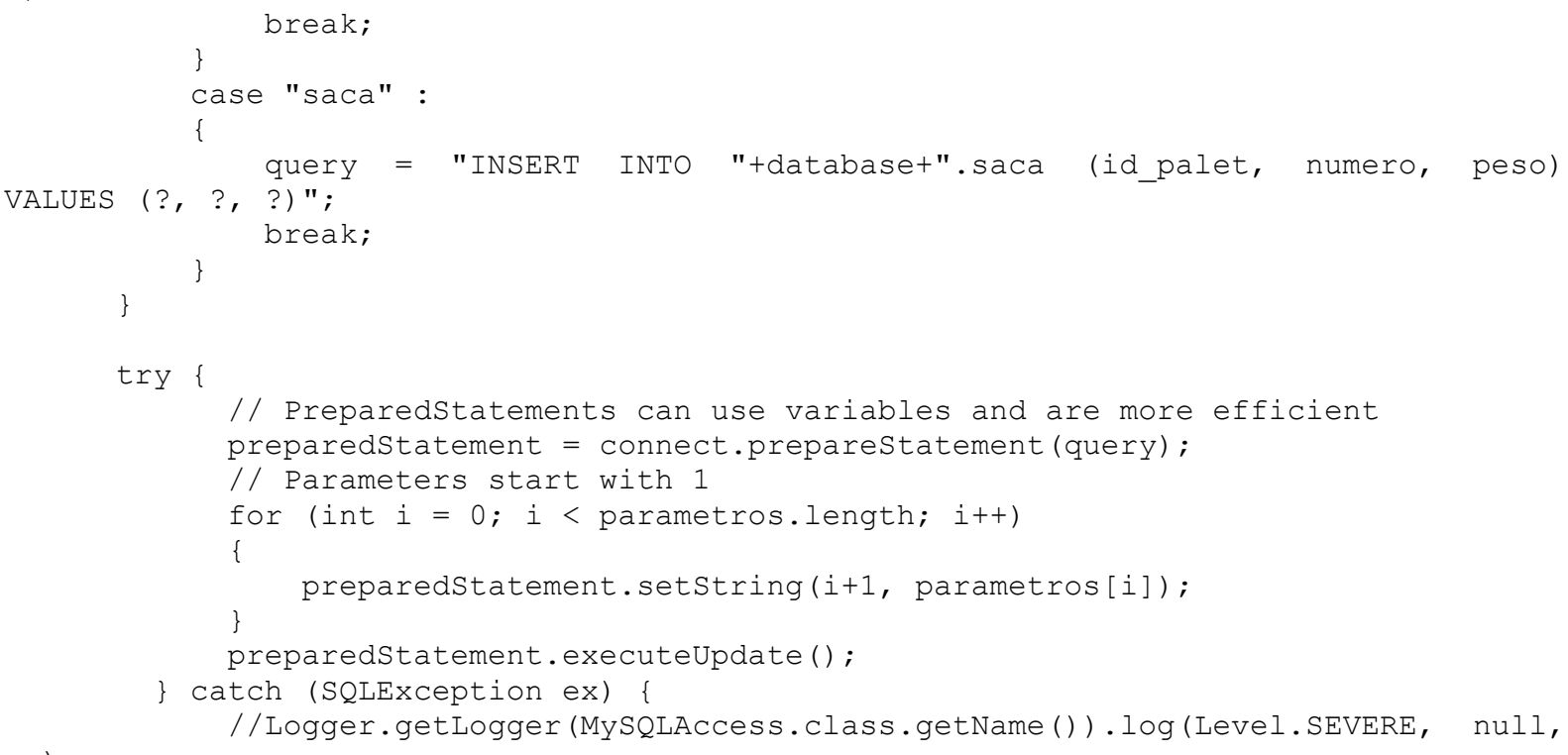




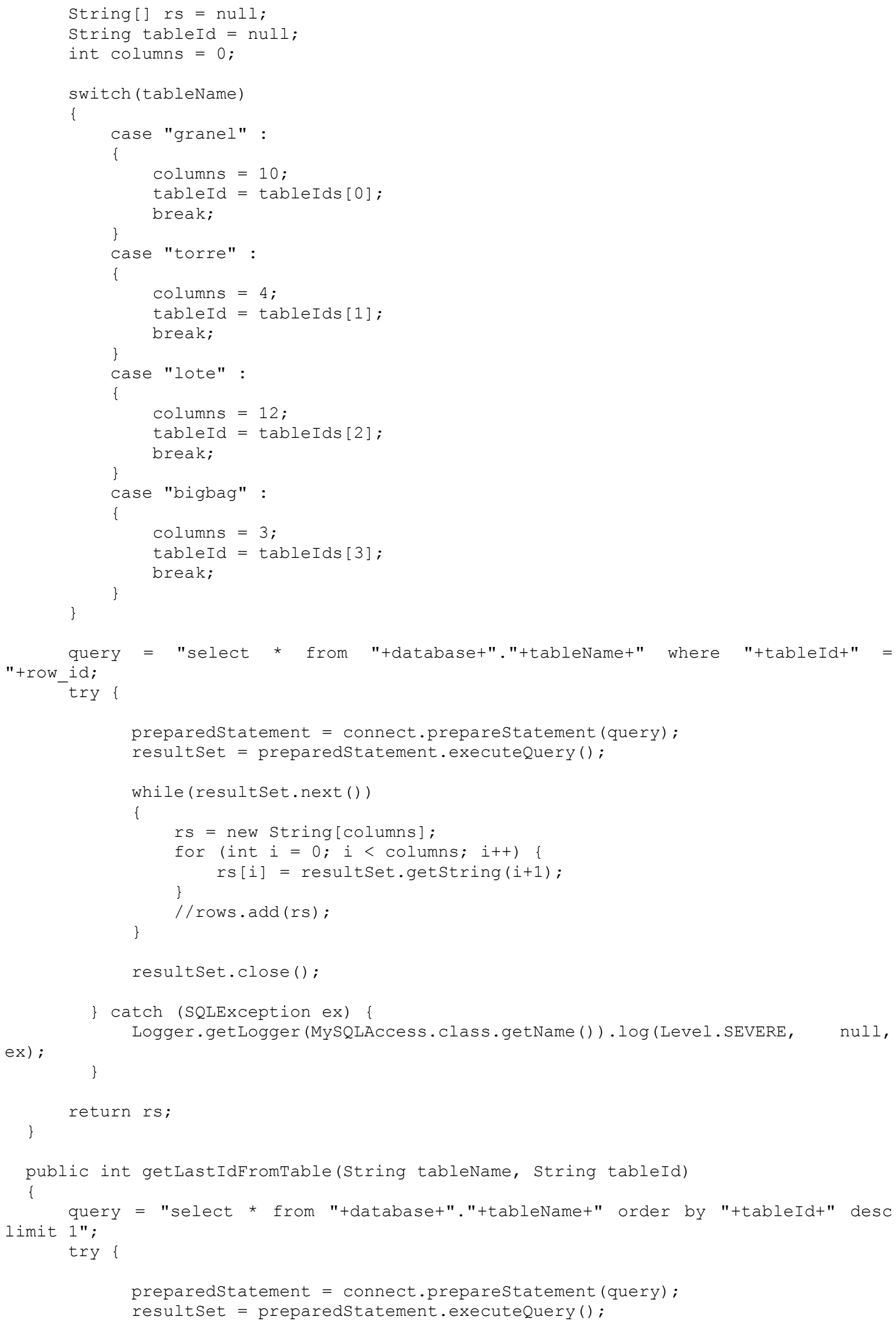




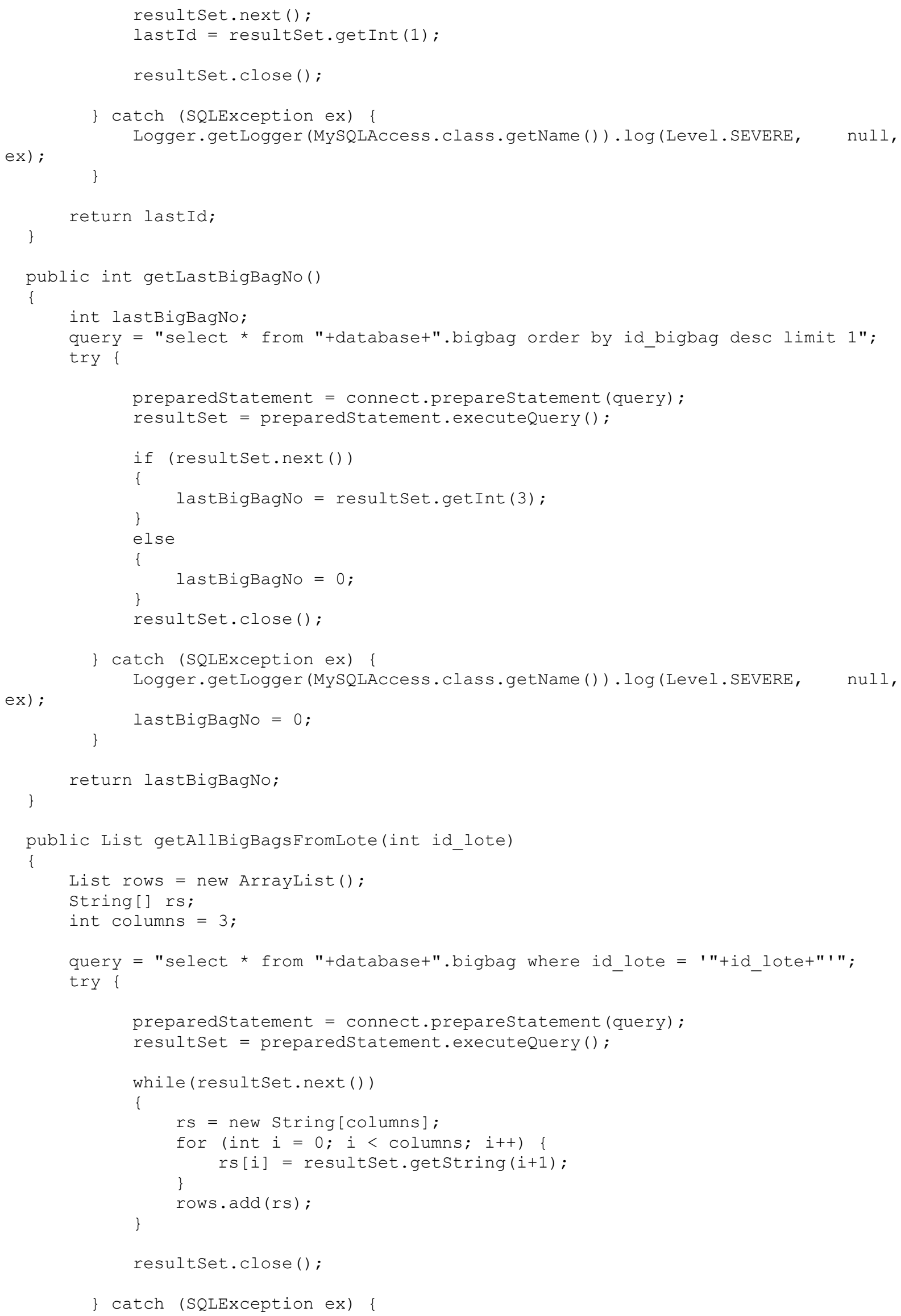


ex) ;

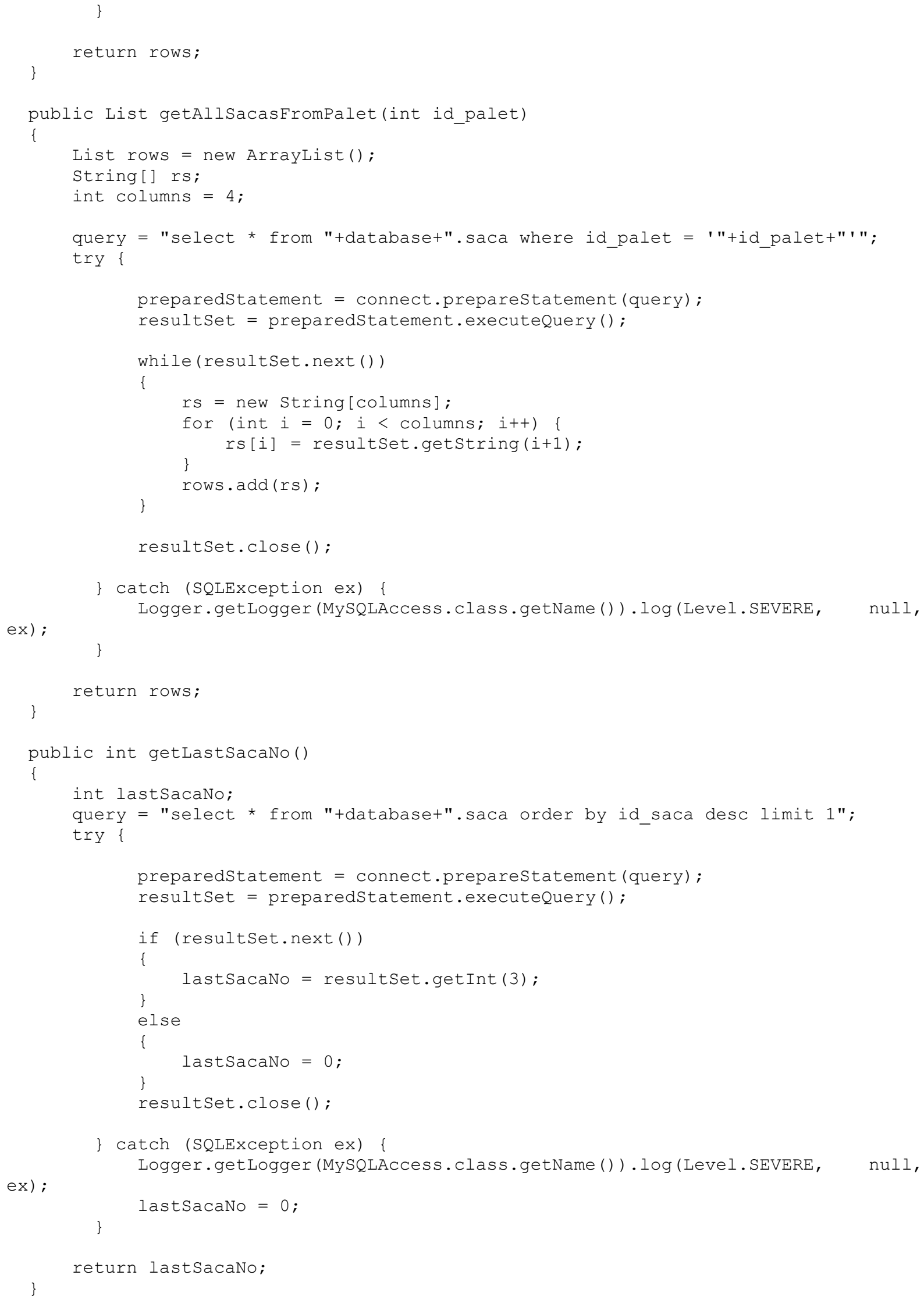


public void criarNovoUsuario(String[] parametros)

\{

query = "INSERT INTO "+database+".usuarios (login, senha, nome, id_role_usuario) VALUES (?, ?, ?, ?)";

try \{

// PreparedStatements can use variables and are more efficient preparedStatement $=$ connect.preparestatement (query)

// Parameters start with 1

preparedStatement.setString (1, parametros[0]);

preparedStatement.setString (2, parametros[1]);

preparedStatement.setString (3, parametros [2]);

preparedStatement.setString (4, parametros [3]);

preparedstatement. executeUpdate ();

\} catch (SQLException ex) \{

ex) ;

Logger.getLogger (MYSQLAccess.class.getName()) .log (Level.SEVERE, null,

\}

public void criarNovoPerfil(String[] parametros)

\{

$(?$, ? ) ";

query = "insert into "+database+".roles_usuarios (nome, permissoes) values

try \{

// PreparedStatements can use variables and are more efficient preparedStatement $=$ connect.preparestatement (query)

// Parameters start with 1

//preparedStatement.setString (1, "id usuario");

preparedstatement.setString (1, parametros[0]);

preparedStatement.setString (2, parametros[1]);

preparedStatement. executeUpdate ();

\} catch (SQLException ex) \{

Logger.getLogger (MySQLAccess.class.getName()) . log(Level.SEVERE, null,

ex) ;

\}

\}

public List getRolesUsuarios()

\{

List roles $=$ new Arraylist ();

String[] rs;

query = "select * from "+database+".roles_usuarios";

try \{

preparedStatement $=$ connect.preparestatement (query);

resultset $=$ preparedStatement. executeQuery ();

while(resultset.next ())

\{

$r S=$ new String $[2]$

rs [1] = resultset.getstring ("nome");

rs[0] = resultSet.getString("id_role_usuario");

roles.add (rs);

\}

resultset.close ();

\} catch (SQLException ex) \{

Logger.getLogger (MYSQLAccess.class.getName()) .log (Level.SEVERE, null,

ex) ;

\}

return roles; 


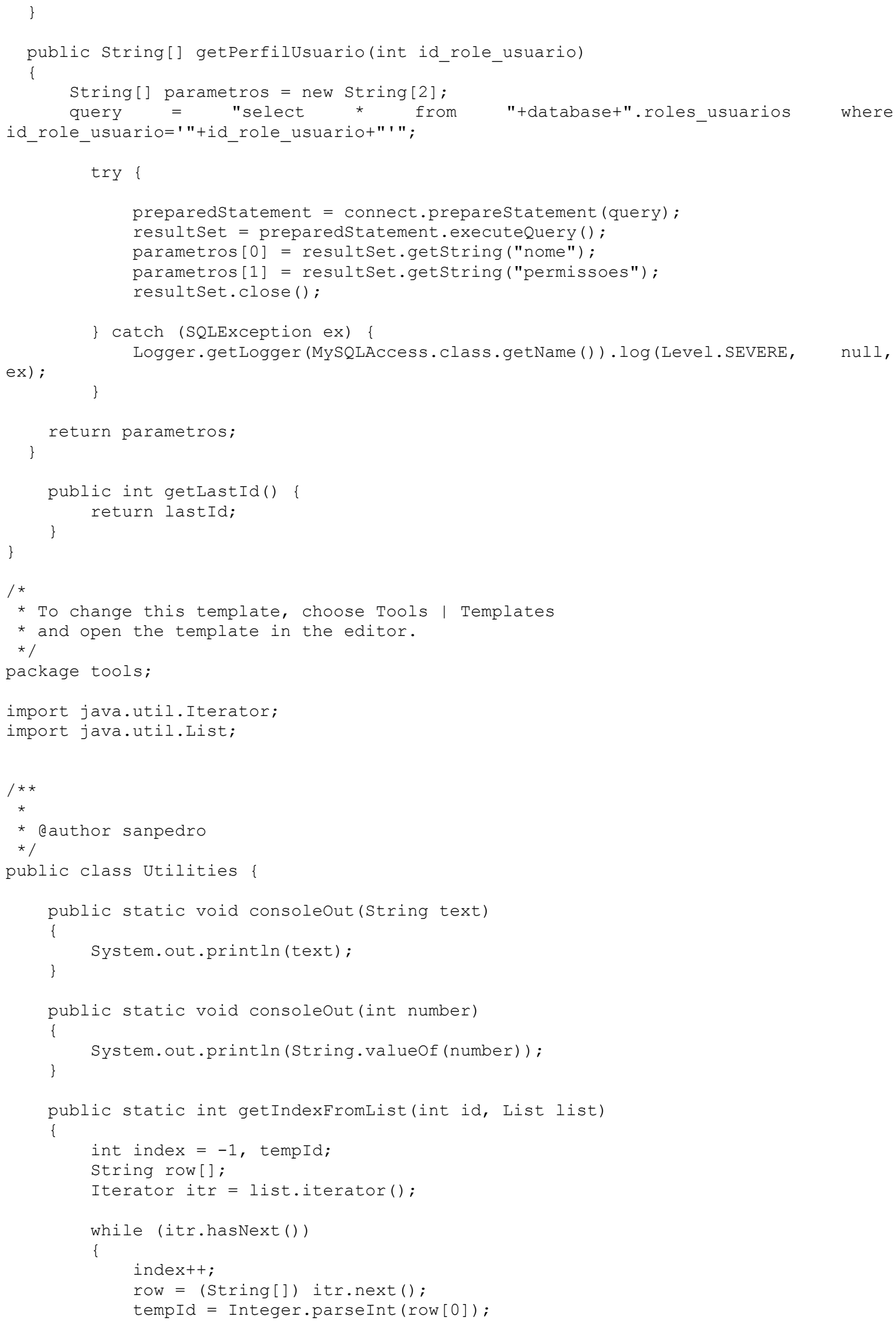


if (tempId $==$ id)

\}

return index;

return -1 ; 